\title{
FAILURE MECHANISM OF RESIN ANCHORED REBAR IN POTASH
}

\author{
A Thesis Submitted to the College of \\ Graduate Studies and Research \\ In Partial Fulfillment of the Requirements \\ For the Degree of Master of Science \\ In the Department of Civil and Geological Engineering \\ University of Saskatchewan \\ Saskatoon
}

By

DARREN NEELY

(C) Copyright Darren David Neely, July, 2014. All rights reserved. 


\section{PERMISSION TO USE}

In presenting this thesis in partial fulfillment of the requirements for a Postgraduate degree from the University of Saskatchewan, I agree that the Libraries of this University may make it freely available for inspection. I further agree that permission for copying of this thesis in any manner, in whole or in part, for scholarly purposes may be granted by the professor or professors who supervised my thesis work or, in their absence, by the Head of the Department or the Dean of the College in which my thesis work was done. It is understood that any copying or publication or use of this thesis or parts thereof for financial gain shall not be allowed without my written permission. It is also understood that due recognition shall be given to me and to the University of Saskatchewan in any scholarly use which may be made of any material in my thesis.

Requests for permission to copy or to make other uses of materials in this thesis/dissertation in whole or part should be addressed to:

Head of the Department of Civil \& Geological Engineering

University of Saskatchewan

Saskatoon, Saskatchewan S7N 5A9

Canada

OR

Dean

College of Graduate Studies and Research

University of Saskatchewan

107 Administration Place

Saskatoon, Saskatchewan S7N 5A2

Canada 


\begin{abstract}
The use of reinforcing bar (rebar) anchored with resin is a common method of rock support in both hard and soft rock mining. The average bond strength, or the load that the support can sustain for a linear length of bond to the rock, is typically determined through a series of pull tests. The average value of bond strength varies widely, since it is dependent on in-situ rock properties and environment. It is an important value because it allows mine engineers to select the appropriate length and pattern spacing of installation for the support. When a stiff support, like resin-anchored rebar, is placed in a weak, soft material, such as potash, the average bond strength tends to be lower in magnitude than for a typical hard rock installation.
\end{abstract}

This research was primarily aimed at determining the failure mechanism, in soft rock applications, by which the support loses adhesion and begins to fail by sliding. Results of field pull testing determined that the resin-rock bond strength was the limiting factor controlling when adhesion loss occurred. This study investigated how the bond strength may vary given a number of variables typically found in a potash mine environment. Results reported from testing did not indicate variation in the bond strength of resin anchored rebar, significant for mining applications, given changes in resin cure time, vicinity to active mining areas, or the rock type to which the resin was adjacent.

Using the results of laboratory and field testing, an equation was developed to estimate load on insitu resin anchored rebar given deformation measurements taken from the field. This equation will help determine safe limits for fracture separations opening in the backs of potash drifts. Investigating the behaviour of resin anchored rebar in potash may lead to methods to improve bond strength and calculation of factors of safety for patterned ground support. 


\section{ACKNOWLEDGMENTS}

Acknowledgement is given to the following groups, and individuals:

PotashCorp Technical Services located at Head Office in Saskatoon, Saskatchewan for sponsoring the research completed as a part of this master's project.

- Arnfinn Prugger, Ph.D., P.Geol., VP, Technical Services

- Lingen Jiang, Ph.D., P.Eng., Rock Mechanics Engineer

- Terry Danyluk, P.Geo., Director, Earth Sciences

- Craig Funk, P.Geo., Chief Geophysicist

PotashCorp's Allan Mine for providing the location of field testing, along with cooperation in the use of materials and labourers.

- Cole Smith, P.Eng., Mine Engineer

- Phil Lepage, P.Eng., Mine General Superintendent

- Gary Hennig, Mine General Foreman

- Dave Murray, E.I.T., Mine Engineer

- Tanner Smith, Mine Engineering Intern

- All the members of the Surveying Department

- All Mine Captains and Production Workers involved with installations

Department of Civil and Geological Engineering at the University of Saskatchewan for providing the opportunity to conduct this research and provide technical support.

- Doug Milne, Ph.D., P.Eng., Associate Professor

- Lisa Feldman, Ph.D., P.Eng., Associate Professor

- Chris Hawkes, Ph.D., P.Geo., Associate Professor

- Bruce Sparling, Ph.D., P.Eng., Professor

- Grant Ferguson, Ph.D., P.Geo., Associate Professor

- Donna-Lynn Beneteau, M.Sc., P.Eng., Research Engineer

- Zig Szczepanik, M.Sc., P.Geo., Rock Mechanics Lab Chief Technician

- Nathan Schartner, Geological Engineering Graduate Student

- Brennan Pokoyoway, Structures Lab Technician

- Kurtis Pegg, Geological Engineering Summer Student

- All the staff at the University of Saskatchewan Engineering Machine Shop

Jeff Thompson, Representative from DSI Canada, Saskatoon

NSERC for providing additional funding for carrying out field and laboratory testing. 


\section{POTASH MINING DEFINITIONS}

Potash - for the purposes of this thesis refers to a rock made up of Halite $(\mathrm{NaCl})$, various clays (insolubles), and at least $18-28 \%$ Sylvite $(\mathrm{KCl})$.

Salt - for the purposes of this thesis refers to a rock made up almost entirely of Halite $(\mathrm{NaCl})$ with trace amounts of clays (insolubles) and a low (1-4\%) content of Sylvite $(\mathrm{KCl})$

Rebar - Reinforcing Bar, refers to a type of ground support in form of a black (uncoated) rebar with a forged bolt head and a slashed (angled) toe tip.

Mechanical Bolt - refers to a straight steel bar, with a forged bolt head, that is anchored using only a mechanical wedge at the toe end of the bolt.

Dywidag Bar - a type of threaded rebar ground support specifically made by Dywidag Systems International, a manufacturer of many types of ground support and mine supplies.

Potash Opening - refers to a room/tunnel underground at a potash mine, most are 10 metres wide by 3 metres high and can be up to several kilometres in length.

Back - the ceiling of an opening underground.

Clay Seam - a thin deposit of clays (insolubles) that has been compacted into a hardened mudstone. There are several of these seams that separate layers of halite and potash.

Beams of Potash/Halite - used to describe the layers of halite or potash formed between clay seams. Often referred to as beams because of the support they provide against in-situ ground stresses.

Borer - a type of continuous mining machine that cuts the tunnel-like openings underground.

Stress-Relief Mining - Mining technique where openings are cut in a spatially specific and timed pattern to sacrifice certain rooms to failure (collapse) in order to preserve other rooms in the pattern.

Critical Bond Length: Length of resin bond which can sustain a load equal to the ultimate load (tensile capacity) of the rebar used. 


\section{NOTATION}

$A_{c}(x)=$ Cross-sectional area of concrete

$A_{s}=$ Cross-sectional area of rebar

$C_{h}=$ Circumference of hole size used

$\delta=$ Deformation measured at a separation in the field

$E=$ Young's modulus

$\varepsilon_{a v g}=$ Average elastic strain along the loaded length

$E_{c}(x)=$ Young's modulus of concrete

$e_{c}(x)=$ Contraction of concrete

$e_{f s}=$ Elongation of free length of steel (rebar)

$e_{s}(x)=$ Elongation of rebar

$E_{s}=$ Young's modulus of rebar

$\varepsilon_{y}=$ Yield strain

$f_{c}(x)=$ Compressive force in concrete

$l_{b}=$ Effective bond length

$l_{f}=$ Free length of rebar

$l_{l}=$ Loaded length

$l_{l y}=$ Yield load development length

$P=$ Applied load

$P_{\text {avg }}=$ Average load on rebar along the bonded length

$P_{\text {max }}=$ Load on rebar at the location of the separation

$P_{y}=$ Load required to yield rebar

$S_{\max }=$ Slip of rebar at the loaded end

$s(x)=$ Slip (deformation) of rebar at the loaded end

$\sigma_{y}=$ Yield strength

$T(x)=$ Load on the rebar at point, $x$, based on load distribution

$u=$ Average resin-rock bond strength

$x=$ Length along the bonded section 


\section{TABLE OF CONTENTS}

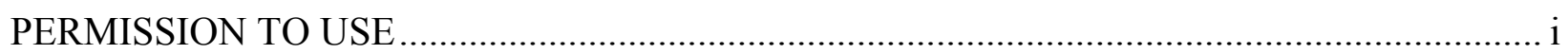

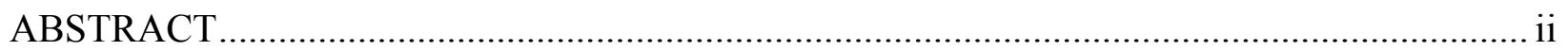

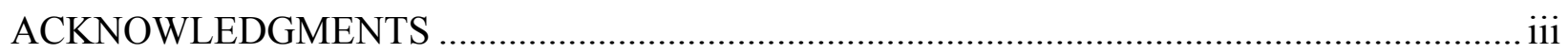

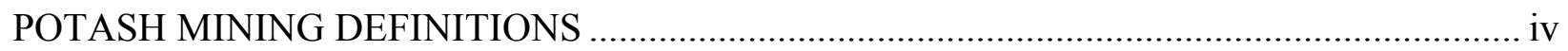

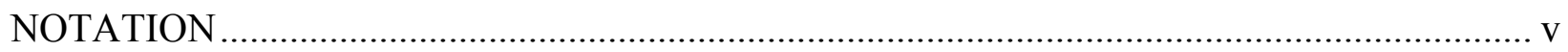

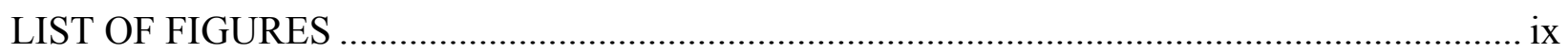

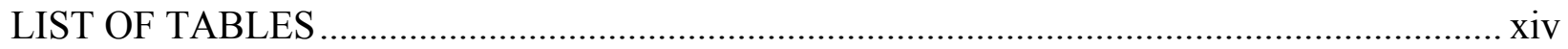

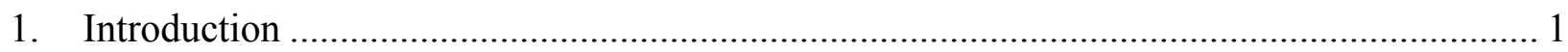

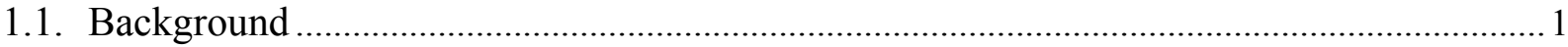

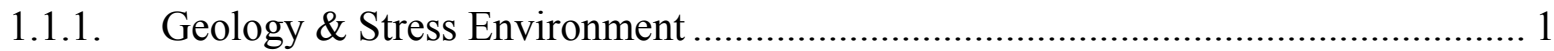

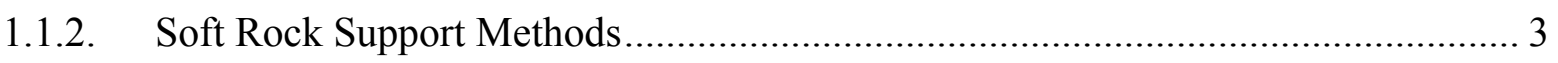

1.1.3. Effects of Potash Mining on Rebar Bolts .......................................................... 5

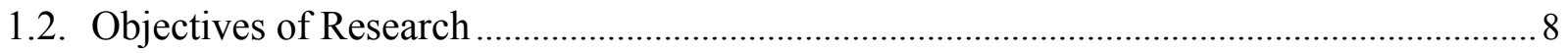

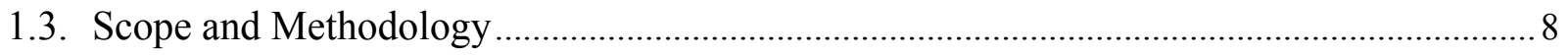

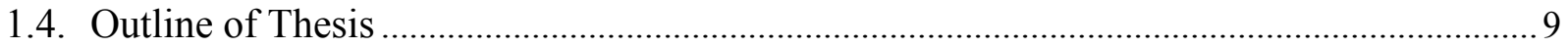

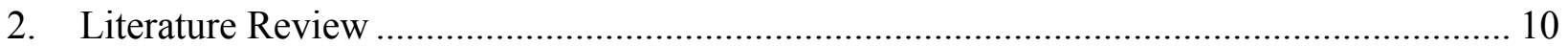

2.1. Potash Rock Mechanical Properties Literature ..................................................................... 10

2.2. Structural Engineering Literature for Post-Installed Rebar Subject to Tensile

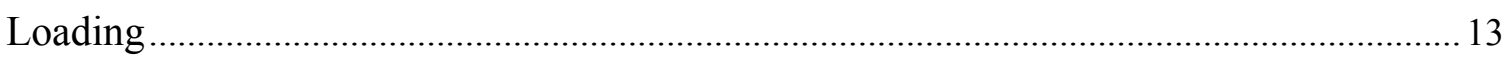

2.3. Mining Engineering Literature on Rebar Subject to Tensile Loading ................................. 15

2.4 Laboratory/Analytical Studies with Combined Shear and Tensile Loading ........................21

2.5 Literature Defining Load Distribution along Resin Anchored Rebar ....................................24

2.6 Laboratory/Field Studies on Resin Anchored Rebar Bolts with Combined Shear and Tensile Loading ……………………………………………....................................... 32

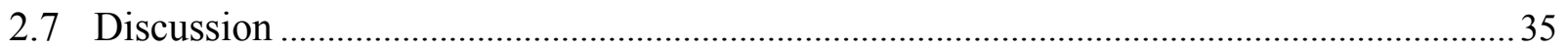

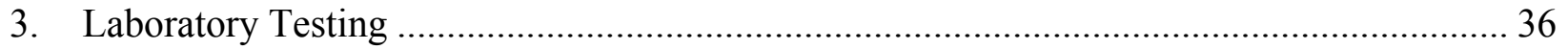

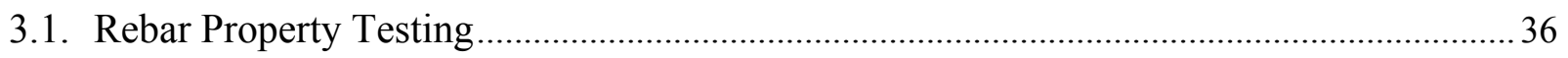

3.1.1. Rebar Property Testing Results ...................................................................... 38

3.2. Rock Testing Program ....................................................................................................... 39

3.2.1. Uniaxial Compressive Strength Testing ………................................................. 40 
3.2.2. Indirect Tensile Strength Testing ........................................................................... 44

3.2.3. Rock Shear Strength Testing .............................................................................. 46

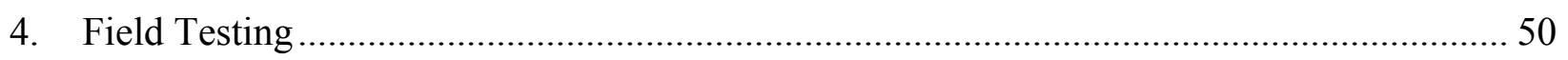

4.1. Field Testing Site Selection ........................................................................................ 50

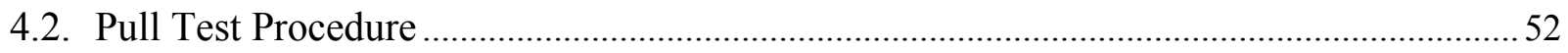

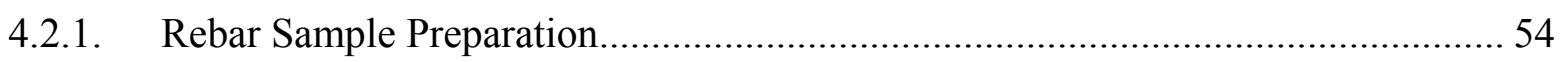

4.2.2. Instruments to Measure Deformation during a Pull Test......................................... 58

4.2.3. Investigating the Effect of Field Variables ............................................................ 64

4.2.4. Pull-Test Quality Control............................................................................................. 71

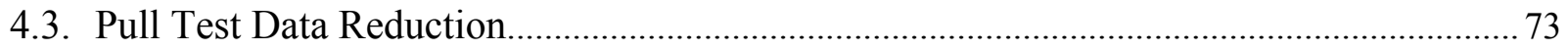

4.3.1. Estimated Pull Test Deformation..................................................................... 74

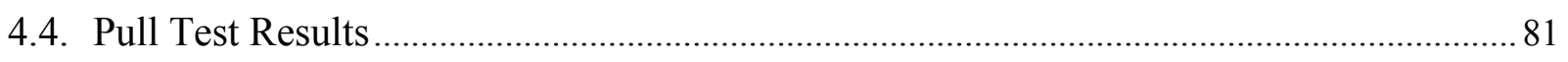

4.4.1. Pull Test Results Determining the Effect of Increased Resin Cure Time............... 82

4.4.2. Pull Test Results Comparing Active to Non-Active Mining Sites ......................... 83

4.4.3. Pull Test Results Comparing Rebar Anchored in Potash and Halite Horizons ...... 86

4.4.4. Effect of Resin Contact Area .......................................................................... 87

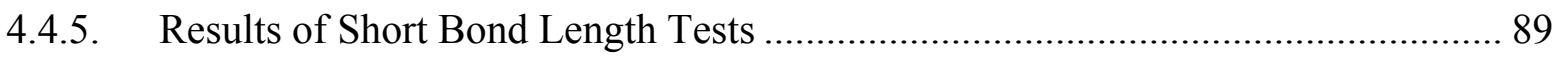

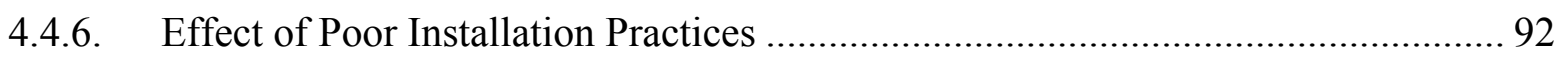

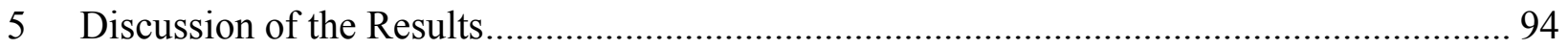

5.1 Field Testing Sources of Error and Suggested Improvements .............................................. 94

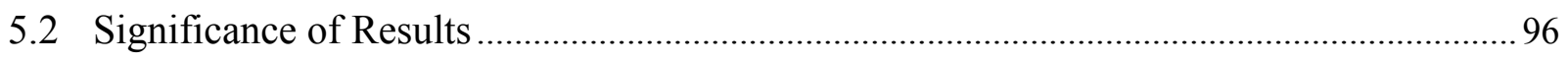

5.3 Estimating Load on Rebar from Measured Field Deformation............................................. 99

6 Conclusions \& Future Work Recommendations ...................................................................... 103

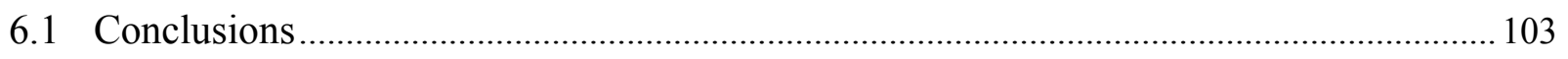

6.1.1 Failure Mechanism of Resin Anchored Rebar in Potash ...................................... 103

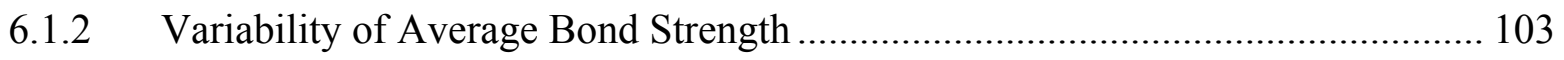

6.1.3 Development of an Equation to Estimate Load on In-Situ Resin Anchored

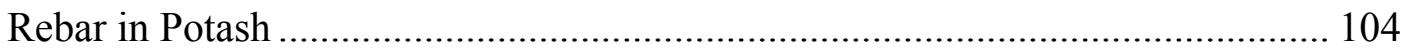

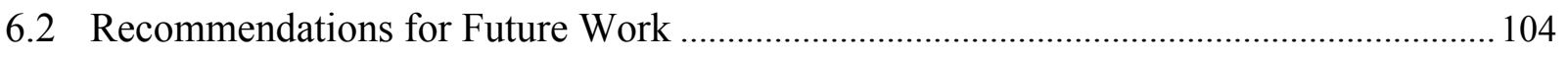

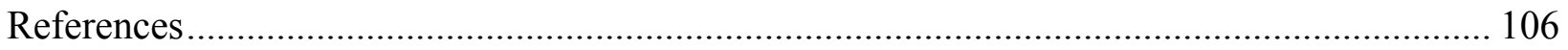

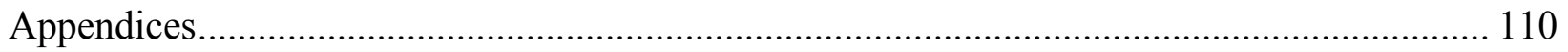


A. Raw Data from Laboratory Testing on Rebar Specimens ........................................... 111

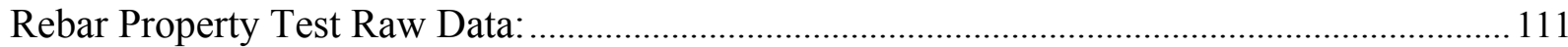

Load vs Deformation and Stress vs Strain Plots: 25mm Rebar Testing

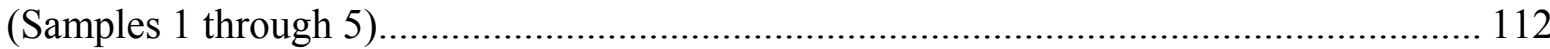

Calculating Maximum Elastic Strain for 25mm Rebar ................................................ 115

Load vs. Deformation and Stress vs. Strain Plots: $16 \mathrm{~mm}$ Rebar Testing

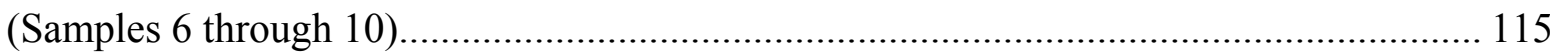

B. Raw Data from Laboratory Tests for Rock Properties ................................................ 119

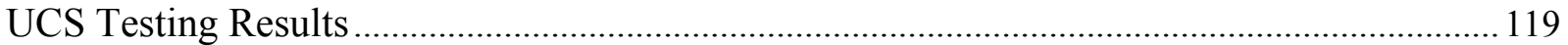

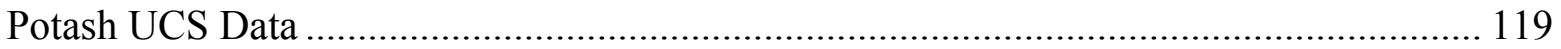

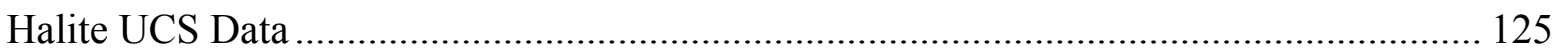

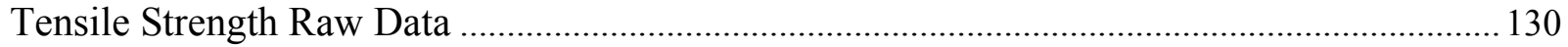

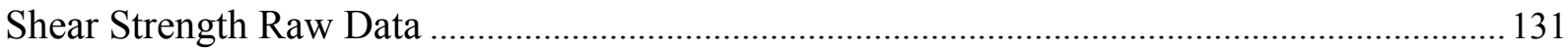

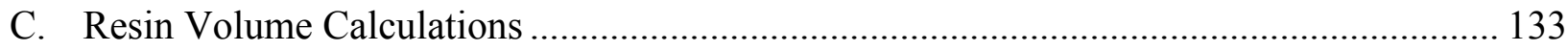

\% Resin Lost if Holes are Over-Drilled: ....................................................................................... 133

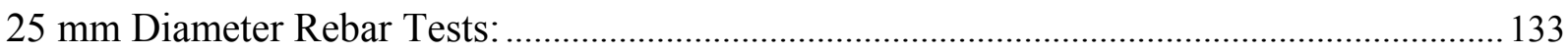

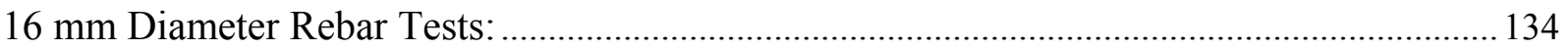

D. Pull Test Process and Data Reduction Process............................................................. 136

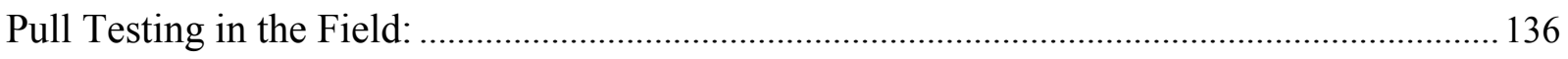

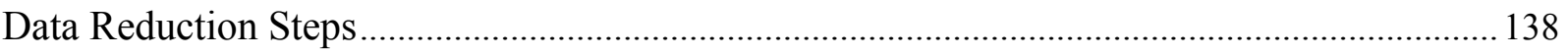

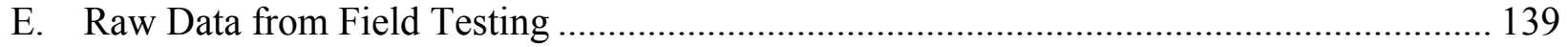

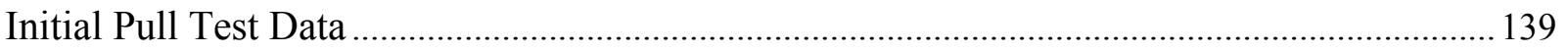

"Borer 6" Testing Site Data (Active Mining Area on Potash Horizon).................................... 148

"North 70" Testing Site Data (Non-Active Mining on Potash Horizon) .................................... 166

"South Storage Bin” Testing Site Data (Non-Active Site on Halite Horizon).......................... 176

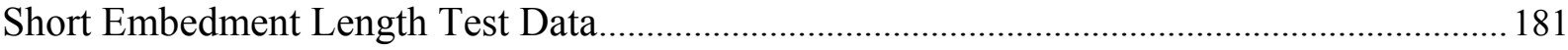

"East305" Testing Site Data (16mm Rebar, Non-Active Site, Potash Horizon) ...................... 182

T-Test for Proximity to Active Mining Pull Test Results.......................................................... 187 


\section{LIST OF FIGURES}

Figure 1.1 Cross-section of the prairie evaporite and surrounding formations (Fuzesy, 1982) ..... 2

Figure 1.2 Clay seams allow shear deformation to occur readily (Hills, 2005) ........................... 2

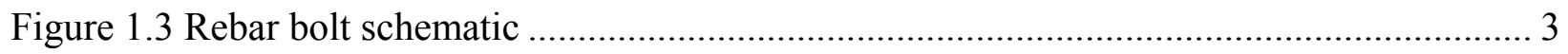

Figure 1.4 Suspension and pinning functions of internal rock support (Lovlin, 2006) ................... 4

Figure 1.5 Mechanical bolt anchored using wedge and bolt plate............................................. 4

Figure 1.6 Examples loading scenarios found in potash mining: (a) Axial, and (b) Shear ............ 5

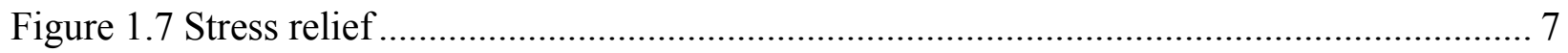

Figure 1.8 Bond strength relationship with rock stiffness after DSI (2009) ……….................... 7

Figure 1.9 Visual inspection of rebar heads, looking up at potash back ...................................... 8

Figure 2.1 Typical stress-strain curve for potash after Duncan and Lajtai, 1993 ........................ 12

Figure 2.2 Effect of loading rate on potash failure point after Duncan and Lajtai, 1993 ............. 12

Figure 2.3 Geological differences between Saskatoon area mines and southeastern mines

after Jones and Prugger (1982) : (a) Cominco, and (b) PCS Rocanville ................................... 17

Figure 2.4 Field stress surrounding rebar in both (a) New, and (b) Old openings ........................ 21

Figure 2.5 Pull test data output (Van Ooteghem, 1982) ........................................................... 21

Figure 2.6 Schematics of testing methods used by: (a) Stillborg (1984) and (b) Dube (1995) .... 24

Figure 2.7 Example showing loading behaviour both before and beyond the elastic limit

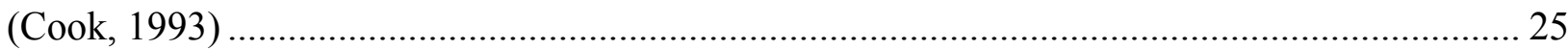

Figure 2.8 Uniform and Elastic Bond-Stress Models from Cook (1993) ………….................. 26

Figure 2.9 Bond stress distribution along a fully grouted rebar after Li and Stillborg (1999) .... 28

Figure 2.10 Load Distribution along Resin Anchored Rebar given Different Bond Stress Models

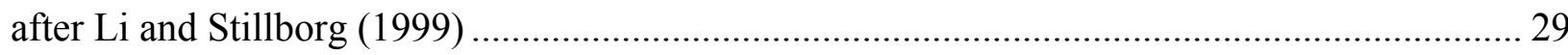

Figure 2.11 Free body diagrams of pull test on rebar embedded in concrete from Feldman

and Bartlett (2007): (a) pull test specimen; (b) concrete in segment at loaded end;

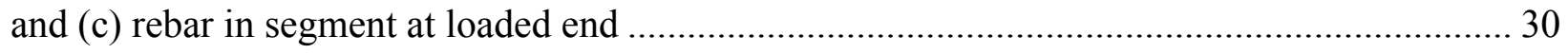

Figure 2.12 Simple adhesion-sliding model modified from Feldman and Bartlett (2007)........... 31

Figure 2.13 Shear and tensile load apparatus schematic after McHugh and Signer (1999) ......... 34

Figure 2.14 Instrumented rebar for shear testing from McHugh and Signer (1999) .................... 34

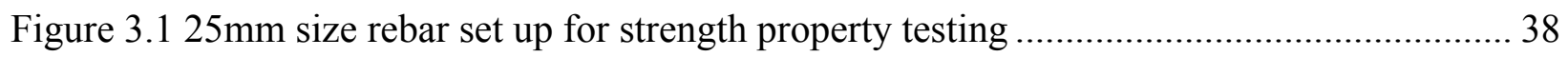

Figure 3.2 Diamond core drill rig used to collect samples at the Allan mine.............................. 40

Figure 3.3 Potash sample loaded in Tinius-Olson material testing machine and outfitted with

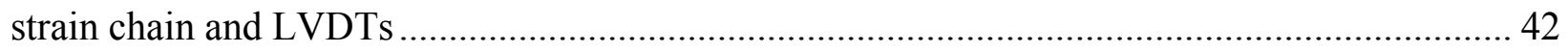

Figure 3.4 Stress-strain plot for potash sample P8 …………………………………........... 43

Figure 3.5 Example of failed potash sample (P31A) after Brazilian tensile strength test............ 45

Figure 3.6 Shear strength test apparatus .................................................................................. 47

Figure 3.7 Shear strength test prepared in the Tinius Olsen materials testing machine ............... 47

Figure 3.8 Top-down view of potash sample in the shear testing apparatus ............................... 48

Figure 3.9 Example of potash sample failed after shear strength test ....................................... 48 
Figure 4.1 Pull tester apparatus used at Allan mine: (a) Hydraulic cylinder attached to rebar

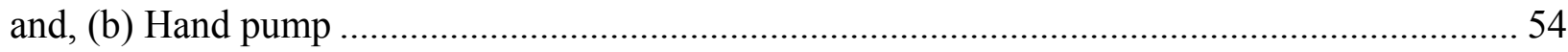

Figure 4.2 Pull collar and square plate washer ................................................................. 55

Figure 4.3 Example of $0.56 \mathrm{~m}$ portion of rebar to be bonded followed by $0.18 \mathrm{~m}$ finished resin

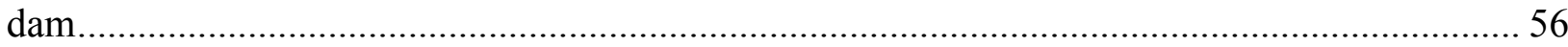

Figure 4.4 Schematic of using resin dams to achieve desired anchorage length........................ 57

Figure 4.5 Wrapping a 0.18 metre length of PVC tubing in electrical tape to secure it to rebar.. 57

Figure 4.6 Uneven surface along back causes apparatus to tilt at the start of test.................... 59

Figure 4.7 Pull test set-up arrangement showing both methods of deformation measurement.... 60

Figure 4.8 Closure rod anchored into potash floor after it is cleaned with shovel ..................... 62

Figure 4.9 Schematic of initial tilt of apparatus during pull test caused by uneven back surface:

(a) Initial extension of rod causing error; (b) No error caused when flat back is present; and (c)

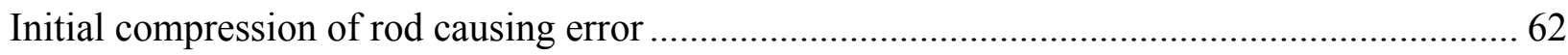

Figure 4.10 String potentiometer connected in field ........................................................... 63

Figure 4.11 View of fishing line connected directly to rebar head with electrical tape .............. 64

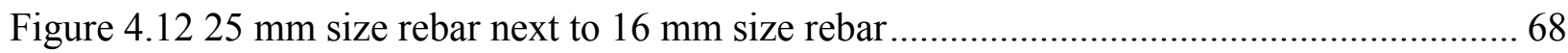

Figure 4.13 (a) Stoper used for installing $16 \mathrm{~mm}$ rebar and (b) Operating the stoper................ 70

Figure 4.14 Auger drill steel marked with paint on bolter....................................................... 72

Figure 4.15 Resin cartridge with birdie attachment........................................................ 73

Figure 4.16 Schematic of pull test: (a) Pull test specimen; (b)Rock segment at loaded end;

(c)Resin segment at loaded end; and (d) Rebar segment at loaded end.................................. 75

Figure 4.17 Load versus incremental deformation from initial tests 11-14 (510 mm bond

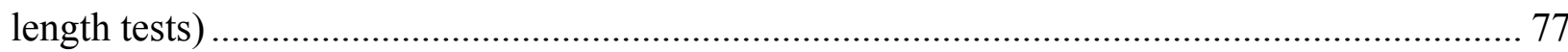

Figure 4.18 Linear load distribution approximated from preliminary testing ........................... 77

Figure 4.19 Estimated load versus incremental deformation for $25 \mathrm{~mm}$ rebar ......................... 79

Figure 4.20 Expected incremental deformation versus all measured results............................. 79

Figure 4.21 Load versus incremental deformation typical result - test 76 (initial sliding load

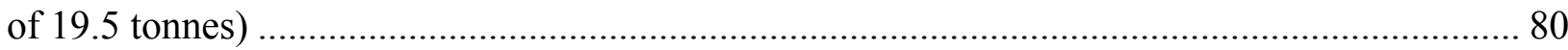

Figure 4.22 Load versus incremental deformation result with no clear initial sliding load -

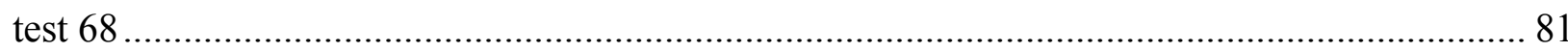

Figure 4.23 Bond strength versus resin cure time from "North70" testing site ........................ 83

Figure 4.24 Comparison of active and non-active mining area closure rates .......................... 84

Figure 4.25 Bond strength versus time since installation at the active mining site................... 85

Figure 4.26 Range of bond strength determined at both active and non-active test sites........... 85

Figure 4.27 Large spikes in incremental deformation plot observed on rebar anchored to

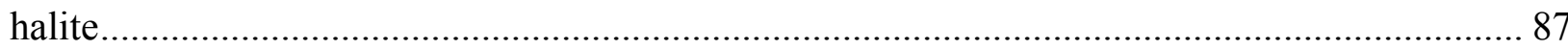

Figure 4.28 Average bond strength versus resin contact area .............................................. 89

Figure 4.29 Initial sliding load versus resin-rock contact area size ...................................... 89

Figure 4.30 Test rebar after sliding the full stroke length of the apparatus ............................. 90

Figure 4.31 Rebar sample pulled from hole............................................................... 91 
Figure 4.32 Broken up resin (grey particles) fallen from hole after pull test .......................... 91

Figure 4.33 Borehole camera view of resin still in hole after being dragged down by rebar....... 92

Figure 4.34 Improperly installed rebar (over drilled length) results: Initial sliding load of 12

tonnes

Figure 4.35 Improperly installed rebar (overspun) result: Initial sliding load approximately 7

tonnes 93

Figure 5.1 Plate to brace pull tester against back modified from ASTM 4435-08 .................... 96

Figure 5.2 Length of resin anchored rebar responsible to sustain load .................................... 98

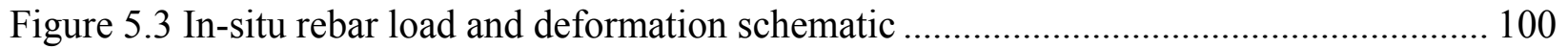

Figure A.1 Load versus Deformation - Test 1 (25mm Rebar)............................................ 112

Figure A.2 Stress versus Strain - Test 1 (25mm Rebar) ...................................................... 112

Figure A.3 Load versus Deformation - Test 2 (25mm Rebar)............................................... 112

Figure A.4 Stress versus Strain - Test 2 (25mm Rebar) ..................................................... 113

Figure A.5 Load versus Deformation - Test 3 (25mm Rebar)............................................. 113

Figure A.6 Stress versus Strain - Test 3 (25mm Rebar) ..................................................... 113

Figure A.7 Load versus Deformation - Test 4 (25mm Rebar)............................................... 114

Figure A.8 Stress versus Strain - Test 4 (25mm Rebar) ....................................................... 114

Figure A.9 Load versus Deformation - Test 5 (25mm Rebar).............................................. 114

Figure A.10 Stress versus Strain - Test 5 (25mm Rebar) ................................................. 115

Figure A.11 Load versus Deformation - Test 6 (16mm Rebar)............................................ 115

Figure A.12 Stress versus Strain - Test 6 (16mm Rebar) .................................................. 116

Figure A.13 Load versus Deformation - Test 7 (16mm Rebar)........................................... 116

Figure A.14 Stress versus Strain - Test 7 (16mm Rebar) ..................................................... 116

Figure A.15 Load versus Deformation - Test 8 (16mm Rebar)............................................. 117

Figure A.16 Stress versus Strain - Test 8 (16mm Rebar) ..................................................... 117

Figure A.17 Load versus Deformation - Test 9 (16mm Rebar) ................................................ 117

Figure A.18 Stress versus Strain - Test 9 (16mm Rebar) ...................................................... 118

Figure A.19 Load versus Deformation - Test 10 (16mm Rebar)......................................... 118

Figure A.20 Stress Versus Strain - Test 10 (16mm Rebar) .................................................. 118

Figure B.1 Potash Sample "P8" Stress vs. Strain Plot from UCS Test.................................... 120

Figure B.2 Potash Sample "P11" Stress vs. Strain Plot from UCS Test.................................. 120

Figure B.3 Potash Sample "P13A" Stress vs. Strain Plot from UCS Test............................... 121

Figure B.4 Potash Sample "P13B" Stress vs. Strain Plot from UCS Test ................................ 121

Figure B.5 Potash Sample "P32" Stress vs. Strain Plot from UCS Test.................................. 122

Figure B.6 Potash Sample "P33A" Stress vs. Strain Plot from UCS Test............................... 122

Figure B.7 Potash Sample "P33B" Stress vs. Strain Plot from UCS Test ............................... 123

Figure B.8 Potash Sample "P37" Stress vs. Strain Plot from UCS Test................................... 123

Figure B.9 Potash Sample "P38A" Stress vs. Strain Plot from UCS Test................................ 124

Figure B.10 Potash Sample "P38B" Stress vs. Strain from UCS Test ................................... 124

Figure B.11 Halite Sample "S15" Stress vs. Stain Plot from UCS Test ................................. 125 
Figure B.12 Halite Sample "S35" Stress vs. Strain Plot from UCS Test........................................ 126

Figure B.13 Halite Sample "S2A" Stress vs. Strain Plot from UCS Test.................................. 126

Figure B.14 Halite Sample "S2B" Stress vs. Strain Plot from UCS Test ..................................... 127

Figure B.15 Halite Sample "S3" Stress vs. Strain Plot from UCS Test....................................... 127

Figure B.16 Halite Sample "S4A" Stress vs. Strain Plot from UCS Test.................................. 128

Figure B.17 Halite Sample "S4B" Stress vs. Strain Plot from UCS Test .................................. 128

Figure B.18 Halite Sample "S4C" Stress vs. Strain Plot from UCS Test ................................... 129

Figure B.19 Halite Sample "6A" Stress vs. Strain Plot from UCS Test ..................................... 129

Figure B.20 Halite Sample "S6B" Stress vs. Strain Plot from UCS Test .................................... 130

Figure D.1 Attaching String Line with Electrical Tape ......................................................... 136

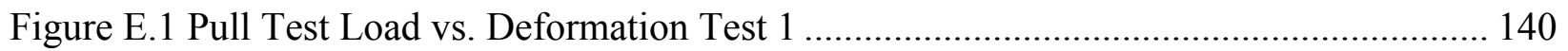

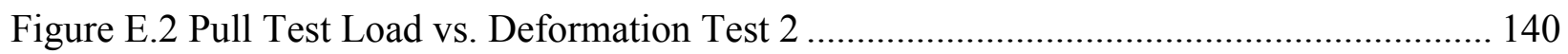

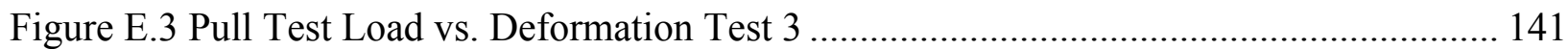

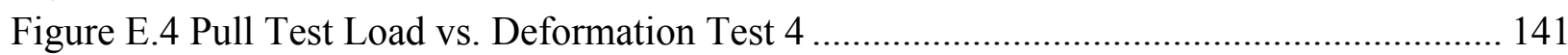

Figure E.5 Pull Test Load vs. Deformation Test 5 ……........................................................ 142

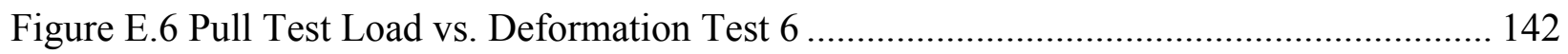

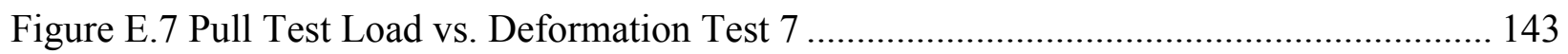

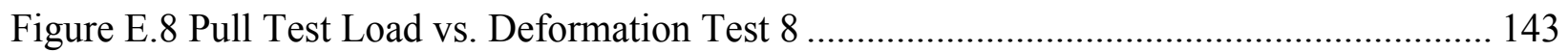

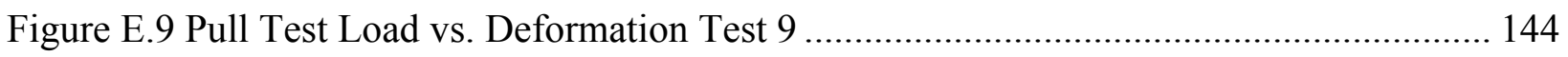

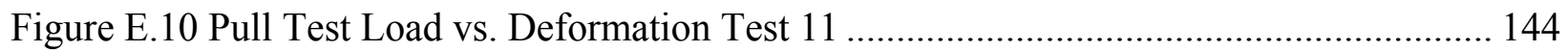

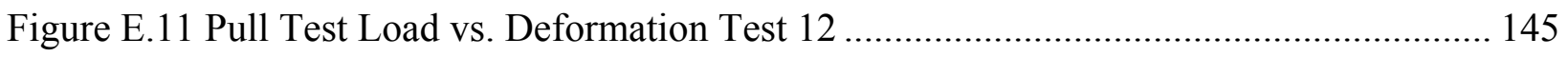

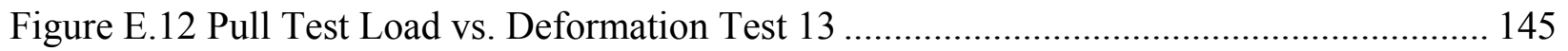

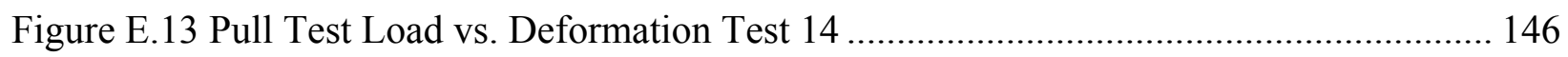

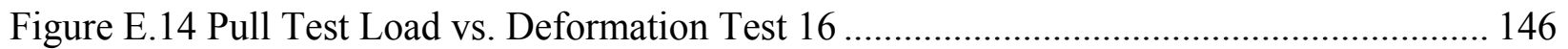

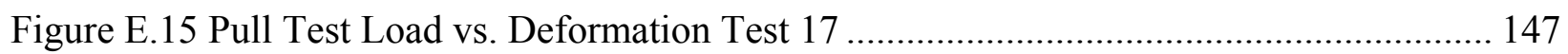

Figure E.16 Pull Test Load vs. Deformation Test 18 ………................................................. 147

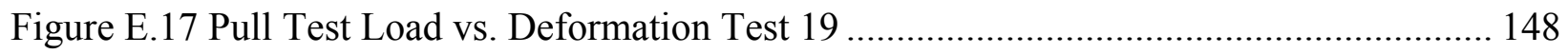

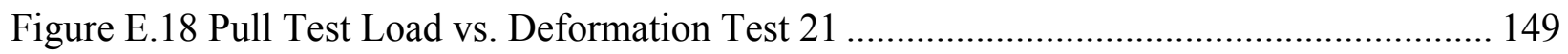

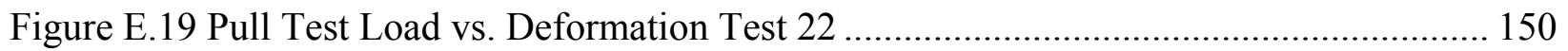

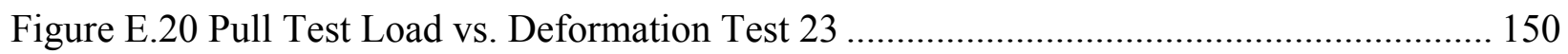

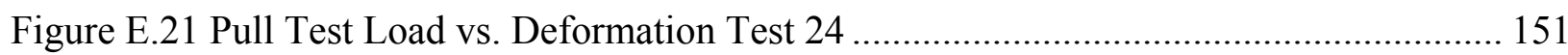

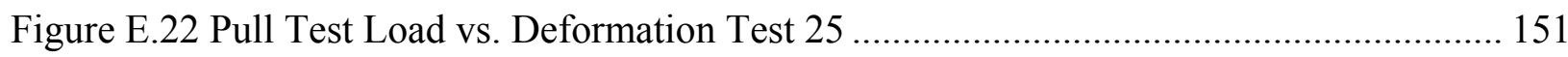

Figure E.23 Pull Test Load vs. Deformation Test 27 ................................................................. 152

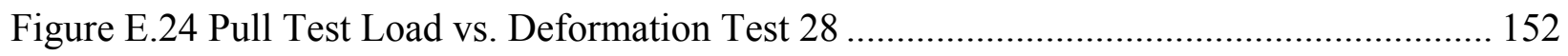

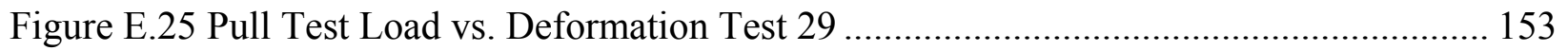

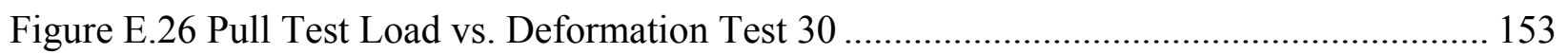

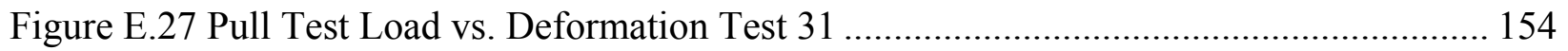

Figure E.28 Pull Test Load vs. Deformation Test 32 _............................................................. 154

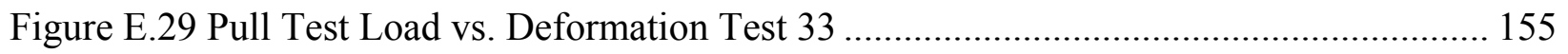

Figure E.30 Pull Test Load vs. Deformation Test 34 ............................................................. 155 


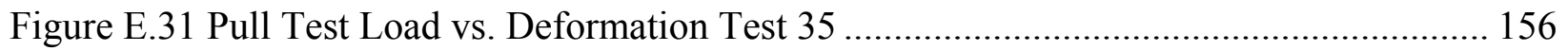

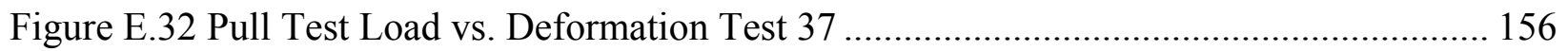

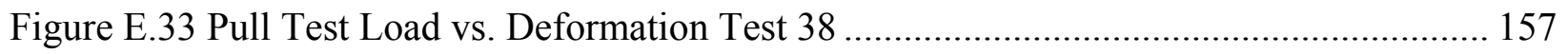

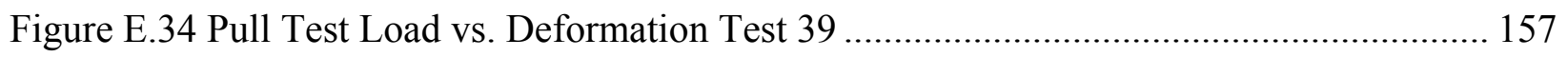

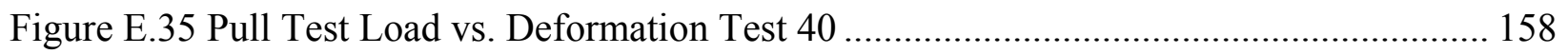

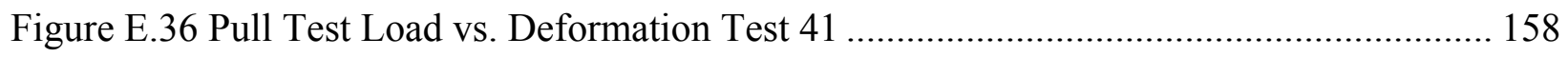

Figure E.37 Pull Test Load vs. Deformation Test 42 .............................................................. 159

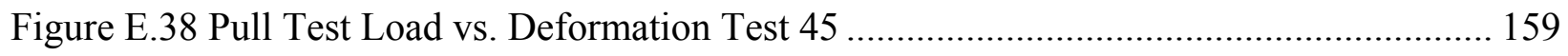

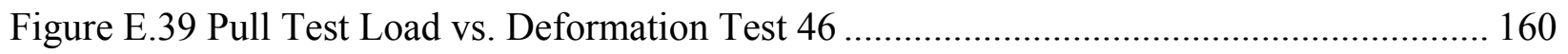

Figure E.40 Pull Test Load vs. Deformation Test 48 .......................................................... 160

Figure E.41 Pull Test Load vs. Deformation Test 49 .......................................................... 161

Figure E.42 Pull Test Load vs. Deformation Test 50 ............................................................ 161

Figure E.43 Pull Test Load vs. Deformation Test 51 ........................................................ 162

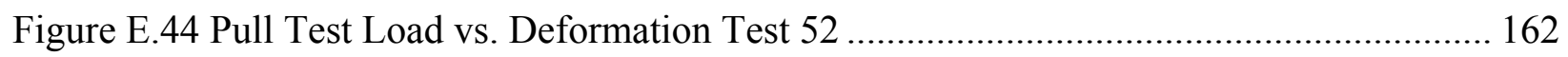

Figure E.45 Pull Test Load vs. Deformation Test 53 ……..................................................... 163

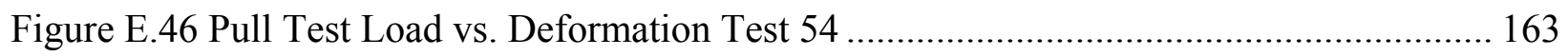

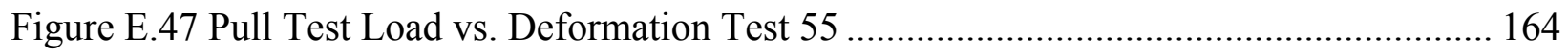

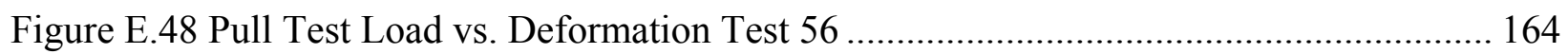

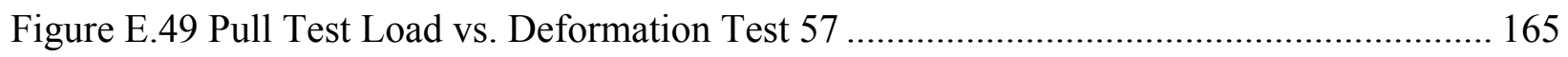

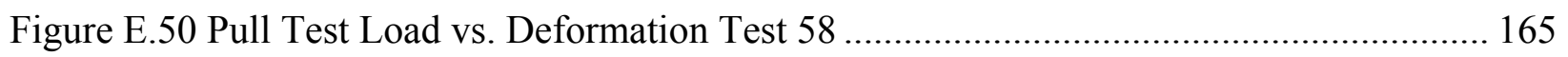

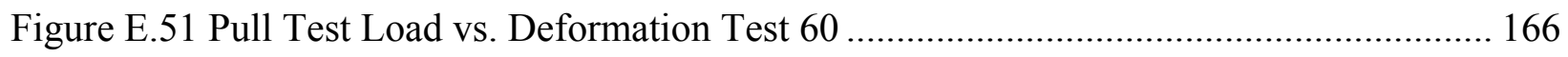

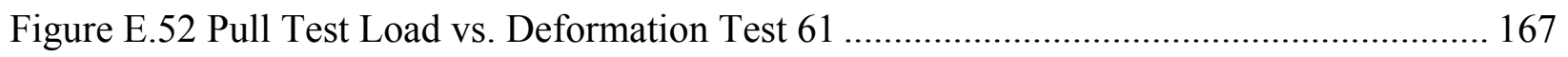

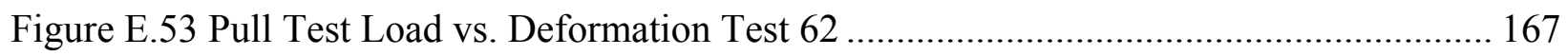

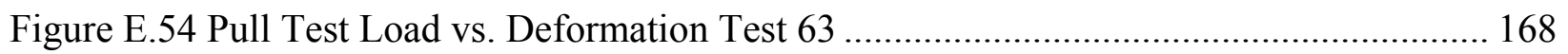

Figure E.55 Pull Test Load vs. Deformation Test 64 ............................................................ 168

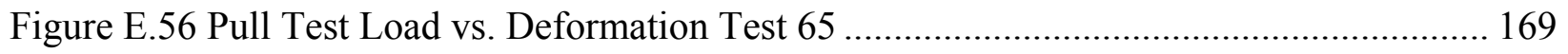

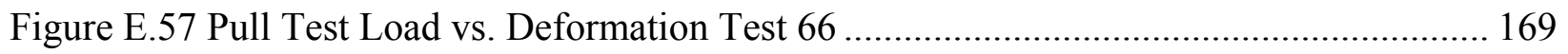

Figure E.58 Pull Test Load vs. Deformation Test 67 ......................................................... 170

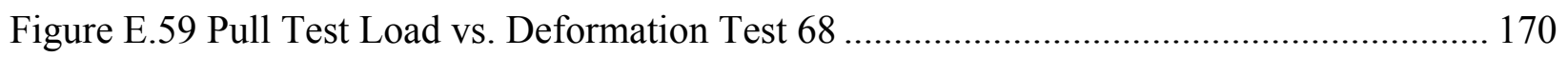

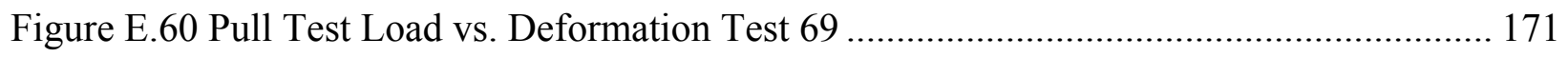

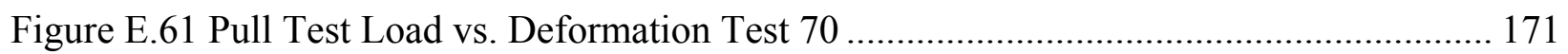

Figure E.62 Pull Test Load vs. Deformation Test 71 ......................................................... 172

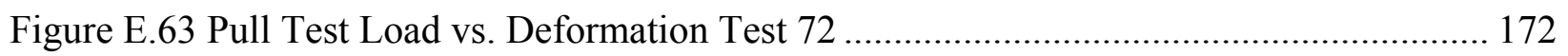

Figure E.64 Pull Test Load vs. Deformation Test 73 .......................................................... 173

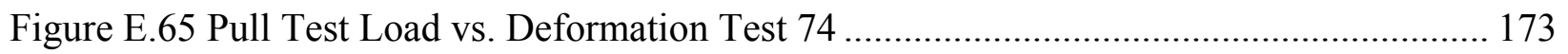

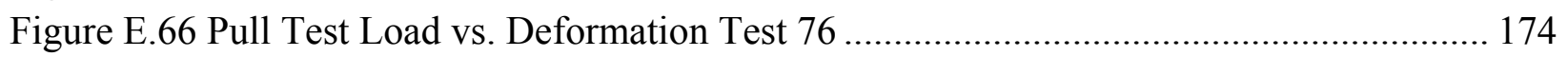

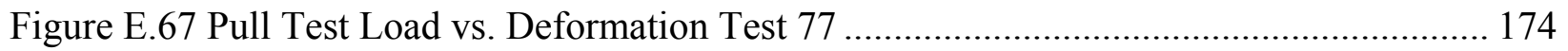

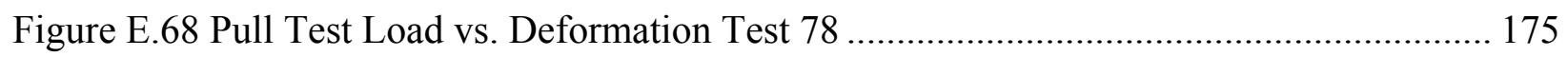

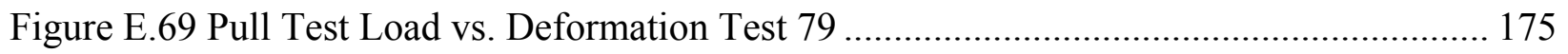

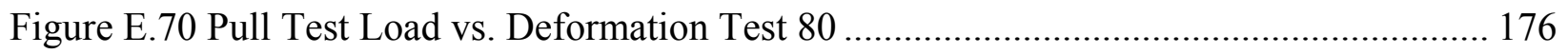




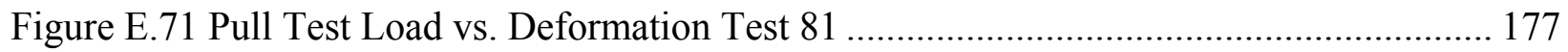

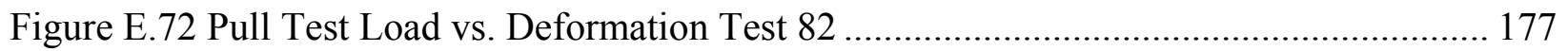

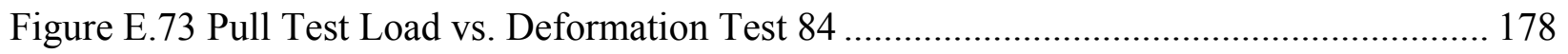

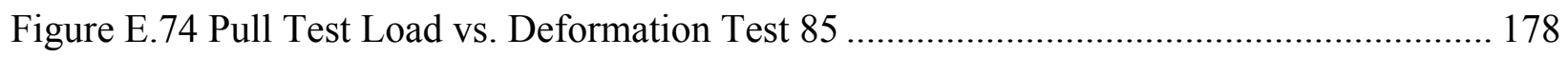

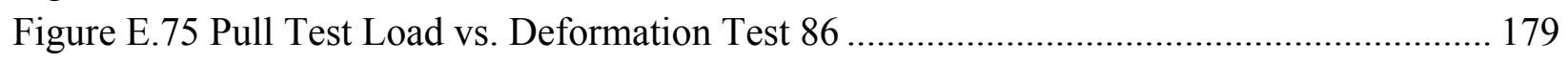

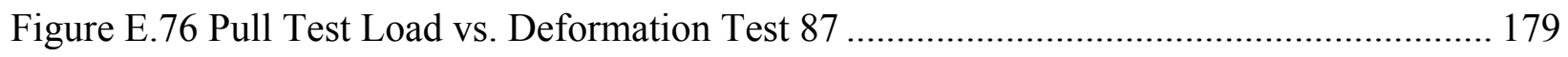

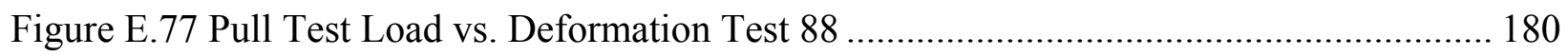

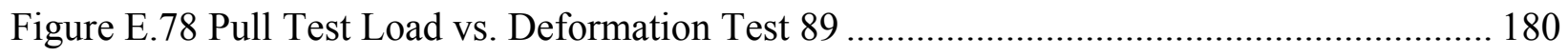

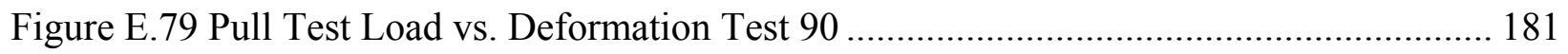

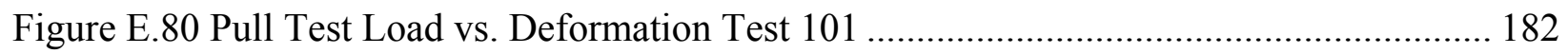

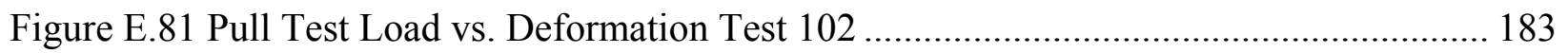

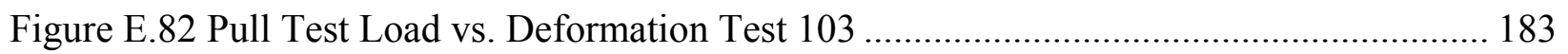

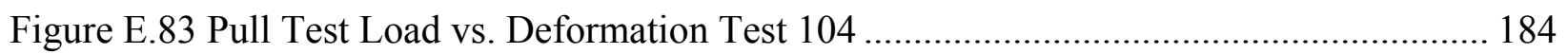

Figure E.84 Pull Test Load vs. Deformation Test 105 ............................................................... 184

Figure E.85 Pull Test Load vs. Deformation Test 106 ........................................................... 185

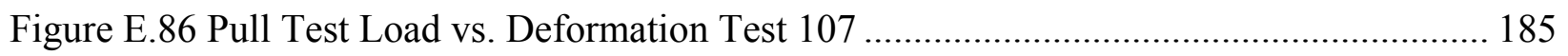

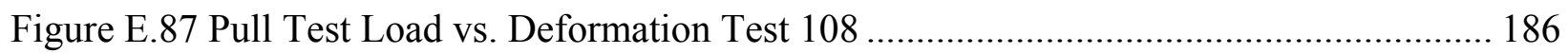

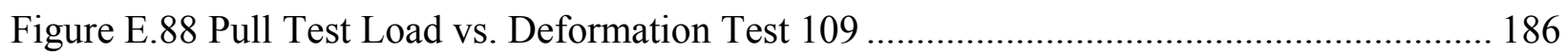

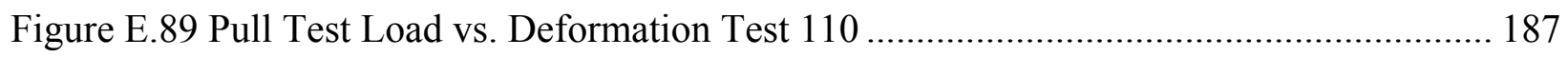

\section{LIST OF TABLES}

Table 2.1 Pull test results from Mosaic K-1 after Kuchling (1987) ........................................... 17

Table 3.1 Laboratory pull test data (5 tests per size of rebar)...................................................... 39

Table 3.2 Average mechanical properties from UCS testing (10 tests each) ………................... 43

Table 3.3 Average Indirect tensile strength test results (10 tests each) ........................................ 45

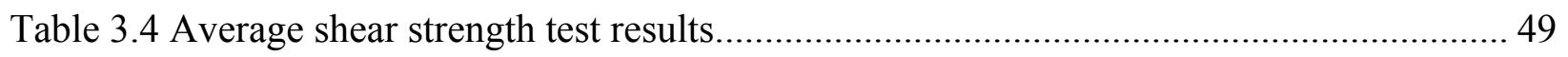

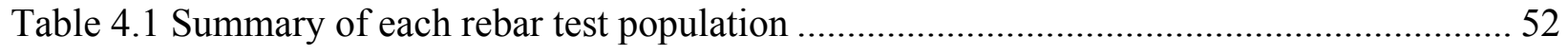

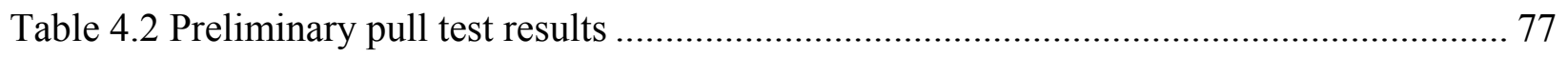

Table 4.3 Average results for $25 \mathrm{~mm}$ rebar at "North70" non-active test site (16 tests).............. 82

Table 4.4 Average results for $25 \mathrm{~mm}$ rebar in active potash zone (25 tests) ............................... 85

Table 4.5 Average results from halite anchored pull tests at "South Storage Bin" site (4 tests).. 87

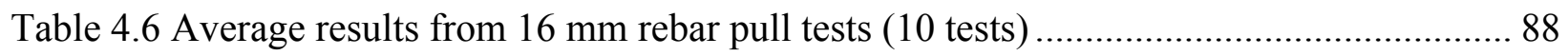

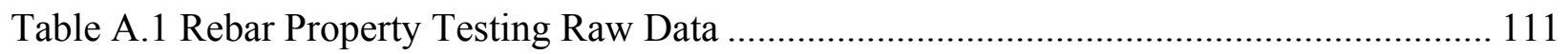

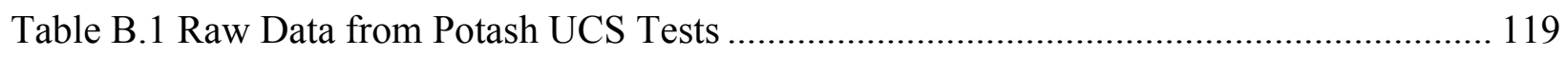

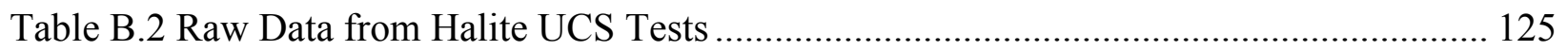

Table B.3 Raw Data from Tensile Strength Tests on Potash...................................................... 130

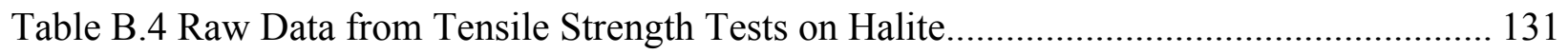

Table B.5 Raw Data from Shear Strength Tests on Potash ...................................................... 131

Table B.6 Raw Data from Shear Strength Tests on Halite ..................................................... 132

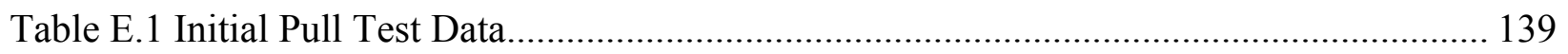


Table E.2 "Borer 6" Site Data............................................................................................... 148

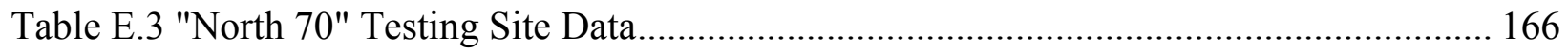

Table E.4 "South Storage Bin" Testing Site Data................................................................. 176

Table E.5 Short Embedment Length Test Data ................................................................ 181

Table E.6 "East 305" Testing Site Data .............................................................................. 182 


\section{Introduction}

This research involves the investigation of the behaviour of fully bonded rebar installed to support openings in underground potash mines. Understanding the bonded length of rebar required to mobilize the steel rebar yield strength and the link between potash deformation and rebar load are research goals which will aid in the design of stable ground support in potash mines.

\subsection{Background}

\subsubsection{Geology \& Stress Environment}

Potash in Saskatchewan is found in the Prairie Evaporite Formation that was deposited in the Middle Devonian time period approximately 400 Million years ago. Figure 1.1 shows the massive evaporite deposit that reaches thicknesses of 150 metres (500 feet) at some points. It is the result of an inland sea that stretched from Peace River Alberta to the Red River area in Manitoba. The arid climate during this time period caused "extreme desiccation and repetitive precipitation of potassium and magnesium salts in halite at the south-eastern extremity of the basin" (Worsley and Fuzesy, 1979).

The Prairie Evaporite is underlain by the Winnipegosis Formation, a carbonate formation dotted with mound-like formations. The mounds are associated with the subsidence of the Prairie Evaporite. Dissolution in the Prairie Evaporite around the margins of the mounds is present and was caused by the release of water during mound compaction (Gendzwill and Wilson, 1987). These mounds are problematic in mining because they cause highly variable geology, often with weak strength characteristics, presenting a challenge for ground support.

Lying above the Prairie Evaporite is the Dawson Bay Formation. This formation is marked by coloured mudstones (Holter, 1969), and is important in regards to potash mining because its higher strength is able to accommodate the increased stresses created by the removal of the potash. Since the Dawson Bay Formation can be water-bearing, and potash is soluble, it is critical that this formation stay intact to prevent the flow of water downward.

Saskatchewan potash mines are located in high stress environments, with relatively weak rock. Potash in this region of the world is typically mined on horizons nearly 1 kilometre deep. In-situ stresses are approximated to be lithostatic and equivalent to the weight of the overlying strata $(\sim 25$ 
MPa) (Ong, 2005). These conditions can lead to shear and dilation along horizontal clay layers located above the drift backs (Figure 1.2). These movements can create blocks or detached beams that require support for safe access. Support is not installed to prevent the stress-driven shear and dilational deformation from occurring, but rather to support the weight of these detached beams or blocks in drift backs.

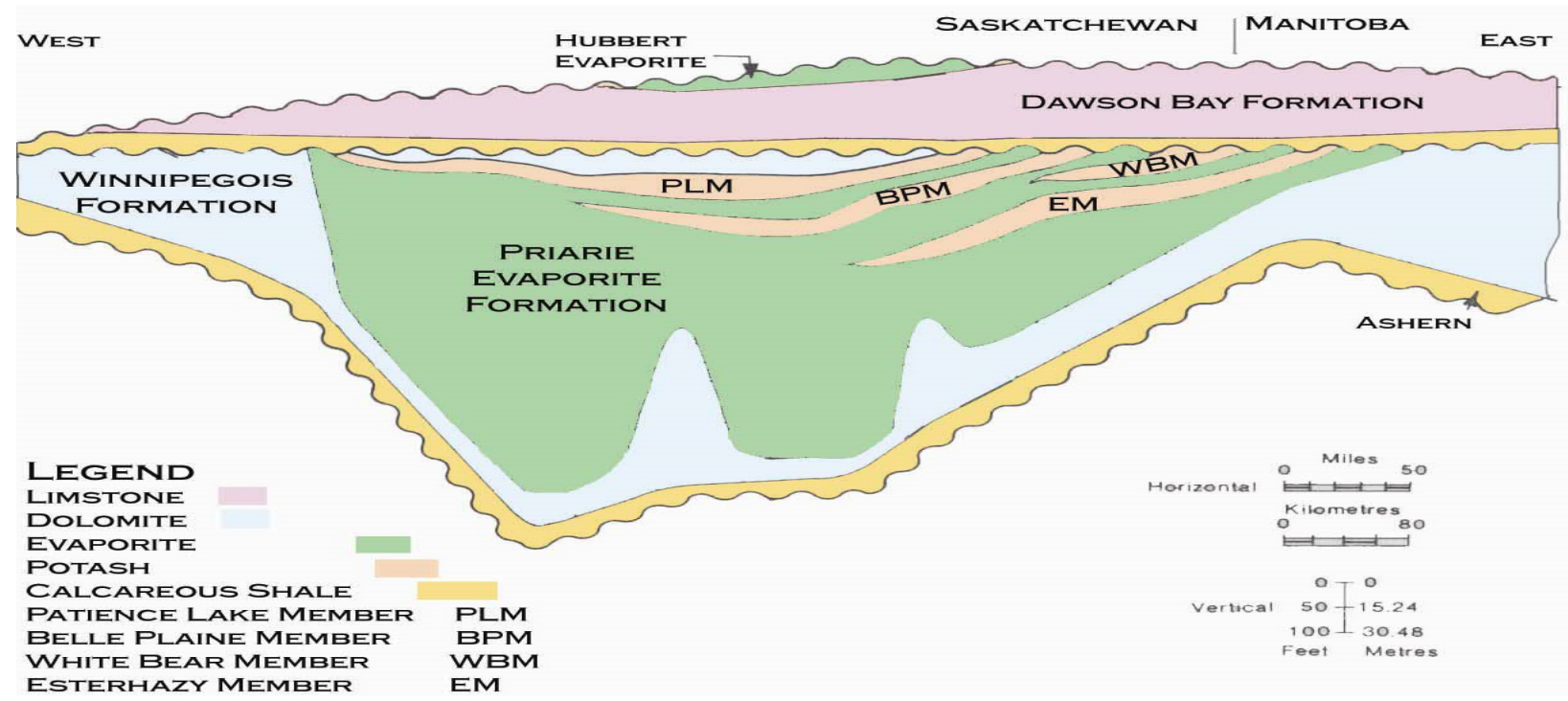

Figure 1.1 Cross-section of the prairie evaporite and surrounding formations (Fuzesy, 1982)
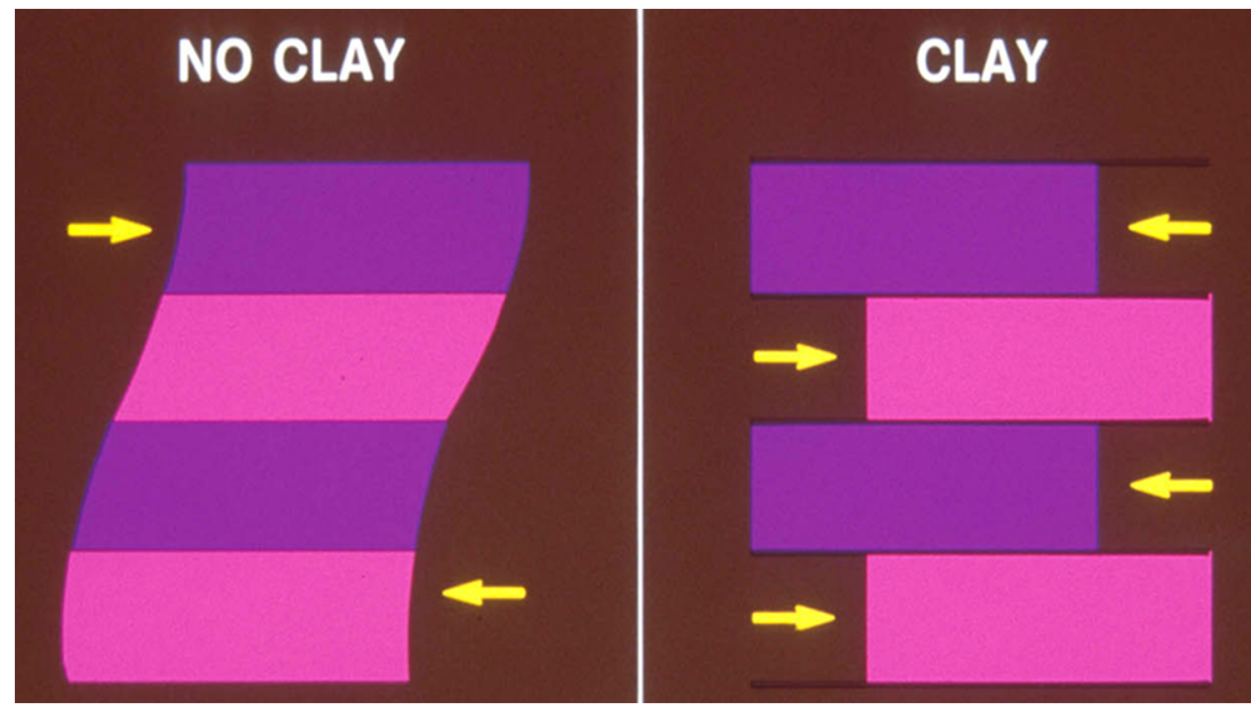

Figure 1.2 Clay seams allow shear deformation to occur readily (Hills, 2005) 


\subsubsection{Soft Rock Support Methods}

In general, rock support consists of reinforcing and retaining elements that serve different functions (Potvin and Hadjigeorgiou, 2000). Reinforcing elements, such as rock bolts, are installed in the rock mass to initially prevent movement along discontinuities. Retaining elements, such as mesh, hold up the dead weight of loose rock. This study specifically investigates reinforcing bar (rebar), a type of rock bolt. These consist of a rebar with a plate secured by a nut or forged bolt head, installed flush to the back, and an anchoring product such as cement or resin (Figure 1.3). The three materials: rock, resin, and rebar acting together can be referred to as a support system.

Rebar creates thick, stiff beams by connecting layers of rock salt separated by clay seams. In addition, the rebar suspends separate layers into thicker, more competent beams in the back (Figure 1.4). Rebar is commonly used as support when openings are required to remain open in the long term and/or when shear deformation is occurring in the surrounding rock. Rebar is selected in these cases because it is anchored to the rock along the entire length, resulting in less axial and shear strain in comparison with mechanical bolts which are free to strain along their entire length (Figure 1.5). Figure 1.6 illustrates how both tension and shear displacements can occur next to support in potash mines along the separations created by the clay seams.

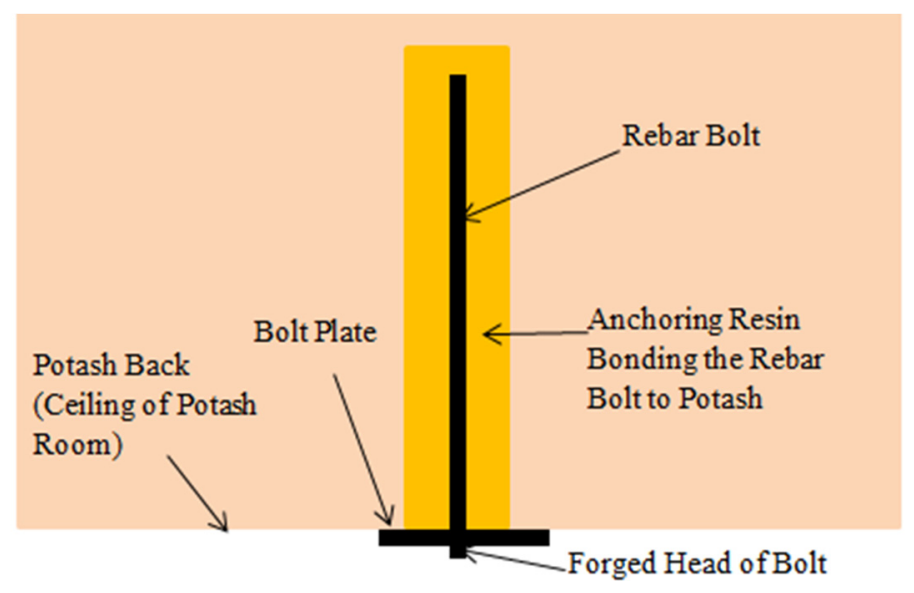

Figure 1.3 Rebar bolt schematic 


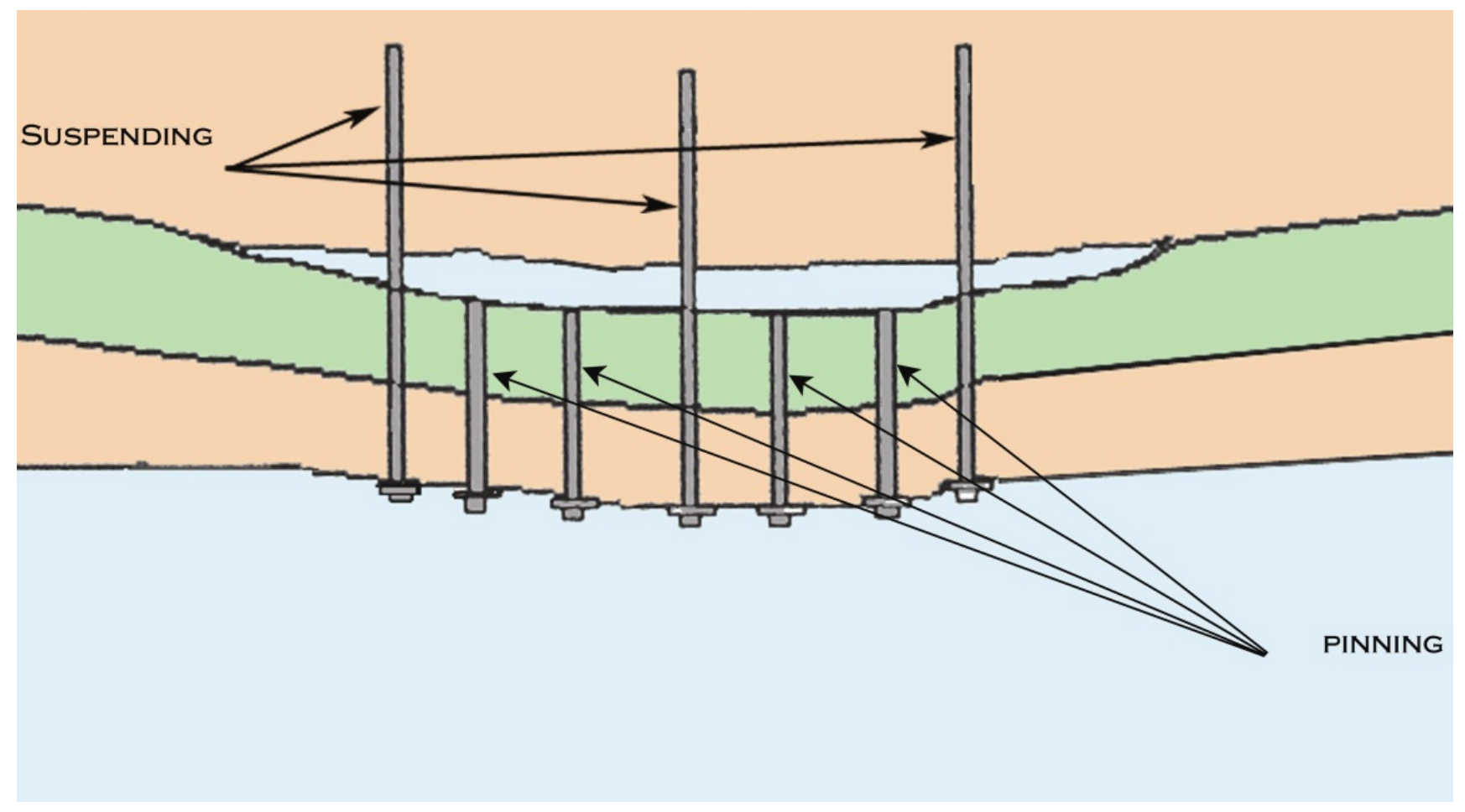

Figure 1.4 Suspension and pinning functions of internal rock support (Lovlin, 2006)

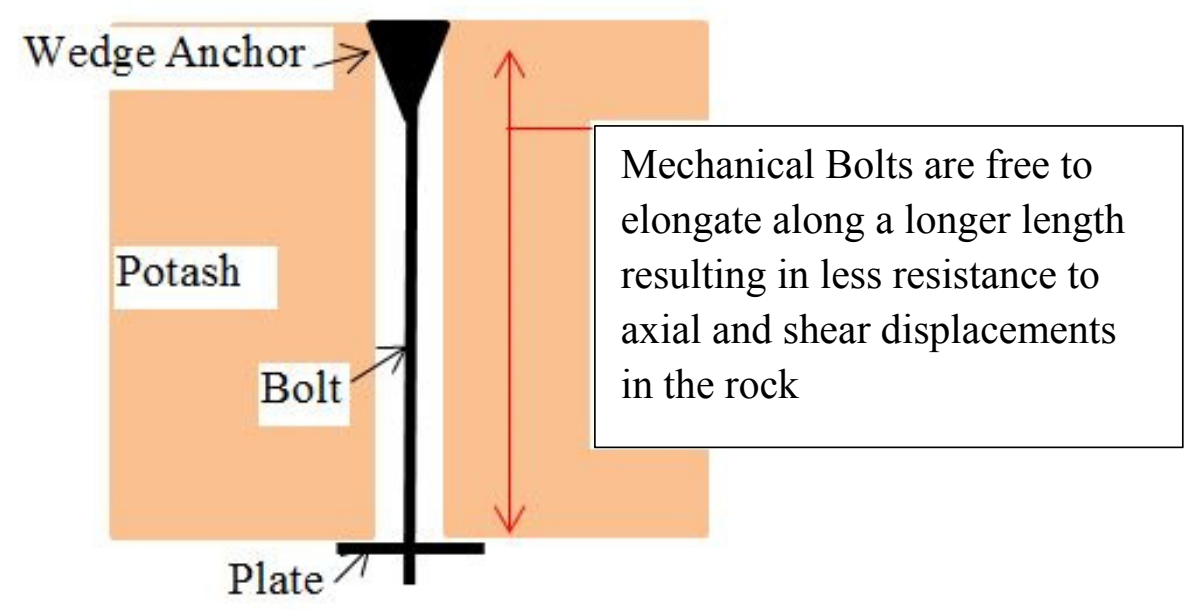

Figure 1.5 Mechanical bolt anchored using wedge and bolt plate 


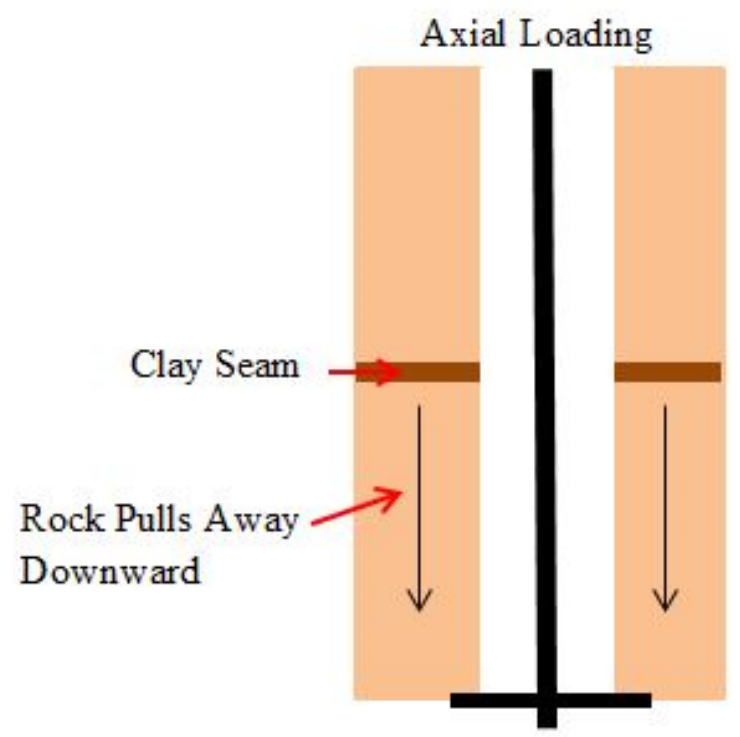

a)

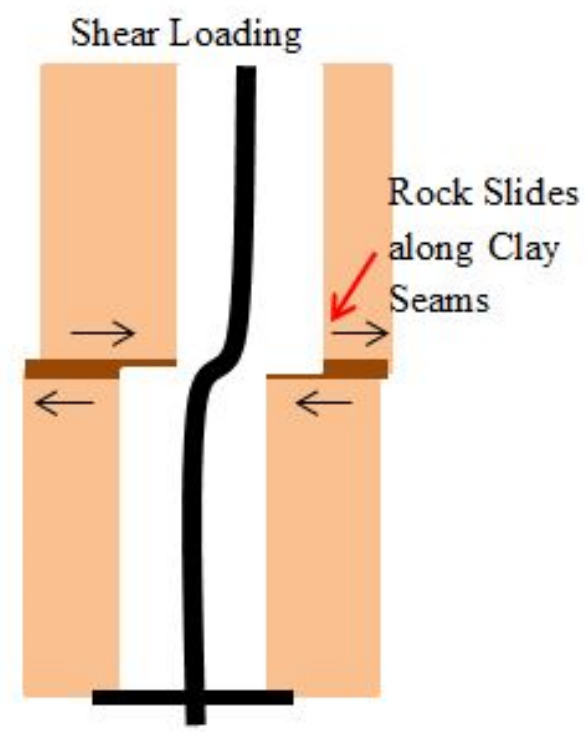

b)

Figure 1.6 Examples loading scenarios found in potash mining: (a) Axial, and (b) Shear

\subsubsection{Effects of Potash Mining on Rebar Bolts}

Potash can be mined using stress-relief patterns that are designed to deflect stress out and away from central openings. This method is common in the Saskatoon area potash mines in Saskatchewan which mine on the Patience Lake Member of the Prairie Evaporate shown in Figure 1.1. Individual openings are cut in a specific order, with the intention that the initial openings will deform and can later fail when in-situ stress surpasses the ultimate strength of the rock. Once failed, stress is deflected upwards, as shown in Figure 1.7. The stress deflection protects the central openings where the workers regularly travel. Over time, horizontal stress will migrate upwards towards the Dawson Bay Limestone, preferentially increasing stress in the rocks that are stiffer (higher Young's modulus). Rebar installed in the potash mines can be near mining faces where they will be subjected to large changes in confining pressure due to stress re-distribution. Ground movement rates near active faces are typically near $3 \mathrm{~mm} /$ day immediately after openings are made. In comparison, areas of a mine that are 100+ days old typically have steady ground movement rates of $0.3 \mathrm{~mm} / \mathrm{day}$ (Hills, 2005). Areas which are more than 300 metres away from an active face will not feel the effects from the current mining (Mackintosh, 1977).

The material that rebar is anchored into in potash mines varies due to geologic anomalies and support length. This varied anchoring material could have an effect on the average bond strength 
provided by the support system. Bond strength defines the resistance to slip along a unit length or unit surface area. To coincide with mining terminology, convenient units for bond strength are $\mathrm{kN}$ per metre, or the more commonly used mass equivalent, tonnes per metre (Hutchinson and Diederichs, 1996). It has been shown previously that rocks with a lower Young's Modulus provide less confinement to the support (Meadows, 1999; Stimpson, 1987a). This relation between average bond strength and the stiffness of the surrounding material is shown in a graph created by DSI for their Dywidag bolts (Figure 1.8). The slope of each line represents bond strength in terms of $\mathrm{kN} / \mathrm{m}$ in Figure 1.8. The DSI graph shows that stiffer rocks, like granite, require less bonded length to sustain the same loads than softer rocks like mudstone.

Shear and normal deformation of potash may continue after rebar is installed. Rebar is fully bonded (embedded) to the rock along the length of the rebar and is only loaded by deformation of the surrounding rock mass. This deformation may occur as strain within the intact rock caused by the dilation of cracks in the rock mass along the rebar. When deformation of the potash occurs at the location of a supported crack or fracture (separation), the load associated with this deformation is transferred along a bonded length of the installed rebar. This is common in potash mines where several clay seams are present above openings. For given steel rebar stiffness, the magnitude of the deformation and the length of bonded rebar (bond length) that deforms determines the load on the rebar. When sufficient deformation occurs for the support to reach its failure load, the length of the bonded support that deforms is called the critical bond length.

Loading can be distributed along a rebar due to strain distributed through the rock, or can be concentrated at discontinuities in the rock mass. This study considers localised deformation at discontinuities where loading and deformation initiate at the point where rock separates along the rebar. Detecting deformation along the bonded portion of the bolt based on inspecting the collar is not feasible. Personnel at the mine cannot detect the separations opening up by observing the rebar and plate (Figure 1.9) and do not have a method to estimate the current load on rebar based on fracture separation measured in empty holes next to the rebar. Separations occurring along discrete layers can eventually approach the deformation capacity of the installed support. When this occurs, re-supporting of the area (installing more rebar) is required to maintain safe access.

The potash mining industry would benefit from attaining a reliable data set to define the average bond strength available and the failure mechanism which governs the capacity of this type of 
support. Defining the bond strength and failure mechanism of this type of support would allow for improved ground support design. With the properties of the rebar and average bond strength defined, an estimate could be made of the load on the support based on deformation.

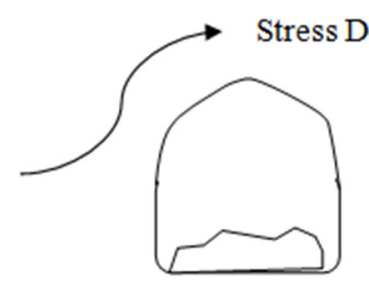

$1^{\text {st }}$

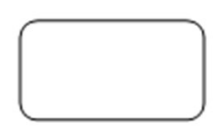

$3^{\text {rd }}$

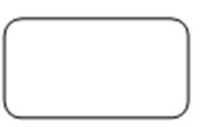

$5^{\text {th }}$

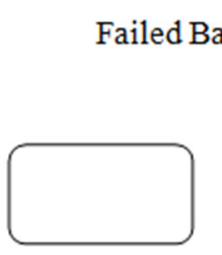

$4^{\text {th }}$

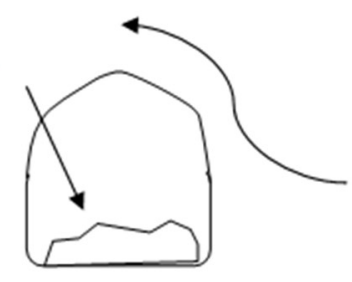

$2^{\text {nd }}$

Order in Which Each Opening Is Cut

Figure 1.7 Stress relief

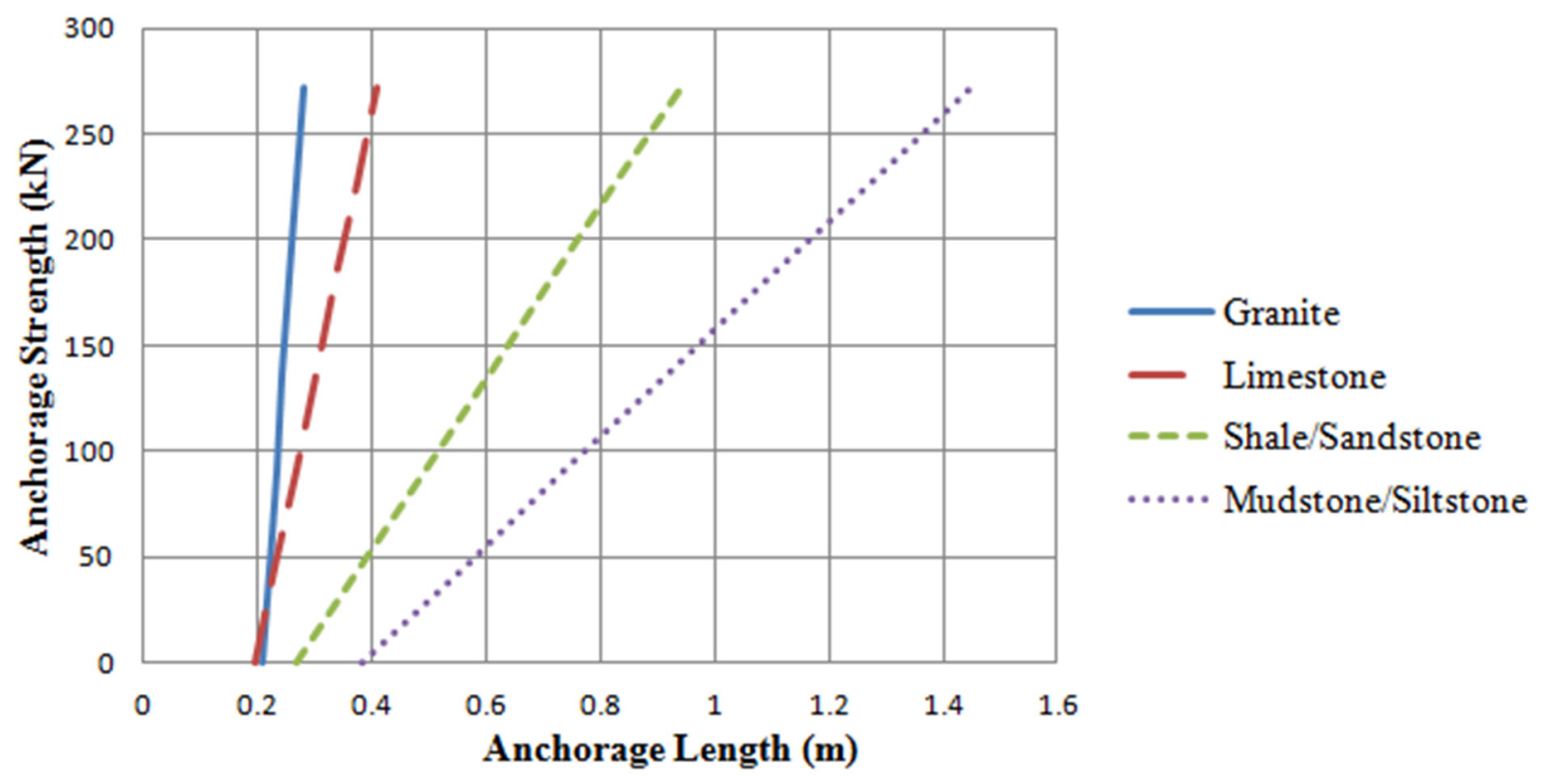

Figure 1.8 Bond strength relationship with rock stiffness after DSI (2009) 


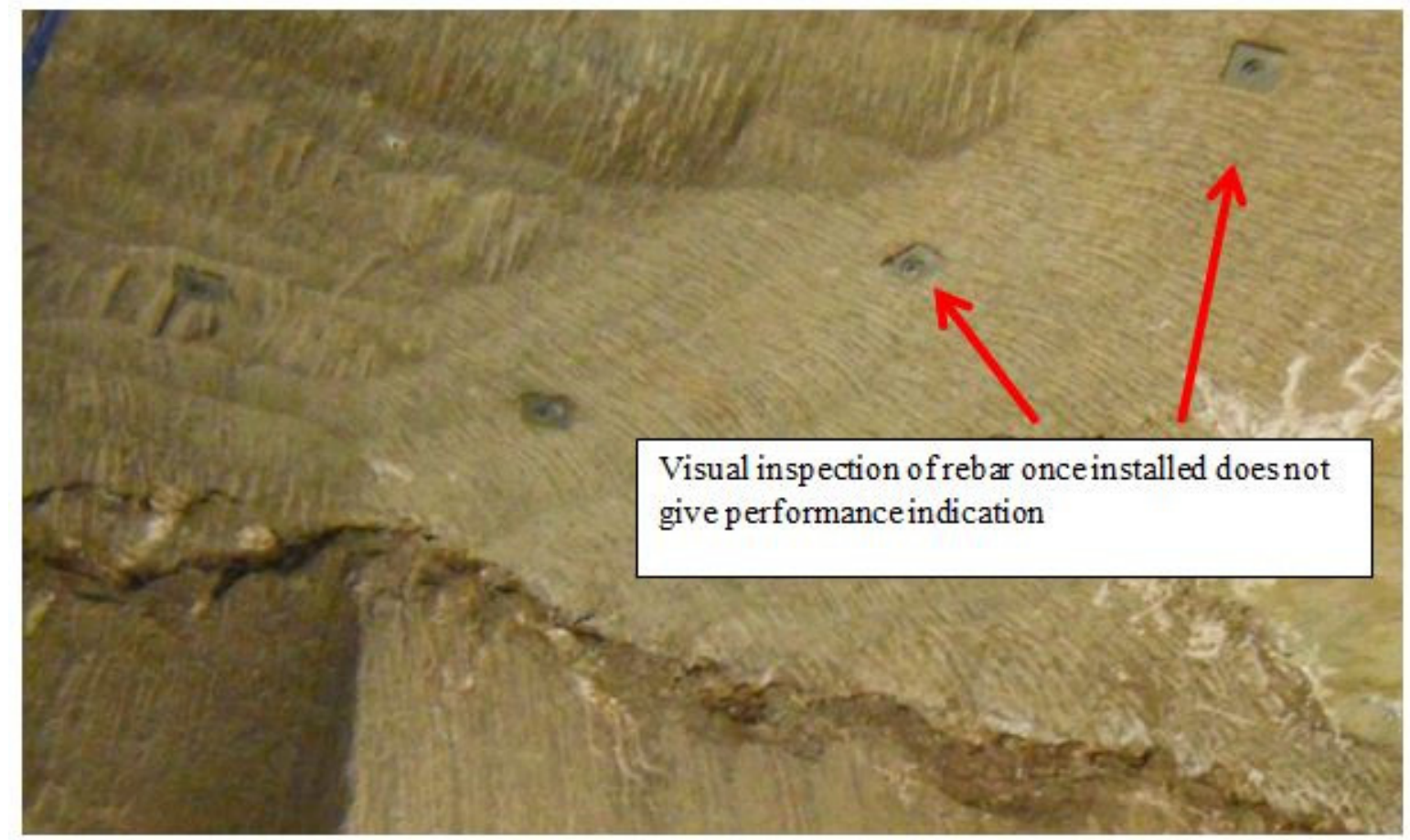

Figure 1.9 Visual inspection of rebar heads, looking up at potash back

\subsection{Objectives of Research}

The primary objective of this research project is as follows:

- To identify potential failure mechanisms of resin anchored rebar in potash. This will define what variables mine engineers can work with to improve ground support design.

Sub-Objectives include the following:

- To measure the variability of the average bond strength of rebar found in the field, due to variable mining conditions and environment. This will identify if there are variables which may have the potential to alter the expected capacity of the system;

- To use average bond strength values found in the field, in conjunction with the mechanical properties of the rebar, rock, and/or resin, to develop an equation to approximate the load on resin anchored rebar supports given measured deformations from the field.

\subsection{Scope and Methodology}

Determining the failure mechanism and the variable bond strength of the resin-anchored rebar support in potash mines in this research project was based on results from both laboratory tests and field tests. The approach involved conducting a number of laboratory tests to define the 
mechanical properties of the rebar used, as well as properties of the rock surrounding the support. In the field, there was a large number of pull tests conducted to define the average bond strength for a range of variables. The results were analyzed to find the support failure mechanism.

The range of variables considered included the rock type that the rebar was installed in and the distance to the advancing mining face. Resin epoxy cure time effects were investigated by conducting tests over a period of time. This project does not include an evaluation of different rebar or resin products and only used the products currently stocked at the Allan mine. Measuring the time-dependent properties of potash and/or halite are out of scope for this project, but the researcher is mindful of their potential significance. Quantification of the elastic properties of the materials used, and the bond strength of the support in the field, was based on laboratory testing and data from the literature.

\subsection{Outline of Thesis}

The following is an outline of the chapters, including a brief summary, included in this thesis.

- Chapter 2. Literature Review: Includes previously completed, relevant research to supplement and/or aid in the testing methodology development and analysis of results.

- Chapter 3. Laboratory Testing: Includes more detailed accounts of each laboratory test conducted and a summary of the results.

- Chapter 4. Field Testing: Includes a detailed description of the field testing completed, data reduction methods and a summary of the results.

- Chapter 5. Discussion of the Results: Includes an interpretation of the results and discusses the significance of the findings.

- Chapter 6. Conclusions and Future Work Recommendations: Summarizes the results and makes suggestions for continuing research on resin anchored rebar in potash. 


\section{Literature Review}

There has been significant work that has been conducted that investigated post-installed resin anchored rebar in structural engineering. Post-installed rebar involves drilling holes into preexisting concrete structures and installing rebar with an adhesive resin anchor. This process is similar to the process of installing rebar in the mining environment. There are many examples in mining literature which include research pertaining to resin anchored rebar, although very few which are specific to potash mines.

This review focuses on literature with both field and laboratory components in order to aid in the development of the testing program conducted as part of this research project. In particular, civil engineering literature will be used to develop a laboratory pull test procedure, as this type of testing is done extensively in structural engineering studies. Geotechnical and mining literature is reviewed to establish the influence that rock mass properties have on rebar installed using resin.

\subsection{Potash Rock Mechanical Properties Literature}

The properties of potash are important to understand when conducting research on resin anchored rebar because load is transferred from the bonded portion of the rebar into the potash. The effectiveness of rebar as ground support is based on the minimum strength properties and deformation properties of the rebar and rock, as well as the rock/resin and resin/rebar interfaces. Understanding how the rock will behave under certain loads is important in estimating deformation that may take place during the testing.

Potash or sylvinite is a combination of potassium salt $(\mathrm{KCl})$ and common halite $(\mathrm{NaCl})$ (Fuzesy, 1982). Potash mines in Saskatchewan are comprised of layers of potash, halite, and clay. Potash layers refer to the beds with both sylvite $(\mathrm{KCl})$ and halite $(\mathrm{NaCl})$ and visible amounts of insoluble minerals (clays). Halite layers refer to beds only containing halite and a traceable amount of clay. Clay refers to beds, or seams, made up of several insoluble minerals. It is this mixture of materials that creates a rock mass with complex mechanical properties. Due to the complex mechanical behaviour of the rock, it has been more common to use empirical methods, rather than mathematical modelling, to predict behaviour in potash mines (Mackintosh, 1975).

In the potash rock itself, crystals of halite and sylvite are often coated in insolubles (clay particles) so the behaviour of all three of these materials in combination governs the behaviour of the rock. 
Duncan and Lajtai's 1993 study on the creep behaviour of potash rocks from Saskatchewan gives some of the best insights into how the material behaves and the following discussion is based on this paper. The elastic limit of potash could be defined as $0 \mathrm{MPa}$ since, as soon as load is applied, the clay particles between the larger crystals begin to deform plastically. However, the elastic limit of the rock is defined typically at approximately $10 \mathrm{MPa}$ since this is the load at which the larger sylvite and halite crystals begin to deform plastically. Figure 2.1 shows a typical stressstrain curve for potash. Each curve represents either the lateral, volumetric, or axial strain response. Labelled in Figure 2.1 are points which define yield stress, crack initiation and crack damage. In the plastic deformation range (above the yield stress point), potash will exhibit microcracking, a brittle behaviour, as well as time dependent creep deformation. Steady state creep allows potash rocks to maintain constant loads with a steady rate of deformation over long periods of time.

Strain rates and the magnitude of the applied load affect the behaviour of potash as shown in the stress versus volumetric strain curve in Figure 2.2. Positive strain in both Figure 2.1 and 2.2 indicates compression while negative strain indicates expansion. The point at which crack damage (dilatancy) becomes the dominant process, leading to failure of the rock, can vary greatly given the rate of strain on the potash. As shown by dots on the figure, loading the potash at high strain rates $(25 \mu \varepsilon / \mathrm{s})$ can lower the point where brittle failure begins to occur to $6 \mathrm{MPa}$ as opposed to being approximately $24 \mathrm{MPa}$ at slow strain rates $(1.1 \mu \varepsilon / \mathrm{s})$. This chart shows that straining the potash slowly $(0.035 \mu \varepsilon / \mathrm{s})$ will result in the rock not displaying brittle deformation, and lower stresses at ultimate conditions.

Load on the rebar support, transferred from deformation of the intact potash, is not considered in this research. Failure of the potash as part of the rock/resin/rebar support system is a consideration in this research. 


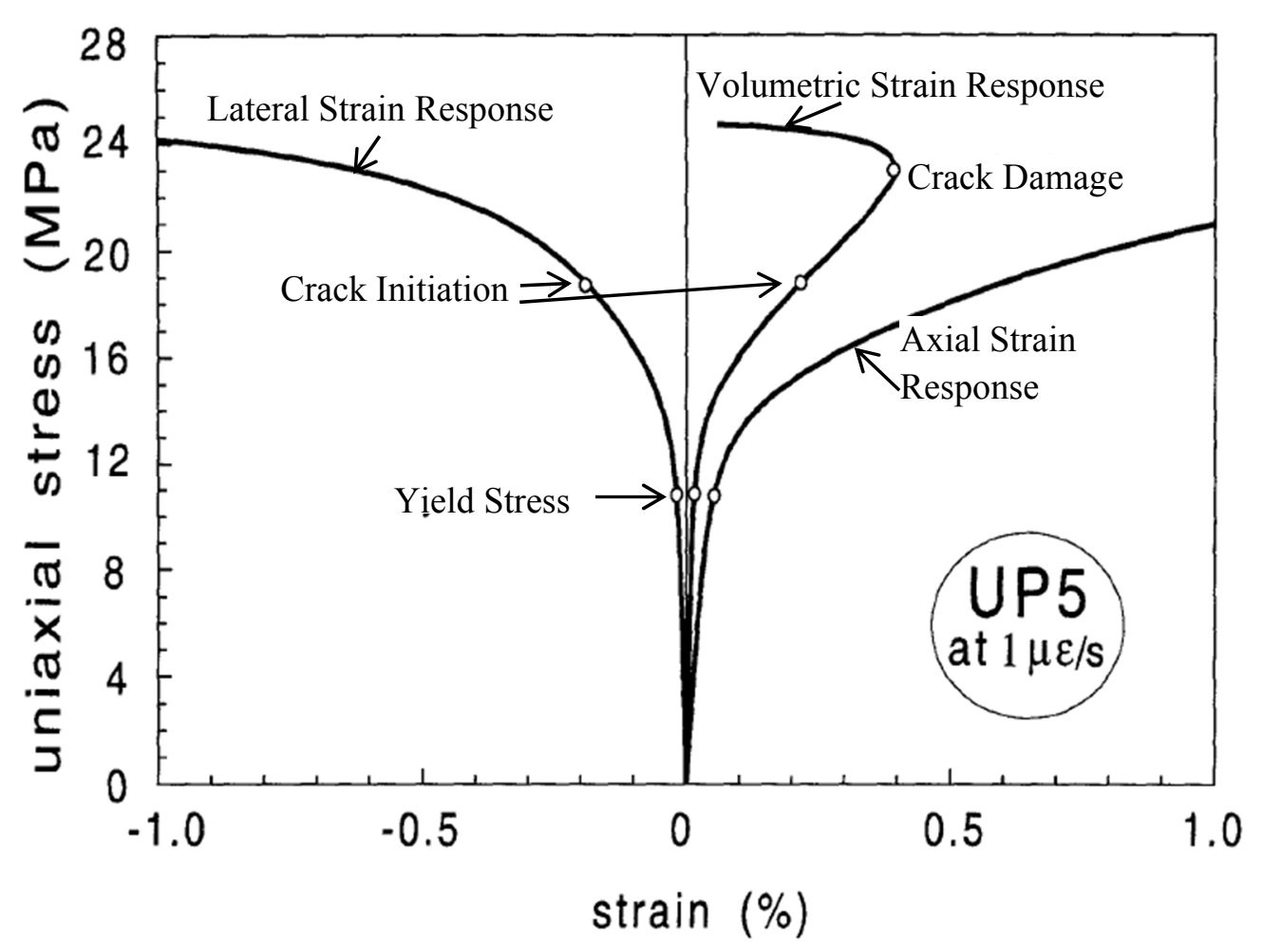

Figure 2.1 Typical stress-strain curve for potash after Duncan and Lajtai, 1993

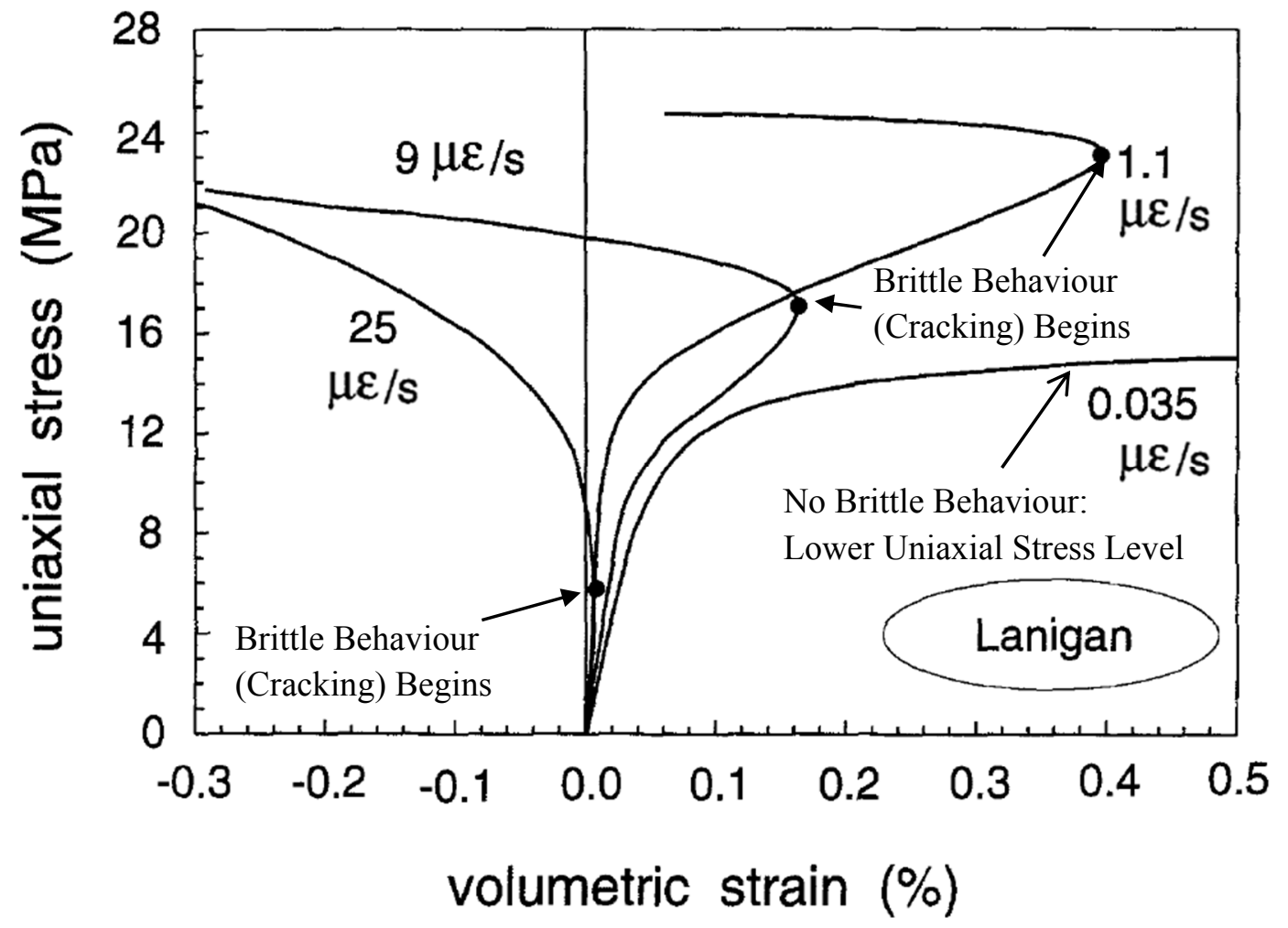

Figure 2.2 Effect of loading rate on potash failure point after Duncan and Lajtai, 1993 
The complex properties of potash are important to understanding rebar support behaviour. For example, any normal compressive loads applied to the rock that exceed the elastic limit of $10 \mathrm{MPa}$ will be important to note, as this is when time-dependent creep behaviour, and brittle cracking becomes substantial (Duncan and Lajtai, 1993).

As shown in Figure 2.2, the behaviour of potash is affected by the rate at which it is strained. This is relevant to the laboratory testing that was conducted as part of this research. The properties of the rock measured in the laboratory will not necessarily reflect the properties of the rock in the field since strain rates in the field are not replicated in the laboratory testing. Strength values in the field may therefore be lower than laboratory tests due to lower strain rates found in-situ.

\subsection{Structural Engineering Literature for Post-Installed Rebar Subject to Tensile Loading}

As mentioned previously, the use of post-installed resin anchored rebar has been the subject of study in structural engineering. Post-installed refers to the case where holes are drilled into an existing structure (generally concrete) and rebar is anchored using an adhesive anchor (resin). This process is common when additions are made onto previously built concrete structures. In the mining environment, holes are drilled into rock and then rebar is placed and anchored using resin. These two activities are not dissimilar, and therefore literature from the structural engineering discipline is important. This section highlights research completed in structural engineering relevant to this research project.

Cook (1993) studied the failure mechanisms of post-installed rebar anchored with chemical bonding agents (i.e. resin). In this study, Cook determined resin anchored rebar systems have constant deformation up to a yield load (for the system), which is dependent on the type of anchor material, embedded length, rebar diameter and hole size. However, beyond the yield load, the rebar/resin anchor system's behaviour was erratic and could not be defined as strain hardening or softening. The erratic behaviour was caused by the resin bond deteriorating between the rebar, resin, and the concrete which caused variable mechanical interlock (friction) once adhesion was destroyed.

Cook (1993) also observed that the elastic limit (bond strength) of the rebar system, which includes the surrounding resin, did not vary if the rebar was fully bonded along its length or if it was partially 
bonded (i.e. the rebar was not bonded to the concrete in the immediate vicinity of the bolt plate). When a force is applied at the bolt plate, only the resin nearest to the bolt plate is loaded. That is, the resin further into the hole is unaffected. If bond strength of a fully bonded rebar had differed from a partially bonded rebar, it would infer that the strength of the concrete had added to the strength of the rebar and resin anchor system. Cook's study determined that the strength of the concrete has negligible contribution to the strength of the reinforcement. In more recent literature, it was determined that the tensile strength of the surrounding concrete has an effect when embedment lengths are short (i.e. less than a metre) (Bargahr and Vogel, 2004).

Cook and Conz (2001) studied a number of factors that could influence bond strength of chemical adhesive anchors by pull-testing rebar installed with various types of resin. Pull testing consisted of attaching a hydraulic ram to the free end of the rebar bolt and pulling it out of the concrete in which it was installed. Baseline comparisons were made to find the effect of various factors. Elevated temperature was shown to be a factor with highly variable effects. While some types of chemical anchors showed an increase in strength, others showed dramatic decreases in bond strength when tested at a higher operating temperature: $43^{\circ} \mathrm{C}$ was used as the high operating temperature in these tests. The compressive strength of concrete was found to be a factor with little effect on the average bond strength. Factors such as having a damp condition in the drill hole reduced bond strength by $77 \%$ on average for all products.

Structural engineering investigations of post-installed anchors focused primarily on maximizing the effectiveness of the bond over shorter lengths. This is because it is not always possible or feasible to drill long holes for rehabilitation and expansion projects. As a result, the focus is on the possibility of the concrete failing in tension as this is more likely to occur with shorter embedment lengths close to a free face (Bargahr and Vogel, 2004). In mining this is not a likely scenario as rebar are typically embedded for lengths of 1.2 to 3 metres. As well, concrete structures and the rebar within them in structural engineering applications, are typically not exposed to the high confining stress regularly found in a mining environment. While this section provides some insight into the types of factors that can influence the strength of rebar anchored with resin, it is important to be aware of the differences between testing environments. 


\subsection{Mining Engineering Literature on Rebar Subject to Tensile Loading}

Van Ooteghem (1982) conducted pull tests on different types of rebar anchored with resin at what was then the Cominco mine (Agrium's Vanscoy mine now). The purpose of the testing was to make a comparison between the forged head rebar and a threaded end rebar. A total of 20 tests were completed, 12 of which were $25 \mathrm{~mm}$ diameter forged head rebar, the same type of rebar used at the Allan mine currently. Cominco was using 1.8 metre lengths of rebar rather than 2.4 metre lengths which are used at the Allan mine.

Testing at Cominco by Van Ooteghem included results where only the load applied versus the duration of the test was recorded and no deformation measurements were taken. Van Ooteghem varied the amount of resin placed in the hole, which controls the bond length between the rebar and the rock. Van Ooteghem recorded the load resisted by the rebar before either the ultimate capacity of the steel was reached resulting in a broken rebar, or the rebar "pulled from the hole." Without any deformation measurements, it is unclear what amount of deformation would define when the rebar had pulled from the hole or if this really did indicate that the rebar had completely pulled free. Out of the 12 tests involving the forged head rebar, 2 tests failed to give any results, 7 tests reached the ultimate strength of the steel and broke the rebar, and 3 tests resulted in "anchorage loss." The average bond strength found from these three tests was reported as 35.7 tonnes/metre.

The testing carried out by Van Ooteghem is typical of what has been previously completed in potash mines. The testing was not detailed with respect to the behaviour of resin anchored rebar, but rather a check of the performance of a small number of tests in order to provide a means to compare different products available. The small number of tests and the lack of definition of what constituted anchorage loss provides little insight into what variables may be important to the performance of this support system in potash mines.

Kuchling (1987) studied the bond strength of resin anchored rebar in potash at the Mosaic K-1

mine in southeast Saskatchewan. At the time, the mine was using $25 \mathrm{~mm}$ diameter, forged head rebar, anchored with 1 to 1.27 metres of resin. The purpose of Kuchling's research was to determine whether this length of resin anchoring was enough to allow the rebar to provide safe working conditions for the miners. 
Table 2.1 shows the data from pull testing conducted by Kuchling. The results showed an average bond strength of 74.9 tonnes/metre ( $735 \mathrm{kN} /$ metre). The steel used in the rebar had a breaking strength of $620 \mathrm{MPa}$ and the rebar had an ultimate load capacity of 31 tonnes. This meant that the critical bond length of resin, or in other words, the bond length with the same failure load as the rebar tensile load capacity, was a minimum of 0.41 metres. The failure mode in Table 2.1 shows that when the bond length is less than the critical bond length, the rebar will pull out of the hole. When there is enough resin to supply a bonded length longer than the critical bond length, the rebar will fail by breaking before the resin anchor fails. Therefore, Kuchling established that the length of resin being used was beyond that required. However, this extra length of resin is the result of requiring a factor of safety which accounts for the uncertainty when installing resin anchored rebar. Uncertainties can include many factors in the quality of installation such as whether the resin stays in place during installation or forms a good bond with the rock and rebar (Villaescusa et al., 2008).

The work conducted by Kuchling was done at the Mosaic K-1 potash mine, where shearing is not a concern due to the large halite bed above the back. As shown in Figure 2.3, PCS Rocanville, which is in the southeast of Saskatchewan like Mosaic K-1, does not have these clay seams which are prone to shear failure. Kuchling did not investigate the effects related to Young's modulus of the rock surrounding the rebar support, possibly due to the lack of variable lithology in the area. It is also unclear how Kuchling ensured that the resin stayed at the top of the hole when only onehalf, one, or two cartridges of resin were used. This could have led to poor installation quality which may have played a role in the rebar pulling out of the hole.

Kuchling's data shows that only four tests were completed and appeared to measure only load during the testing process and not deformation. Testing carried out by Kuchling was only intended to serve as a quality control check on current practices. As per Van Ooteghem's testing, Kuchling only varied the amount of resin used to anchor the rebar. Tests like these do not define the failure mechanism or identify any specific variable that may help to improve the anchorage. Kuchling's data shows an average bond strength twice that of the 35.7 tonnes/metre found by Van Ooteghem. It is possible that Kuchling calculated his anchorage strength based on the peak load reached during the test and Van Ooteghem based his on the load at which anchorage loss began to occur. The geology which the rebar was anchored to is also not stated in either case and this may have had an 
influence. Since neither of these papers detail the method used to calculate the average bond strength, it is difficult to assess the large difference in results.

Table 2.1 Pull test results from Mosaic K-1 after Kuchling (1987)

\begin{tabular}{|c|c|c|c|c|}
\hline Resin Packages & $\begin{array}{c}\text { Resin Anchor } \\
\text { Length (m) }\end{array}$ & $\begin{array}{c}\text { Rebar Bolt } \\
\text { Load (tonnes) }\end{array}$ & $\begin{array}{c}\text { Load per } \\
\text { Length } \\
\text { (tonnes/m) }\end{array}$ & Failure Mode \\
\hline 0.5 & 0.216 & 15.7 & 72.7 & Pulled Out \\
\hline 1 & 0.396 & 30.6 & 77.3 & Pulled Out \\
\hline 2 & 0.762 & 32.3 & - & Bolt Failed \\
\hline 2 & 0.762 & 34.3 & - & Bolt Failed \\
\hline
\end{tabular}

Several Clay Bands Present Directly above Mining Horizon

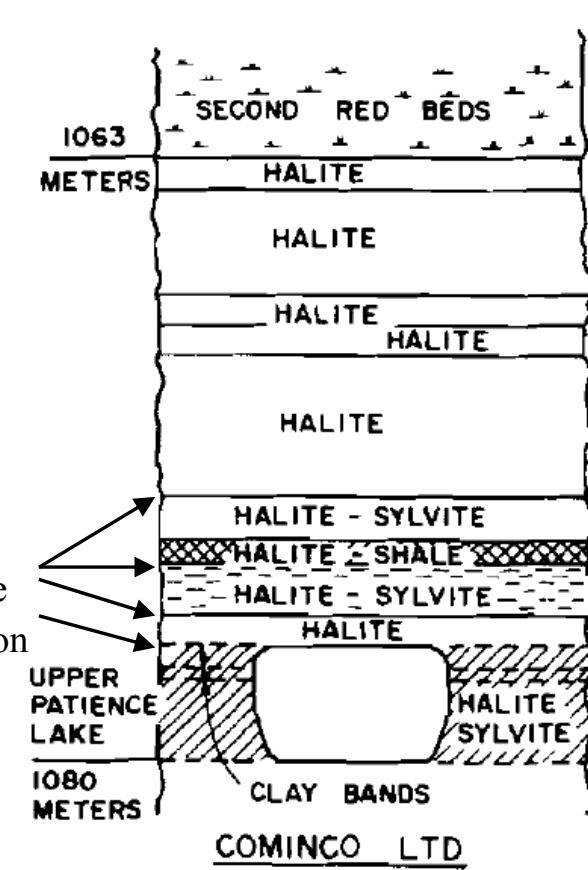

(a)

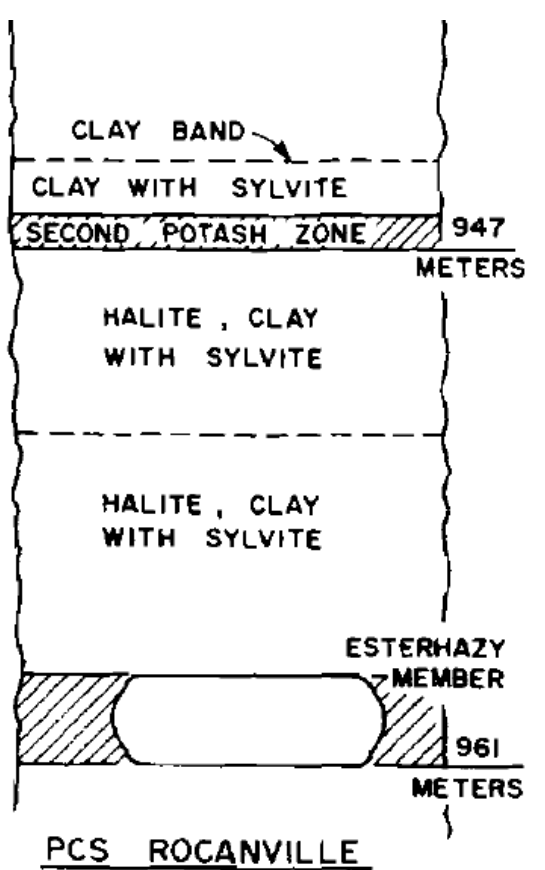

(b)

Figure 2.3 Geological differences between Saskatoon area mines and southeastern mines after Jones and Prugger (1982) : (a) Cominco, and (b) PCS Rocanville 
Stimpson (1994) wrote an overview on rock bolting and reinforcement. In this overview it is stated that the load transfer performance of resin anchored rebar depends on the shear stress capacity of the two interfaces between both the resin and rock and the resin and rebar surfaces. The interface shear strength is determined by several factors including but not limited to: bolt diameter, hole size, confinement, rock strength, resin strength, installation procedures, and the mechanical properties of the rebar. This implies that these variables may be important to identify, test, or control in field and laboratory testing when trying to identify the failure mechanism of resin anchored rebar.

Mark et al. (2002) investigated pull testing done on fully embedded (with resin) rebar in U.S. coal mines. The researchers stated that standard pull tests cannot be done on rebar that are anchored for their entire length because pull testing would only test the ultimate strength of the rebar itself because the loading at the bolt plate seldom extends more than 0.46-0.61 metres (18-24 inches) up the resin column. This is because resin anchors are very strong and capable of handling several tens of tonnes of load per metre of bond, while a $25 \mathrm{~mm}$ diameter rebar, for example, may have an ultimate load capacity in the range of 30 tonnes. The pull testing therefore reaches the ultimate capacity of the bolt when a relatively short length of the resin anchor is loaded. The bolt therefore breaks. This provides little or no useful information on the strength of the resin anchor and average bond strength. This test would indicate whether the resin anchor near the bolt plate is of good quality but gives no indication with respect to the remaining resin located further away from the bolt plate.

In order to test the quality of the resin anchor and not the ultimate capacity of the bolt, the short encapsulation pull test (SEPT) methodology was used by Mark et al. (2002). SEPT is a pull test where only the top 0.3 metres ( 12 inches) of the bolt is anchored with resin ( 0.3 metres at the end furthest from the free face). Pull testing over this short length provides information on the effectiveness of the bond between the resin and rock. The quality of the bond is measured by calculating the load applied per length of resin bond. It was observed that rocks with lower strengths typically had poorer bond strength per resin anchor length. Therefore, weaker rocks need longer resin anchor lengths to achieve the same anchorage strength as stronger rocks.

Mark et al. (2002) suggested that because resin anchors resist slipping using mechanical interlock and not adhesion, steps can be taken to improve the performance of resin anchored bolts. 
Mechanical interlock rather than adhesion means that the strength of the bond is a result of frictional forces due to the irregular surfaces of both the rock and rebar. Holes with rougher edges improve the frictional resistance, which prevents the bolt from pulling out of the hole. It may be true that, once the bond between either the resin/rebar or resin/rock surface is broken, mechanical interlock would provide additional strength; however, before the bond is broken, adhesion between the surfaces involved would have a significant role in providing anchorage. Mark et al. (2002) disregarded the role of adhesion by focusing on the mechanical interlock which would be present once the adhesion has been destroyed.

Mark et al. (2002) collected information from other studies conducted across the United States, and did not actually conduct pull testing. The report does not indicate what different types of resin might have been used in the findings of the bond strengths. When mechanical interlock is discussed as the failure mechanism for resin anchored rebar, there is no mention of whether this would vary given the type of rock. It could be postulated that weak and strong rock settings may have different failure mechanisms present; however, Mark et al. (2002) does not discuss this.

A study completed by Villaescusa et al. (2008) discusses problems which can occur during the installation of resin anchored rebar that have an effect on the anchorage provided. With a smaller annulus size, problems with poor resin mixing and the resin cartridge's plastic wrapper remaining intact to tangle around the rebar bolt can be reduced. A smaller annulus size ensures that the rebar will be encapsulated by resin and air will be removed, leaving no gaps which would form if a large volume is available for the resin to mix in. A larger annulus size provides too much room and prevents vigorous mixing, resulting in the cartridge wrapper remaining intact, and the development of air gaps entrained within the resin. Proper mixing of the resin and destruction of the wrapper from the resin cartridge ensures good contact between the resin anchor, the rock, and the rebar.

Confining stresses present were not investigated in field testing as a variable affecting the anchorage, though Stimpson (1994) indicated these stresses as a variable affecting the performance of resin anchored rebar. If the bonded length of the rebar is near the surface of the opening there would be less confinement. This may reduce the role of the rock's compressive strength in influencing the results. 
The location of the rebar in the mine was also not mentioned in previous studies. Large concentrations of horizontal stresses immediately above or below openings recently made would provide a squeezing effect surrounding the installed rebar. Figure 2.4 shows the orientation of horizontal stresses concentrating above a newer opening (Figure 2.4(a)) and an older opening (Figure 2.4(b)). In the older opening, stress has had time to dissipate and the magnitude of horizontal stresses directly above the openings is less than immediately after the opening was made. Larger magnitudes of horizontal stress directly above the opening may increase the frictional bond between the rock, resin, and rebar when mechanical interlock is providing anchorage. For this reason, areas of a mine that are in virgin ground may be able to provide better anchorage, reaching higher peak loads, than areas in a mine which have been open for long periods of time and no longer have large amounts of stress concentrated around them.

Literature related to field pull tests completed on rebar in potash and other soft-rock type mines lacks the detail to define how bond strength is influenced by variables that exist within the mining environment. The literature found showed pull testing results completed more as a quick check of the anchorage being provided in one area or another in a mine. Completing enough pull tests to determine the failure mechanism and define how bond strength may vary is likely too timeconsuming for many engineering departments to undertake along with other daily obligations. Figure 2.5 shows typical data output from a pull test completed by Van Ooteghem (1982). Without any deformation recorded, the focus is the maximum load reached during the test. Defining where the bond between surfaces fails (when adhesion is destroyed) requires deformation measurements and testing with bond lengths that will ensure bond failure before steel yield or failure. This research project will fill in missing information concerning resin anchored rebar performance in various environments found in potash mines. 


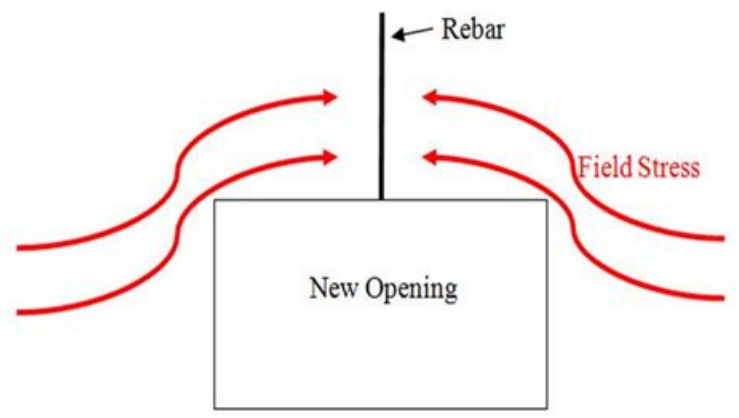

(a)

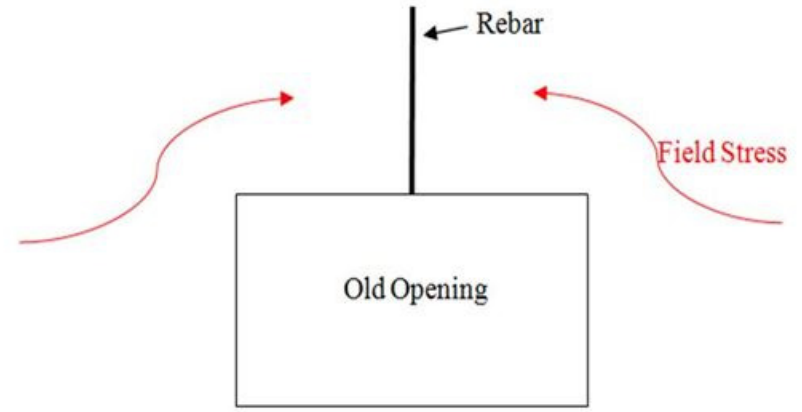

(b)

Figure 2.4 Field stress surrounding rebar in both (a) New, and (b) Old openings

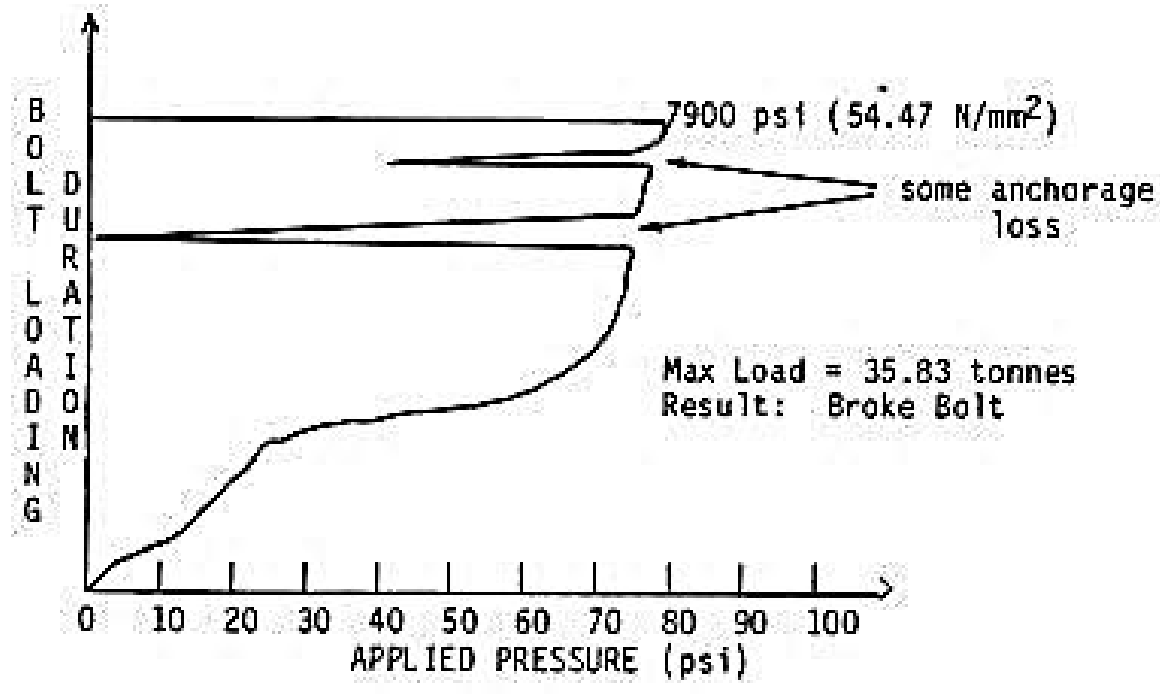

Figure 2.5 Pull test data output (Van Ooteghem, 1982)

\subsection{Laboratory/Analytical Studies with Combined Shear and Tensile Loading}

Stimpson (1987a) conducted an analytical study, using classical beam theory equations, to determine the shear stiffness of resin anchored rebar in layered strata. According to this study, grouted bolts installed across discontinuities can limit the interlayer slip due to their inherent shear stiffness. Variables such as separation or aperture thickness, inclination of bolt to separation, and the moduli of surrounding materials were included in the model and the following general relationships were determined: 
- Larger bolt diameters are stiffer;

- Stiffer rock allows for greater shear resistance per shear deformation magnitude from the bolts;

- The modulus of elasticity of the grout (resin) does not have a significant effect on the shear resistance.

Stimpson (1987b) also studied the effects of the position of rebar, across the width of an opening, in order to prevent shear and tensile deformation. He found that rebar in the centre of the opening are subject to tension alone and have increasing components of shear as they are placed closer to the abutments (pillars) on either side. His results showed that when rebar are placed at a distance of $20 \%$ of the total span away from the abutment, they optimally decreased the amount of shear deformation. Therefore, rebar spacing will impact how the bolts resist movement.

No in-situ testing was done to confirm the analytical results in these two studies by Stimpson. The optimization of the position of the rebar was done through computer modelling. As well, Stimpson used elastic beam theory for stress-analysis and did not state how effects found due to the variable composition and strength of natural rock and associated geological anomalies would affect the analysis. Inherent variation of geological materials could be accounted for through extensive field testing.

Cable bolts, made up of seven steel strands wound together, are used in hard rock mining applications to suspend layers of rock. Cable bolts, similar to rebar, are typically inserted in predrilled holes and grouted with cement or resin. Cable bolt deformation behaviour has been previously studied under combined loading (shear and tension) conditions. Reviewing literature on cable bolts provides insight on how deformation and loading may occur in rebar in this combined loading condition.

Dube (1995) performed testing on cable bolts subjected to both tensile and shear loading in combination. He found that with an increased magnitude of shear, the bond strength increased due to more frictional resistance from the bending cable bolts and crushing of the cement grout. In other words, the cable was more resistant to pulling out once it was bent at a separation experiencing shear displacement. The bond strength increased due to the mechanical interlock 
provided by the bending, but the capacity of the cable bolt was compromised by the combined loading and would break at a lower load applied at the collar.

There are two methods found in the literature for testing rock support such as cable bolts or rebar while they are subject to a combination of tension and shear forces. One method involves confining the cable or rebar using blocks of rock while the second method uses steel cylinders surrounding the bolts to provide confinement. Schematics of both are shown in Figure 2.6. Stillborg (1984) used one method where continuous cable bolts were grouted into two separate granite blocks. The granite blocks were then pulled apart axially while being moved laterally in opposite directions. Difficulty in testing was encountered for these specimens because of failure developing in the granite blocks before the cable bolts failed (Stillborg, 1984).

Dube (1995) used an apparatus where a single cable bolt was grouted into two separated steel cylinders to simulate the cable bolt being anchored into sections of rock moving relative to each other. Previously, blocks of rock, rather than confining tubes, were thought to be preferable for the experiment for more realistic confinement and borehole wall conditions. The rock would be softer and crush when the cable bolt contacts it at higher applied loads. The confining steel cylinders were stronger and did not deform. Stillborg (1984) explains that since blocks of rock in the laboratory do not replicate the confinement provided by a surrounding body of rock in the field, the dilation around the cables during pull out often caused the surrounding rock to fail in tension. The use of strong steel cylinders in the laboratory by Dube (1995) did not replicate the borehole wall deformation that would occur in the field. Steel cylinders, however, were able to provide improved confinement to the cable bolt and grout compared to the blocks of rock so that deformation and loading behaviour of the cable bolt could be tested under conditions close to that of the field. The method involving steel cylinders proved to be more successful in gathering data from the laboratory testing. 


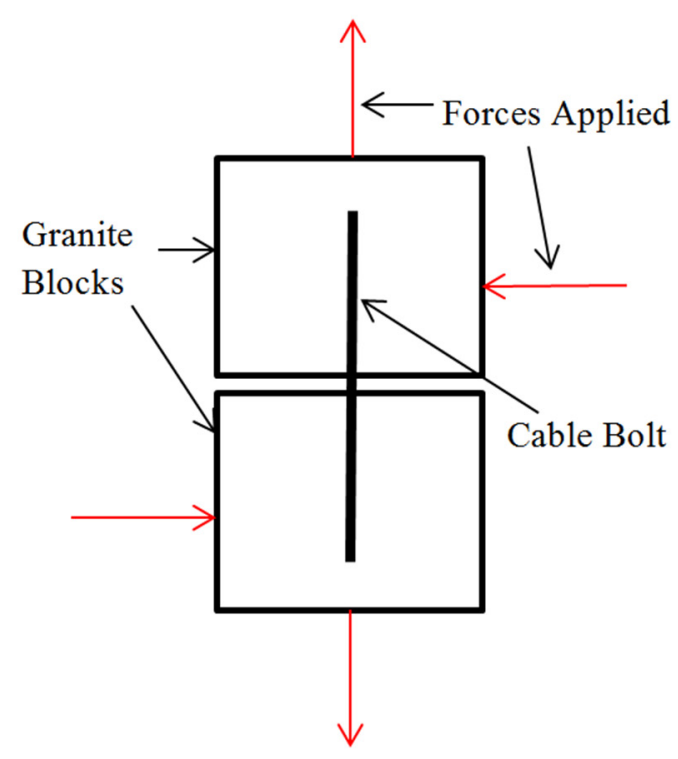

Stillborg (1984)

(a)

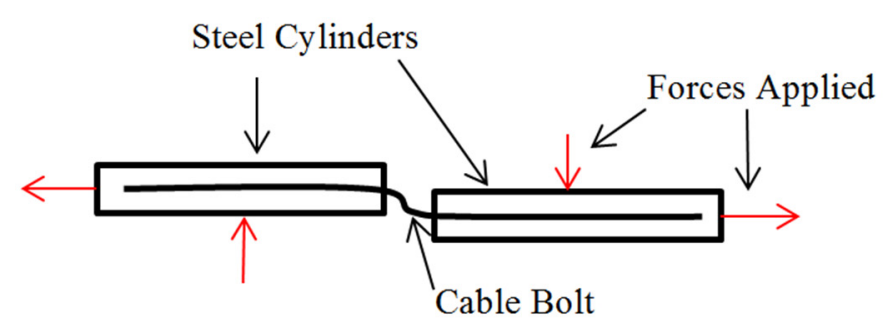

Dube (1995)

(b)

Figure 2.6 Schematics of testing methods used by: (a) Stillborg (1984) and (b) Dube (1995)

\subsection{Literature Defining Load Distribution along Resin Anchored Rebar}

The typical load versus deformation behaviour of a resin anchored rebar can be seen in Figure 2.7 (Cook, 1993). Cook explains that the bonded anchor system loads linearly up to an elastic limit, which may be less than or equal to the yield strength of the rebar (Figure 2.7). The elastic limit of the anchor system is less than the yield strength of the rebar when the bond strength fails before the yield strength of the rebar is exceeded. Beyond the elastic limit of the anchor system, the adhesion which existed between the resin/rebar or resin/rock contact surfaces has been destroyed and the strength of the anchor becomes dependent on the mechanical friction available and behaviour becomes unpredictable and erratic. Defining this elastic limit or load when sliding begins has not been previously accomplished with pull test data from potash mines, as reviewed in Section 2.3. Since strength provided by the mechanical interlock can be variable, the load used to calculate average bond strength may be more appropriately defined by the load that exists at this elastic limit when sliding of the rebar system begins. This sliding may be rebar sliding out of the epoxy or the epoxy and rebar sliding out of the hole in the rock. 


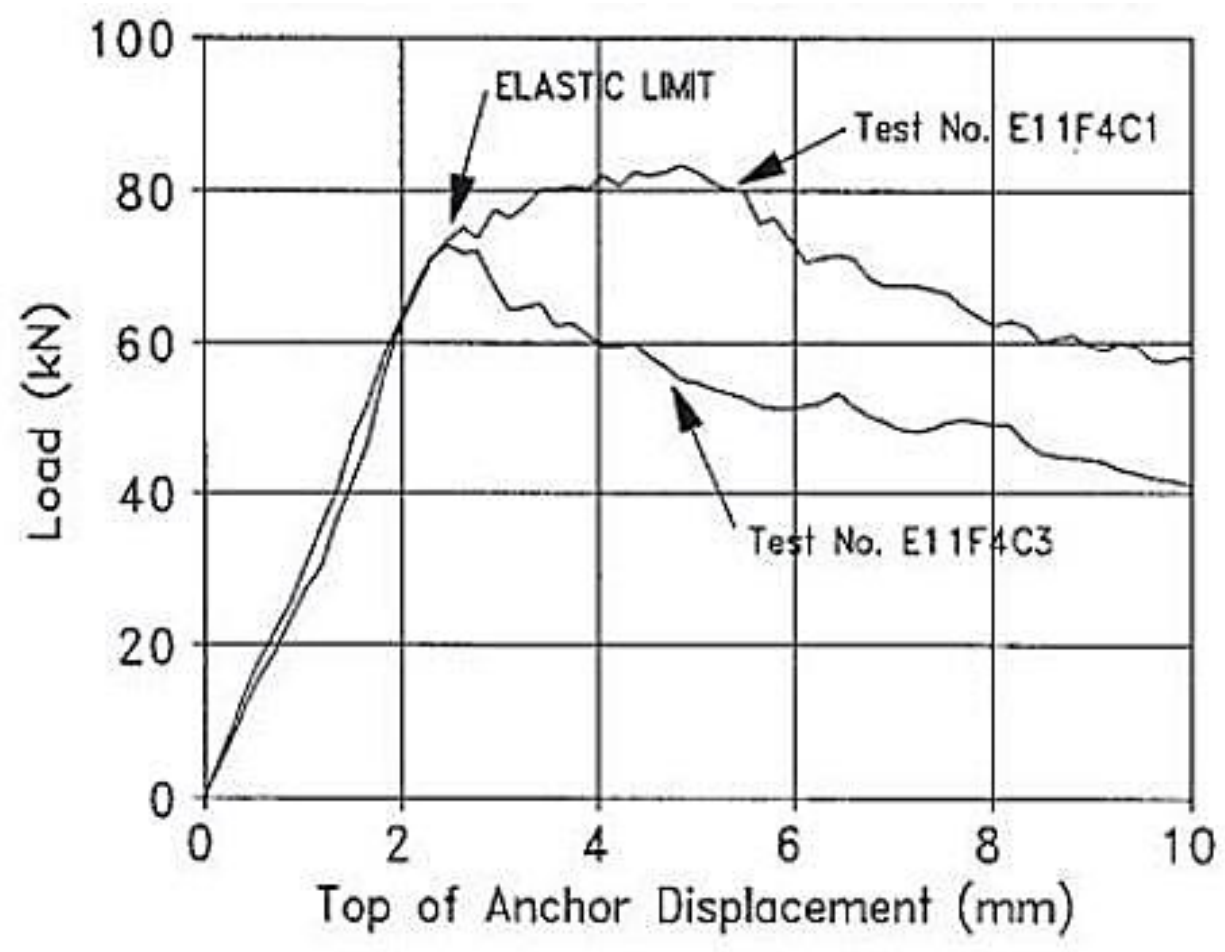

Figure 2.7 Example showing loading behaviour both before and beyond the elastic limit (Cook, 1993)

In order to define the loading behaviour before this elastic limit is exceeded, Cook (1993) described two bond models for adhesive anchors: the uniform bond-stress model and the elastic bond-stress model. Figure 2.8 displays the distribution of the bond (shear) stress assumed by both models along an anchored rebar. The uniform bond-stress model is simplistic and defines the capacity of the anchor by using a uniform bond stress present on the adhesive anchor. The uniform bond stress is determined by taking the load at the elastic limit and dividing it by the surface area of the anchor. This assumes an average bond stress exists across the entire adhesive anchor length at all loads low enough to have not yet exceeded the capacity of the adhesion. This simplifies the load distribution along the bonded portion of the rebar. 


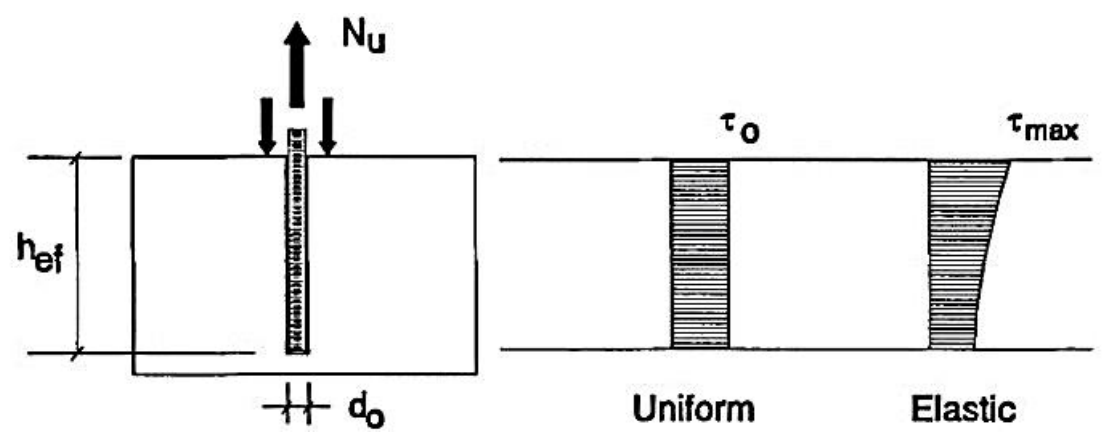

Figure 2.8 Uniform and Elastic Bond-Stress Models from Cook (1993)

The elastic bond stress model is similar, but instead of a constant bond stress, a maximum bond stress value is determined followed by a decrease in bond stress. Cook (1993) states that the elastic model, based on 'rational analysis', defines the bond stress decrease along the bonded portion, as a hyperbolic tangent function. The bond stress is at a maximum where load is being transferred from the anchor to the rock/concrete surface across an intact adhesive anchor (resin). The bond stress decreases due to the anchor surface further from the applied load not yet being engaged to transfer load at lower loads. It is acknowledged in the elastic model that the load distribution along the adhesive anchor is not linear. The load at any point along the length of the anchor will depend on the load transfer characteristics of the adhesive anchor (average bond strength), and whether the adhesive bond still exists between all three materials which, in Cook's case, was rebar, resin, and concrete.

Li and Stillborg (1999) developed an analytical non-linear bond stress model for fully grouted rock bolts (rebar). They state that when anchored rebar are placed under a tensile load, failure will occur either in the bolt-grout interface, the grout medium, or the grout-rock interface or in the bolt (rebar) itself. Where this failure occurs depends on which one of these is weakest. The load distribution along the bonded anchor is defined by the decoupling that occurs at an increasing distance from the loaded end of the bolt. There are three components to the bond strength that control the decoupling: adhesion, mechanical interlock, and friction.

Figure 2.9 shows the distribution of bond stress along a fully grouted rebar suggested by Li and Stillborg (1999). Figure 2.9 is similar to a load deformation graph with the zero deformation point being at the right side of the graph (point 1). As the deformation between the rock and the rebar increases, the bond stress of the system increases to point 2 (maximum bond stress). Continued deformation, past the peak, moves the bond stress to the post peak range (point 2 to point 3 ) and 
eventually only the residual bond stress is present (point 3 to point 4). The bond stress then decreases to zero where both the shear and adhesive strength of the bond has been destroyed, close to the loaded end of the rebar (point 5). Complete bond failure occurs when decoupling occurs over the entire bonded length. This model is different from the models proposed by Cook (1993) in that the bond stress varies along the length of the support depending on whether decoupling has occurred or not. It is a more complex function to more accurately determine the load distribution along a fully grouted rebar.

Cook, Burtz and Ansley (2003) again discussed the uniform bond stress model previously described. In this report, the uniform bond stress model is recommended where the embedment length of an adhesive anchor does not exceed 25 times the anchor diameter. Within this embedment length range, the uniform stress model provides comparable results to other more complex models. The average bond stress found from the uniform model was shown to result in less than 4\% error, given the embedment length limit of 25 times the anchor diameter (McVay, Cook, and Krishnamurthy, 1996). Use of this model greatly simplifies the process of defining the load distribution along resin anchored rebar.

A comparison of Li and Stillborg's model of load distribution with the simplistic uniform bond stress model is shown in Figure 2.10. The use of the uniform bond stress model allows for an assumption that load decreases linearly along the bonded length. In Figure 2.10, the uniform bond stress model has been superimposed on the more complex model. Given the uniform bond stress, the peak elastic load is at the loaded end of the rebar and decreases linearly over the bonded length. The more complex model presented by Li and Stillborg shows that most of the load is concentrated near the loaded end of the rebar where only residual bond is present. This is followed by a quick decrease in load along the portion where the bond is still intact. 

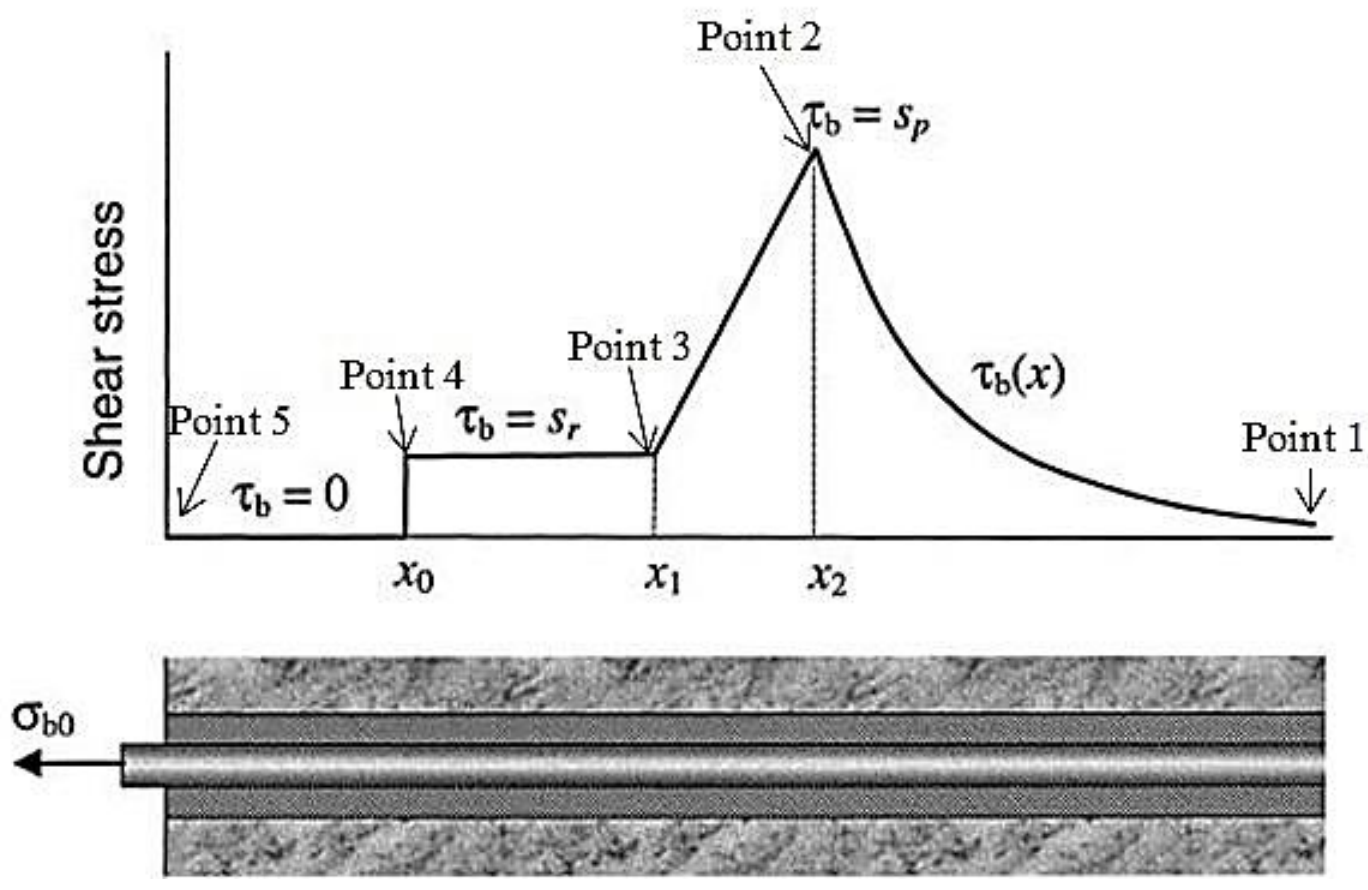

Figure 2.9 Bond stress distribution along a fully grouted rebar after Li and Stillborg (1999) 


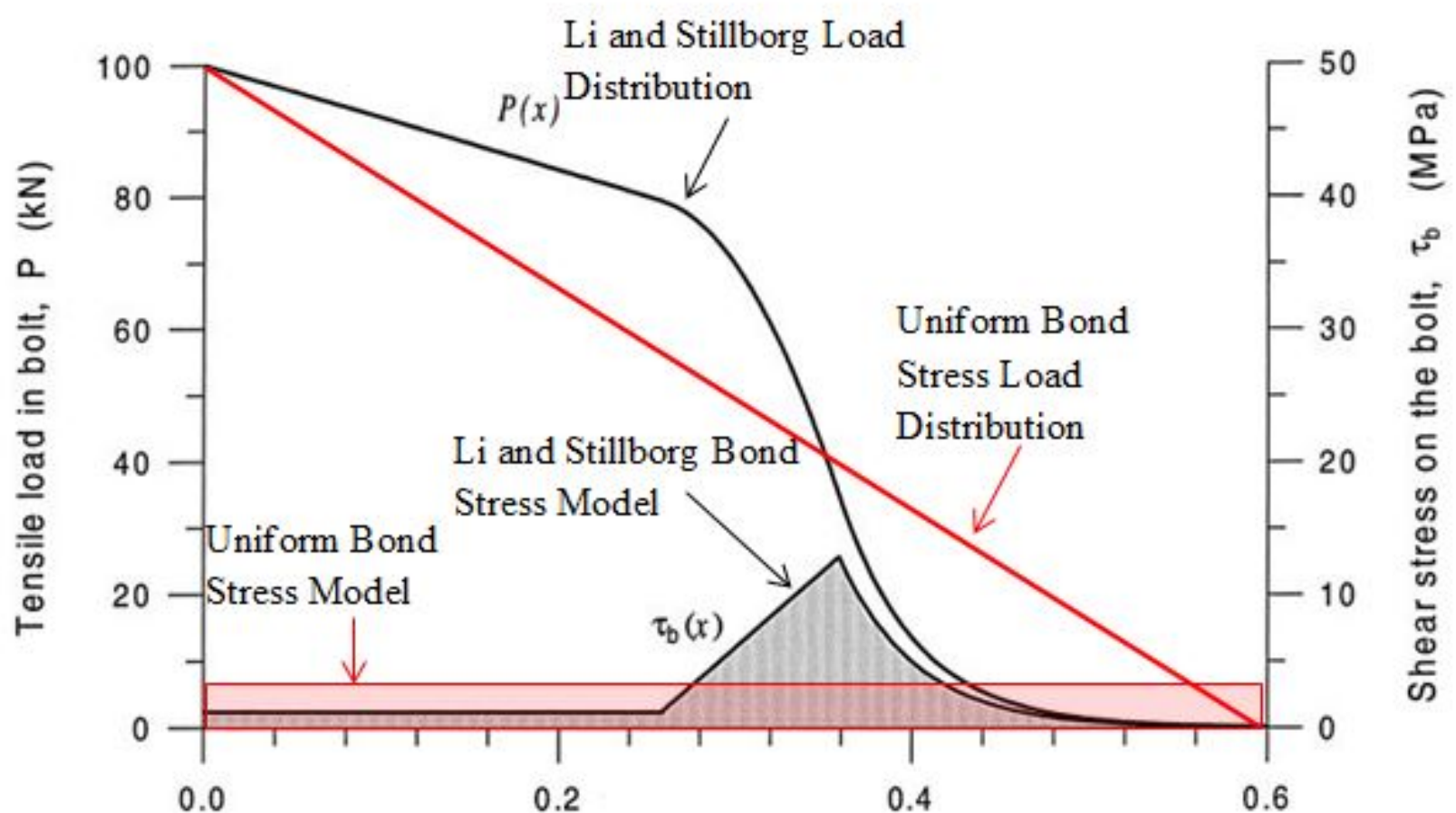

Distance from borehole collar, $x(\mathrm{~m})$

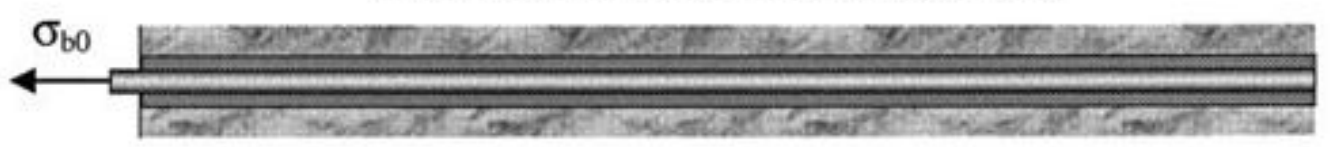

Figure 2.10 Load Distribution along Resin Anchored Rebar given Different Bond Stress Models after Li and Stillborg (1999)

Use of the uniform bond stress model will aid in developing a theoretical equation to predict expected deformation given a certain load placed on resin anchored rebar in the field. To conform to the simplified theory, the bonded length of any testing will be limited to not more than 25 times the diameter of the rebar.

Feldman and Bartlett (2007) describe the mechanics involved when tensile loads are applied to smooth rebar anchored in concrete. Figure 2.11 shows the free body diagrams of a rebar resisting an applied tensile load. The applied load, $P$, is resisted by: the tensile force in the bar, $T(x)$, uniform compressive stress within the concrete, $\mathrm{f}_{\mathrm{c}}(x)$, and the distribution of bond stress along the bonded length engaged $(l-x)$. Slip of the rebar along the concrete interface will not occur until the effective bond length $\left(l_{b}\right)$, or length of bond resisting the applied load becomes equal to the total length bonded $(l)$. Slip is resisted by the elongation of the rebar, $\mathrm{e}_{\mathrm{s}}(\mathrm{x})$, and the contraction of the concrete, $\mathrm{e}_{\mathrm{c}}(\mathrm{x})$. Equations 2.1 and 2.2 describe the portion of slip from the rebar and concrete, respectively. 
Assuming that in Equation 2.2., the concrete stress is uniform over a constant cross-sectional area, Equation 2.3 can be used to describe the concrete stress. Combining the slip from both the rebar and concrete, Feldman and Bartlett derive the maximum relative slip occurring at the loaded end of a sample (Equation 2.4).

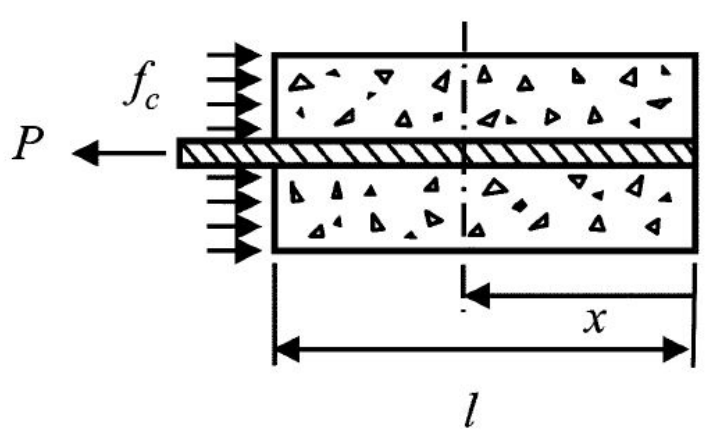

(a)

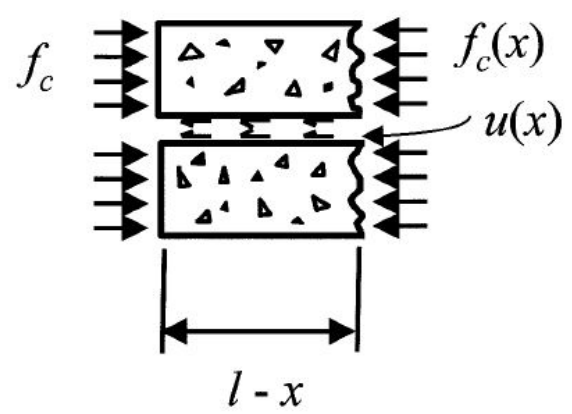

(b)

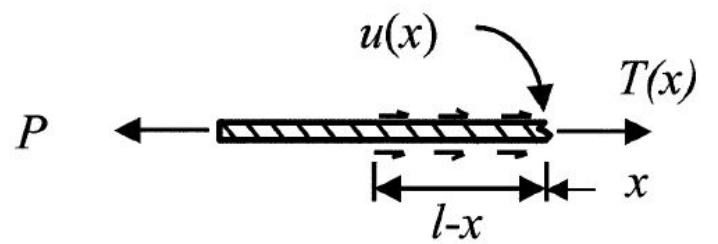

(c)

Figure 2.11 Free body diagrams of pull test on rebar embedded in concrete from Feldman and Bartlett (2007): (a) pull test specimen; (b) concrete in segment at loaded end; and (c) rebar in segment at loaded end

$$
e_{s}(x)=\int_{0}^{x} \frac{T(x)}{A_{S} E_{S}} d x
$$

where: $\quad e_{s}(x)=$ Elongation of rebar;

$T(x)=$ Load on the rebar at point, $x$, based on load distribution;

$A_{s}=$ Cross-sectional area of rebar; and

$E_{s}=$ Young's modulus of rebar.

$$
e_{c}(x)=\int_{0}^{x} \frac{f_{c}(x)}{E_{c}} d x
$$

where: $\quad e_{c}(x)=$ Contraction of concrete;

$f_{c}(x)=$ Compressive force in concrete; and

$E_{c}=$ Young's modulus of concrete. 


$$
f_{c} \cong-\frac{T(x)}{A_{c}}
$$

where: $\quad A_{c}(x)=$ Cross-sectional area of concrete.

$$
s_{\text {max }}=\left(\frac{1}{A_{s} E_{s}}+\frac{1}{A_{c} E_{c}}\right) \int_{0}^{l} T(x) d x
$$

where: $\quad s_{\max }=$ Maximum slip of rebar at the loaded end

When describing the distribution of bond stress and tensile load in the rebar, Feldman and Bartlett (2007) use the simple adhesion-sliding bond model. This model is based on a uniform adhesion bond existing between the rebar and concrete until slip initiates. Once adhesion loss occurs, slip initiates and is only resisted by the sliding bond stress capacity (Figure 2.12). This model is similar to the uniform bond stress model used by Cook (1993). This model does not include the mechanical interlock which would be present with deformed (ribbed) rebar which are used in mining applications. Deformed rebar are interlocked with resin due to their rough surface and as such, this simple adhesion-sliding bond model would be a simplification of the bond stress along this surface. The smooth surface between resin and rock however, would be similar to that of the smooth rebar and concrete.

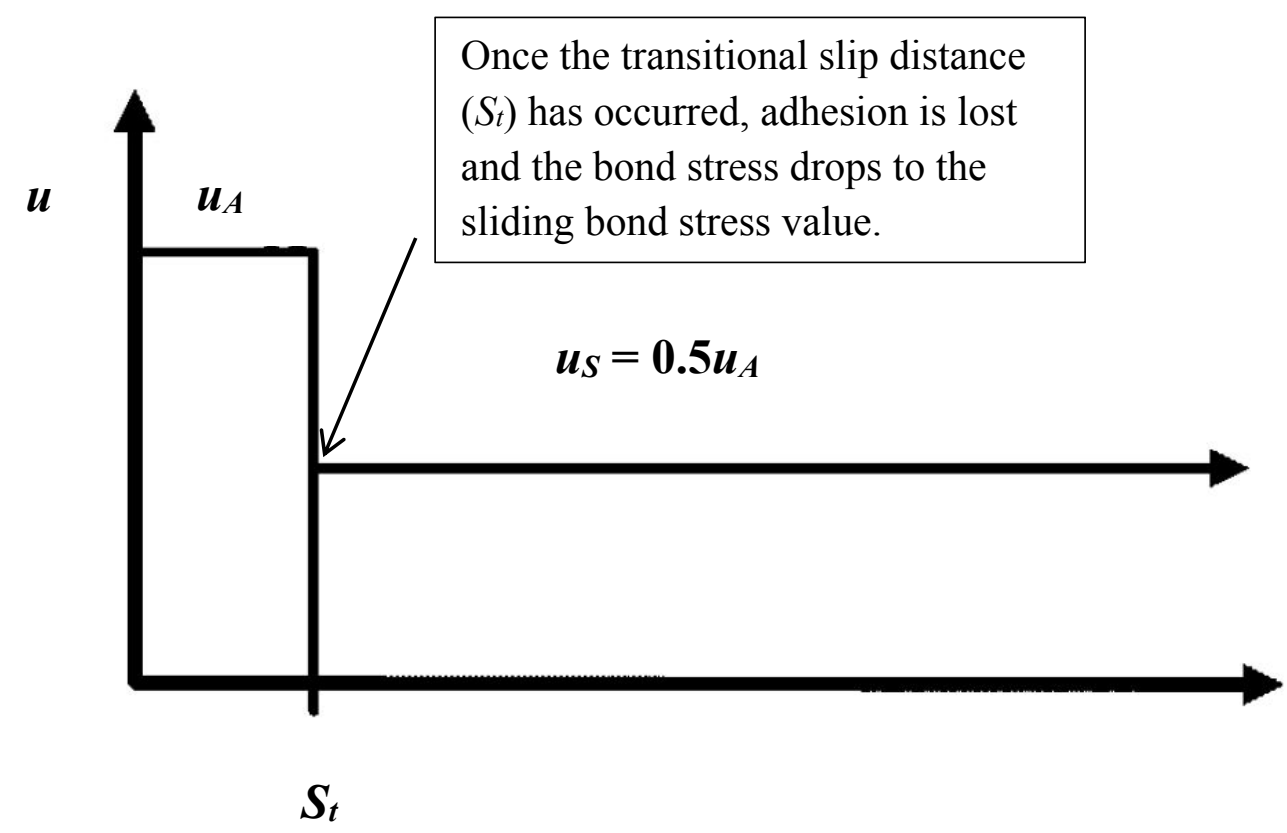

Figure 2.12 Simple adhesion-sliding model modified from Feldman and Bartlett (2007) 
Feldman and Bartlett also describe how at the point where adhesion is lost and only mechanical friction remains, a significant increase in the rate of slip will occur. Historically, pull testing programs using resin anchored rebar in potash have not defined the average bond strength using this point where adhesion is lost. Feldman and Bartlett's study of rebar embedded in concrete serves to give a method to both approximate the slip which can be expected during testing and, as well, assess the data collected to determine the load when adhesion is lost. Graphing the rate of slip, or incremental deformation, is a feasible method to determine when adhesion is lost.

\subsection{Laboratory/Field Studies on Resin Anchored Rebar Bolts with Combined Shear and Tensile Loading}

Literature was reviewed to establish whether data collected in the laboratory, with regards to load distributions on rebar in combined loading conditions, can assist in interpreting field results. This section outlines studies where field results were obtained, in addition to analytical or laboratory results.

Signer et al. (1997) used instrumented rebar to study the combined loading of anchored rebar. The rebar in the 1997 study were placed in coal mines with various geological conditions above the openings. Due to strain gauges being placed on both sides of the rebar, bending of the rebar due to shear displacements in the rock mass could be observed. The strain values in tension or in compression were converted into loads on the rebar. The loads the instrumented rebar were supporting in the field were then used for the purpose of designing rebar support patterns. Since the data showed the loads present on the support, engineers were able to make informed decisions on whether rebar spacing could be increased or decreased.

McHugh and Signer (1999) furthered this research on fully embedded rebar under shear loads using the slotted rebar in the laboratory. The aim of this testing was to establish the load distribution along the rebar with both shear and tensile loads present and establish if the field results could be replicated in the laboratory. Figure 2.13 shows fully embedded rebar in two separated concrete blocks that were loaded axially, while the bottom block of concrete had a shear load applied. Strain gauges were placed in slots along the rebar equidistant from the separation on 
either side of the two blocks; Figure 2.14 shows this configuration as used to monitor the axial and bending loads.

The laboratory results were then compared with field testing previously done at coal mines (Singer et al. 1997) to determine if the relationships established in the laboratory could be applied to insitu conditions. In the field, rebar bolts were placed into shale, while in the laboratory, rebar were installed into concrete blocks with a compressive strength that was similar to the shale at the time of testing. This study was able to replicate the field results of bond strength with laboratory testing. Similar separation displacements showed similar load distributions in both field and laboratory tests. Separations were simulated in the lab by controlling the size of the gap between the two blocks shown in Figure 2.13. The field results had more variation due to differences in geology, while the average values for bond strength in the laboratory and field were reported to be consistent. The results of this study showed that axial loading had little effect on the resistance of the rebar to shear loading and that the rebar capacity when resisting shear movement was $76 \%$ of the axial capacity of the rebar.

These studies show that results in the field can be replicated in the laboratory. Although the laboratory apparatus worked for McHugh and Signer's 1999 study, concrete would not replicate the complicated behaviour exhibited by potash. Procuring blocks of potash for an apparatus in the laboratory would be not only expensive but challenging in terms of the equipment and resources that would be needed. As well, some degree of confinement would still need to be applied to the concrete in order to simulate field conditions. 


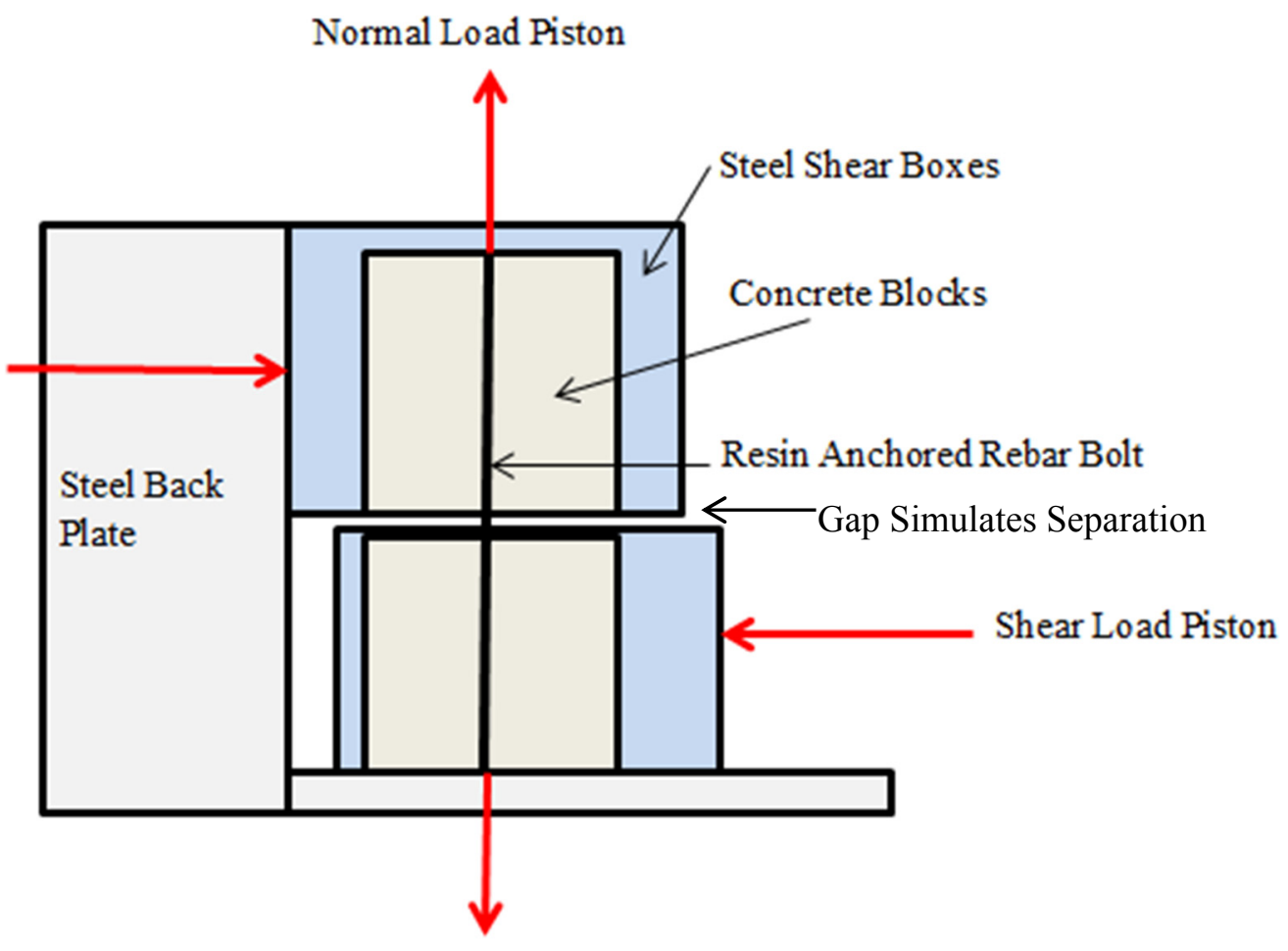

Figure 2.13 Shear and tensile load apparatus schematic after McHugh and Signer (1999)

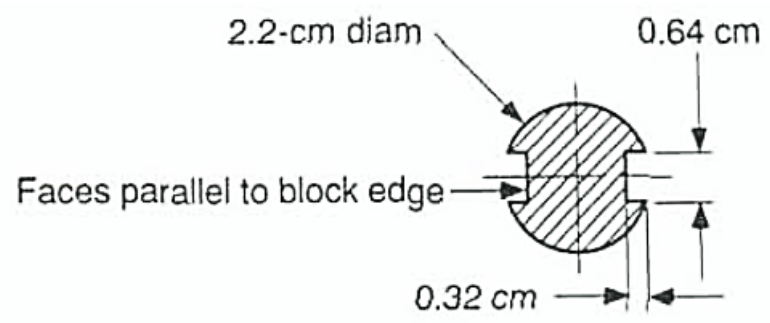

Section A-A

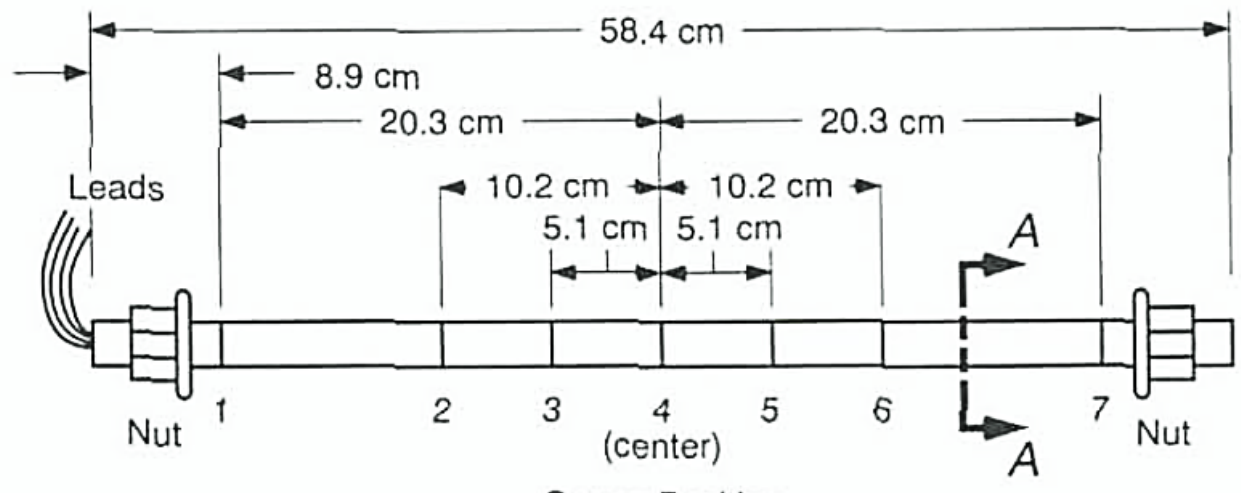

Gauge Position

Figure 2.14 Instrumented rebar for shear testing from McHugh and Signer (1999) 


\subsection{Discussion}

This literature search shows there are many studies that have investigated the loading behaviour of resin anchored rebar whether they are post-installed into existing concrete structures or installed in various geological horizons in mines. Observing the effects of combined loading where both tensile and shear forces are present has been studied analytically, in the laboratory and in the field. Gaps in the literature that have been identified and which are addressed in this research project are as follows:

- Identify the failure mechanism (weak link) of resin anchored rebar system when used in potash mines;

- Examine how the average bond strength varies in potash mines given changes in mining conditions and environment;

- Directly relate deformation to a load present on rebar (i.e. measure amount of tensile and/or shear movement that has occurred and develop a relationship that can be used to convert those measurements to a load present in the rebar).

Investigating the effect that variables in the potash mines have on the bond strength of rebar used for support will extend the knowledge base for mining engineers who are required to make decisions about the quality and design of ground support. Gathering data to relate the deformation in the surrounding area and equate it to a load present on the rebar will be of value for making decision regarding the need for additional rebar. 


\section{Laboratory Testing}

This chapter describes the design of the laboratory experimental program for this research project 3. as well as outlines the laboratory testing procedures and results, including details on sample procurement, testing methods, and instruments used. Results for rebar and rock properties are given in this chapter to provide required background data for subsequent sections on field testing methods and results. Laboratory testing included determining the mechanical properties of both 3. . rebar and the various rock types from the field. Rock properties were determined both to distinguish the different rock types at pull testing sites, and to aid in determining the failure mechanism of the support system. Rebar was tested to confirm the properties of the actual rebar used in field testing.

3. testing and rock testing. Testing completed on rebar was conducted in the Structural Engineering Laboratory, while the rock property testing was conducted in the Rock Mechanics Laboratory. 3. Both laboratories are located at the University of Saskatchewan. The purpose of these testing programs was to accurately determine the properties of the materials used in field testing.

3.

\subsection{Rebar Property Testing}

In order to evaluate the results of pull testing in the field, the properties of the rebar used must be Pecorded. The properties required include:

3.

- Yield Strength (stress at which irrecoverable deformation begins to occur);

- Ultimate Strength (maximum stress sustained by the sample during the test); and

- Young's Modulus (the rate of stress increase per unit strain within the elastic range).

3.

The property most relevant to this research project was the yield strength. The yield strength for each size of rebar that was tested in the field was determined during laboratory testing in order to aid in selecting the bond length for use in the field. During field pull tests, the observation of significant, irrecoverable, or non-linear deformation of the rebar, resin, and rock support system $\boldsymbol{p}$ sior to the yield strength of the rebar being reached would indicate bond failure rather than irrecoverable deformation of the rebar sample.

3. 
These tests were carried out by randomly selecting five samples of both $25 \mathrm{~mm}$ and $16 \mathrm{~mm}$ diameter rebar, each from their own respective heat batch. A heat batch of rebar refers to rebar that were formed at the same time using the same steel at the manufacturing location. Different heat batches of rebar can have different properties, so it was ensured that rebar of the same size used in this research project were from the same heat batch. The $16 \mathrm{~mm}$ diameter rebar, which are not commonly used in potash mining, were delivered by Dywidag Systems International (DSI) to the mine specifically for this research project and were from the same heat batch. The $25 \mathrm{~mm}$ diameter rebar, however, were delivered to the mine site on a weekly basis. To ensure all $25 \mathrm{~mm}$ diameter rebar would be from the same heat batch, a total of 130 samples of the $25 \mathrm{~mm}$ sized rebar were taken from the same delivery and stored in a secure location in order to provide enough samples for both the field tests and laboratory tests. Both sizes of rebar used were Grade 400 rebar.

Mechanical property testing for both the $16 \mathrm{~mm}$ and $25 \mathrm{~mm}$ sized rebar was performed using a consistent methodology. Rebar samples were cut into four foot lengths with five samples of both sizes collected. Figure 3.1 shows one of these four foot lengths of rebar placed in the material testing machine. A linear potentiometer, reading over a gauge length of $200 \mathrm{~mm}$, was attached to each sample to read the deformation of the rebar during this testing, up until the yield load was reached.

The standard testing procedure outlined in ASTM E8-E8M-11 was followed (ASTM, 2011). Each sample was loaded in the testing machine and centred into the wedge grips located on the top and bottom of the testing machine (Figure 3.1). Load was then applied to each sample at a strain rate of $20 \mathrm{~mm} / \mathrm{min}$. Instron Partner version 8.0.4.0 software was used to control the machine while National Instruments Labview version 8.0 was used to record the output from data acquisition device connected to the linear potentiometer (LVDT). The linear potentiometer was removed once the yield load had been exceeded to avoid damage or destruction of the device. Capturing accurate deformation up until the yield load of the samples allowed for the Young's modulus of each sample to be calculated. Loading continued until the ultimate strength was reached. 


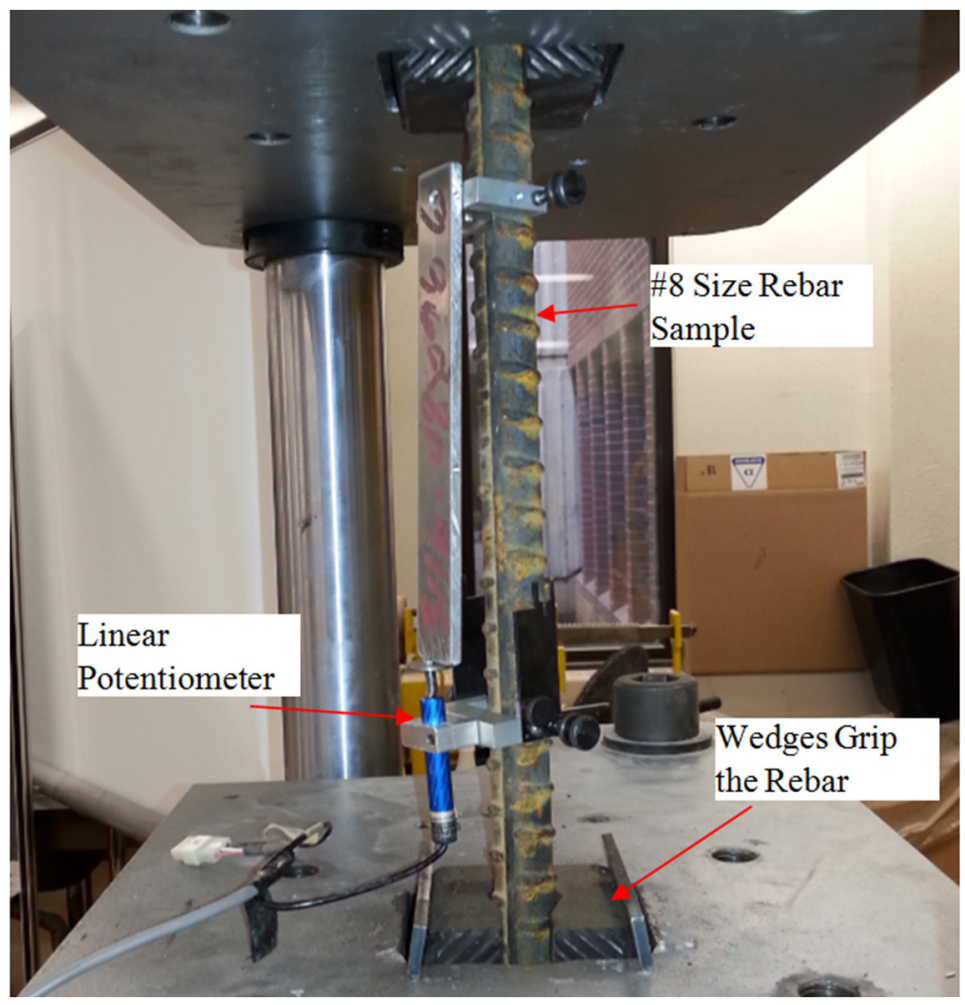

Figure $3.125 \mathrm{~mm}$ size rebar set up for strength property testing

The ultimate strength measured during pull testing was recorded for each sample. The yield stress for each sample was determined by using the standard method as outlined in ASTM A615 (ASTM, 2012). Determining the yield stress involves observing where there was a well-defined yield point during the test. For each sample tested, the yield stress was indicated by a plateau, where continued sample deformation occurred without an increase in applied load.

A value for Young's modulus was determined by calculating the slope of the linear elastic portion of the stress-strain plot. Deformation measurements were taken from the voltage changes output from the potentiometer. Load values were converted to stress by dividing the nominal crosssectional area for each rebar size tested. Young's modulus was calculated by using the slope of the linear elastic region of the stress versus strain curve.

\subsubsection{Rebar Property Testing Results}

Results of the laboratory pull testing to determine the mechanical properties of the rebar used in this research project are summarized in Table 3.1. The raw data along with plots of load versus deformation and stress versus strain within the linear elastic range for each sample are included in Appendix A. 
Table 3.1 Laboratory pull test data (5 tests per size of rebar)

\begin{tabular}{|c|c|c|c|}
\hline & $\begin{array}{c}\text { Average Ultimate } \\
\text { Strength, MPa } \\
\text { (Std. Dev *) } \\
(\mathbf{C O V} * *)\end{array}$ & $\begin{array}{c}\text { Average Yield } \\
\text { Strength, MPa } \\
\text { (Std. Dev **) (COV } * *)\end{array}$ & $\begin{array}{c}\text { Average Young's } \\
\text { Modulus, GPa } \\
\text { (Std. Dev.*) (COV } * *)\end{array}$ \\
\hline $\mathbf{1 6} \mathbf{~ m m ~ A v e r a g e : ~}$ & $565(4.00)(0.50 \%)$ & $480(7.50)(1.59 \%)$ & $191(33.0)(17.6 \%)$ \\
\hline $\mathbf{2 5} \mathbf{~ m m}$ Average: & $612(10.2)(1.68 \%)$ & $409(39.4)(9.62 \%)$ & $181(12.3)(6.80 \%)$ \\
\hline
\end{tabular}

*Std. Dev. - standard deviation **COV - coefficient of variation

\subsection{Rock Testing Program}

Representative core samples of potash and halite were taken from two different horizons at the Allan Mine for testing in the University of Saskatchewan Rock Mechanics Laboratory. The goal was to determine if there were significant differences in the properties of the rock since they may have an effect on the performance of resin anchored rebar, as discussed in Sections 2.2 through 2.4. The variables considered during testing included Young's modulus, Poisson's ratio, uniaxial compressive strength (UCS), tensile strength (indirect or "Brazilian”), and shear strength.

Three replications of tests were conducted on the cores collected from the mine including: unconfined compressive strength tests, the indirect tensile strength, and a guillotine style shear strength test. The guillotine style shear strength test involved constructing an apparatus and developing a test procedure at the University of Saskatchewan, specifically for the purpose of investigating the shear strength of potash and halite core samples.

A total of 60 samples which were representative of potash and halite horizons were collected at the Allan mine using the Hilti Diamond Core Drill shown in Figure 3.2. The core samples had a diameter of $68 \mathrm{~mm}$ with a rough cylindrical surface and variable lengths which depended on the length of intact core which could be obtained from each hole. In the field, each sample was marked to identify the horizon it came from with either a P (for Potash) or S (for Salt or Halite) and a number to identify the position within the coring area. Samples were sealed in a plastic bag for transportation. Test samples were marked with an additional, 'A', 'B', or ' $C$ ' label in the lab if the test sample was cut from the same intact piece of core. 


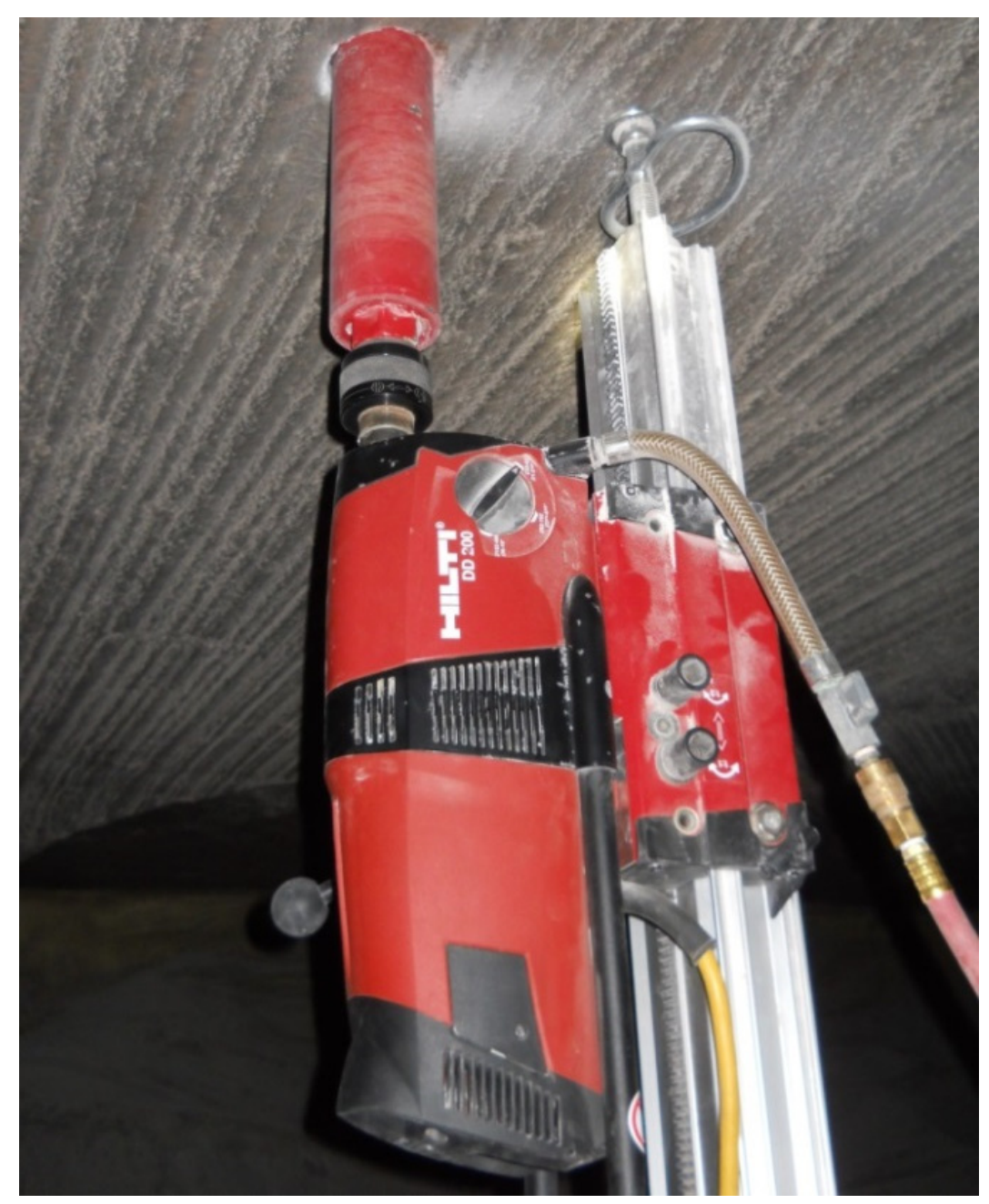

Figure 3.2 Diamond core drill rig used to collect samples at the Allan mine

\subsubsection{Uniaxial Compressive Strength Testing}

Due to the compression loads placed on rock when resin anchored rebar are loaded in the field, UCS tests were done on each rock type. A significant difference in the UCS between the two rock types could result in poorer performance of resin anchored rebar. As discussed in Section 2.2, Bargahr and Vogel (2004) suggest that the strength of the surrounding material (concrete in their case) has a negligible effect on the strength of the reinforcement; however, it was unknown if this also is the case for a potash mining application. Determining the UCS of each rock type, whether influential on the strength of resin anchored rebar or not, would still be of value to the engineers at the mine because determining mechanical properties of the rock had not previously been completed for the Allan mine. 
The unconfined compressive strength test was used to determine the majority of the rock properties needed to define both the potash and halite horizons being tested in this project. ASTM D701210 was followed to find Young's modulus, Poisson's ratio, and uniaxial compressive strength (ASTM, 2010). Modifications to this standard testing procedure included using a sample diameter of $68 \mathrm{~mm}$ instead of the recommended $47 \mathrm{~mm}$. A larger core size is commonly used to obtain estimates of potash properties due to the large crystal size often present in the rock. Ten samples from each of the different geological horizons were tested.

Samples were cut to a length of more than twice the diameter. The ends of each sample were made flat and parallel to one another using a rock saw and belt sander. The sample dimensions were measured using digital calipers to take three measurements and calculate an average value. A circumferential strain chain was used to measure circumferential strain and linear potentiometers were used to measure the axial deformation during the test. Figure 3.3 shows the UCS test set-up with both the strain chain and potentiometers positioned on the sample. The axial and circumferential strain measurements were required to calculate Poisson's ratio, and together were used to determine the sample volume change.

Samples were placed into the Tinius-Olsen materials testing machine where a constant loading rate of $223 \mathrm{~N} / \mathrm{s}$ was applied until failure occurred within 2 to 15 minutes. The data obtained from the strain measuring devices was then used to calculate both the Young's modulus and Poisson's ratio for the sample.

Analysis of the elastic properties and strength of each rock sample was completed by following the calculations outlined in ASTM D7012-10 (ASTM, 2010). For each sample, stress versus lateral, axial, and volumetric strain plots were established. The only modification made to standard analysis techniques involved the calculation of Poisson's ratio. As mentioned in Section 2.1, potash and halite samples behave plastically at lower loads and higher loading rates than most other rock types. The measurement of the elastic constants, Young's modulus and Poisson's ratio measurement are challenging due to the complex makeup of the rock.

The Poisson's ratio is normally found by taking the lateral and axial strains at $50 \%$ of the UCS value. However, at this load in the potash and halite samples, plastic deformation and spalling of the sample has already begun making the values for Poisson's ratio using this method inaccurate, 
as often the value was greater than 0.5. Instead, values of Poisson's ratio in this research project were calculated when the volumetric strain reached a maximum value (note: in the case of this study, contractile strains are positive). The values of lateral and axial strain were recorded at this point of maximum volumetric strain (Figure 3.4) and Poisson's ratio was calculated. This value of Poisson's ratio is a more appropriate estimate of the property since it was calculated while the rock was still behaving nearly elastically. For example, the sample in Figure 3.4 had a Poisson's ratio of 0.74 when calculated the traditional way. Young's modulus was found using the standard procedure provided in ASTM D7012-10 (ASTM, 2010); however, it should be noted that these values will not necessarily reflect in-situ properties. Loading rates in the lab will likely not represent field loading conditions due to sample disturbance and relative high loading rates compared to those in the field. In comparison to the field pull tests, the loading rates are similar in that both tests apply the maximum loads over a time frame of 2 to 15 minutes.

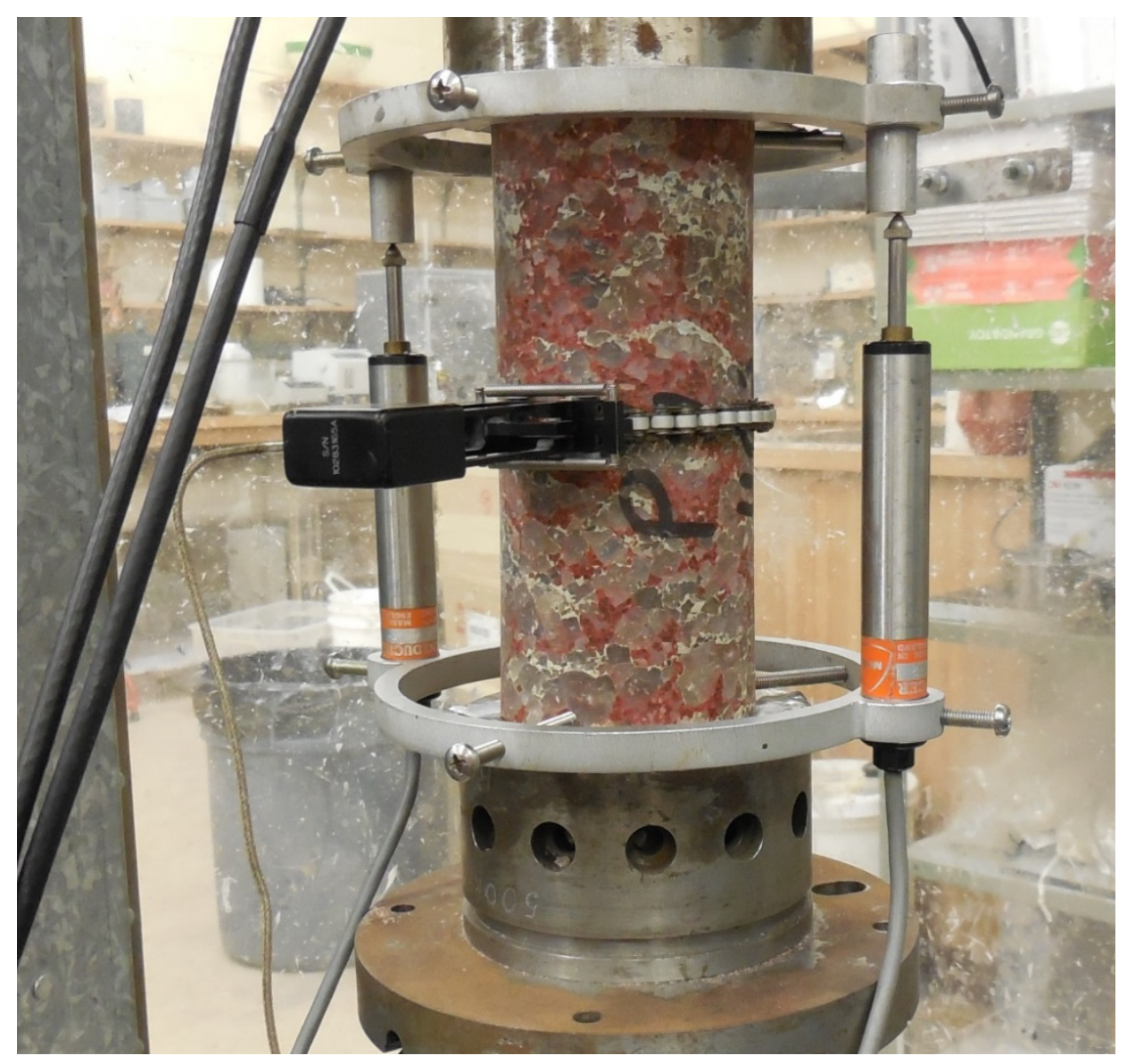

Figure 3.3 Potash sample loaded in Tinius-Olson material testing machine and outfitted with strain chain and LVDTs 


\subsubsection{Uniaxial Compressive Strength Testing Results}

The average results determined from the uniaxial compressive strength tests conducted on the potash and halite samples are presented in Table 3.2. Ten samples of each rock type were tested. Raw data, along with stress versus strain plots for each sample, are reported in Appendix B. An example of a stress-strain plot, showing the point of maximum volumetric strain can be found in Figure 3.4.

Table 3.2 Average mechanical properties from UCS testing (10 tests each)

\begin{tabular}{|c|c|c|c|}
\hline & $\begin{array}{c}\text { Average UCS, MPa } \\
\text { (Std. Dev.) (COV.) }\end{array}$ & $\begin{array}{c}\text { Average Young's } \\
\text { Modulus, GPa } \\
\text { (Std. Dev.) (COV.) }\end{array}$ & $\begin{array}{c}\text { Average Poisson's } \\
\text { Ratio, MPa } \\
\text { (Std. Dev.) (COV.) }\end{array}$ \\
\hline Potash: & $25.4(2.44)(9.59 \%)$ & $2.82(0.452)(16.0 \%)$ & $0.30(0.042)(14.3 \%)$ \\
\hline Halite: & $21.7(1.95)(9.01 \%)$ & $6.25(1.43)(22.7 \%)$ & $0.282(0.045)(15.8 \%)$ \\
\hline
\end{tabular}

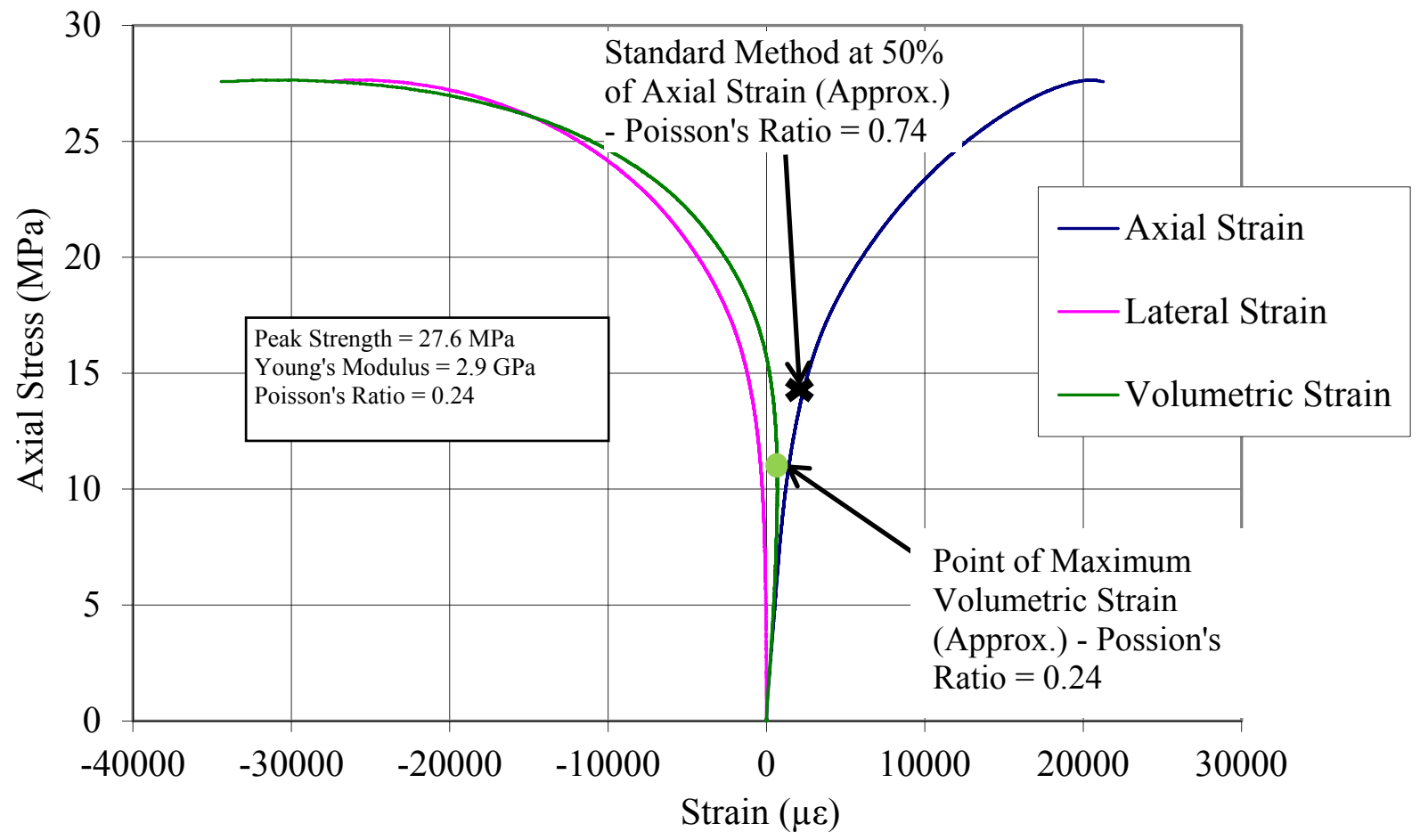

Figure 3.4 Stress-strain plot for potash sample P8 


\subsubsection{Indirect Tensile Strength Testing}

The tensile strength of each rock type was calculated to determine whether a significant difference existed between the two rock types. As described in Section 2.2, the material surrounding resin anchored rebar has a possibility of failing in tension when short embedment lengths are used near a free face (Bargahr and Vogel, 2004). With the rebar in this research project being embedded as deeply as 2.4 metres into the rock, it is unlikely that the rock will fail in tension. However, the tensile strength of each rock type assisted in determining if there was a large variation in properties between rock types.

ASTM D3967-08 was used as the testing method and procedure to obtain values for tensile strength for both the potash and halite samples (ASTM, 2008a). Samples were again $68 \mathrm{~mm}$ in diameter and discs were cut from the core samples with a length to diameter ratio less than 0.7. The samples ends were finished to make them flat and parallel using a rock saw and belt sander. The samples were placed in the Tinius-Olsen materials testing machine. A loading rate of 223N/s was then used to test the samples until failure occurred within 2 to 15 minutes. The data collected during this test included load versus time. The tensile strength of the rock was then found using the peak load reached during the test and the sample dimensions.

Analysis for the indirect tensile strength tests followed the standard calculations outlined in ASTM D3967-08 (ASTM, 2008a). The cross-sectional area was determined using the average of three measurements of the sample diameter as well as the thickness of the sample. The peak load is recorded during testing. The sample must fail along a break that is parallel to the direction of loading and splits the sample approximately in half. Figure 3.5 shows an example of a successful test sample of potash found in testing. No samples failed in any manner other than parallel to the loading direction; had there been, those results would have been discarded.

\subsubsection{Indirect ("Brazilian") Tensile Strength Testing Results}

The average results for the indirect tensile strength tests conducted on potash and halite samples are presented in Table 3.3. Ten samples of each rock type were tested. The results from the potash and halite samples display similar tensile strengths for both types of rock. Raw data for each sample tested are reported in Appendix B. 
Table 3.3 Average Indirect tensile strength test results (10 tests each)

\begin{tabular}{|r|c|}
\hline & $\begin{array}{c}\text { Indirect Tensile Strength, MPa } \\
\text { (Std. Dev.) (COV.) }\end{array}$ \\
\hline Potash: & $1.75(0.181)(10.4 \%)$ \\
\hline Halite: & $1.73(0.248)(14.3 \%)$ \\
\hline
\end{tabular}

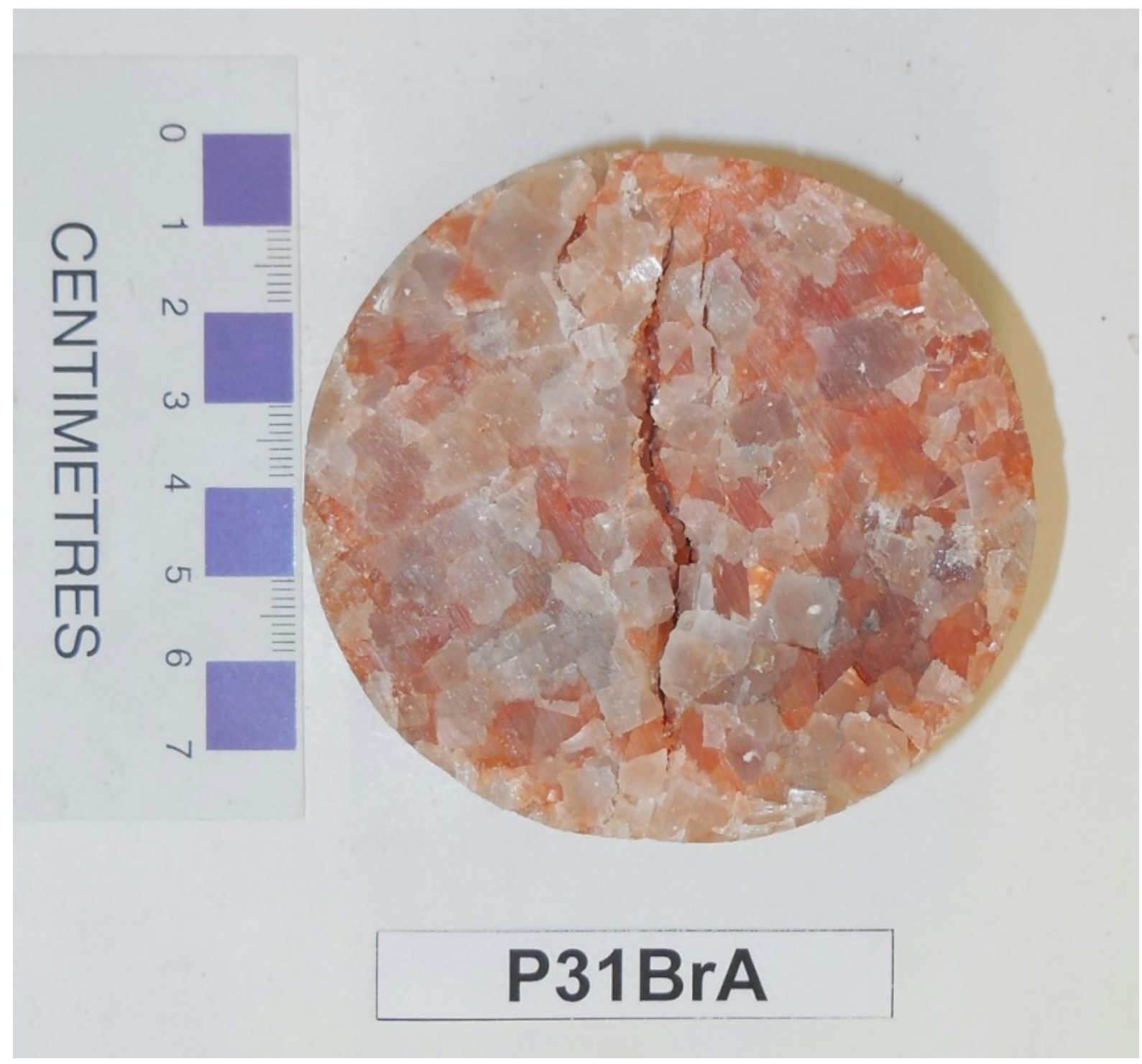

Figure 3.5 Example of failed potash sample (P31A) after Brazilian tensile strength test 


\subsubsection{Rock Shear Strength Testing}

A testing apparatus had to be developed and constructed to obtain measurements of shear strength for potash. There was no literature available to indicate that a ring-shear (guillotine style) test had previously been used successfully on a potash sample. Shear strength is an important property because when a resin anchored rebar transfers load into the adjacent rock, a shear force is applied to the rock due to the load transfer through the resin. In order to determine whether the support system weak link is the low shear strength of the rock, a value had to be determined. The guillotine style testing apparatus was constructed based on a shear strength test described in Goodman (1989). The apparatus was built to accommodate the potash and halite cores collected from the mine and was designed to induce two shear planes through the core.

The guillotine style apparatus was constructed at the University of Saskatchewan Engineering Shops. The shear testing apparatus was able to seat the $68 \mathrm{~mm}$ diameter cores taken from the field in a position which allowed for a downward load to be applied by the Tinius-Olsen materials testing machine. Figure 3.6 shows the testing apparatus with a potash core loaded inside and the $76 \mathrm{~mm}$ wide loading block sitting on top of the core sample. Figure 3.7 shows the apparatus inside the testing machine, ready to test. The samples were cut with a rock saw to a length of more than twice the diameter. The cylindrical surface area of these samples was made smooth with a belt sander to ensure even contact with the arched loading platens. An uneven cylindrical surface would cause stress concentrations.

Loading platens built into the apparatus concentrate the shear stress on two planes (Figure 3.6). Additional loading platens that are $15.25 \mathrm{~mm}$ wide were placed on the top of the sample (Figure 3.8) to concentrate the load applied by the $76 \mathrm{~mm}$ wide block on to the two planes. On both ends, the sample rested on $30.5 \mathrm{~mm}$ wide platens. Loading was applied at a rate of $46 \mathrm{~N} / \mathrm{s}$ in order to fail the sample within 2 to 15 minutes. The test ended when the rock failed in shear. The shear strength was then determined using the peak load recorded during the test and the measured sample dimensions. The test was considered a success only if both of the intended shear planes failed simultaneously. Figure 3.9 shows an example of a successful failed sample. All samples tested failed in this manner. 


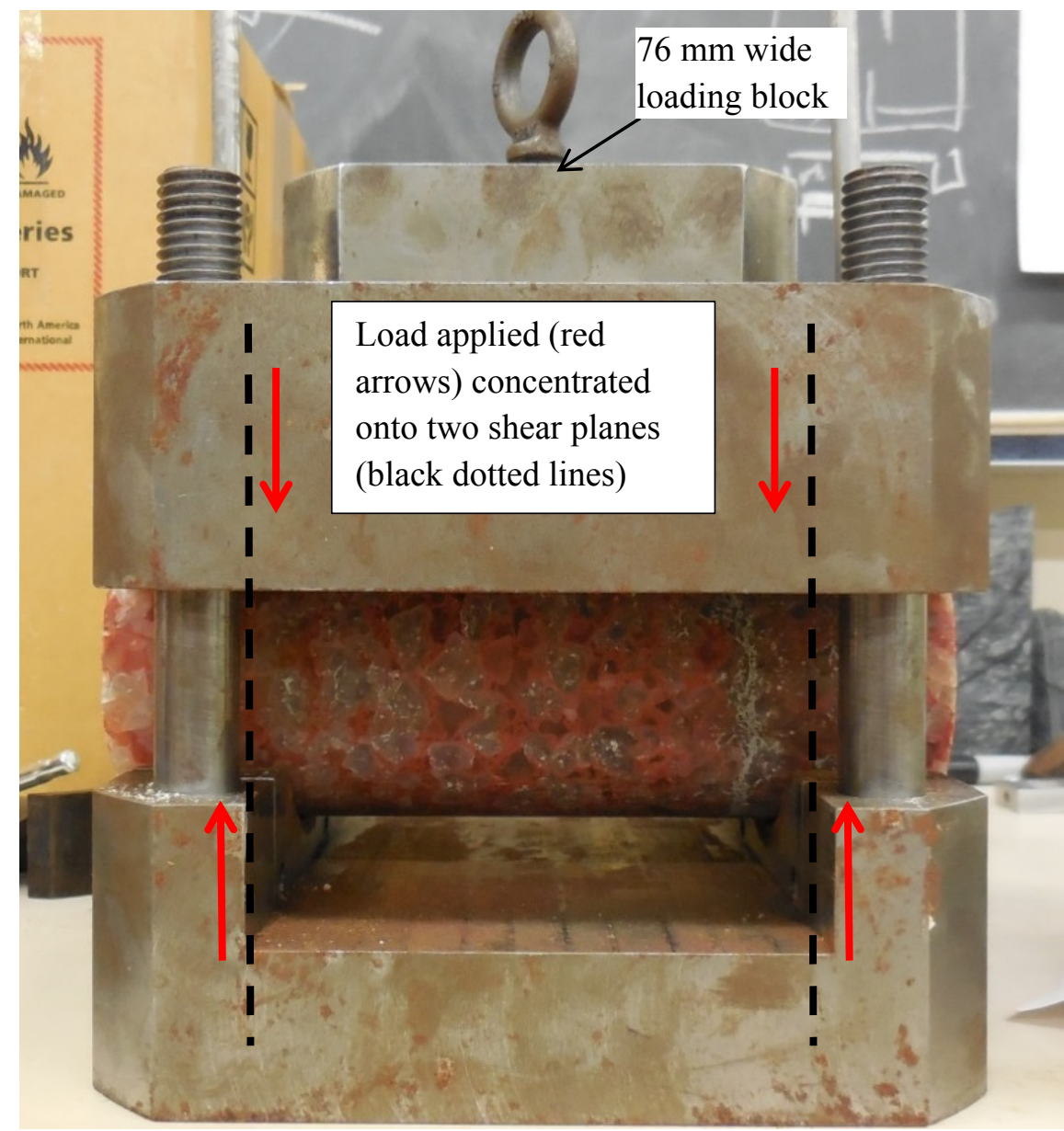

Figure 3.6 Shear strength test apparatus

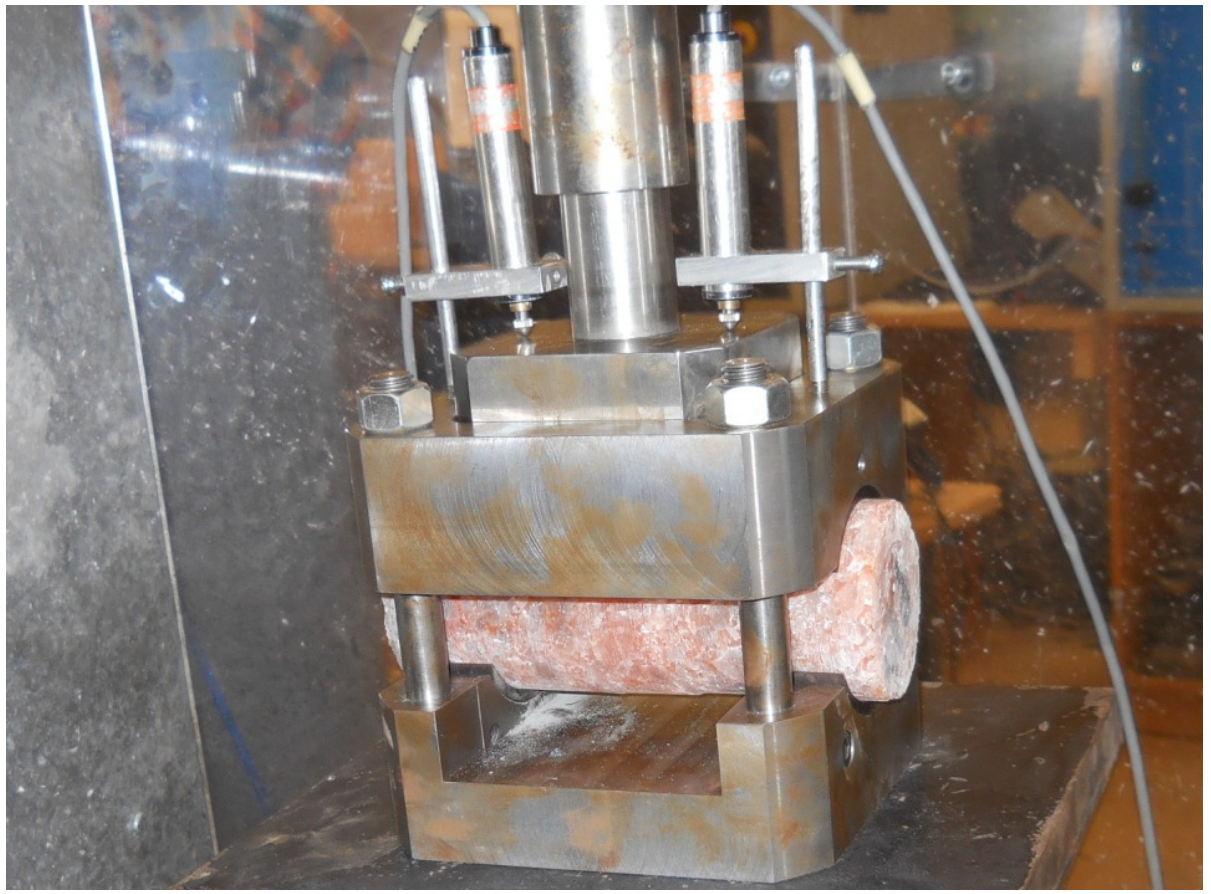

Figure 3.7 Shear strength test prepared in the Tinius Olsen materials testing machine 


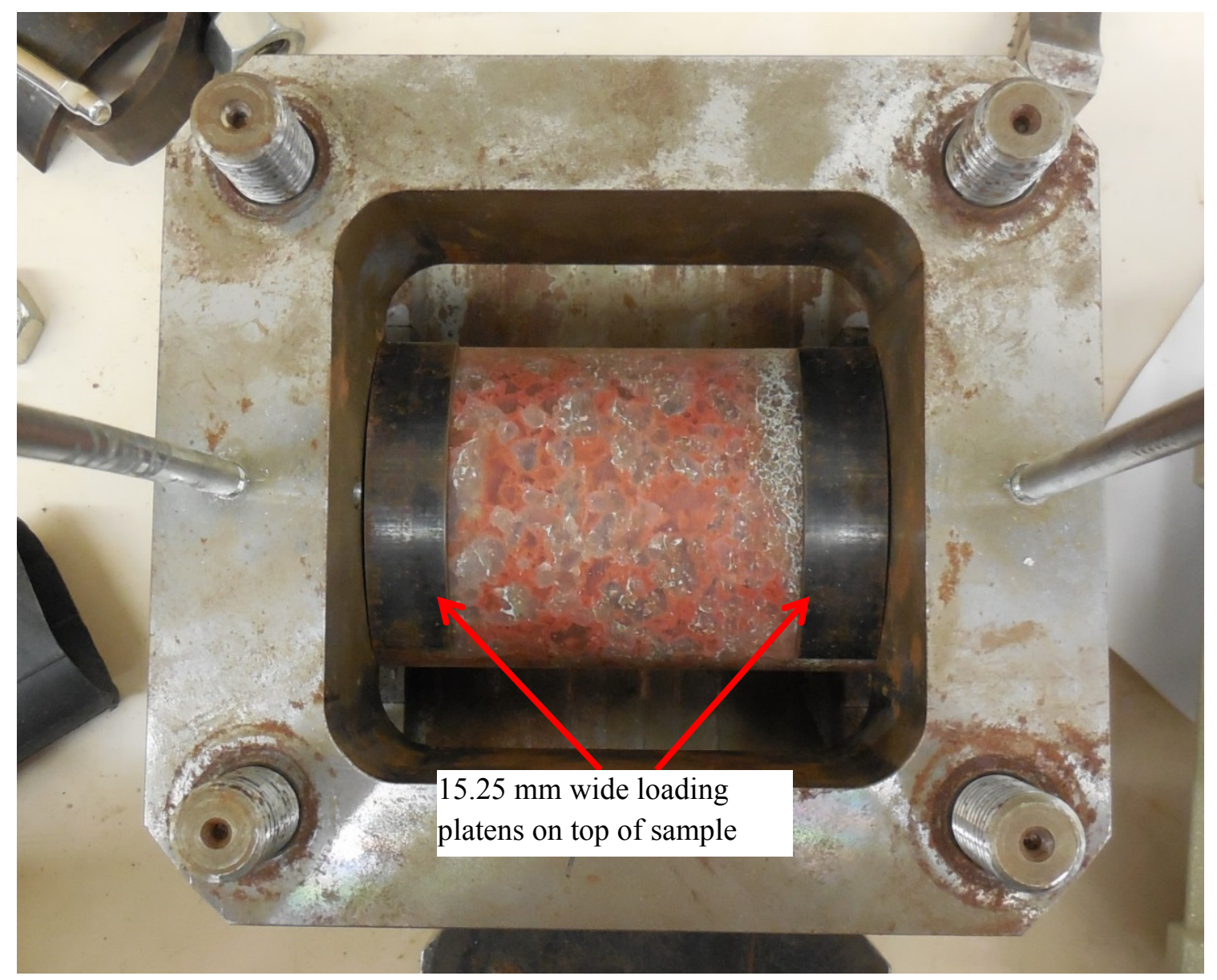

Figure 3.8 Top-down view of potash sample in the shear testing apparatus

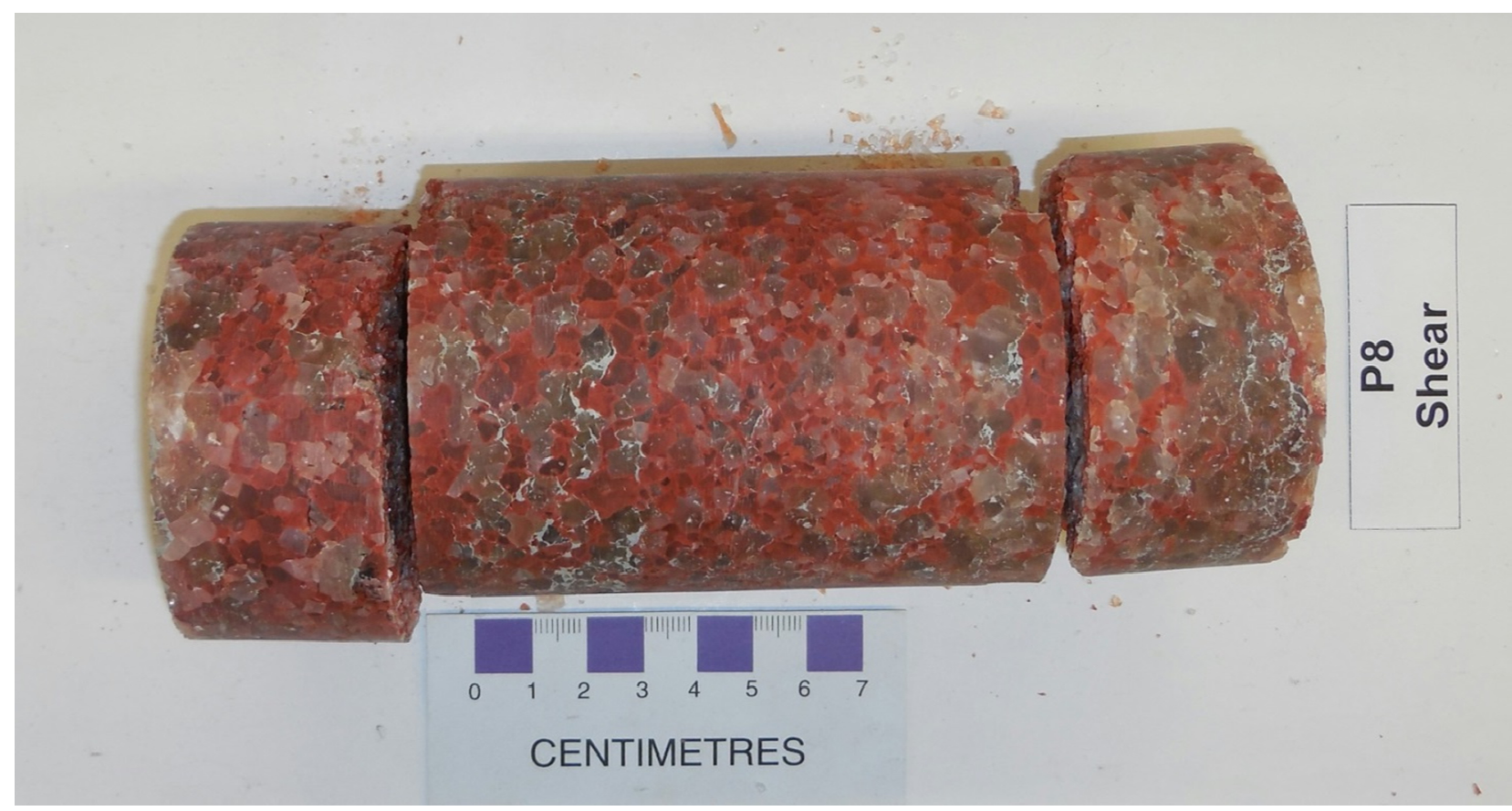

Figure 3.9 Example of potash sample failed after shear strength test 


\subsubsection{Rock Shear Strength Testing Results}

The average results for shear strength tests conducted on potash and halite samples are presented in Table 3.4. Ten tests were conducted for each rock type. Raw data with the results of each of the tests for potash and halite are reported in Appendix B.

Table 3.4 Average shear strength test results

\begin{tabular}{|r|c|}
\hline & $\begin{array}{c}\text { Average Shear Strength, MPa } \\
\text { (Std. Dev.) (COV.) }\end{array}$ \\
\hline Potash: & $6.99(1.84)(26.3 \%)$ \\
\hline Halite: & $8.61(1.61)(18.7 \%)$ \\
\hline
\end{tabular}




\section{Field Testing}

Field Testing took place at Potash Corporation of Saskatchewan's Allan mine, located approximately 50 kilometers southeast of Saskatoon, Saskatchewan. The Allan mine has been in production since 1968 and currently uses stress-relief mining techniques, as discussed in Section 1.1.3. With over 40 years of production, there are extensive workings covering an area of roughly 9 square kilometres. The Allan mine regularly uses both fully bonded rebar, Dywidag bars, and mechanical rock bolts for support where it is required. Several horizontal clay seams positioned at different depths into the back above the mining level, as discussed in Section 1.1, are susceptible to separation and shear displacements which dictate the need for ground support at the mine.

This chapter outlines the testing procedure used to conduct pull testing on resin anchored rebar samples in the field. Data reduction methods used to extract results from raw test data are described, and the average results are provided. A standard pull test procedure can be found in ASTM D4435-08 (ASTM, 2008b); however, this section will describe why standard methods do not always provide satisfactory results in the potash mining environment.

In mining, the peak load that the support sustains prior to the rebar either breaking or pulling free from the hole has typically been used to calculate the bond strength. For the purposes of this research project, bond strength is determined using the load at which the adhesion is lost (i.e. when the rebar begins to slide out of the hole) and does not include the additional strength provided by the frictional bond. This assumes the simplified adhesion sliding model (Feldman and Bartlett, 2007) described in Section 2.5. The frictional bond can be variable and unpredictable (Cook, 1993), and so it should not be relied upon to provide additional load capacity to the support system. All of the following uses of the term bond strength refer to the capacity of the adhesive bond only.

\subsection{Field Testing Site Selection}

The 110 rebar specimens used in field testing were split into six different populations installed at various locations around the Allan mine. At these locations, pull tests determined the load at which the bond began to fail (where the rebar began to pull free from the hole). Determining this load allowed for the determination of the average bond strength. As discussed earlier in Section 1.1.3, bond strength is a term used in the mining industry used to describe the capacity of resin anchored rebar, commonly in terms of load per unit length of bond. An overall average value of bond 
strength was determined from each different population of rebar tested. This average value associated with each site specific factor allowed the effect of different factors to be compared.

The site specific factors investigated as a part of this research were: resin cure time, rock type, and proximity to active mining. Table 4.1 shows a summary of each testing population and the purpose for each. Resin cure time refers to the amount of time which has passed since installation. Investigating rock type involved determining if there was a difference between rebar installed in potash and halite rock. Investigating the effect of proximity to active mining involved testing rebar in areas that were either at an active mining face (area where a borer is cutting presently) or in a non-active area. Generally, an active mining face is in ground that has very recently (days to weeks) been opened, while a non-active area has typically been open for several years. As described in Section 1.1.3, openings which are more than 300 metres away from an active opening will not feel the effects of current mining (Mackintosh, 1977).

To investigate the effect of resin contact area, one test population was completed using $16 \mathrm{~mm}$ diameter rebar in smaller holes. Using a smaller diameter rebar and hole size varied the contact area between the rebar and resin as well as between the resin and rock. The load at which adhesion was lost could be divided by the nominal contact area of both the rebar and rock surface. This calculation resulted in a stress along these surfaces and is the traditional way of reporting bond strength.

In addition to investigating these site specific factors, one test section involved using short embedment lengths. A bond length of $100 \mathrm{~mm}$ was used on $25 \mathrm{~mm}$ diameter rebar in an attempt to ensure the adhesion bond was exceeded at a low enough load that the pull testing apparatus would have the capacity and stroke length available to overcome the remaining frictional strength and fully remove the rebar from the hole. Full removal of the rebar allowed for visual inspection of the rebar after undergoing bond failure. Visual inspection allowed for the condition of the resin to be observed after complete failure. It was unknown if the resin would remain intact along the rebar, break up in the hole, or remain intact along the rock surface. 
Table 4.1 Summary of each rebar test population

\begin{tabular}{|l|l|}
\hline Testing Section & Purpose \\
\hline $\begin{array}{l}\text { Initial Pull Tests - (20 Tests) } \\
\text { ("North 70" Location) }\end{array}$ & Investigated various bond lengths, and the testing method. \\
\hline $\begin{array}{l}\text { Non-Active/Potash Geology } \\
\text {-(20 Tests) ("North 70" }\end{array}$ & $\begin{array}{l}\text { Provided information on the bond strength expected when } \\
\text { rebar are placed in long term, older openings. }\end{array}$ \\
\hline $\begin{array}{l}\text { Active/Potash Geology - } \\
\text { Location) }\end{array}$ & $\begin{array}{l}\text { Provided information on the bond strength expected from rebar } \\
\text { placed near active faces over a period of one year (typical } \\
\text { mining panel life). }\end{array}$ \\
\hline $\begin{array}{l}\text { Non-Active/Halite Geology } \\
\text { (10 Tests) ("South Storage } \\
\text { Bin" Location) }\end{array}$ & $\begin{array}{l}\text { Provided information on whether rebar anchored into a halite } \\
\text { back behave significantly different from those anchored into } \\
\text { potash. }\end{array}$ \\
\hline $\begin{array}{l}\text { Short Embedment - } \\
\text { (10 Tests) ("South Storage } \\
\text { Bin" Location) }\end{array}$ & $\begin{array}{l}\text { Provided visual observations following testing on the failure } \\
\text { mechanism of resin anchored rebar. }\end{array}$ \\
\hline $\begin{array}{l}\text { 16mm Sized Rebar (Smaller } \\
\text { ("East 305" Location) }\end{array}$ & $\begin{array}{l}\text { Provided information on whether there was a relationship } \\
\text { between bond strength and the resin-rock or resin-rebar contact } \\
\text { area. }\end{array}$ \\
\hline
\end{tabular}

\subsection{Pull Test Procedure}

The pull tests provided data on the average bond strength data and were conducted in varied field locations. A general description of the pull test set-up and testing procedure included installing a rock bolt, rebar in this case, and then using a hydraulic cylinder to apply a load while simultaneously measuring the deformation of the rebar. Pull testing was conducted on 100 samples of $25 \mathrm{~mm}$ diameter rebar and 10 samples of $16 \mathrm{~mm}$ diameter rebar.

Figure 4.1 shows the pull testing equipment that was used in the testing at the mine. This equipment was made available by the Allan mine for this research. Load was applied manually with a hand pump connected to a hydraulic cylinder. The gauge on the hand pump displayed units of load in tons. The smallest increment available on the gauge from 0 to 5 tons ( 0 to 4.54 tonnes) 
was 0.625 tons $(0.567$ tonnes). On the gauge, smaller increments of 0.5 tons ( 0.45 tonnes $)$ were available from loads of 5 tons (4.54 tonnes) and above.

Load was applied to the $25 \mathrm{~mm}$ rebar initially in increments of 2.5 tons (2.27 tonnes) from 0 to 10 tons ( 0 to 9.07 tonnes); increments of 1 ton (0.907 tonnes) were used thereafter. Less frequent measurements were recorded at the beginning of tests because seating effects decreased the accuracy of the data in this initial range. Seating effects describe initial inaccurate deformation recordings due to the initial slack in the system and/or initial positioning of the apparatus on the rock surface as load began to be applied. Initial slack was the result of not placing the apparatus tightly against the rock. The apparatus would re-position itself, depending on the roughness of the rock surface on to which it was seating. The magnitude of this effect was greater for certain deformation measuring instruments; this is discussed further in Section 4.2.2.

Load was applied to the $16 \mathrm{~mm}$ rebar initially in increments of 0.625 tons $(0.567$ tonnes $)$ up to a value of 5 tons (4.54 tonnes), after which an increment of 0.5 tons ( 0.45 tonnes) was used. Seating effects were also evident in these tests but, given the smaller load range (0-12 tonnes) for the 16 $\mathrm{mm}$ sized rebar, smaller loading increments were still used to note as much detail as possible before the end of the tests.

For both the $16 \mathrm{~mm}$ and $25 \mathrm{~mm}$ rebar tests, deformation readings were recorded using a linear potentiometer and a string potentiometer at each loading increment; details of both methods are described in Section 4.2.2. The result of each test was a table of load and deformation measurements. This was plotted as load versus both cumulative deformation and incremental deformation. The results of the test are discussed in Section 4.3.

The completion of each pull test was marked by either the apparatus approaching the capacity of the system (27 tonnes) or when the deformation readings became time dependent and difficult to manually record. When deformation readings began to continuously change between loading increments, the rebar was assumed to be sliding out of the hole. When this occurred, the load was decreasing and the deformation reading was increasing with time and manual recording was no longer accurate. The sliding of rebar specimens indicated that adhesion had already been lost and recording further measurements was not necessary for the purposes of this research project. 


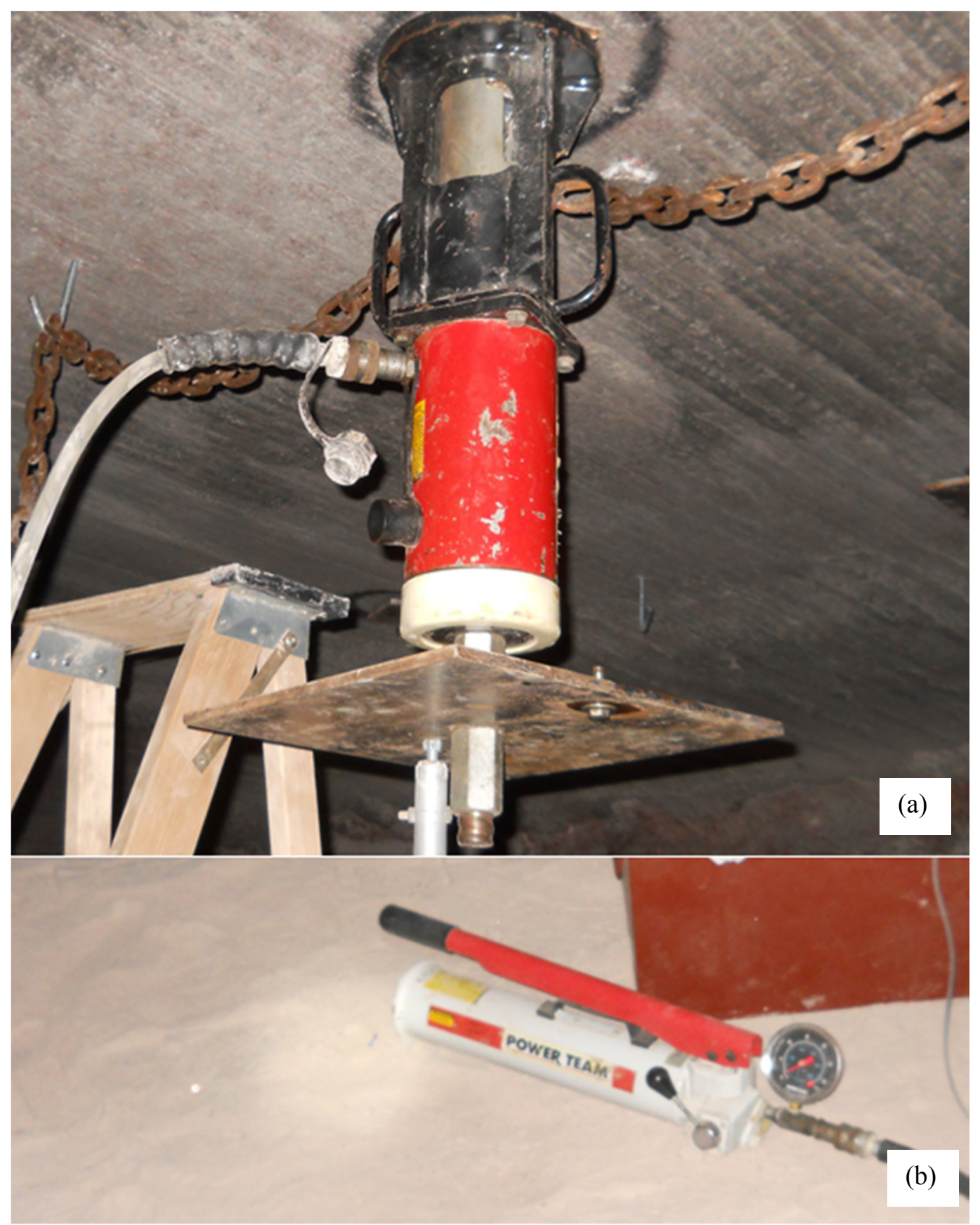

Figure 4.1 Pull tester apparatus used at Allan mine: (a) Hydraulic cylinder attached to rebar and, (b) Hand pump

\subsubsection{Rebar Sample Preparation}

To begin the preparation of samples, the length of each rebar tested was recorded. The length was measured from the washer of the forged bolt head to the toe end, where an angled cut has been made by the supplier to facilitate the puncturing of resin cartridges. A pull collar and square plate washers were then placed on all rebar samples. Figure 4.2 shows the pull collar and washer on the 
forged head end of the rebar. The rebar were numbered in the order that they were prepared, but not necessarily the order in which they were tested.

After completing the measurements, labelling, and adding the collar and plates, each rebar was outfitted with a resin dam to increase the diameter of the bar. This was to help contain the inserted resin in the top of the hole and to ensure excess resin did not bond to the rebar where it was not desired. The length where resin was bonded to the rebar is referred to as the bond length. The resin dam ensured that this length was known and maintained during and after the installation process.

Typically, when bond strength is investigated in mines, the short encapsulation pull test (SEPT) method is employed for testing resin anchored rebar, as described by Mark et al. (2002). The SEPT method involves using a 0.3 metre bond length to determine the average bond strength of resin anchored rebar. However, previous testing at the Allan mine, conducted by Smith (2008), showed that using $300 \mathrm{~mm}$ bond lengths on 2.4 metre long rebar in potash resulted in highly variable pull test results. Smith described that the variability in the data was thought to be caused by the difficulty in drilling the holes for the rebar to an accurate depth. Since a small volume of resin was being inserted to provide the $300 \mathrm{~mm}$ bond length, holes over-drilled only by 2.5 to 5 $\mathrm{cm}$ would result in $14 \%$ of the resin lost to the top of the hole (above the rebar) where it would not contribute in bonding the rebar to the rock. (This calculation is in Appendix C)

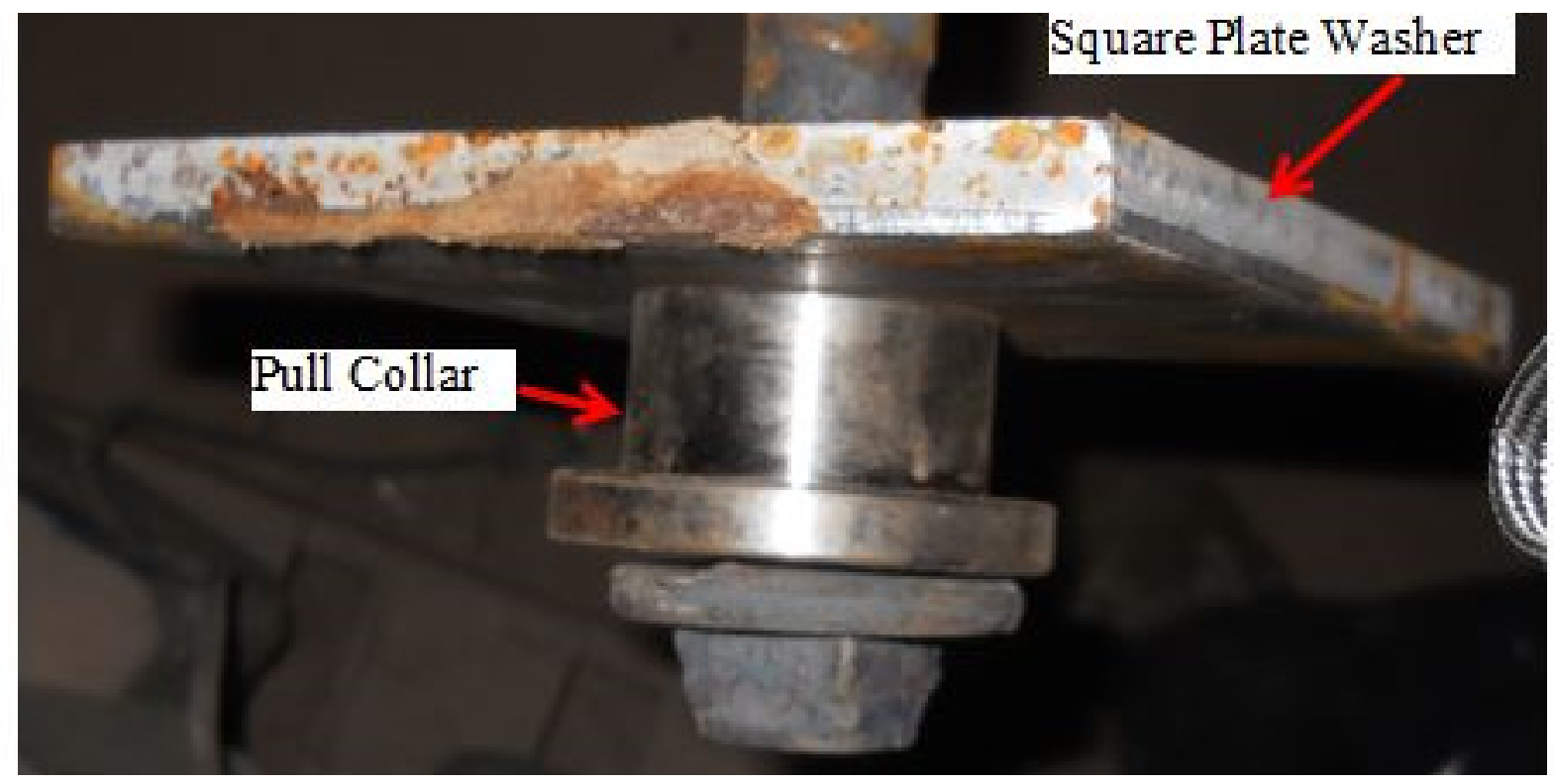

Figure 4.2 Pull collar and square plate washer 
Based on the past testing conducted by Smith (2008), it was decided to use longer bond lengths during an initial testing phase. This initial testing phase involved placing resin dams at different positions along the rebar samples to create four different bond lengths to test. The data from these initial tests were later used to decide upon a single bond length to use for the remainder of tests. All of these initial tests were conducted on $25 \mathrm{~mm}$ diameter rebar. The four different bond lengths tested in this initial phase were:

- $610 \mathrm{~mm}(2 \mathrm{ft})$

- $560 \mathrm{~mm}(1.83 \mathrm{ft})$;

- $510 \mathrm{~mm}(1.67 \mathrm{ft})$;

- $460 \mathrm{~mm}(1.5 \mathrm{ft})$.

The resin dam was placed on the rebar at a distance equal to the desired bond length, measured from the toe (or slashed) end of the rebar (Figure 4.3). Using the known volume of resin being inserted into each $36.5 \mathrm{~mm}$ diameter hole (two $300 \mathrm{~mm}$ long, $28 \mathrm{~mm}$ diameter resin cartridges) the resin dams prevented excess resin from bonding to the rebar. The resin dam also had to be large enough in diameter to ensure that resin stayed at the top of the hole. Calculations for the size of each resin dam used for each bond length tested are provided in Appendix C. Figure 4.4 shows a schematic of a resin dam on an installed rebar.

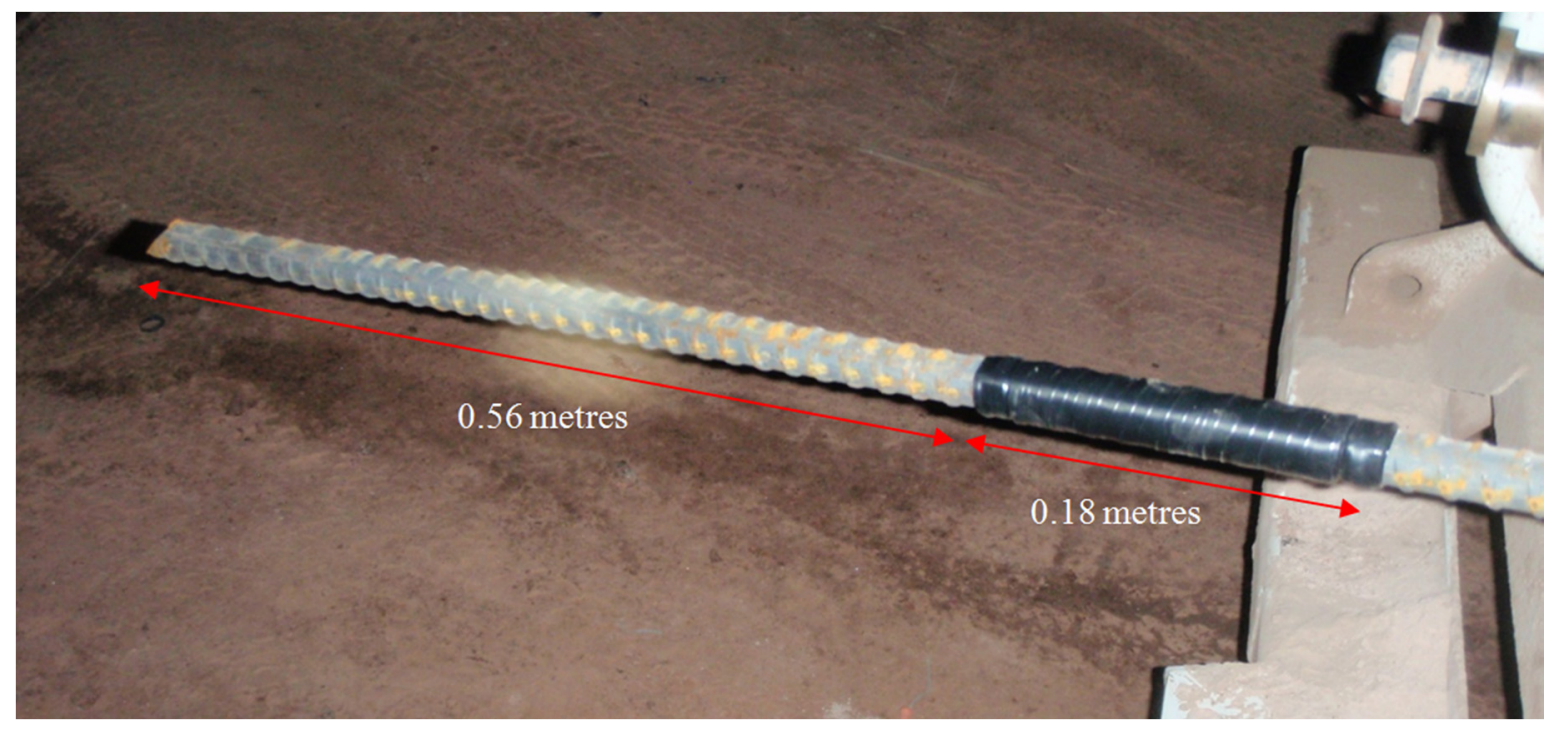

Figure 4.3 Example of $0.56 \mathrm{~m}$ portion of rebar to be bonded followed by $0.18 \mathrm{~m}$ finished resin dam 


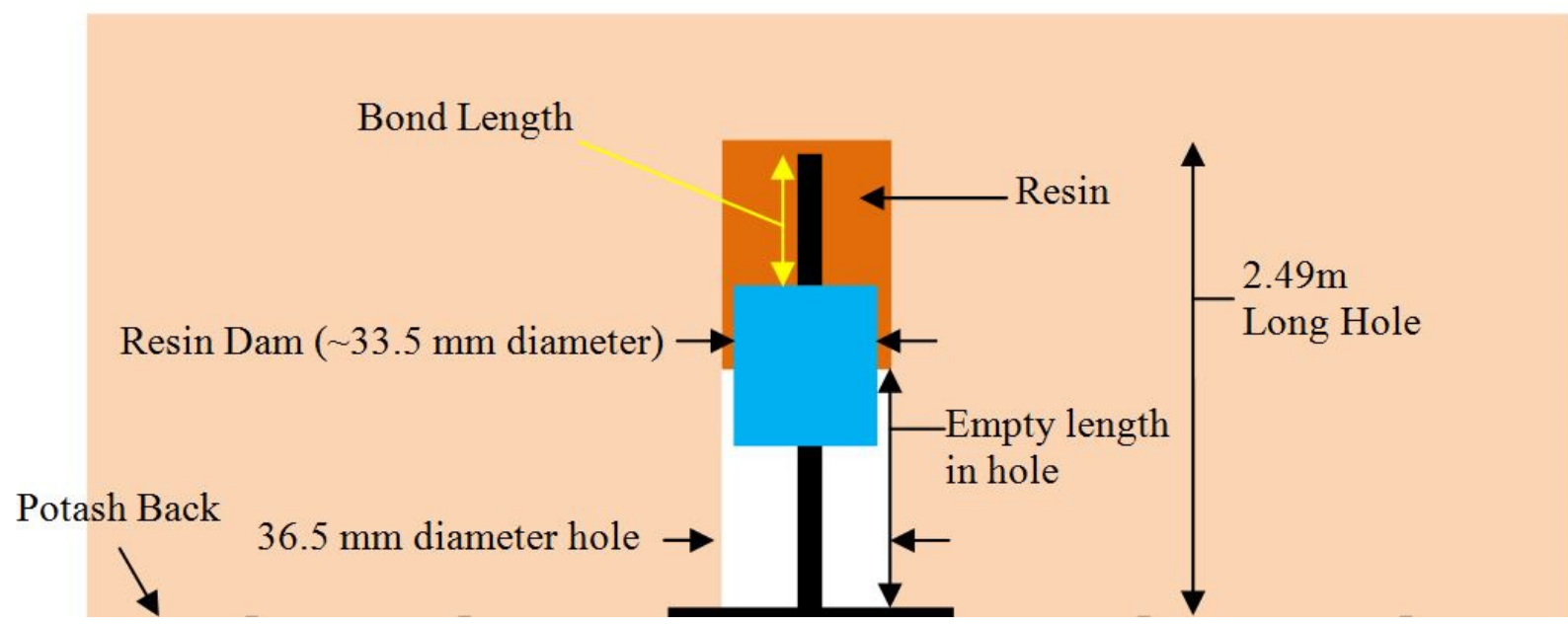

Figure 4.4 Schematic of using resin dams to achieve desired anchorage length

For simplicity, and due to the availability of materials, clear PVC tubing (25.4 mm I.D.) and electrical tape were used to form the resin dams. Measurements were taken to ensure that the resin dam diameters were in the range of 32 to $34 \mathrm{~mm}$. This size range reduced the centred gap between the resin dam and rock in the hole to 1.3 to $2.3 \mathrm{~mm}$. This diameter of resin dam reduced the centred gap between the resin dam and rock while not being large enough to come into contact with the hole during installation, thereby preventing damage. Typically, one overlapping layer of electrical tape was required along the PVC tubing to obtain the desired diameter. Figure 4.5 shows the tape overlapping onto the PVC tubing to form a resin dam. Digital calipers were used to obtain three diameter measurements along the length of the resin dam; resin dams that were not within the desired average diameter range were discarded.

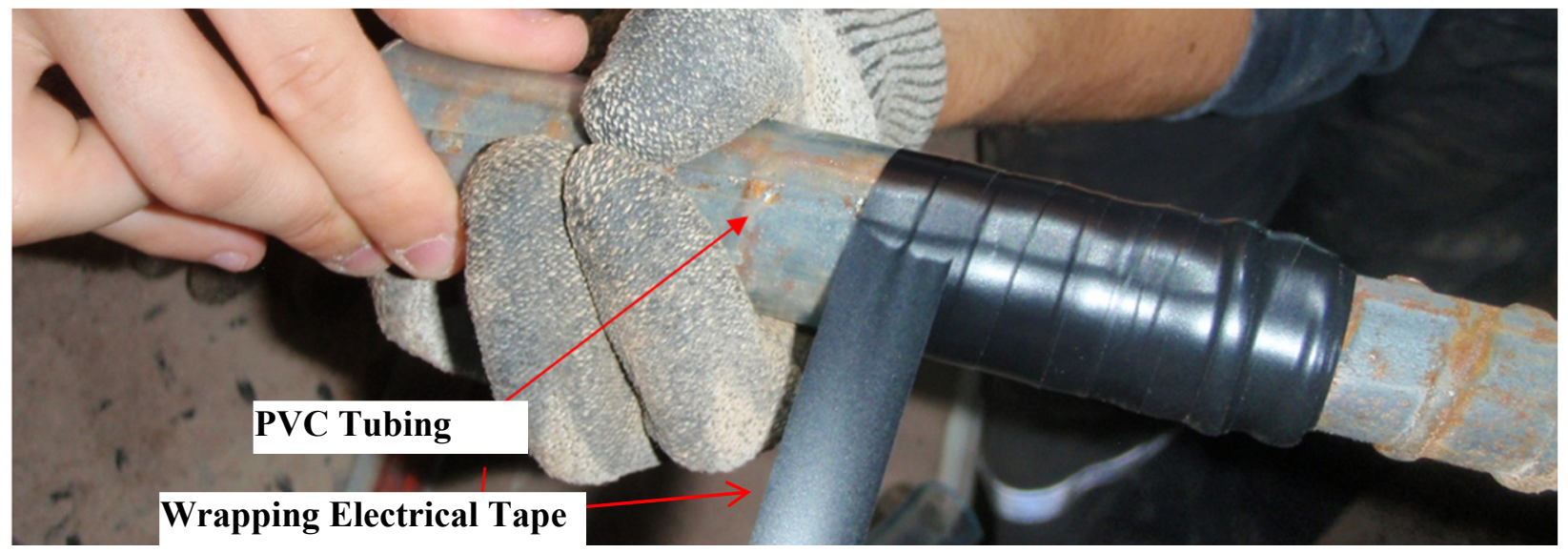

Figure 4.5 Wrapping a 0.18 metre length of PVC tubing in electrical tape to secure it to rebar 


\subsubsection{Instruments to Measure Deformation during a Pull Test}

Several challenges exist when measuring deformation during a pull test in potash. Since potash is a soft, weak rock, the rock directly bearing the pull test apparatus can deform upwards during the test due to the high load concentration. This concern had to be addressed because obtaining accurate deformation data was crucial to the analysis of the results relating to the failure mechanism of the support system. Further, the back can be very uneven due to the excavation technique of the continuous borers. Uneven surfaces may cause errors in deformation measurements because, when load is applied, the apparatus may tilt and pull at an angle as shown in Figure 4.6. It was therefore apparent that measuring deformation accurately may not be easily accomplished using standardized testing techniques in a potash mine.

Two instruments for measuring deformation were used during field testing in this project: a linear potentiometer and a string potentiometer. The linear potentiometer was a Penny and Giles model SLS320, purchased from Durham Instruments. The string potentiometer was a Celesco model SP2-4, purchased from Intertechnology. A schematic showing the set-up of both instruments is shown in Figure 4.7. Both instruments recorded the downward movement of the rebar head relative to the floor of the underground opening as load was applied manually.

The linear potentiometer was used for the initial testing phase. The linear potentiometer was attached to two separate tubes, forming a collapsible rod. An aluminum tube on the upper half and a smaller diameter copper rod on the bottom half were connected with the linear potentiometer. As the apparatus moved downward as the rebar deformed or slipped, the aluminum rod slid over the copper rod and displaced the linear potentiometer. The closure rod was attached to the apparatus with a $10 \mathrm{~mm}$ bolt. When the test was ready to be carried out, a $10 \mathrm{~mm}$ Hilti pin was shot into the potash floor to attach the closure rod to the floor. Placement of the pin into the floor was completed with a plumb bob to ensure that the rod was installed vertically. Uneven surfaces are often found along the floor. In older workings, the floor can be covered in loose potash (muck), and the surfaces can be uneven due to years of traffic acting on them. In these cases, the floor was re-shaped with a shovel to ensure that the closure rod was firmly anchored (Figure 4.8). Once anchored at both ends, the closure rod could be read continuously throughout the test. 


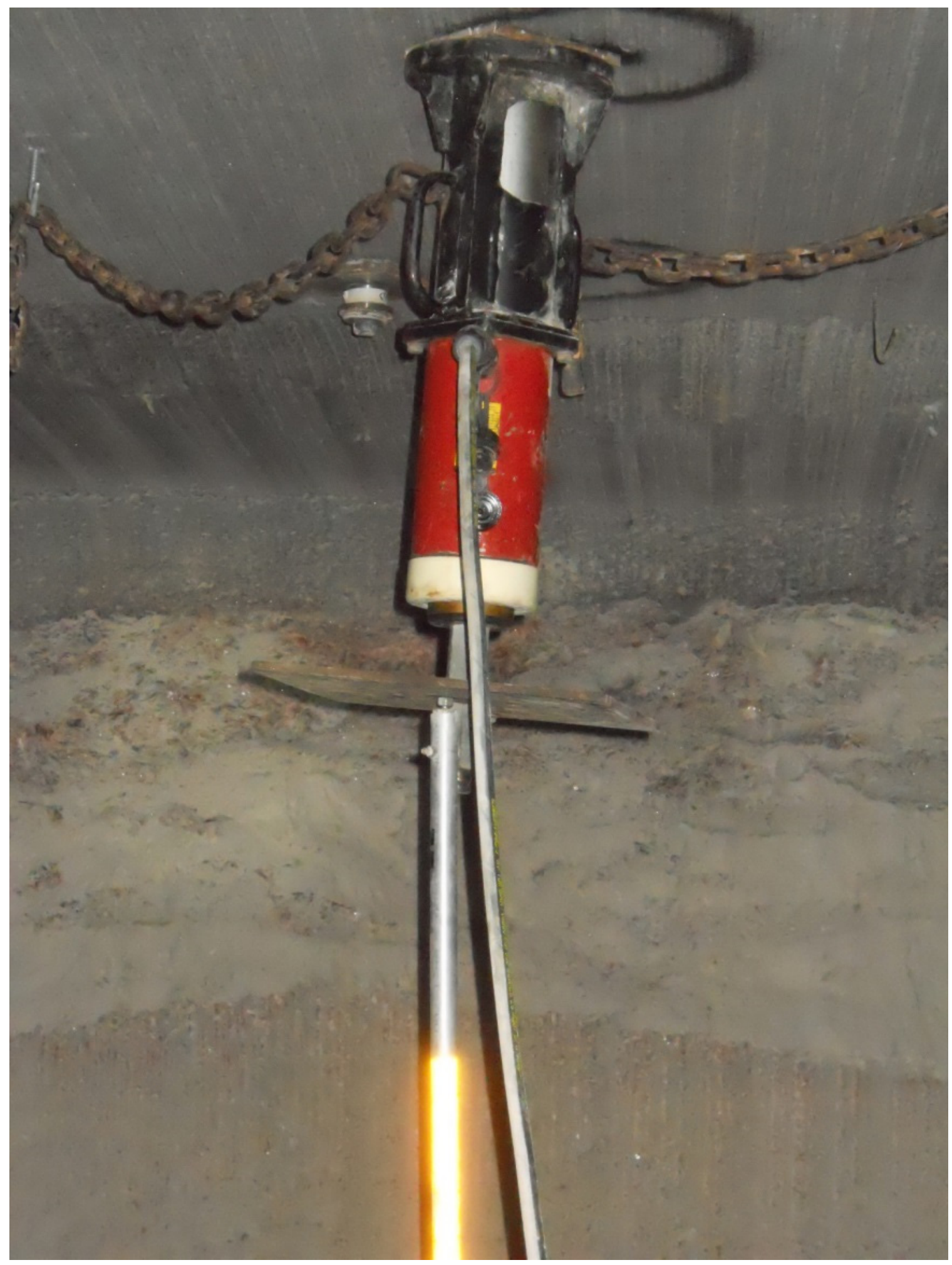

Figure 4.6 Uneven surface along back causes apparatus to tilt at the start of test 


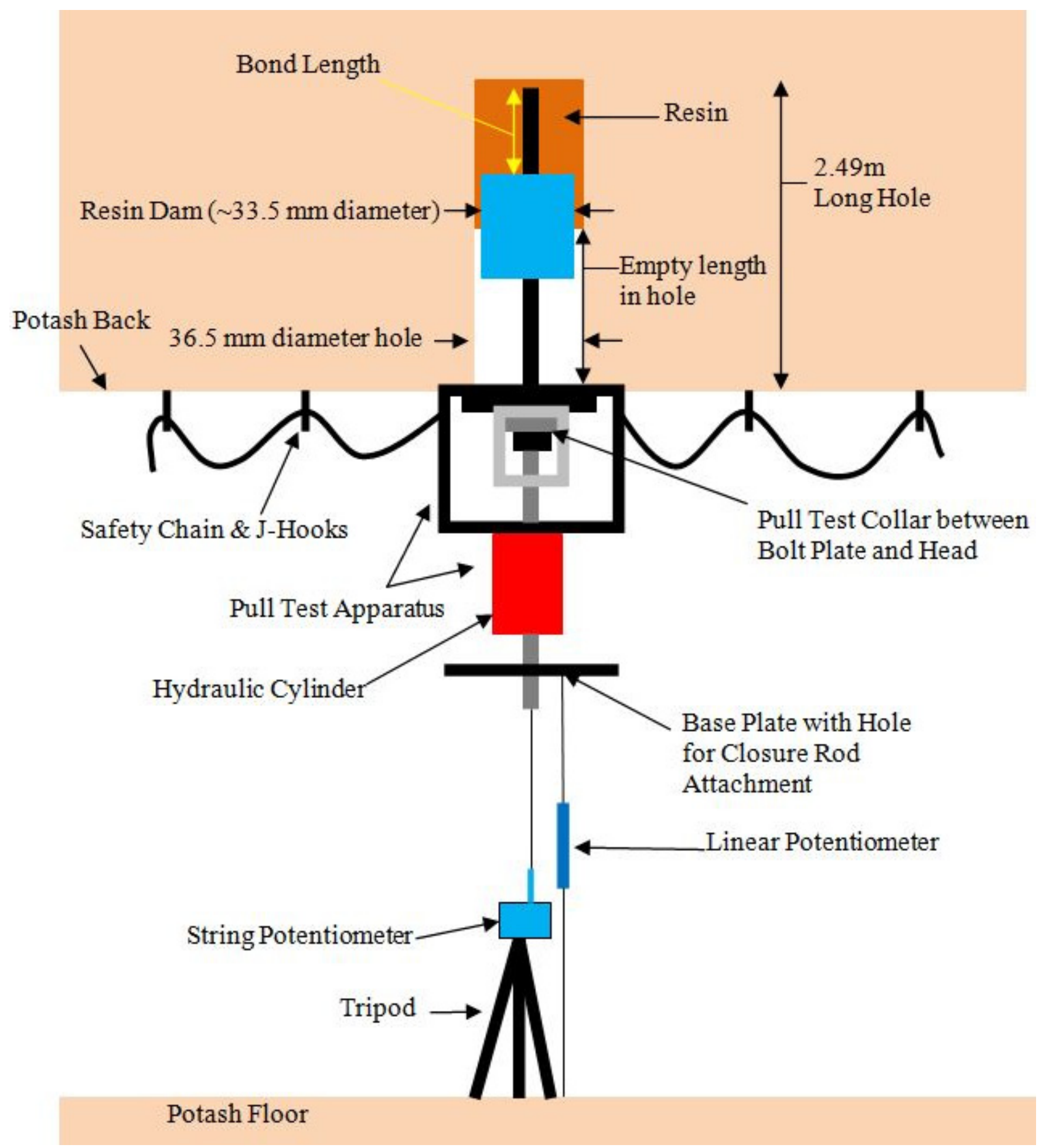

Figure 4.7 Pull test set-up arrangement showing both methods of deformation measurement 
The closure rod measured displacement by delivering a voltage continuously to a multi-meter. Voltage change readings were converted into linear displacement measurements in units of millimetres. Given the short duration of the test (10 minutes), the input voltage was measured at the beginning of the test and was assumed to remain steady during the test. Output voltage increases indicated downward movement and voltage decreases indicated upward movement.

There were disadvantages in using the closure rod. The movement of the apparatus at the beginning of the test, caused by the uneven surface on the back, caused erroneous measurements of deformation that were related to the plate seating, not the rebar actually deforming or pulling out of the epoxy. Figure 4.9 shows a simplified schematic of the seating effects that occurred due to the uneven back that caused tilting of the loading apparatus and resulted in inaccurate readings from the closure rod. Both upward and downward movements were possible due to this tilting. It was not always possible to position the rod to avoid this movement. Tests completed with the closure rod accurately displayed the relative rate of movement with increased load, as well as the load at which the support system began to slide out of the hole; however, the magnitude of total deformation may not have been accurate.

The string potentiometer was used in an effort to improve the accuracy of the deformation measurements. The string potentiometer worked in a similar fashion to the linear potentiometer. A spring loaded string-line extended out of the instrument, the position of which controlled the output voltage that decreased linearly as the string-line was drawn back into the instrument. This instrument was connected directly to the rebar head using a string that was anchored on the rebar head using a general purpose epoxy (PermaPoxy 1 minute epoxy) and some electrical tape which held the string to the rebar head while the epoxy set. The string was a braided 9 kilogram fishing line. Once the epoxy set, after 24 hours, the line was capable of withstanding the 142 grams of tension placed on it during each test. The string potentiometer was bolted to a block of wood, which was then clamped to a tripod. Figure 4.10 shows the string potentiometer connected in the field. 


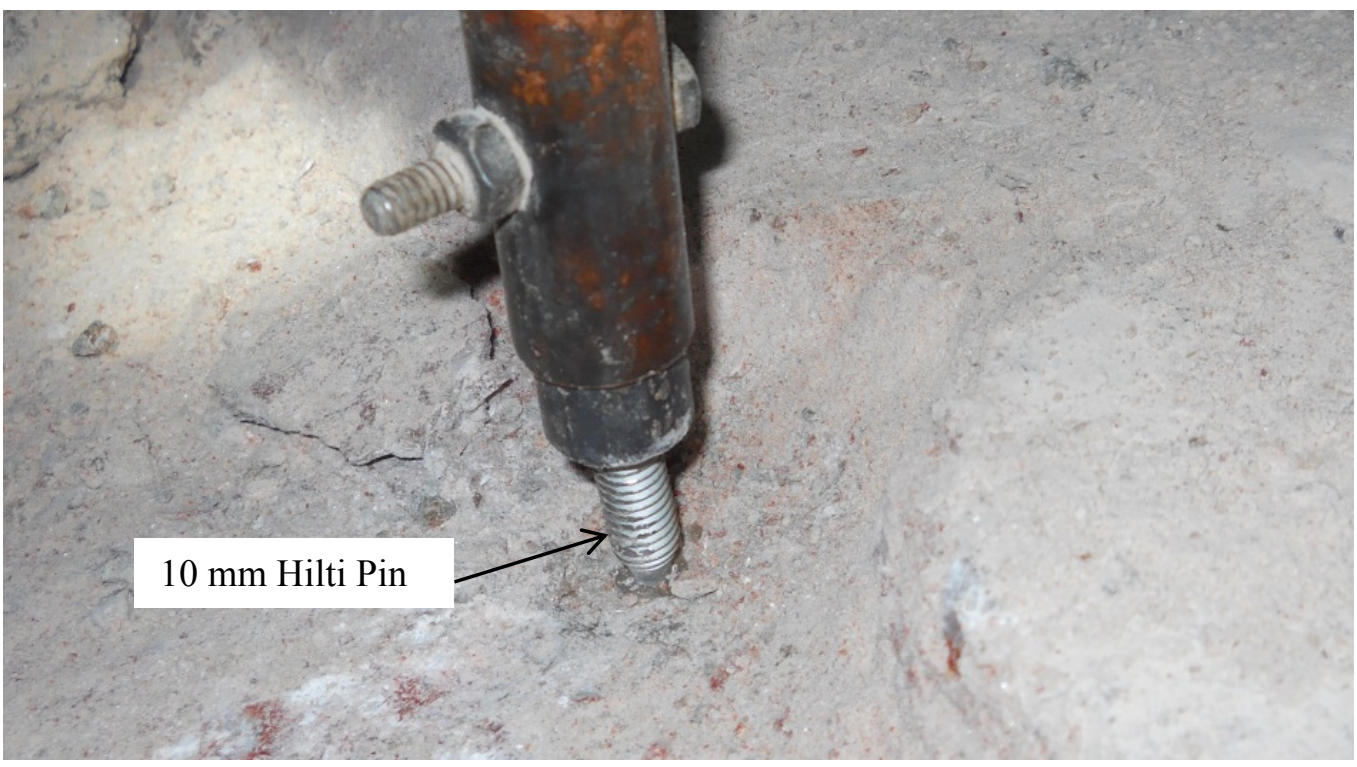

Figure 4.8 Closure rod anchored into potash floor after it is cleaned with shovel

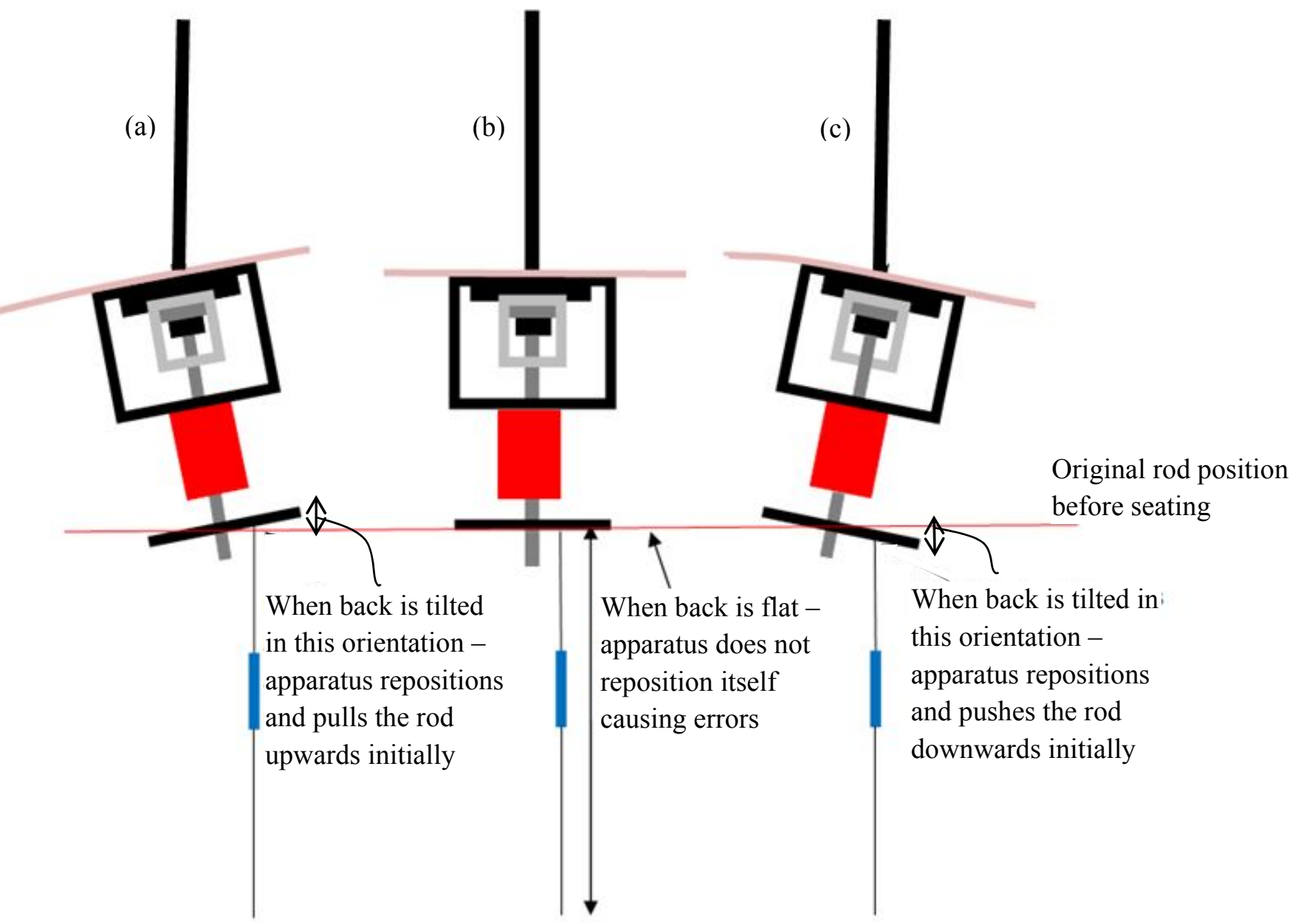

Figure 4.9 Schematic of initial tilt of apparatus during pull test caused by uneven back surface: (a) Initial extension of rod causing error; (b) No error caused when flat back is present; and (c) Initial compression of rod causing error 


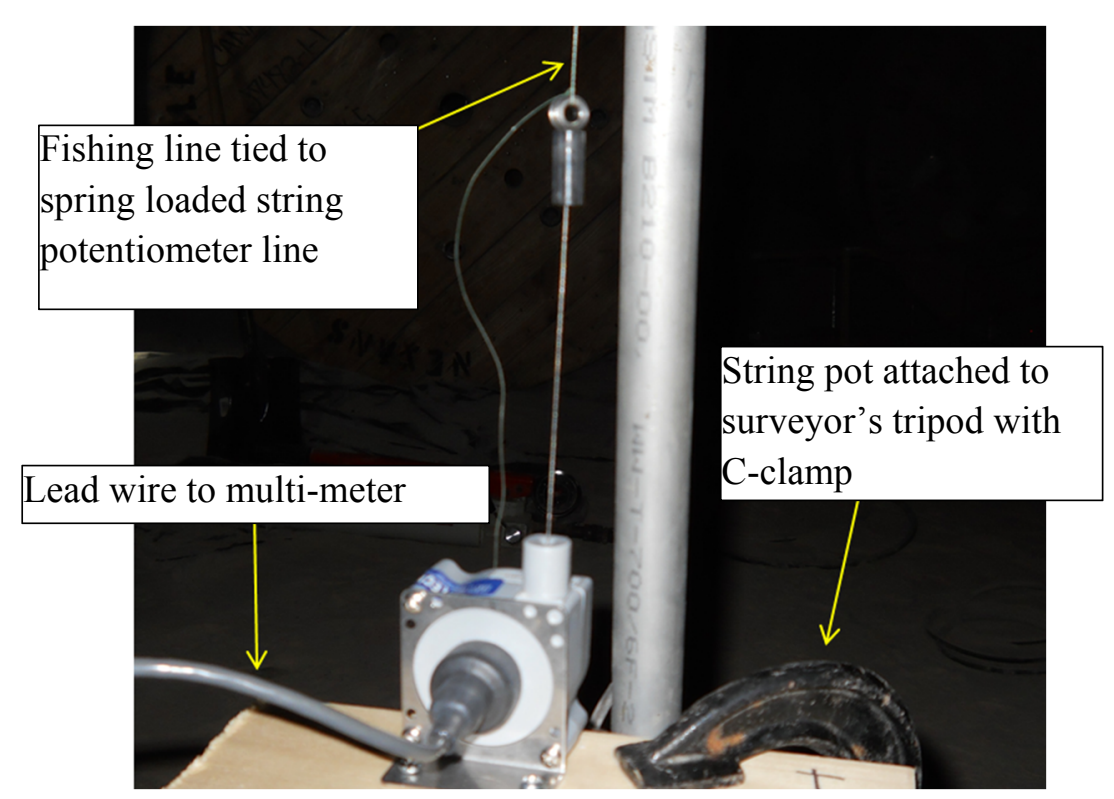

Figure 4.10 String potentiometer connected in field

By attaching the string potentiometer directly to the rebar head and not the apparatus, the instrument did not pick up the erroneous measurements caused by the plate tilting. The deformation measurements recorded by the string potentiometer, accurately represented the magnitude of deformation that occurred to the anchored rebar during the test. Some additional effort was needed to install the fishing line at least one day ahead of any testing. Tying the fishing line to the string potentiometer took minimal effort, and, like the closure rod, this instrument was able to display a continuous readout of voltage change (displacement) during the entire test on a multi-meter.

Figure 4.11 shows how the fishing line was connected to the rebar head and that it ran down a central hole through the loading frame apparatus. The fishing line was free to move with the rebar as it was pulled out of the hole. When the fishing line moved downward with the rebar, the spring took up the slack and the spring line retracted back into the string potentiometer. The change in measured voltage was used to calculate the displacement. Deformation measurements involved a degree of error due to instrument accuracy. The string potentiometer can be read to within $+/-$ $0.001 \mathrm{~V}$ or $0.014 \mathrm{~mm}$. This measurement accuracy of $0.014 \mathrm{~mm}$ is equivalent to the approximate elastic deformation of the 1.9 metres of unbonded rebar under a load of $76 \mathrm{~N}$. This indicates that deformation measurement accuracy was adequate, given that loads of $200 \mathrm{kN}$ and above were applied during pull tests, an error of $+/-76 \mathrm{~N}$ would be a small fraction of the total load applied. 


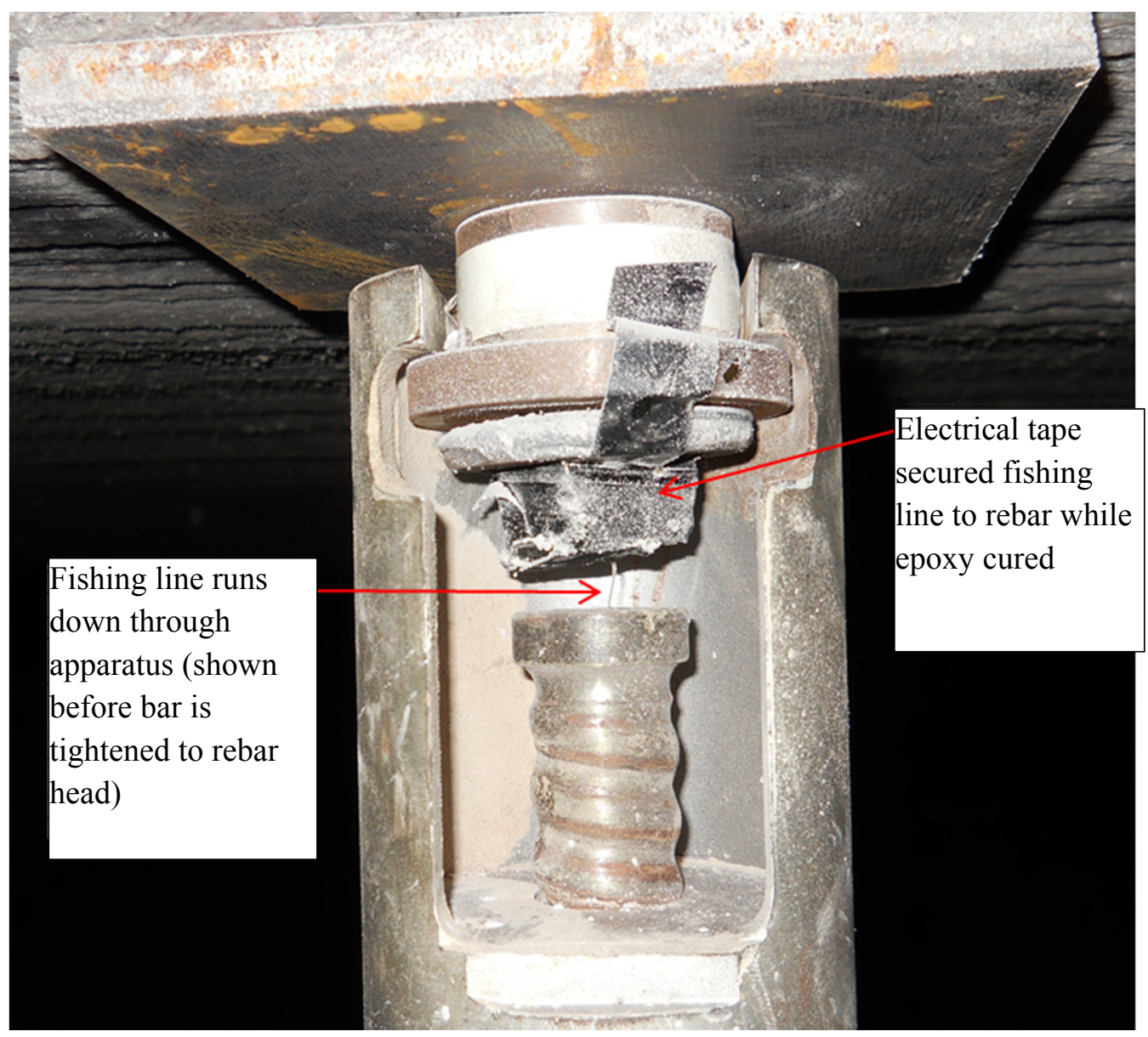

Figure 4.11 View of fishing line connected directly to rebar head with electrical tape

\subsubsection{Investigating the Effect of Field Variables}

The methods used to isolate field variables and assess their effect on bond strength per metre of anchorage are described in this section. Rebar was installed in four different locations at the Allan mine in an effort to single out environmental variables for testing. The following will describe the test sites where the effect of each variable on the average bond strength was investigated.

Some test sites provided test data which was used to simultaneously investigate the effect of multiple variables while other test sites isolated a single variable. For example, one population of rebar was used to investigate resin cure time, potash horizon rock type, and the influence of a destressed rock mass due to a lack nearby mining activity. These tests not only provided information on the resin cure time but were indicative of the average bond strength provided by resin anchored rebar installed in areas with similar rock types and proximity to active mining. In contrast, rebar installed on the halite horizon were only used to assess the effect of that specific rock type on the 
average bond strength. Multiple variables were tested at some sites in order to reduce the number tests needed and, therefore, the number of rebar to be installed. Installing rebar involved allocating resources and personnel at the Allan mine and, therefore, interrupted daily operations. Optimizing the quantity of test sites and rebar installed aided in the research being carried out efficiently alongside daily mine operations.

\subsubsection{Resin Cure Time}

Cure time refers to the amount of time between mixing the resin in the hole during rebar installation and completing the pull test. Resins do not set instantly, and most need some time to develop their full strength. For example, the specifications for the resin being used at Allan state that full anchorage strength is reached after 24 hours, and that $80-90 \%$ of this strength is achieved within 60-120 seconds of installation (DSI, 2008). These estimates are based on a resin temperature of $22^{\circ} \mathrm{C}$ at the time of installation.

In a potash mine, holes are made with percussion drills and the dust created by the process is not removed from the hole before the support is installed. Potash dust is present during the resin mixing process and this additive might affect cure time. Temperature effects for the particular resin being used have been tested in DSI laboratories, but not in the field. Allan has an underground temperature of $28^{\circ} \mathrm{C}$, which is similar to the $22^{\circ} \mathrm{C}$ laboratory testing temperature, and increased temperatures will only cause resin to cure more quickly (DSI, 2008). Temperature effects were therefore expected to be minimal and were not expected to have any negative effects, so this factor was not of significant interest in this research. Temperature was not measured during testing. The in-situ pull tests that were used to investigate the effect of cure time on average bond strength were conducted to assess whether there was a significant difference in the average bond strength over a time range of 11 to 125 days.

To isolate the effect of cure time, the rebar was installed in an older area of the mine, located more than 300 metres away from any active mining where stress-relief and other factors would not influence the results. An eight year old main development entry, located four miles north of the mine shafts at Allan, was selected. The name of this test site was "North70," as per the name of the entry at the Allan mine. The rebar was installed in the centre of this entry. Neither shear deformation or bed separation (tensile deformation) were expected during the duration of the test. The closure rate was measured to confirm that the area was not affected by active mining sites (the 
nearest active site was over 1000 metres to the north). Internal documents at the Allan mine describe that a closure rate of $0.1 \mathrm{~mm} /$ day is typical for a non-active (stress-relieved) area (PCS Allan, 2013). The closure rate was measured using a closure rod installed at the test site which provided data over the duration of the testing period to verify the rate of ground closure; this data is shown later with the results in Section 4.4.2.

A total of twenty rebar specimens were pulled at different times to assess how bond strength per metre of anchorage changed with the increased cure time. Five testing periods were used in order to test all twenty samples. The cure time varied from 11, 13, 57, 106, and 125 days after installation. Originally, the plan called for 5 bolts to be pulled in each interval, and for these time intervals to be even; however, this was not always possible. These times were selected based on equipment availability and depended on the operations occurring in and around the testing area. Detailed test result data is presented in Appendix E.

\subsubsection{Rock Type}

Rebar was anchored into potash and halite horizons to determine if there was a significant difference in the anchorage strength between the two different rock types. Pull tests representative of rebar anchored into potash were those completed at the "North70" test site, which were also used to investigate resin cure time. Pull tests representative of rebar anchored into halite were completed at a separate location called the "South Storage Bin", as per the name of the entry where these rebar were installed.

The "North70" test site included twenty rebar specimens. The bond length was anchored along a section of rock representative of potash at the Allan mine. The "South Storage Bin" site included only ten rebar specimens since resin cure time was not being investigated for these specimens. Similar to the "North70" test site, the "South Storage Bin" was located in an entry which was located more than 300 metres away from any active mining and had been open for over a decade. The "South Storage Bin" was located approximately one mile north of the mine shafts. Both sites included rebar installed with the same bond length, were non-active mining areas, and had similar cure time durations. The significant difference between the sites was the rock type in which the rebar was anchored; therefore, the average bond strength determined at each site represented the suggested bond strength typical of each rock type. 


\subsubsection{Effect of Proximity to Active Mining}

Stresses around potash mine openings are initially concentrated around the opening boundaries and are shed away over time (Section 1.1.3) causing induced stresses to decrease (Mackintosh, 1975; Hills, 2005). As the induced stress decreases, frictional bonds between the rock mass and rebar bolts decrease, causing a decrease in bond strength (Lovlin, 2006; Martin et al., 2004). It was therefore important to determine whether the average bond strength is significantly different when it is placed in an active mining area as opposed to a non-active area.

The active site for rebar was selected in a new development entry being cut by Borer No. 6 and is called the "Borer 6" test site. The rebar at "North 70" were representative of a non-active mining area and were used for comparison. The rebar at "Borer 6" were installed when the opening was just 53 days old, while the rebar in "North70" were installed when the opening was 3000 days old. The rebar at the active site were installed in the middle entry, as per the non-active site. Similar to the "North70" site, a closure rod was used to monitor closure rates which demonstrated the difference between active and non-active mining areas. At the Allan mine, typical closure rate for a recently opened room is initially very rapid, and is approximately 30mm/day (PCS Allan, 2013).

A total of 40 rebar were installed in the active site, rather than just 10 or 20 . The larger quantity of specimens was used so that pull testing could be performed over the duration of a year in the active site (one year is the typical life span of an active mining panel). Tests were completed at 125, 160, 258, 270, 275, 313, 316, and 318 days. Similar to "North70," these times depended on operations at the mine and even time intervals were not possible. Average bond strengths at "Borer 6 " were determined over the study duration to see how they compared to the average bond strength

found at "North70." The expectation was that, if there was a significant difference between the sites, that difference may decrease over time as the "Borer 6" site location became further away from where the borer was cutting in the panel. Initially, the test site was located approximately 50 metres south of the borer; by the end of the testing duration, the site was approximately 500 metres south of the borer.

\subsubsection{Effect of Resin Contact Area}

To vary the contact area that the resin had with both the rock and rebar surfaces, a group of ten, smaller diameter $(16 \mathrm{~mm})$ rebar were installed and pull-tested to compare with results from $25 \mathrm{~mm}$ sized rebar. The toe ends of both sizes of rebar are shown in Figure 4.12. These tests were 
conducted to compare the average bond strength results along both the resin-rock and resin-rebar contact areas, between both sizes of rebar.

Testing the $16 \mathrm{~mm}$ diameter rebar required the hole size diameter to be decreased from $36.5 \mathrm{~mm}$ to $28.5 \mathrm{~mm}$. When hole size is much greater than the rebar diameter, the rebar cannot mix the resin while it is being spun into the hole. If hole size was not decreased, the rebar would not be large enough compared to the hole to effectively mix the resin. When the resin does not completely mix, portions of it will remain uncured and provide no support to the system. Reducing the hole size to $28.5 \mathrm{~mm}$ for the $16 \mathrm{~mm}$ diameter rebar provided an annulus size of approximately $6.25 \mathrm{~mm}$. The $25 \mathrm{~mm}$ diameter rebar were placed in a $36.5 \mathrm{~mm}$ diameter hole and had a similar annulus size of $5.75 \mathrm{~mm}$. These hole sizes followed guidelines provided by the supplier (DSI) and conformed to standard practice at the Allan mine.

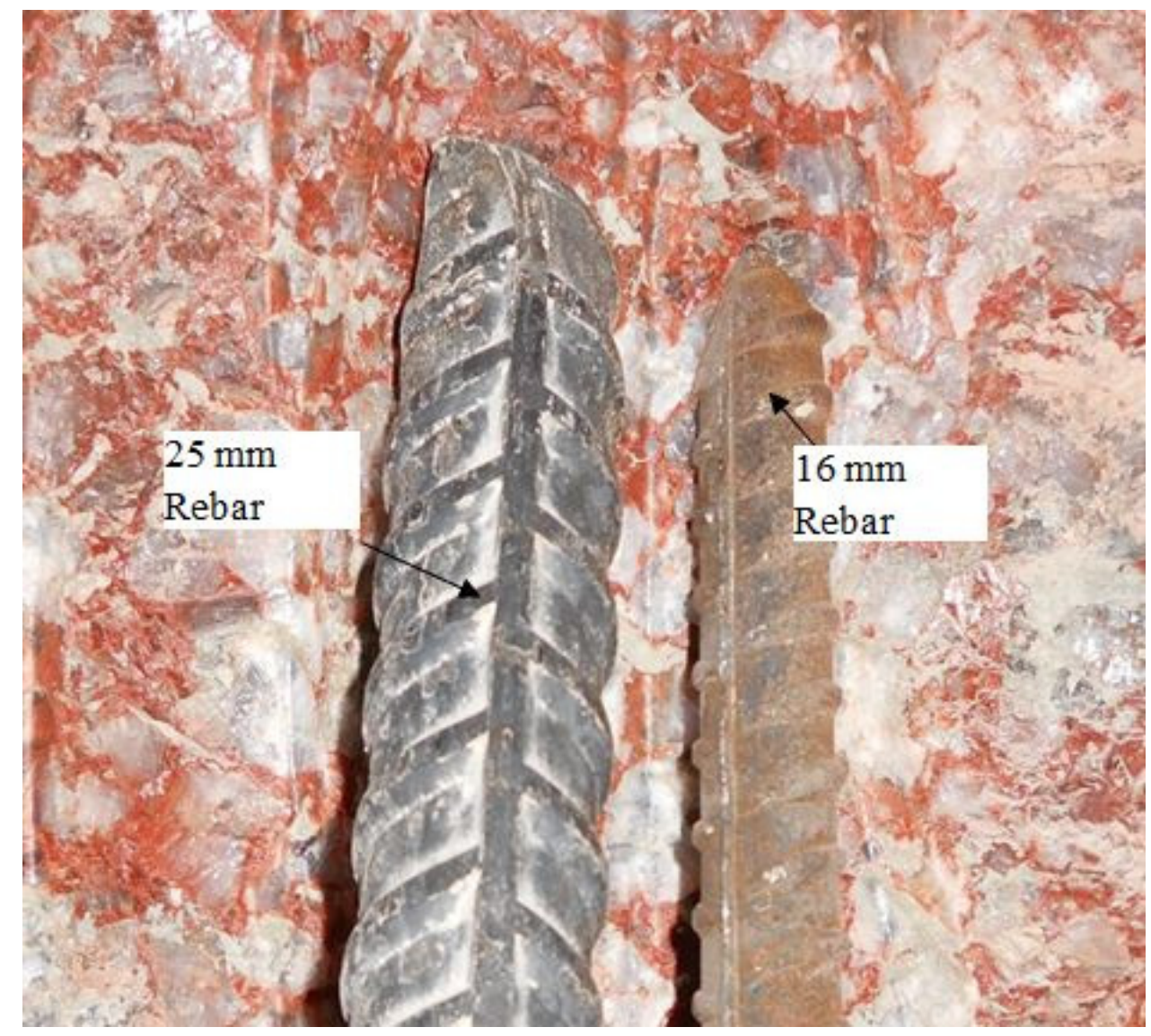

Figure $4.1225 \mathrm{~mm}$ size rebar next to $16 \mathrm{~mm}$ size rebar

The $16 \mathrm{~mm}$ rebar pull test results were compared to the "North70" site results. The $16 \mathrm{~mm}$ rebar were installed in the centre of a development entry located 6 miles north of the mine shafts. Like 
the "North70" test site, this area was located more than 300 metres from active mining and had been open for nearly a decade. The name of this location was "East305," as per the entry's name at the Allan mine.

The only other difference between the "North70" and "East305" test sites, besides the rebar and hole sizes, was the machine used for installation. Rather than being installed by the usual bolting machine used at the Allan mine, the smaller $16 \mathrm{~mm}$ rebar were installed with a stoper (Figure 4.13) due to the small cutting bit sizes needed to drill the holes. Similar to the usual bolting machine, a stoper uses percussion drilling to form the hole; however, instead of using auger steel to remove cuttings from the hole, it relies on air flow and gravity to move the cuttings.

Both the bolting machine and stoper result in a similarly smooth cored hole lining. The main difference between the two machines was the additional manual labour required for the operation of the stoper and the lack of auger steel used to remove cuttings from the hole while using the bolting machine. The spin time for the rebar with the stoper was increased from 3 to 6 seconds to compensate for the fact that the stoper spins at $300 \mathrm{rpm}$ rather than at $600 \mathrm{rpm}$ for the bolting machine. This ensured that approximately 30 revolutions were still used to mix the resin.

Smaller collars were used on the $16 \mathrm{~mm}$ rebar to ensure that the load transferred effectively from the pull tester into the rebar, and did not concentrate on the rim of the rebar head. These smaller collars had $24 \mathrm{~mm}$ diameter holes as opposed to the pull collars for the $25 \mathrm{~mm}$ rebar which had 34 $\mathrm{mm}$ diameter holes in the centre. The same square plates used on the $25 \mathrm{~mm}$ rebar were also used on the $16 \mathrm{~mm}$ rebar. Similar construction techniques were used for resin dams and measurements were done on both sizes of rebar. The only modification made to the resin dams on the smaller 16 $\mathrm{mm}$ rebar was that the PVC tubing used had an inner diameter of $15.8 \mathrm{~mm}$, rather than $25.4 \mathrm{~mm}$. 


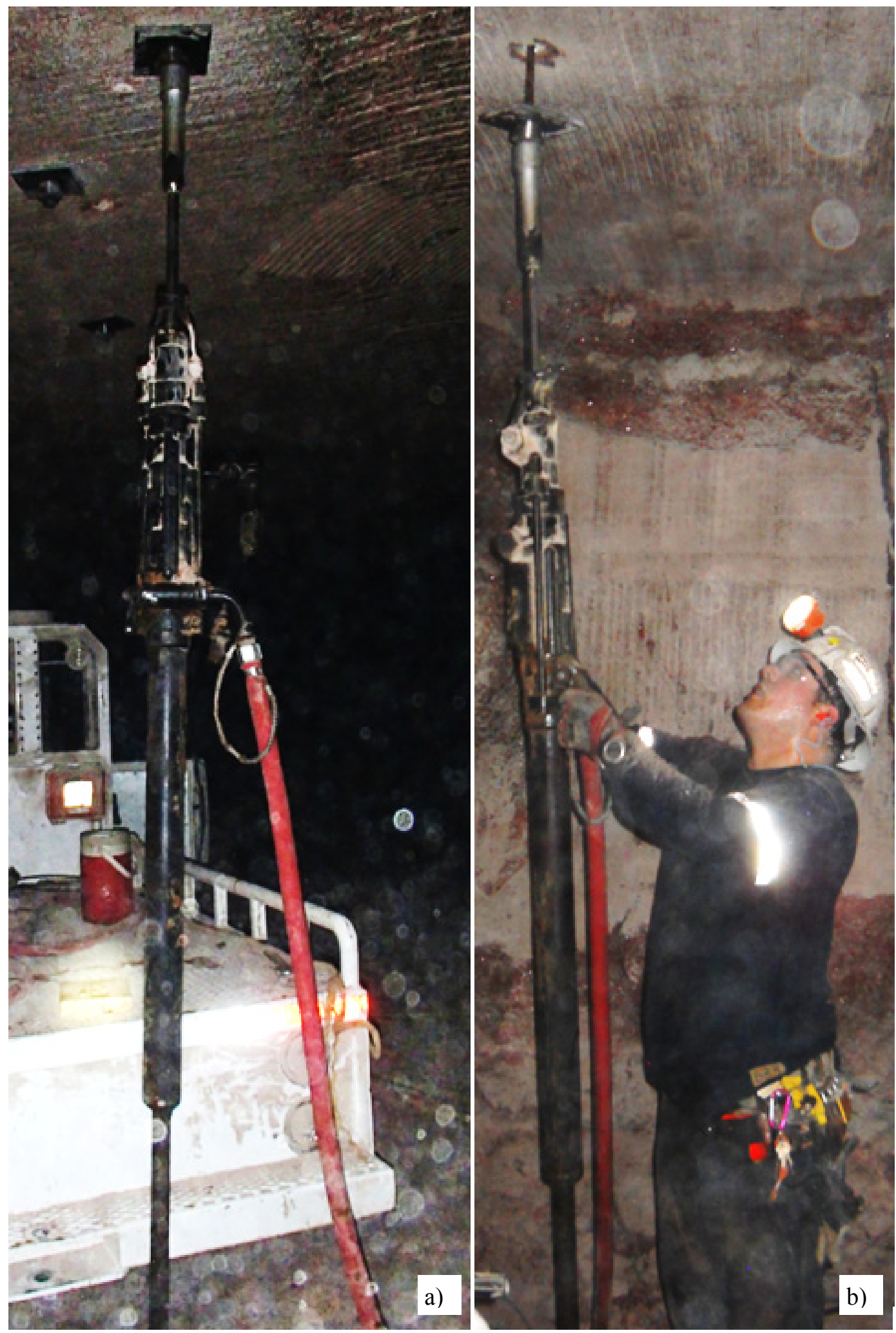

Figure 4.13 (a) Stoper used for installing $16 \mathrm{~mm}$ rebar and (b) Operating the stoper 


\subsubsection{Conditions of Resin after Sliding}

A separate population of rebar was installed with the intention of using a bond length short enough to enable the pull-testing apparatus to pull the rebar free from the hole, as damage to the resin is visible only when the rebar is completely removed from the hole. Ten $25 \mathrm{~mm}$ rebar were prepared with $100 \mathrm{~mm}$ bond lengths. One, $300 \mathrm{~mm}$ long resin cartridge (the smallest length available) was inserted. These rebar were installed near the "South Storage Bin" testing site. Since these rebar were pulled to the point that they pulled free from the hole, the string potentiometer was not used to measure deformation as it would have been susceptible to damage. Instead, the peak load applied during the test before the rebar began to dislodge from the hole was recorded. After removing the rebar from the hole, visual observations were made of the rebar and a bore hole camera was used to note the condition of the hole.

\subsubsection{Pull-Test Quality Control}

This section outlines measures used to control the quality of installations for the rebar specimens. In general, for all installations, there were a few variables that could not be controlled as they depended on the operators of the bolting equipment. Operation of this equipment could occasionally result in less than perfect installations. Attention was given to noting when an installation did not go according to regular procedure so that test results associated with these irregular installations could be interpreted and the results properly taken into account.

To begin the installation, the auger style drill steel must be marked to indicate the correct depth of the hole. Hole depth was $2.45 \mathrm{~m} \mathrm{(50} \mathrm{mm} \mathrm{longer} \mathrm{than} \mathrm{the} \mathrm{rebar,} \mathrm{to} \mathrm{ensure} \mathrm{good} \mathrm{toe} \mathrm{bond} \mathrm{of} \mathrm{the}$ rebar). This marking was generally accomplished with a bright colour of spray paint on the drill steel (Figure 4.14). One operator would then control the drilling of the hole while the other operator would be in charge of placing the drill steel onto the drill and aligning it to drill vertically into the potash back. The rebar were installed using a square 1.2 metre by 1.2 metre spacing pattern. This spacing pattern is used as the standard pattern at the Allan mine and was familiar to the operators. 


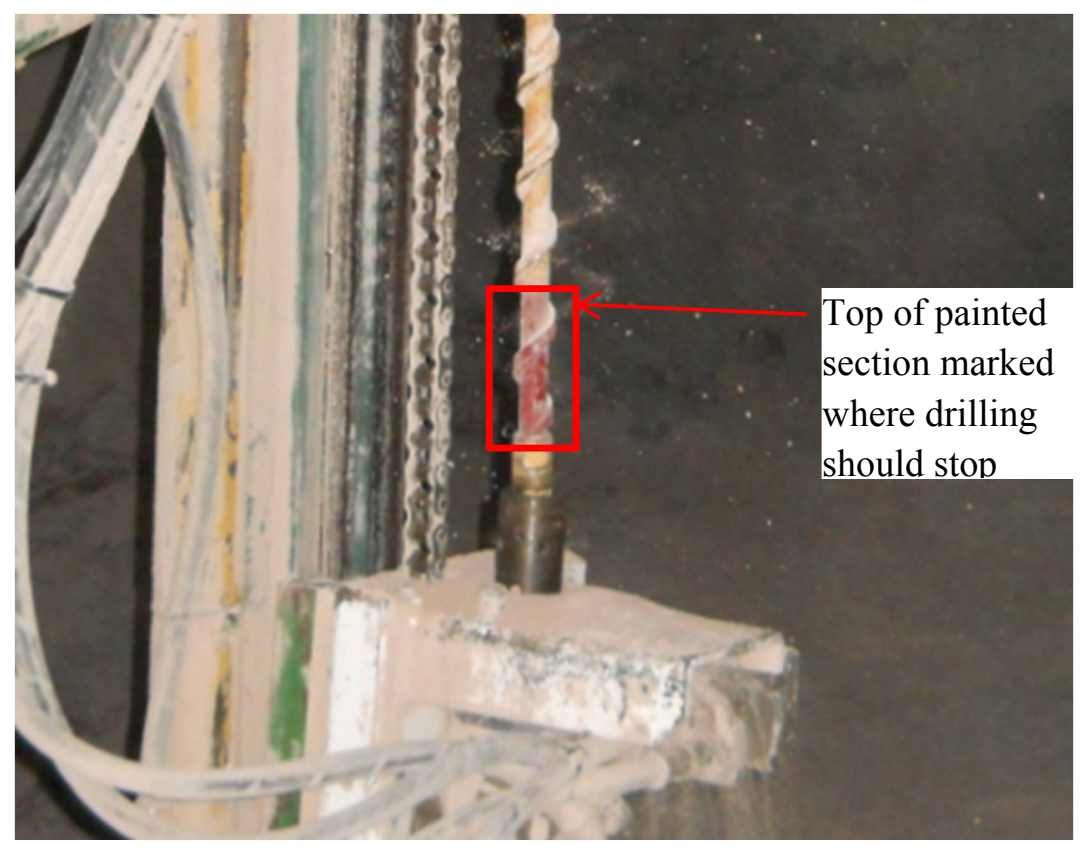

Figure 4.14 Auger drill steel marked with paint on bolter

Drill speed was dependent on the skill level of the operator, with more experienced operators using a medium speed (300 RPM) to drill the hole with a consistent advance. Inexperienced operators either drilled very slowly (below 300 RPM) or too quickly ( 600 RPM). Drilling speed could affect the quality of the installation (hole irregularity, roughness, and depth); incorrect drilling speed was occasionally noted. Variability occurred in the position of the drill hole and the angle of the drill hole (away from vertical). The accumulation of dust sometimes caused the drill steel to become jammed in the hole when drill speed wasn't well controlled. This resulted in holes featuring a lot of debris and very rough walls.

After the hole was drilled, the resin cartridges would be inserted into the hole with the assistance of plastic "birdies" used to help hold the resin up the hole before the rebar was inserted. Figure 4.15 shows a resin cartridge with the "birdie" attached. The operator would spin the rebar slowly while inserting it into the hole to allow the rebar to break open and rip apart the resin cartridges once it reached the top of the hole. As soon as the rebar was fully inserted, the operator was required to spin the rebar at full speed (600 RPM) for 3-5 seconds to achieve the recommended number of revolutions for mixing (DSI, 2008). This is known as the spin time, and is based upon the type of resin being used. The rebar was then held in place in the hole with the bolter for at least one minute; this is the hold time and again is based on the resin type being used. The hold time allows the resin to set and begin to cure. 


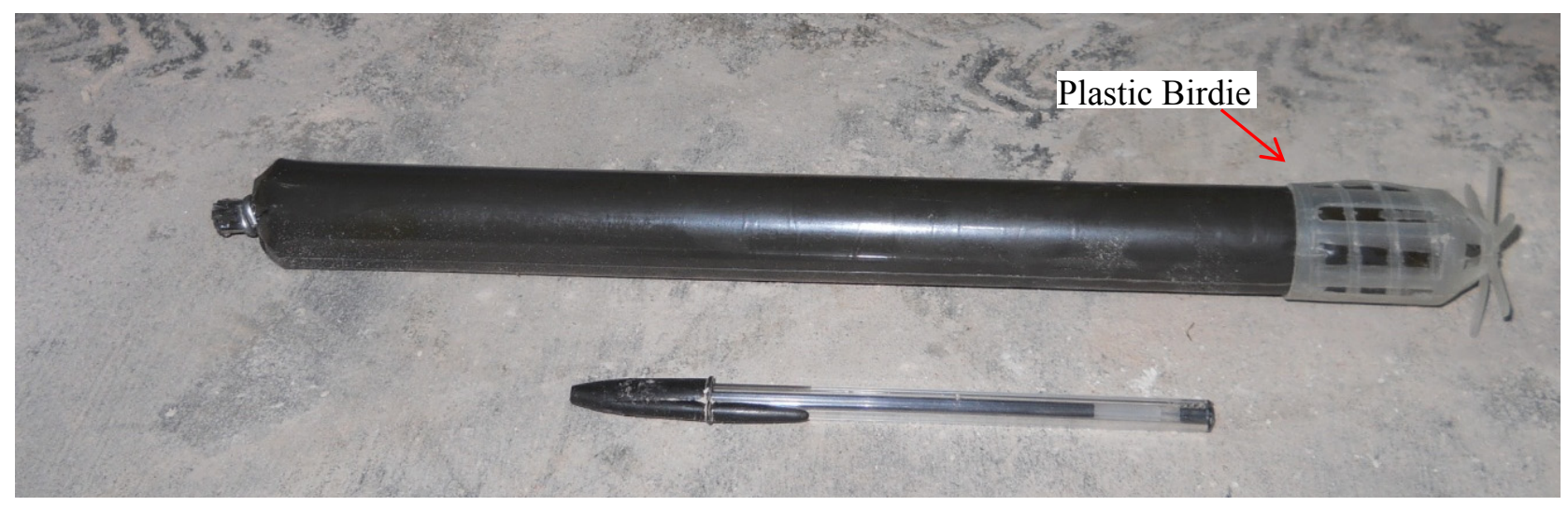

Figure 4.15 Resin cartridge with birdie attachment

The author was always present during installation to ensure that the same procedure was used for each of the test rebar used in this research project. When possible, rebar specimens were still tested after operators made errors in the installations such as: over-drilling, over-spinning the resin or not completing the proper hold time. Errors were noted to observe their effect on the bond strength and became part of the study. Installation practice at Allan did not include cleaning out the holes after drilling.

Controlling the quality of the materials used was completed by taking precautions with each set of materials:

- The test rebar were taken from the same heat batch;

- Plates and collars used were inspected to ensure they were in good condition and were not corroded or damaged;

- Resin required the highest level of control. Since storage of resin underground at high temperatures $\left(27^{\circ}\right.$ to $\left.30^{\circ}\right)$ can decrease the shelf-life by as much as $50 \%$ (Stare, 2012), the resin used was always inspected beforehand, and only resin that had been stored for less than 2 months was used. This is well within the 6 month storage life limit used by engineers at the Allan mine.

\subsection{Pull Test Data Reduction}

Traditionally, pull tests are conducted until the support load capacity decreases following attainment of a peak value. This coincides with the frictional bond resistance dropping to a residual value as described in Section 2.5. The assessment of traditional pull testing data consists of simply recording the peak load, ideally coupled with deformation measurements. However, given the 
inconsistent behaviour of resin anchored rebar when only mechanical friction remains to resist load (Cook, 1993), this research involved determining the load at which adhesion was lost. The point of adhesion loss was assessed to develop minimum safe separation dilation guidelines. It was difficult to non-subjectively identify a discrete load which corresponded to initial sliding of the rebar using a load versus cumulative deformation plot. However, preliminary testing showed a fairly constant plot of incremental deformation at low loads, often followed by a marked increase in incremental deformations. As described elsewhere (Feldman and Bartlett, 2007), the point at which adhesion is lost can be indicated by a significant increase in the rate of slip (incremental deformation). Therefore, the load at which incremental deformation began to increase significantly, as identified from a review of the raw data obtained, could be approximated as the load at which adhesion was lost (initial sliding load).

The following section describes the data reduction method conducted on raw data to determine the initial sliding load, and to determine the resulting average bond strength. The theory behind the estimated rate of incremental deformation expected for each pull test in the field is included. Expected incremental deformation values were used to put limits on which data was acceptable. Only acceptable results were included in calculating average bond strength values.

\subsubsection{Estimated Pull Test Deformation}

Deformation of the rebar that occurred during the pull test occurred along both the free (not bonded) length of rebar and the bonded length of rebar. Figure 4.16 shows a schematic of a resin anchored rebar specimen used in this research project. The free length of rebar carried the total applied load, $P$, while the bonded length of rebar only carried a load which diminished with bonded distance as the load was transferred to the rock through the resin-rebar bond, resin, and resin-rock bond. The load distribution in the bonded length of rebar, $T(x)$, depends on the bond strength provided by the resin and rock surfaces.

Elongation along the free length of rebar, $e_{f s}$, can be calculated using Equation 4.1, since the load applied was constant along this entire free length, $l_{f}$. For the bonded length, the average bond stress on either of the two interfaces can be approximated by using a constant value before adhesion was lost and sliding of the rebar occurred (Cook, 1993; Feldman \& Bartlett, 2007). At low loads $P$, only a portion of the bond length was required to resist the tensile load. If a constant bond strength was available, this portion of the bond length (loaded length, $l l$ ) increased linearly with 
the applied load, up to a maximum value, $P_{\max }$. At the maximum applied load $P_{\max }$, the loaded length was equal to the total bond length available. At this point, adhesion was lost and sliding initiated. If the maximum applied load reached at the time of initial sliding was less than the load required to yield the rebar, the pre-sliding deformation was estimated using the elastic properties of the rebar.
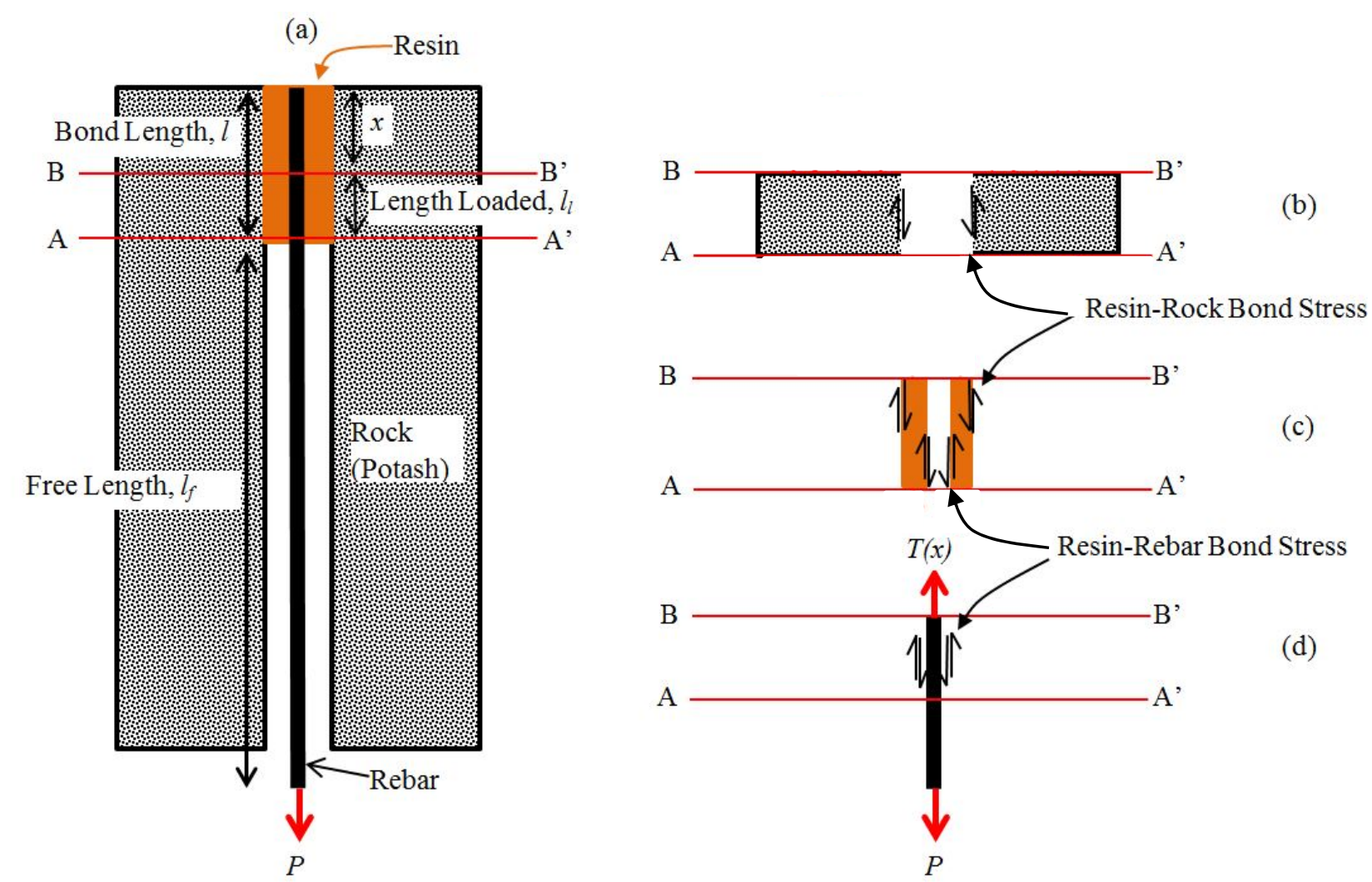

Figure 4.16 Schematic of pull test: (a) Pull test specimen; (b)Rock segment at loaded end; (c)Resin segment at loaded end; and (d) Rebar segment at loaded end

$$
e_{f s}=\frac{P}{A_{s} E_{S}}{ }^{*} l_{f}
$$

Where: $\quad e_{f s}=$ Elongation of free length of rebar;

$P=$ Applied load;

$A_{s}=$ Cross-sectional area of rebar;

$E_{s}=$ Young's modulus of rebar; and

$l_{f}=$ Free length of rebar. 
To determine the load distribution in the bonded length of rebar $T(x)$, an approximation of the maximum applied load before initial sliding began was needed. Preliminary testing results were used to approximate this initial sliding load. The incremental deformation versus load was plotted for each of the initial twenty pull tests completed. The optimum bond length would allow sliding to initiate at an applied load less than the load required to yield the rebar (21.2 tonnes for $25 \mathrm{~mm}$ rebar). If the bond length was too long, sliding would not initiate until applied loads were beyond that required to yield the rebar. In this case, defining the load at which sliding initiates would not be possible. If the bond length was too short, it would be too sensitive to small variations in the installed bond length (Smith, 2008).

Table 4.2 shows the average results for the preliminary tests completed. The shortest bond length with consistent results (a low coefficient of variation) was the $510 \mathrm{~mm}$ length. These results show that the $510 \mathrm{~mm}$ bond length did not allow the maximum applied load to exceed the load required to yield the rebar. Also shown are the values for bond strength when the initial sliding load is divided by the bond length and by the nominal rebar and resin contact areas respectively. Results for the $560 \mathrm{~mm}$ and $610 \mathrm{~mm}$ bond lengths show that these lengths are also acceptable; however, using the shorter bond length minimizes the chance of initial sliding load values exceeding the yield load. The $460 \mathrm{~mm}$ bond length had more varied results; this length appeared to be too short to test as consistently as the others.

The results from these four preliminary test lengths were then used to estimate the maximum applied load (initial sliding load) and determine a linear relationship between load applied and the loaded length. Figure 4.17 shows the load versus incremental deformation plots for the four 510 $\mathrm{mm}$ bond length tests. As per Feldman and Bartlett (2007), the load at which adhesion is lost would be marked by an increase in the rate of slip, or incremental deformation. Figure 4.17 shows that this average load is at approximately 18 tonnes. This was used as the approximation for the maximum applied load before sliding initiated.

Using the assumption that a constant and uniform bond stress exists before adhesion is lost (Cook, 1993; Feldman \& Bartlett, 2007), a linear load distribution can be approximated along the bonded portion of the rebar. The 18 tonnes at the loaded end would linearly decrease to a value of 0 over the bonded length. Figure 4.18 shows the load distribution along the bonded length of rebar based 
on an assumed constant bond stress. The load distribution function, $T(x)$, can be defined using the slope and intercept of the line in Figure 4.18. Equation 4.2 defines the assumed linear load distribution based on the $510 \mathrm{~mm}$ bond length tests on $25 \mathrm{~mm}$ diameter rebar.

Table 4.2 Preliminary pull test results

\begin{tabular}{|c|c|c|c|c|c|c|c|}
\hline $\begin{array}{c}\text { Bond } \\
\text { Length } \\
\text { (mm) }\end{array}$ & $\begin{array}{c}\text { Initial } \\
\text { Sliding } \\
\text { Load } \\
\text { (tonnes) }\end{array}$ & $\begin{array}{c}\text { Initial } \\
\text { Sliding } \\
\text { Load } \\
\text { Standard } \\
\text { Variation } \\
\text { (tonnes) }\end{array}$ & $\begin{array}{c}\text { Initial } \\
\text { Sliding } \\
\text { Load } \\
\text { COV. } \\
\mathbf{( \% )}\end{array}$ & $\begin{array}{c}\text { Bond } \\
\text { Strength } \\
\text { (Linear) } \\
\text { (tonnes/m) }\end{array}$ & $\begin{array}{c}\text { Resin- } \\
\text { Rebar } \\
\text { Bond } \\
\text { Strength } \\
\text { (MPa) }\end{array}$ & $\begin{array}{c}\text { Resin- } \\
\text { Rock } \\
\text { Bond } \\
\text { Strength } \\
\text { (MPa) }\end{array}$ & $\begin{array}{c}\text { \# of } \\
\text { Rebar } \\
\text { Tested }\end{array}$ \\
\hline 610 & 20.2 & 0.402 & 1.99 & 33.2 & 4.14 & 2.84 & 5 \\
\hline 560 & 17.1 & 0.975 & 5.70 & 30.6 & 3.83 & 2.62 & 4 \\
\hline $\mathbf{5 1 0}$ & $\mathbf{1 7 . 4}$ & $\mathbf{1 . 0 5}$ & $\mathbf{6 . 0 5}$ & $\mathbf{3 4 . 3}$ & $\mathbf{4 . 2 8}$ & $\mathbf{2 . 9 3}$ & $\mathbf{4}$ \\
\hline 460 & 16.3 & 2.55 & 15.62 & 35.7 & 4.45 & 3.05 & 4 \\
\hline
\end{tabular}

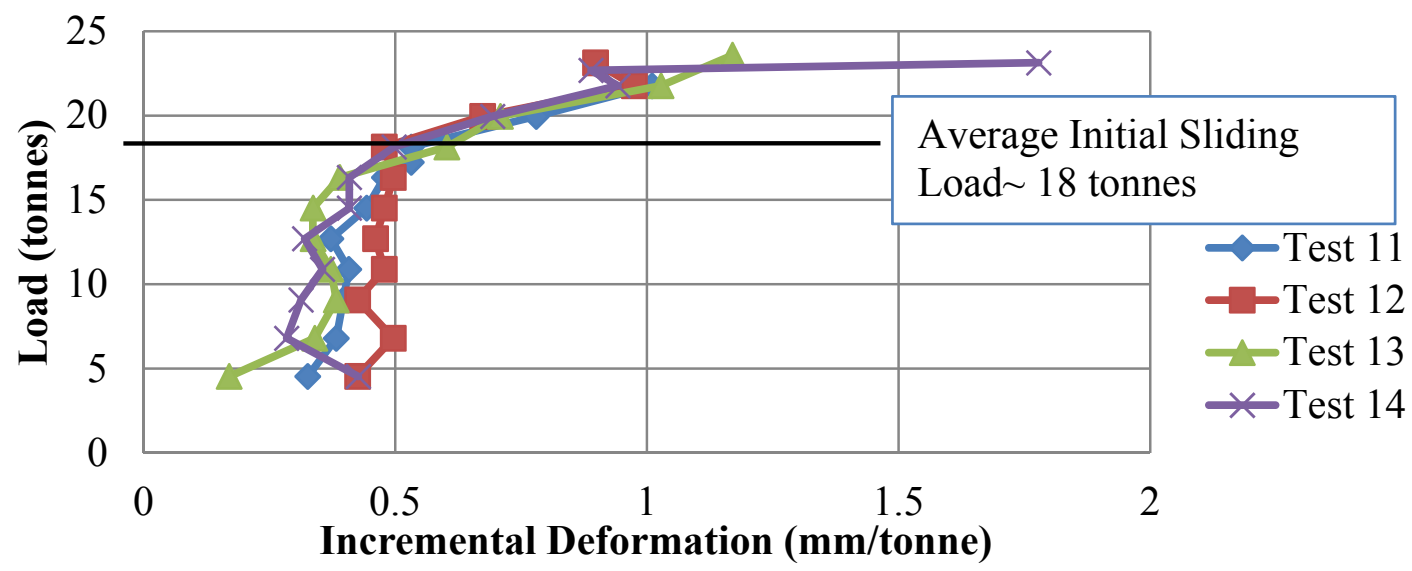

Figure 4.17 Load versus incremental deformation from initial tests $11-14$ (510 $\mathrm{mm}$ bond length tests)

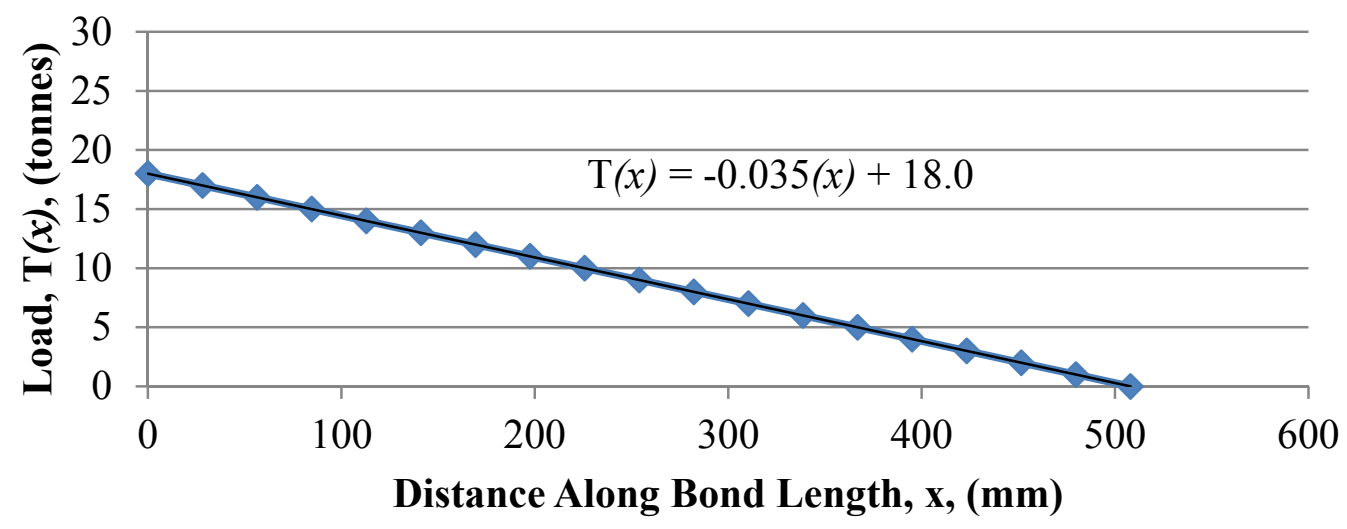

Figure 4.18 Linear load distribution approximated from preliminary testing

$$
T(x)=-0.035(x)+18.0
$$


Deformation of both the free length and the bonded length can be approximated by combining Equations 4.1 and 4.2 into Equation 4.3. The first portion of Equation 4.3 determines the deformation of the rebar along the free length, while the later portion applies the load distribution to approximate the deformation of the rebar along the bonded length. In this equation, the shear deformation of the resin and deformation of the rock mass are not accounted for. Testing to determine the shear modulus of the resin was not conducted as a part of this research project. This was due to difficulty in reproducing a resin sample in the lab with the properties of the resin used in the field. Further work towards this is recommended for the future. The area of the rock which is influenced by the test is unknown, so the deformation of the rock is unable to be included. It is recognized that this approach may underestimate the actual deformation of the free end of the rebar, however, the equation is a useful approximation for estimating the general trend in deformation as a function of load.

$$
s(x)=\frac{P}{A_{s} E_{S}} * l_{f}+\left(\frac{1}{A_{s} E_{S}}\right) \int_{0}^{x} T(x) d x
$$

Using Equation 4.3, the deformation which occurred as the applied load and the loaded length increased up until the adhesion is lost was plotted for the $25 \mathrm{~mm}$ rebar. A similar approximation was completed for the $16 \mathrm{~mm}$ rebar. Using the approximation from Equation 4.3, Figure 4.19 shows the expected incremental deformation from the $25 \mathrm{~mm}$ diameter rebar which ranged from $0.21 \mathrm{~mm} /$ tonne to $0.26 \mathrm{~mm} /$ tonne. The range for the $16 \mathrm{~mm}$ diameter rebar was $0.62 \mathrm{~mm} /$ tonne to $0.66 \mathrm{~mm} /$ tonne.

Due to the removal of the influence of the resin and rock components from the equation, this approximation was conservative compared to deformation values measured in the field. Figure 4.20 displays the expected incremental deformation for the $25 \mathrm{~mm}$ diameter rebar versus all measured incremental deformation from field tests. In Figure 4.20, measured values are typically larger than expected. This is due to the components of deformation not accounted for, as well as error associated with the testing method. 


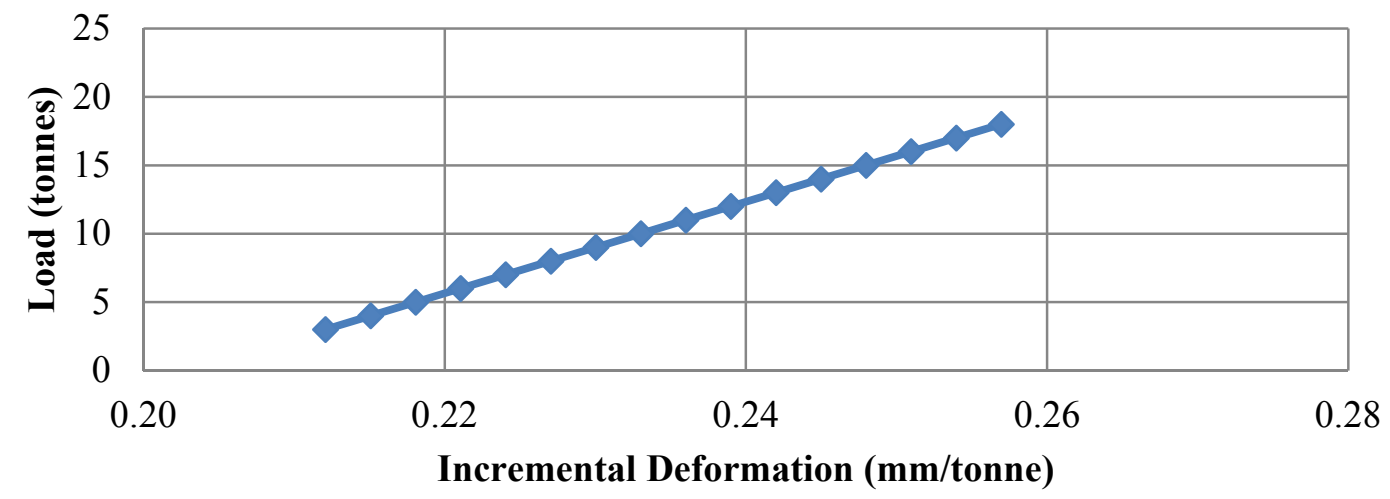

Figure 4.19 Estimated load versus incremental deformation for $25 \mathrm{~mm}$ rebar

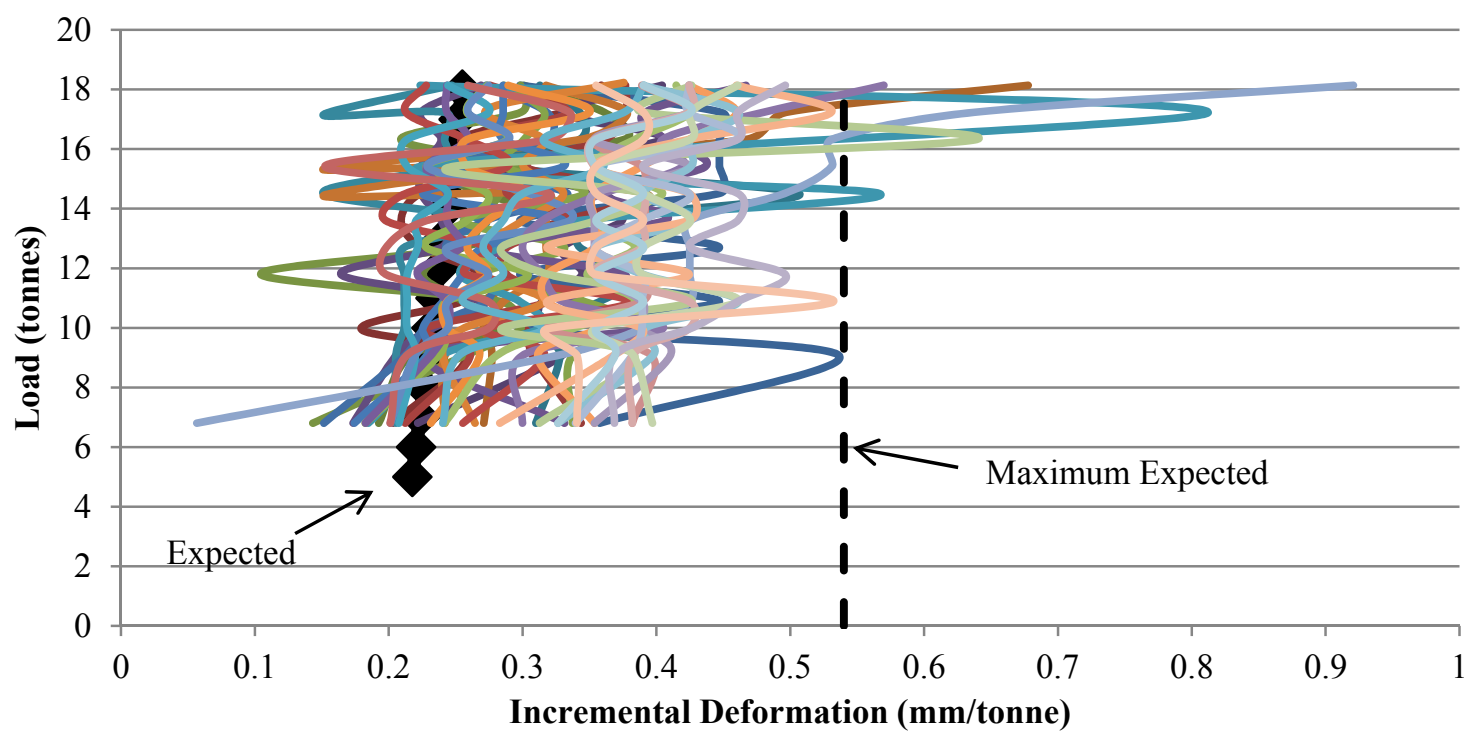

Figure 4.20 Expected incremental deformation versus all measured results

With the variability that typically exists in field testing, error in field data was expected due to the accuracy of the instruments as well as from the variable conditions in the mining environment. For example, the load gauge on the pull testing equipment could only be read to $+/-0.5$ tons $(0.45$ tonnes) and, given the 1 tonne measurement increment, a 50\% error range to the load values recorded was possible. Therefore, it was expected that field values may fall outside of the expected incremental deformation ranges, and that an acceptable range of error would be needed. Considering the large degree of variability found in the field (Figure 4.20), a limit of $+/-100 \%$ was placed on these ranges. This $100 \%$ range on the estimated values allowed for limits to define acceptable data, while also acknowledging the inevitable variation in data obtained in field testing. If too many test results were discarded, the validity of the testing and interpretation would be put in question. Figure 4.20 shows that most field data plotted within the $100 \%$ error range. The 
acceptable incremental deformation ranges were 0 to $0.52 \mathrm{~mm} /$ tonne for the $25 \mathrm{~mm}$ rebar and 0 to $1.30 \mathrm{~mm} /$ tonne for the $16 \mathrm{~mm}$ rebar. These acceptable range limits of incremental deformation were drawn on each load-versus-deformation plot.

An allowance for error, added to the expected incremental deformation ranges from Equation 4.3, provided for the development of guidelines to determine acceptable field data. Data points that fell outside the established boundaries were considered suspect and were interpreted in more detail to determine if testing errors had occurred.

The procedure for determining the initial sliding load from each raw data set is outlined in Appendix D. Along with data falling outside the acceptable incremental deformation ranges, data did not always display a distinct point at which the incremental deformation began to increase. Some deformation data showed constant behaviour at low loads, making it difficult to determine the point at which adhesion was lost. Figure 4.21 displays the typical incremental deformation plot with a typical result. The incremental deformation was initially near constant, followed by a significant increase, indicating adhesion loss. In contrast, Figure 4.22 displays a pull test with data where it is difficult to distinguish the initial sliding load where adhesion is lost; therefore, the initial sliding load could not be estimated.

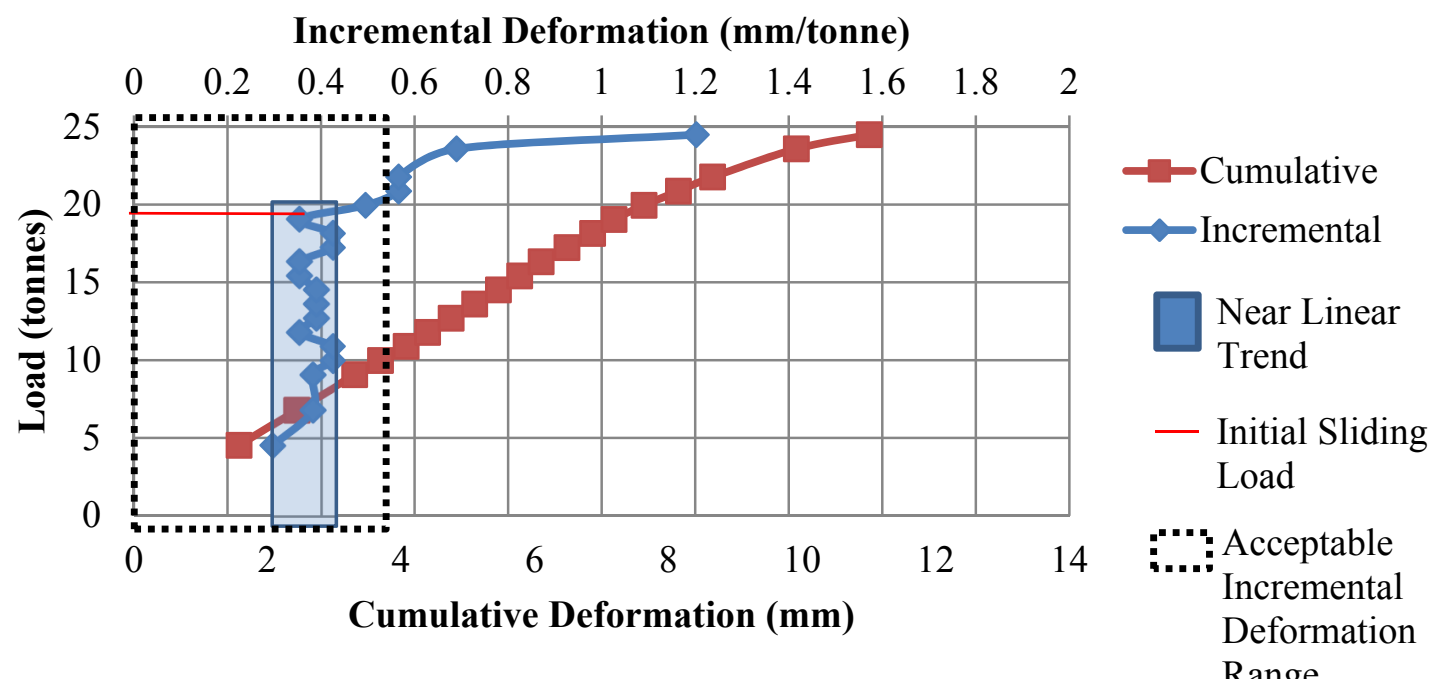

Figure 4.21 Load versus incremental deformation typical result - test 76 (initial sliding load of 19.5 tonnes) 


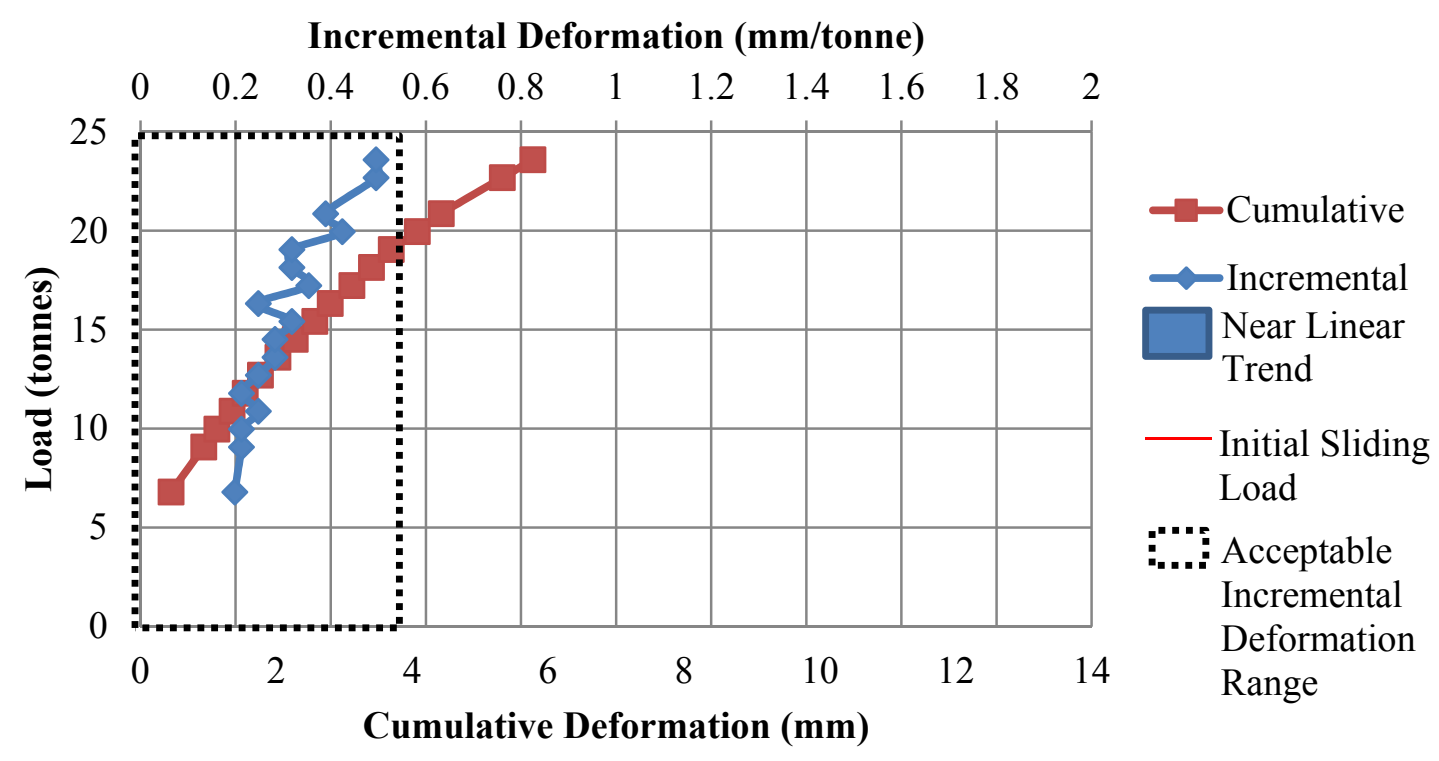

Figure 4.22 Load versus incremental deformation result with no clear initial sliding load - test 68

\subsection{Pull Test Results}

This section presents the average pull test results for each set of tests as described in Section 4.2.3. Plots of load versus both cumulative and incremental deformation for each test are provided in Appendix E. The plots are used to determine the following properties for each test: the initial sliding load, and the bond strength per metre of anchorage, and the stress on both the resin-rebar and the resin-rock interfaces (bond strength for each interface). Load results are reported in tonnes rather than in kilo-Newtons for field testing to adhere with mining convention.

The average results for all tests are tabulated in this section. Of the 110 pull test specimens installed, a total of thirteen of these test rebar were either damaged by mining equipment after installation or were installed improperly resulting in the tests not being carried out. Errors in six tests included: over-drilling the hole length, over spinning the resin, or using improper hold times. These results are included at the end of this section and are not included in calculations of average values. These results are valuable in terms of emphasising the importance of proper installation procedure in the field.

A total of nine tests included incremental deformation data points which fell outside the acceptable range, preventing an initial sliding load from being determined. Four additional tests did not display a distinct deviation in the incremental deformation data, so an initial sliding load could not be determined. 
As described in Section 4.2.1, preliminary testing completed on $25 \mathrm{~mm}$ rebar included four different bond lengths. It was shown in Section 4.3.1 that the $510 \mathrm{~mm}$ bond length was selected as the bond length to be used for all $25 \mathrm{~mm}$ rebar tests. All results for $25 \mathrm{~mm}$ rebar that are listed in the following sections used a $510 \mathrm{~mm}$ bond length. It was described in Section 4.2.3.4 that the $16 \mathrm{~mm}$ diameter rebar used a $180 \mathrm{~mm}$ bond length, based on the results of the preliminary testing.

\subsubsection{Pull Test Results Determining the Effect of Increased Resin Cure Time}

Results from the "North70" test site were used to determine if there was any significant effect on the bond strength achieved with an increase in the resin cure time. The cure time ranged from 2 to 125 days. An average initial sliding load of 18 tonnes, with a coefficient of variation of 7.6\% was obtained from the raw data. Table 4.3 shows the average data collected from the "North70" test site. Of the twenty rebar installed at this location, one was installed improperly, and there was no initial sliding load that could be determined for three tests. Sixteen tests were therefore used to calculate the average results shown in Table 4.3.

Figure 4.23 shows the bond strength results versus cure time. The data on Figure 4.23 shows a minor trend suggesting a small decrease in the bond strength over a time frame of four months. A linear trend plotted on Figure 4.23 suggests a slight decline in bond strength versus cure time of 0.01 tonnes/metre/day; however, this change in bond strength over the 125 day time frame (1.25 tonnes/metre) is less than the standard deviation measured from this population ( 2.8 tonnes/metre). This suggests this decline is not significant. Therefore, a constant bond strength capacity can be expected from resin anchored rebar in an area without active mining.

Table 4.3 Average results for $25 \mathrm{~mm}$ rebar at "North 70" non-active test site (16 tests)

\begin{tabular}{|c|c|c|c|c|}
\hline & $\begin{array}{c}\text { Initial Sliding } \\
\text { Load } \\
\text { (tonnes) }\end{array}$ & $\begin{array}{c}\text { Bond Strength } \\
\text { (Linear) } \\
\text { (tonnes/metre) }\end{array}$ & $\begin{array}{c}\text { Resin-Rebar } \\
\text { Bond Strength } \\
\text { (MPa) }\end{array}$ & $\begin{array}{c}\text { Resin-Rock } \\
\text { Bond Strength } \\
\text { (MPa) }\end{array}$ \\
\hline Average: & 18 & 36 & 4.5 & 3.1 \\
\hline Minimum: & 16 & 32 & 3.9 & 2.7 \\
\hline Maximum: & 20 & 39 & 4.9 & 3.4 \\
\hline $\begin{array}{c}\text { Standard } \\
\text { Deviation: }\end{array}$ & 1.4 & 2.8 & 0.35 & 0.24 \\
\hline $\begin{array}{c}\text { Coefficient of } \\
\text { Variation: }\end{array}$ & \multicolumn{4}{|c}{$7.6 \%$} \\
\hline
\end{tabular}




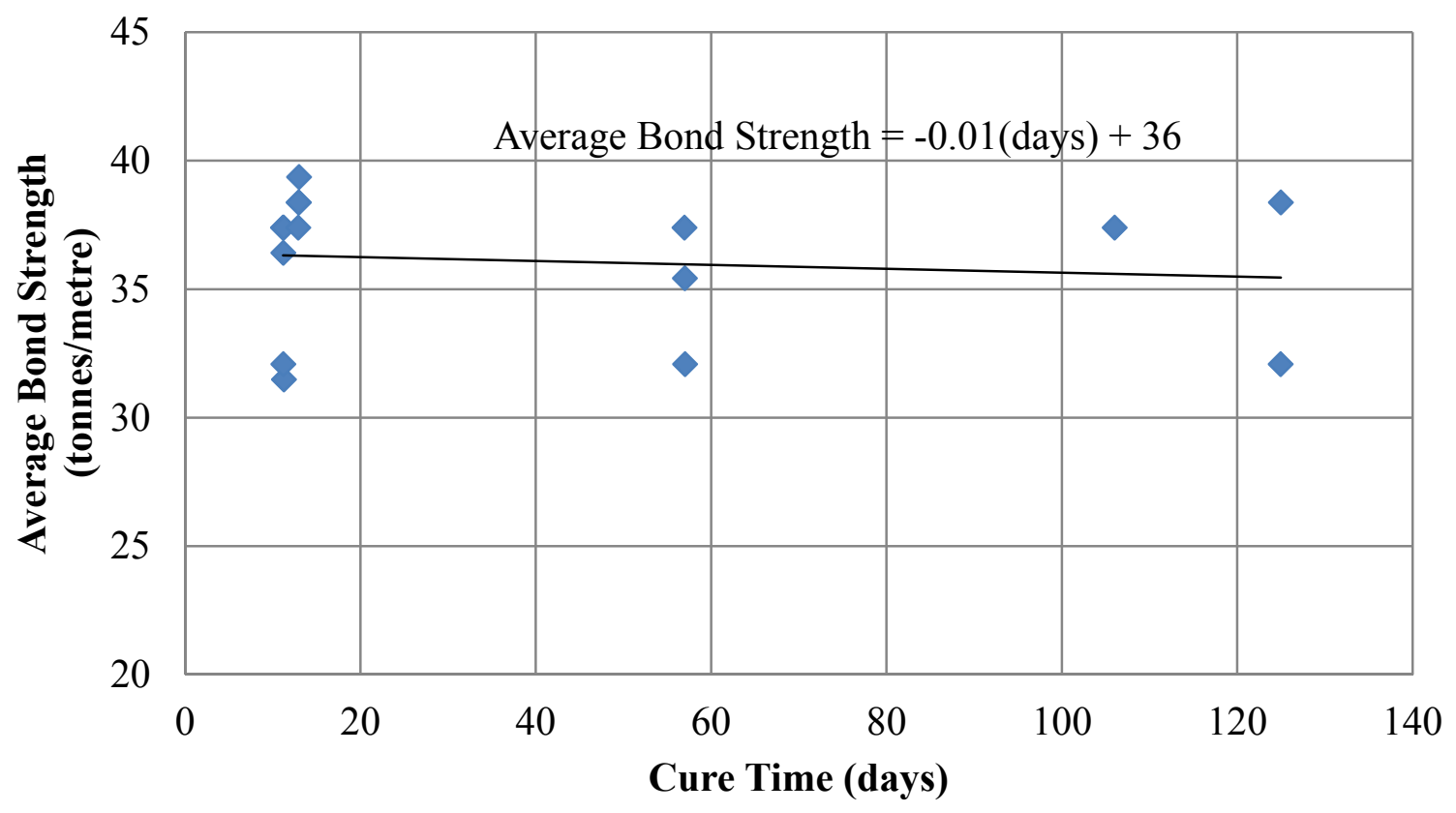

Figure 4.23 Bond strength versus resin cure time from "North70" testing site

\subsubsection{Pull Test Results Comparing Active to Non-Active Mining Sites}

Results from the "North70" and "Borer 6" test sites were used to determine if a significant difference in average bond strength was noted between a non-active and an active mining area. Test rebar in the active area at "Borer 6" were installed when the active mining face was approximately 50 metres to the north and the age of the opening was 53 days. At the end of the testing period, 318 days later, the active mining face had advanced away from the site to a location approximately 500 metres north. The distance from ongoing mining and the age of the opening is related to stress conditions as described in Section 1.1.3. In contrast, the "North70" site was more than 3000 days old and the nearest active mining face was more than 1000 metres to the north.

Figure 4.24 shows the ground closure data collected in both areas. Ground closure is measured using a linear potentiometer as described in Section 4.2.2. The ground closure rates at "North70" were very low, averaging $0.1 \mathrm{~mm} /$ day, confirming that changing stress conditions were minimal in this area during the testing period. Ground closure rates at "Borer 6" were typical of newly opened ground. Initial movement was rapid at 0.9 to $1.0 \mathrm{~mm}$ /day and dropped off to around 0.3 $\mathrm{mm} /$ day by the end of the testing period. This data confirms that the test sites were in areas of the 
mine experiencing different stress change conditions and were representative of active and nonactive mining areas.

Table 4.4 shows the average data collected from the active mining test site. Of the forty rebar installed at this site, twenty-five had results where an initial sliding load could be determined: five were installed improperly, six were damaged after installation but before testing, and four had results for which the initial sliding load could not be interpreted. Figure 4.25 shows the results for bond strength at the active site over the duration of the testing period.

Table 4.3 shows the average data collected from the non-active mining site. There is not a noticeable difference between the results of average bond strength from "North70" and "Borer 6" as the minimum and maximum ranges overlap (Figure 4.26). Increased variation in average bond strength at the active site is likely due to test population size being $50 \%$ more than from the nonactive site. The average bond strength from the active site was 5.5\% more than from the nonactive site. A t-test conducted with the data from the active and non-active mining areas showed that the difference in average bond strength determined is not significant (This calculation is shown in Appendix E).

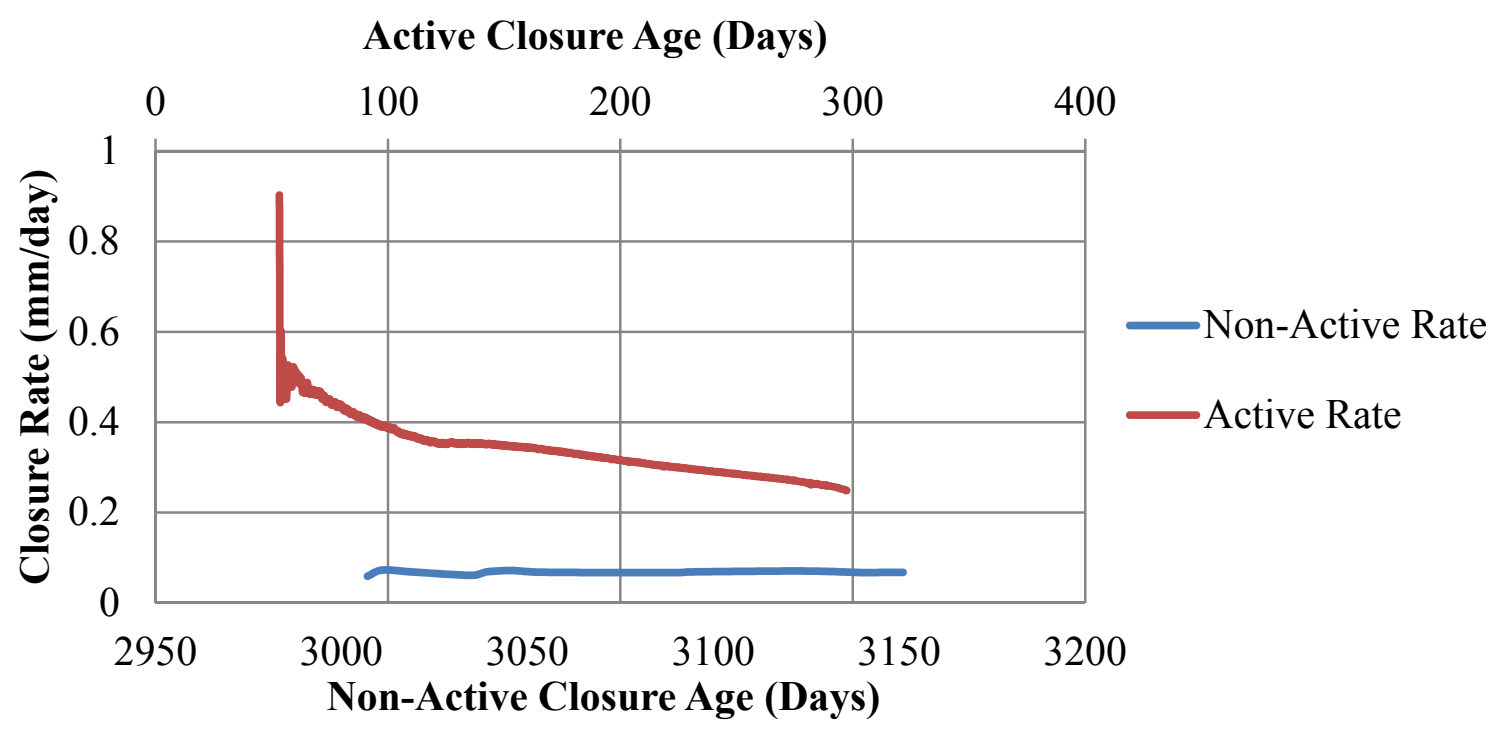

Figure 4.24 Comparison of active and non-active mining area closure rates 
Table 4.4 Average results for $25 \mathrm{~mm}$ rebar in active potash zone (25 tests)

\begin{tabular}{|c|c|c|c|c|}
\hline & $\begin{array}{c}\text { Initial Sliding } \\
\text { Load } \\
\text { (tonnes) }\end{array}$ & $\begin{array}{c}\text { Bond Strength } \\
\text { (Linear) } \\
\text { (tonnes/metre) }\end{array}$ & $\begin{array}{c}\text { Resin-Rebar } \\
\text { Bond Strength } \\
\text { (MPa) }\end{array}$ & $\begin{array}{c}\text { Resin-Rock } \\
\text { Bond Strength } \\
\text { (MPa) }\end{array}$ \\
\hline Average: & 19 & 38 & 4.7 & 3.2 \\
\hline Minimum: & 13 & 26 & 3.2 & 2.2 \\
\hline Maximum: & 22 & 43 & 5.4 & 3.7 \\
\hline $\begin{array}{c}\text { Standard } \\
\text { Deviation: }\end{array}$ & 1.9 & 3.7 & 0.46 & 0.31 \\
\hline $\begin{array}{c}\text { Coefficient of } \\
\text { Variation: }\end{array}$ & \multicolumn{4}{|c}{$9.7 \%$} \\
\hline
\end{tabular}

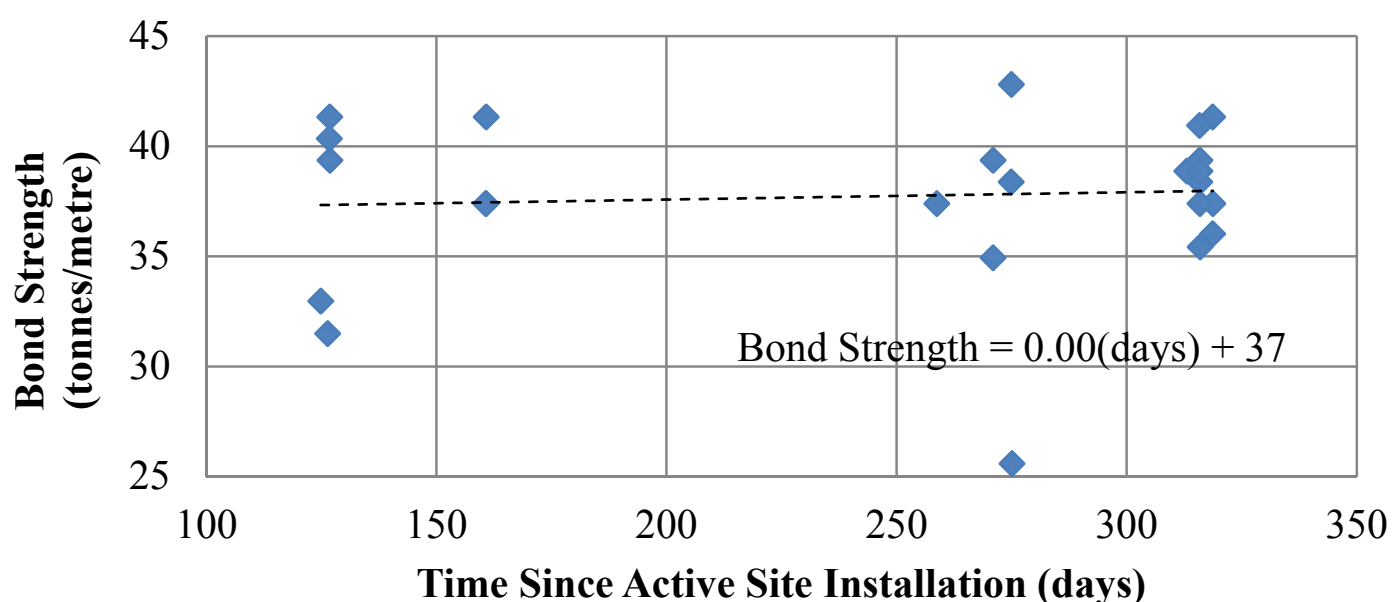

Figure 4.25 Bond strength versus time since installation at the active mining site

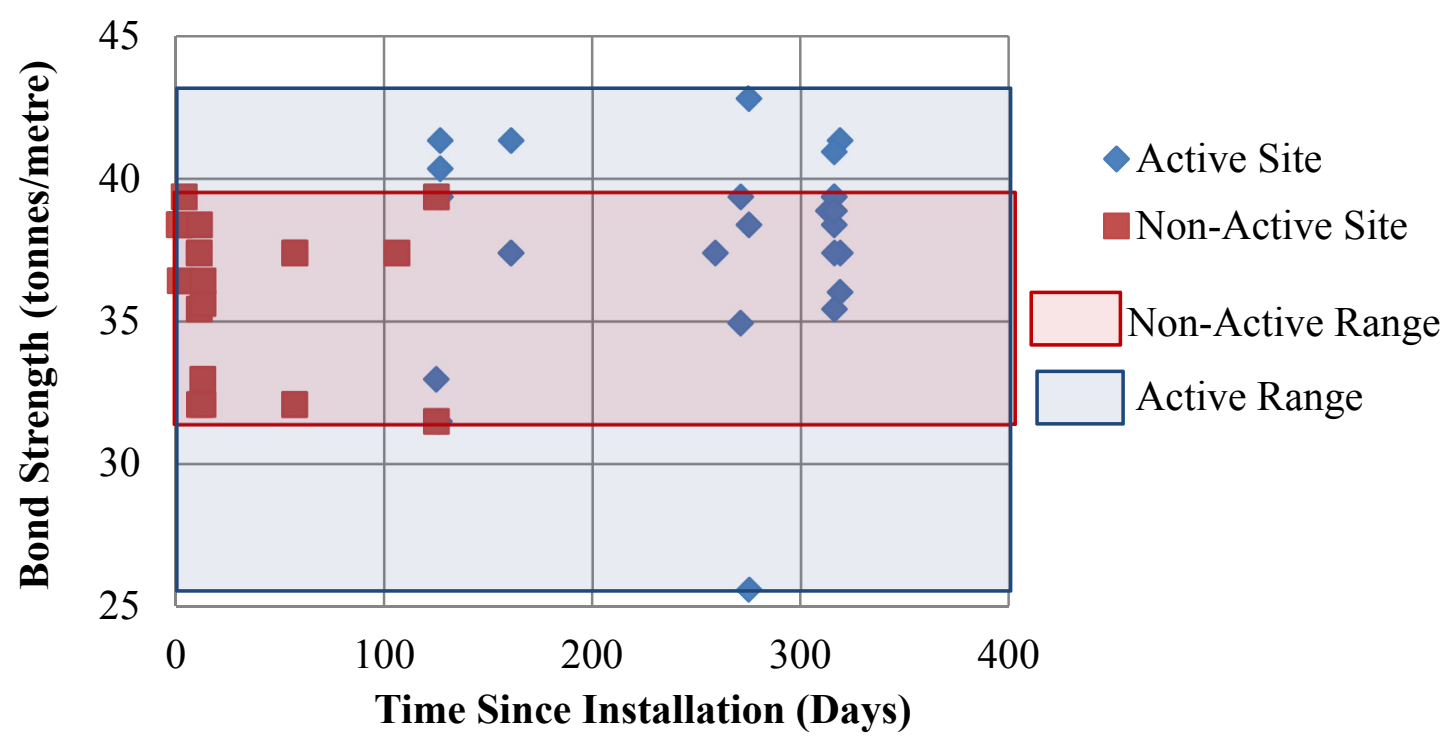

Figure 4.26 Range of bond strength determined at both active and non-active test sites 


\subsubsection{Pull Test Results Comparing Rebar Anchored in Potash and Halite Horizons}

Results from the "North70" (Table 4.3) and "South Storage Bin" test sites were compared to determine if the rock type that the rebar was anchored to had a significant effect on the average bond strength. The average results from the rebar installed at the "South Storage Bin" site are shown in Table 4.5. One rebar was damaged by mining equipment after installation and could not be tested. The testing of a second rebar was discontinued following a malfunction of the hydraulic cylinder. Testing of the remaining eight rebar at this site had unique challenges compared to all other testing sites. Only four of the remaining tests produced a load versus incremental deformation plot with a clear initial sliding load. Considering the small sample size, the results may not be representative of actual resin anchored rebar behaviour when anchored to halite.

The difficulty in observing the initial sliding load was unique to the "South Storage Bin" test site in that the behaviour observed from the incremental deformation plots were not observed at any other test site. This behaviour included large spikes in incremental deformation at low load values followed by a return to the initial constant values. Figure 4.27 shows an example of this type of pattern. Also, loud pops as the rebar slid out of the hole were observed. The behaviour is unusual in that the rebar appeared to lose adhesion, slide quickly, and then regain a slip rate similar to that of when adhesion still existed.

Given the small number of tests, any conclusions about this pattern would be speculative. This speculation includes that gaps in the resin, either by presence of air or the resin cartridge plastic wrapper, may have caused uneven loading. The large increases in incremental deformation would be caused when load was distributed over these poorly mixed sections. Further testing would be required to determine if these were anomalies or if this type of behaviour is specific to resin anchored rebar anchored to halite.

The average bond strength determined for the rebar installed at the "North70" site was 36 tonnes/metre while the average bond strength determined from the four tests anchored in halite was 35 tonnes/meter. These results indicate similar average bond strengths for potash and halite zones but are questionable due to the small number of successful tests at the "South Storage Bin" location. 
Table 4.5 Average results from halite anchored pull tests at "South Storage Bin" site (4 tests)

\begin{tabular}{|c|c|c|c|c|}
\hline & $\begin{array}{c}\text { Initial Sliding } \\
\text { Load } \\
\text { (tonnes) }\end{array}$ & $\begin{array}{c}\text { Bond Strength } \\
\text { (Linear) } \\
\text { (tonnes/metre) }\end{array}$ & $\begin{array}{c}\text { Resin-Rebar } \\
\text { Bond Strength } \\
\text { (MPa) }\end{array}$ & $\begin{array}{c}\text { Resin-Rock } \\
\text { Bond Strength } \\
\text { (MPa) }\end{array}$ \\
\hline Average: & 18 & 35 & 4.4 & 3.0 \\
\hline Minimum: & 14 & 27 & 3.3 & 2.3 \\
\hline Maximum: & 22 & 42 & 5.3 & 3.6 \\
\hline $\begin{array}{c}\text { Standard } \\
\text { Deviation: }\end{array}$ & 3.8 & 7.4 & 0.93 & 0.64 \\
\hline $\begin{array}{c}\text { Coefficient of } \\
\text { Variation: }\end{array}$ & \multicolumn{4}{|c|}{$21 \%$} \\
\hline
\end{tabular}

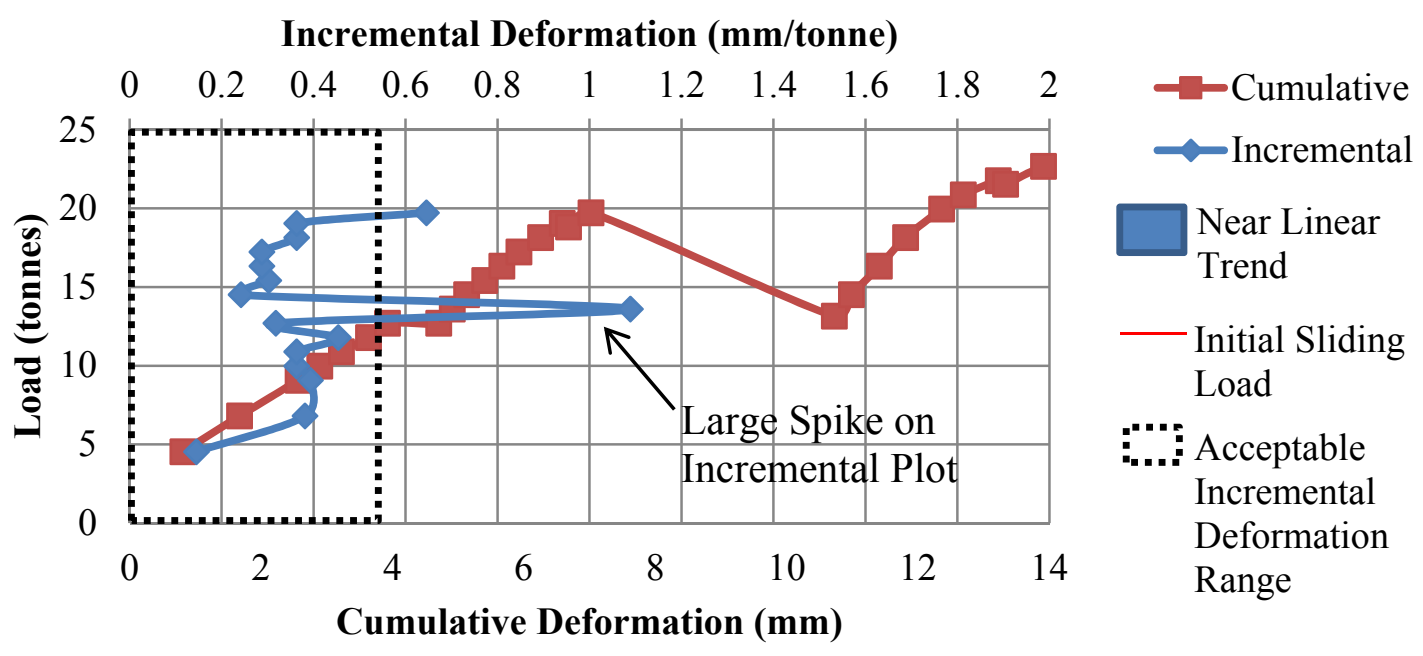

Figure 4.27 Large spikes in incremental deformation plot observed on rebar anchored to halite

\subsubsection{Effect of Resin Contact Area}

This section compares the results of the $25 \mathrm{~mm}$ sized rebar tested at "North70" test site (Table 4.3) to the $16 \mathrm{~mm}$ sized rebar tested at "East305" test site (Table 4.6). Ten samples were tested and all tests were successfully installed and had easily identified initial sliding loads. Comparison between the initial sliding load and bond strength values determined from the $16 \mathrm{~mm}$ and $25 \mathrm{~mm}$ tests was completed to identify the weakest material or surface in the support system.

The average initial sliding load for the $16 \mathrm{~mm}$ and $25 \mathrm{~mm}$ diameter rebar can be used to calculate the maximum bond stress at the resin-rock and resin-rebar interfaces. It can be assumed that the 
same interface is failing for both sizes of rebar. It can also be expected that the failing interface should have a constant bond stress when sliding initiates. For the $16 \mathrm{~mm}$ rebar, the average resinrebar bond stress was 5.8 MPa and the average resin-rock bond stress was 3.2MPa when the initial sliding load was achieved. For the $25 \mathrm{~mm}$ rebar, the average resin-rebar bond stress was $4.6 \mathrm{MPa}$ and the average resin-rock bond stress was 3.1 MPa. Figure 4.28 displays average bond strengths determined for each resin contact area. The average bond strength found along the resin-rock contact area remains constant while increasing resin-rebar contact area resulted in lower values over the range of contact areas tested. This data indicates that sliding initiates on the resin-rock interface at a bond stress near $3 \mathrm{MPa}$.

These results suggest that failure of the rebar is a result of adhesion between the resin and rock surfaces being exceeded. When this occurs, sliding initiates and the capacity of the rebar becomes less predictable since it is dependent on the sliding friction available. Using the data from preliminary tests, as well as the "North70" $25 \mathrm{~mm}$ diameter rebar and the $16 \mathrm{~mm}$ diameter rebar tests, Figure 4.29 shows the suggested linear increase of the initial sliding load with an increased resin-rock contact area.

Table 4.6 Average results from $16 \mathrm{~mm}$ rebar pull tests (10 tests)

\begin{tabular}{|c|c|c|c|c|}
\hline & $\begin{array}{c}\text { Initial Sliding } \\
\text { Load } \\
\text { (tonnes) }\end{array}$ & $\begin{array}{c}\text { Bond Strength } \\
\text { (Linear) } \\
\text { (tonnes/metre) }\end{array}$ & $\begin{array}{c}\text { Resin-Rebar } \\
\text { Bond Strength } \\
\text { (MPa) }\end{array}$ & $\begin{array}{c}\text { Resin-Rock } \\
\text { Bond Strength } \\
\text { (MPa) }\end{array}$ \\
\hline Average: & 5.1 & 29 & 5.8 & 3.2 \\
\hline Minimum: & 4.2 & 24 & 4.9 & 2.6 \\
\hline Maximum: & 7.0 & 39 & 8.2 & 4.3 \\
\hline $\begin{array}{c}\text { Standard } \\
\text { Deviation: }\end{array}$ & 0.91 & 5.0 & 1.1 & 0.56 \\
\hline $\begin{array}{c}\text { Coefficient of } \\
\text { Variation: }\end{array}$ & \multicolumn{3}{|c|}{$18 \%$} \\
\hline
\end{tabular}




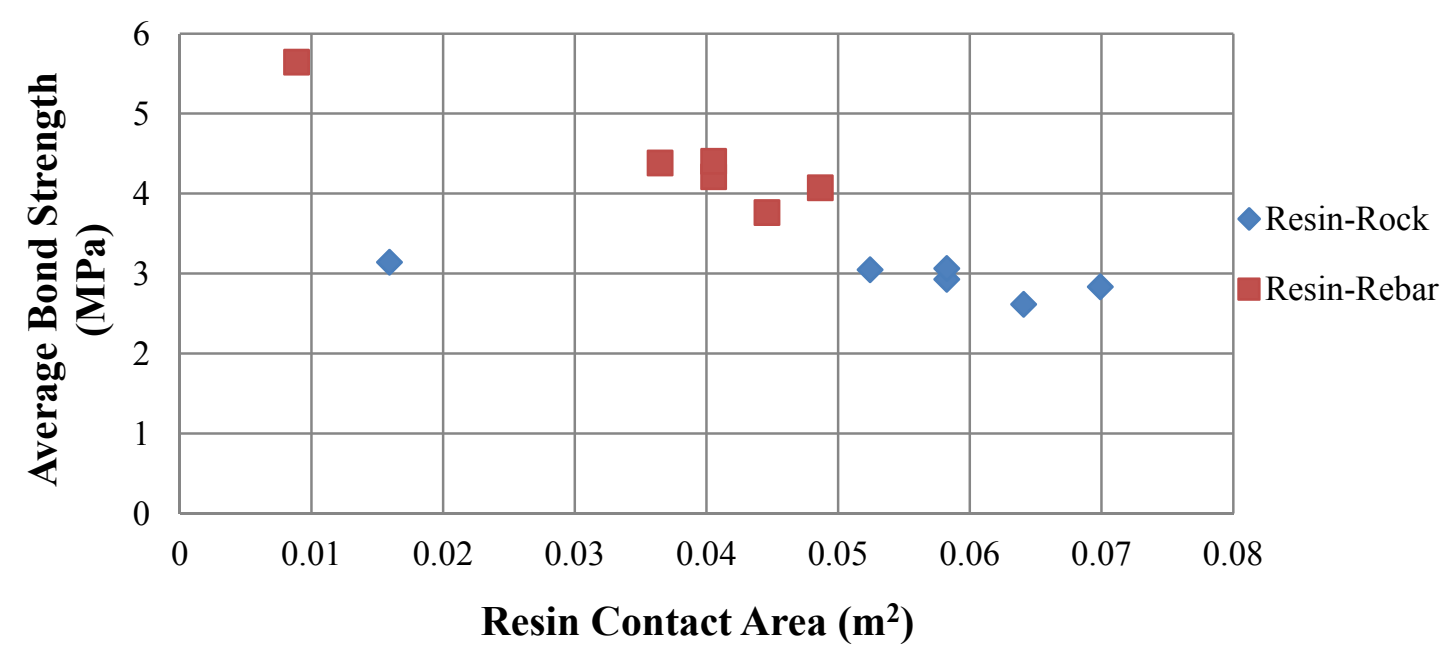

Figure 4.28 Average bond strength versus resin contact area

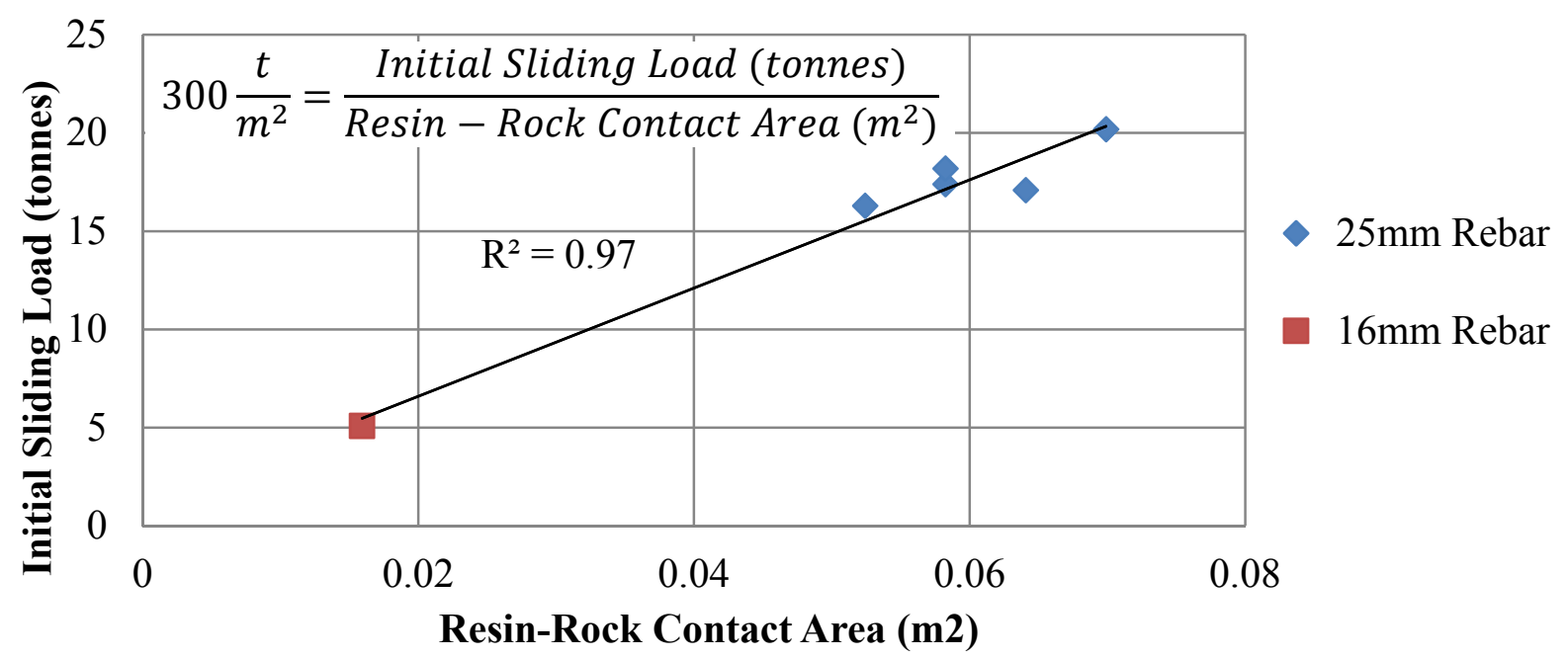

Figure 4.29 Initial sliding load versus resin-rock contact area size

\subsubsection{Results of Short Bond Length Tests}

Testing of $25 \mathrm{~mm}$ rebar with short, $100 \mathrm{~mm}$ bond lengths was conducted in an effort to observe the physical damage resulting from resin anchored rebar being pulled completely out of the hole. Results from these tests included only the peak load recorded during each test. The peak loads recorded during each test can be found in Appendix E.

Two of the rebar were damaged by mining equipment after their installation but before they could be tested. Of the remaining eight rebar, four were able to be completely pulled from the hole. The stroke length of the hydraulic cylinder on the pull tester was $300 \mathrm{~mm}$, if the rebar did not pull free 
within the first $300 \mathrm{~mm}$ of sliding, the pull tester was not able to be braced against the rock to apply additional load to the rebar. The four rebar which did not pull free had adequate mechanical friction to resist the loads applied by the pull tester over the stroke length. Figure 4.30 shows where the pull testing apparatus was still attached to a rebar which was unable to be pulled free after load had been applied over the full stroke length.

Figure 4.31 shows a test rebar which was fully removed from the hole. Resin is still visible on this rebar but some was notably missing. This was the general result for each of the rebar which pulled free from the hole. It was observed that by the time the rebar pulled free, quite a bit of resin had crumbled into small pieces and fallen out of the hole during the test (Figure 4.32). A view up the hole with a borehole camera revealed the rest of the broken up resin at a location approximately 0.6 metres into the hole (Figure 4.33).

This observation of resin in the hole, approximately 1.8 metres below its original location, indicates that the resin was being dragged out along the rock surface by the rebar. The pieces of resin falling out of the hole during the test were probably a result of the resin being damaged during this dragging process and breaking free from the rock and rebar.

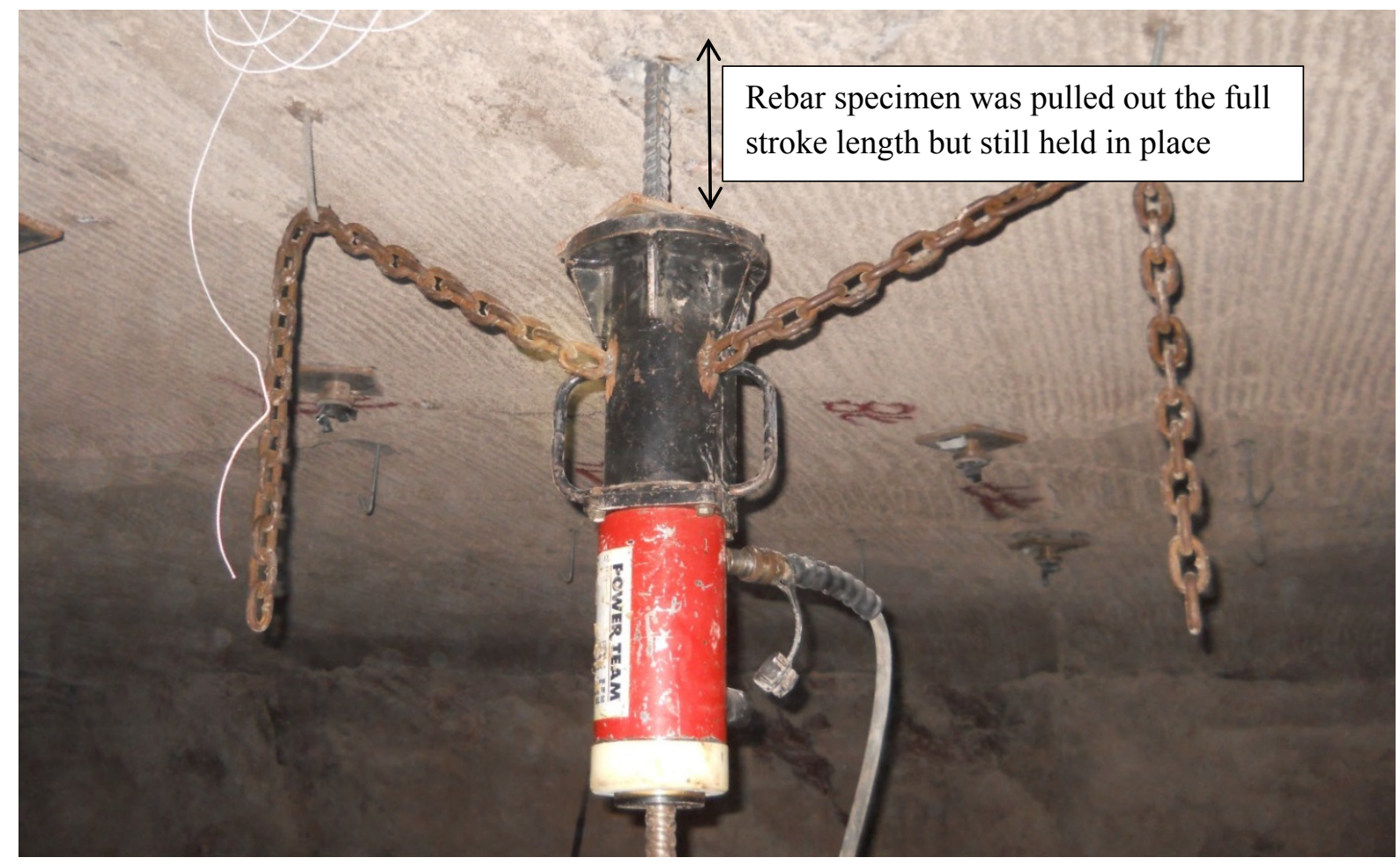

Figure 4.30 Test rebar after sliding the full stroke length of the apparatus 


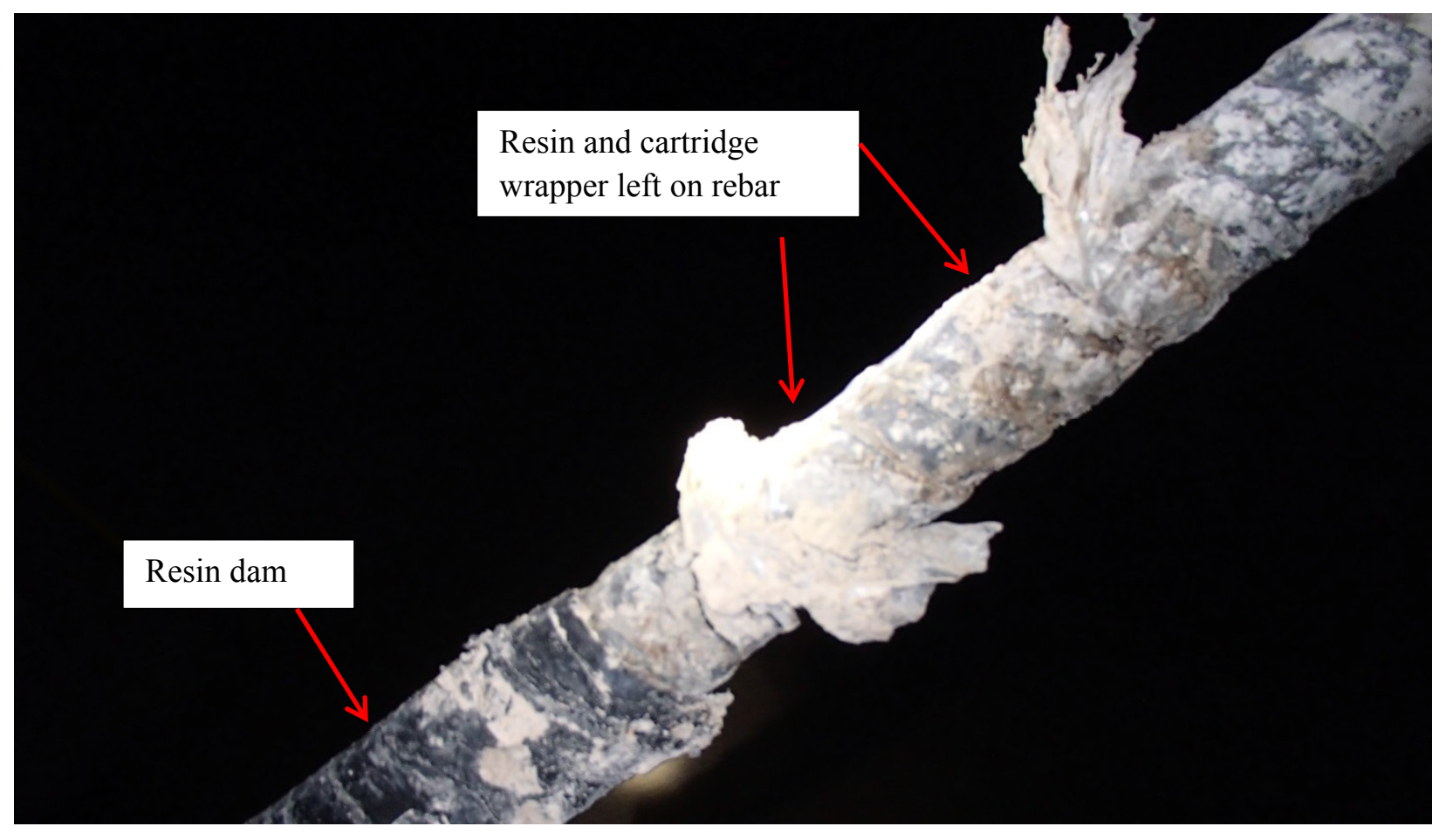

Figure 4.31 Rebar sample pulled from hole

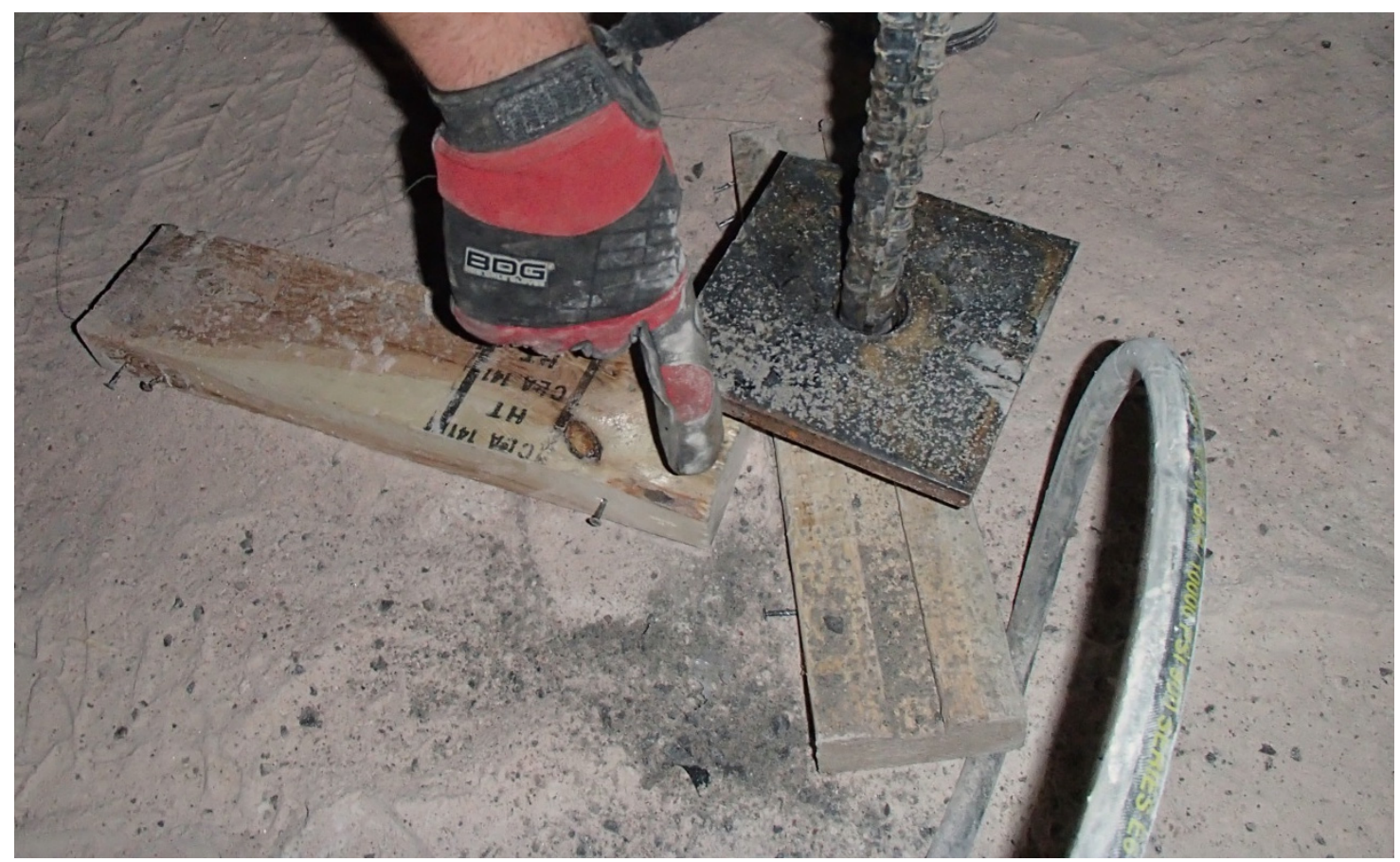

Figure 4.32 Broken up resin (grey particles) fallen from hole after pull test 


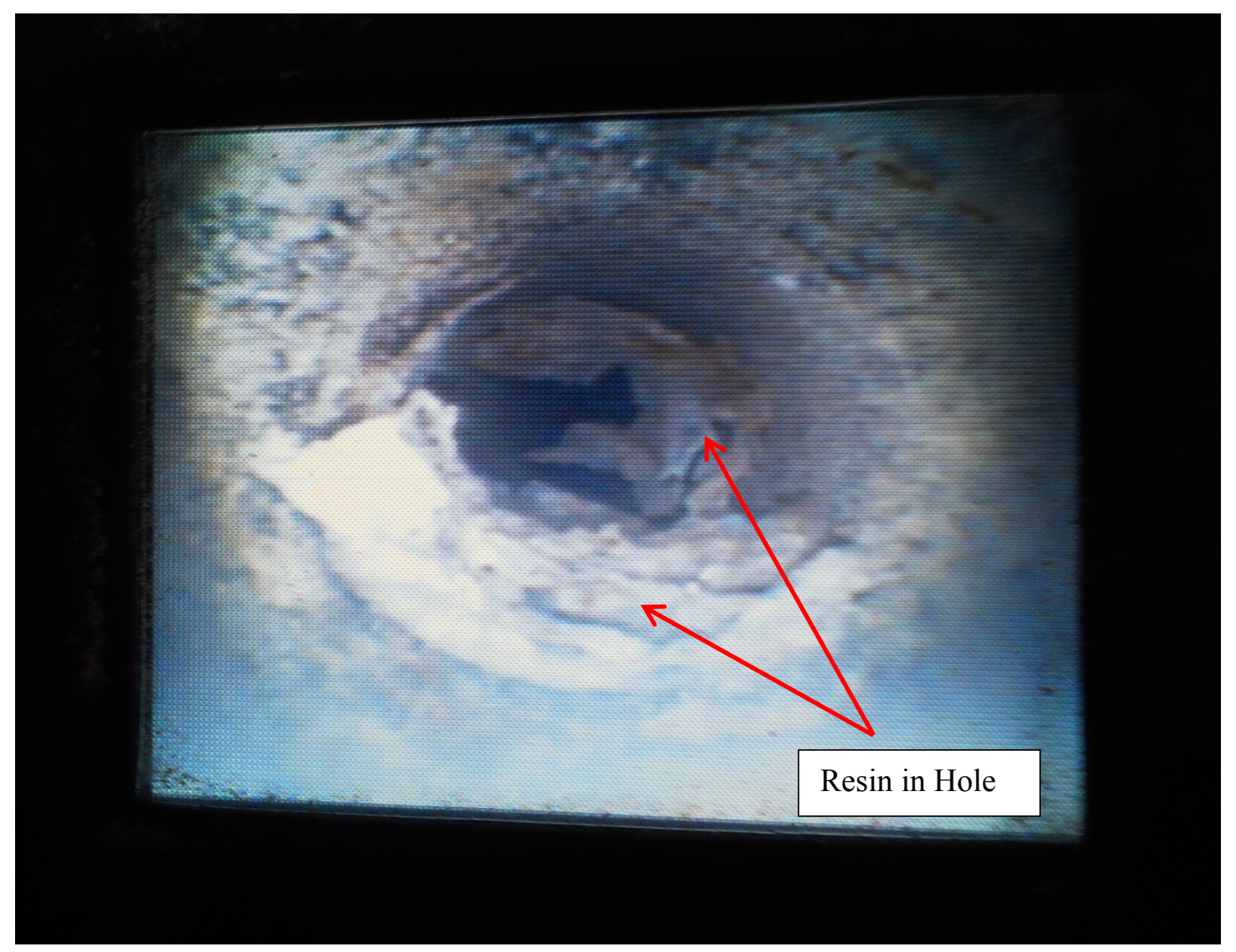

Figure 4.33 Borehole camera view of resin still in hole after being dragged down by rebar

\subsubsection{Effect of Poor Installation Practices}

Improper installation practices were noted so their effect could be observed. These test results did not contribute to the averages calculated from each test site, but did provide valuable information regarding the effect of not adhering to the correct installation procedure. Improper installation was not a common occurrence, but six of the 110 installations were affected by improper practices. Errors made during installations for this research project included:

- Over-drilling the hole length (causing resin loss to the top of the hole);

- Not following proper spin times (over spinning resin causing it to break-up in hole);

- Not following proper hold time (resin does not set properly before resisting load). The average initial sliding load observed for all $25 \mathrm{~mm}$ diameter rebar was 18.7 tonnes. Figure 4.34, shows an example of a rebar which has been installed into a hole which was over-drilled in length (Test 62). The hole was over-drilled by $94 \mathrm{~mm}$, creating a volume above the rebar 2.9 times larger than the volume created by drilling the hole length to be $50 \mathrm{~mm}$ longer than the rebar length 
as per standard practice. In this case, $26 \%$ of the resin installed was lost to the extra length drilled at the top of the hole. The initial sliding load in this case has decreased to 12 tonnes, a $36 \%$ decrease from the average value observed. Test 21 (Figure 4.35), which was over-spun, had an initial sliding load of approximately 7 tonnes, a $63 \%$ decrease from the average value. It is therefore evident that proper installation procedures must be followed to get the expected capacity of the resin anchored rebar.

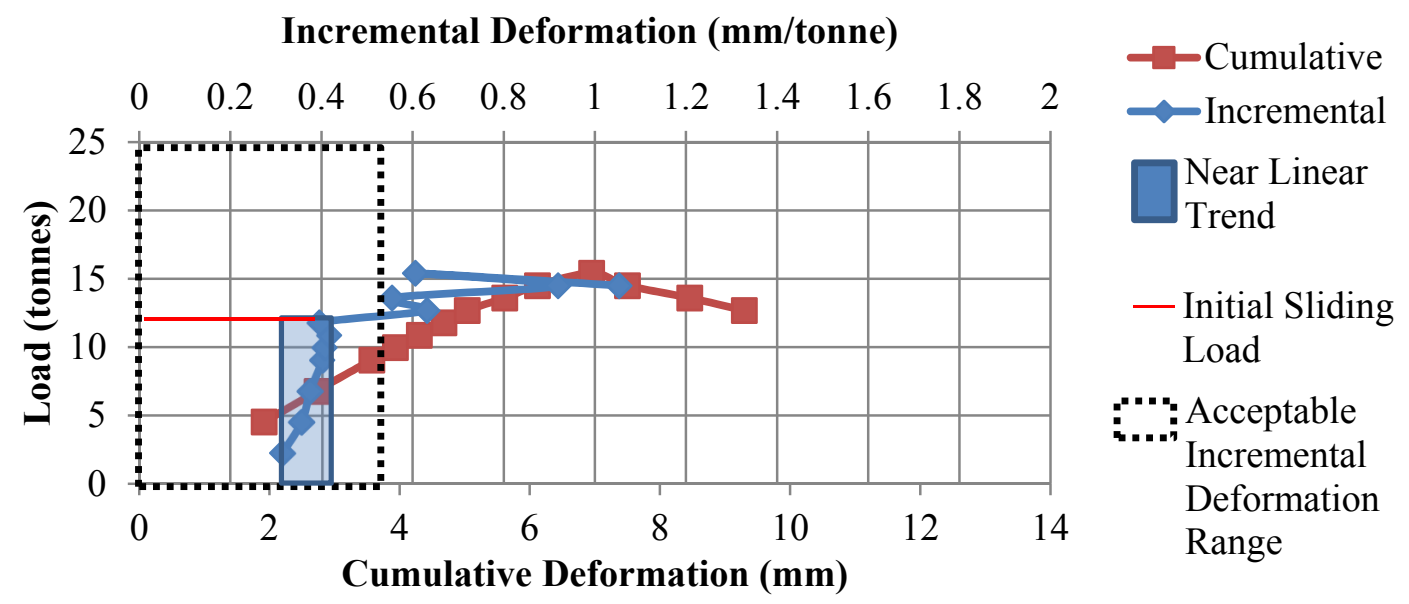

Figure 4.34 Improperly installed rebar (over drilled length) results: Initial sliding load of 12 tonnes

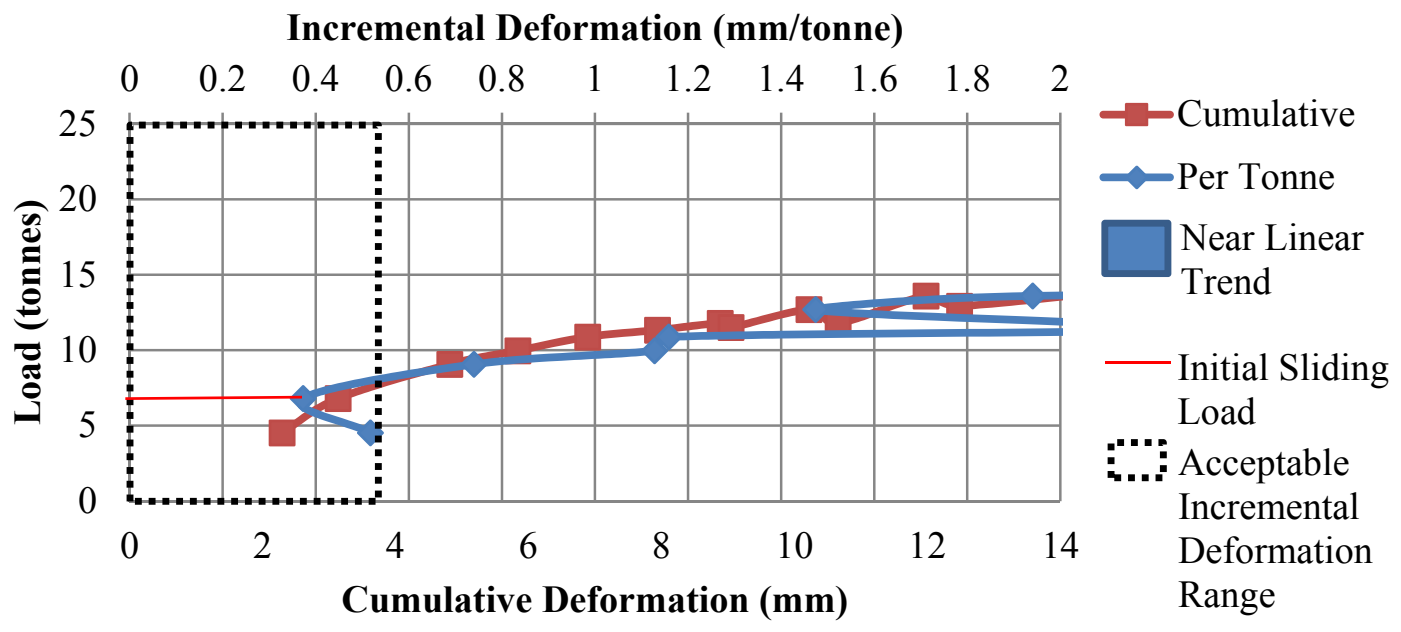

Figure 4.35 Improperly installed rebar (overspun) result: Initial sliding load approximately 7 tonnes 


\section{Discussion of the Results}

The general goal of this research project was to determine the failure mechanism for resin anchored rebar in potash. To reach this goal, a simple, inexpensive pull test procedure was developed. This section discusses the significance of this testing method and the results, sources of error, and challenges encountered during testing. A brief discussion of how the results can be applied in industry, relating measured field deformation to the load on installed resin anchored rebar, is also covered.

\subsection{Field Testing Sources of Error and Suggested Improvements}

The pull testing method at the Allan mine has been improved by applying simple resin dams and the use of inexpensive string potentiometers. The materials required are readily available and the process does not require significant additional effort over current pull test techniques. The test method involves measuring the initial sliding load when adhesion is lost, rather than a peak load which is often due to mobilized mechanical friction, which can occur after significant sliding of the rebar. Establishing the capacity of the support system at the point where adhesion is lost provides a conservative load limit upon which engineers can base their ground support calculations. Although the testing method has been improved by using a string potentiometer as the means for measuring deformation, the method was not without challenges. During the project, observed sources of error resulting from the selected testing method were recorded.

The deformation and load measurements involve a degree of error due to instrument accuracy, as discussed in Section 4.2.2. Reading error may also be a factor since the instrumentation was read manually in the poorly lit dusty mine environment. A pull testing apparatus equipped with the means to measure and record deformations and/or load electronically using a laptop or data logger would improve the accuracy. However, complicating the testing procedure and increasing the expense of conducting such tests underground would be deterrents to completing additional testing. Using a method as outlined in this research project simplifies the process and decreases the associated costs. Mine engineers could use a test like this to conduct their own periodic quality control testing to increase their knowledge of the capacity of resin anchored rebar. 
An error in the test procedure that was not easily identified occurred when the string line was not securely attached to the rebar head (Section 4.2.2). Although the rebar head was cleaned before the test, and the string was fully immersed in epoxy and held in place with electrical tape while the epoxy set, the bond did not always hold throughout the test. If the string line slips from the epoxy during a test, it could be very difficult to detect. At low loads ( 0 to 5 tonnes), this error could be detected if deformation continued without the application of additional load.

A potential problem with an uneven back and tilted equipment was discussed in Section 4.2.2 and shown in Figure 4.9. Equipping the apparatus with bolts attached to a plate that would help to brace and level the hydraulic cylinder against the back could possibly resolve this issue. This type of plate is often used in hard rock mines where the rock surface is much more uneven than what is found in potash mines. Figure 5.1 from ASTM 4435 (ASTM, 2008b) shows a common method of bracing equipment. Bolts are tightened to brace a loading plate against the rock. This type of equipment would be an asset in future testing. Any bolts used in this manner would need to be modified to have a large contact area with the rock due to the soft nature of potash. Otherwise bolts would likely compress into the rock during the tests.

Some errors in the test were due to operator and equipment issues during installation. DSI recommends 30 revolutions for proper mixing (DSI, 2008). When the bolter is set to the maximum rotation speed of $600 \mathrm{rpm}$, an installation spin time of 3-5 seconds resulted. There was no way to verify if the maximum $600 \mathrm{rpm}$ was obtained at the maximum rotation speed setting; a lower setting speed could adversely affect the epoxy mix and resulting strength. Due to the high demand and heavy use of the bolters in the mine, regular maintenance was not always possible and the maximum rotation speed may not always be achieved. Poor performance of the hydraulics on the bolter could also affect the pressure applied during the recommended hold time for the resin to set. If the bolter was not able to sustain pressure to hold the rebar in place for one minute as recommended, the resin would not be given adequate time to set before supporting the dead weight of the rebar. These factors were difficult to control, but could have an effect on the quality of the resulting bond between these materials. 


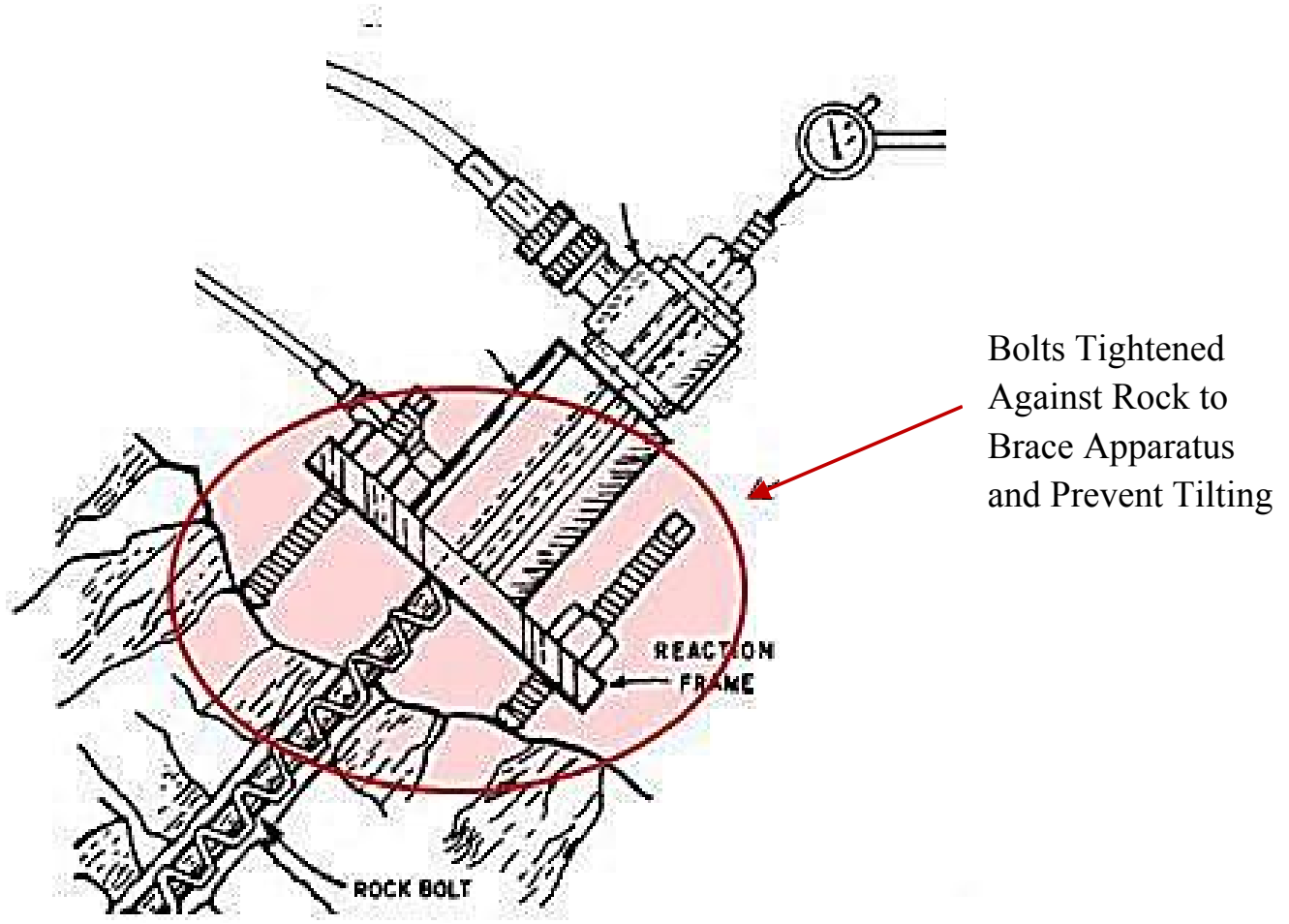

Figure 5.1 Plate to brace pull tester against back modified from ASTM 4435-08

Another error during installation is referred to as "gloving." Gloving occurs when the resin cartridge wrapper does not break up during mixing and ends up wrapping around the rebar, preventing the rebar from bonding with the resin. The resin cartridge wrapper can also remain intact and end up covering part of the hole surface area preventing the resin from bonding to the rock. There is no way to determine if this mixing error has occurred without pulling the rebar out of the hole: to do so, however, could also tear apart the large pieces of wrapper causing the problem. In tests where larger magnitudes of incremental deformation (outside the acceptable range described in Section 4.3) were recorded, the interference of the resin wrapper on either one or both of the interfaces may have occurred.

A large degree of variability in results occurred more often in field testing compared to lab testing. This is due to the reduced amount of control on test conditions. The sources of installation error should be considered in any future testing to assist in the interpretation of field data. The data is still useful as long as the shortcomings involved are well understood.

\subsection{Significance of Results}

This experimental program included both laboratory and field testing. The laboratory testing was conducted to verify material properties of the steel rebar and determine the properties of the 
potash and halite located in the field pull testing sites. Field testing was conducted to determine the failure mechanism and failure strength of the rebar support system.

Laboratory testing involved, for the most part, standard tests to determine the mechanical properties of both rebar and rock samples. The shear strength tests that were conducted on both the potash and halite samples involved constructing an apparatus to conduct a guillotine style shear strength test on cores taken from a potash mine. This type of test is not commonplace for a potash mine core and is not documented in the literature. There is scope for future testing to be conducted to determine whether the shear strength of potash and halite core is related to different loading rates and different magnitudes of confining stress.

Section 4.4 highlighted the results of the field testing with respect to the main objectives of this research project. Identifying the failure mechanism of resin anchored rebar support was the primary objective of the research. The variability of the average bond strength was assessed by conducting pull tests in various locations around the mine and the results in Section 4.4 showed that no significant difference was apparent due to the proximity to active mining. Results from tests where the rock type was varied were inconclusive and varying cure time had results which suggested a small decrease in average bond strength with resin cure time. The results from Section 4.4.4 indicated that the adhesion available on the resin-rock interface limits the initial sliding load value on short bond lengths. Using data from all pull test sites, the average resin-rock bond strength was $3.2 \mathrm{MPa}$ or 37 tonnes/metre for the $25 \mathrm{~mm}$ diameter rebar used at the Allan mine. This resin-rock bond strength value in potash mining was not previously available in literature.

The calculated bond strength of 37 tonnes per metre can also be used to determine ground support requirements. The load required for the $25 \mathrm{~mm}$ rebar to reach its yield strength is 21.2 tonnes. The minimum bond length required for a $25 \mathrm{~mm}$ resin anchored rebar to reach its yield strength is therefore $580 \mathrm{~mm}$.

In Section 2.3 it was described that pull tests commonly identify the peak load reached by resin anchored rebar. This load can depend on the sliding friction available, which can be unpredictable and unreliable (Cook, 1993). Given the findings of the current experimental program, a more conservative approach would be to use the resin-rock bond strength to determine what level of load will be developed before adhesion is lost. Using this approach, a bond length of at least 580 
$\mathrm{mm}$ is needed with the $25 \mathrm{~mm}$ rebar to ensure that adhesion loss does not occur before the rebar yields. In situations where a bond length of $580 \mathrm{~mm}$ is not available, $25 \mathrm{~mm}$ diameter rebar could begin to slide out. Figure 5.2 shows this situation where a bond length, which may be shorter than $580 \mathrm{~mm}$, may be supporting the total load on the rebar.

Given the results from Section 4.4, the following failure mechanism for resin anchored rebar is proposed:

- Adhesion loss and sliding initiates as a result of the average resin-rock bond strength being exceeded;

- After adhesion loss, the support system may continue to sustain additional load due to sliding friction between the resin and rock surface, but this can be unpredictable (Cook, 1993) and should not be relied upon.

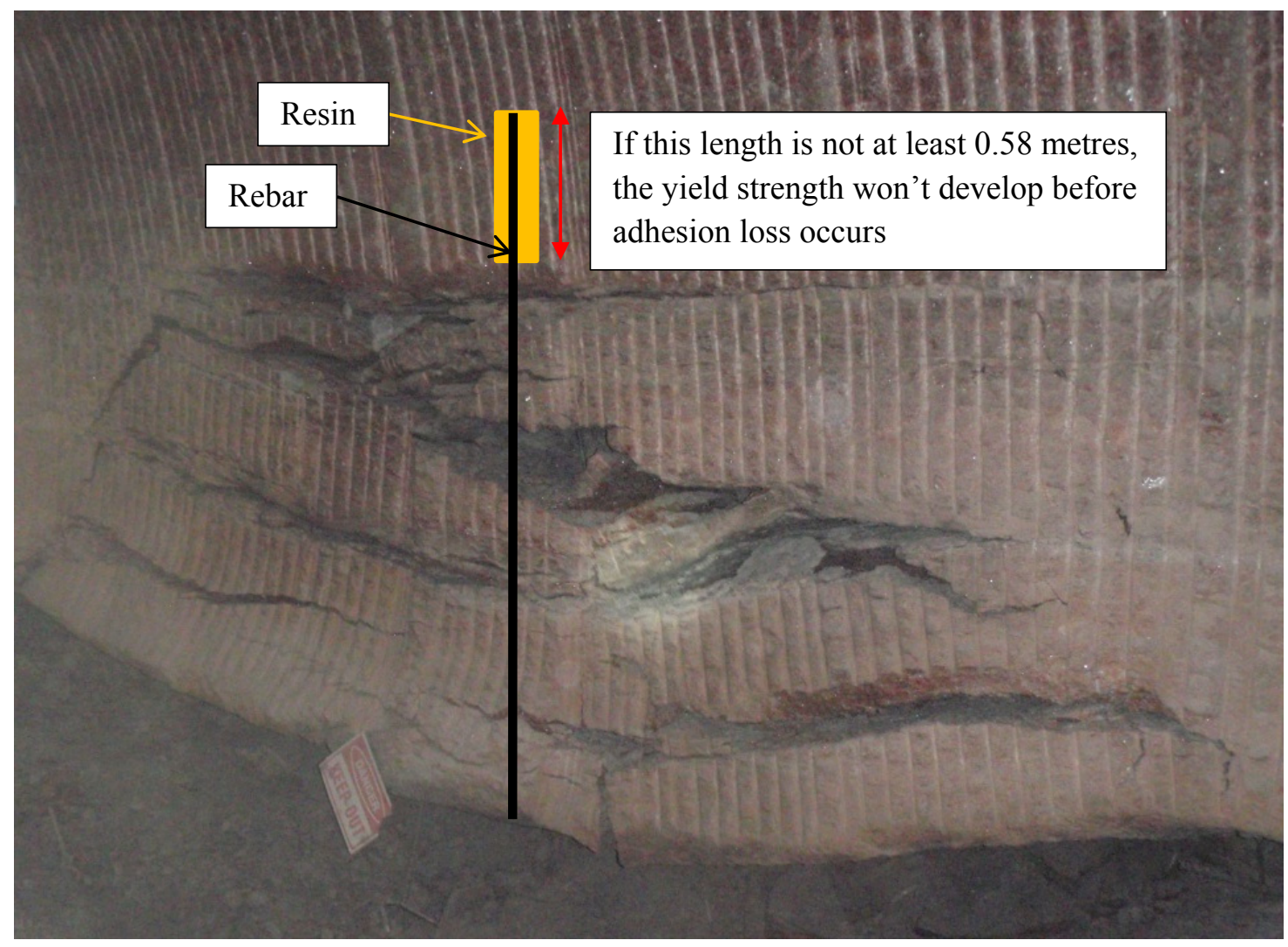

Figure 5.2 Length of resin anchored rebar responsible to sustain load 


\subsection{Estimating Load on Rebar from Measured Field Deformation}

The estimation of the capacity of installed rebar, based on measured field deformation, was the ultimate goal of this research. Based on laboratory and field testing, an equation is proposed to link deformation measurements, at known discrete locations, to the maximum load on installed rebar support. When rebar are fully embedded in resin, the load on the rebar cannot be estimated by mine personnel in the field by visual inspection as described in Section 1.1. Axial load in the rebar initiates at layers of separation in the rock mass and this load is distributed along the bond between rebar, resin and rock. Since the loading points on in-situ rebar are located at the separations which open up at discrete depths in the back, the deformation occurring in the rebar is not visible. The width of these separations can be measured in empty test holes alongside the installed rebar, but no equation currently exists to estimate the load on the rebar given this deformation recorded in the field.

Figure 5.3 shows a schematic of the deformation and associated load distribution along a resin anchored rebar in the field, adjacent to an opening fracture. The deformation occurs due to a separation forming on a plane of weakness, often associated with a clay seam. Simplifying assumptions are needed to develop an equation that can estimate the load associated with this deformation. The load present due to a clay seam opening is assumed to be distributed along a length of the resin anchored rebar support system. The load distribution is assumed to be linear, based on a constant average bond strength available before adhesion loss occurs. This was shown graphically in Figure 2.10 in Section 2.5 (Cook, 1993; Feldman \& Bartlett, 2007).

A linear load distribution implies that the maximum load, present at the separation, will linearly decrease to zero over the loaded length. For example, assume a separation has opened and induced an axial load of 18.7 tonnes on an installed rebar bolt installed across the separation. Given that the bond strength for $25 \mathrm{~mm}$ diameter rebar installed in a $36.5 \mathrm{~mm}$ diameter hole is 37 tonnes/metre, the loaded length $l$, can be estimated as:

$$
l_{l}=\frac{\text { Maximum Load }}{\text { Bond strength per metre }}=\frac{18.7 \text { tonnes }}{37 \text { tonnes } / \text { metre }}=0.51 \mathrm{~m}
$$

This loaded length would be present on both sides of the crack as the rebar resists the rock separating. Given the field testing results, an axial load of 18.7 tonnes would be present at the crack and 0.0 tonnes $510 \mathrm{~mm}$ away, giving an average load of 9.4 tonnes. The average strain, 
corresponding to the average load in this example, would exist along a $510 \mathrm{~mm}$ bond length on either side of the separation. The total deformation caused would equal the average strain multiplied by the loaded length on each side of the separation. Solving for average strain and loaded length in terms of the load at the separation, $P_{\max }$, provides an estimate of the load on the rebar given the measured deformation, $\delta$ :

$$
\delta=2 \varepsilon_{\text {avg }} l_{l}
$$

where:

$$
\begin{aligned}
& \varepsilon_{a v g}=\text { Average elastic strain along the loaded length; } \\
& l_{l}=\text { Loaded length } \text { and } \\
& \delta=\text { Deformation measured at a separation in the field. }
\end{aligned}
$$

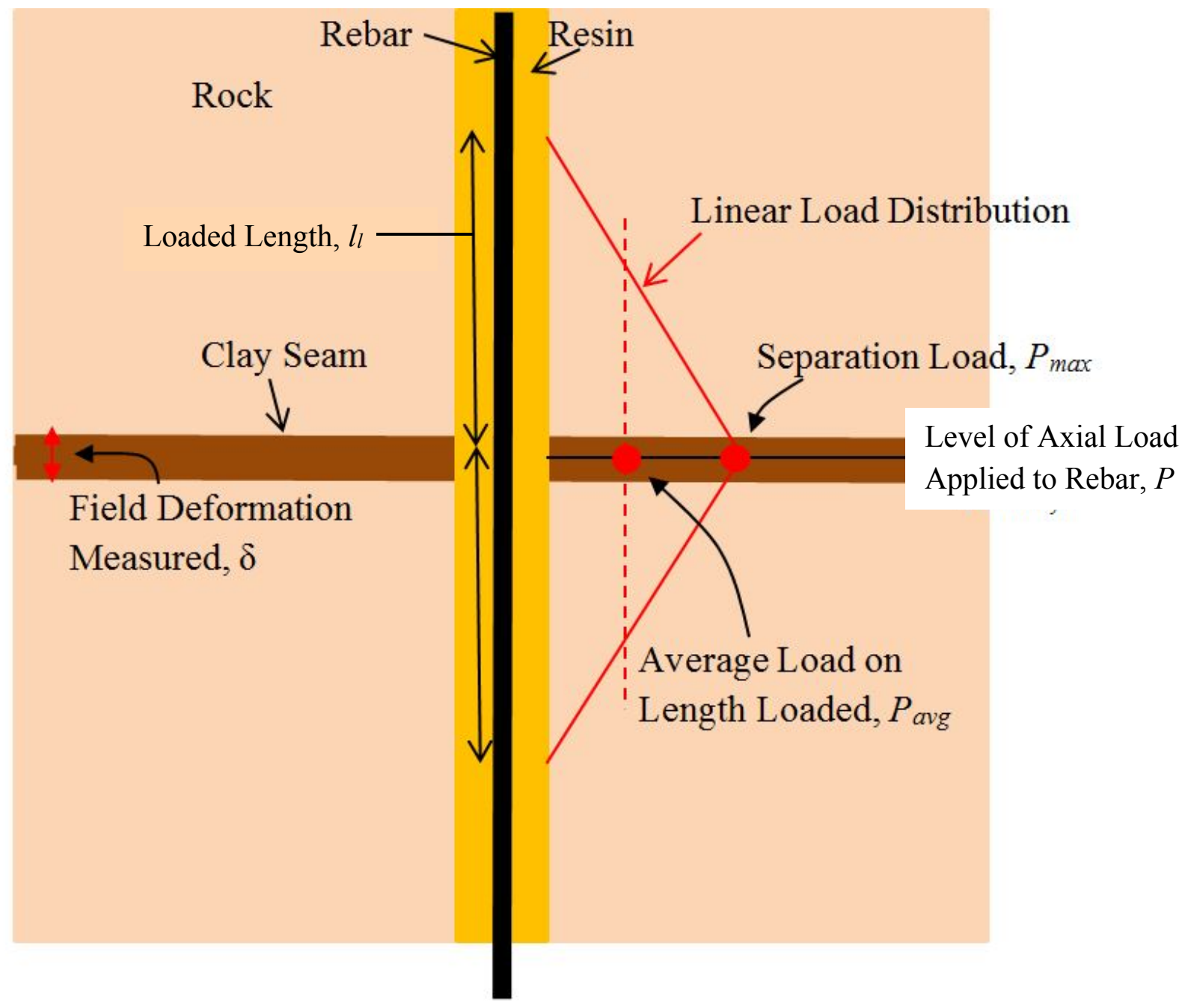

Figure 5.3 In-situ rebar load and deformation schematic 
The average strain may be approximated using a linear relation, assuming the load remains in the elastic range. Laboratory testing results showed a nominal value of the load required to yield rebar, $P_{y}$. The strain associated with the yield strength, $\varepsilon_{y}$, can be calculated using elastic theory. Using the yield strain calculated, the strain associated with any load within the elastic limits may be calculated as:

$$
\varepsilon_{\text {avg }}=\left(\frac{P_{a v g}}{P_{y}}\right) \varepsilon_{y}
$$

Where: $\quad P_{\text {avg }}=$ Average load on rebar along the bonded length; and $P_{y}=$ Load required to yield rebar; and $\varepsilon_{y}=$ Yield strain

To define the loaded length in terms of load on the rebar, a relationship similar in form to Equation 6.3 is used. The loaded length, when the load equal to the nominal load required to yield the rebar is applied, can be solved for using Equation 6.4. The loaded length associated with the nominal load required to yield the rebar can be defined as the yield load development length, $l_{l y}$. The loaded length depends on the average bond strength; results from field testing on $25 \mathrm{~mm}$ rebar indicate the critical bond strength was on the resin-rock interface, $u$, and was equal to $3.2 \mathrm{MPa}$. In the elastic range, the loaded length in-situ can then be calculated from the proportional relation shown in Equation 6.5.

$$
l_{l y}=\left(\frac{P_{y}}{u C_{h}}\right)
$$

where:

$$
\begin{aligned}
& u=\text { Average resin-rock bond strength; } \\
& C_{h}=\text { Circumference of hole size used; and } \\
& l_{l y}=\text { Yield load development length. }
\end{aligned}
$$

$$
l_{l}=\left(\frac{P_{\max }}{P_{y}}\right) l_{l y}
$$

where: $\quad P_{\max }=$ Load on rebar at the location of the separation.

The average load on the rebar, shown in Figure 5.3, is equal to half the load at the separation. This assumes the simplification of a linear load distribution is used. The average load at the separation 
can be substituted in Equation 6.3. Equation 6.3 and Equation 6.5 can then be combined to define deformation measured in the field in terms of the maximum axial load in the rebar at the separation, Equation 6.6.

$$
\delta=2\left[\left(\left(\frac{P_{\max } / 2}{P_{y}}\right) \varepsilon_{y}\left(\frac{P_{\max }}{P_{y}}\right) l_{l y}\right)\right]
$$

The unknown in Equation 6.6 is the $P_{\max }$ term and therefore can be solved for. Rearranging Equation 6.6 to solve for $P_{\max }$ directly is shown in Equation 6.7.

$$
P_{\max }=\sqrt{\frac{\delta\left(P_{y}\right)^{2}}{\varepsilon_{y} l_{l y}}}
$$

Equation 6.7 is limited to estimating loads resisted by resin anchored rebar that are within the elastic range. This equation is valid when the separation on which the deformation is occurring is in a position such that there is at least a bond length equal to or greater than the yield load development length previously described (Equation 6.4) on each side of the separation. For the $25 \mathrm{~mm}$ rebar, this length is $580 \mathrm{~mm}$. If a shorter bond length is available, the rebar will begin to slide before the nominal yield load can be attained.

Equation 6.7 provides a method of estimating the magnitude of fracture separation which results in yielding of the installed support. When properties for the $25 \mathrm{~mm}$ diameter rebar from both laboratory and field testing are inserted into Equation 6.7, as shown above, it is estimated that a deformation of $1.3 \mathrm{~mm}$ is required to induce the nominal 21.2 tonne yield load. Currently, the method of measuring deformation is as simple as using a measuring tape to manually collect separation magnitudes. Manually reading measuring tapes would not be able to track deformations of less than $1.3 \mathrm{~mm}$. More accurate methods of measurement in the field are therefore required if the load on resin anchored rebar is to be monitored.

$$
\begin{gathered}
21.2 \text { tonnes }=\sqrt{\frac{\delta(21.2 \text { tonnes })^{2}}{0.0022(580 \mathrm{~mm})}} \\
\delta=1.3 \mathrm{~mm}
\end{gathered}
$$




\section{Conclusions \& Future Work Recommendations}

This chapter summarizes the conclusions drawn from the results of the laboratory and field testing programs. Conclusions are drawn for each of the objectives, identifying the failure mechanism, assessing the variation in average bond strength, and forming an equation to estimate in-situ loads on resin anchored rebar. Recommendations for future work are also described in this chapter. Field testing of resin anchored rebar in potash previously has been limited and continuing testing will improve the application of this type of support.

\subsection{Conclusions}

The experimental program described herein has resulted in the development of a simple, inexpensive, and repeatable testing method that can be employed by mine engineers to conduct quality control tests on resin anchored rebar in potash mines. One hundred and ten field pull tests were conducted in the Allan mine. Only limited and isolated testing of resin anchored rebar has been conducted in potash mines prior to this research. A large database of test results has resulted from the experimental program and serves as a reference for future testing. The data reduction methods and analysis of results has been presented and can be followed for future testing.

\subsubsection{Failure Mechanism of Resin Anchored Rebar in Potash}

Results from this project indicate that the average bond strength achieved along the resin-rock interface limits the capacity of resin anchored rebar with short bond lengths in potash. Adhesion loss occurs and sliding initiates when the bond stress along this interface reaches an average stress of 3.2 MPa. Results suggest, but do not definitively conclude, that increasing the contact area of the resin-rock interface increases the initial sliding load, and is limited by the yield strength of the size of rebar used. At the Allan mine, use of a $36.5 \mathrm{~mm}$ diameter hole to install $25 \mathrm{~mm}$ size rebar resulted in an average bond strength of 37 tonnes/metre. A bond length of $580 \mathrm{~mm}$ is therefore needed to develop the nominal yield load for the $25 \mathrm{~mm}$ rebar used (21.2 tonnes).

\subsubsection{Variability of Average Bond Strength}

Conducting pull tests in various locations at the Allan mine was used to investigate the variability of average bond strength when cure time, proximity to active mining, and rock type were varied. Results from testing which varied cure time showed the average bond strength did not significantly vary with increasing cure time. Analysis of results from testing where proximity to active mining 
was varied determined no significant difference between the active and non-active sites. The difference in confining stress magnitude at the active and non-active sites may impact results where the additional capacity of the system provided by friction is assessed. The magnitude of confining stress does not impact the adhesion between materials therefore; no difference between these two test sites was noted. Results with respect to the effect of rock type were inconclusive. The highly variable results may be attributed to poor mixing, or these results may be unique to rebar anchored to halite. Further testing is required with respect to the effect of rock type on the average bond strength.

\subsubsection{Development of an Equation to Estimate Load on In-Situ Resin Anchored Rebar in Potash}

An equation to estimate the load on in-situ resin anchored rebar was developed based on the mechanical properties defined in laboratory and field testing, and the deformations measured in the field. The equation is relevant only when the reinforcement remains within the elastic range. Previously, no such equation was available. The deformation estimated using this equation indicates that less than $2 \mathrm{~mm}$ of separation will cause loads in the $25 \mathrm{~mm}$ diameter rebar to exceed the elastic limit.

The small amount of movement estimated along bonded sections highlights the stiff nature of resin anchored rebar ground support. An understanding that resin anchored rebar in potash will allow minimal movement within their elastic range is valuable to engineers in the field. When deformations exceed the elastic range estimate, it may indicate the support is yielding, or that it is not fully bonded with resin, or that the support is not influencing the ground in the area where the deformation measurement has been taken. Awareness of the limits of this type of support provides the ability to better assess the performance of resin anchored rebar in the field and the surrounding ground conditions.

\subsection{Recommendations for Future Work}

During the course of this research project, many questions were raised which require further testing to answer. Future testing on resin anchored rebar could include more sizes of rebar, additional hole diameters, more testing in halite, shear strength testing on resin anchored rebar in potash, and testing using instrumented rebar to more accurately determine in-situ loads from deformations in 
the field. Potash mines use resin anchored rebar to maintain the integrity of long term openings; future testing could improve the safety of installations using resin anchored rebar support.

Future testing should be conducted where rebar and hole size are further varied. This could determine whether the results in this research, which suggest that average bond strength is proportional to hole size, is true for a greater range of rebar and hole sizes. Testing should also be conducted to determine the effect of anchoring the rebar into layers of halite. A larger sample size of twenty or more rebar, employing the testing methods developed for this research project, could provide an indication of differences in the average bond strength between rebar bonded in halite and potash.

Further testing is also needed to determine the shear strength of resin anchored rebar. Conservative factors of safety have worked well in the industry, but due to the importance of the support provided by resin anchored rebar under shearing loads, further research is advised. Equipping resin anchored rebar with instrumentation could determine the in-situ load distribution when axial and/or shear loads are applied to the support. Instrumentation which has this capability is currently being developed (Hyett, 2013). This could improve the accuracy and reduce the limitations of the equation developed as a part of this research which estimates load on in-situ resin anchored rebar.

This research is an initial step towards giving the mine engineer the tools to understand the limiting factors of the average bond strength capacity and relate measured field deformation to the load on installations using resin anchored rebar support in potash mines. 


\section{References}

ASTM. ASTM A615/A615M-12 Standard Specification for Deformed and Plain Carbon-Steel Bars for Concrete Reinforcement. West Conshohocken: ASTM International, 2012.

ASTM. (a) ASTM D3967-08 Standard Test Method for Splitting Tensile Strength of Intact Rock. West Conshohocken: ASTM International, 2008.

ASTM. (b) ASTM D4435-08 Standard Test Method for: Rock Bolt Anchor Pull Test. West Conshohocken: ASTM International, 2008.

ASTM. ASTM D7012-10 Standard Test Method for Compressive Strength and Elastic Moduli of Intact Rock Core Specimens under Varying States of Stress and Temperatures. West Conshohocken: ASTM International, 2010.

ASTM. ASTM E8/E8M - 11 Standard Test Methods for Tension Testing of Metallic Materials. West Conshohocken: ASTM International, 2011.

Bargahr, R., and T. Vogel. "Bond Performance of Post-Installed Rebars." 5th International PhD Symposium in Civil Engineering. London: Taylor and Francis Group, 2004.

Budynas, R., and K. Nisbett. In Shigley's Mechanical Engineering Design 8th Ed., by R. Budynas and K. Nisbett, 217 . McGraw-Hill Science/Engineering/Math, 2006.

Cook, R. "Behavior of Chemically Bonded Anchors." ASCE Journal of Structural Engineering Vol. 119, No. 9 (1993): 2744-2762.

Cook, R., and R. Conz. "Factors Influencing Bond Strength of Adhesive Anchors." ACI Structural Journal Vol. 98, No. 1 (2001): 77-86.

Cook, R., J. Burtz, and M. Ansley. Design Guidelines and Specifications for Engineered Grouts.

Engineering Report, Gainesville: University of Florida, 2003.

DSI. DSI Underground Systems. January 2009. http://www.dsigroundsupport.com/products/rebar-rockbolts/rebar-rockbolts.html (accessed May 14, 2012).

DSI. Ground Support - Ground Lok Resin Capsules Information Sheet. December 2008. http://www.dsigroundsupport.com/downloads/brochures-ground-support.html?content_id=2862 (accessed March 20, 2012).

DSI. Tension Jack/Pull Test Kit. January 2009. http://www.dsigroundsupport.com/products/rebar-rockbolts/tension-jackpull-test-kit.html (accessed March 28, 2012).

Dube, S. A Laboratory Study on the Behaviour of Cable Bolts Subjected to Combined Tensile and Shear Loads. Kingston: Queen's University, 1995. 
Duncan, E.J., and E. Lajtai. "The Creep of Potash Salt Rocks from Saskatchewan." Geotechnical and Geological Engineering Vol. 11, No. 3 (1993): 159-184.

Feldman, L.R., and F.M. Bartlett. "Bond Stresses Along Plain Steel Reinforcing Bars in Pullout Specimens." ACI Structural Journal Vol. 104, No. 6 (2007): 685-692.

Fuzesy, A. Potash in Saskatchewan. Regina: Saskatchewan Department of Mineral Resources, 1982.

Gendzwill, D., and N. Wilson. "Form and Distribution of Winnipegosis Mounds in Saskatchewan." Rocky Mountain Assocition of Geologists. Denver, 1987. 109-117.

Goodman, R. "Rock Strength and Failure Criteria." In Introduction to Rock Mechanics, by R. Goodman, 55-100. John Wiley \& Sons, 1989.

Hills, R. "PCS Training Power Point Presentation entitled "Rock Mechanics part 2"." Received from Doug Beattie 2010. 2005.

Holter, M. The Middle Devonian Prairie Evaporite of Saskatchewan. Regina: Saskatchewan Department of Mineral Resources, 1969.

Hutchinson, D.J., and M.S. Diederichs. "Bond Strength." In Cablebolting in Underground Mines, by D.J. Hutchinson and M.S. Diederichs, 77. Richmond: BiTech Publishers, 1996.

Hyett, A, B.J. Forbes, and A.J.S. Spearing. "Enlightening Bolts: Using Distributed Optical Sensing to Measure the Strain Profile along Fully Grouted Rock Bolts." International Conference on Ground Control in Mining. Morgantown, 2013.

Johnston, J.L., and D.J. Cox. Instrumentation Procedures for Fully Grouted Rock Bolts. Information Circular, United States Department of the Interior Bureau of Mines, 1994.

Jones, P.R., and F.F. Prugger. "Underground Mining in Saskatchewan Potash." Mining Engineering, 1982: 1677-1683.

Kuchling, K. I.M.C. K-1 Mine Rebar Rockbolt Evaluation . I.M.C., 1987.

Li, C., and B. Stillborg. "Analytical Models for Rock Bolts." International Journal of Rock Mechanics and Mining Sciences, 1999: 1013-1029.

Lovlin, T. Potash Mine Support. Saskatoon: University of Saskatchewan, 2006.

Mackintosh, A. "Applied Rock Mechanics: The Development of Safe Travelways at the Cominco Potash Mine." 10th Canadian Rock Mechanics Symposium. Kingston: Department of Mining Engineering Queen's University, 1975. 69-97.

Mackintosh, A.D. "Strata Control in a Deep Saskatchewan Potash Mine." Cominco Report, Vanscoy, 1977. 
Mark, C., C. Compton, D. Oyler, and D. Dolinar. "Anchorage Pull Testing for Fully Grouted Roof Bolts." 21st International Conference on Ground Control in Mining. Morgantown: West Virginia University , 2002. 105-113.

Martin, L, D Milne, M Ruest, and R Pakalnis. Evaluation of Instrumented Cable Bolts in Cement Grout to Determine Physical and Numerical Modeling Properties. Spokane: NIOSH, 2004.

McHugh, E., and S. Signer. "Roof Bolt Responses to Shear Stress: Laboratory Analysis." 18th Conference on Ground Control in Mining. Spokane: National Institute for Occupational Health and Safety, 1999. 232-238.

McVay, M., R. Cook, and K. Krishnamurthy. "Pullout Simulation of Postinstalled Chemically Bonded Anchors." Journal of Structural Engineering, 1996: 1016-1024.

Meadows, M. Ground Support Pull Test Results. 1999 Soft Rock Conference Paper, Canadian Insitute of Mining, Metallurgy, and Petroleum, 1999.

Milne, Doug. "Preliminary Relationship Between Crack Dilation and Cable Load." Noranda Internal Correspondence, 1993.

Ong, Victor. "Potash Rock Mechanics Principles - An Overview." PCS Internal Document, 2005.

PotashCorp - Allan . Archived Closure Rod Data . Internal Document, PCS, 2013.

Potvin, Y., and J. Hadjigeorgiou. "Selection and Design of Ground Support Systems, Theory and Practice." Annual General Meeting. Toronto: CIM, 2000.

Signer, S. Field Verification of Load Transfer Mechanics of Fully Grouted Roof Bolts. Report of Investigations, United States Department of the Interior Bureau of Mines, 1990.

Signer, S. Load Behavior of Grouted Bolts in Sedimentary Rock. Spokane: National Institute for Occupational Safety and Health, 2000.

Signer, S., D. Cox, and J. Johnston. "A Method for the Selection of Rock Support Based on Bolt Loading Measurements." 16th Conference on Ground Control in Mining. Spokane: National Institute for Occupational Safety and Health, 1997. 183-190.

Smith, Cole. "Rebar Pull Testing." PCS Internal Document, 2008.

Stare, Melanie, interview by Darren Neely. Storage of Resin Capsules (March 20, 2012).

Stillborg, B. Experimental Investigation of Steel Cables for Rock Reinforcement in Hard Rock. PhD Thesis, University of Lulea, 1984.

Stimpson, B. "Rock Bolting and Reinforcement - An Overview." Workshop on Rock Mechanics and Ground Control in the Soft Rock and Coal Industries. Saskatoon, 1994. 
Stimpson, B. (a) "An Analytical Method for Determining Shear Stiffness of an Inclined Grouted Bolt Installed Across an Open Discontinuity." International Journal of Mining and Geological Engineering Vol. 5, No. 3 (1987): 299-305.

Stimpson, B. (b) "Optimizing the Reinforcement Effect of Full-Column, Untensioned, Grouted Bolts in Bedded Mine Roofs." International Journal of Mining and Geological Engineering, 1987: 285298.

Van Ooteghem, R. Testing of Resin Anchored Bolt Systems. Cominco Potash Operations Report, Colonsay : Cominco Ltd. , 1982.

Villaescusa, E, R Varden, and R Hassell. "Quantifying the Performance of Resin Anchored Rock Bolts in the Australian Underground Hard Rock Mining Industry." International Journal of Rock Mechanics \& Mining Sciences, 2008: 94-102.

Worsley, N., and A. Fuzesy. "The Potash-bearing Members of the Devonian Prairie Evaporite os Southeastern Saskatchewan, South of the Mining Area." Economic Geology, 1979: 377-388. 


\section{Appendices}

The appendix contains the following sections:
A: Raw Data from Laboratory Tests on Rebar Specimens
B: Raw Data from Laboratory Tests for Rock Properties
C: Resin Volume Calculations
D: Pull Test Process and Data Reduction Process
E: Raw Data from Field Testing 


\section{A. Raw Data from Laboratory Testing on Rebar Specimens}

This portion of the appendices provides the raw data from the laboratory testing conducted on both rebar and rock samples.

\section{Rebar Property Test Raw Data:}

Table A.1 shows the results from each of the ten rebar samples.

Table A.1 Rebar Property Testing Raw Data

\begin{tabular}{|c|c|c|c|}
\hline $\begin{array}{c}\text { Nominal Rebar } \\
\text { Diameter (mm) }\end{array}$ & $\begin{array}{c}\text { Ultimate Strength } \\
\text { (MPa) }\end{array}$ & $\begin{array}{c}\text { Yield Strength } \\
\text { (MPa) }\end{array}$ & $\begin{array}{c}\text { Young's Modulus } \\
\text { (GPa) }\end{array}$ \\
\hline 16 & 565 & 475 & 133 \\
\hline 16 & 560 & 470 & 195 \\
\hline 16 & 565 & 475 & 161 \\
\hline 16 & 565 & 480 & 196 \\
\hline 16 & 570 & 490 & $\mathbf{1 7 9}$ \\
\hline $\mathbf{1 6}$ mm Average: & $\mathbf{5 6 5}$ & $\mathbf{4 8 0}$ & 173 \\
\hline Standard Deviation: & $\mathbf{4 . 0 0}$ & $\mathbf{7 . 5 0}$ & 176 \\
\hline 25 & 606 & 393 & 203 \\
\hline 25 & 606 & 391 & 180 \\
\hline 25 & 609 & 393 & 175 \\
\hline 25 & 609 & 389 & $\mathbf{1 8 1}$ \\
\hline 25 & 630 & 479 & $\mathbf{1 2 . 3}$ \\
\hline Standard Deviation: & $\mathbf{6 1 2}$ & $\mathbf{4 0 9}$ & $\mathbf{3 9 . 4}$ \\
\hline
\end{tabular}

The following figures show the load versus deformation plots used to find the load at which the rebar entered plastic deformation. The magnitude of deformation includes error from the wedge grips allowing the rebar to slip during the test. Also included are stress versus strain plots which used the data collected from the LVDT measuring strain over a $200 \mathrm{~mm}$ gauge length. 
Load vs Deformation and Stress vs Strain Plots: 25mm Rebar Testing (Samples 1 through 5)

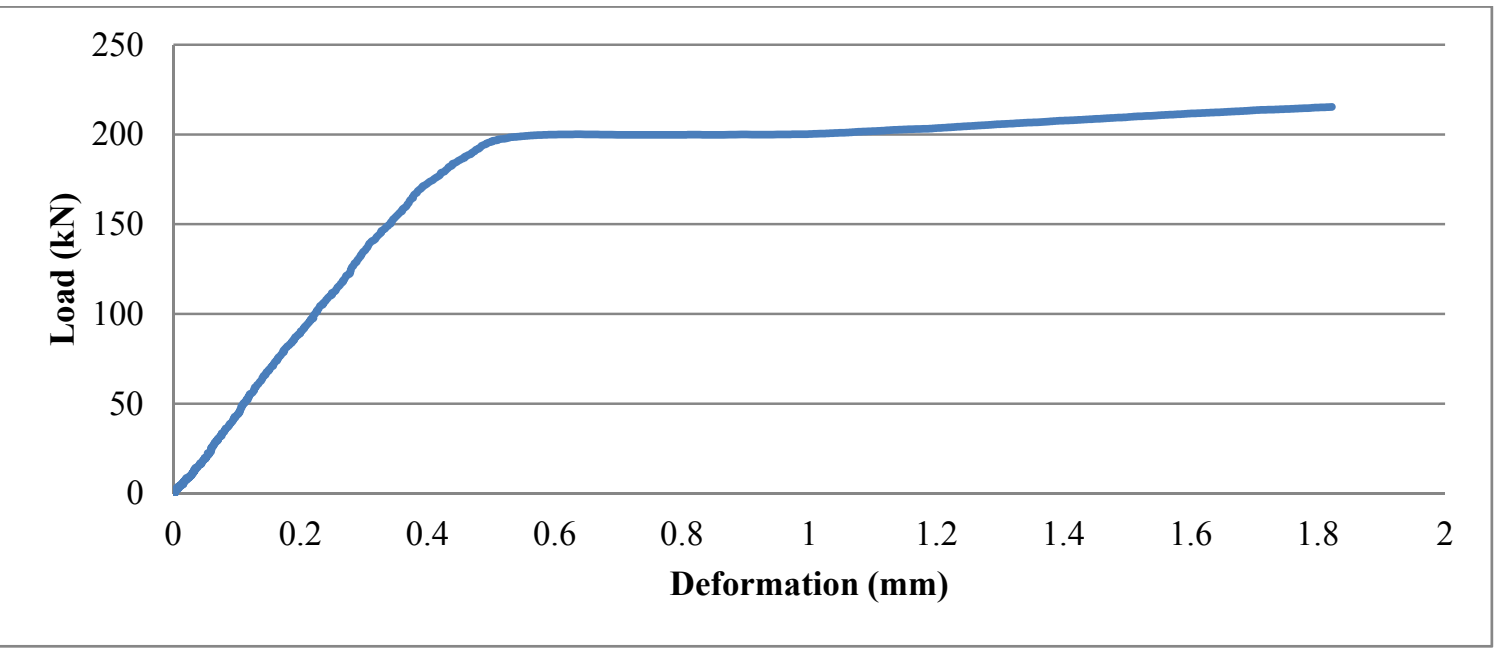

Figure A.1 Load versus Deformation - Test 1 (25mm Rebar)

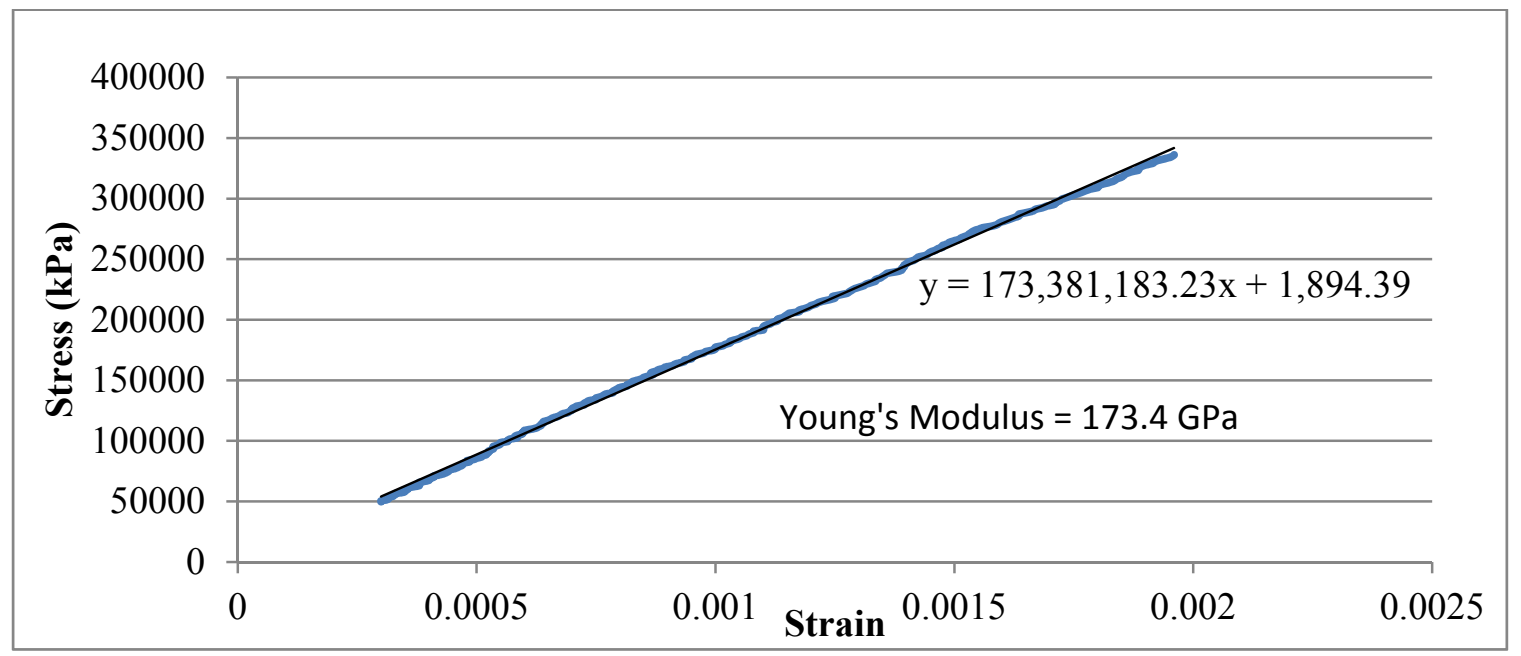

Figure A.2 Stress versus Strain - Test 1 (25mm Rebar)

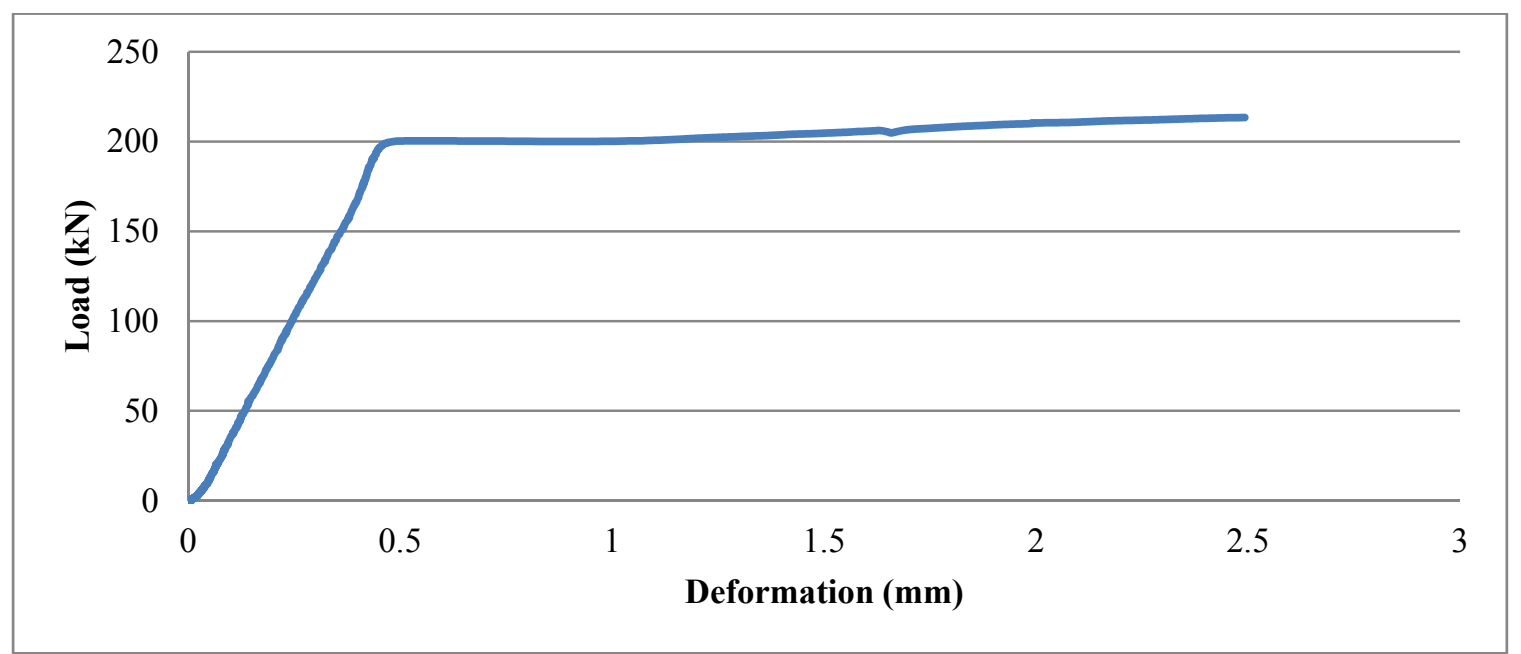

Figure A.3 Load versus Deformation - Test 2 (25mm Rebar) 


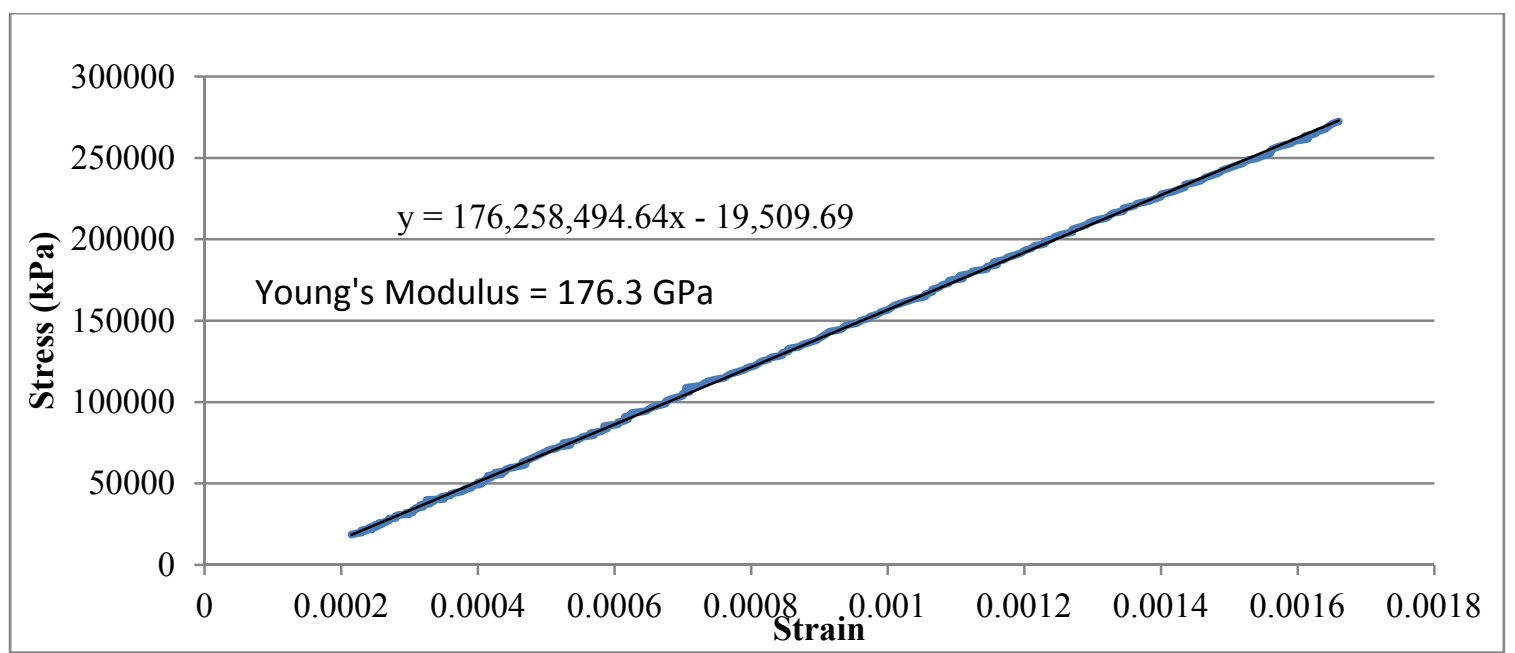

Figure A.4 Stress versus Strain - Test 2 (25mm Rebar)

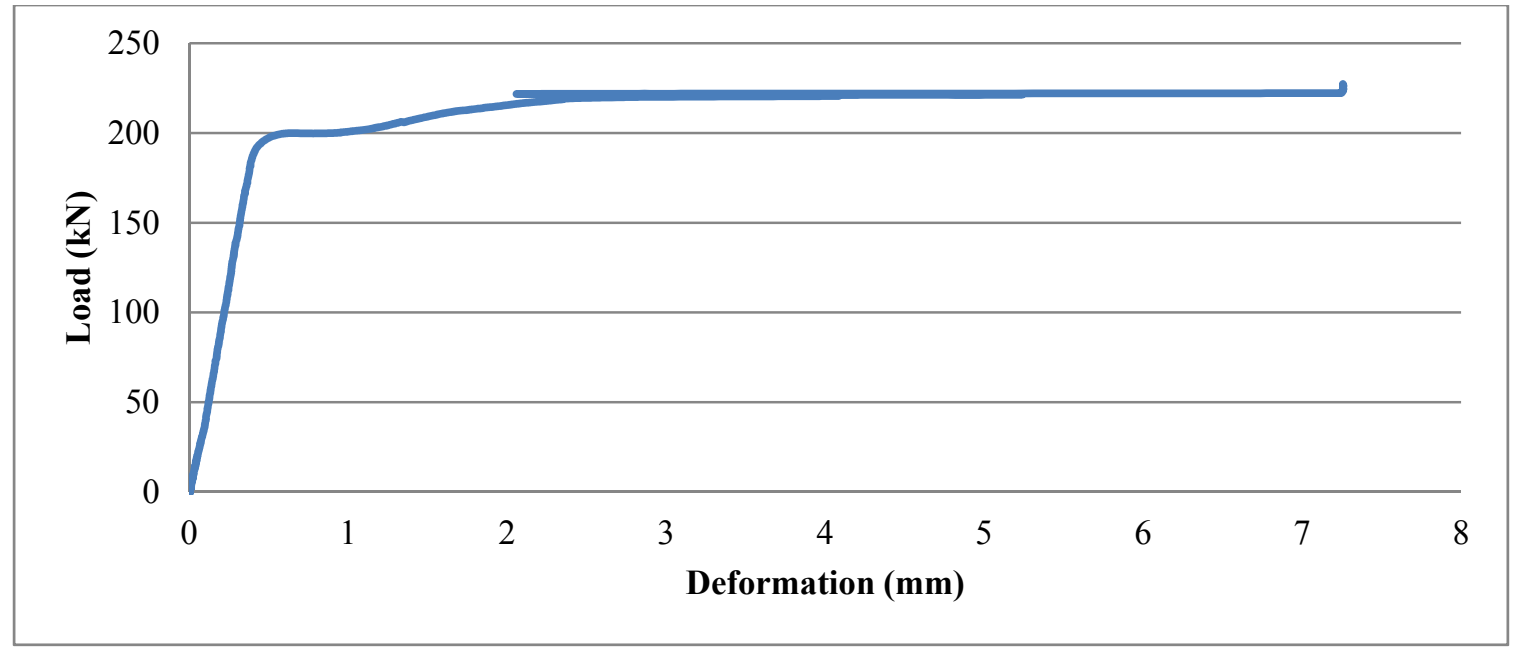

Figure A.5 Load versus Deformation - Test 3 (25mm Rebar)

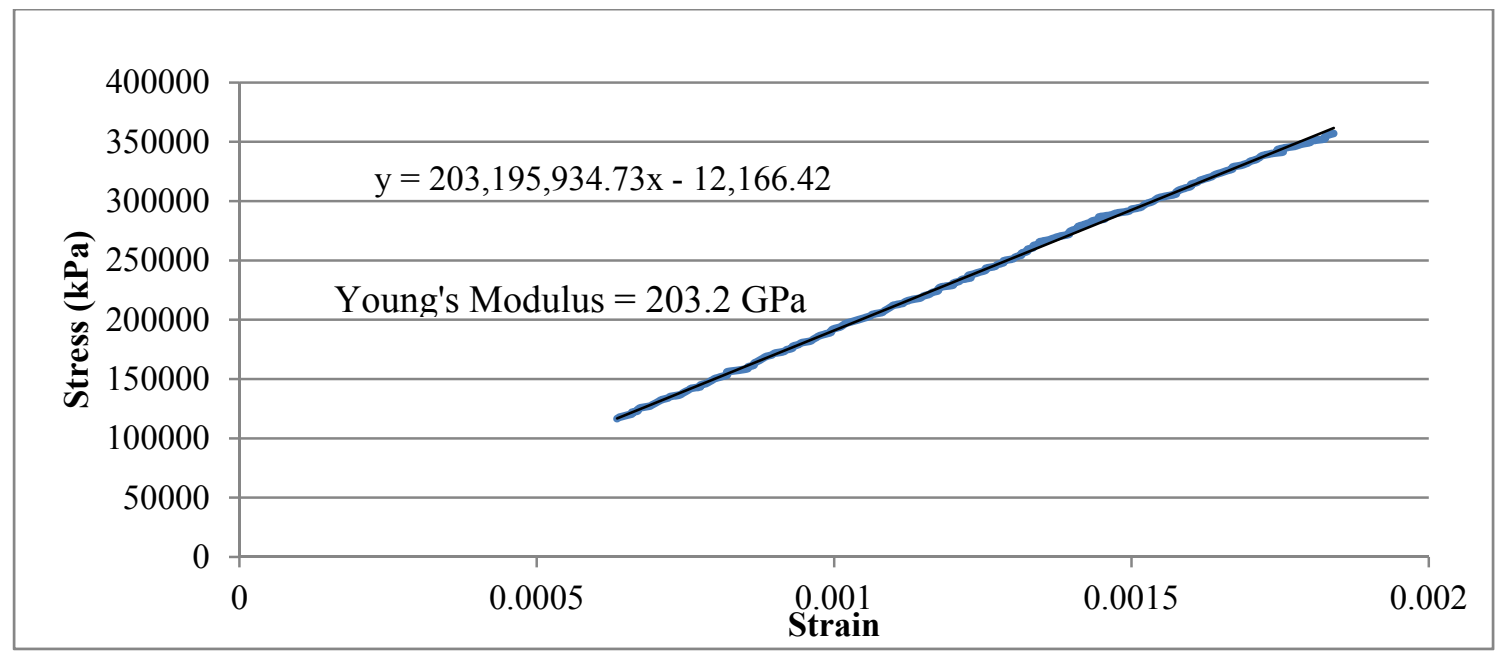

Figure A.6 Stress versus Strain - Test 3 (25mm Rebar) 


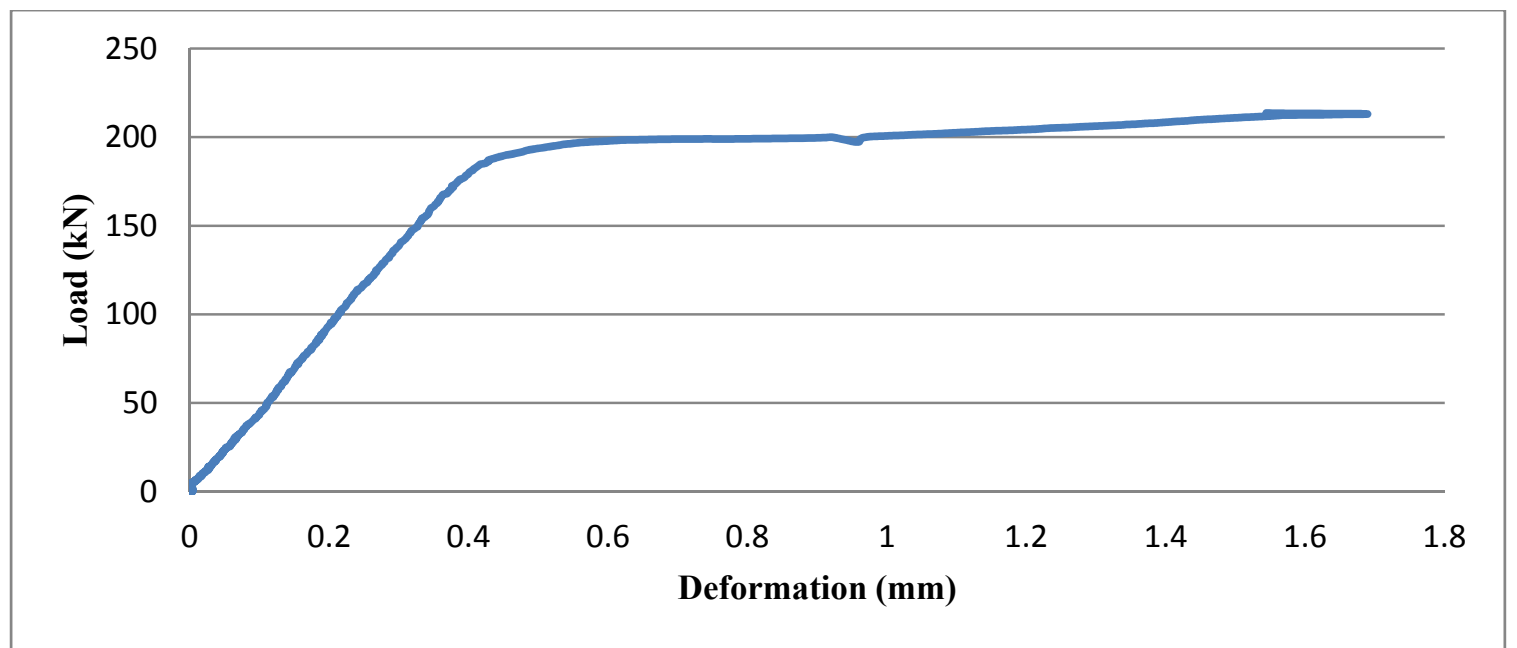

Figure A.7 Load versus Deformation - Test 4 (25mm Rebar)

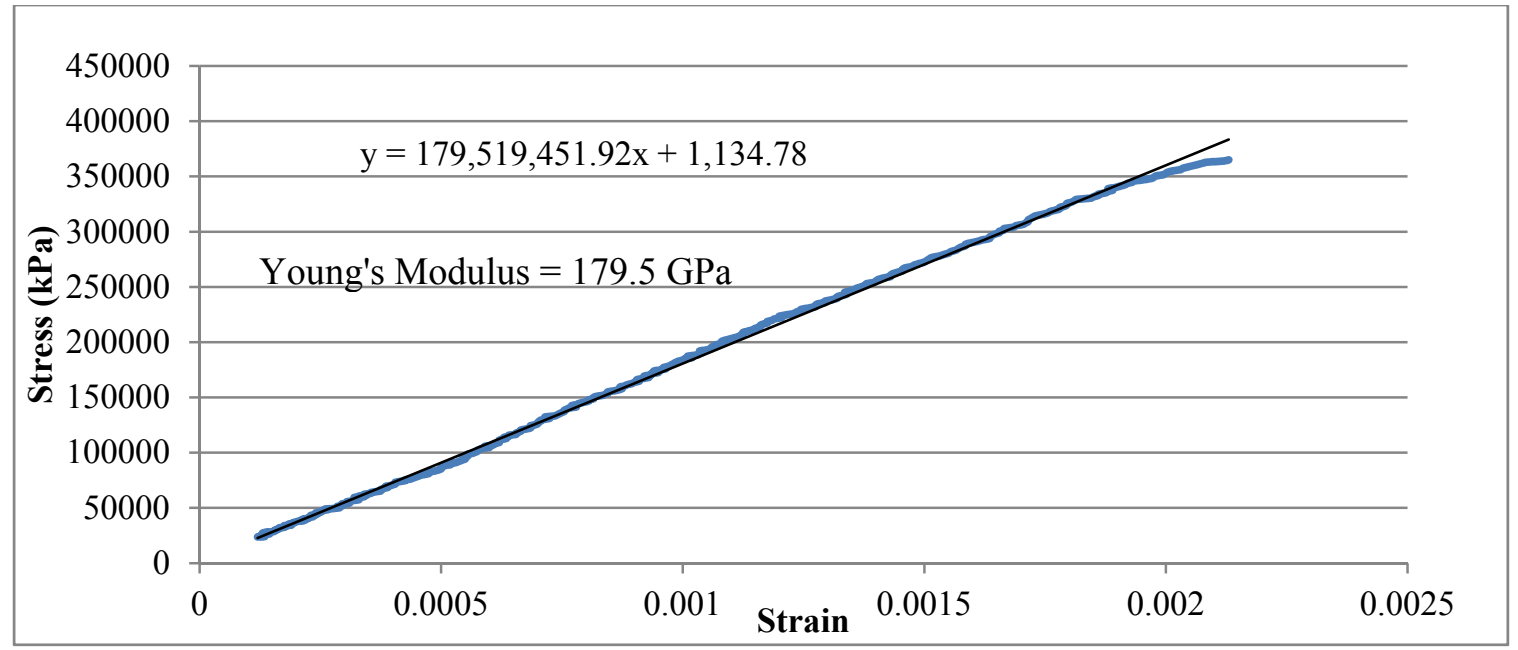

Figure A.8 Stress versus Strain - Test 4 (25mm Rebar)

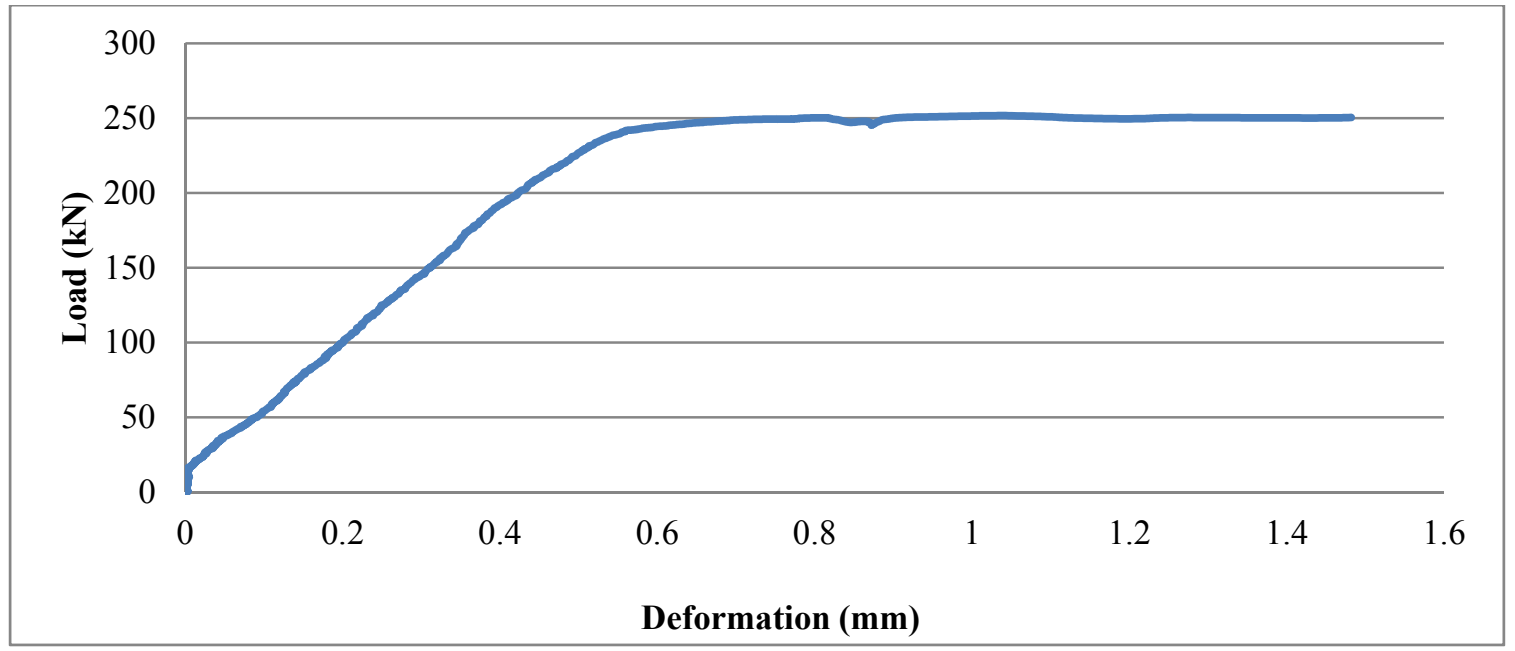

Figure A.9 Load versus Deformation - Test 5 (25mm Rebar) 


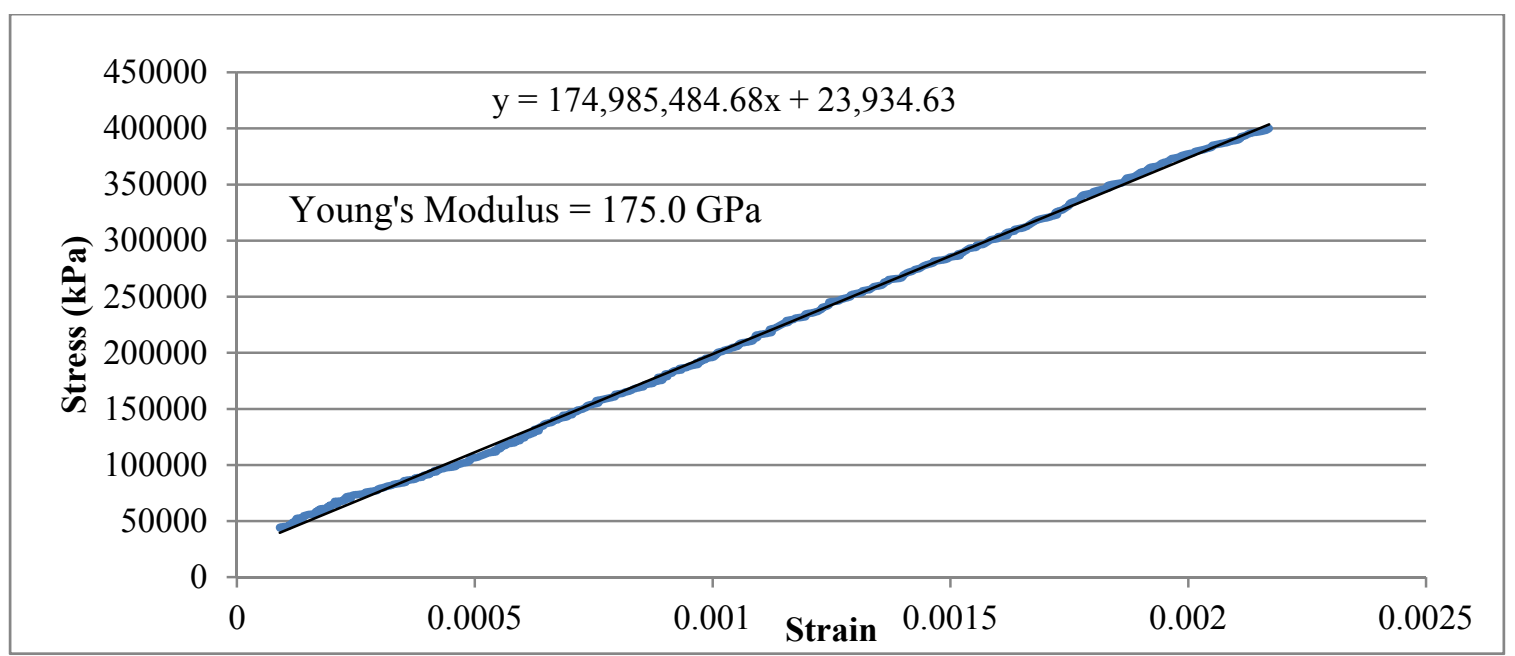

Figure A.10 Stress versus Strain - Test 5 (25mm Rebar)

\section{Calculating Maximum Elastic Strain for 25mm Rebar}

The average maximum elastic strain can be found by taking the average yield load stress and dividing it by the average young's modulus found for the $25 \mathrm{~mm}$ rebar. This value was used to form the equation to approximate load on rebar given measured deformation.

$$
\begin{aligned}
& \varepsilon_{\text {max.elastic }}=\frac{\sigma_{\text {yield }}}{E_{\text {average }}} \\
& \sigma_{\text {yield }}=\frac{{\text { Yield } \text { Load }_{\text {avg }}}_{\text {Area }_{\text {nominal }}}}{509 \mathrm{~mm}^{2}}=409 \mathrm{MPa} \\
& \varepsilon_{\text {max.elastic }}=\frac{409 \mathrm{MPa}}{184600 \mathrm{MPa}}=0.00222=0.22 \%
\end{aligned}
$$

Load vs. Deformation and Stress vs. Strain Plots: 16mm Rebar Testing (Samples 6 through 10)

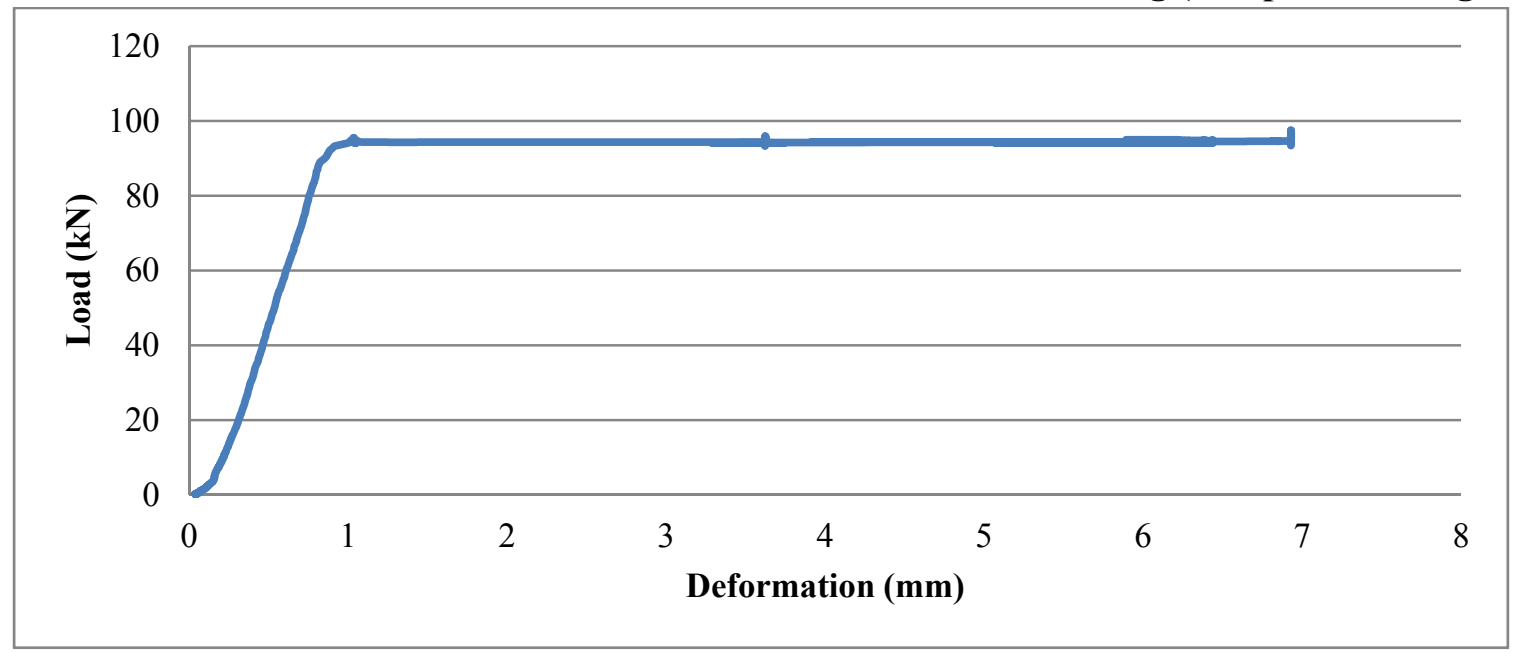

Figure A.11 Load versus Deformation - Test 6 (16mm Rebar) 


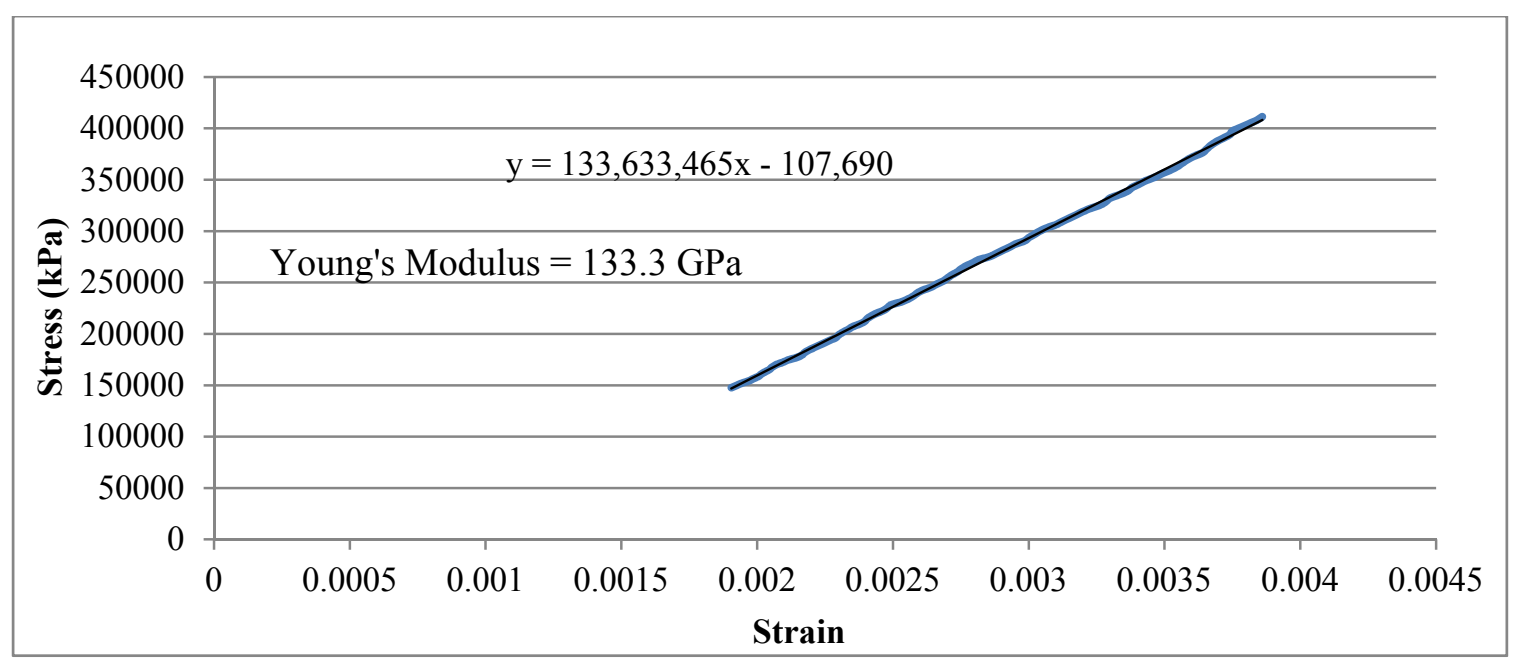

Figure A.12 Stress versus Strain - Test 6 (16mm Rebar)

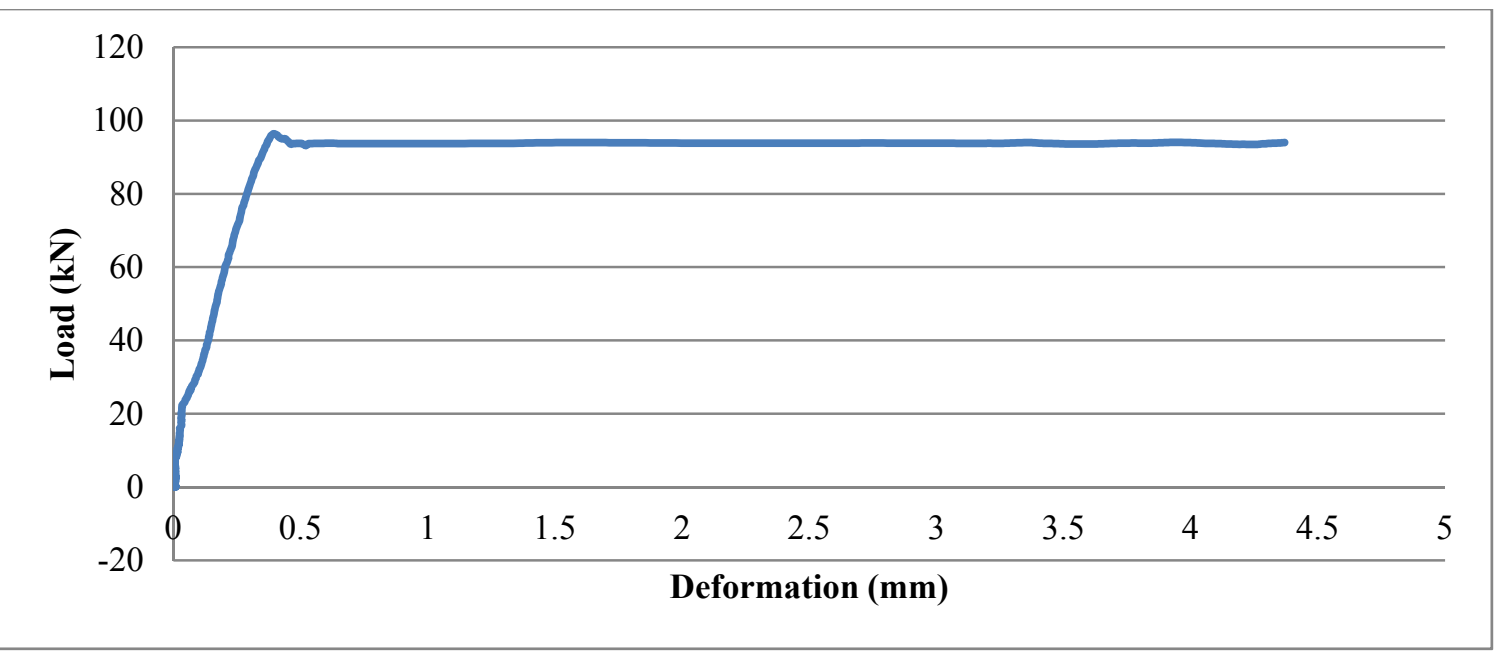

Figure A.13 Load versus Deformation - Test 7 (16mm Rebar)

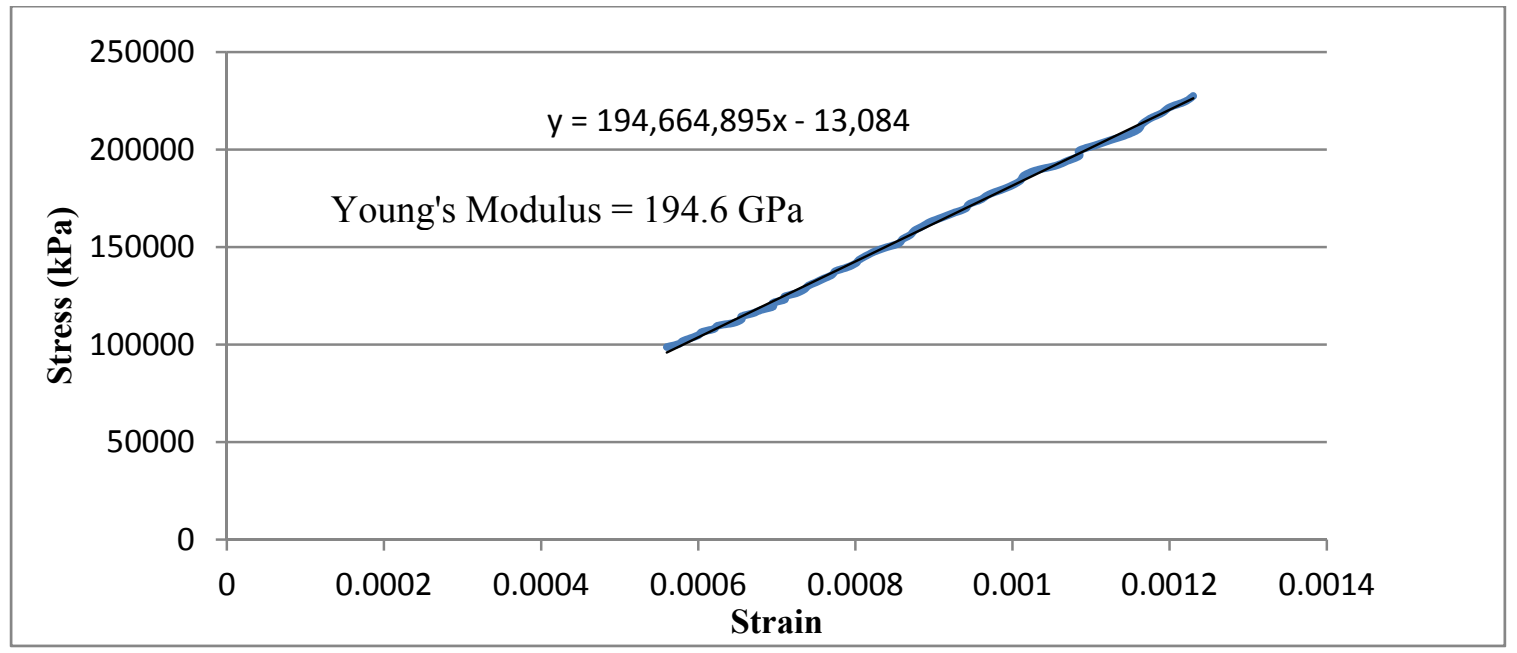

Figure A.14 Stress versus Strain - Test 7 (16mm Rebar) 


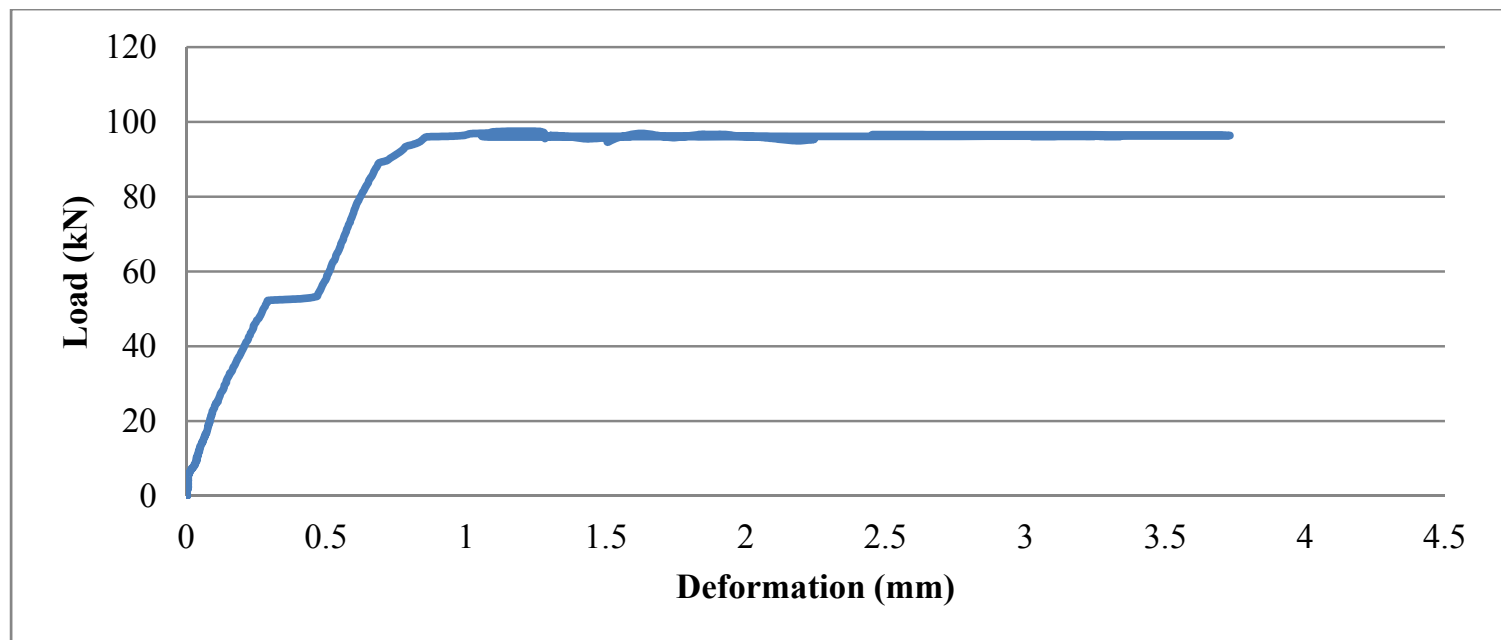

Figure A.15 Load versus Deformation - Test 8 (16mm Rebar)

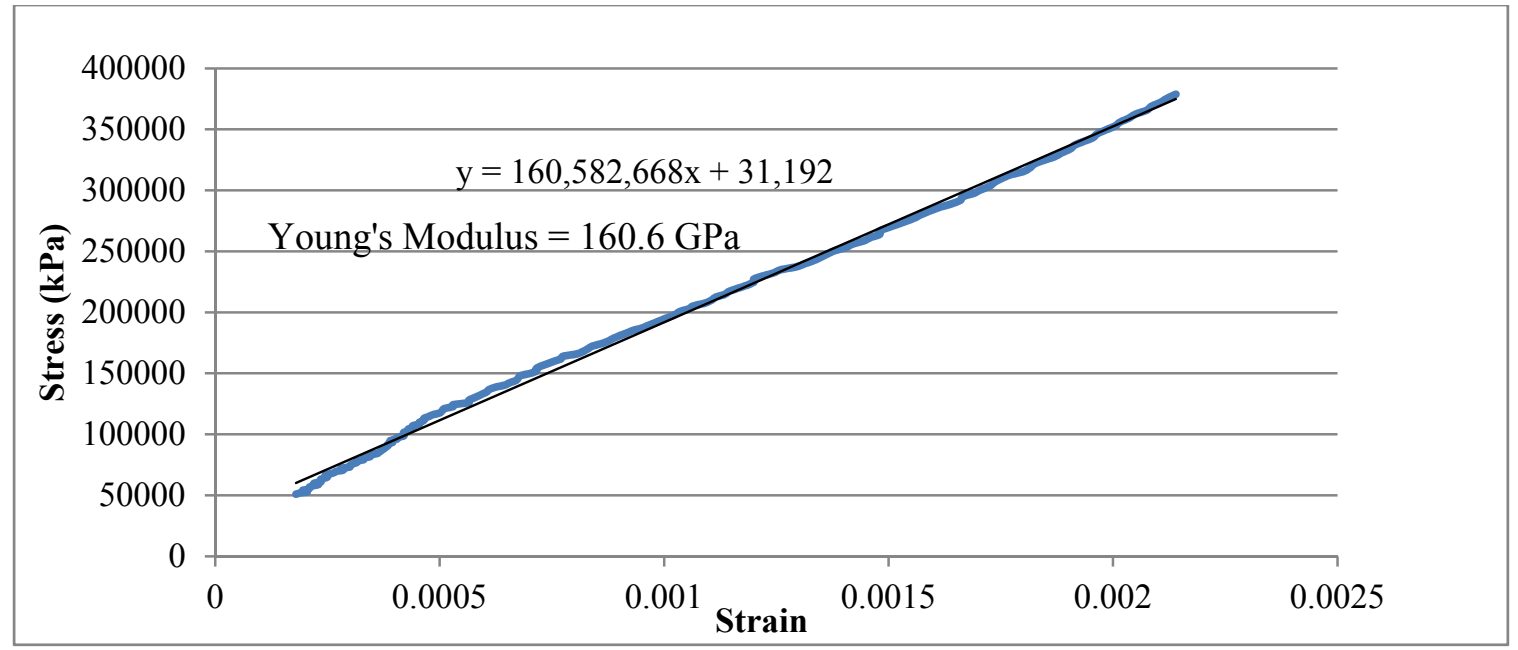

Figure A.16 Stress versus Strain - Test 8 (16mm Rebar)

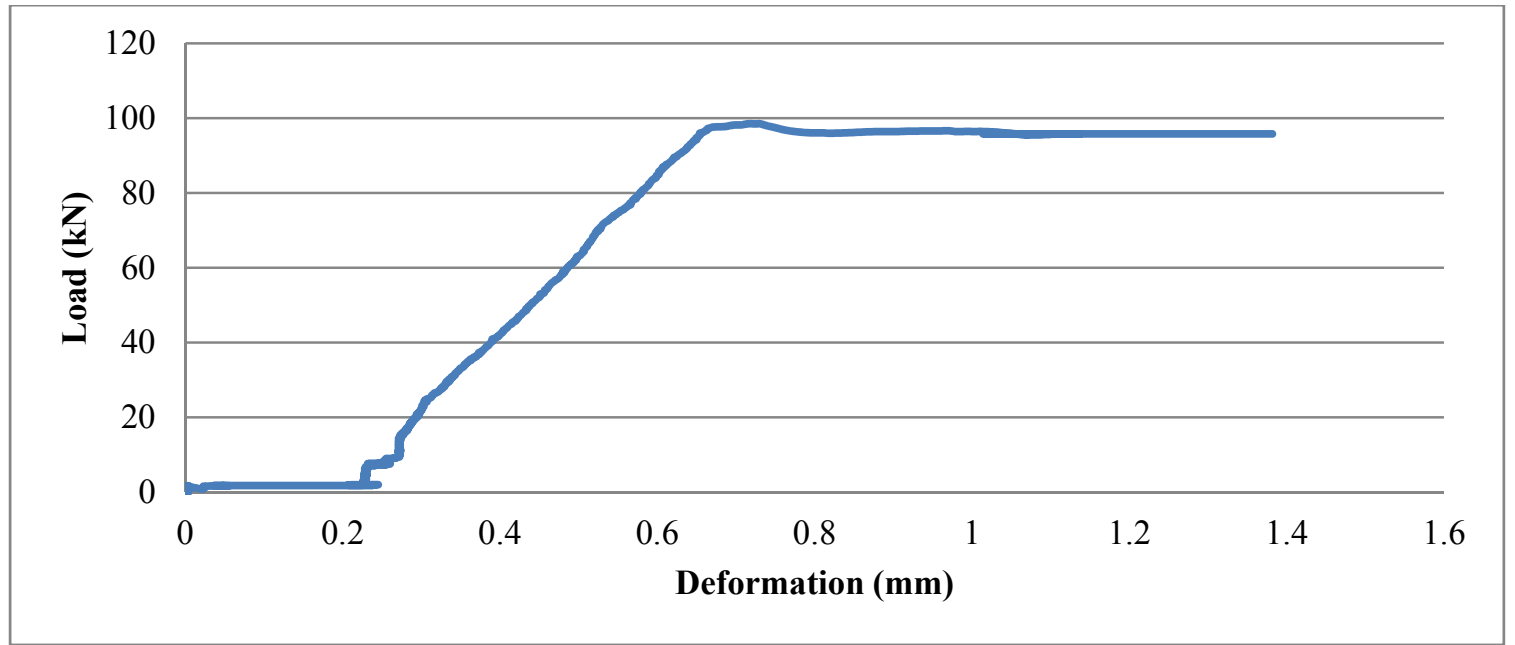

Figure A.17 Load versus Deformation - Test 9 (16mm Rebar) 


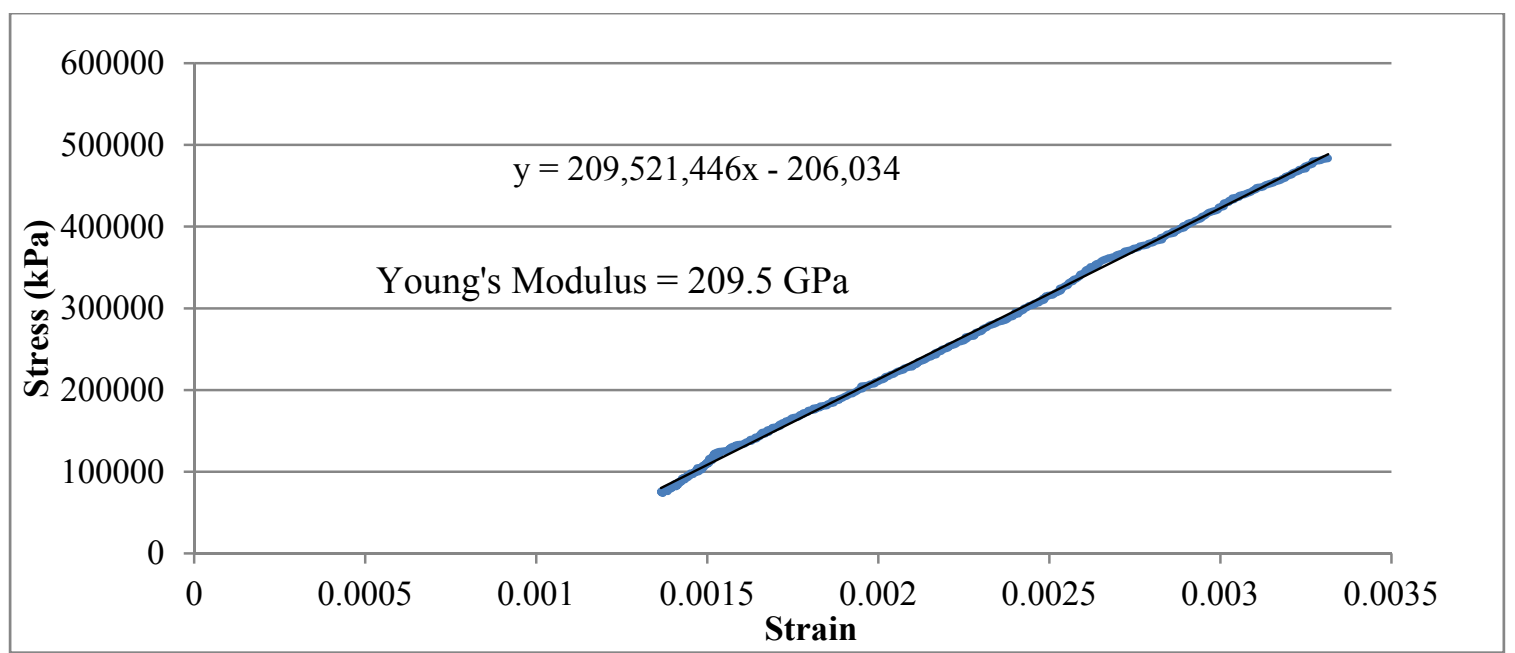

Figure A.18 Stress versus Strain - Test 9 (16mm Rebar)

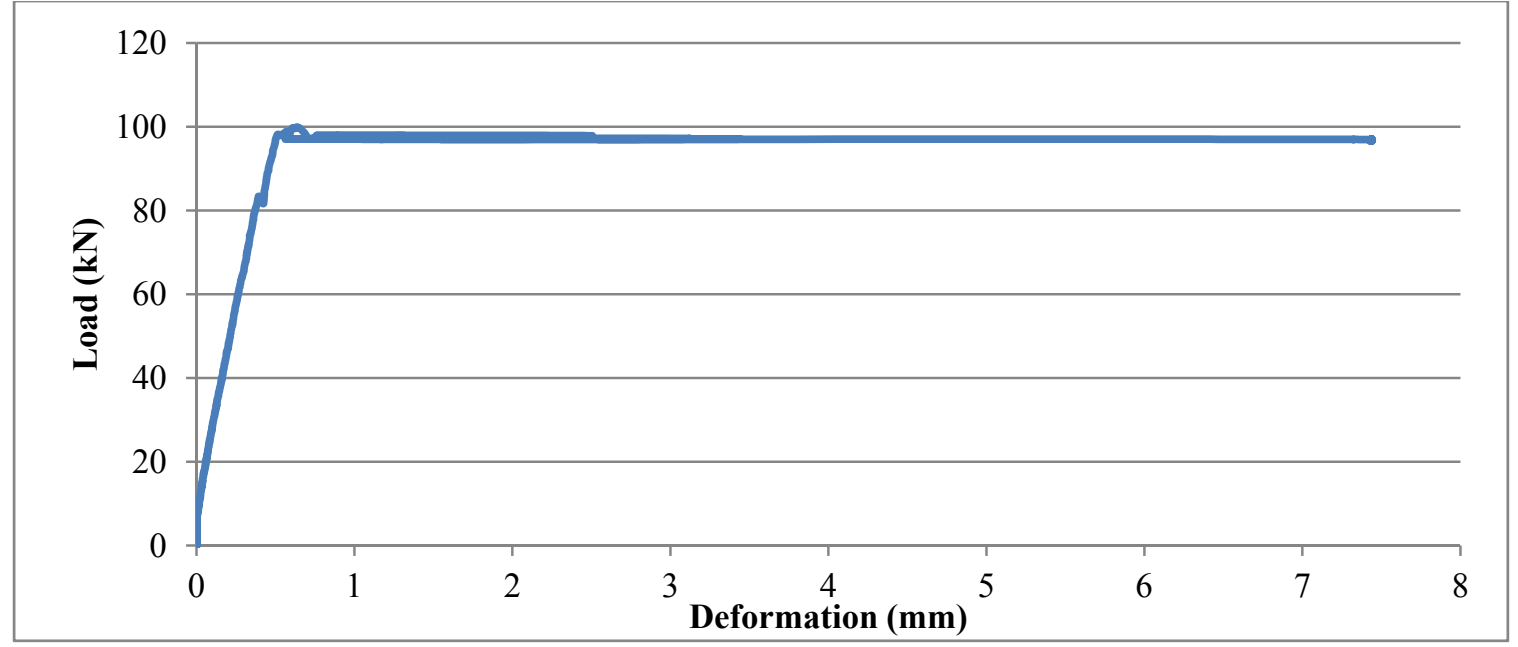

Figure A.19 Load versus Deformation - Test 10 (16mm Rebar)

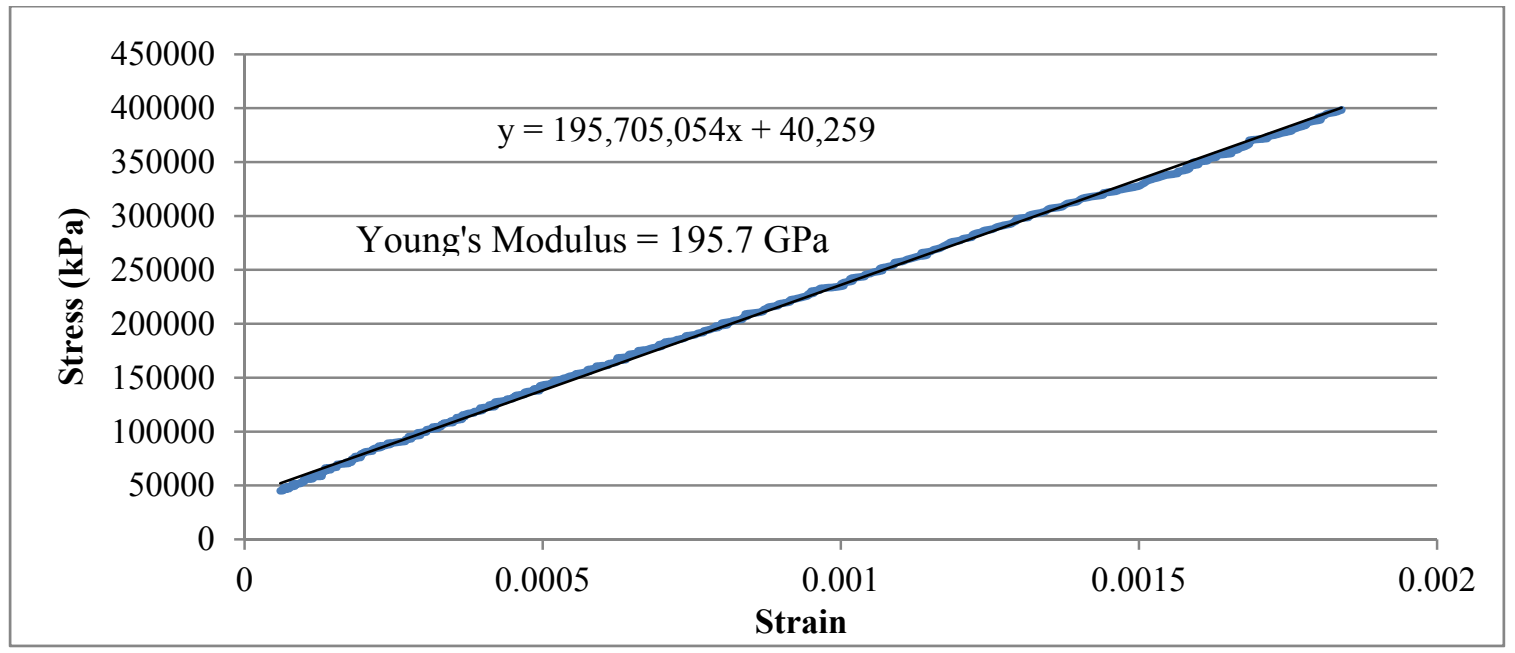

Figure A.20 Stress Versus Strain - Test 10 (16mm Rebar) 


\section{B. Raw Data from Laboratory Tests for Rock Properties}

This appendix includes the raw data collected from each of the laboratory tests completed on core samples taken from the Allan mine. UCS, tensile strength, and shear strength test results are listed in the following tables and figures.

\section{UCS Testing Results}

Included in the following are the tabulated results for each UCS test conducted. Tables B.1 and B.2 show the raw data from the potash and halite tests respectively. The following figures show stress versus strain plots from both potash and halite core taken from the Allan mine. Strain is shown in terms of axial, lateral, and volumetric on each plot.

Potash UCS Data

Table B.1 Raw Data from Potash UCS Tests

\begin{tabular}{|l|lllccc|}
\hline $\begin{array}{l}\text { Sample } \\
\text { No. }\end{array}$ & $\begin{array}{l}\text { Length } \\
(\mathbf{m m})\end{array}$ & $\begin{array}{l}\text { Diameter } \\
(\mathbf{m m})\end{array}$ & $\begin{array}{l}\text { Density } \\
(\mathbf{g} / \mathbf{c c})\end{array}$ & $\begin{array}{l}\text { UCS } \\
\text { (MPa) }\end{array}$ & $\begin{array}{l}\text { Young's } \\
\text { Modulus } \\
\text { (GPa) }\end{array}$ & $\begin{array}{l}\text { Poisson's } \\
\text { Ratio }\end{array}$ \\
\hline P8 & 176.55 & 70.37 & 2.12 & 27.6 & 2.9 & 0.24 \\
P11 & 171.78 & 70.75 & 2.10 & 24.2 & 2.8 & 0.27 \\
P13A & 159.3 & 70.91 & 2.11 & 27.6 & 3.0 & 0.25 \\
P13B & 159.05 & 70.77 & 2.08 & 23.2 & 3.4 & 0.27 \\
P32 & 171.44 & 70.71 & 2.12 & 24.1 & 3.1 & 0.3 \\
P33A & 174.29 & 70.48 & 2.13 & 29.0 & 2.6 & 0.32 \\
P33B & 169.92 & 70.54 & 2.08 & 22.4 & 3.4 & 0.36 \\
P37 & 171.77 & 70.35 & 2.12 & 23.7 & 1.9 & 0.27 \\
P38A & 174.26 & 70.69 & 2.11 & 28.4 & 2.5 & 0.33 \\
P38B & 169.42 & 70.07 & 2.09 & 24.0 & 2.6 & 0.35 \\
\hline Average: & 169.78 & 70.56 & 2.11 & $\mathbf{2 5 . 4}$ & $\mathbf{2 . 8}$ & $\mathbf{0 . 3 0}$ \\
& & Standard Deviation: & $\mathbf{2 . 4 4}$ & $\mathbf{0 . 4 5}$ & $\mathbf{0 . 0 4}$ \\
\hline
\end{tabular}




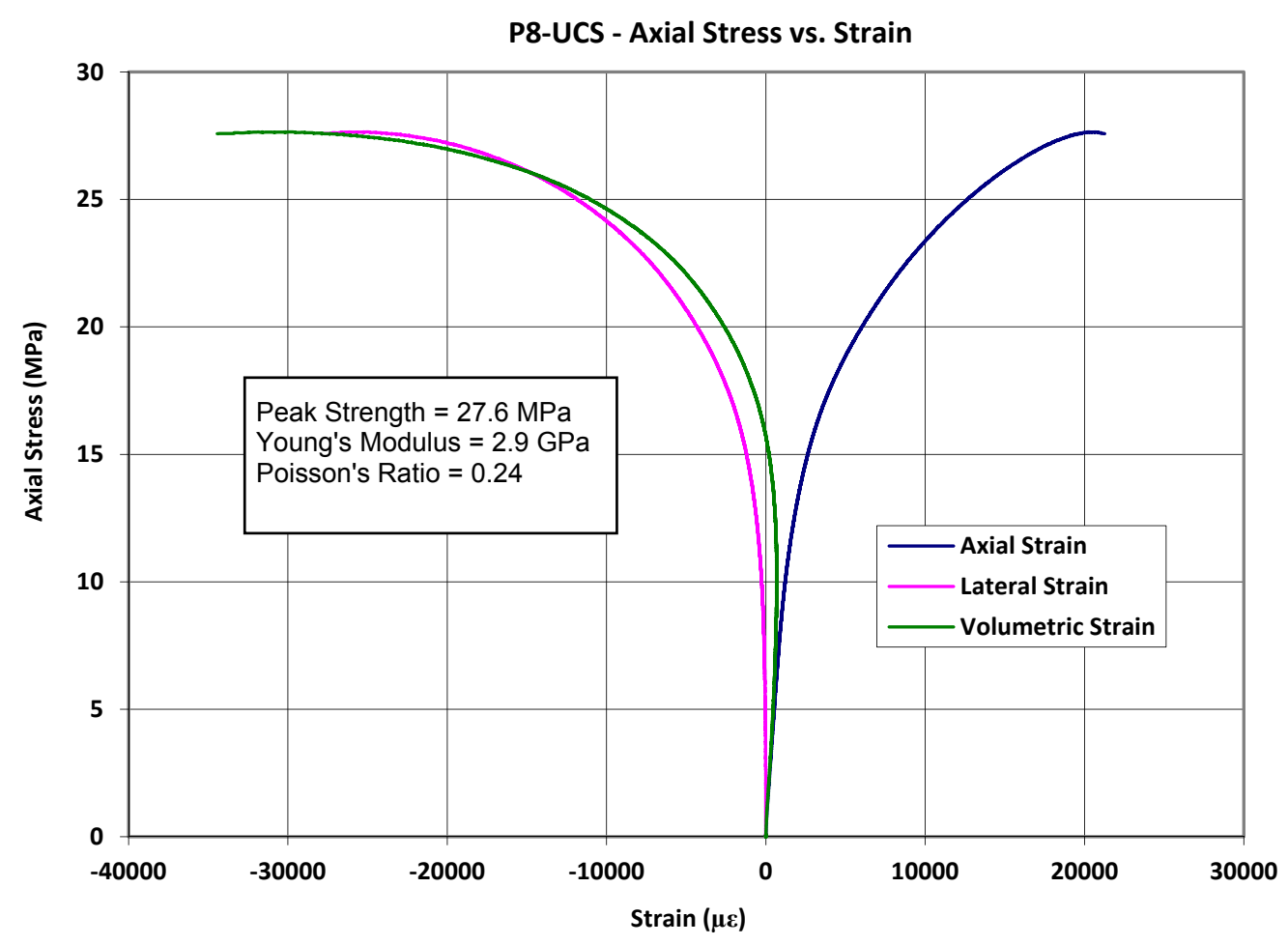

Figure B.1 Potash Sample "P8" Stress vs. Strain Plot from UCS Test

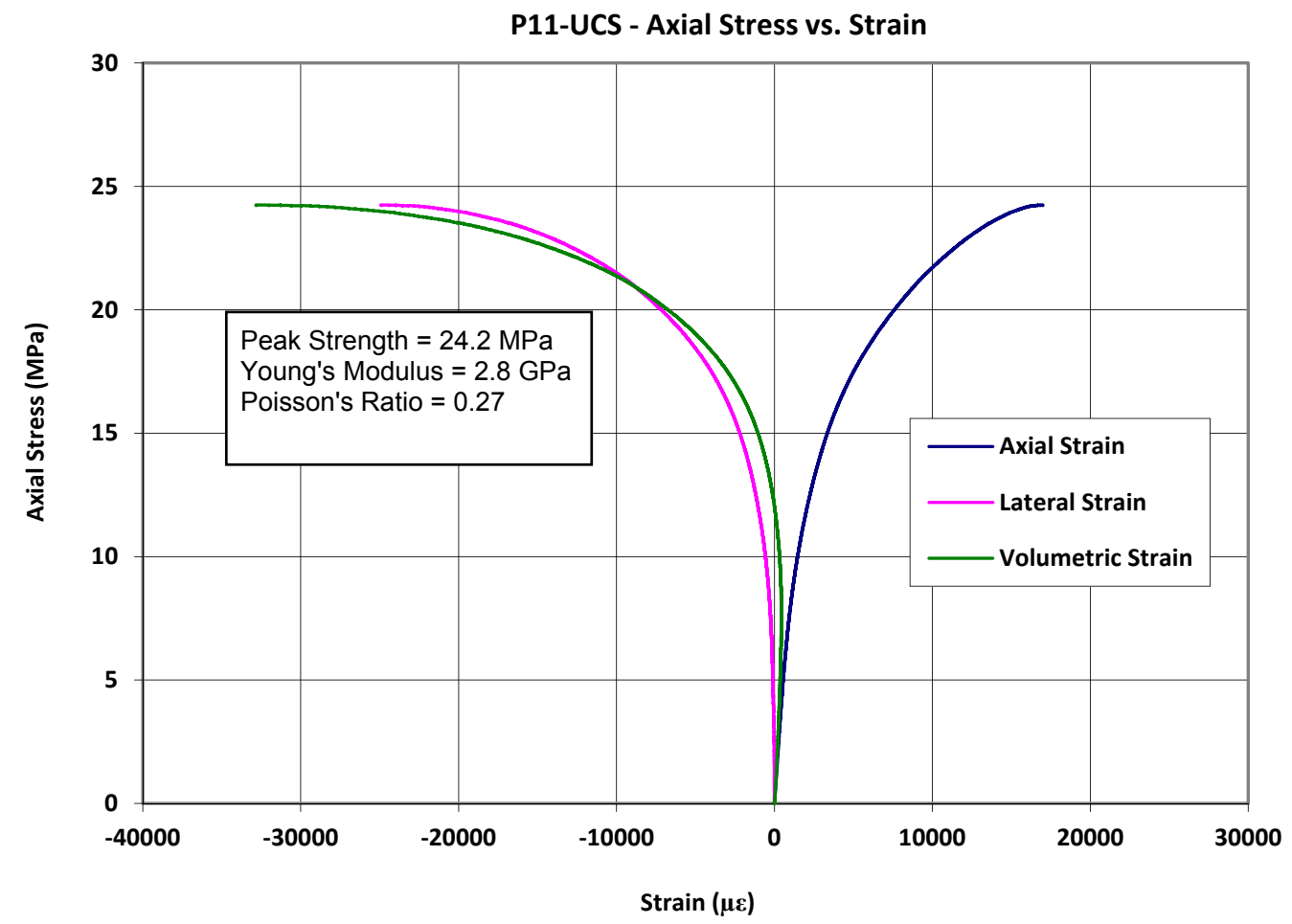

Figure B.2 Potash Sample "P11" Stress vs. Strain Plot from UCS Test 


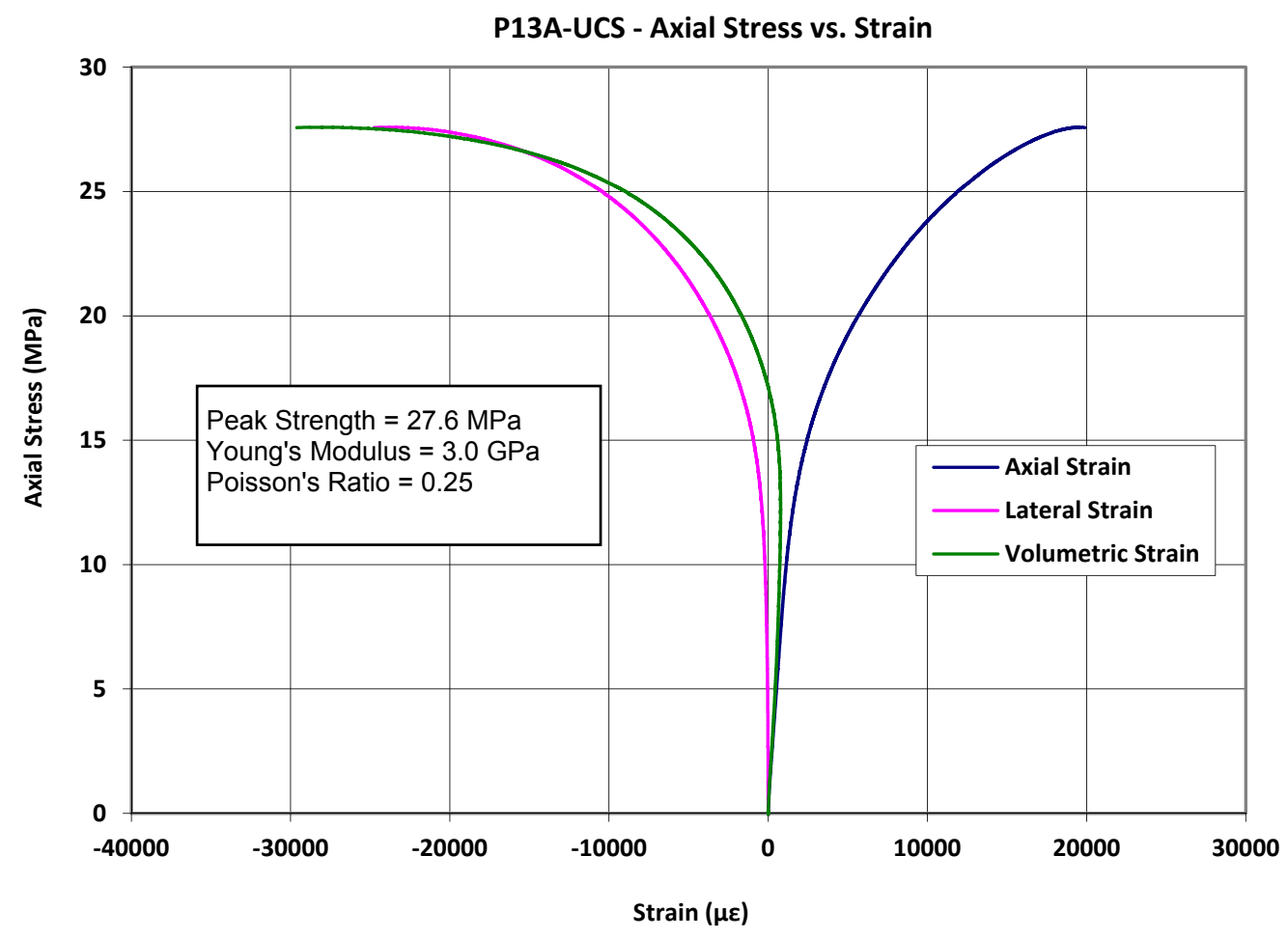

Figure B.3 Potash Sample "P13A" Stress vs. Strain Plot from UCS Test

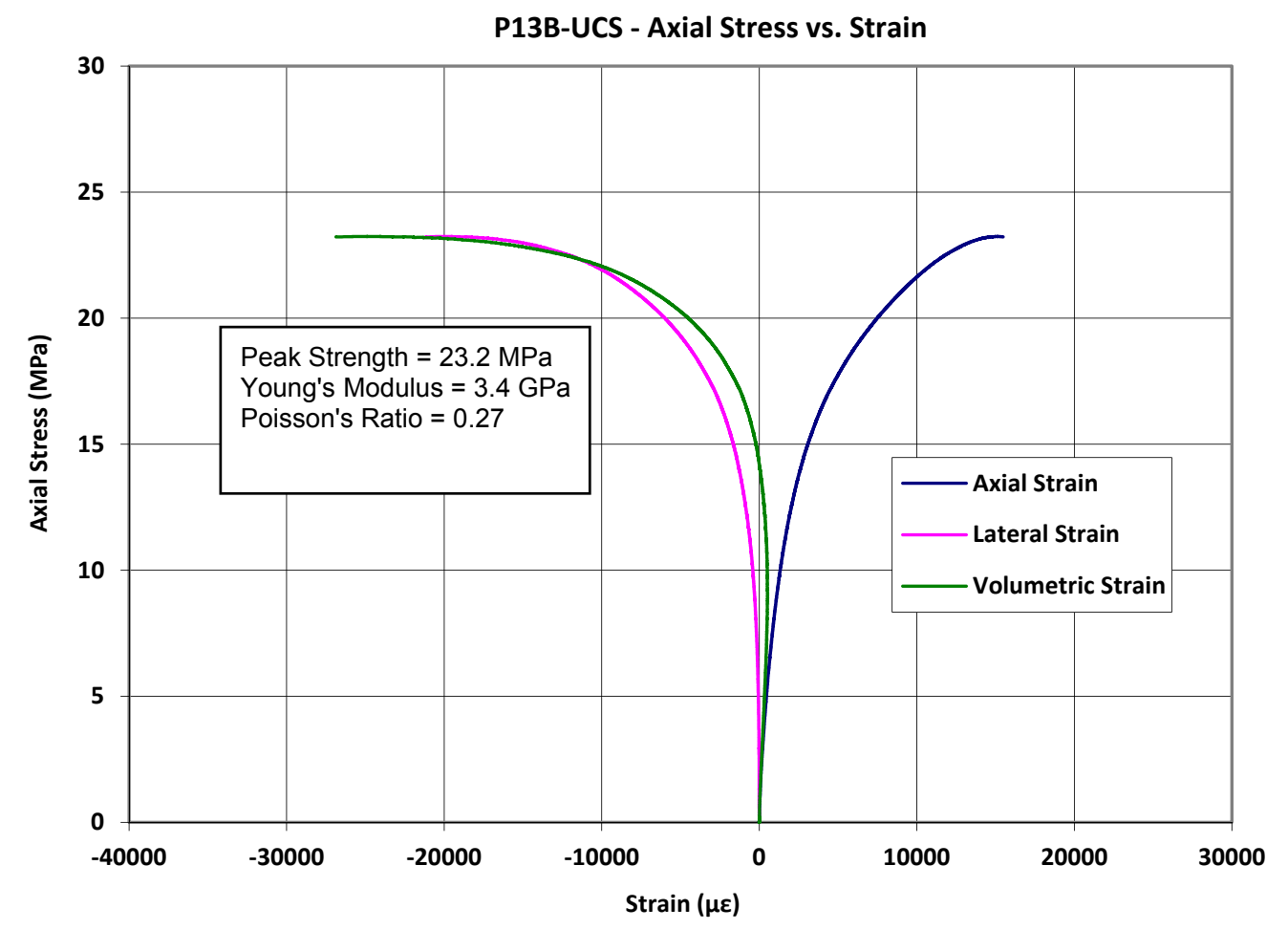

Figure B.4 Potash Sample "P13B" Stress vs. Strain Plot from UCS Test 


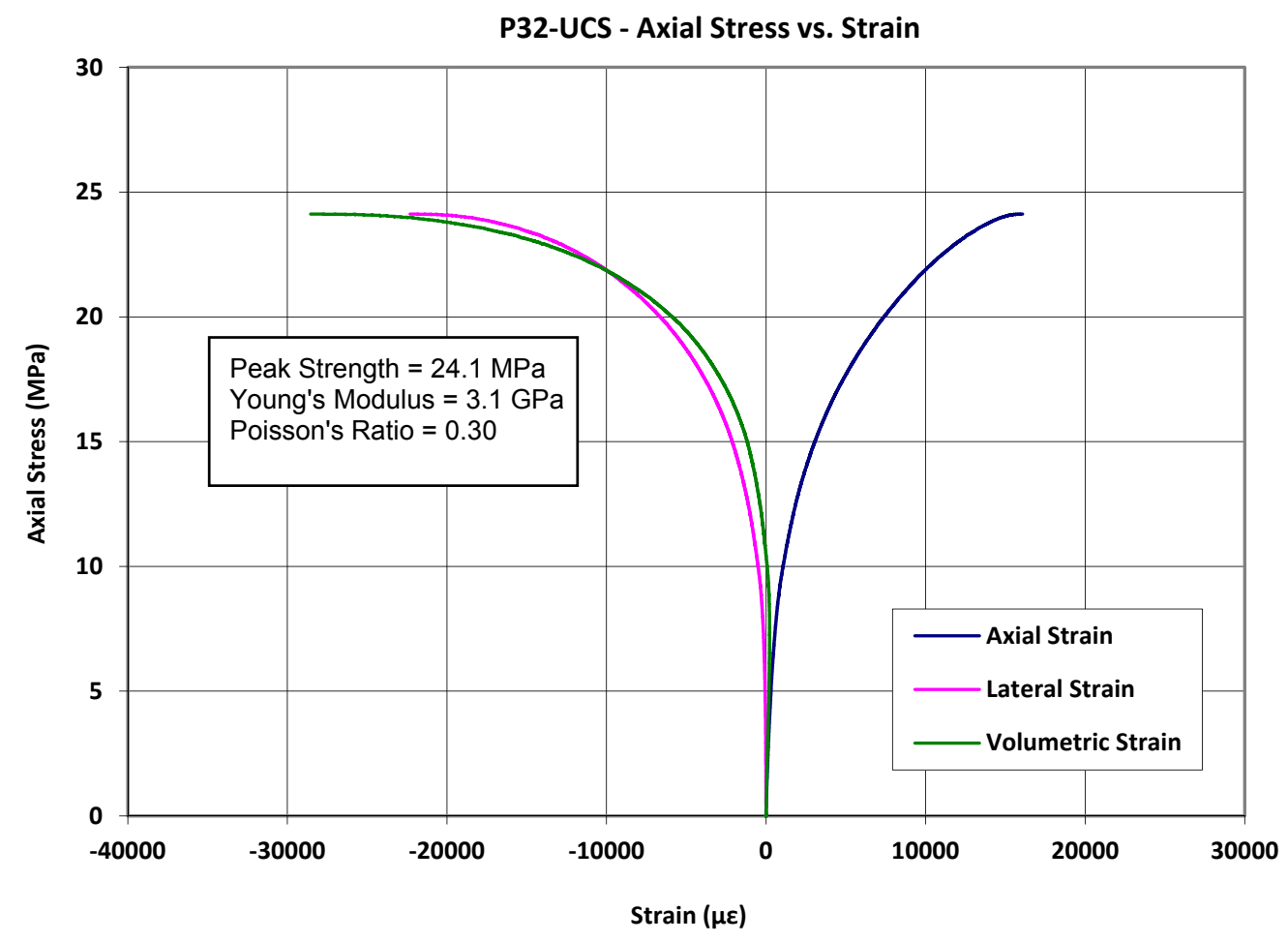

Figure B.5 Potash Sample "P32" Stress vs. Strain Plot from UCS Test

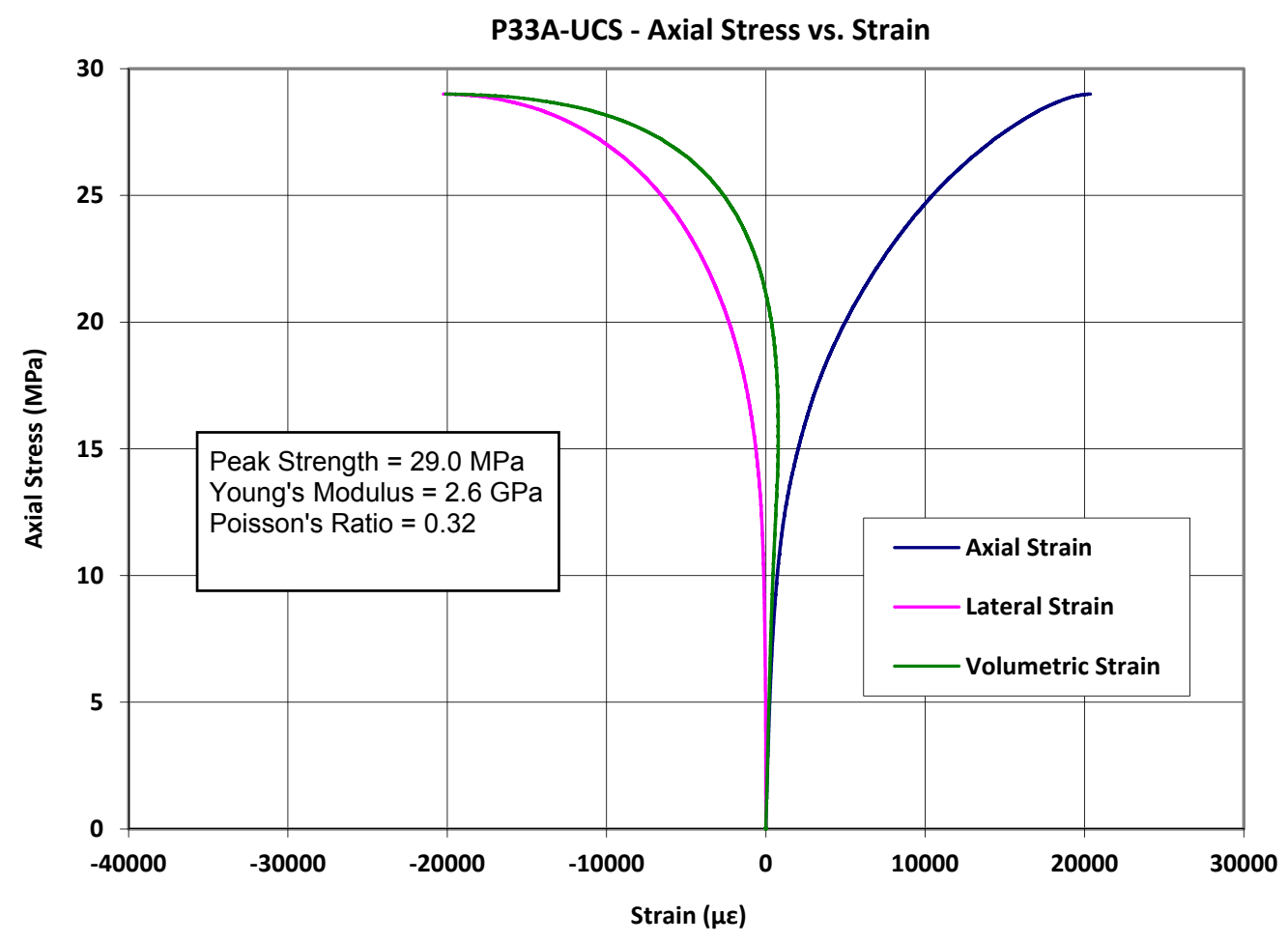

Figure B.6 Potash Sample "P33A" Stress vs. Strain Plot from UCS Test 


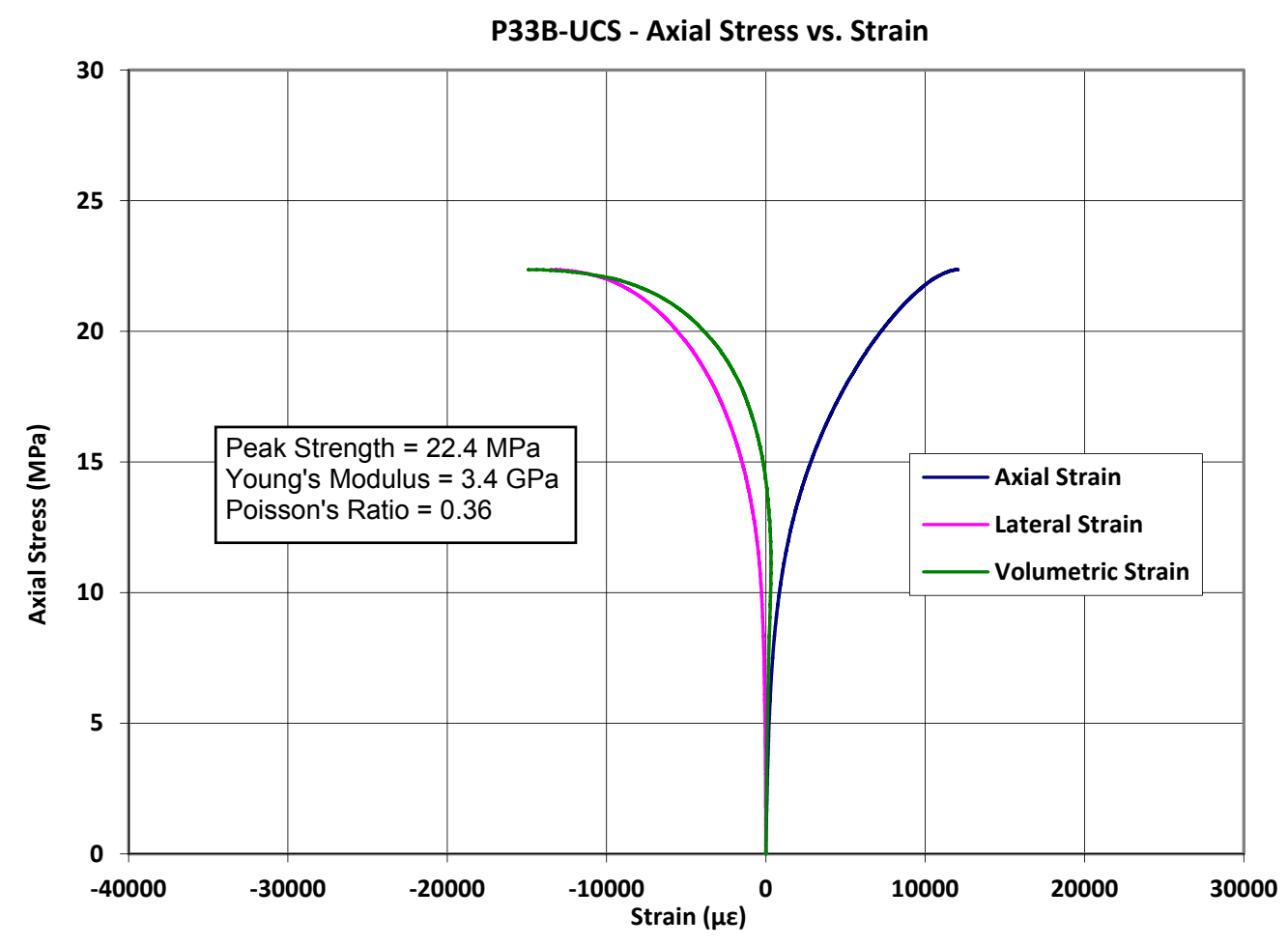

Figure B.7 Potash Sample "P33B" Stress vs. Strain Plot from UCS Test

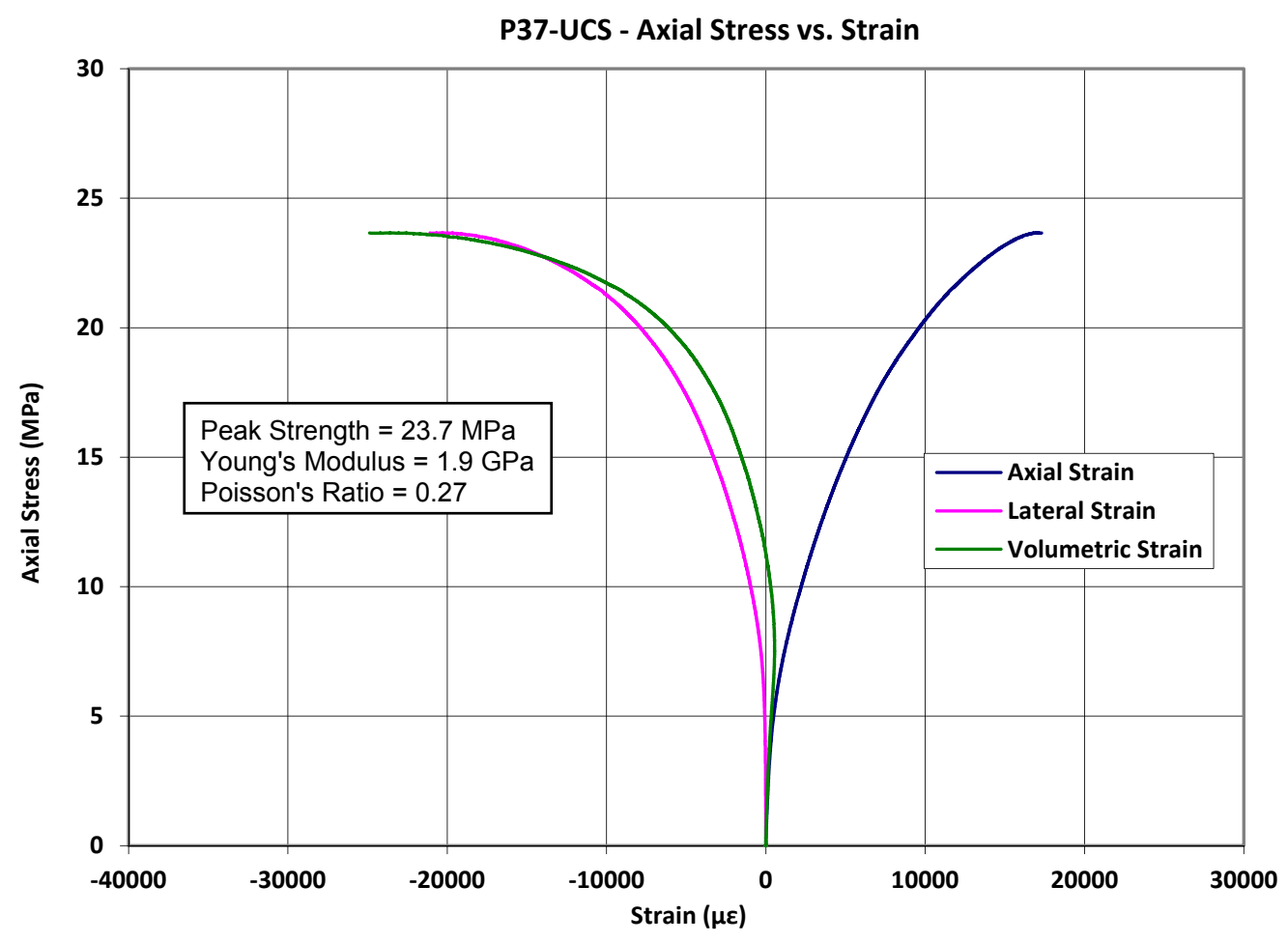

Figure B.8 Potash Sample "P37" Stress vs. Strain Plot from UCS Test 


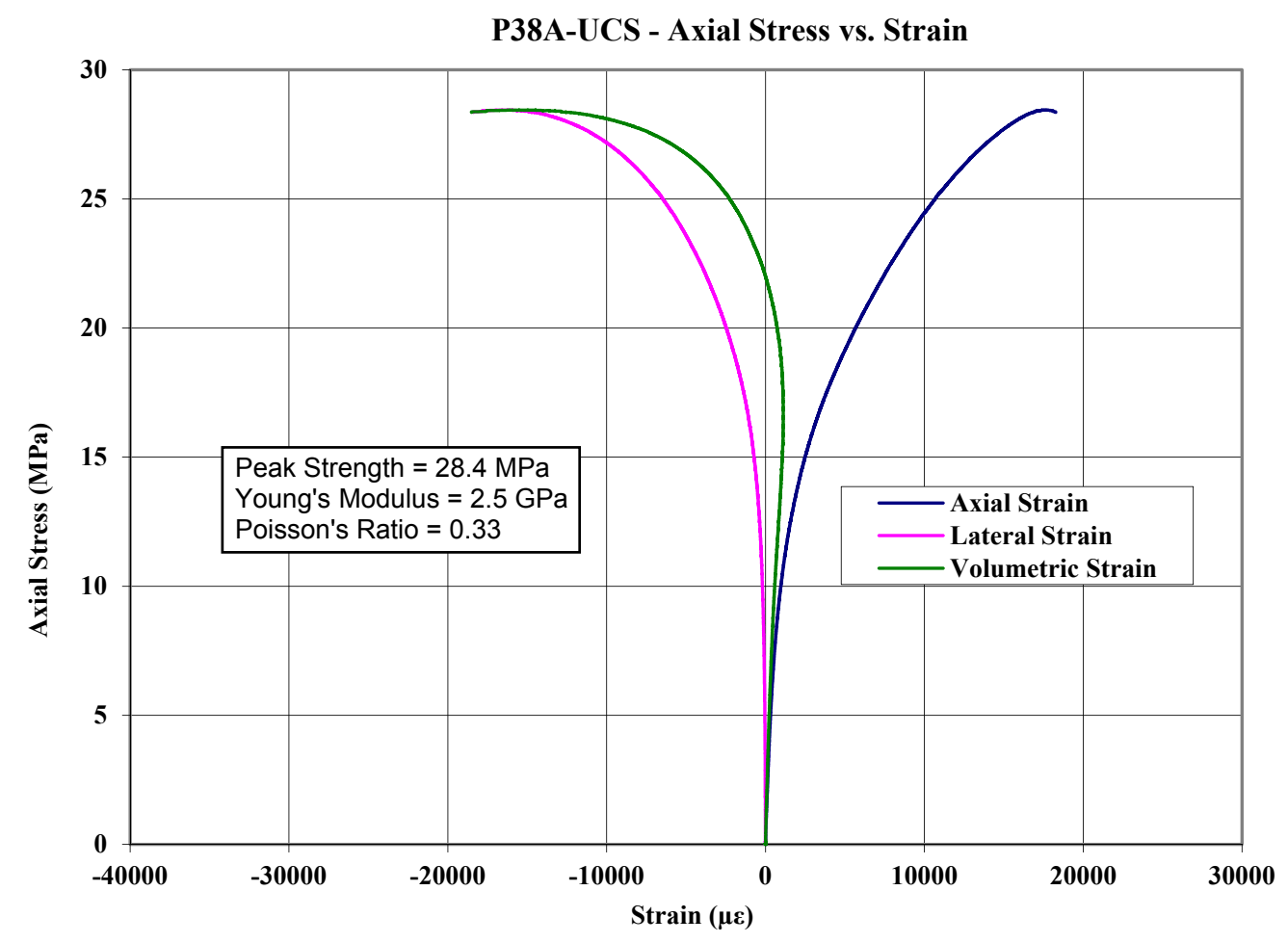

Figure B.9 Potash Sample "P38A" Stress vs. Strain Plot from UCS Test

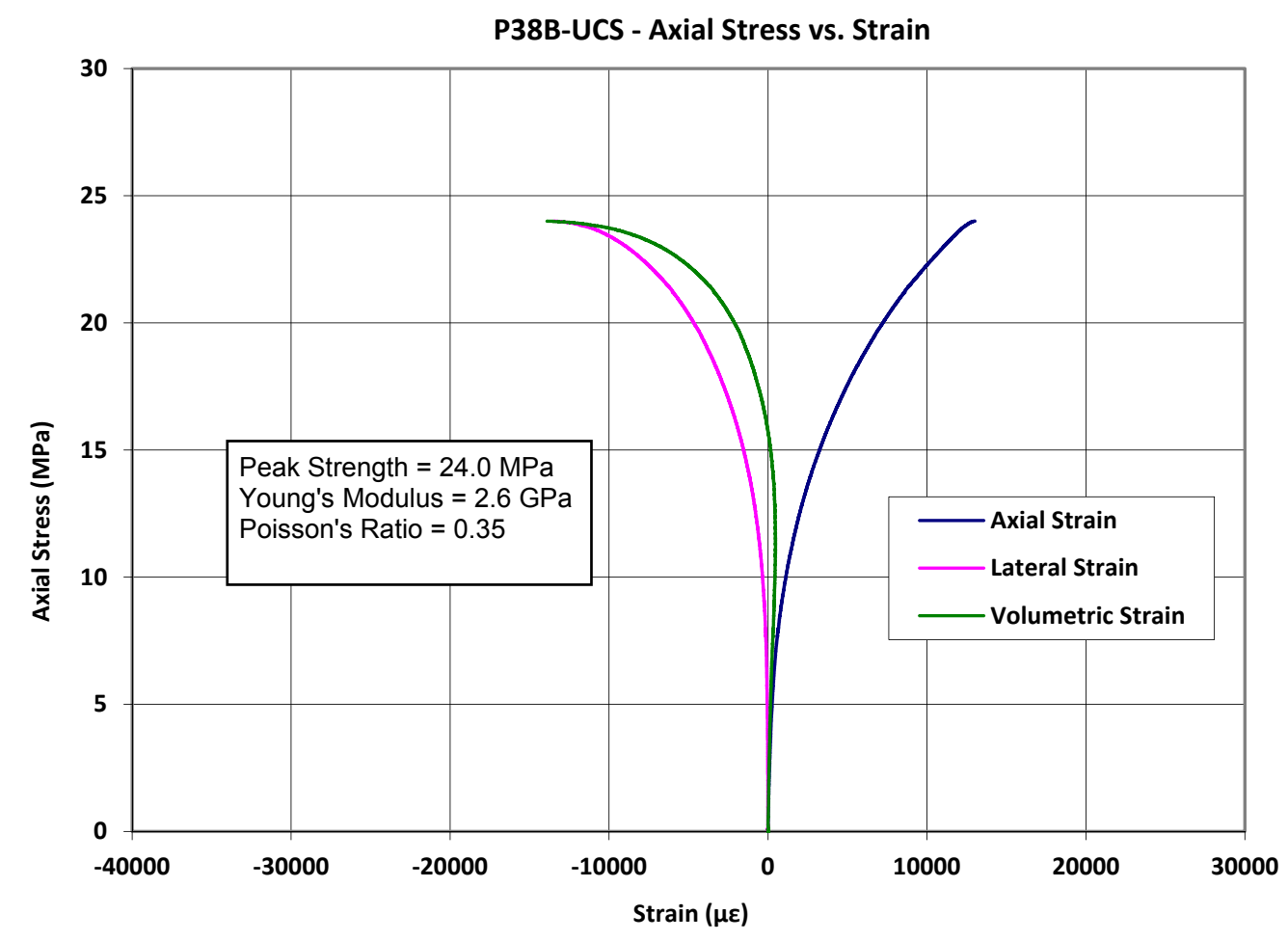

Figure B.10 Potash Sample "P38B" Stress vs. Strain from UCS Test 
Halite UCS Data

Table B.2 Raw Data from Halite UCS Tests

\begin{tabular}{|l|llcccc|}
\hline $\begin{array}{l}\text { Sample } \\
\text { No. }\end{array}$ & $\begin{array}{l}\text { Length } \\
(\mathbf{m m})\end{array}$ & $\begin{array}{l}\text { Diameter } \\
(\mathbf{m m})\end{array}$ & $\begin{array}{l}\text { Density } \\
(\mathbf{g} / \mathbf{c c})\end{array}$ & $\begin{array}{l}\text { UCS } \\
(\mathbf{M P a})\end{array}$ & $\begin{array}{l}\text { Young's } \\
\text { Modulus } \\
(\mathbf{G P a})\end{array}$ & $\begin{array}{l}\text { Poisson's } \\
\text { Ratio }\end{array}$ \\
\hline S2A & 156.94 & 69.88 & 2.17 & 21.1 & 5.6 & 0.28 \\
S15 & 160.89 & 69.93 & 2.15 & 23.1 & 7.1 & 0.27 \\
S2B & 162.62 & 69.89 & 2.14 & 19.3 & 6.7 & - \\
S4B & 154.88 & 69.67 & 2.12 & 22.1 & 7.3 & 0.29 \\
S4A & 159.42 & 69.83 & 2.20 & 21.5 & 4.4 & 0.24 \\
S3 & 145.75 & 68.92 & 2.19 & 20.2 & 7.2 & 0.25 \\
S35 & 167.68 & 69.08 & 2.14 & 19.2 & 4.9 & 0.26 \\
S4C & 156.73 & 69.88 & 2.17 & 20.9 & 8.6 & 0.39 \\
S6A & 173.29 & 70.27 & 2.19 & 24.5 & 6.5 & 0.3 \\
S6B & 167.68 & 69.73 & 2.16 & 24.7 & 4.2 & 0.26 \\
\hline Average: & 160.59 & 69.71 & 2.16 & $\mathbf{2 1 . 7}$ & $\mathbf{6 . 3}$ & $\mathbf{0 . 2 8}$ \\
& \multicolumn{7}{|c|}{ Standard Deviation: } & $\mathbf{1 . 9 5}$ & $\mathbf{1 . 4 3}$ & $\mathbf{0 . 0 4}$ \\
\hline
\end{tabular}

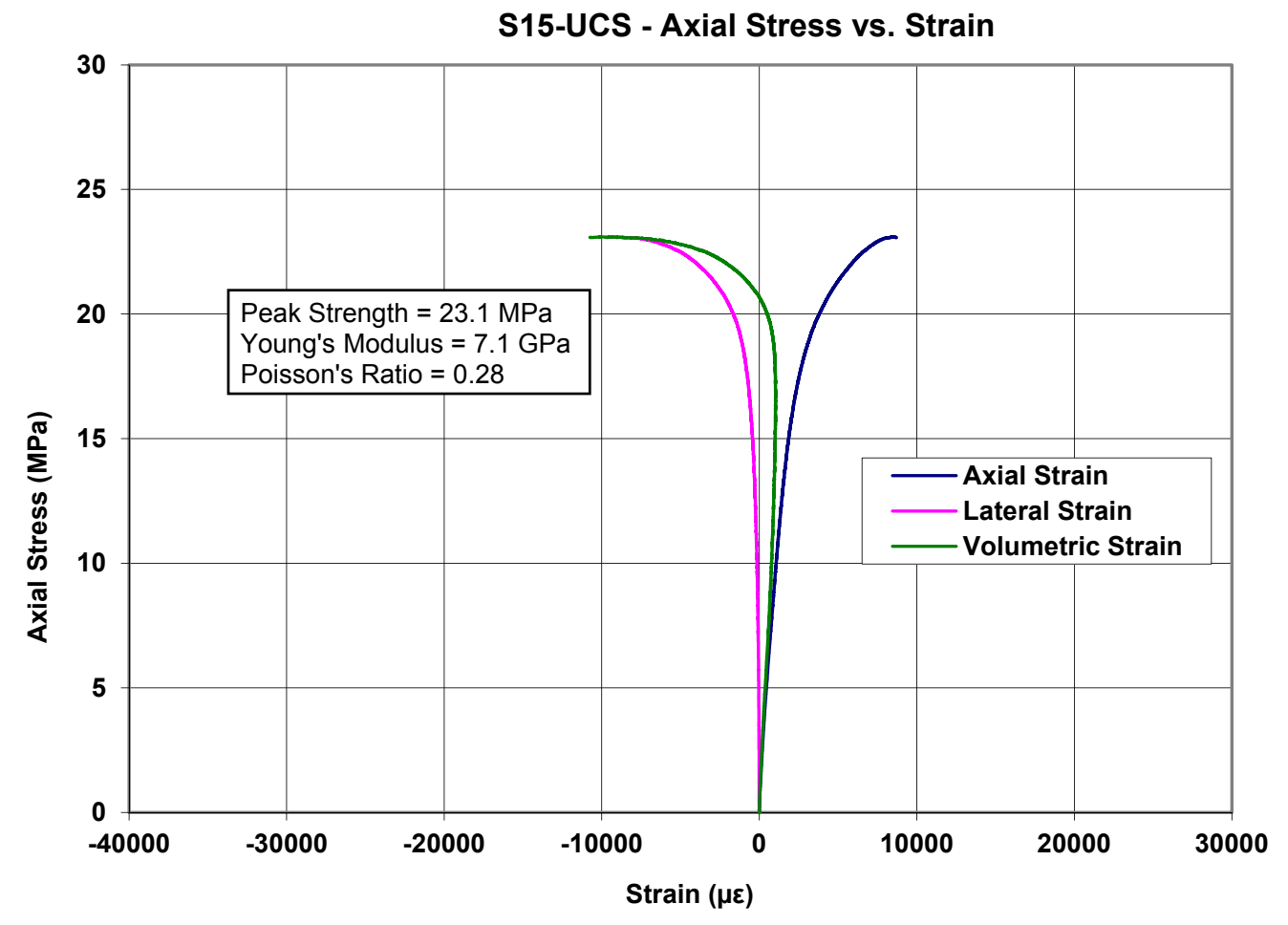

Figure B.11 Halite Sample "S15" Stress vs. Stain Plot from UCS Test 


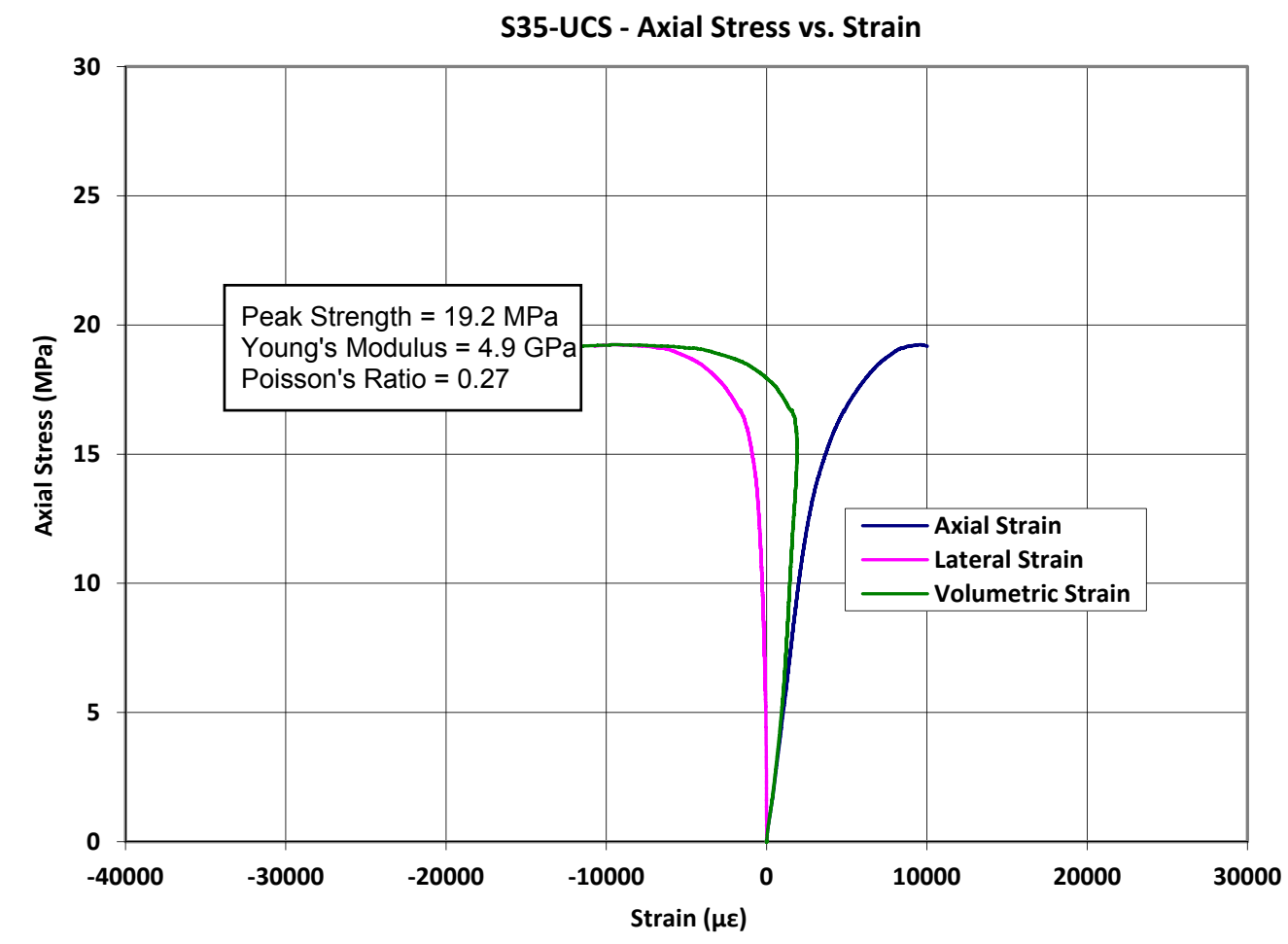

Figure B.12 Halite Sample "S35" Stress vs. Strain Plot from UCS Test

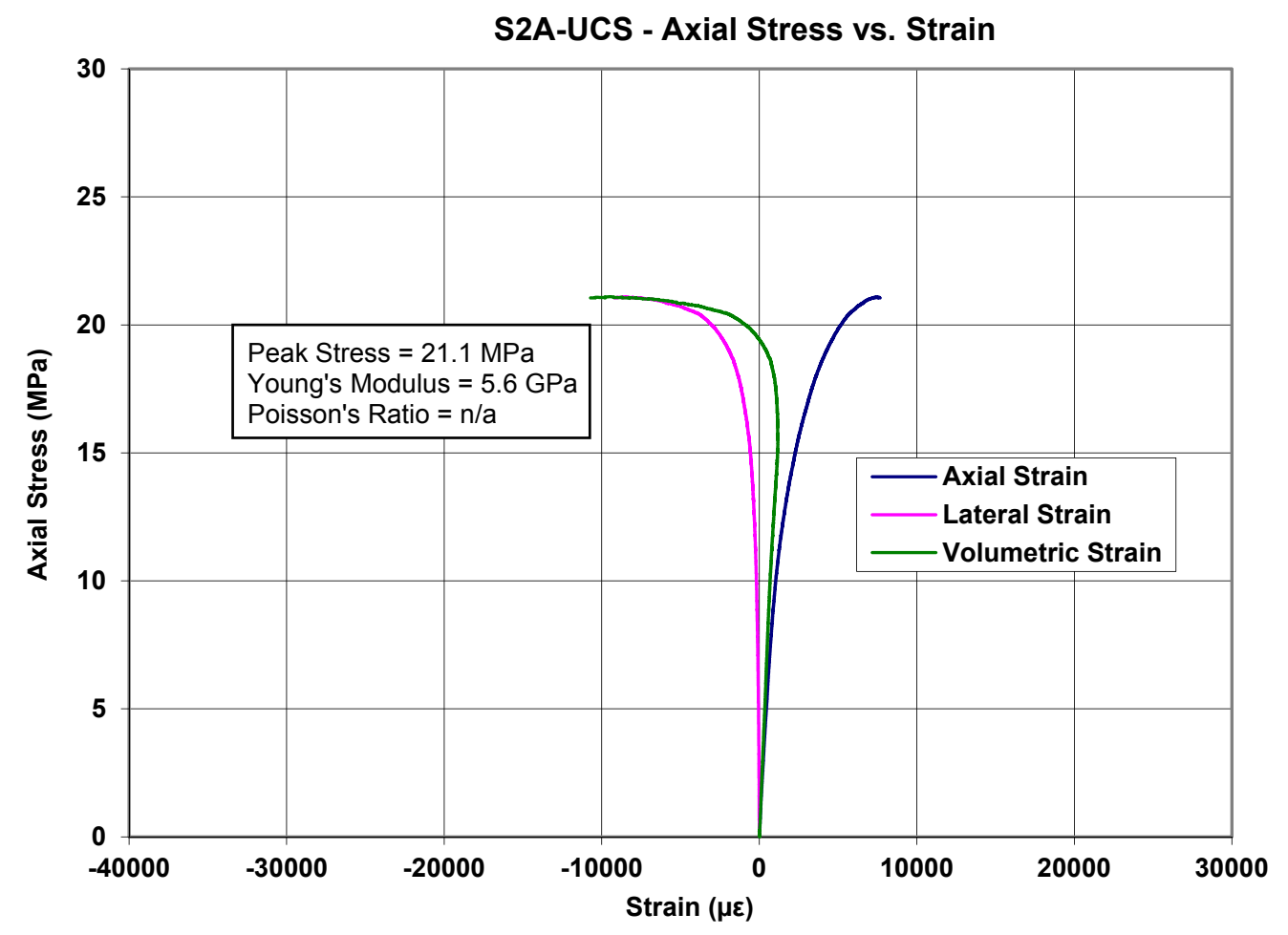

Figure B.13 Halite Sample "S2A" Stress vs. Strain Plot from UCS Test 


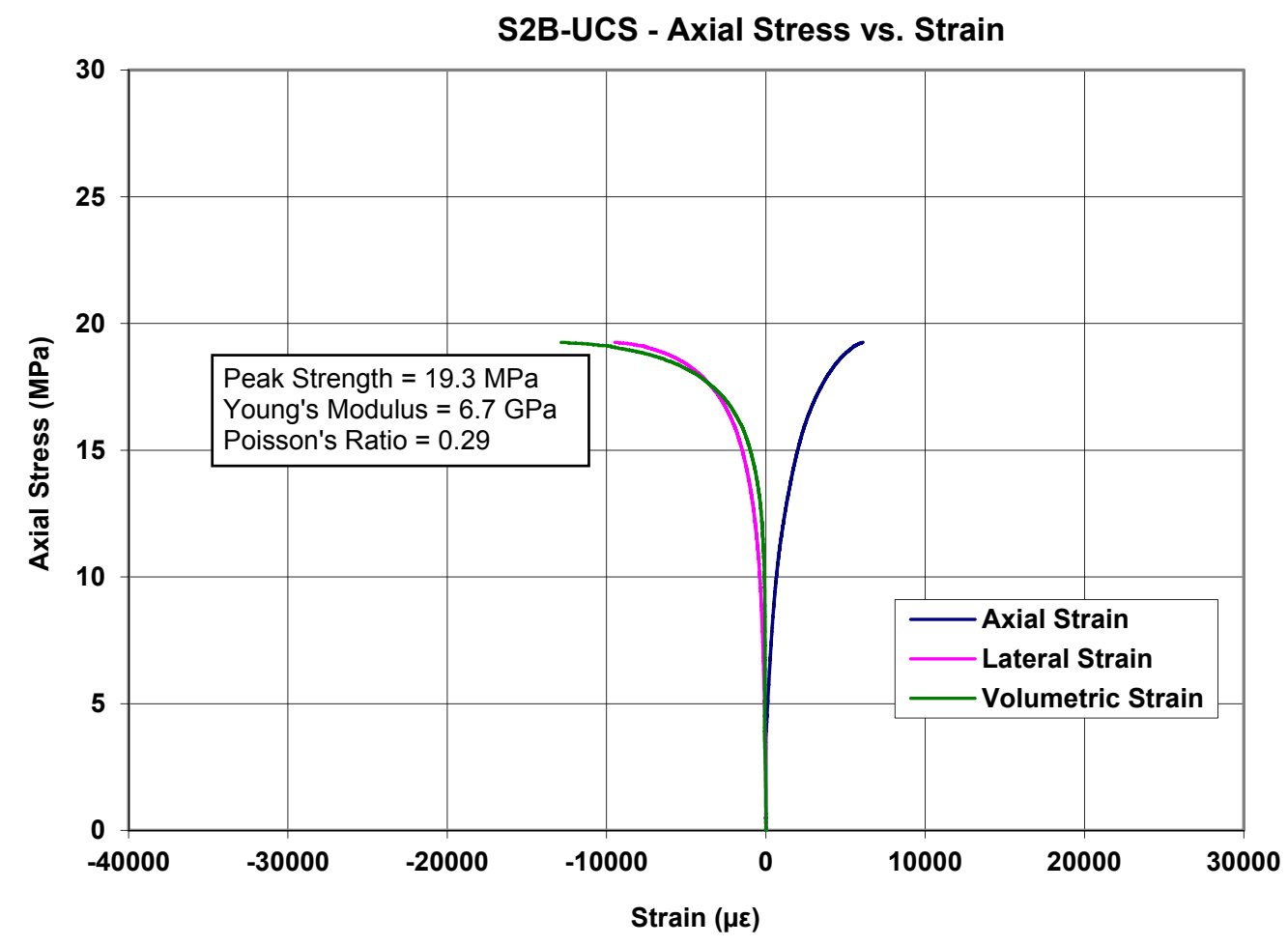

Figure B.14 Halite Sample "S2B" Stress vs. Strain Plot from UCS Test

S3-UCS - Axial Stress vs. Strain

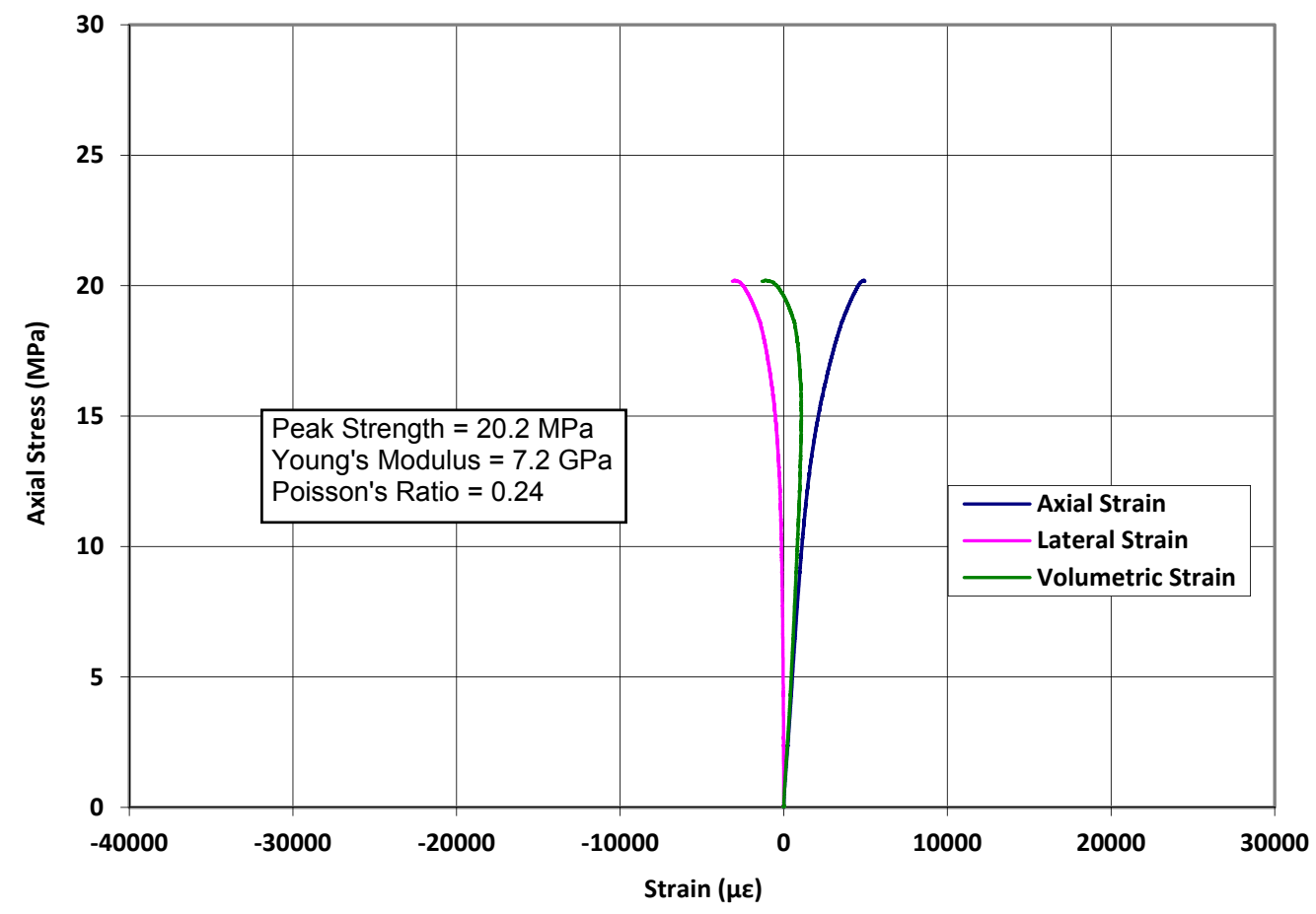

Figure B.15 Halite Sample "S3" Stress vs. Strain Plot from UCS Test 


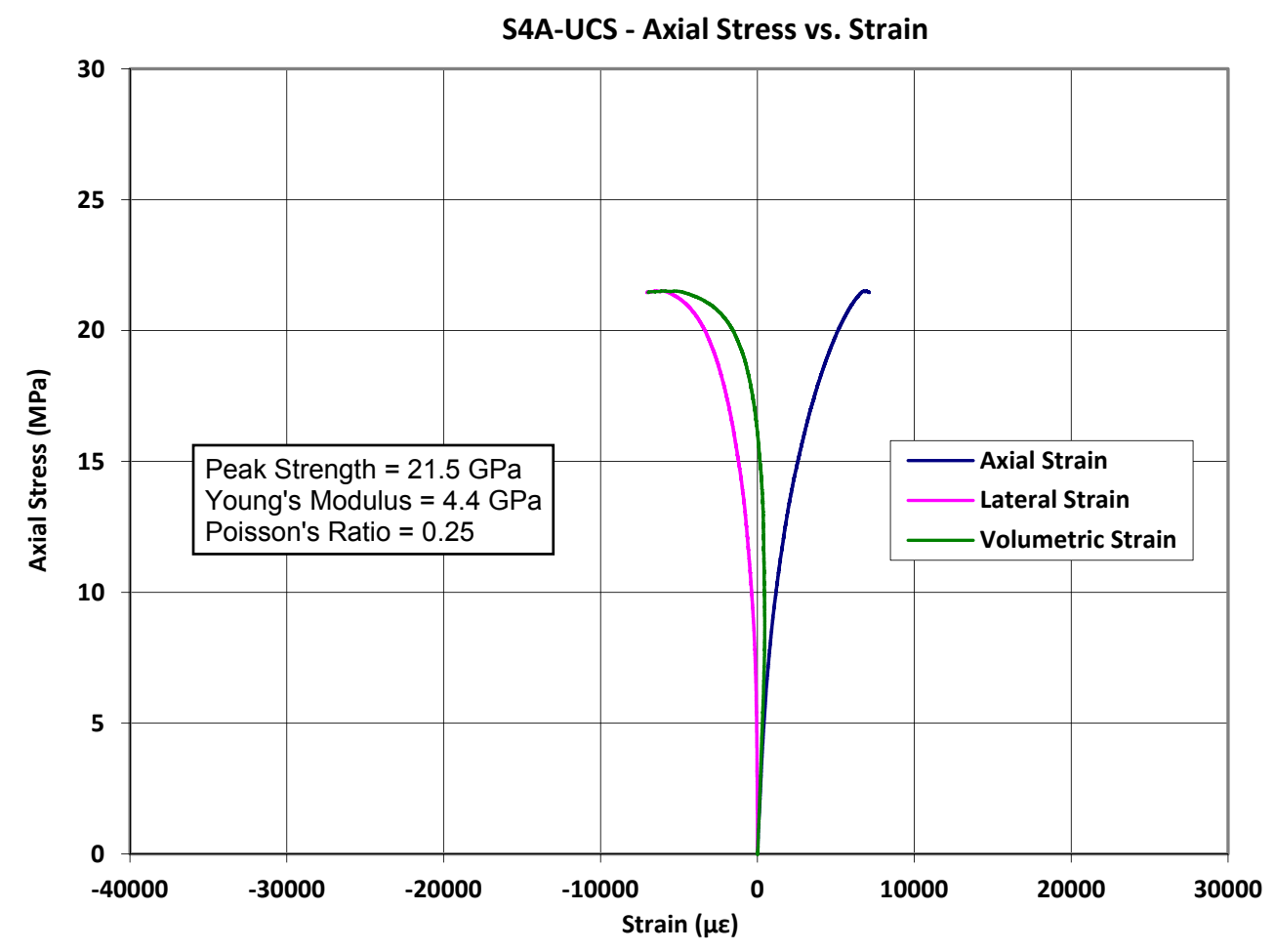

Figure B.16 Halite Sample "S4A" Stress vs. Strain Plot from UCS Test

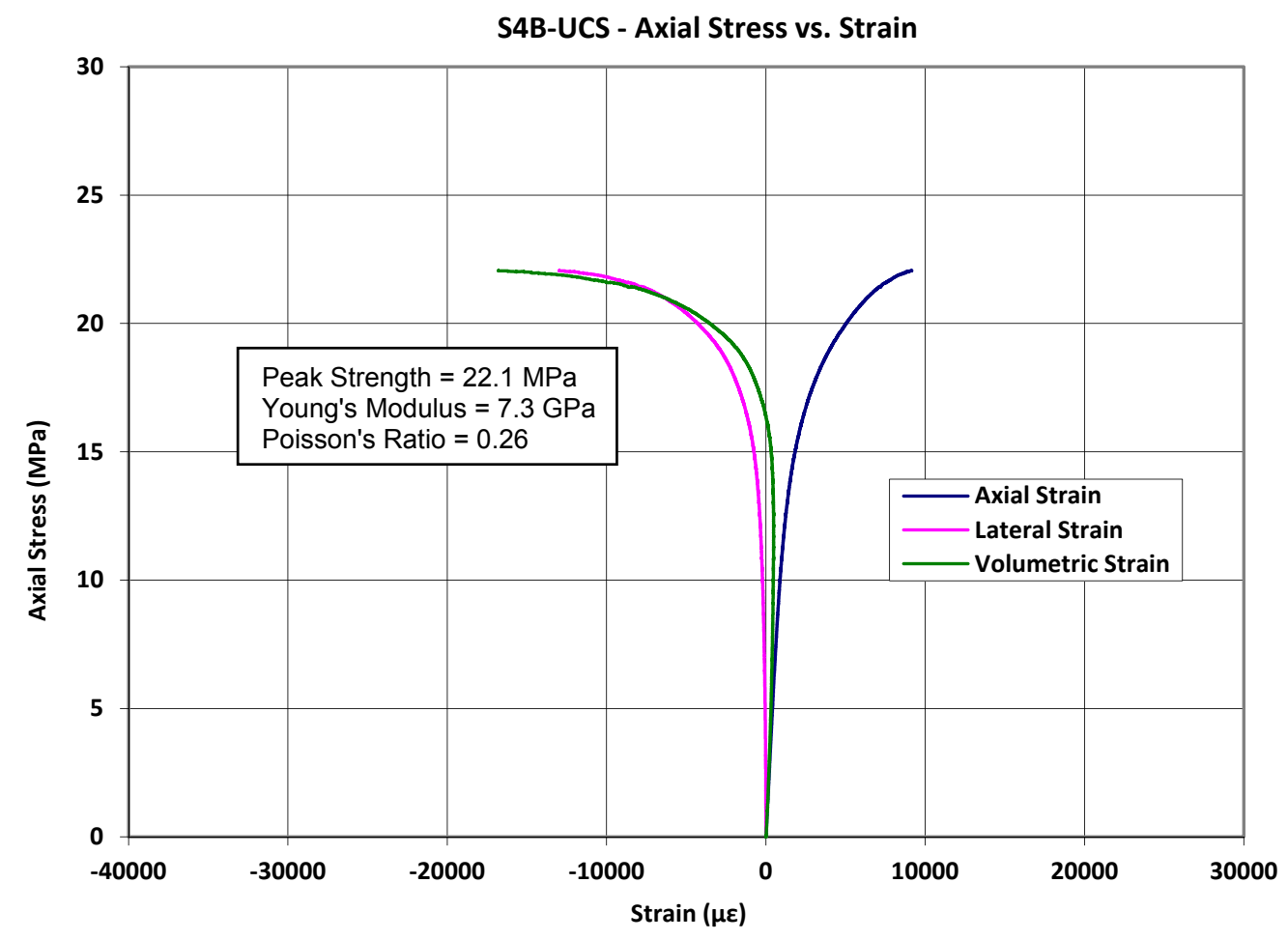

Figure B.17 Halite Sample "S4B" Stress vs. Strain Plot from UCS Test 


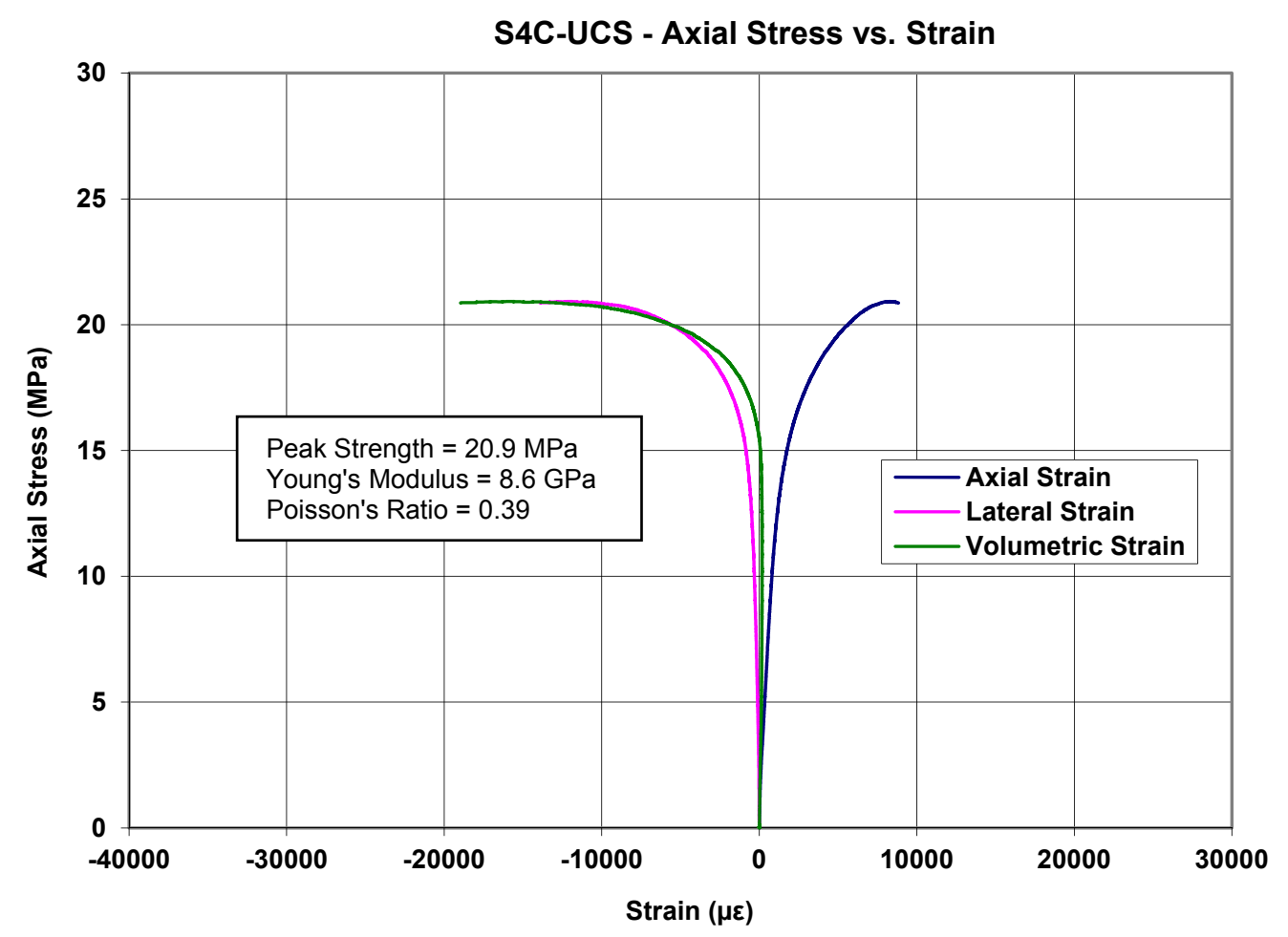

Figure B.18 Halite Sample "S4C" Stress vs. Strain Plot from UCS Test

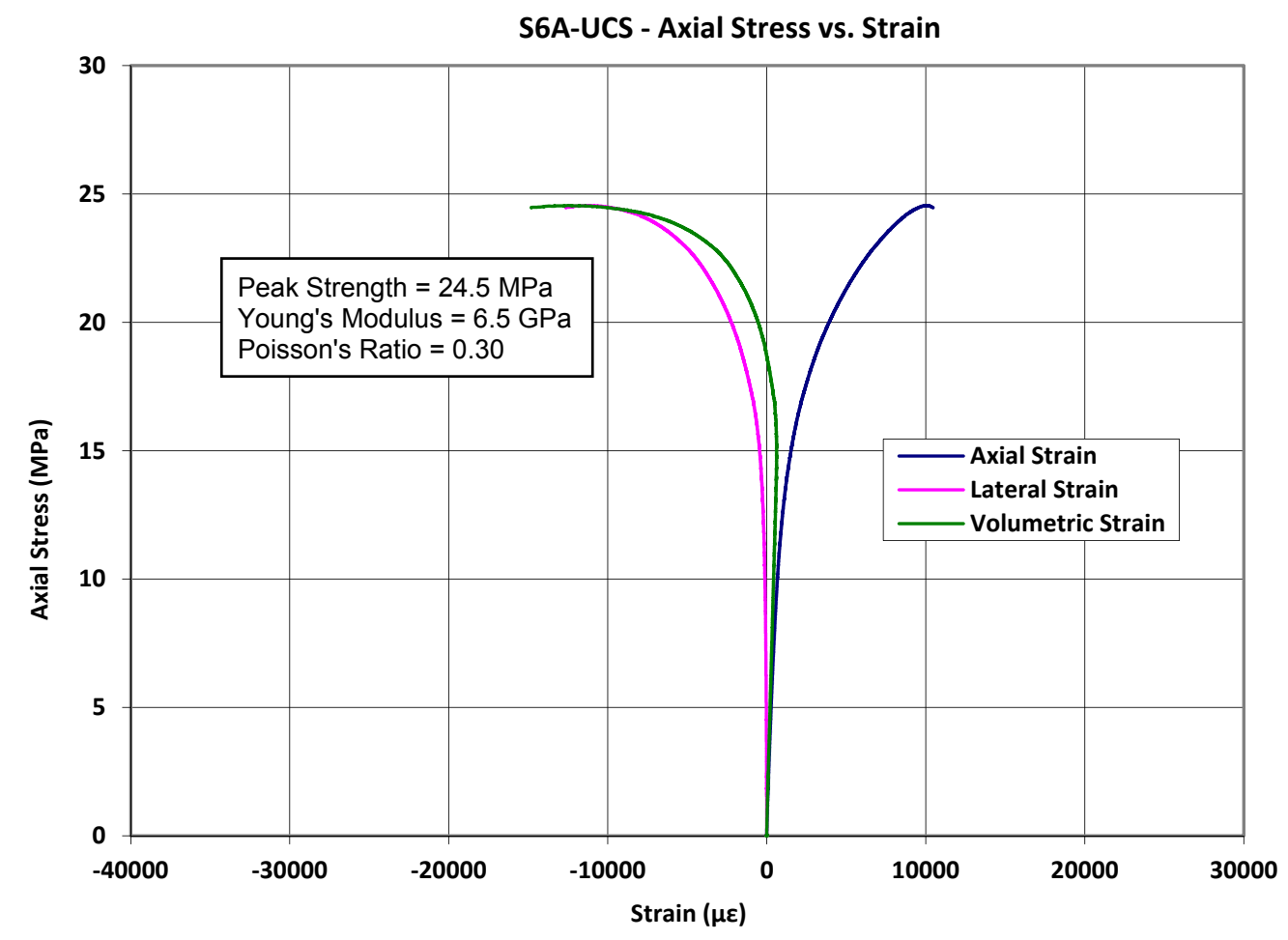

Figure B.19 Halite Sample "6A" Stress vs. Strain Plot from UCS Test 


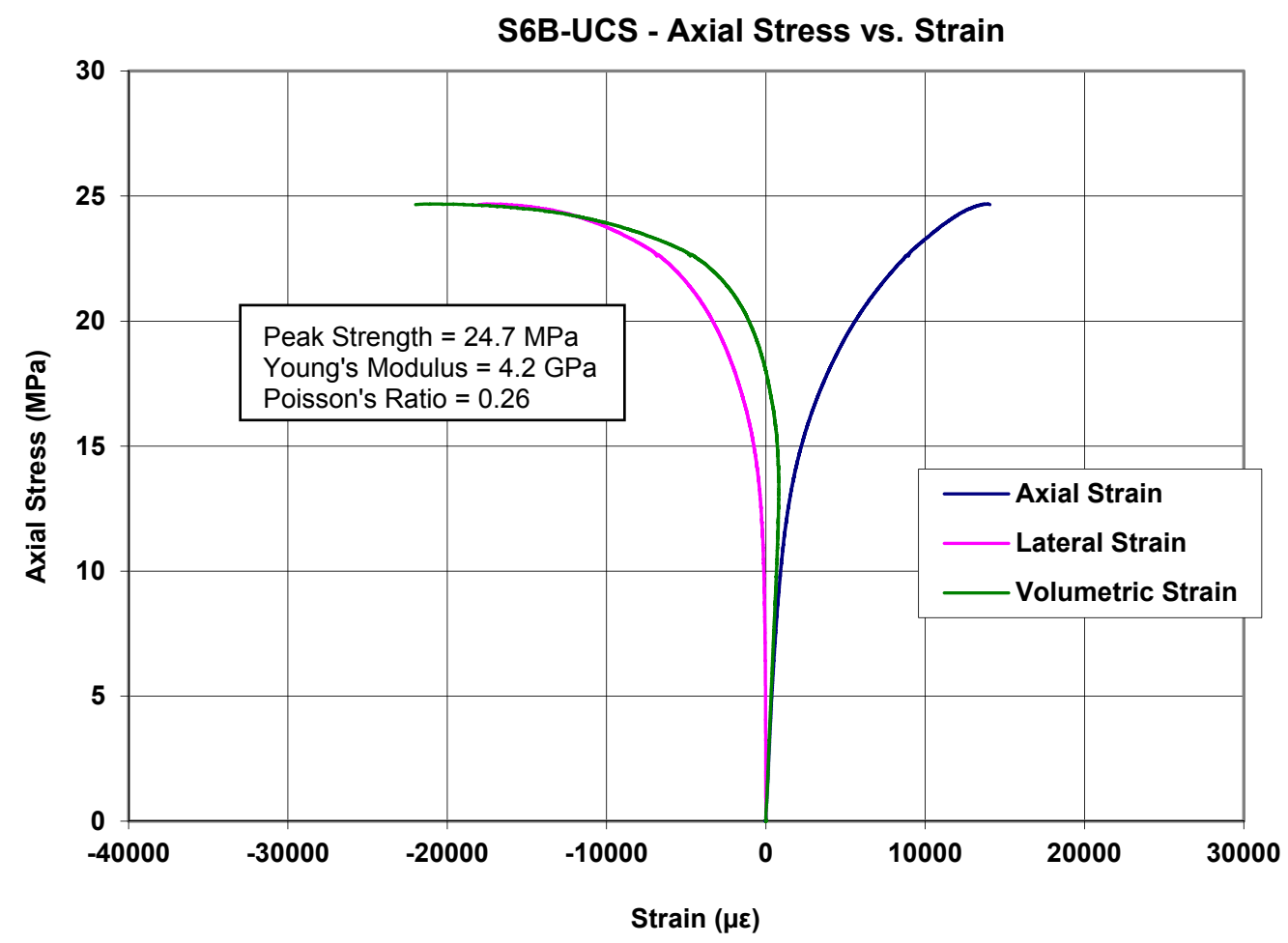

Figure B.20 Halite Sample "S6B" Stress vs. Strain Plot from UCS Test

\section{Tensile Strength Raw Data}

Tables B. 3 and B.4 show the tensile strength data collected for the potash and halite samples respectively.

Table B.3 Raw Data from Tensile Strength Tests on Potash

\begin{tabular}{|c|c|c|c|}
\hline Sample No. & $\begin{array}{c}\text { Length } \\
(\mathbf{m m})\end{array}$ & $\begin{array}{c}\text { Diameter } \\
(\mathbf{m m})\end{array}$ & $\begin{array}{c}\text { Splitting Tensile } \\
\text { Strength (MPa) }\end{array}$ \\
\hline P36BrA & 45.91 & 71.37 & 2.06 \\
\hline P36BrB & 46.02 & 71.27 & 1.66 \\
\hline P36BrC & 47.09 & 70.69 & 1.85 \\
\hline P36BrD & 46.32 & 70.27 & 1.87 \\
\hline P36BrE & 46.73 & 70.74 & 1.57 \\
\hline P31BrA & 41.55 & 70.51 & 1.64 \\
\hline P31BrB & 45.23 & 70.84 & 1.60 \\
\hline P31BrC & 46.57 & 70.68 & 1.49 \\
\hline P33Br & 43.43 & 70.52 & 1.93 \\
\hline P37Br & 42.41 & 70.78 & 1.80 \\
\hline Average: & 45.13 & 70.77 & $\mathbf{1 . 7 5}$ \\
\hline \multicolumn{4}{|c|}{ Standard Deviation: } \\
\hline
\end{tabular}


Table B.4 Raw Data from Tensile Strength Tests on Halite

\begin{tabular}{|c|c|c|c|}
\hline Sample No. & $\begin{array}{c}\text { Length } \\
(\mathrm{mm})\end{array}$ & $\begin{array}{c}\text { Diameter } \\
(\mathrm{mm})\end{array}$ & $\begin{array}{l}\text { Splitting Tensile } \\
\text { Strength (MPa) }\end{array}$ \\
\hline \multirow{2}{*}{$\begin{array}{l}\text { S15BrA } \\
\text { S15BrB }\end{array}$} & 42.18 & 70.35 & 1.78 \\
\hline & 40.27 & 70.44 & 1.56 \\
\hline S65BrA & 45.51 & 70.67 & 1.44 \\
\hline S65BrB & 45.13 & 70.53 & 1.71 \\
\hline S45BrA & 45.93 & 70.79 & 1.70 \\
\hline \multirow{2}{*}{$\begin{array}{c}\text { S45BrB } \\
\text { S5BrA }\end{array}$} & 43.33 & 70.86 & 1.77 \\
\hline & 45.77 & 70.03 & 2.05 \\
\hline S5BrB & 44.26 & 70.19 & 1.53 \\
\hline \multirow{2}{*}{$\begin{array}{l}\text { S5BrC } \\
\text { S5BrD }\end{array}$} & 41.78 & 70.95 & 1.53 \\
\hline & 47.14 & 71.17 & 2.24 \\
\hline \multirow[t]{2}{*}{ Average: } & 44.13 & 70.60 & 1.73 \\
\hline & \multicolumn{2}{|c|}{ Standard Deviation: } & 0.25 \\
\hline
\end{tabular}

\section{Shear Strength Raw Data}

Tables B.5 and B.6 show the raw data collected from the shear strength tests completed on potash and halite samples respectively.

Table B.5 Raw Data from Shear Strength Tests on Potash

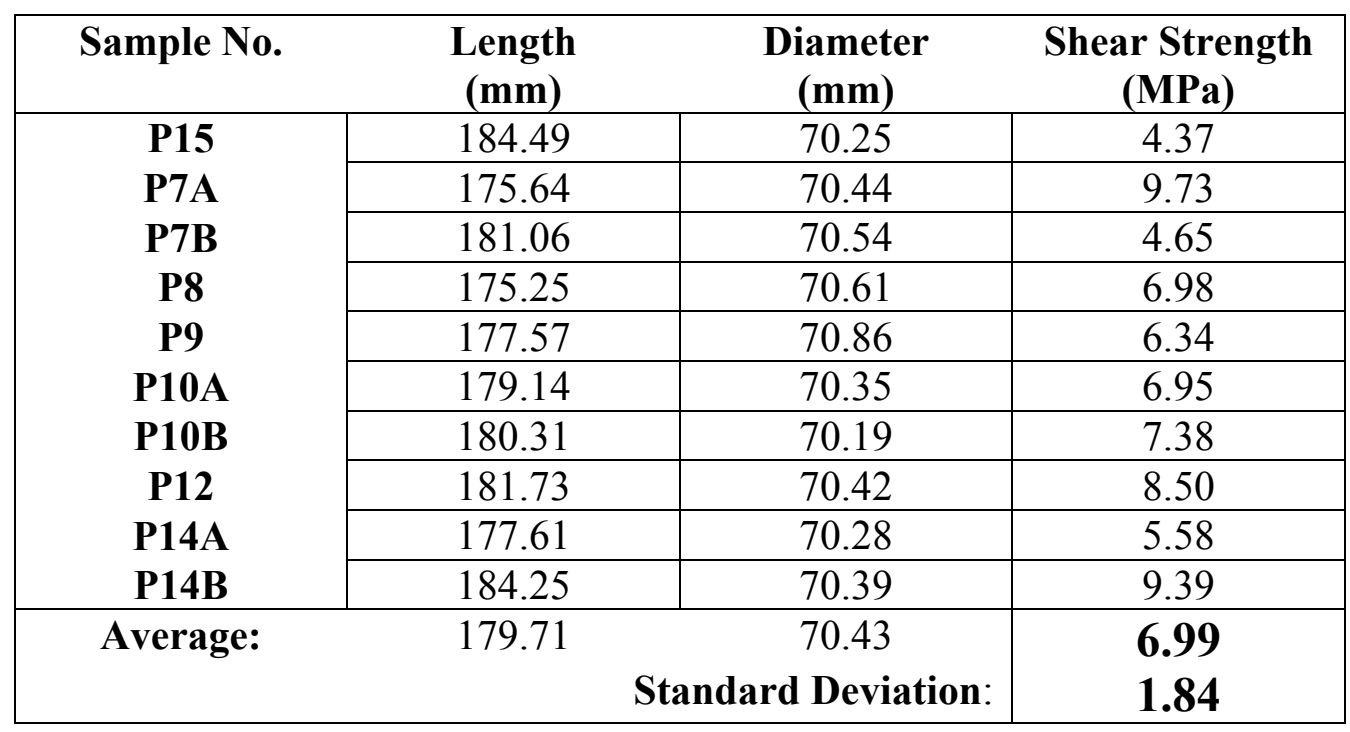


Table B.6 Raw Data from Shear Strength Tests on Halite

\begin{tabular}{|c|c|c|c|}
\hline Sample No. & $\begin{array}{c}\text { Length } \\
(\mathbf{m m})\end{array}$ & $\begin{array}{c}\text { Diameter } \\
(\mathbf{m m})\end{array}$ & $\begin{array}{c}\text { Shear Strength } \\
(\mathbf{M P a})\end{array}$ \\
\hline S55 & 172.51 & 70.49 & 9.78 \\
\hline S1A & 171.27 & 69.82 & 9.37 \\
\hline S1B & 181.12 & 70.42 & 8.13 \\
\hline S3 & 177.91 & 70.52 & 10.36 \\
\hline S25A & 175.76 & 69.97 & 6.49 \\
\hline S25B & 181.07 & 69.87 & 6.64 \\
\hline S15 & 172.75 & 69.94 & 7.18 \\
\hline S45B & 176.85 & 70.63 & 8.30 \\
\hline S45A & 188.97 & 69.87 & 8.48 \\
\hline S65 & 186.75 & 69.43 & 11.36 \\
\hline Average: & 178.50 & $\begin{array}{l}\quad 70.10 \\
\text { ard Deviation: }\end{array}$ & $\begin{array}{l}8.61 \\
1.61 \\
\end{array}$ \\
\hline
\end{tabular}




\section{Resin Volume Calculations}

This appendix contains the calculations involving the position of resin in the hole after installation. These calculations were to ensure the desired bond length was achieved given the volume of resin and size of resin dam used. Calculations are shown to determine the volume of resin which would become ineffective in the case of over drilling the length of a hole. Each bond length used in testing has an associated calculation to show the size of resin dam which was required.

General numbers used in the calculations involve the following:

For 25 (25.4) $\mathrm{mm}$ diameter rebar; a hole diameter of $36.5 \mathrm{~mm}$ is used.

$25 \mathrm{~mm}$ rebar required a $28 \mathrm{~mm}$ diameter resin cartridges, 305 (304.8) $\mathrm{mm}$ in length.

For $16(15.875) \mathrm{mm}$ diameter rebar; a hole diameter of $28.5 \mathrm{~mm}$ is used.

$16 \mathrm{~mm}$ rebar required $25 \mathrm{~mm}$ diameter resin cartridges, 305 (304.8) $\mathrm{mm}$ in length

Resin dam diameter varied in the field but for calculations with $25 \mathrm{~mm}$ rebar, a $33 \mathrm{~mm}$ diameter dam is assumed. For the $16 \mathrm{~mm}$ rebar, a $22.5 \mathrm{~mm}$ diameter dam is used.

\section{\% Resin Lost if Holes are Over-Drilled:}

Typically, holes can be over-drilled due to operator error during the installation. This is a major concern when using small amounts of resin such as in the pull tests done during this project.

For example: if 1 resin cartridge is used (as in testing done by Smith (2008)) and the hole is overdrilled by only $2.5 \mathrm{~cm}(1$ "), the resin lost is:

$$
\begin{gathered}
V_{\text {cartridge }}=\pi 14 \mathrm{~mm}^{2} *(305 \mathrm{~mm})=187681.26 \mathrm{~mm}^{3} \\
V_{\text {Lost }}=\pi 18.25 \mathrm{~mm}^{2} *(25.4 \mathrm{~mm})=26577.2 \mathrm{~mm}^{3} \\
\text { \%Resin } \text { Lost }_{\text {Lo }}=\frac{26577.2}{187681.26}=14.2 \%
\end{gathered}
$$

\section{5 mm Diameter Rebar Tests:}

Resin volume per $28 \mathrm{~mm}$ diameter, $305 \mathrm{~mm}$ long cartridge:

$$
V_{\text {cartridge }}=\pi 14 \mathrm{~mm}^{2} *(304.8 \mathrm{~mm})=187681.26 \mathrm{~mm}^{3}
$$


Two cartridges being used:

$$
V_{\text {Resin }}=2 * 187681.26=375362.52 \mathrm{~mm}^{3}
$$

Void space available to be filled with resin:

Every hole will have $50.8 \mathrm{~mm}$ of empty space at the top (standard installation procedure)

$$
V_{\text {top of hole }}=\pi 18.25 \mathrm{~mm}^{2} *(50.8 \mathrm{~mm})=53154.41 \mathrm{~mm}^{3}
$$

Depending on bond length, each bolt will have a certain amount of annular space between the hole wall and the rebar:

For $0.46 \mathrm{~m}$ Bond Length:

$$
V_{0.46 m \text { Annular }}=\pi\left(18.25^{2}-12.7^{2}\right) \mathrm{mm}^{2} *(457.2 \mathrm{~mm})=246723.05 \mathrm{~mm}^{3}
$$

For $0.51 \mathrm{~m}$ Bond Length:

$$
V_{0.51 m \text { Annular }}=\pi\left(18.25^{2}-12.7^{2}\right) \mathrm{mm}^{2} *(508 \mathrm{~mm})=274136.73 \mathrm{~mm}^{3}
$$

For $0.56 \mathrm{~m}$ Bond Length:

$$
V_{0.56 m \text { Annular }}=\pi\left(18.25^{2}-12.7^{2}\right) \mathrm{mm}^{2} *(558.8 \mathrm{~mm})=301550.40 \mathrm{~mm}^{3}
$$

For $0.23 \mathrm{~m}$ Bond Length:

$$
V_{0.23 m \text { Annular }}=\pi\left(18.25^{2}-12.7^{2}\right) \mathrm{mm}^{2} *(228.6 \mathrm{~mm})=123361.53 \mathrm{~mm}^{3}
$$

Therefore, the resin dam would have to have the capacity to block the leftover resin from coming into contact with the rebar. This volume of left over resin is calculated for each bond length test by:

$$
V_{\text {Left over }}=V_{\text {Resin }}-\left(V_{\text {top of hole }}+V_{X X m \text { Annular }}\right)
$$

The minimum length of the $33 \mathrm{~mm}$ diameter resin dams was then be calculated using:

$$
L_{\text {Minimum }}=V_{\text {Left over }} / \pi\left(18.25 \mathrm{~mm}^{2}-16.5 \mathrm{~mm}^{2}\right)
$$

\section{6 mm Diameter Rebar Tests:}

Resin volume per $25 \mathrm{~mm}$ diameter, $305 \mathrm{~mm}$ long cartridge:

$$
V_{\text {cartridge }}=\pi 12.5 \mathrm{~mm}^{2} *(304.8 \mathrm{~mm})=149618.35 \mathrm{~mm}^{3}
$$

Void space available to be filled with Resin:

Every hole will have $50.8 \mathrm{~mm}$ of empty space at the top (standard installation procedure)

$$
V_{\text {top of hole }}=\pi 14.25 \mathrm{~mm}^{2} *(50.8 \mathrm{~mm})=32407.33 \mathrm{~mm}^{3}
$$


Depending on bond length, each bolt will have a certain amount of annular space between the hole walls and the rebar:

For $0.18 \mathrm{~m}$ Bond Length:

$$
V_{0.18 m \text { Annular }}=\pi\left(14.25^{2}-7.9375^{2}\right) \mathrm{mm}^{2} *(177.8 \mathrm{~mm})=78233.25 \mathrm{~mm}^{3}
$$

Therefore, the resin dam would have to have the capacity to block the leftover resin from coming into contact with the rebar. This volume of left over resin is calculated for each bond length test by:

$$
V_{\text {Left over }}=V_{\text {Resin }}-\left(V_{\text {top of hole }}+V_{X X m \text { Annular }}\right)
$$

The minimum length of the $22.5 \mathrm{~mm}$ diameter resin dams could then be calculated using:

$$
L_{\text {Minimum }}=V_{\text {Left over }} / \pi\left(14.25 \mathrm{~mm}^{2}-11.25 \mathrm{~mm}^{2}\right)
$$

For example: the resin dams used for these 10 tests had to be a minimum of $162 \mathrm{~mm}$ (6.4") long therefore, a 200mm (8") dam would be used to account for some error in the field. 


\section{Pull Test Process and Data Reduction Process}

This appendix serves as a basic guide for any future testing using similar techniques as outlined in this thesis. An outline of the process using the method described in Section 5 is described in bullet form. Steps followed in the data reduction process, described in Section 5.2, are listed in the following as well.

\section{Pull Testing in the Field:}

The basic steps for conducting the pull test used in this research project are as follows:

- Assembled rebar samples (pull collar, plate, resin dam) and labelled.

- Acquired resin cartridges which had been stored for no more than 2 months underground.

- Operations installed samples as per standards at Allan mine. Engineering supervised installations to observe improper installation techniques (hole length drilled, spin times, hold times, crooked installation, etc.).

- At least one day prior to planned pull testing, rebar heads were cleaned with a wire brush and degreasing agent in order to attach string lines.

- Attach string lines only to rebar planned to be tested, string line hanging from rebar for long periods of time when used will be subject to damage.

- Figure D. 1 shows the method of attaching the string line. Line was circled onto electrical tape, covered in general use epoxy, and glued to rebar head.

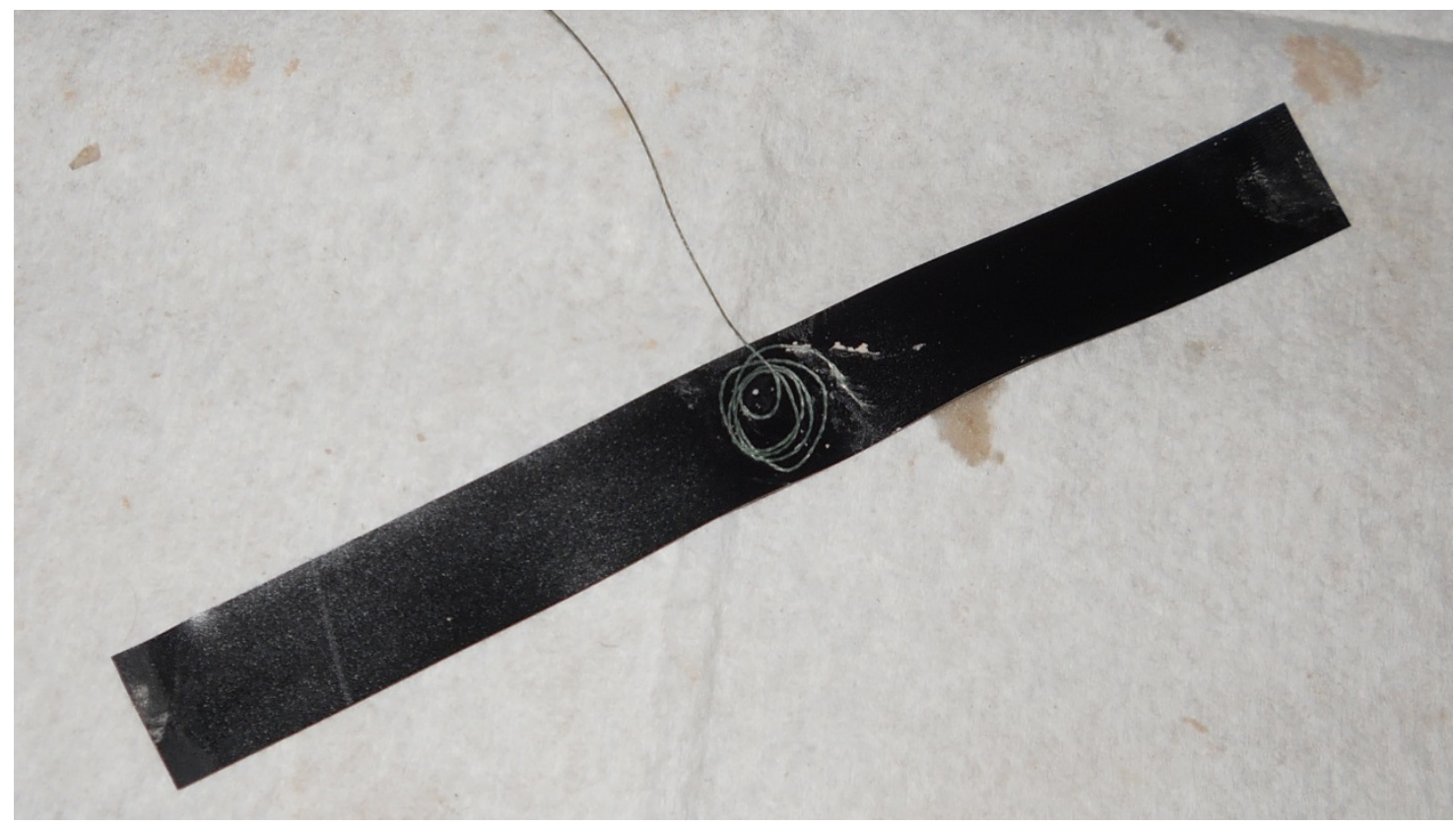

Figure D.1 Attaching String Line with Electrical Tape 
- String line was run down the centre of pull testing apparatus so it was free to move downward and measure the deformation at the loaded end of the rebar.

- The string line can be attached to a small plumb bob in order to position the string potentiometer directly below the rebar head and ensure a vertical string line. A level on the tripod can be used to ensure the instrument sits on a level surface.

- A minimum of two people are required to conduct a pull test. One person to apply load manually and one to read the multi-metre readings and record both load and voltage during the test. Depending on the size of apparatus, two people are often needed to connect the apparatus to the rebar samples safely.

- Seating effects such as initial slack in system, tilt of the apparatus can affect results at low loads.

- Excessive deformation recorded early on when load is not being applied can indicate that the string line did not adhere to the rebar head. Discontinue the test and reattach a new string line for testing later, if possible.

- Excessive tilt of the apparatus typically resulted in the apparatus coming into contact with the string line due to the angle of the apparatus away from vertical. If the line is not free to be pulled into the instrument under the spring loaded tension, readings are not accurate.

- Excessive tilt also results in the apparatus applying a torque to the rebar head more than it is applying a tensile load along the length of the rebar.

- Deformation readings (voltage readings) were taken once load had been applied followed by a 15 second pause. This pause allows testers to observe whether load is bleeding off or if deformation is continuing to occur without further load being applied.

- Once load begins to bleed off or deformation begins to continuously occur, it is likely sliding has initiated.

- To track the slip of the rebar past the point of adhesion loss, load and deformation were recorded at the beginning and end of the 15 second wait period. This captured the downward movement of rebar while load was decreasing. A technique similar to this could be used to assess the frictional capacity of the sliding rebar once adhesion loss occurs.

- Load and deformation readings were taken after sliding appeared to have initiated. If possible, readings were taken until at least the yield strength of the rebar had been exceeded. 


\section{Data Reduction Steps}

The process used for extracting an initial sliding load from each field test is summarized in the list below.

- Plot load versus incremental deformation, along with the load versus cumulative displacement.

- Observe the initial near-linear trend in the incremental deformation plot.

- Observe whether near-linear trend values fall within the expected ranges given the size of rebar being tested ( 0 to $0.53 \mathrm{~mm} /$ tonne for $25 \mathrm{~mm}$ sized rebar or 0 to $1.35 \mathrm{~mm} /$ tonne for $16 \mathrm{~mm}$ sized rebar).

- The initial sliding load can be determined from observing the load at which the incremental deformation plot displays a clear departure from the near-linear trend.

- Data which does not display an initial near-linear trend, and/or does not have a plot displaying a clear departure from the near linear range is indeterminate data.

- Incremental deformation data which falls outside the acceptable range is not interpretable and not used to calculate average values. 


\section{E. Raw Data from Field Testing}

This appendix includes the tabulated raw data for each pull test conducted in the field. Plots of load versus both incremental and cumulative deformation are also included. Data is grouped by the testing site.

\section{Initial Pull Test Data}

Table E.1 shows the data collected during the initial testing phase. The following figures show the load versus deformation plots from each test in the initial phase.

Table E.1 Initial Pull Test Data

\begin{tabular}{|c|c|c|c|c|c|c|}
\hline $\begin{array}{l}\text { Test } \\
\text { No. }\end{array}$ & $\begin{array}{c}\text { Bond } \\
\text { Length (m) }\end{array}$ & $\begin{array}{c}\text { Cure Time } \\
\text { (days) }\end{array}$ & $\begin{array}{c}\text { Initial } \\
\text { Sliding Load } \\
\text { (tonnes) }\end{array}$ & $\begin{array}{c}\text { Bond } \\
\text { Strength } \\
\text { (Linear) } \\
\text { (tonnes } / \mathrm{m} \text { ) }\end{array}$ & $\begin{array}{c}\text { Resin- } \\
\text { Rebar Bond } \\
\text { Strength } \\
(\mathrm{MPa}) \\
\end{array}$ & $\begin{array}{c}\text { Resin-Rock } \\
\text { Bond } \\
\text { Strength } \\
(\mathrm{MPa}) \\
\end{array}$ \\
\hline 1 & 0.61 & 2.0 & 20.4 & 33.5 & 4.3 & 2.9 \\
\hline 2 & 0.61 & 2.0 & 20.4 & 33.5 & 4.3 & 2.9 \\
\hline 3 & 0.61 & 2.0 & 20.4 & 33.5 & 4.3 & 2.9 \\
\hline 4 & 0.61 & 2.0 & 20.4 & 33.5 & 4.3 & 2.9 \\
\hline 5 & 0.61 & 2.0 & 19.5 & 32.0 & 4.1 & 2.7 \\
\hline 6 & 0.56 & 8.0 & 17.8 & 31.9 & 4.1 & 2.8 \\
\hline 7 & 0.56 & 8.0 & 18.1 & 32.4 & 4.1 & 2.8 \\
\hline 8 & 0.56 & 8.0 & 16.3 & 29.1 & 3.7 & 2.5 \\
\hline 9 & 0.56 & \multicolumn{5}{|c|}{ Rebar/Back crooked, unable to test } \\
\hline 10 & 0.56 & 8.0 & 16.3 & 29.2 & 3.7 & 2.5 \\
\hline 11 & 0.51 & 2.0 & 18.1 & 35.6 & 4.5 & 3.0 \\
\hline 12 & 0.51 & 1.6 & 18.5 & 36.4 & 4.6 & 3.1 \\
\hline 13 & 0.51 & 2.1 & 16.3 & 32.1 & 4.1 & 2.7 \\
\hline 14 & 0.51 & 3.9 & 16.8 & 33.0 & 4.2 & 2.8 \\
\hline 15 & 0.51 & \multicolumn{5}{|c|}{ Rebar/Back crooked, unable to test } \\
\hline 16 & 0.46 & 6.9 & 14.5 & 31.7 & 4.0 & 2.7 \\
\hline 17 & 0.46 & 6.9 & \multicolumn{4}{|l|}{ Indeterminate } \\
\hline 18 & 0.46 & 7.0 & 18.1 & 39.6 & 5.1 & 3.4 \\
\hline 19 & 0.46 & 7.0 & \multicolumn{4}{|l|}{ Indeterminate } \\
\hline 20 & 0.46 & \multicolumn{5}{|c|}{ Rebar damaged before testing } \\
\hline
\end{tabular}




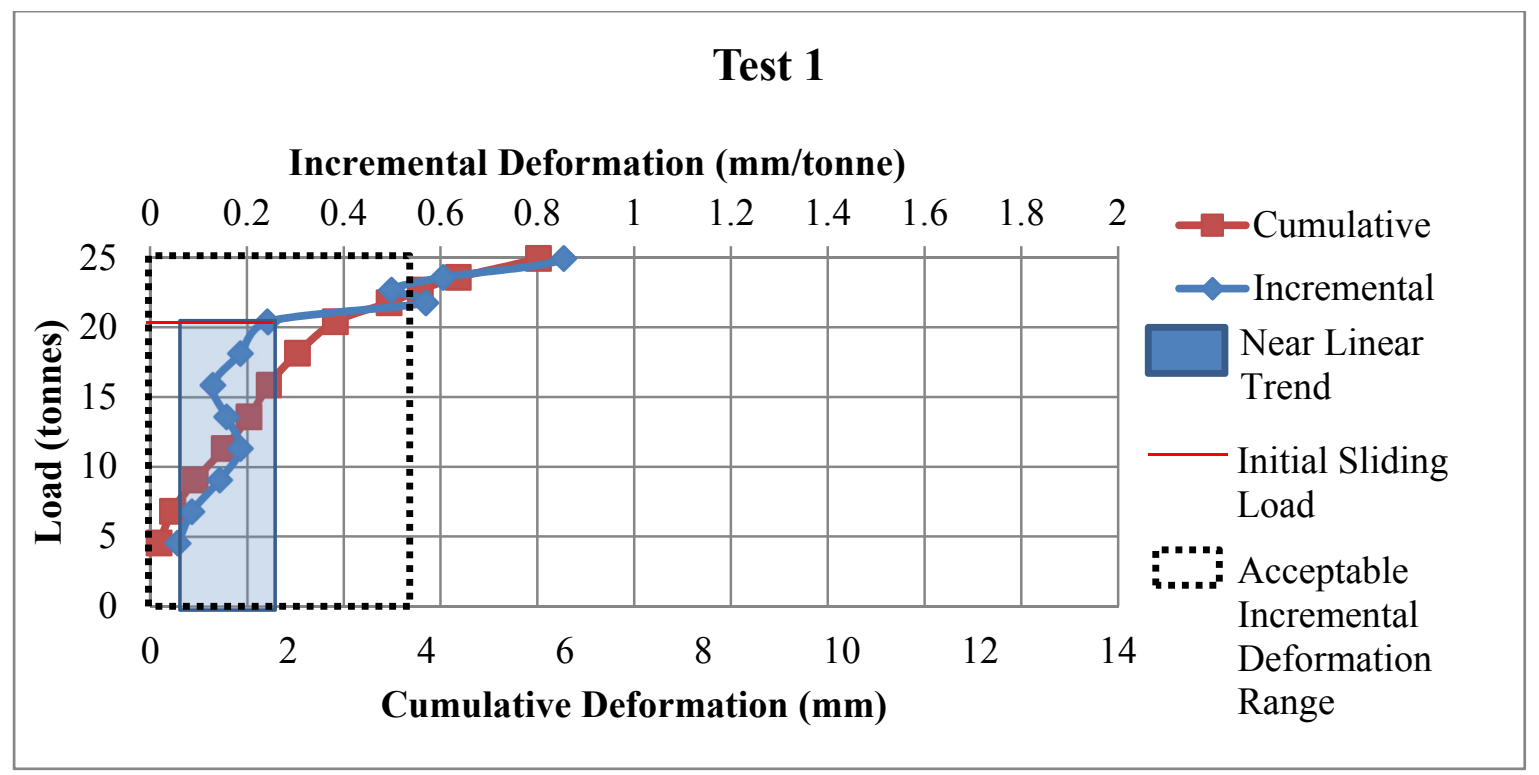

Figure E.1 Pull Test Load vs. Deformation Test 1

\section{Test 2}

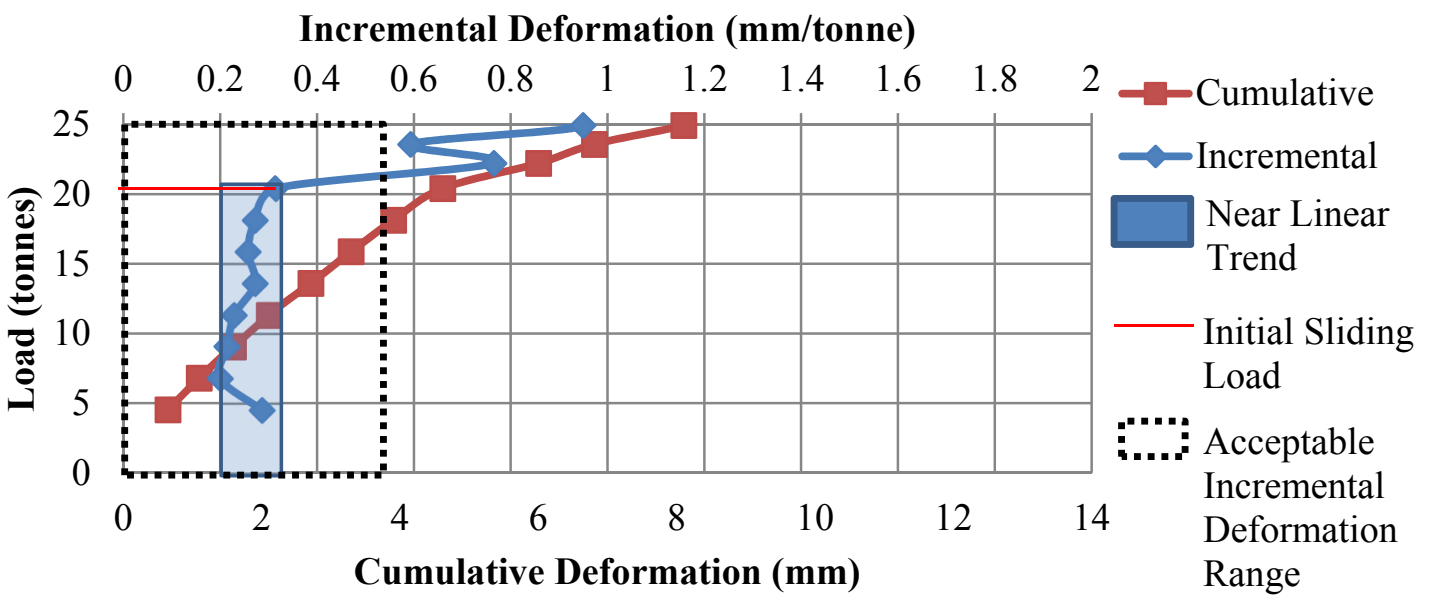

Figure E.2 Pull Test Load vs. Deformation Test 2 


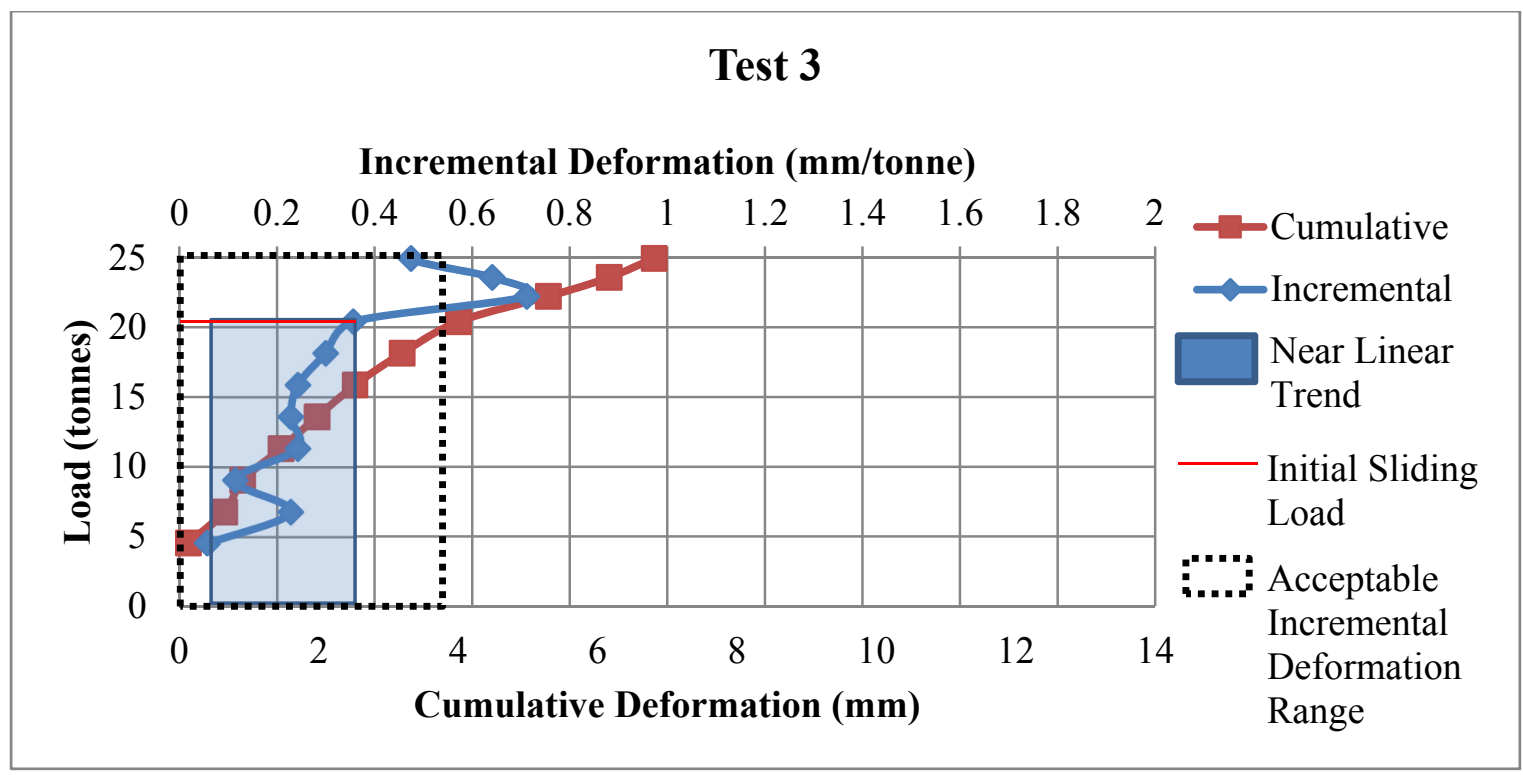

Figure E.3 Pull Test Load vs. Deformation Test 3

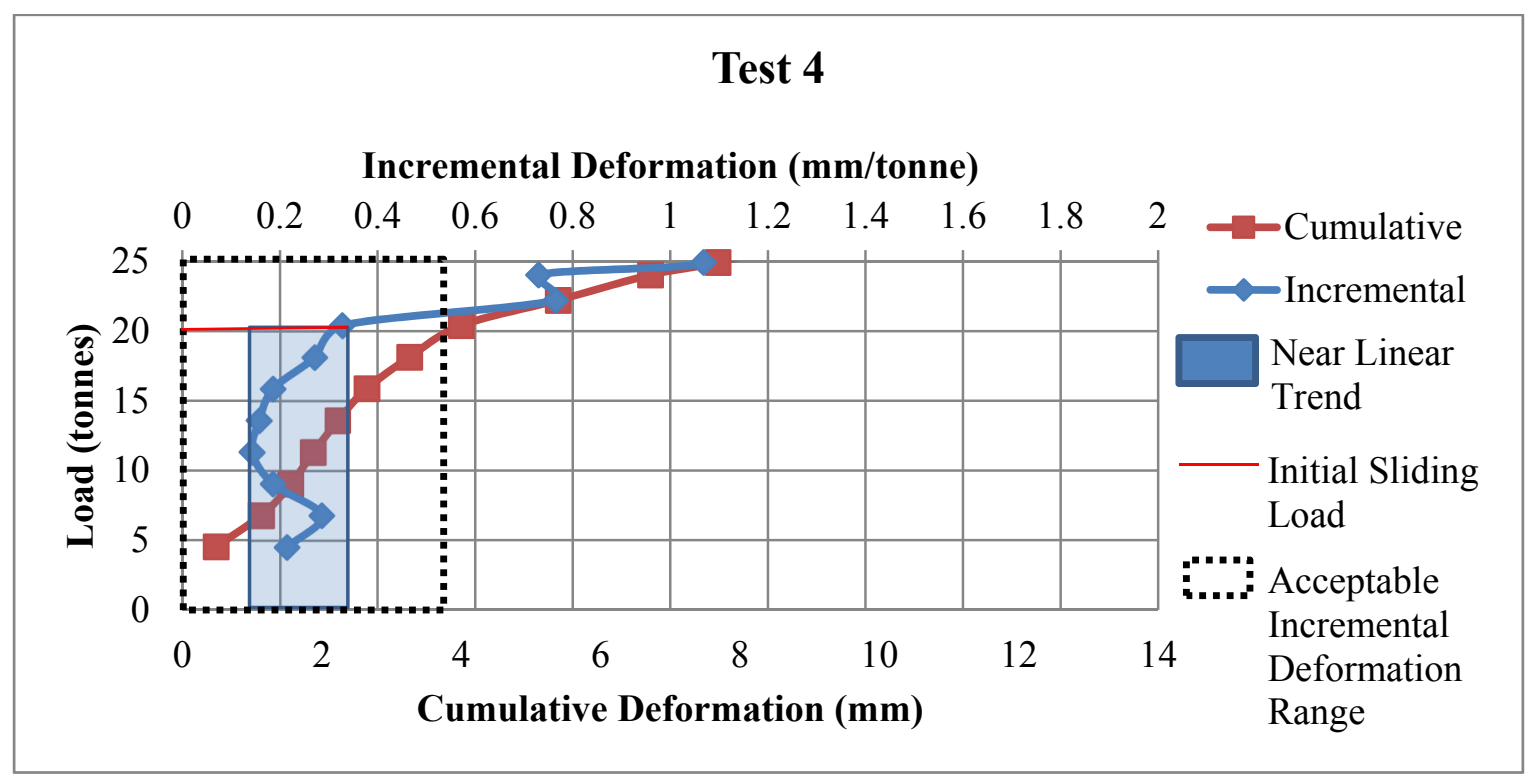

Figure E.4 Pull Test Load vs. Deformation Test 4 


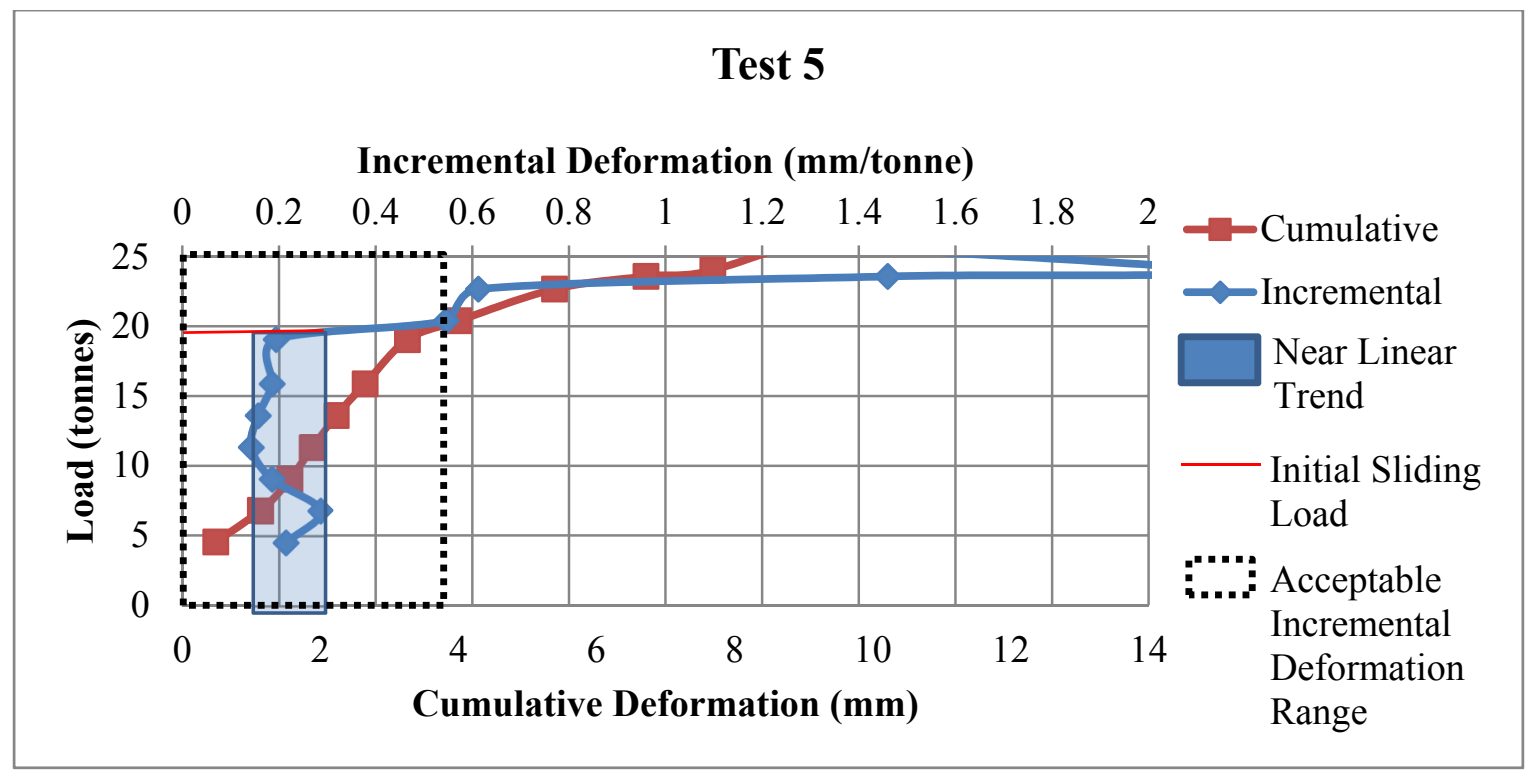

Figure E.5 Pull Test Load vs. Deformation Test 5

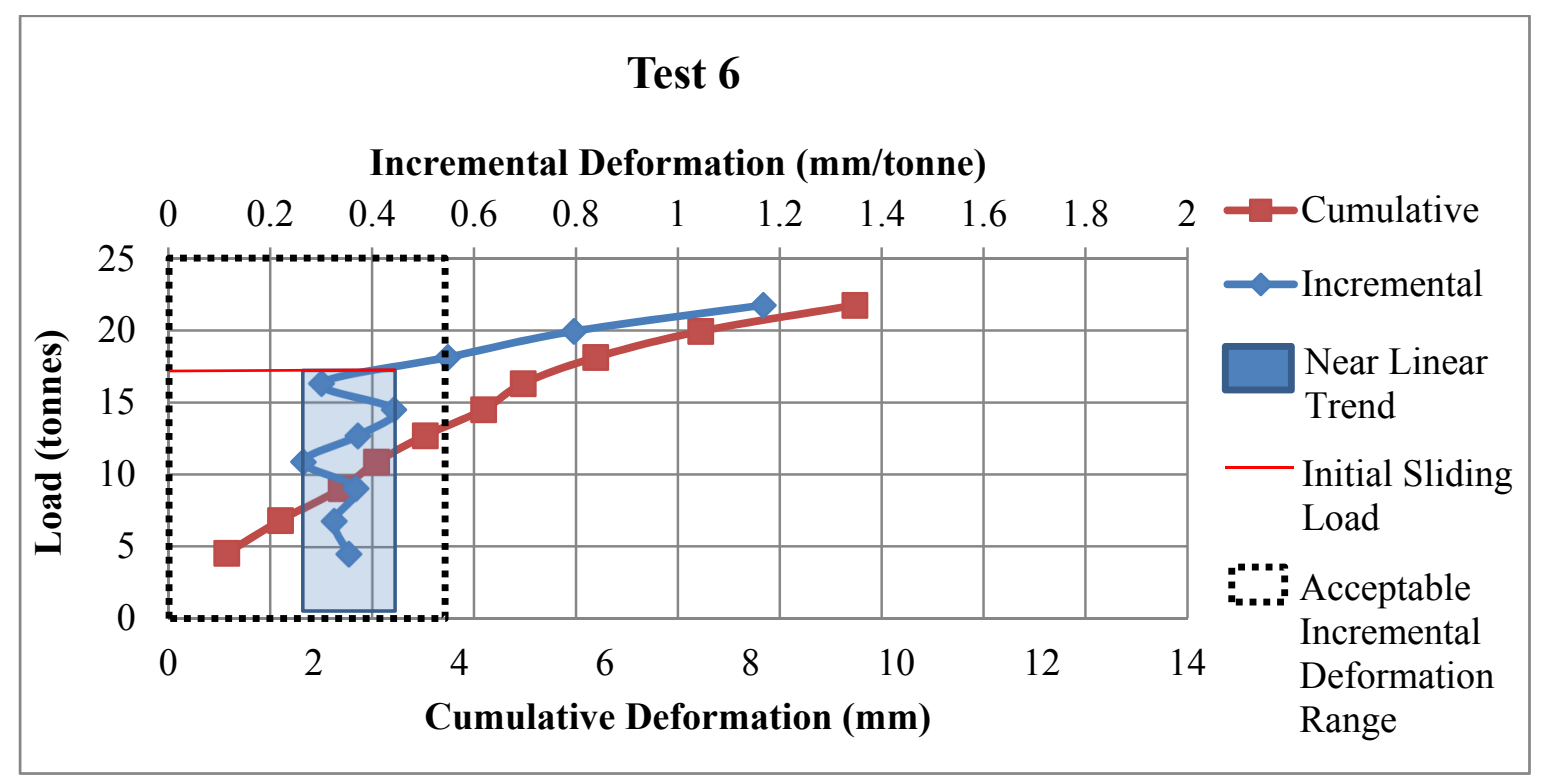

Figure E.6 Pull Test Load vs. Deformation Test 6 


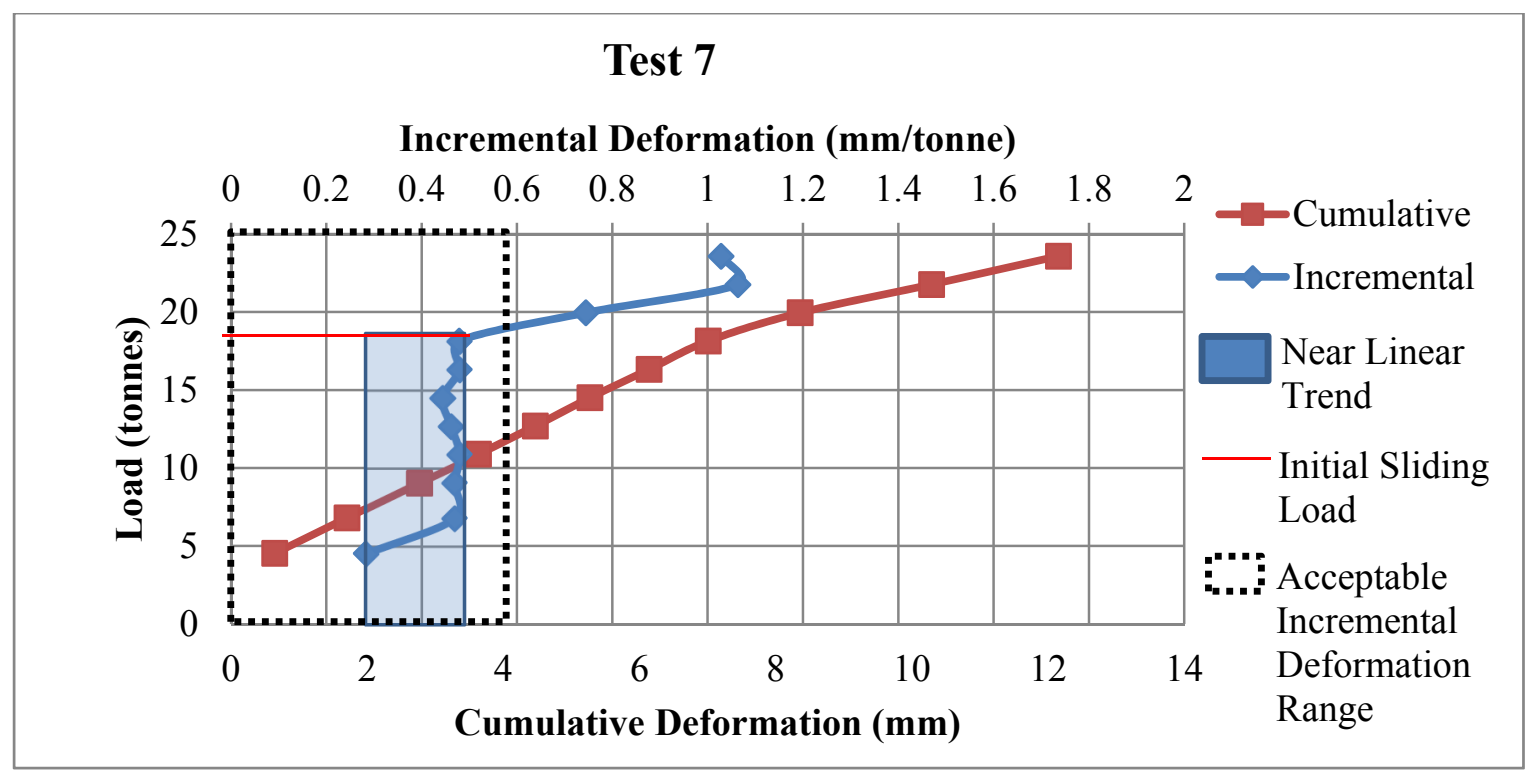

Figure E.7 Pull Test Load vs. Deformation Test 7

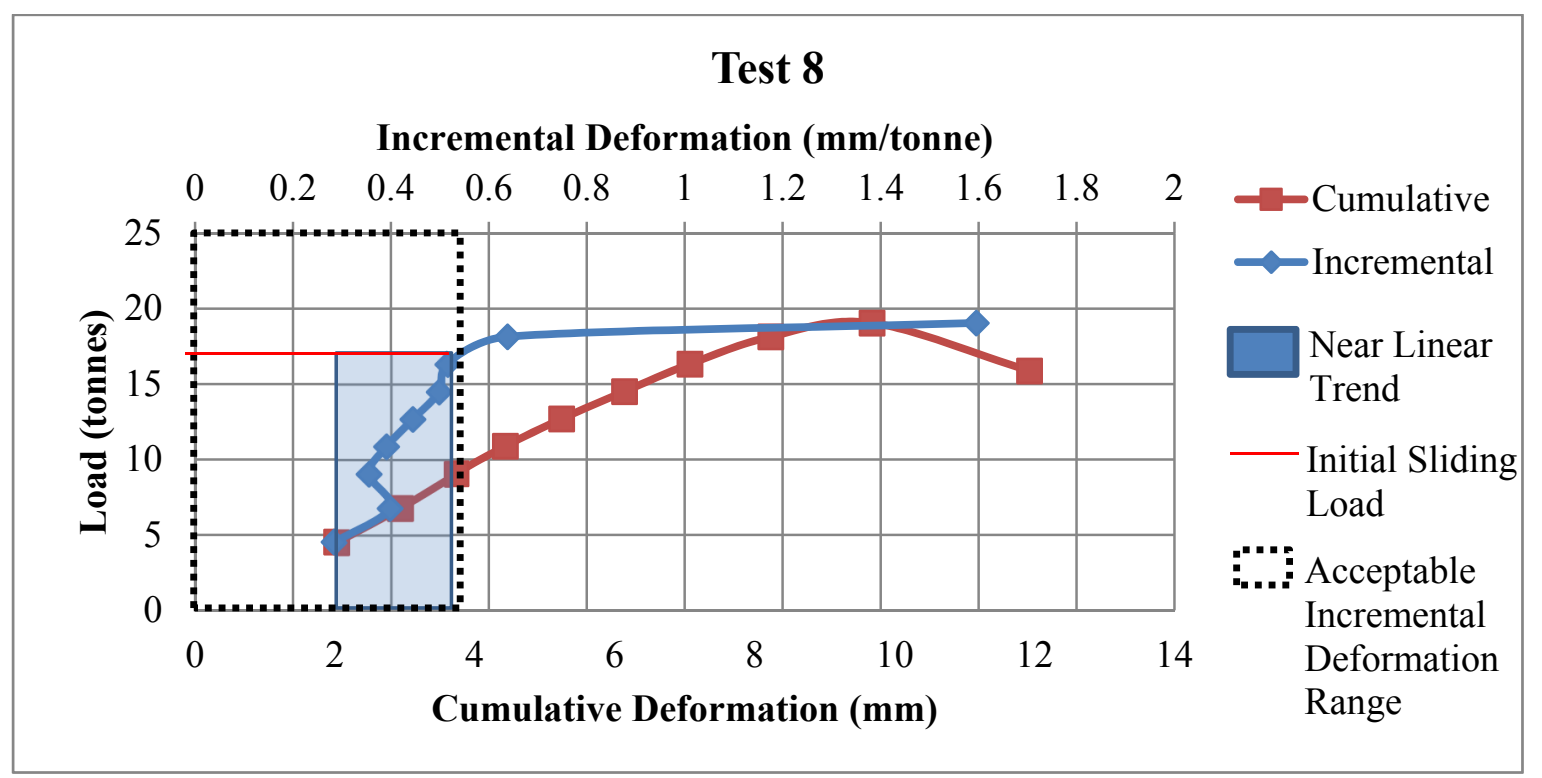

Figure E.8 Pull Test Load vs. Deformation Test 8 


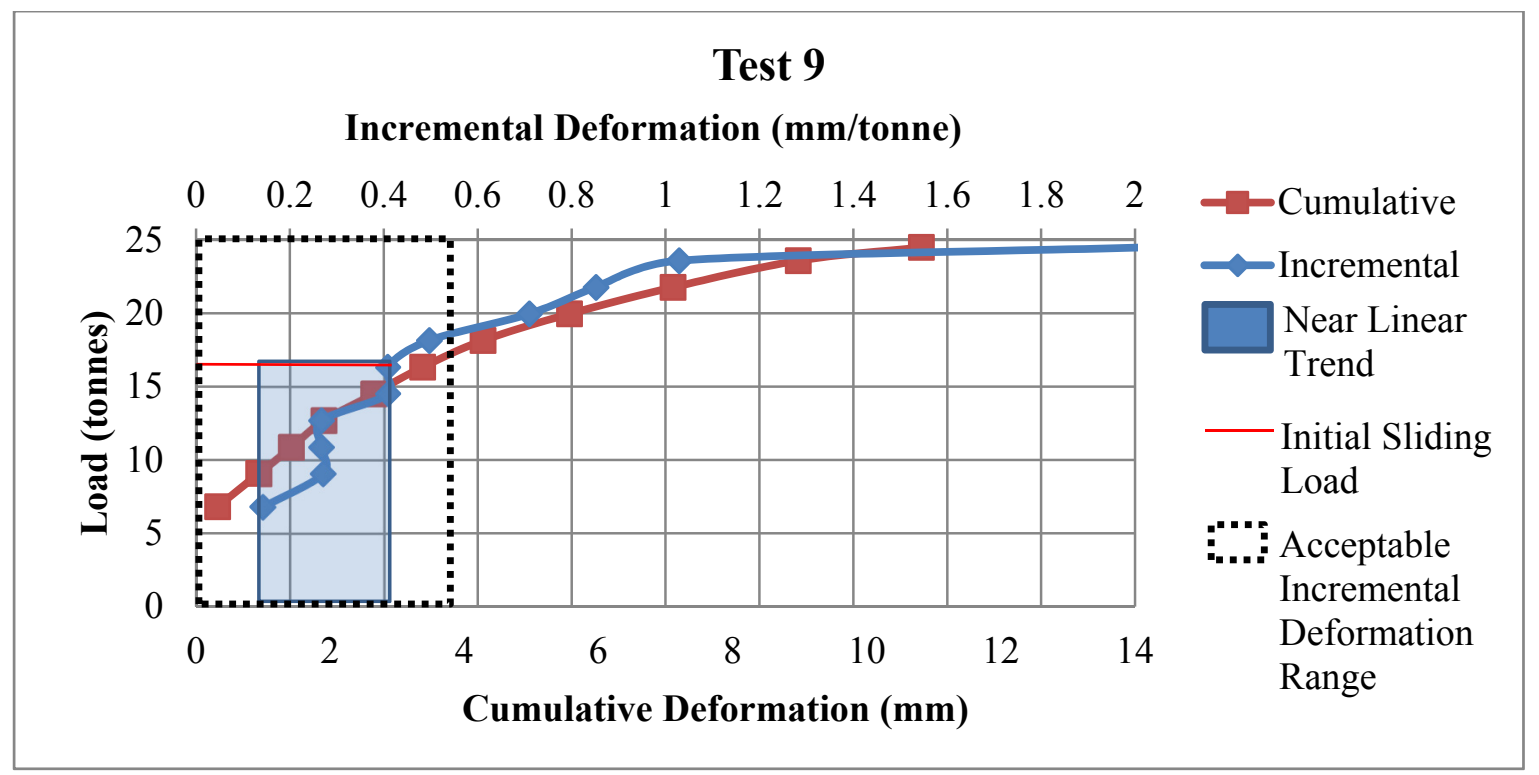

Figure E.9 Pull Test Load vs. Deformation Test 9

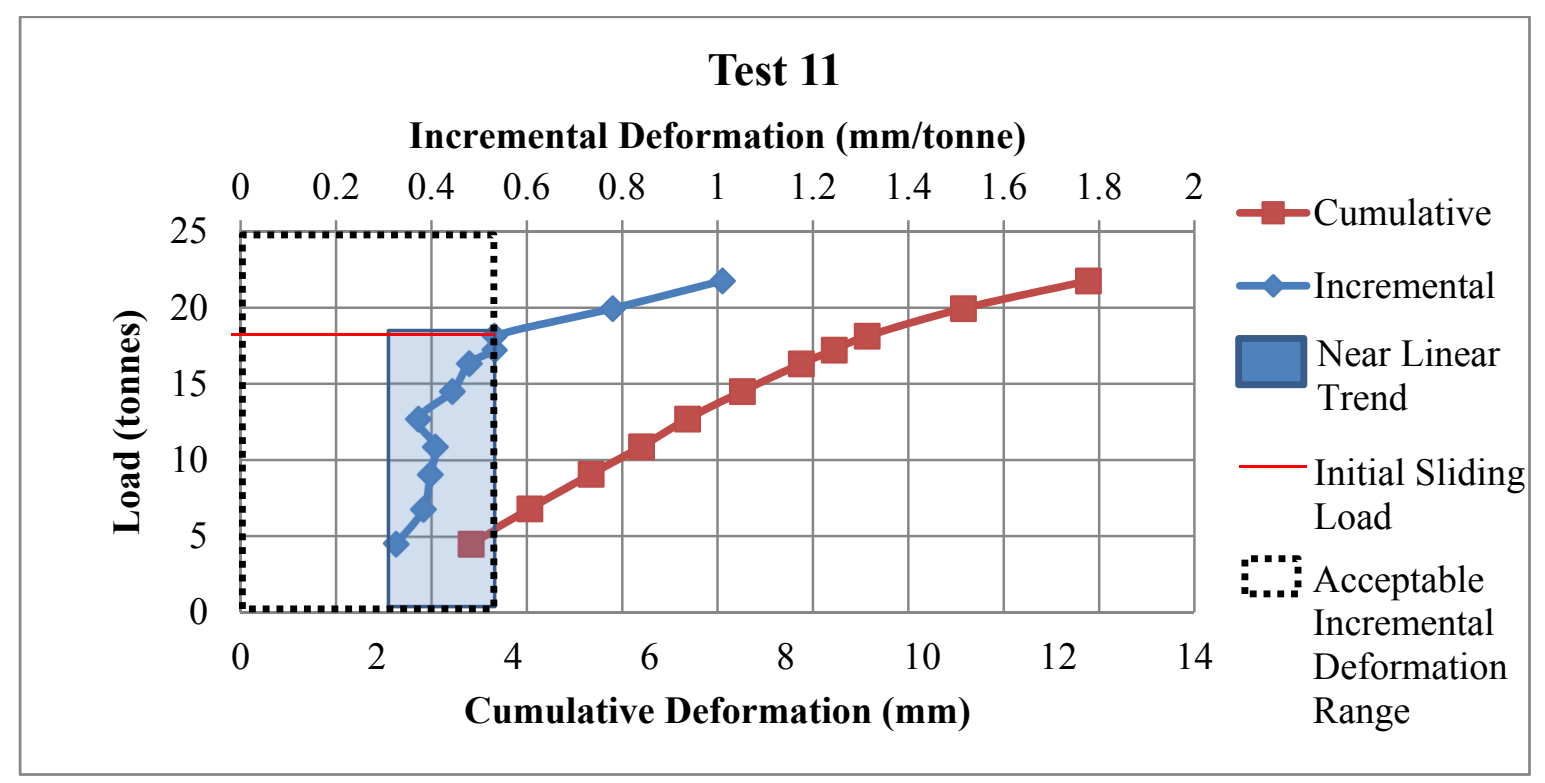

Figure E.10 Pull Test Load vs. Deformation Test 11 


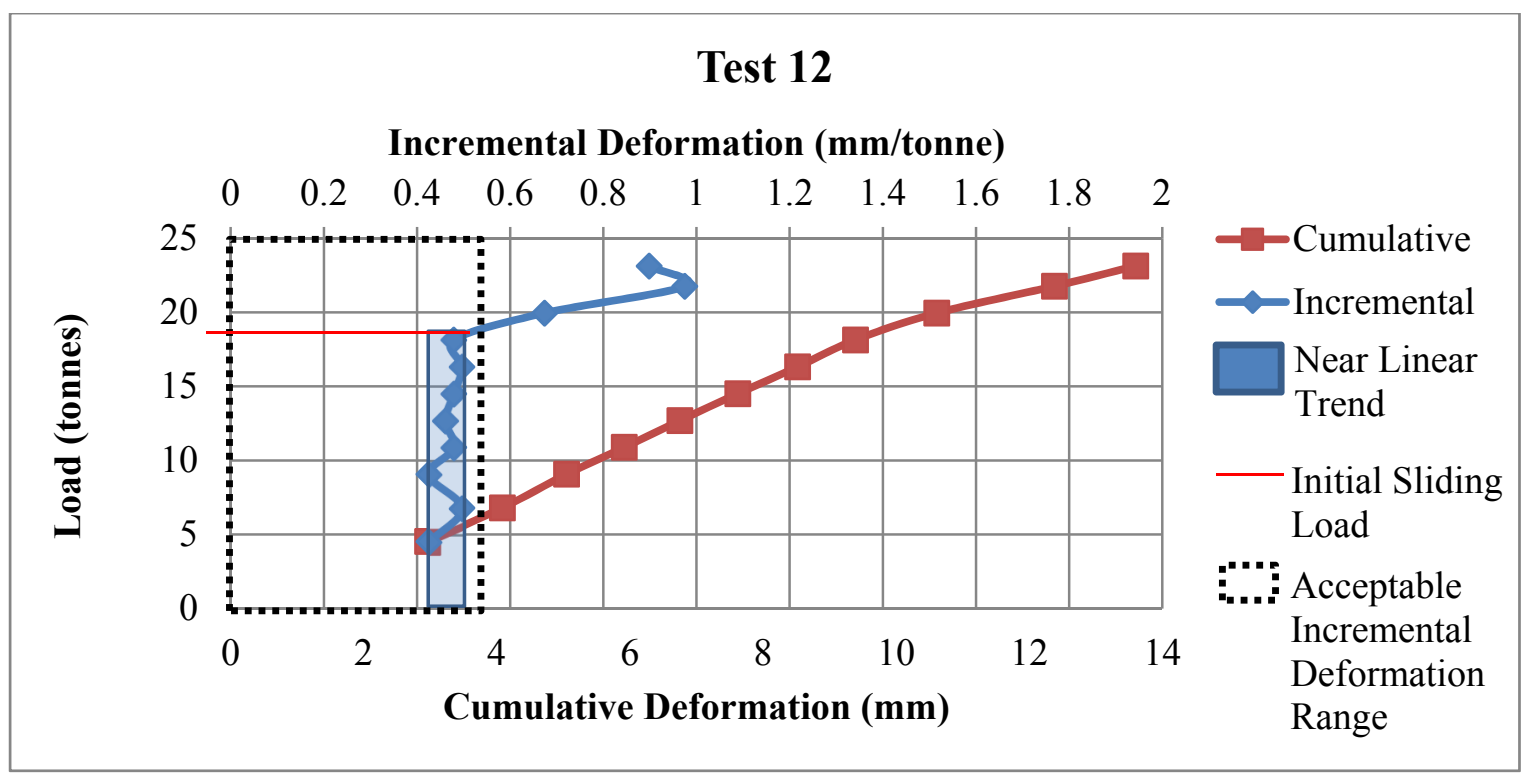

Figure E.11 Pull Test Load vs. Deformation Test 12

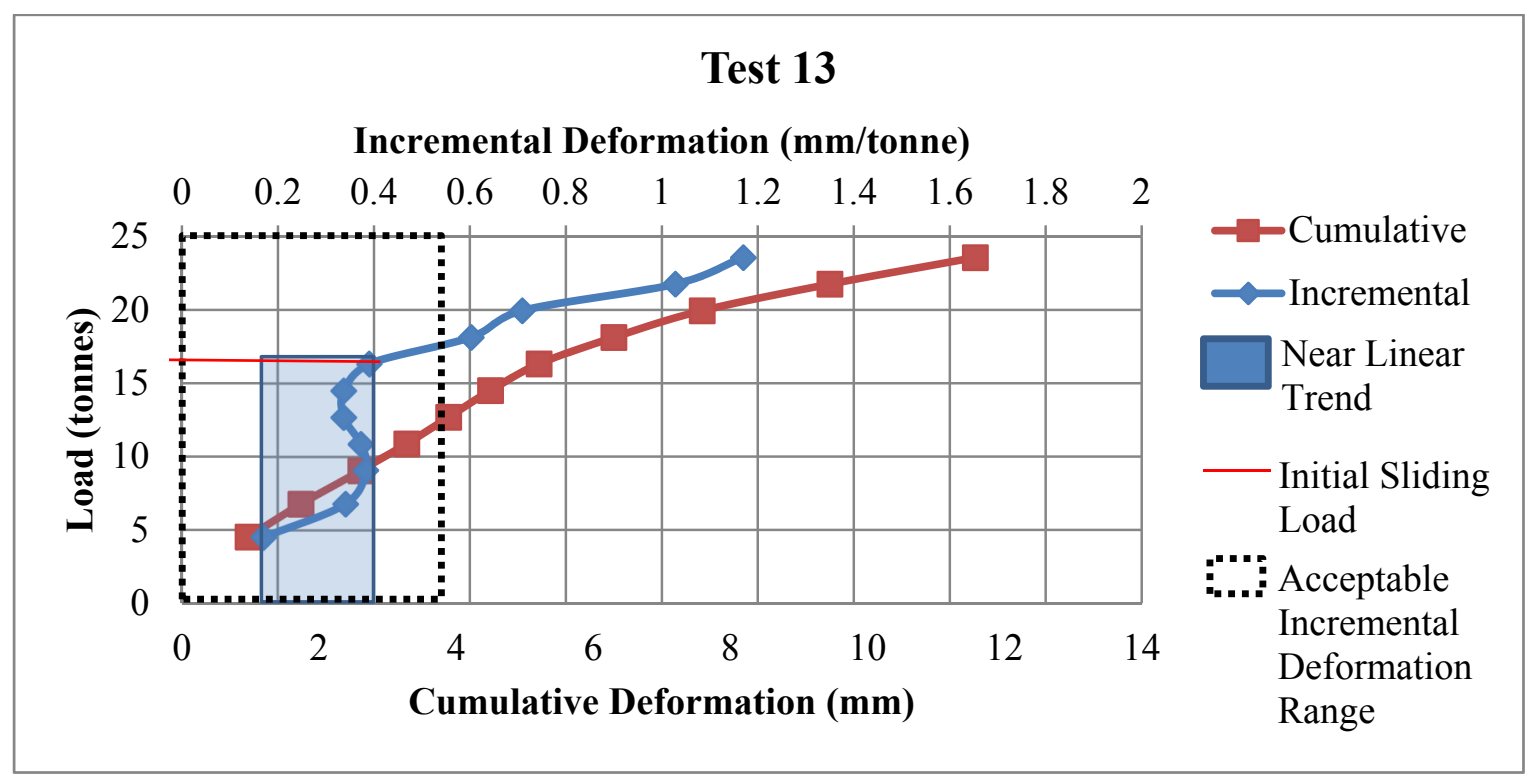

Figure E.12 Pull Test Load vs. Deformation Test 13 


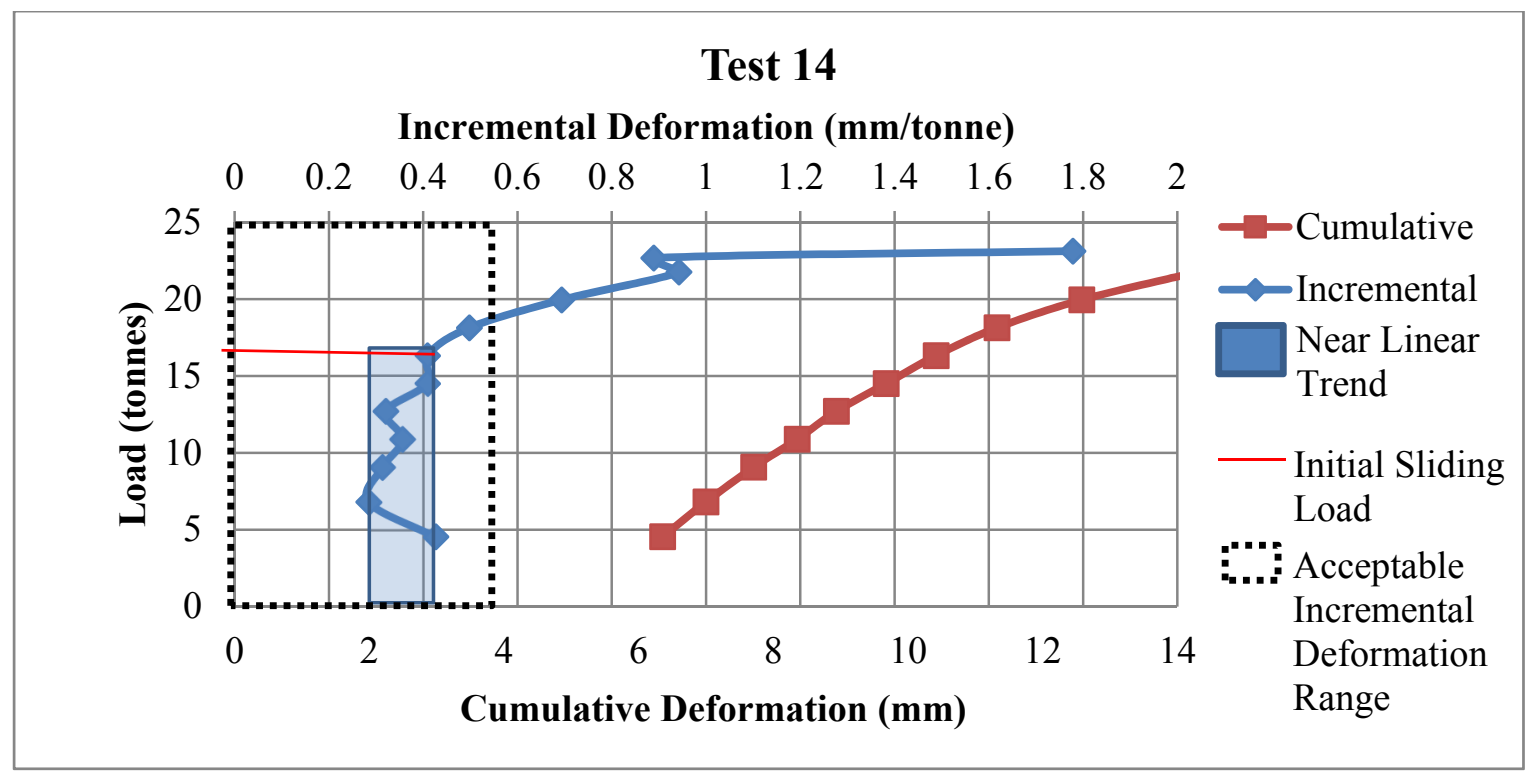

Figure E.13 Pull Test Load vs. Deformation Test 14

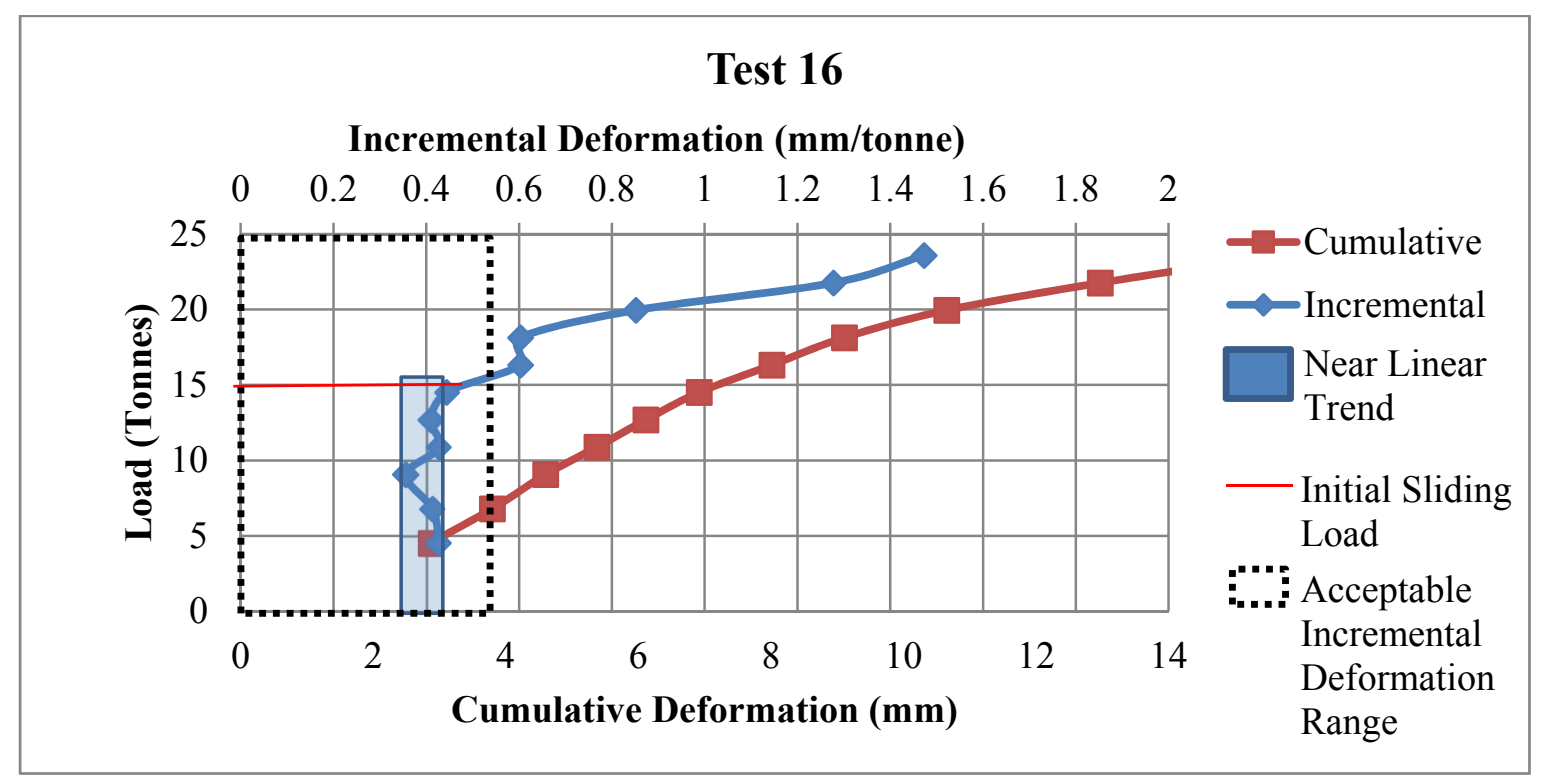

Figure E.14 Pull Test Load vs. Deformation Test 16 


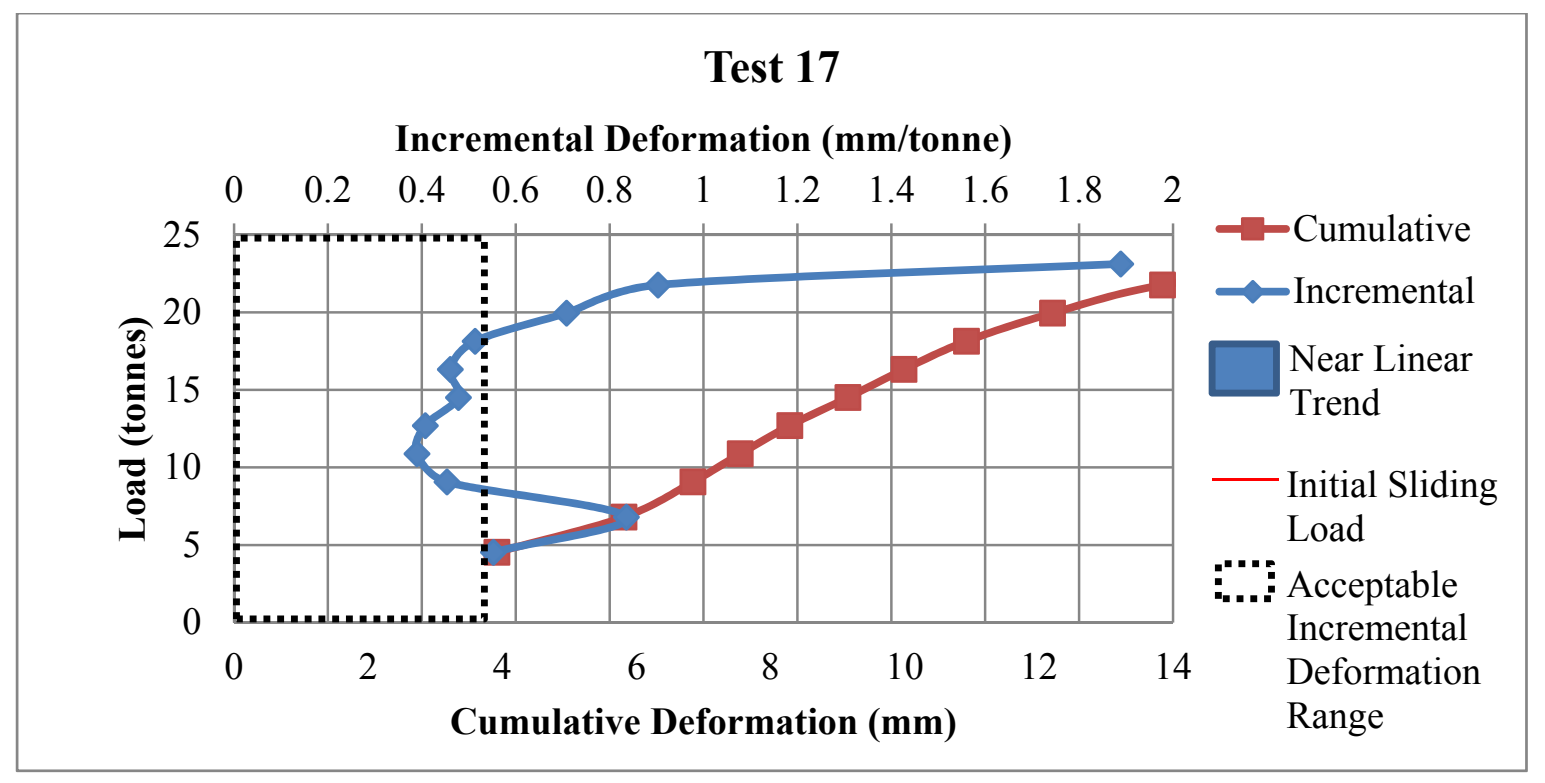

Figure E.15 Pull Test Load vs. Deformation Test 17

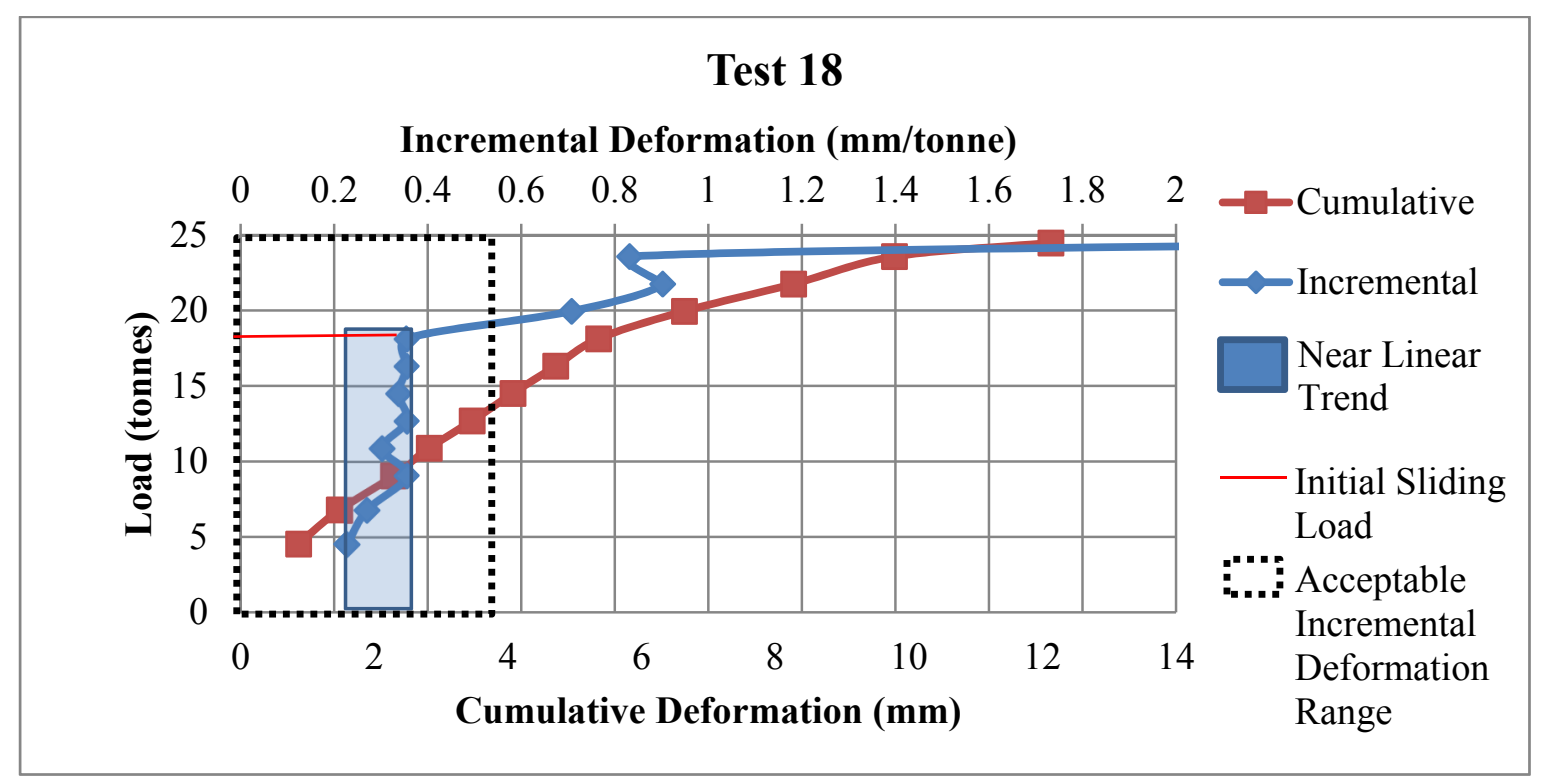

Figure E.16 Pull Test Load vs. Deformation Test 18 


\section{Test 19}

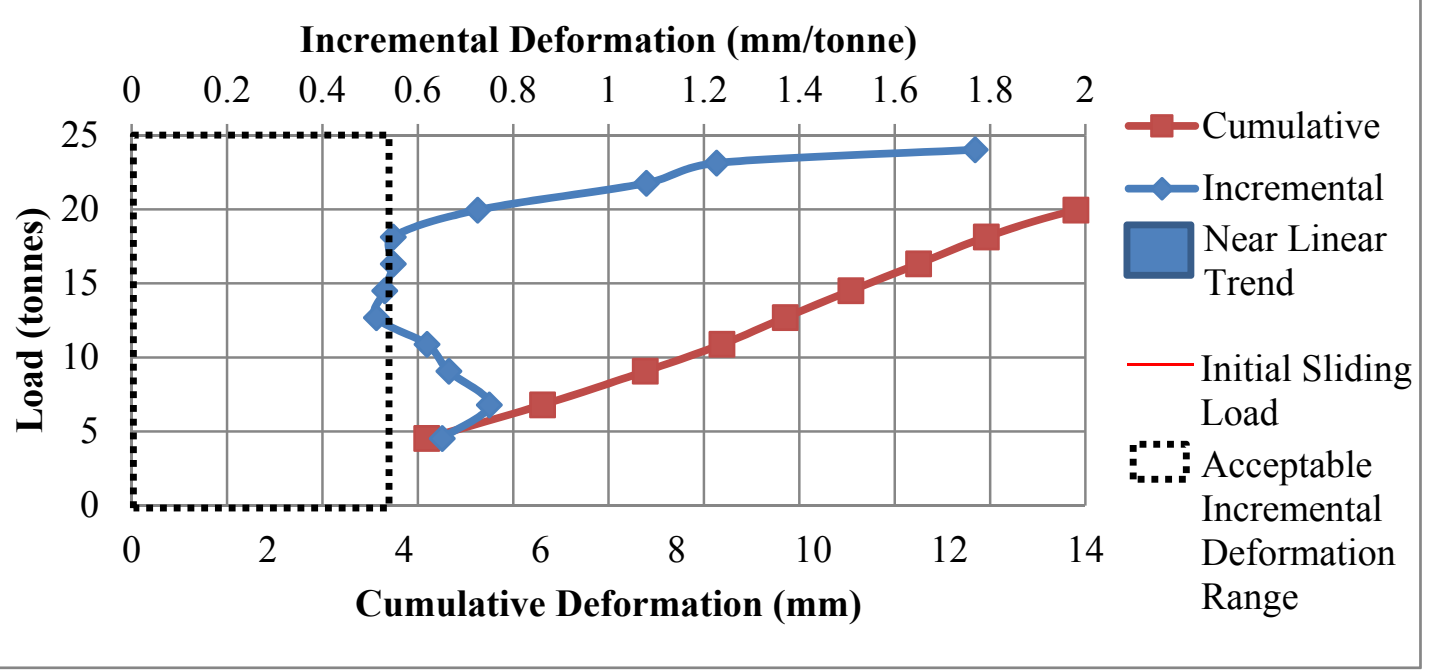

Figure E.17 Pull Test Load vs. Deformation Test 19

\section{"Borer 6" Testing Site Data (Active Mining Area on Potash Horizon)}

Table E. 2 shows the data collected from the rebar installed at the "Borer 6" testing site. The following figures show the load versus deformation plots for each test conducted.

Table E.2 "Borer 6" Site Data

\begin{tabular}{|c|c|c|c|c|c|}
\hline Test No. & $\begin{array}{c}\text { Cure Time } \\
\text { (days) }\end{array}$ & $\begin{array}{c}\text { Initial Sliding } \\
\text { Load } \\
\text { (tonnes) }\end{array}$ & $\begin{array}{c}\text { Bond } \\
\text { Strength } \\
\text { (Linear) } \\
\text { (tonnes/m) }\end{array}$ & $\begin{array}{l}\text { Resin-Rebar } \\
\text { Bond } \\
\text { Strength } \\
\text { (MPa) }\end{array}$ & $\begin{array}{l}\text { Resin-Rock } \\
\text { Bond } \\
\text { Strength } \\
\text { (MPa) }\end{array}$ \\
\hline 21 & 124.8 & \multicolumn{4}{|c|}{ Installed Improperly: Over spun resin } \\
\hline 22 & 124.9 & 16.8 & 33.0 & 4.2 & 2.8 \\
\hline 23 & 126.8 & 20.0 & 39.4 & 5.0 & 3.4 \\
\hline 24 & 126.8 & 21.0 & 41.3 & 5.3 & 3.5 \\
\hline 25 & 126.7 & 20.5 & 40.4 & 5.2 & 3.5 \\
\hline 26 & \multicolumn{5}{|c|}{ Rebar/Back crooked, unable to test } \\
\hline 27 & 126.4 & 16.0 & 31.5 & 4.0 & 2.7 \\
\hline 28 & 160.7 & 19.0 & 37.4 & 4.8 & 3.2 \\
\hline 29 & 258.7 & \multicolumn{4}{|l|}{ Indeterminate } \\
\hline 30 & 160.8 & 19.0 & 37.4 & 4.8 & 3.2 \\
\hline 31 & 160.8 & 21.0 & 41.3 & 5.3 & 3.5 \\
\hline 32 & 258.7 & 19.0 & 37.4 & 4.8 & 3.2 \\
\hline 33 & 258.8 & \multicolumn{4}{|c|}{ Installed Improperly: Hole length over drilled } \\
\hline 34 & 318.7 & 18.3 & 36.0 & 4.6 & 3.1 \\
\hline 35 & 318.7 & 21.0 & 41.3 & 5.3 & 3.5 \\
\hline 36 & \multicolumn{5}{|c|}{ Rebar/Back crooked, unable to test } \\
\hline 37 & 318.7 & \multicolumn{4}{|l|}{ Indeterminate } \\
\hline
\end{tabular}




\begin{tabular}{|c|c|c|c|c|c|}
\hline 38 & 318.7 & 19.0 & 37.4 & 4.8 & 3.2 \\
\hline 39 & 318.7 & \multicolumn{4}{|c|}{ Indeterminate } \\
\hline 40 & 318.8 & \multicolumn{4}{|c|}{ Installed Improperly: Hole length over drilled } \\
\hline 41 & 313.1 & 19.8 & 38.9 & 5.0 & 3.3 \\
\hline 42 & 313.1 & \multicolumn{4}{|c|}{ Indeterminate } \\
\hline 43 & \multicolumn{5}{|c|}{ Rebar Damaged Before Testing } \\
\hline 44 & \multicolumn{5}{|c|}{ Rebar Damaged Before Testing } \\
\hline 45 & 271.0 & 20.0 & 39.4 & 5.0 & 3.4 \\
\hline 46 & 270.9 & 17.8 & 34.9 & 4.5 & 3.0 \\
\hline 47 & \multicolumn{5}{|c|}{ Rebar/Back crooked, unable to test } \\
\hline 48 & 275.1 & 13.0 & 25.6 & 3.3 & 2.2 \\
\hline 49 & 274.9 & \multicolumn{4}{|c|}{ Installed Improperly: Over spun resin } \\
\hline 50 & 275.0 & \multicolumn{4}{|c|}{ Installed Improperly: Hole length over drilled } \\
\hline 51 & 274.9 & 19.5 & 38.4 & 4.9 & 3.3 \\
\hline 52 & 274.9 & 21.8 & 42.8 & 5.5 & 3.7 \\
\hline 53 & 315.8 & 20.0 & 39.4 & 5.0 & 3.4 \\
\hline 54 & 315.8 & 20.8 & 40.9 & 5.2 & 3.5 \\
\hline 55 & 315.9 & 19.5 & 38.4 & 4.9 & 3.3 \\
\hline 56 & 315.9 & 18.0 & 35.4 & 4.5 & 3.0 \\
\hline 57 & 315.9 & 20.0 & 39.4 & 5.0 & 3.4 \\
\hline 58 & 315.9 & 19.8 & 38.9 & 5.0 & 3.3 \\
\hline 59 & \multicolumn{5}{|c|}{ Rebar Damaged Before Testing } \\
\hline 60 & 315.9 & 19.0 & 37.4 & 4.8 & 3.2 \\
\hline
\end{tabular}

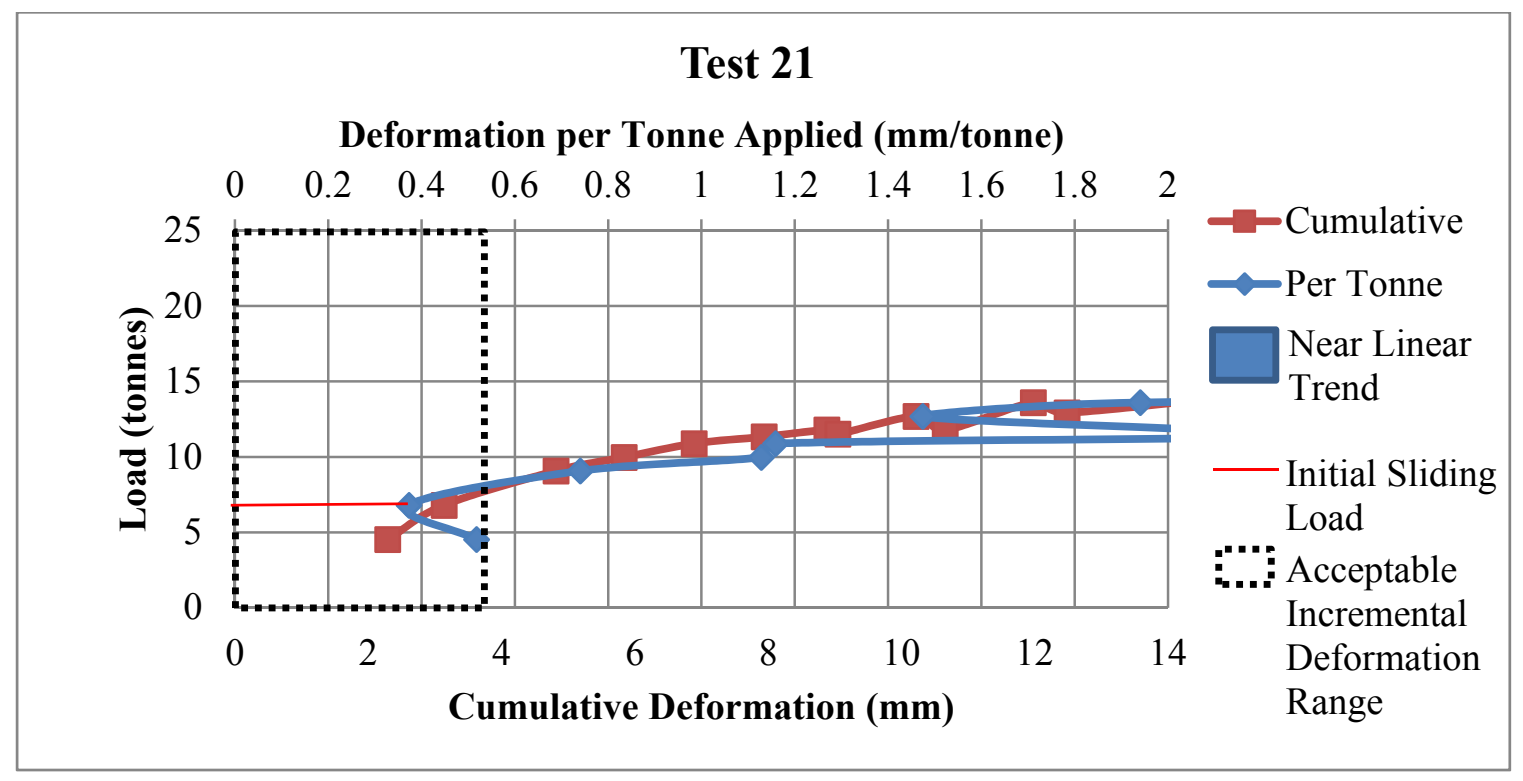

Figure E.18 Pull Test Load vs. Deformation Test 21 


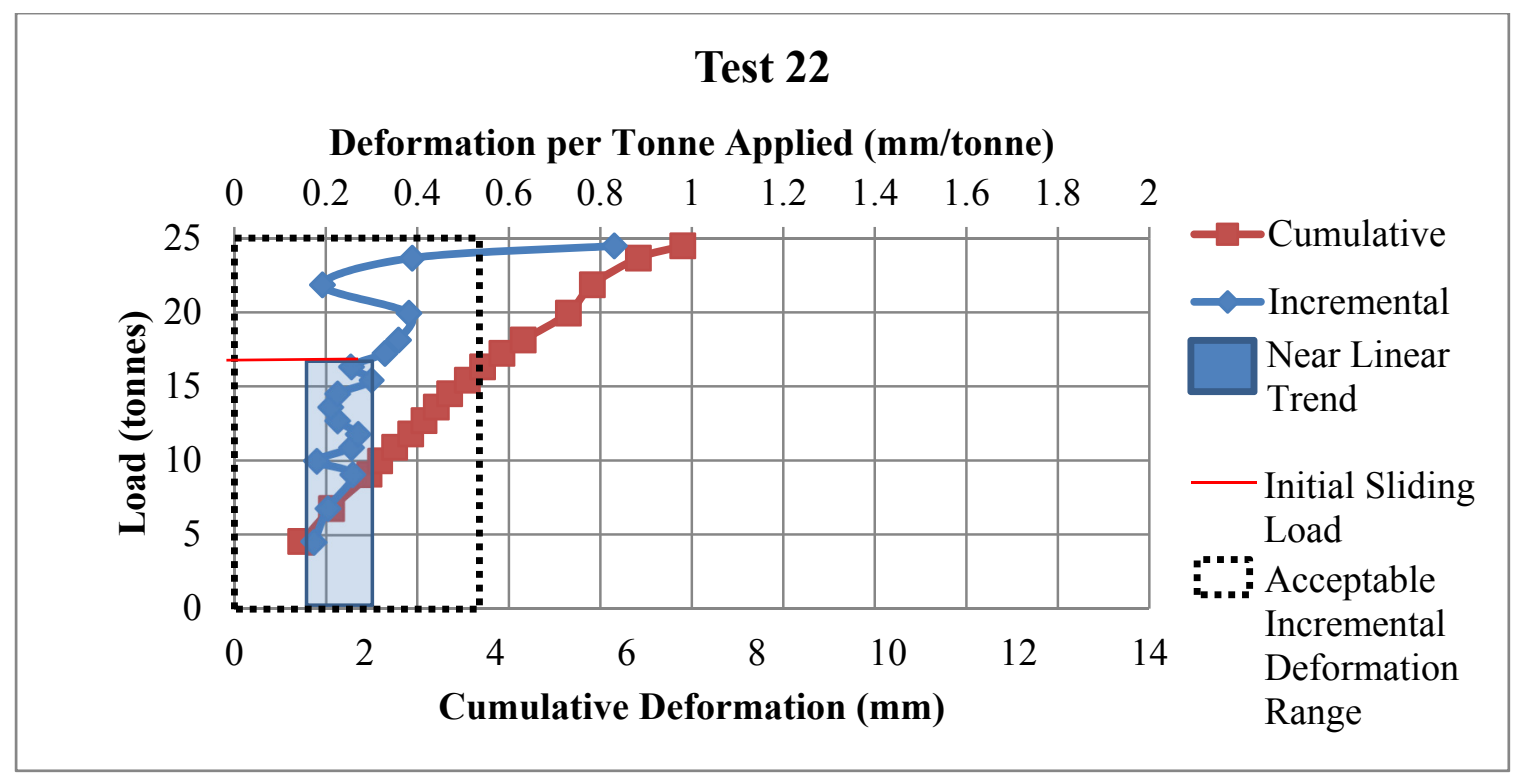

Figure E.19 Pull Test Load vs. Deformation Test 22

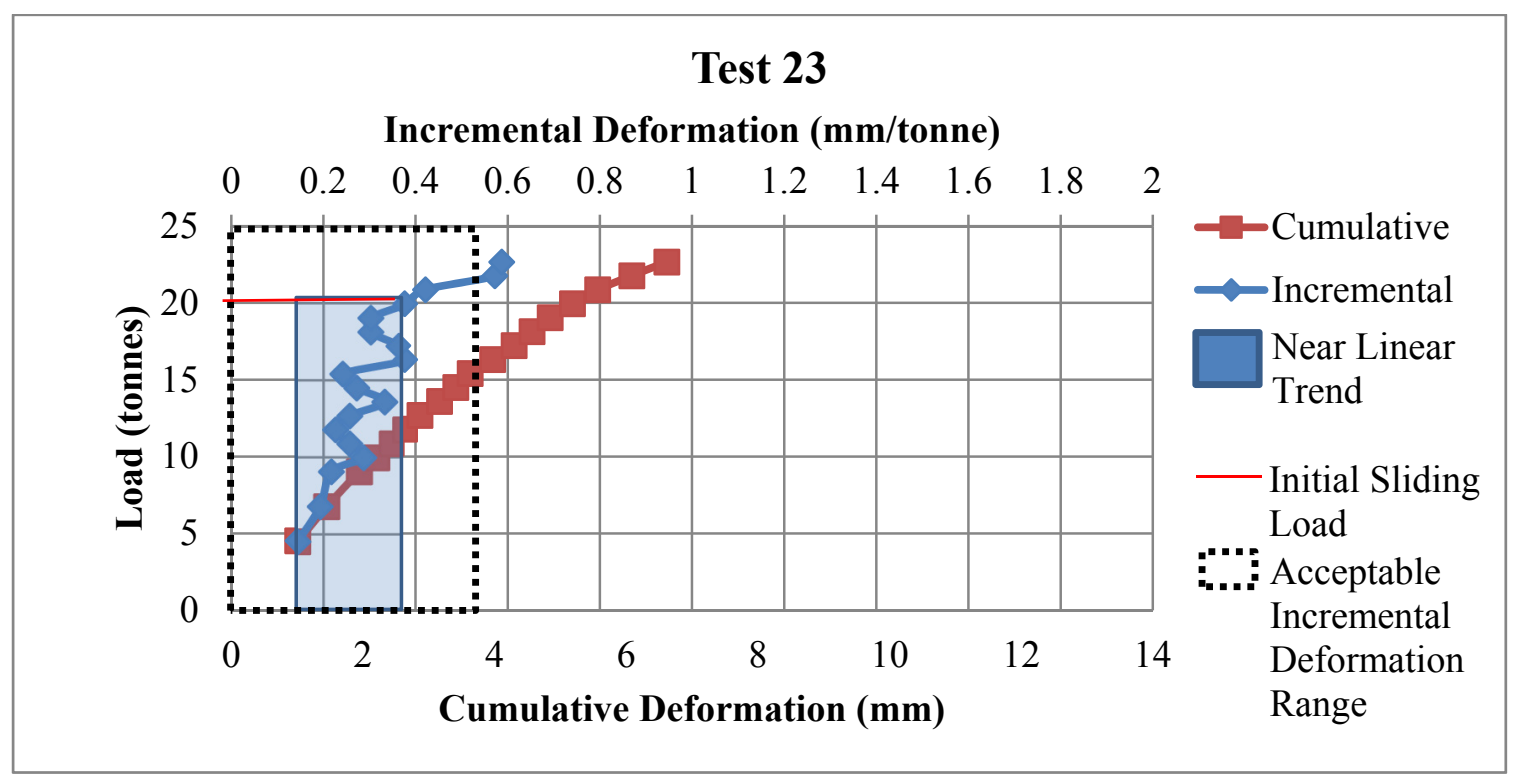

Figure E.20 Pull Test Load vs. Deformation Test 23 


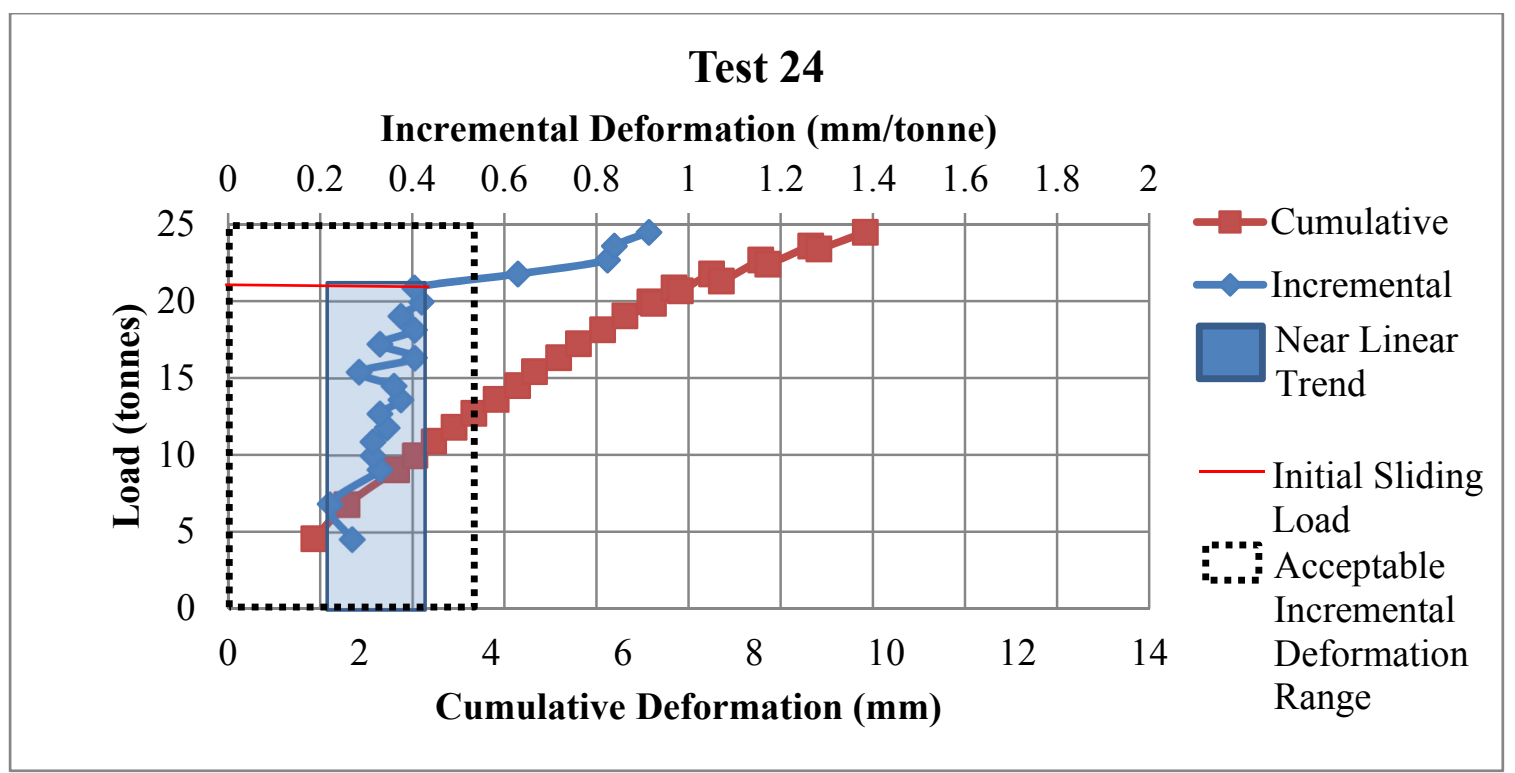

Figure E.21 Pull Test Load vs. Deformation Test 24

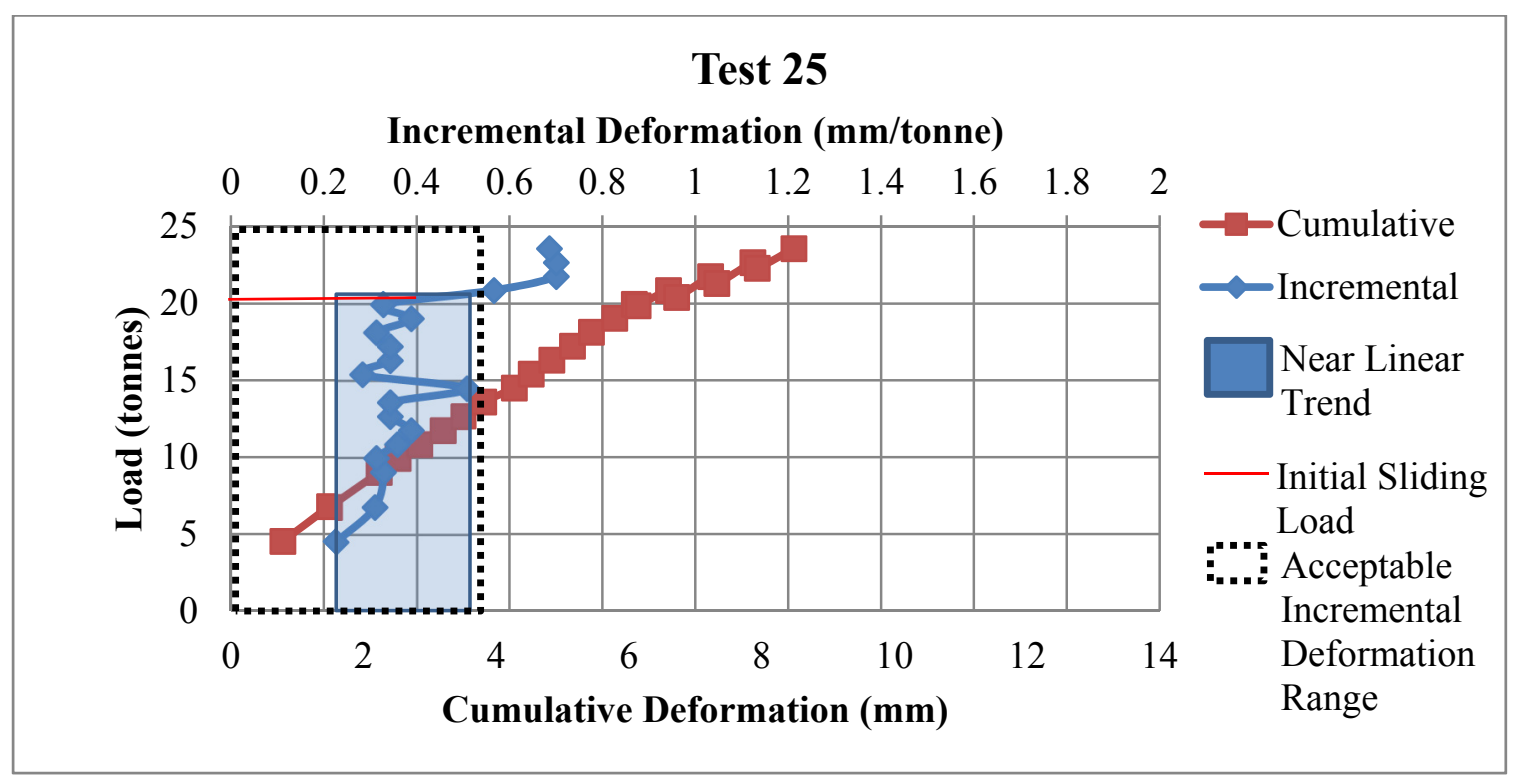

Figure E.22 Pull Test Load vs. Deformation Test 25 


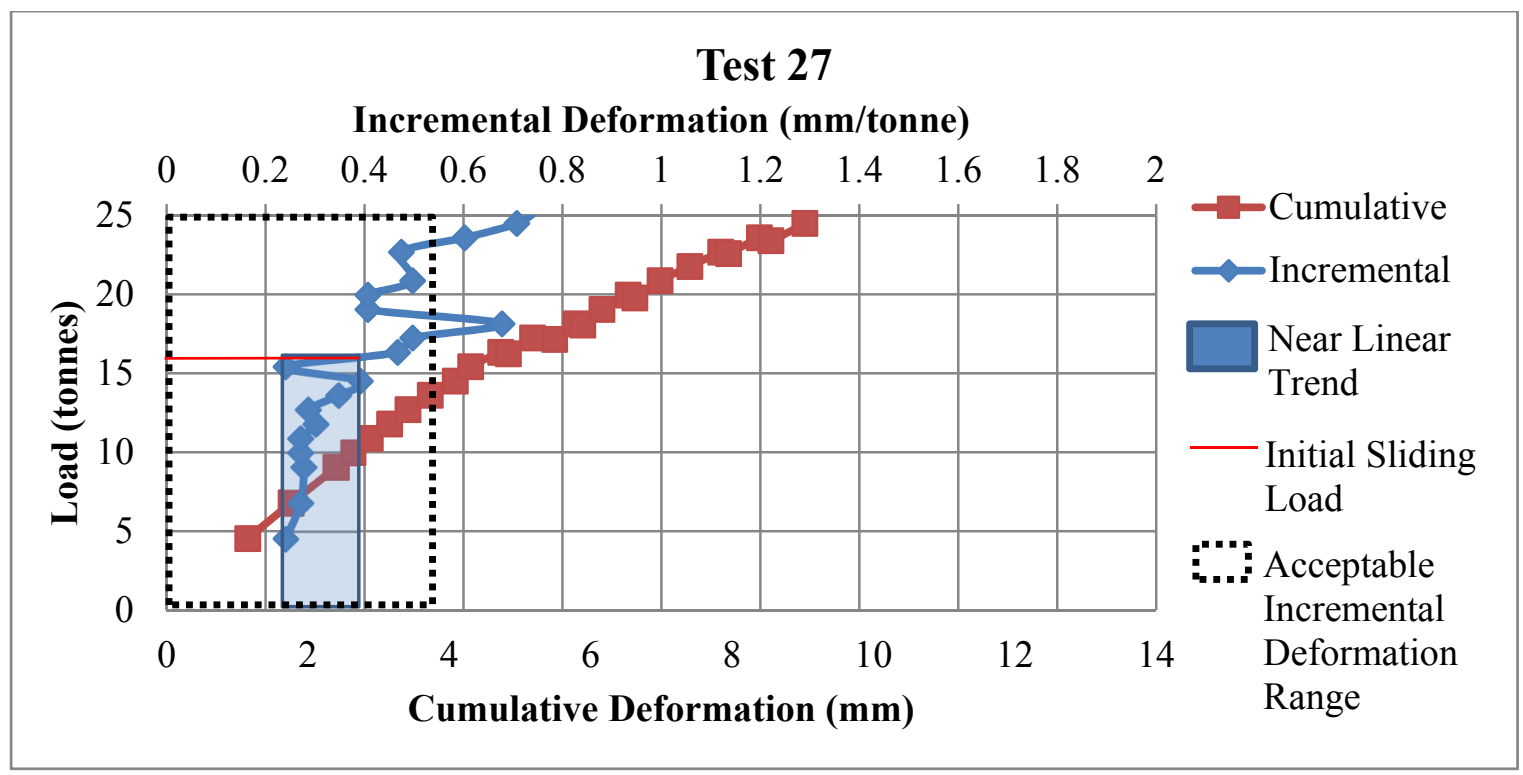

Figure E.23 Pull Test Load vs. Deformation Test 27

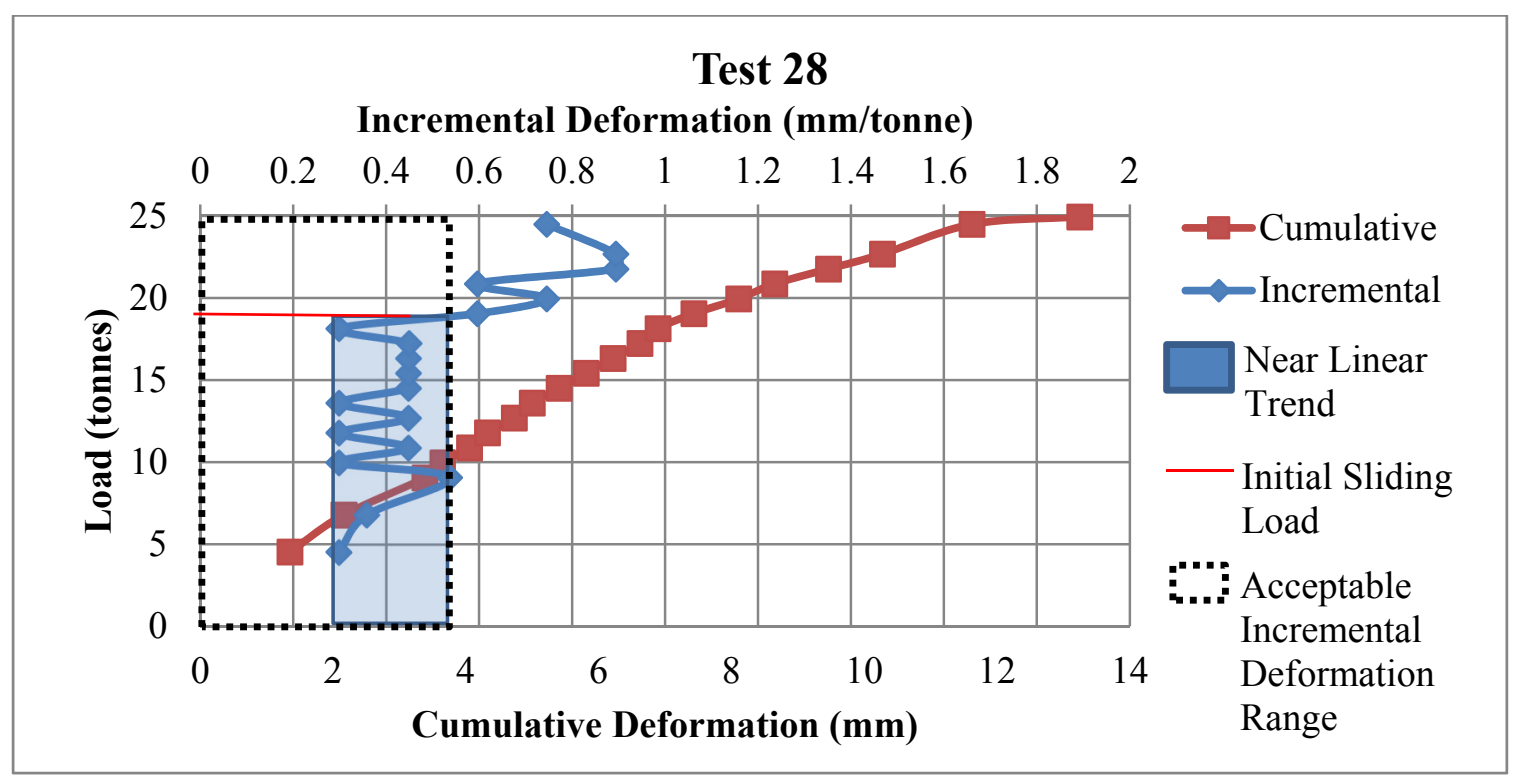

Figure E.24 Pull Test Load vs. Deformation Test 28 


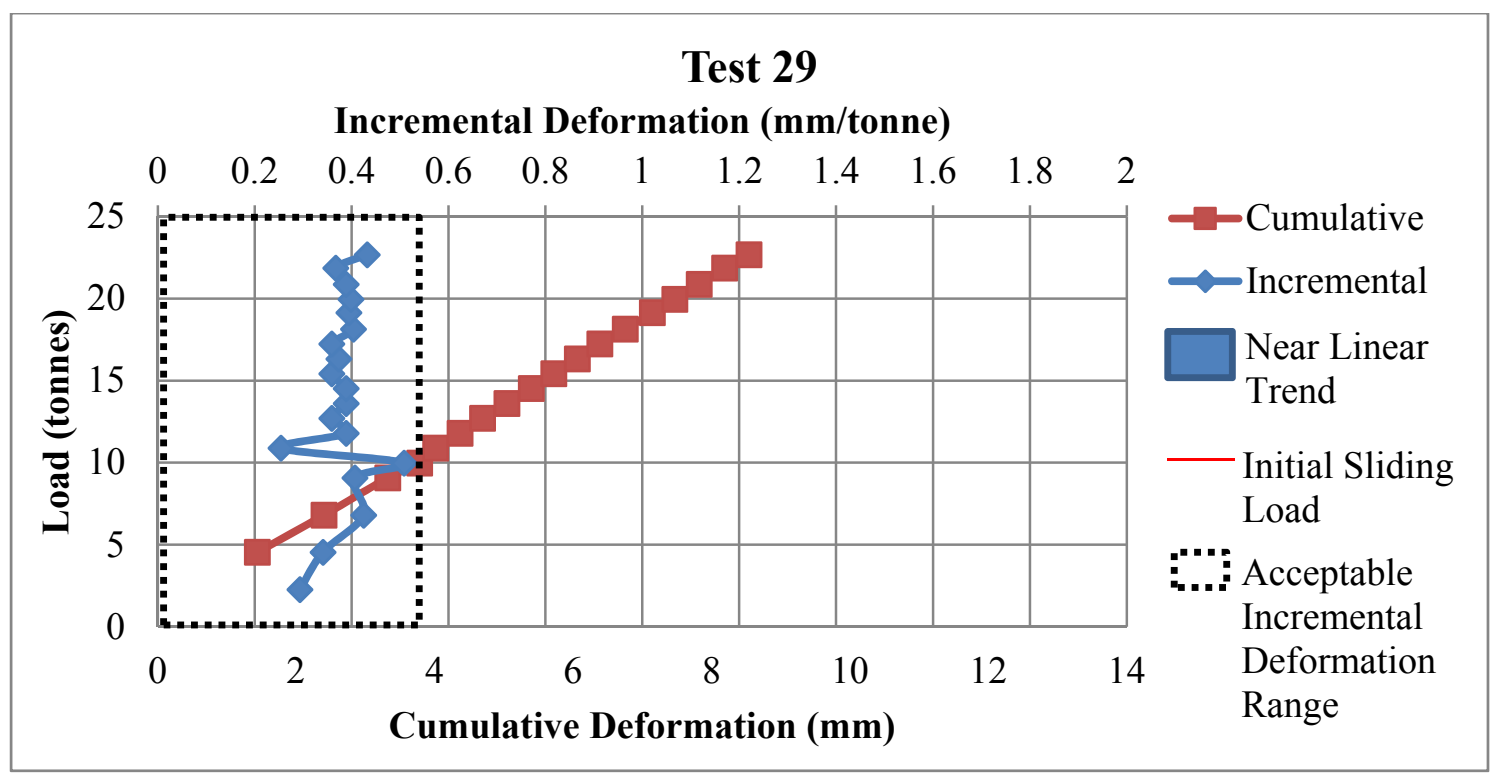

Figure E.25 Pull Test Load vs. Deformation Test 29

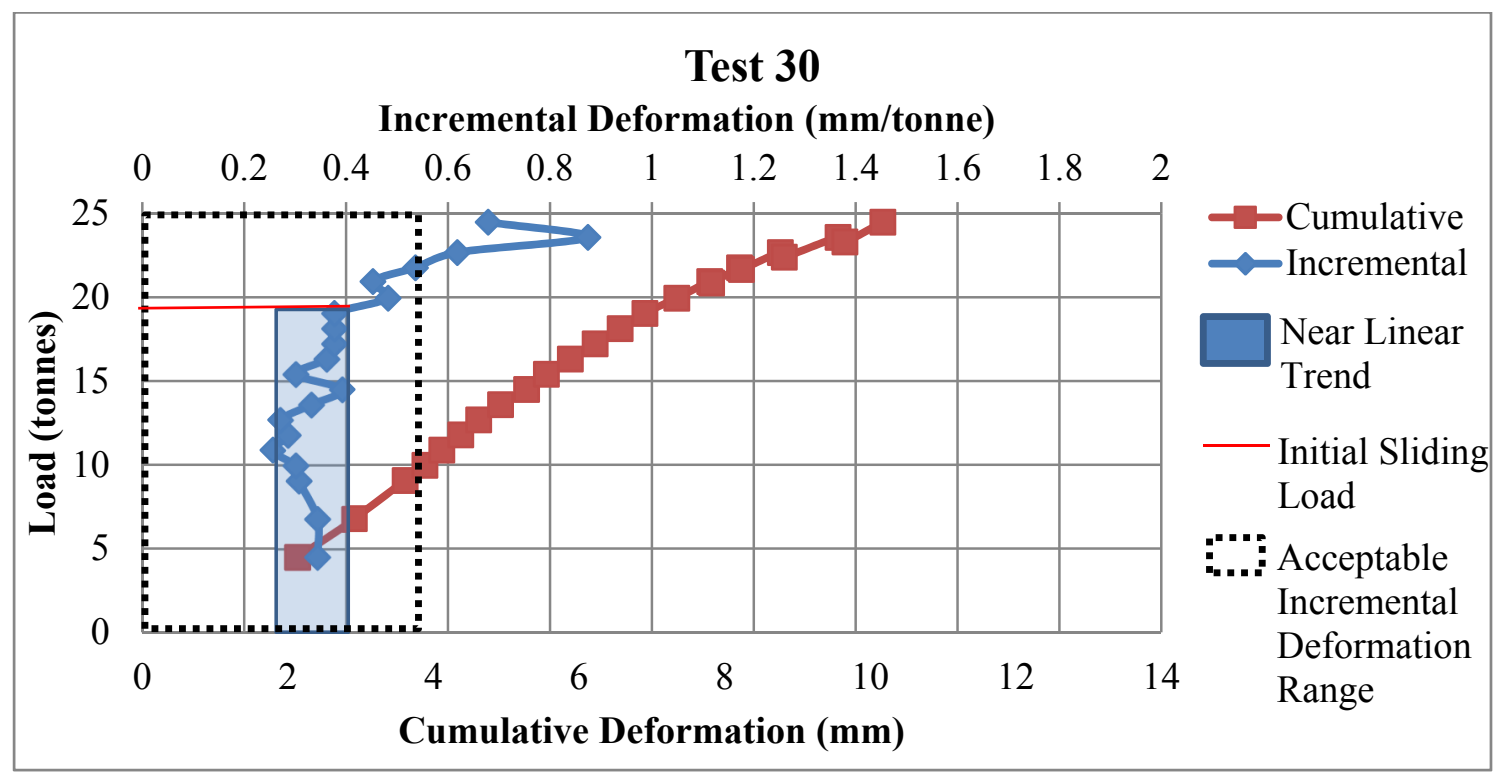

Figure E.26 Pull Test Load vs. Deformation Test 30 


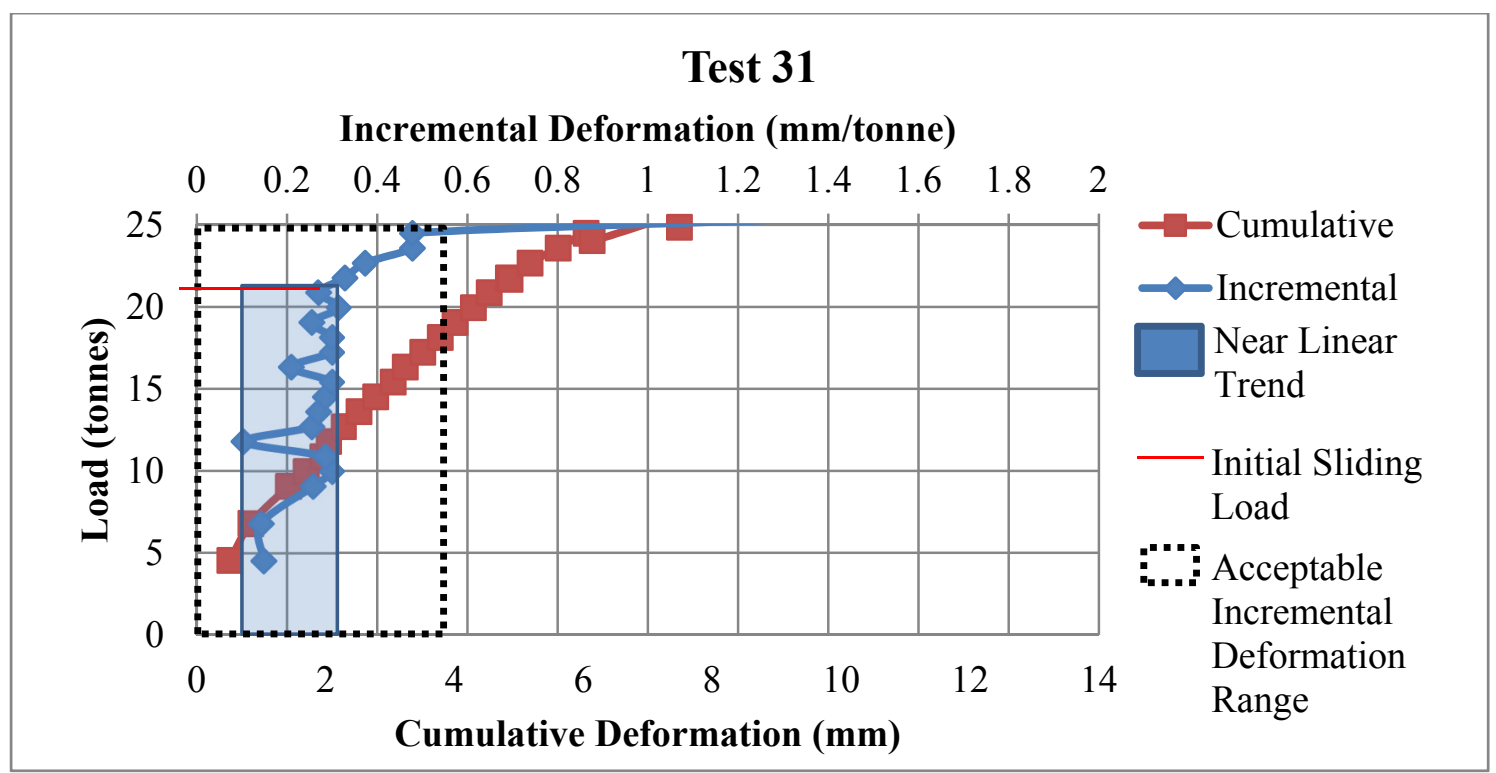

Figure E.27 Pull Test Load vs. Deformation Test 31

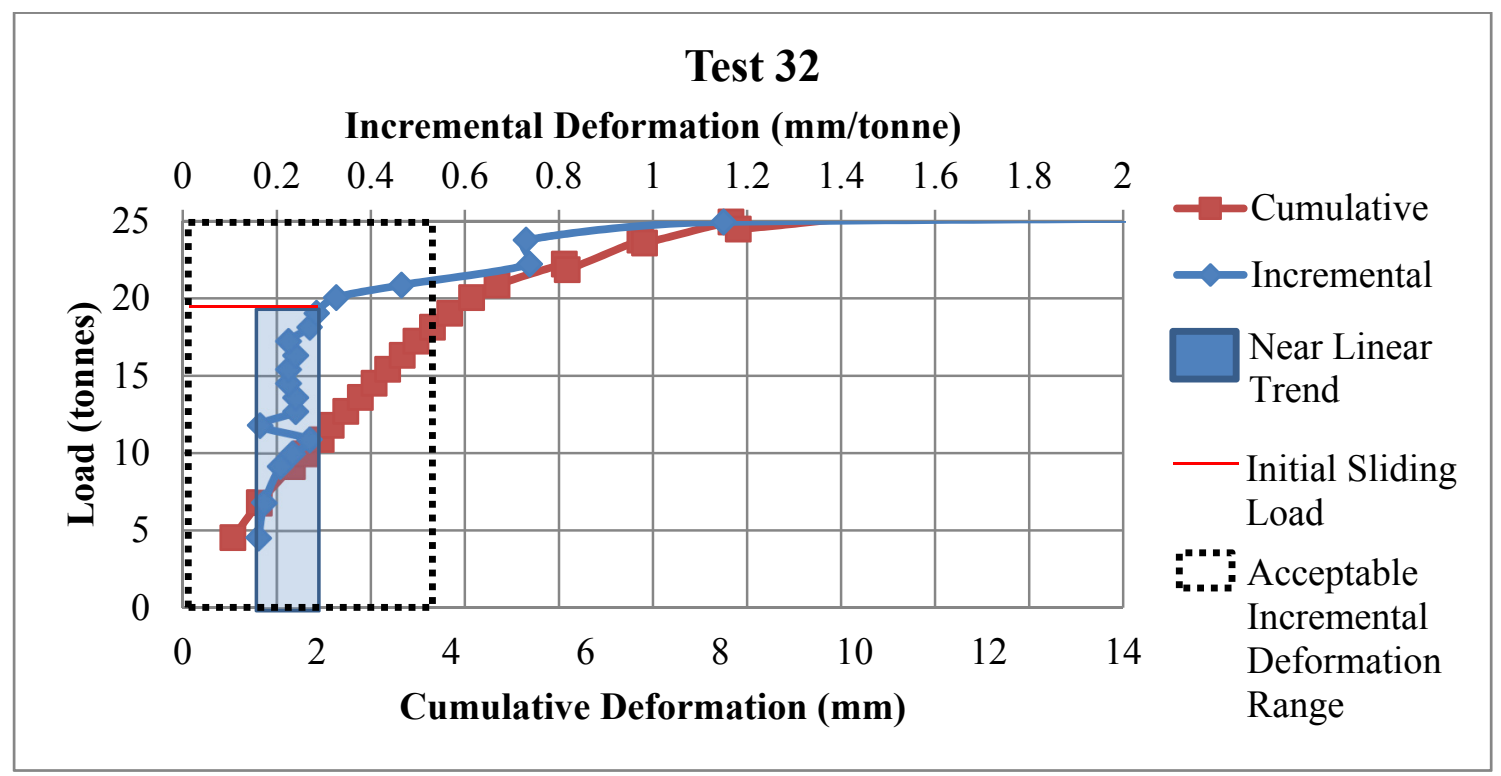

Figure E.28 Pull Test Load vs. Deformation Test 32 


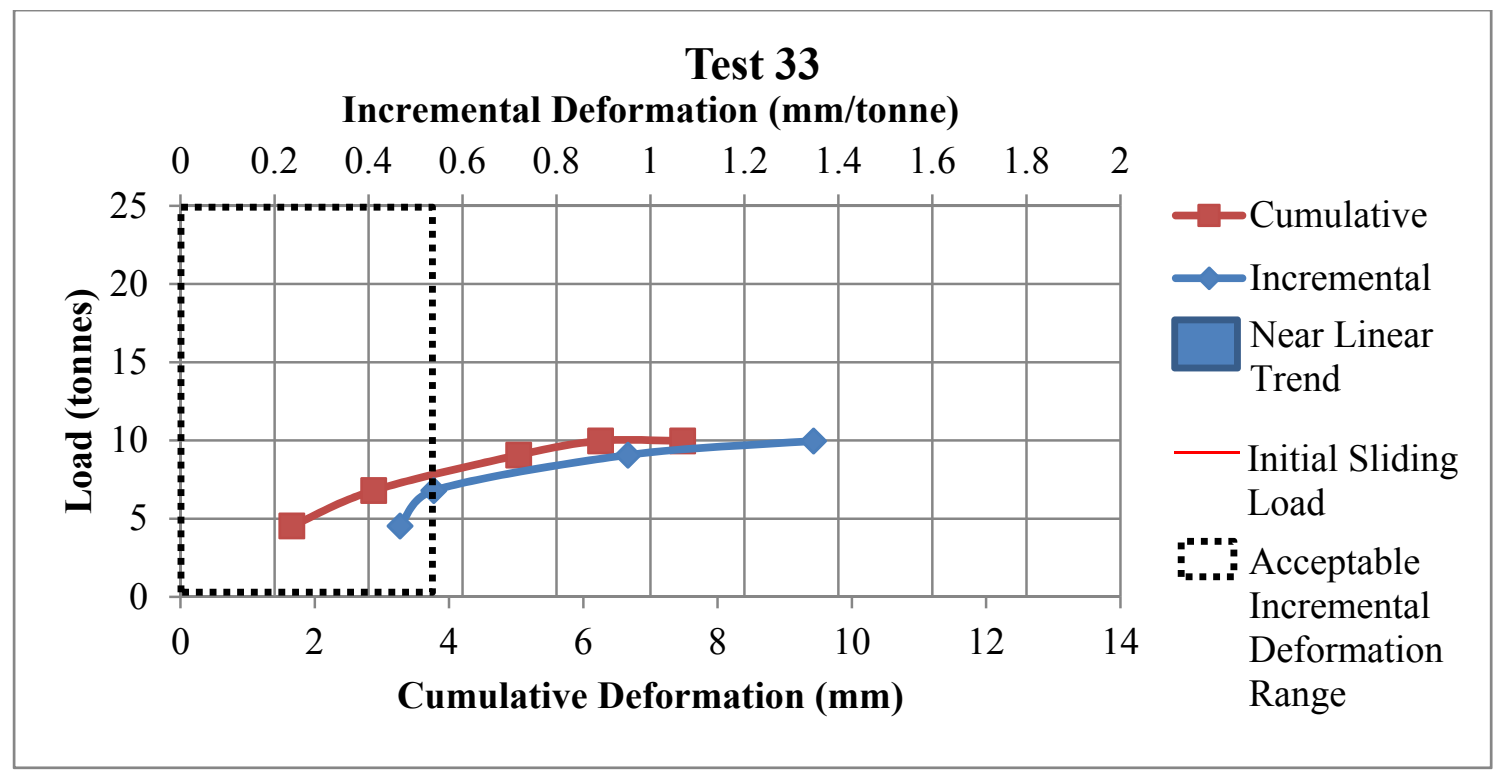

Figure E.29 Pull Test Load vs. Deformation Test 33

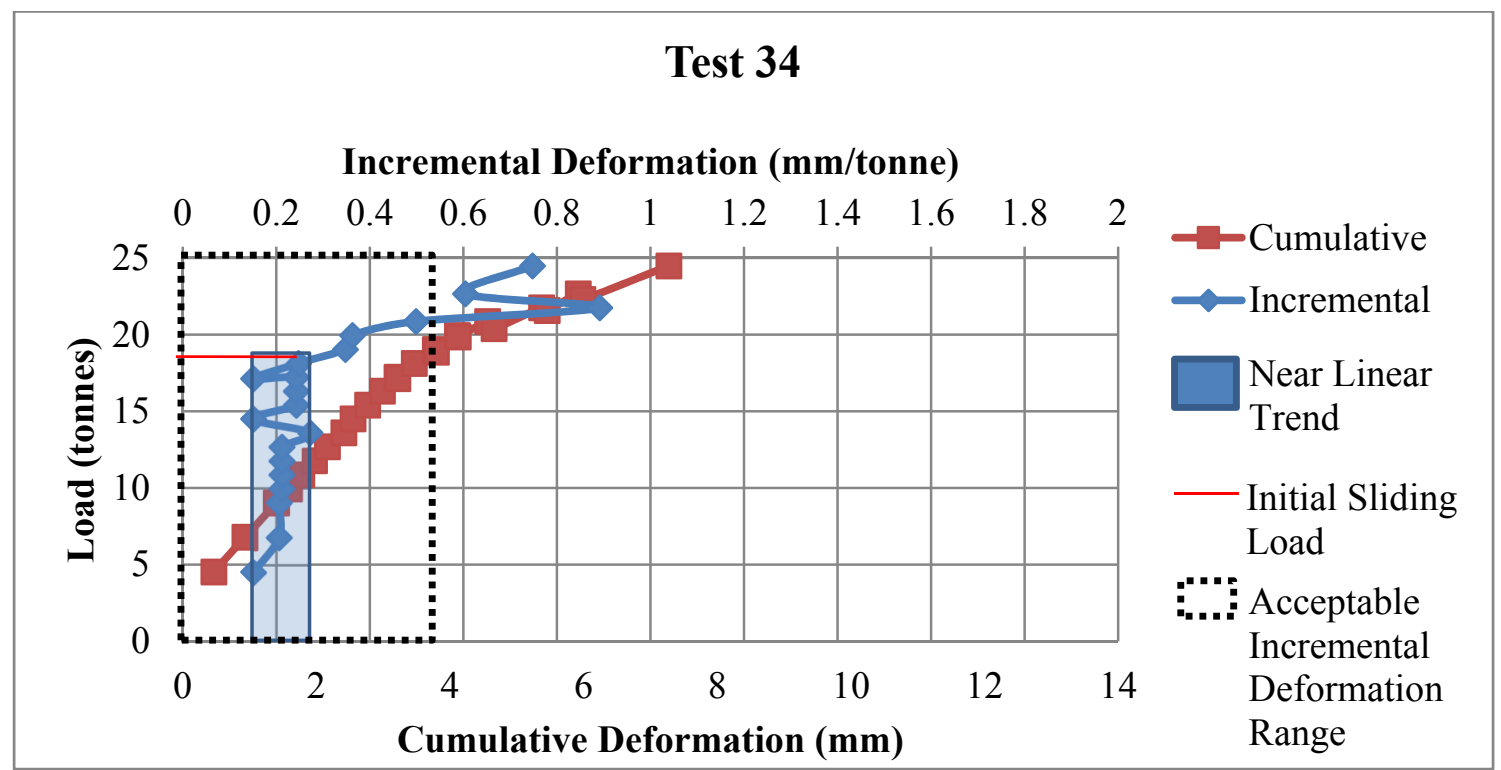

Figure E.30 Pull Test Load vs. Deformation Test 34 


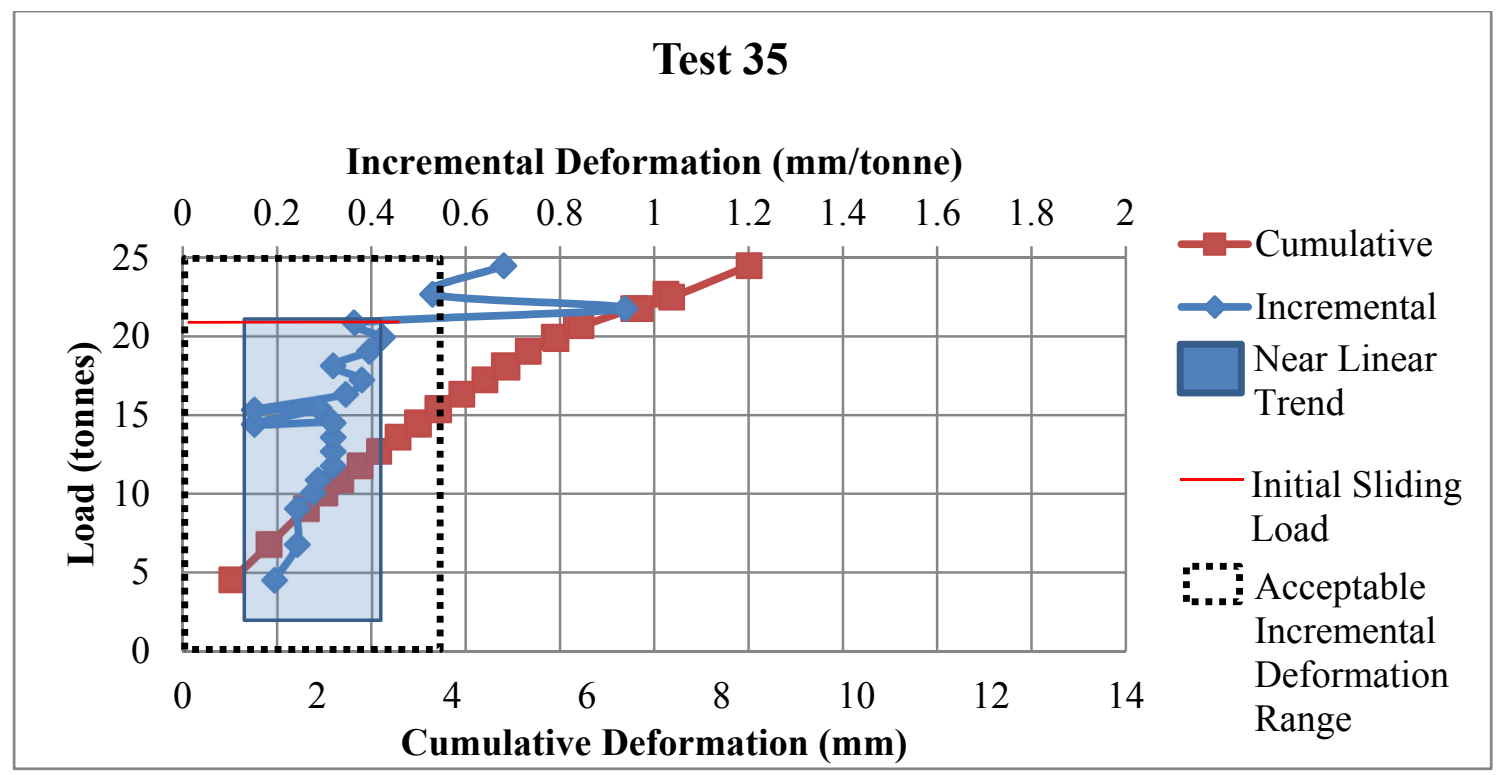

Figure E.31 Pull Test Load vs. Deformation Test 35

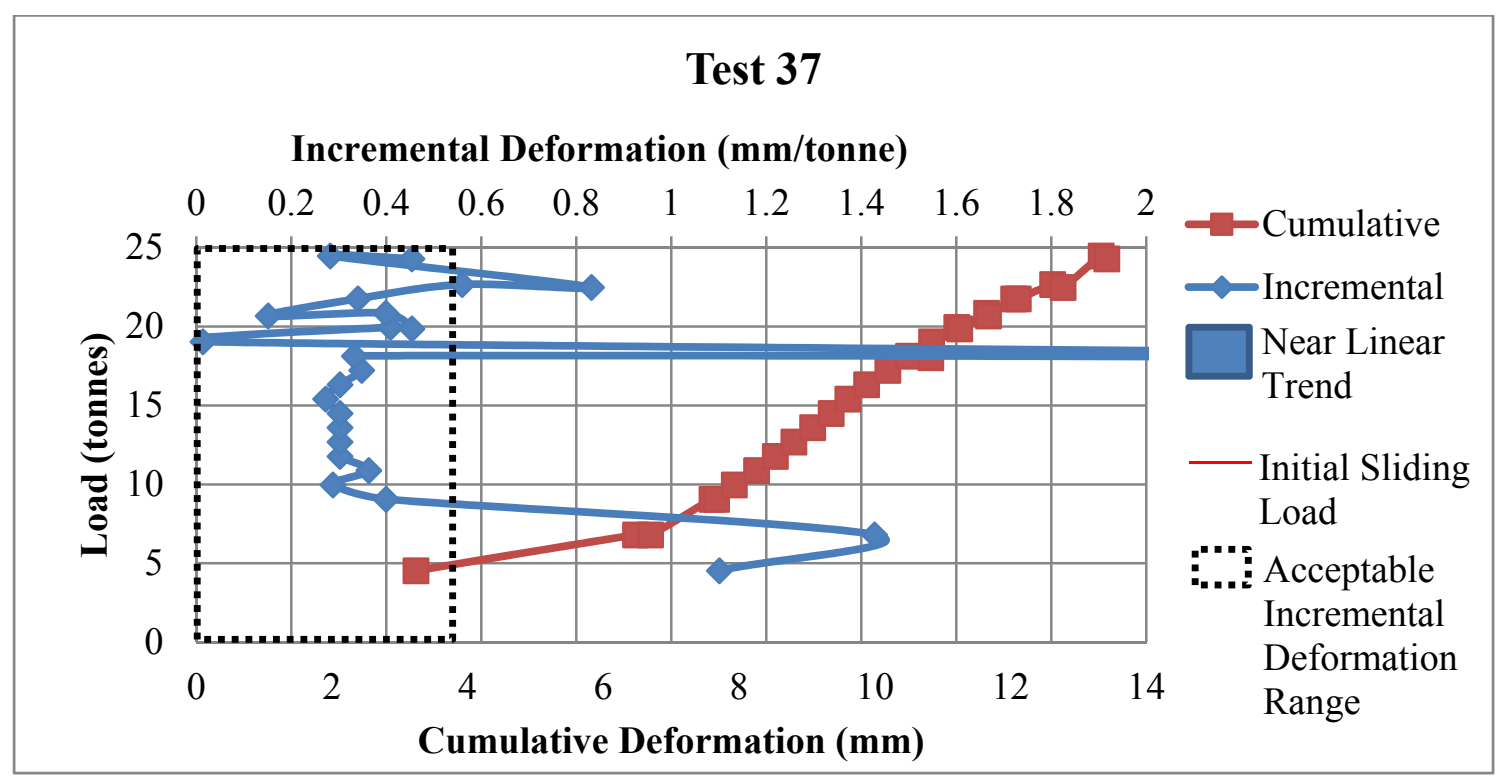

Figure E.32 Pull Test Load vs. Deformation Test 37 


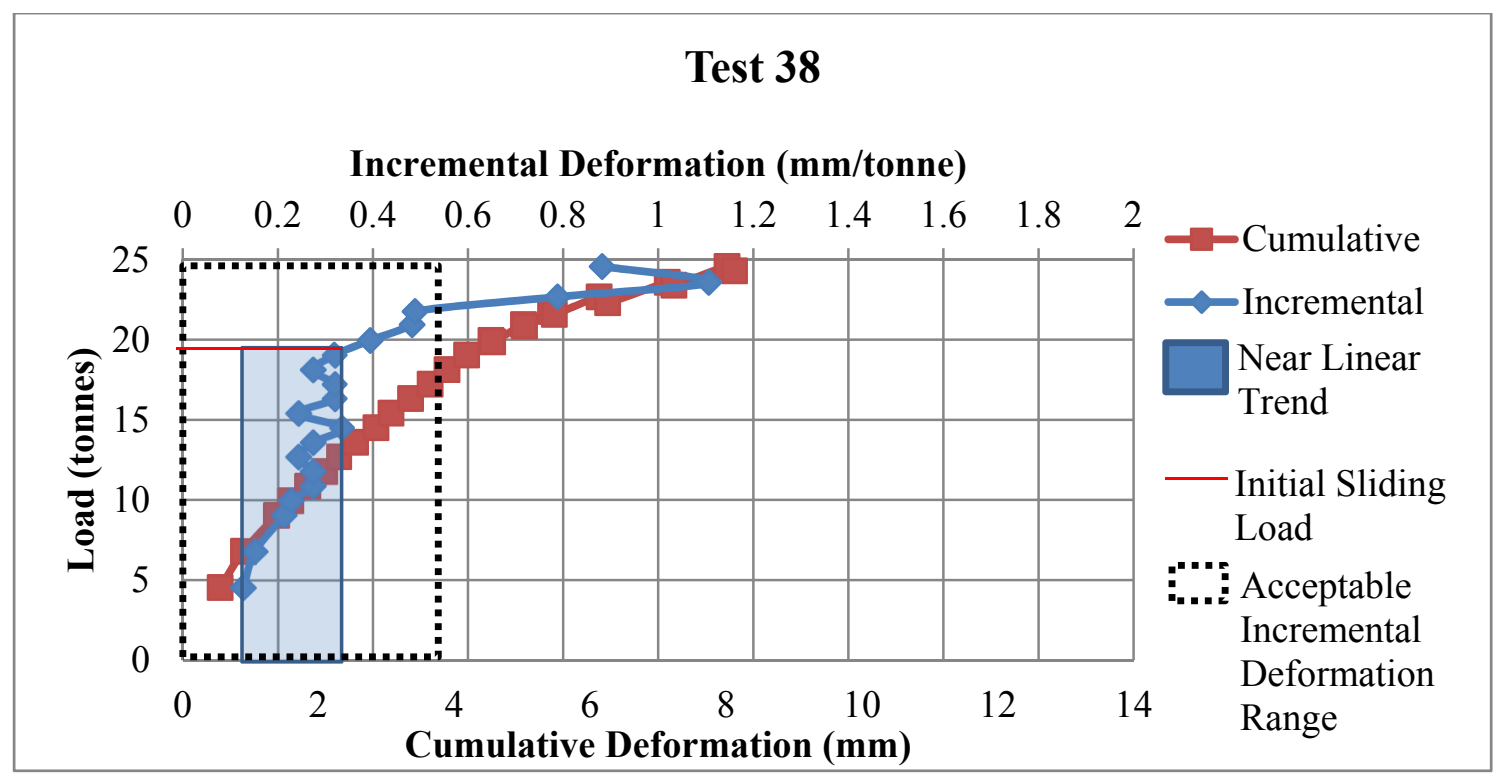

Figure E.33 Pull Test Load vs. Deformation Test 38

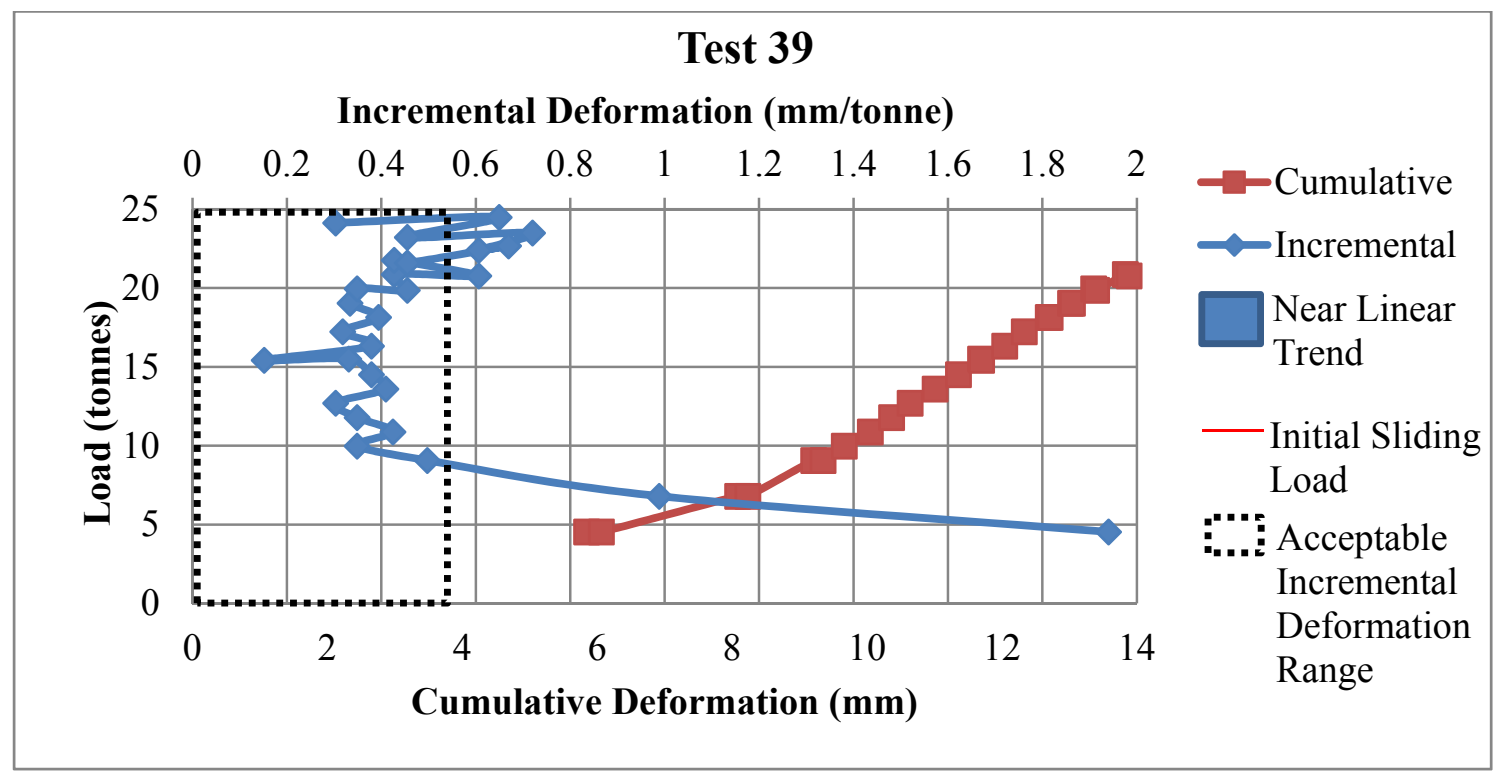

Figure E.34 Pull Test Load vs. Deformation Test 39 


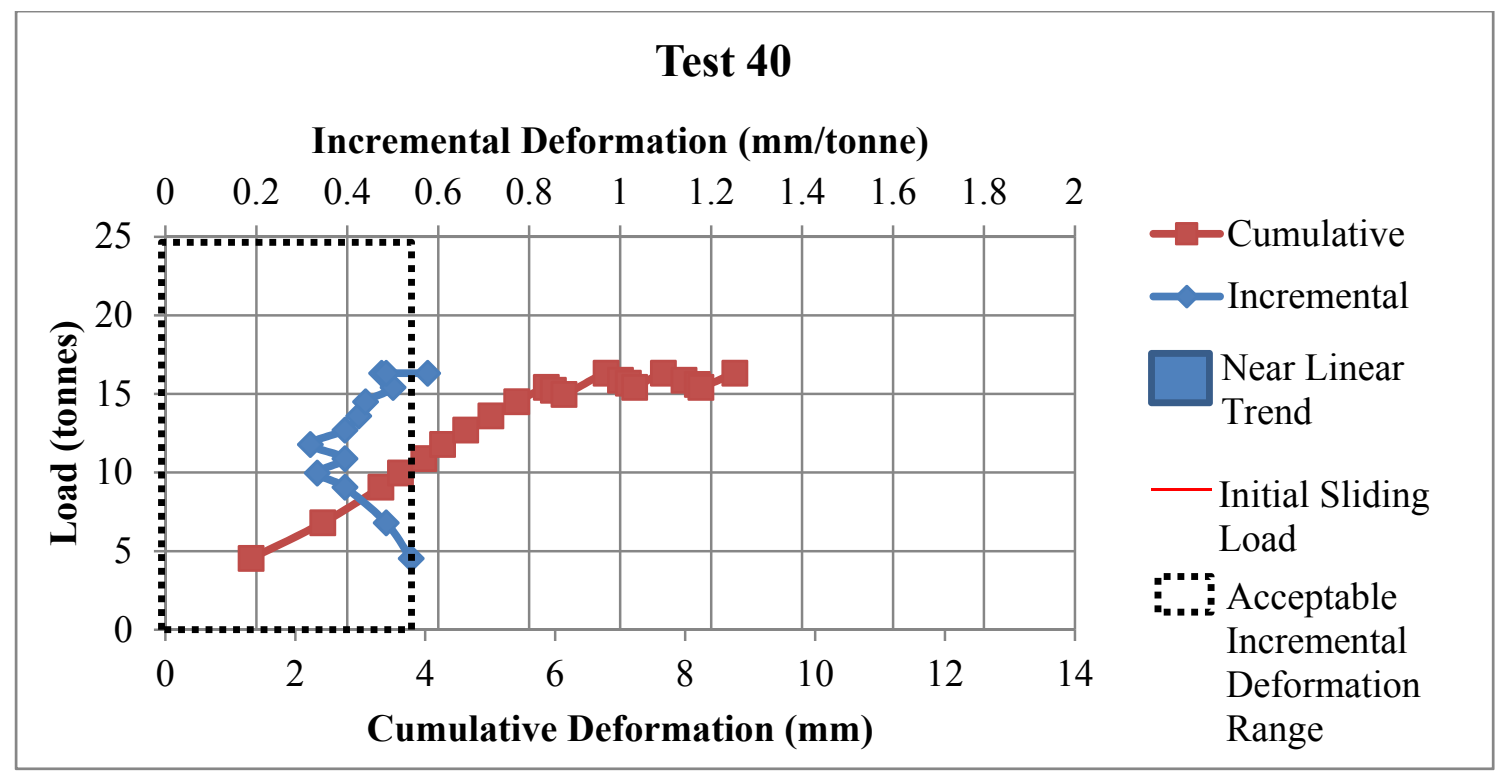

Figure E.35 Pull Test Load vs. Deformation Test 40

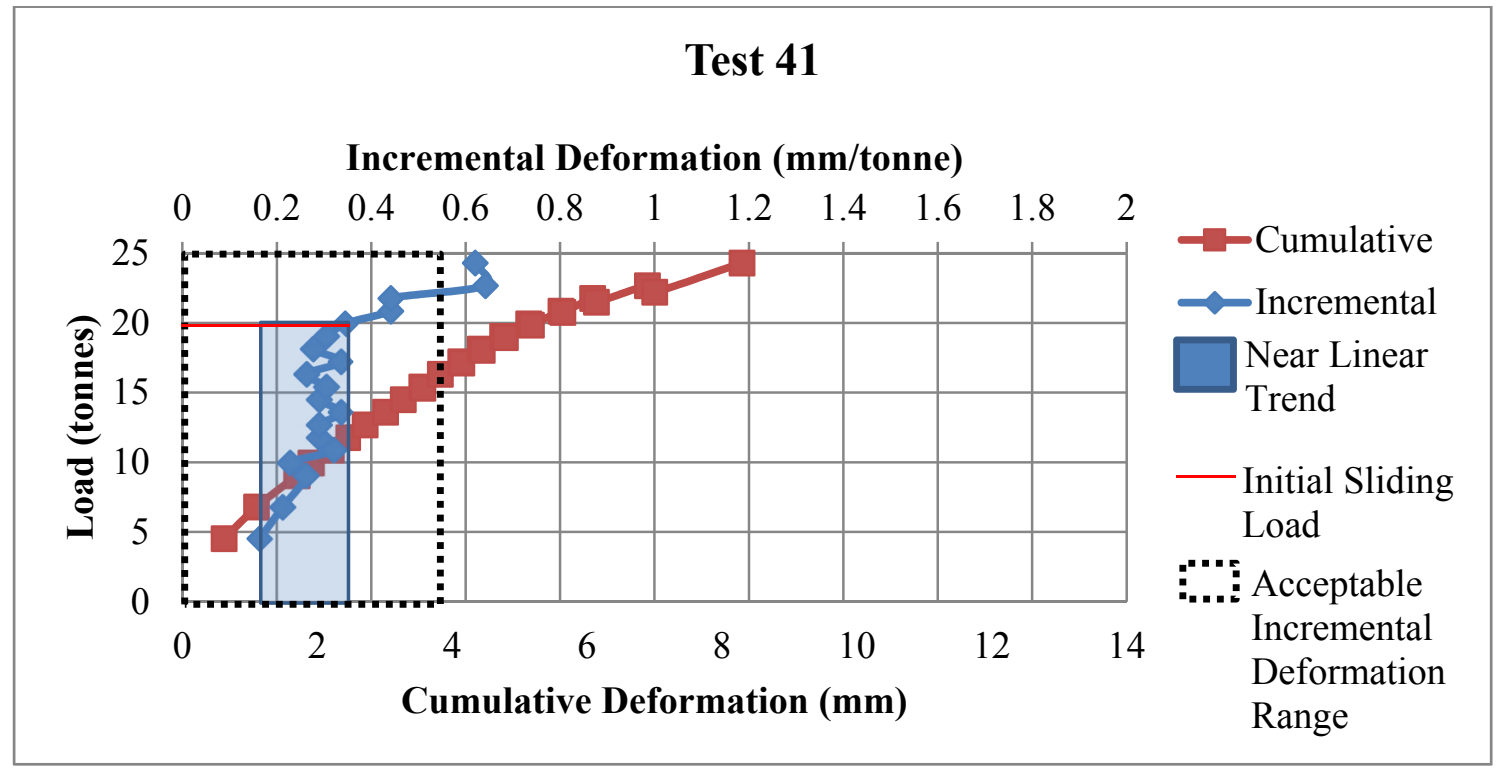

Figure E.36 Pull Test Load vs. Deformation Test 41 


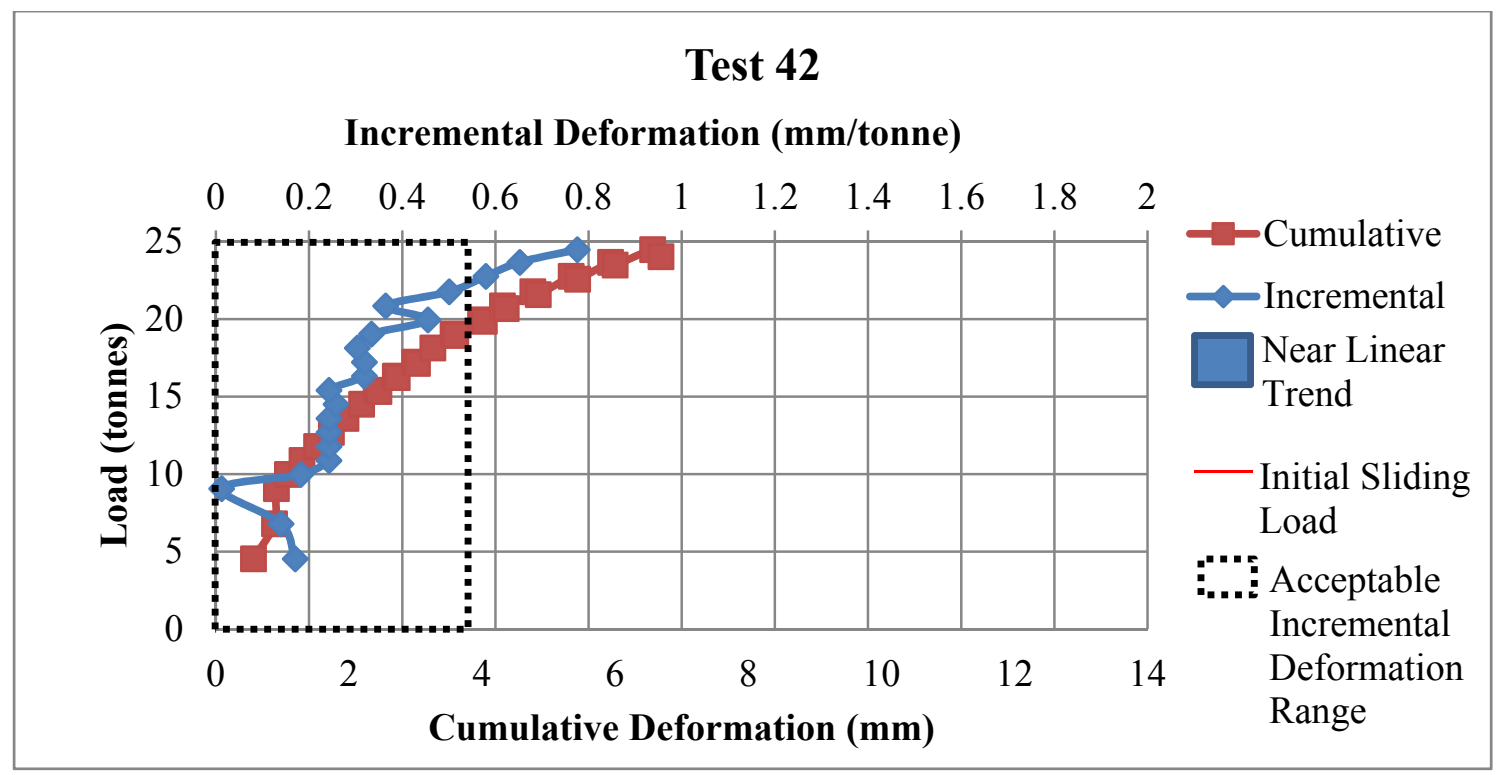

Figure E.37 Pull Test Load vs. Deformation Test 42

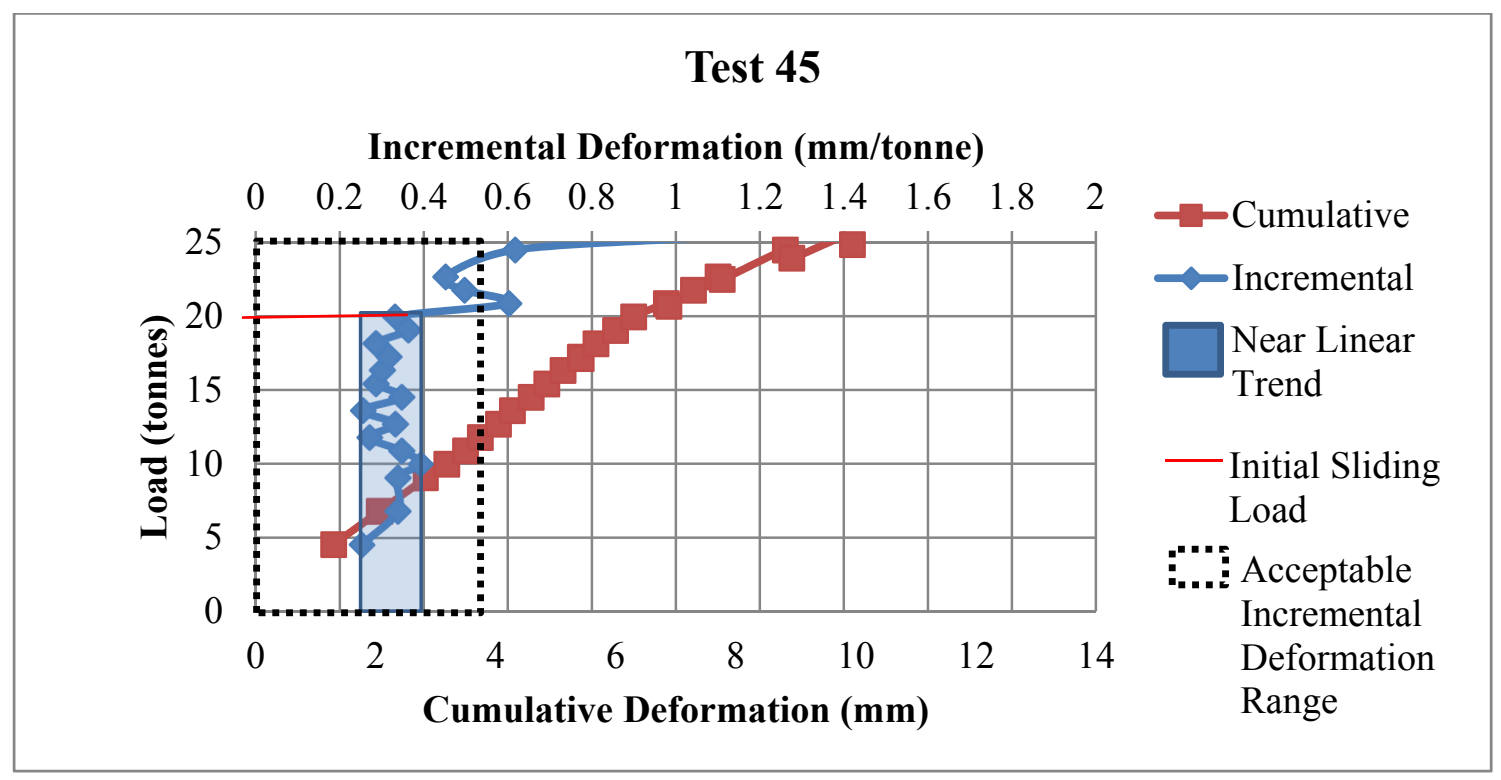

Figure E.38 Pull Test Load vs. Deformation Test 45 


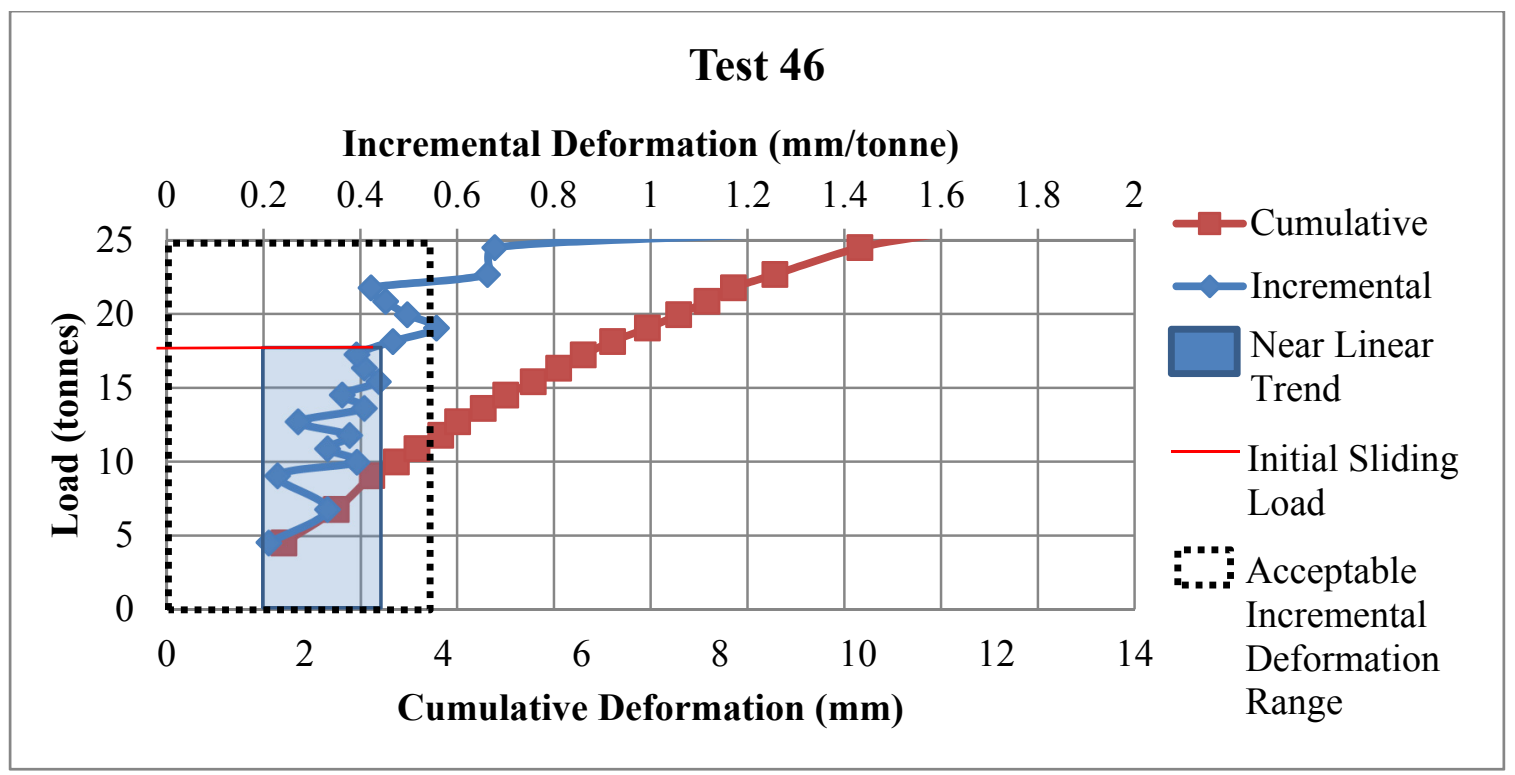

Figure E.39 Pull Test Load vs. Deformation Test 46

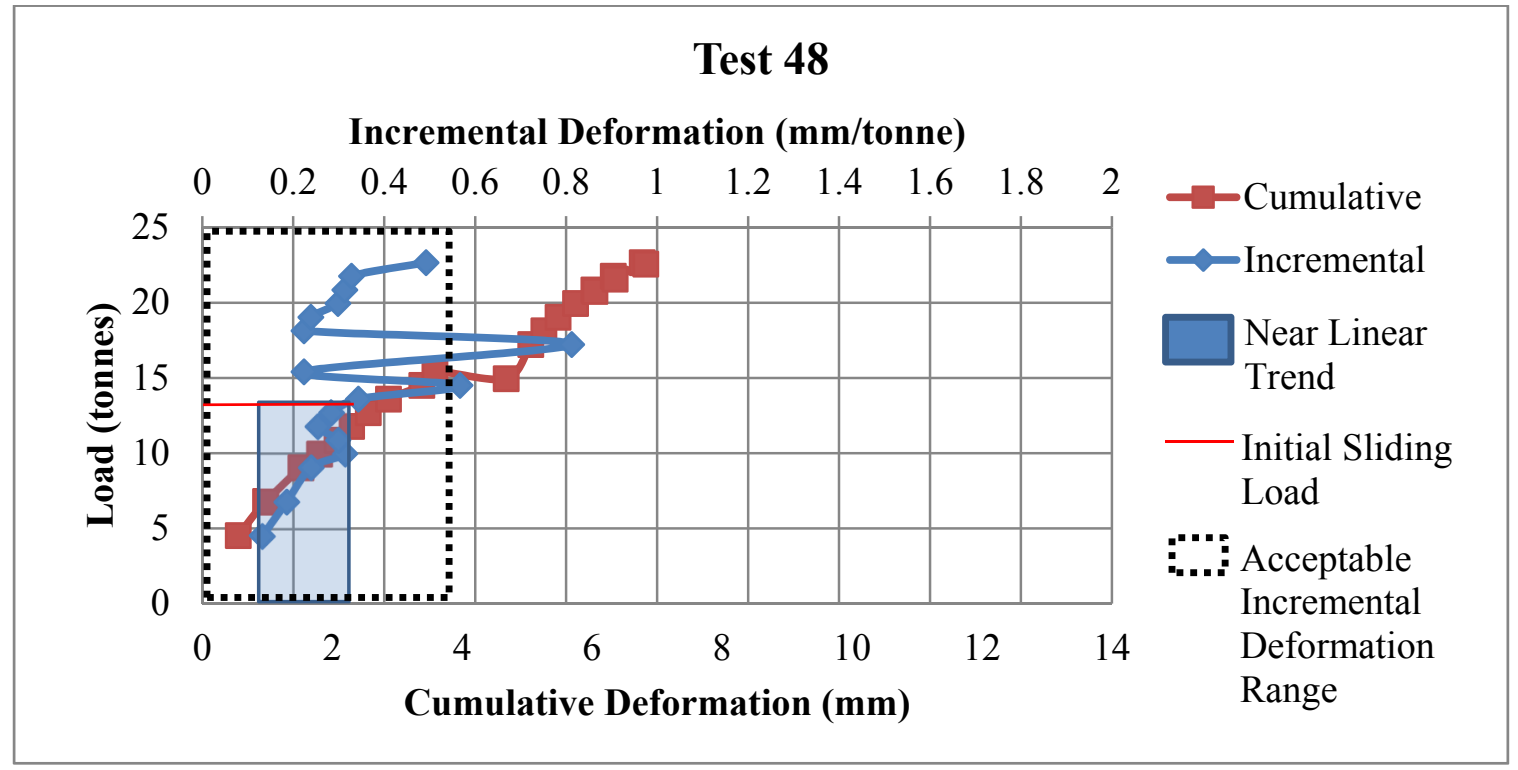

Figure E.40 Pull Test Load vs. Deformation Test 48 


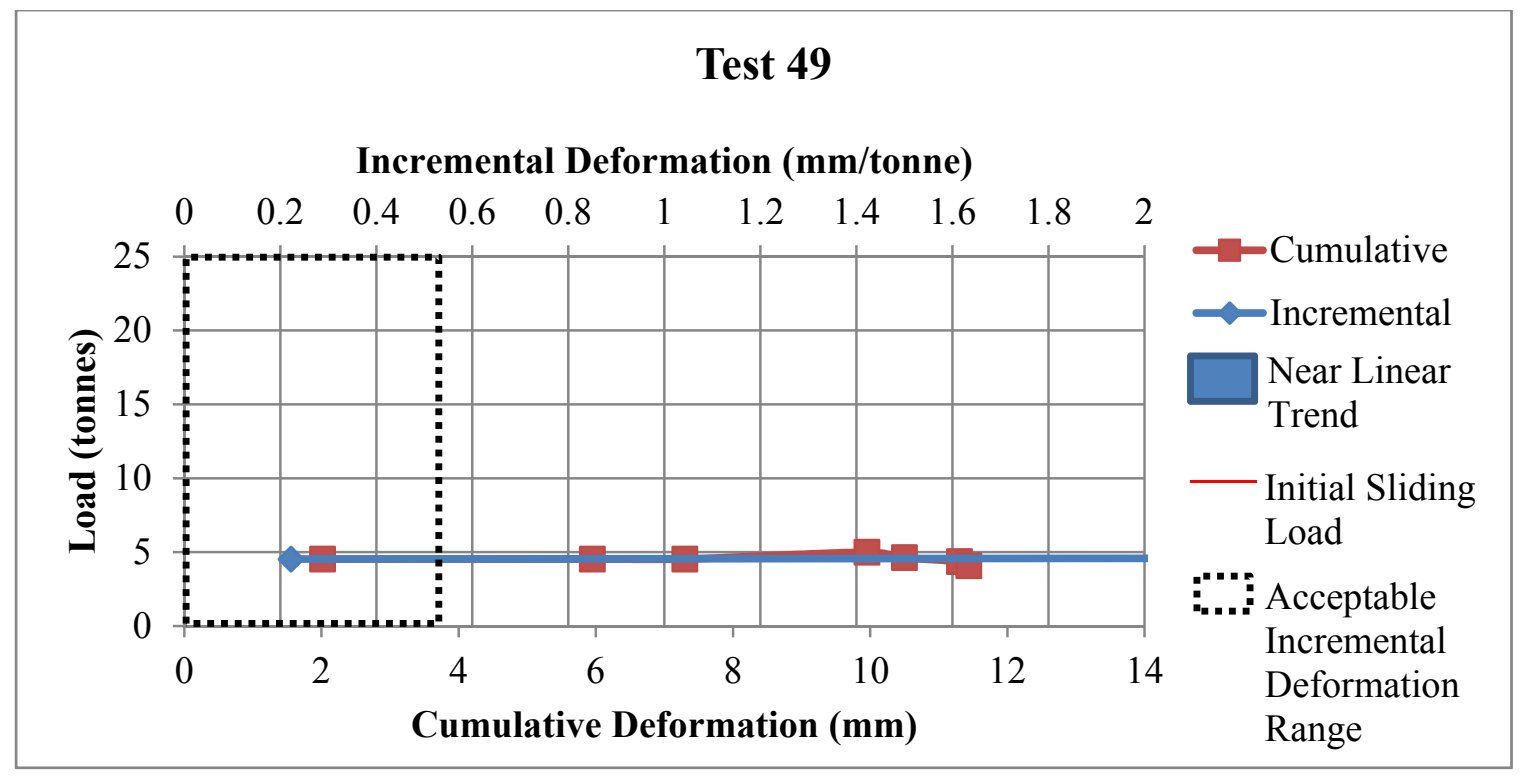

Figure E.41 Pull Test Load vs. Deformation Test 49

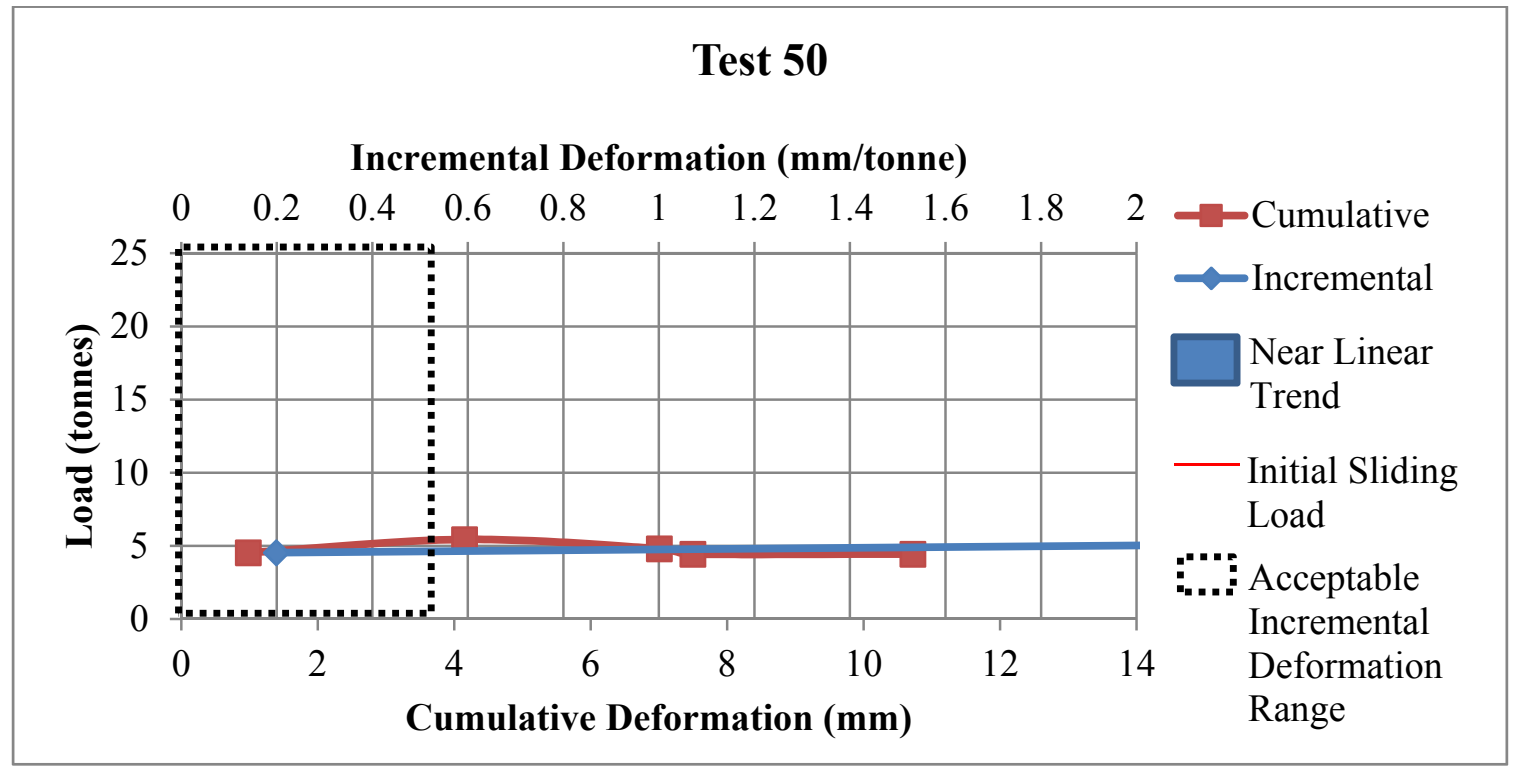

Figure E.42 Pull Test Load vs. Deformation Test 50 


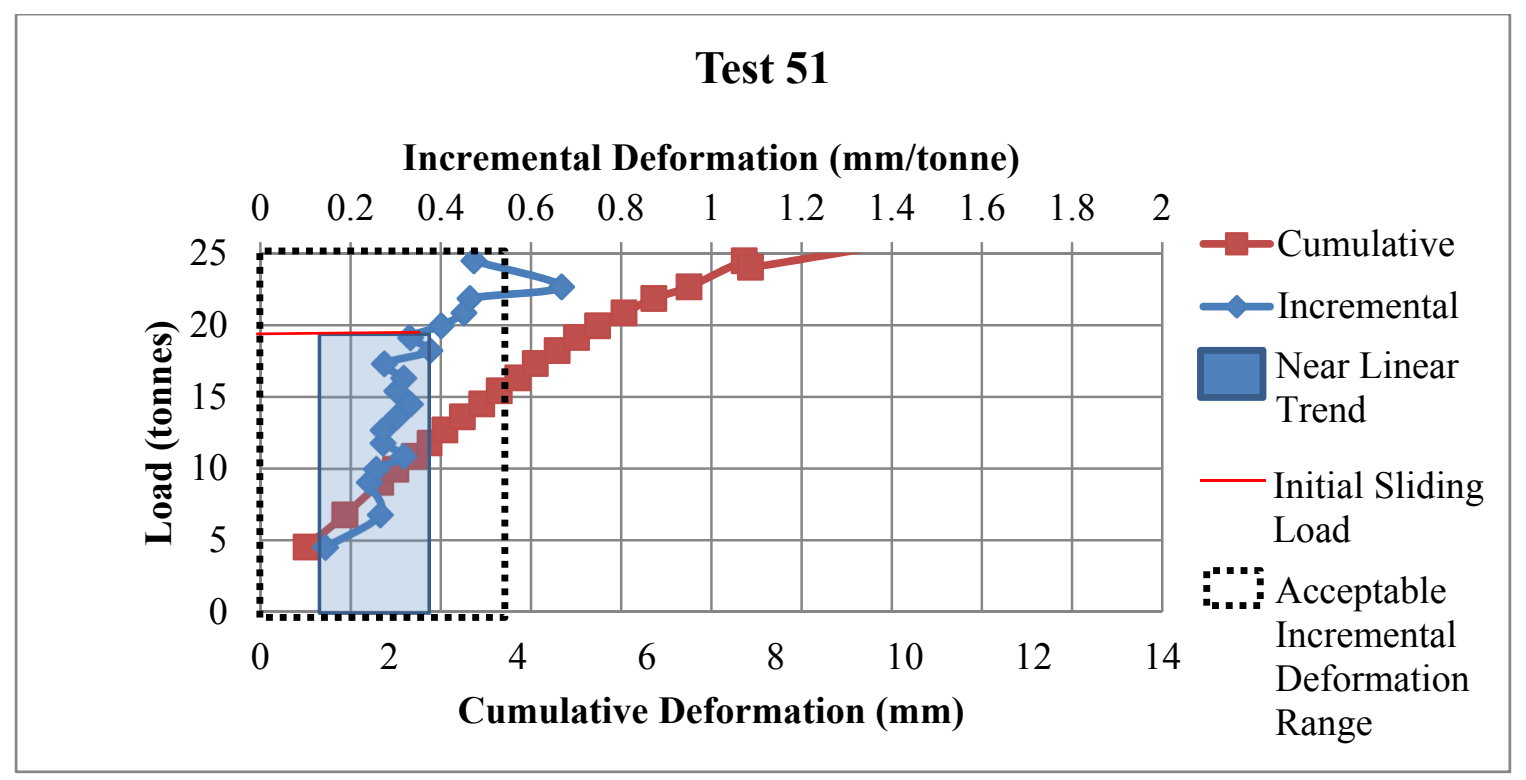

Figure E.43 Pull Test Load vs. Deformation Test 51

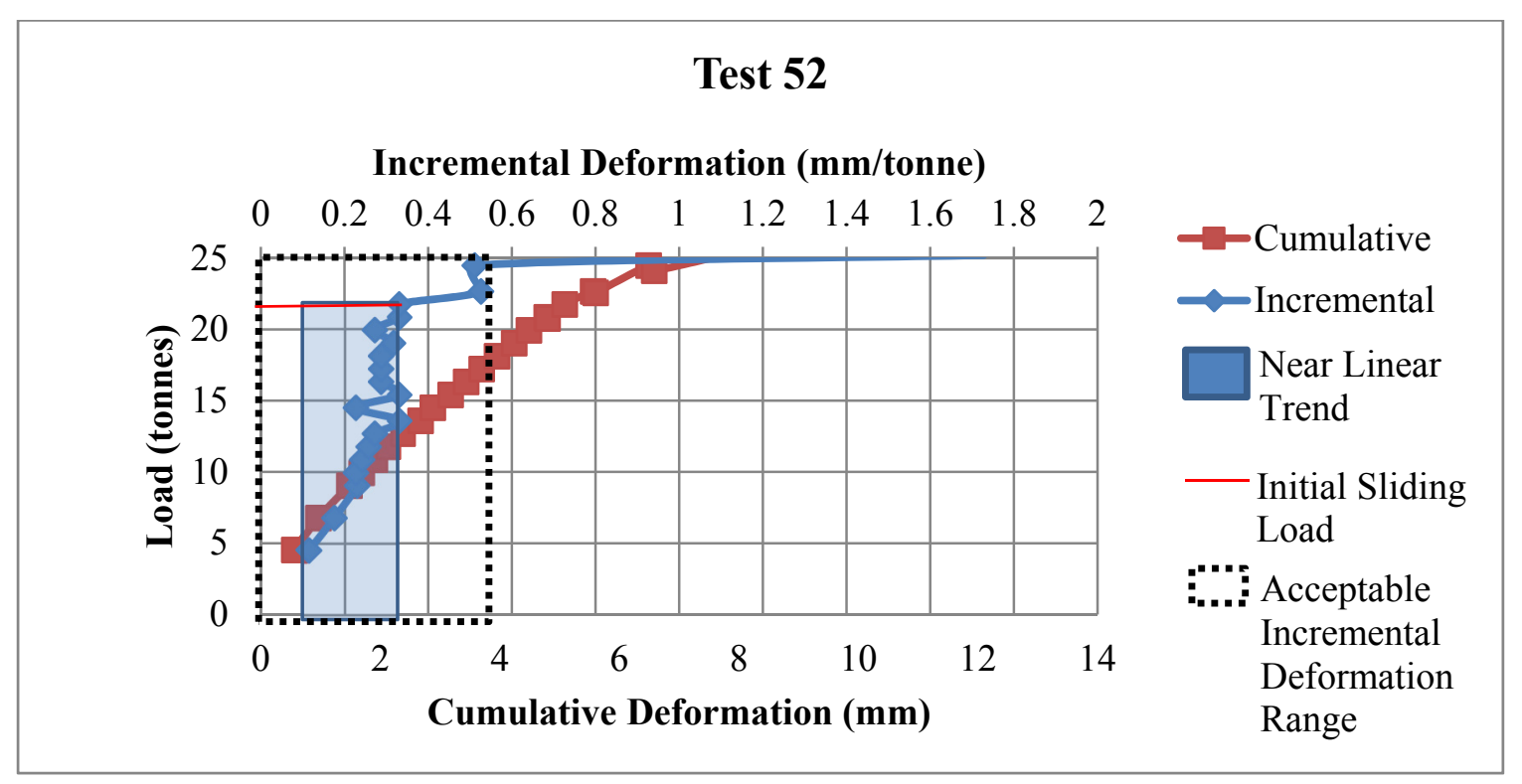

Figure E.44 Pull Test Load vs. Deformation Test 52 


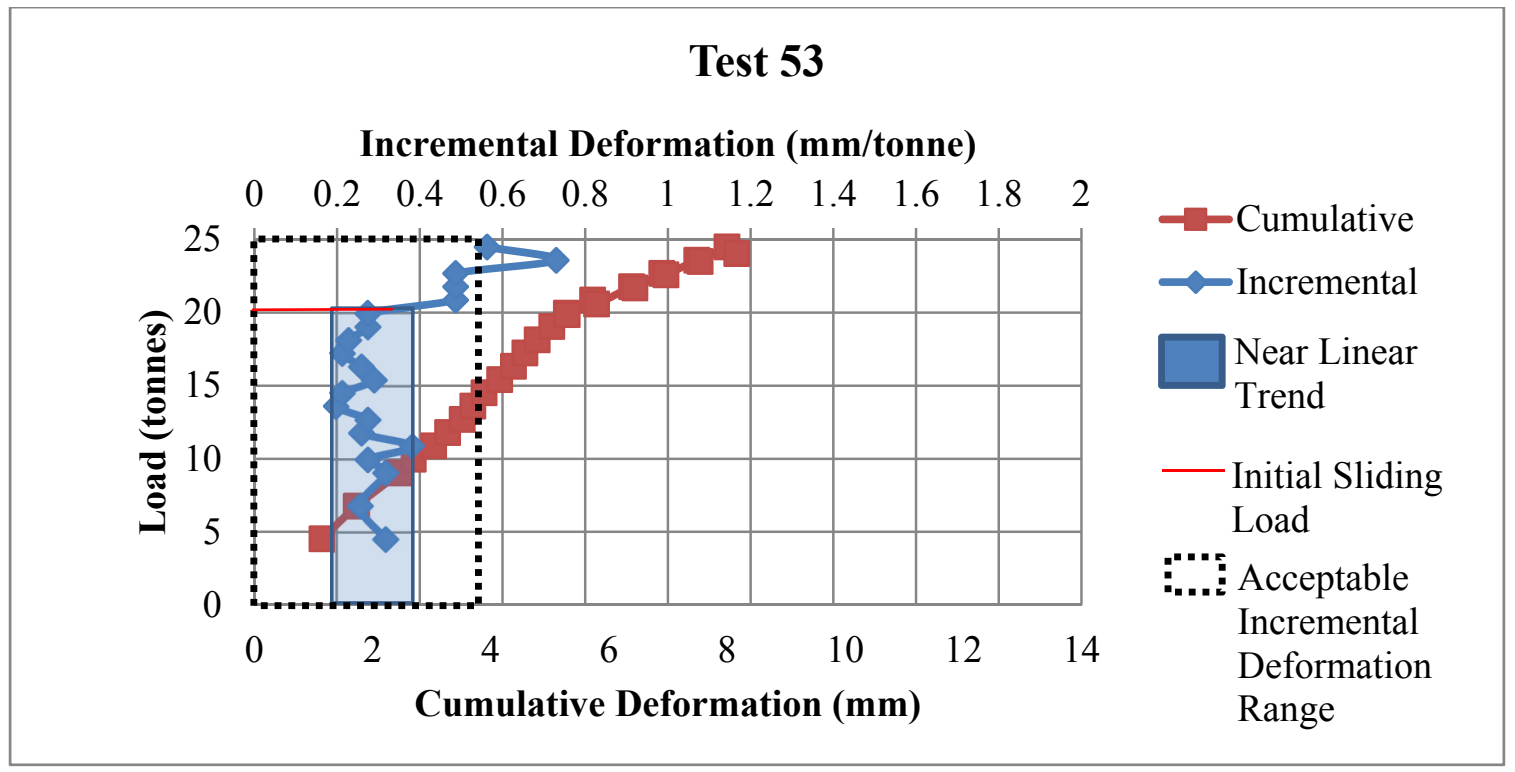

Figure E.45 Pull Test Load vs. Deformation Test 53

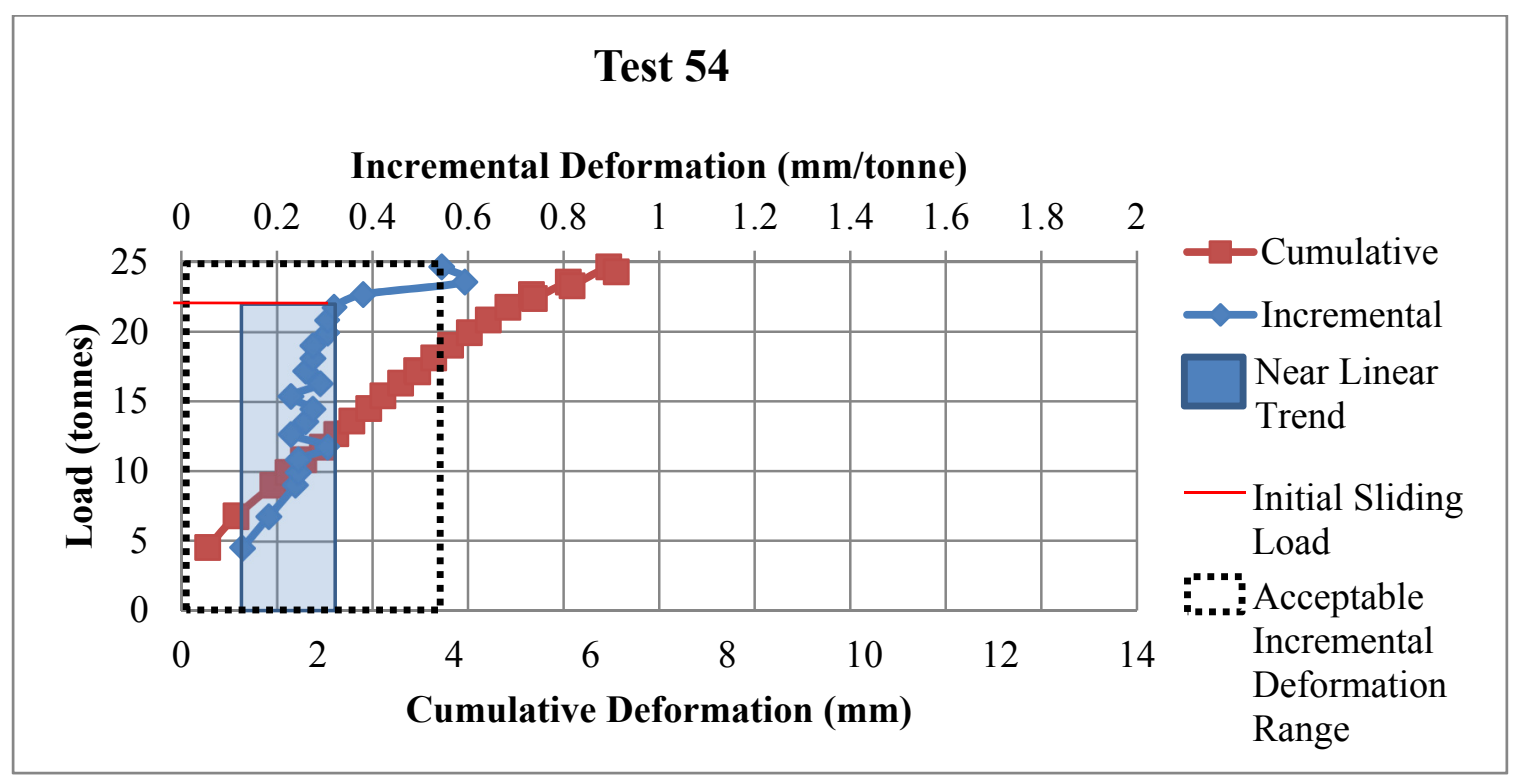

Figure E.46 Pull Test Load vs. Deformation Test 54 


\section{Test 55}

Incremental Deformation ( $\mathrm{mm} /$ tonne)

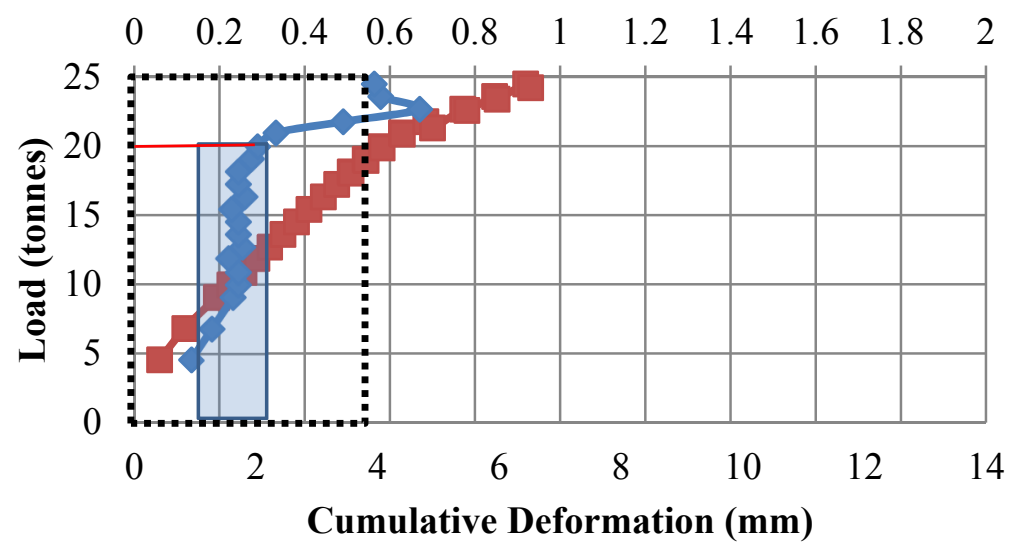

- Cumulative

$\sim$ Incremental Near Linear Trend

— Initial Sliding Load

:....:Acceptable Incremental Deformation Range

Figure E.47 Pull Test Load vs. Deformation Test 55

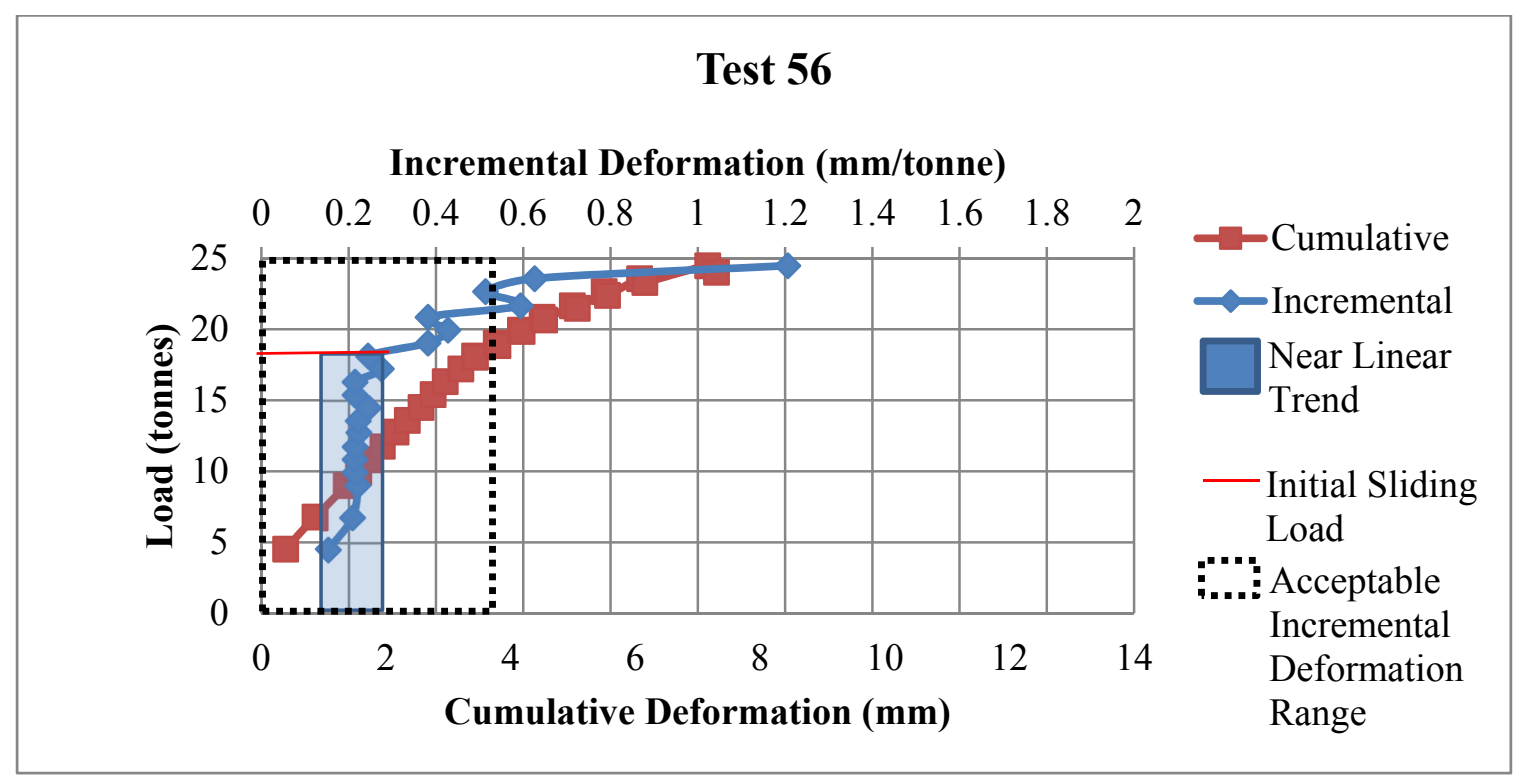

Figure E.48 Pull Test Load vs. Deformation Test 56 


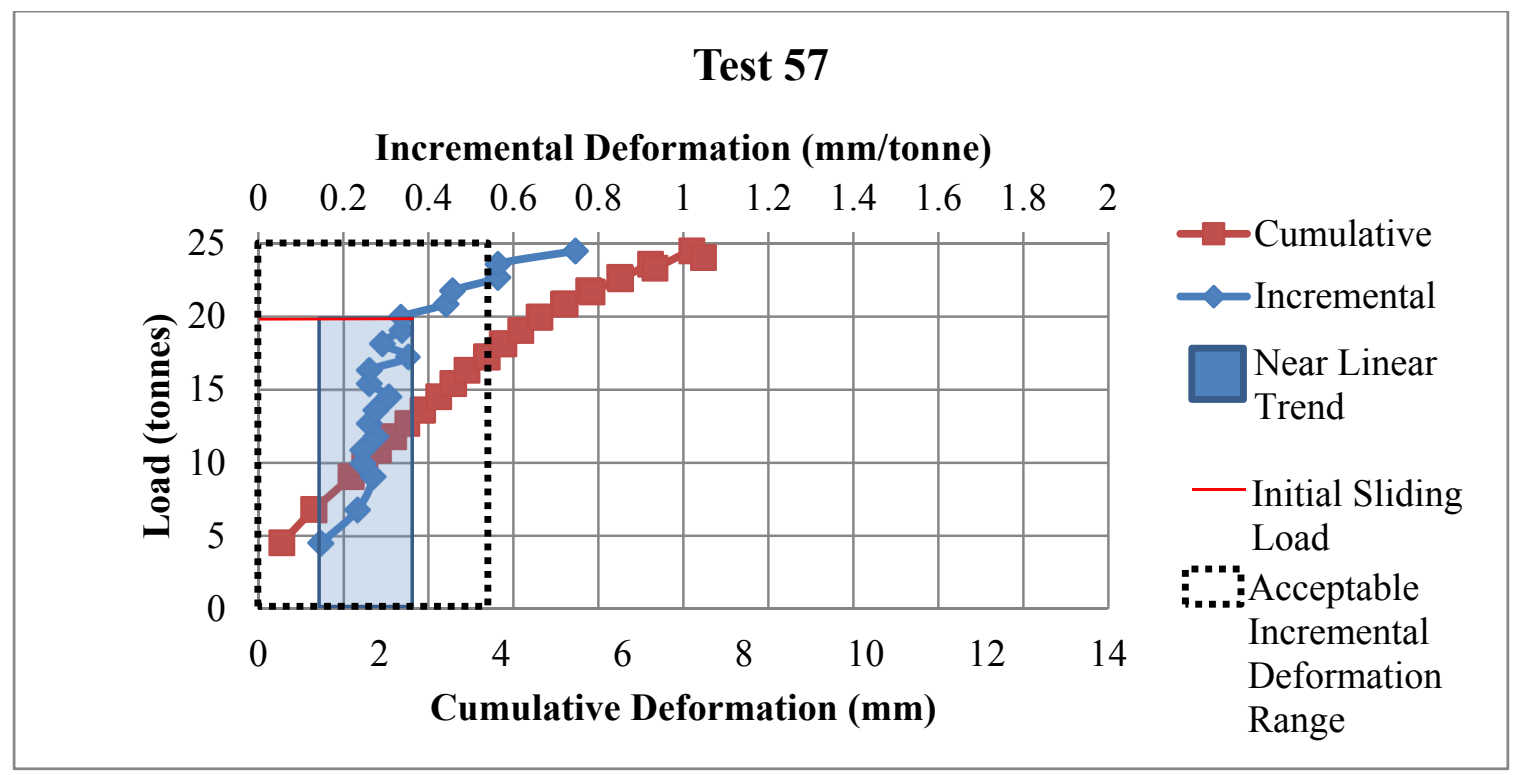

Figure E.49 Pull Test Load vs. Deformation Test 57

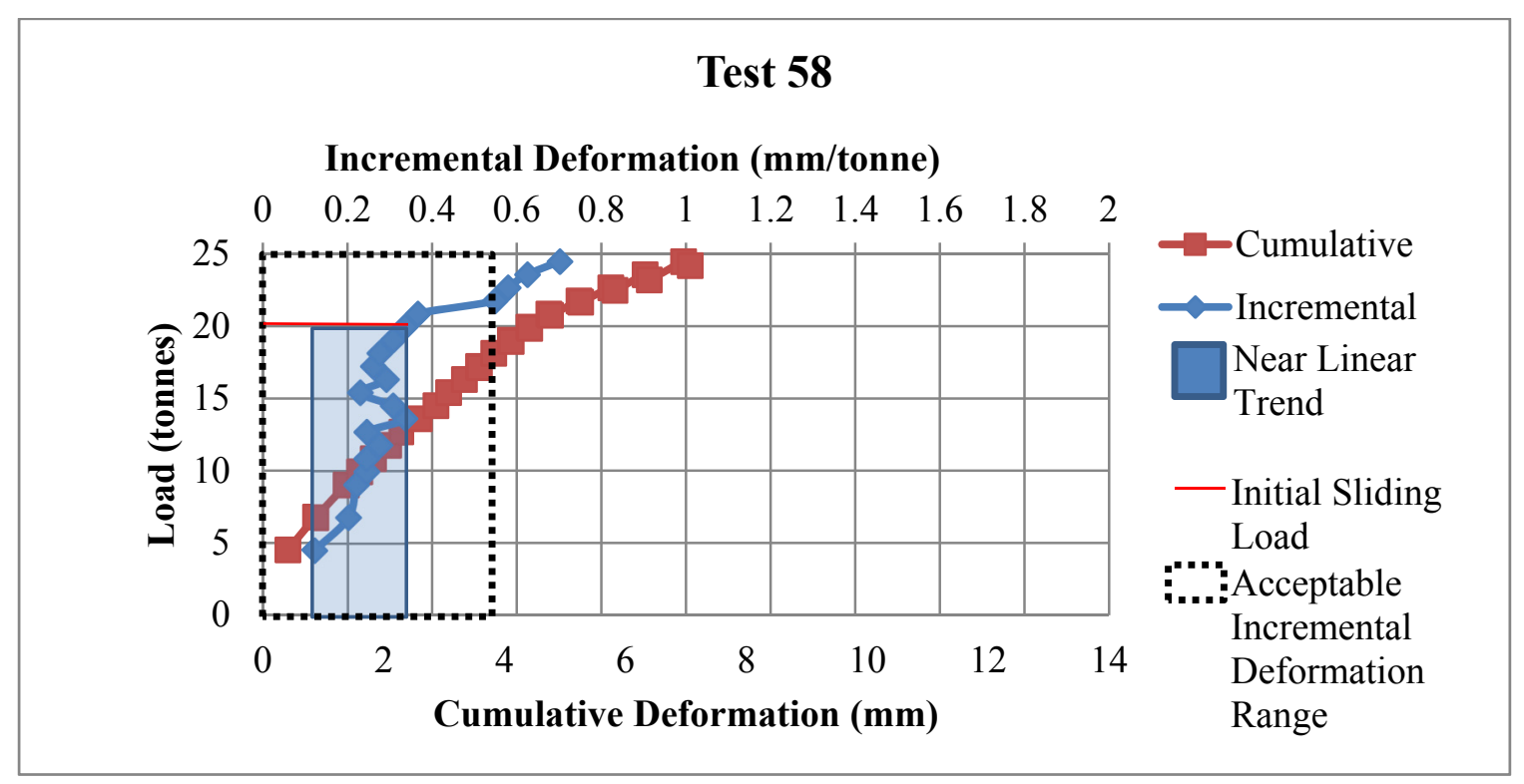

Figure E.50 Pull Test Load vs. Deformation Test 58 


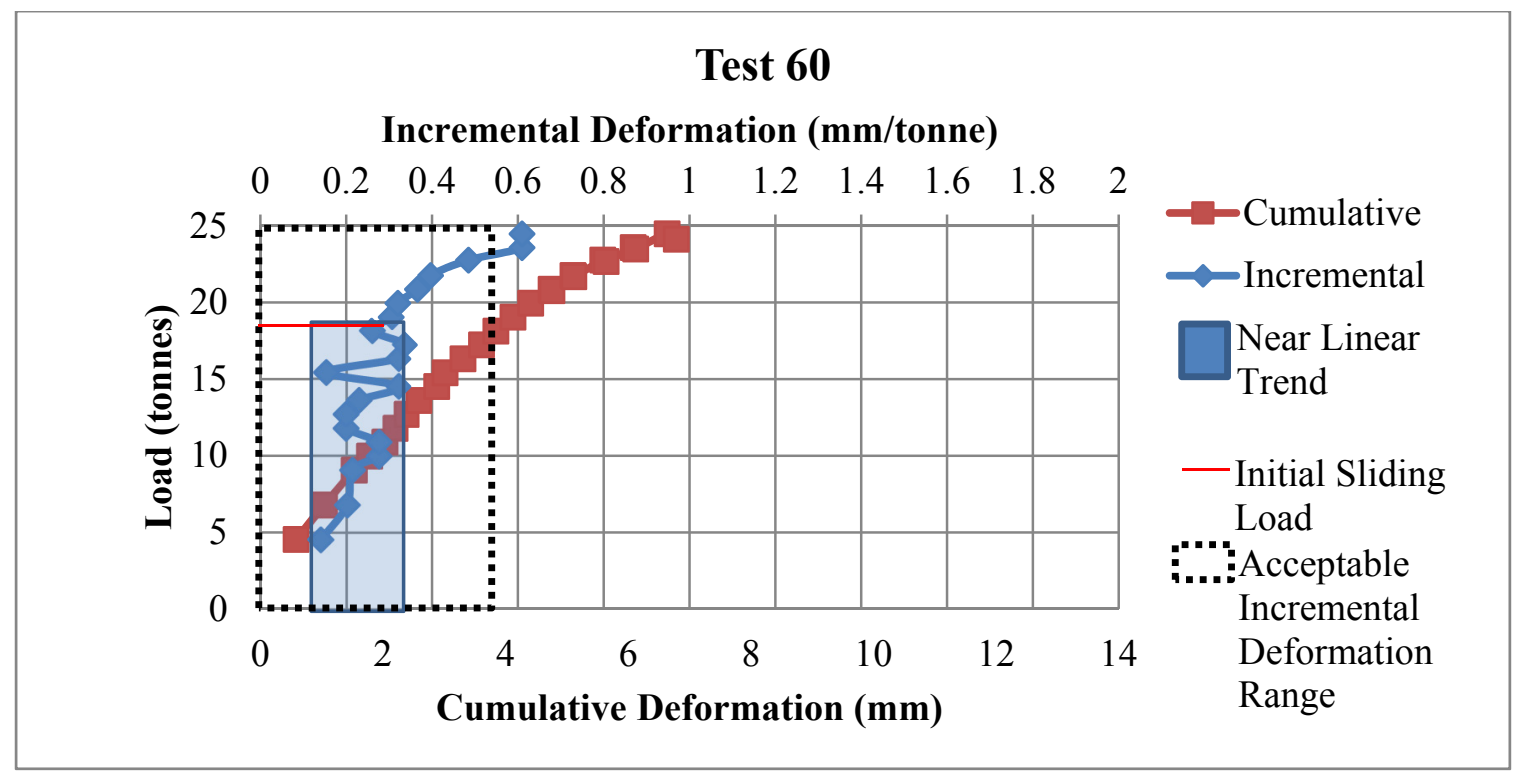

Figure E.51 Pull Test Load vs. Deformation Test 60

"North 70" Testing Site Data (Non-Active Mining on Potash Horizon)

Table E. 3 shows the data collected from the "North70" testing site. The following figures show the load versus deformation plots for each test.

Table E.3 "North 70" Testing Site Data

\begin{tabular}{|c|c|c|c|c|c|}
\hline Test No. & $\begin{array}{c}\text { Cure Time } \\
\text { (days) }\end{array}$ & $\begin{array}{c}\text { Initial Sliding } \\
\text { Load } \\
\text { (tonnes) }\end{array}$ & $\begin{array}{c}\text { Bond } \\
\text { Strength } \\
\text { (Linear) } \\
\text { (tonnes/m) }\end{array}$ & $\begin{array}{c}\text { Resin-Rebar } \\
\text { Bond } \\
\text { Strength } \\
\text { (MPa) }\end{array}$ & $\begin{array}{l}\text { Resin-Rock } \\
\text { Bond } \\
\text { Strength } \\
\text { (MPa) }\end{array}$ \\
\hline 61 & 106.0 & 19.0 & 37.4 & 4.8 & 3.2 \\
\hline 62 & 106.0 & \multicolumn{4}{|c|}{ Installed Improperly: Hole length over drilled } \\
\hline 63 & 124.9 & 16.3 & 32.1 & 4.1 & 2.7 \\
\hline 64 & 125.0 & 19.5 & 38.4 & 4.9 & 3.3 \\
\hline 65 & 57.0 & 18.0 & 35.4 & 4.5 & 3.0 \\
\hline 66 & 57.0 & 16.3 & 32.1 & 4.1 & 2.7 \\
\hline 67 & 57.0 & 19.0 & 37.4 & 4.8 & 3.2 \\
\hline 68 & 57.0 & \multicolumn{4}{|l|}{ Indeterminate } \\
\hline 69 & 56.9 & \multicolumn{4}{|l|}{ Indeterminate } \\
\hline 70 & 56.9 & 16.0 & 31.5 & 4.0 & 2.7 \\
\hline 71 & 11.3 & 19.0 & 37.4 & 4.8 & 3.2 \\
\hline 72 & 11.2 & 19.0 & 37.4 & 4.8 & 3.2 \\
\hline 73 & 11.2 & 16.3 & 32.1 & 4.1 & 2.7 \\
\hline 74 & 11.2 & \multicolumn{4}{|l|}{ Indeterminate } \\
\hline 75 & 11.2 & 18.5 & 36.4 & 4.6 & 3.1 \\
\hline 76 & 11.2 & 19.5 & 38.4 & 4.9 & 3.3 \\
\hline 77 & 13.0 & 19.5 & 38.4 & 4.9 & 3.3 \\
\hline
\end{tabular}




\begin{tabular}{|l|l|l|l|l|l|}
\hline 78 & 13.0 & 20.0 & 39.4 & 5.0 & 3.4 \\
\hline 79 & 13.0 & 19.0 & 37.4 & 4.8 & 3.2 \\
\hline 80 & 12.9 & 21.0 & 41.3 & 5.3 & 3.5 \\
\hline
\end{tabular}

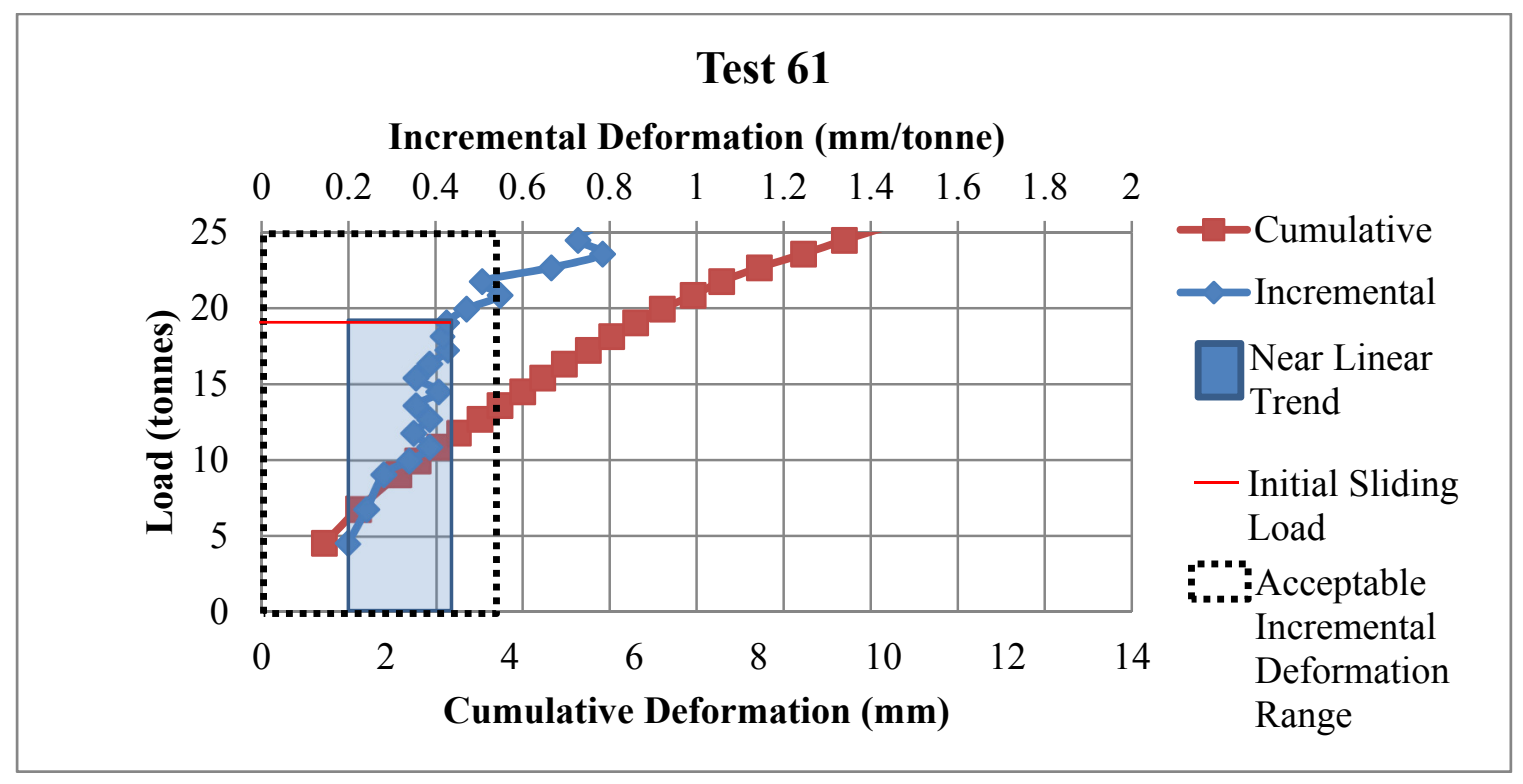

Figure E.52 Pull Test Load vs. Deformation Test 61

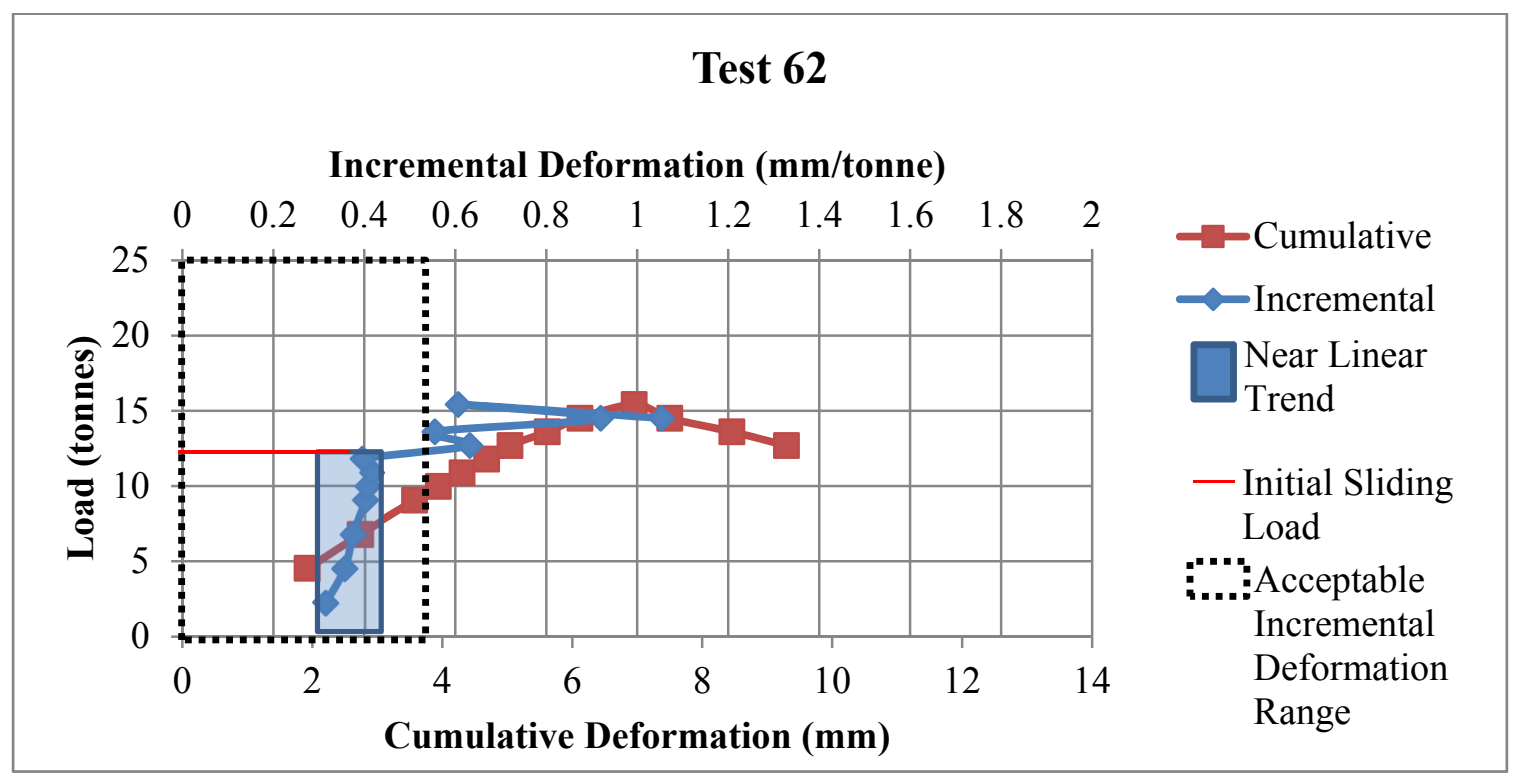

Figure E.53 Pull Test Load vs. Deformation Test 62 


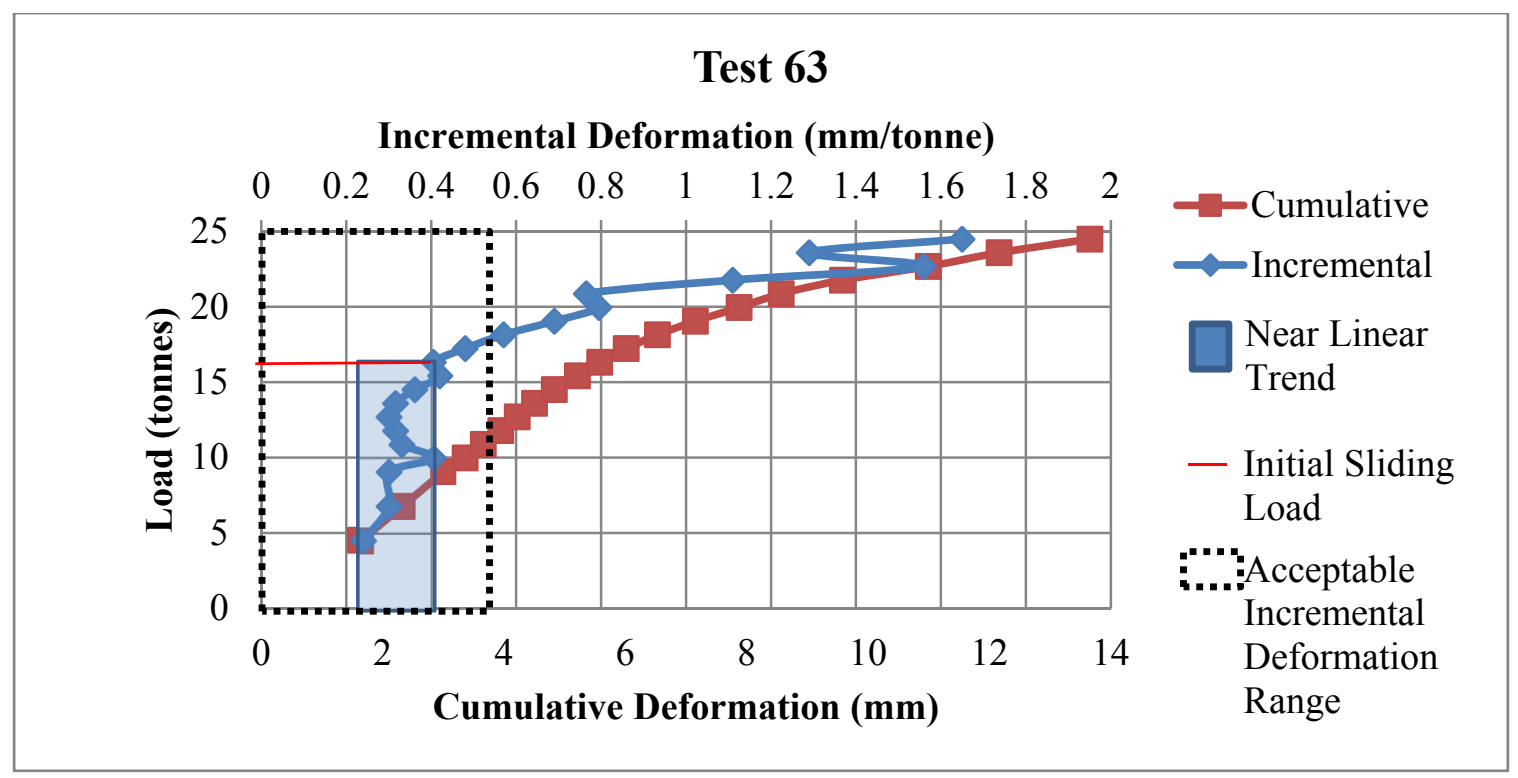

Figure E.54 Pull Test Load vs. Deformation Test 63

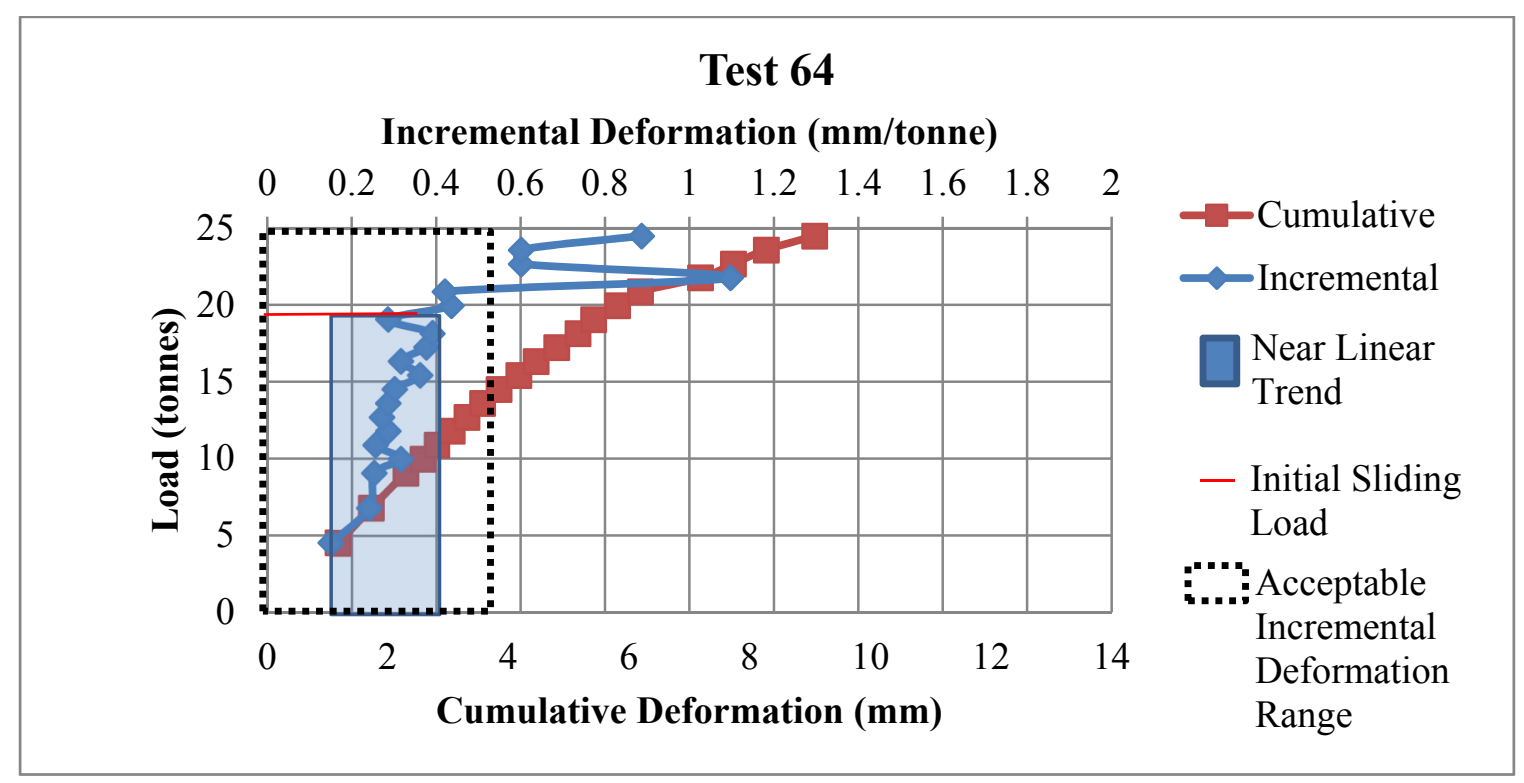

Figure E.55 Pull Test Load vs. Deformation Test 64 


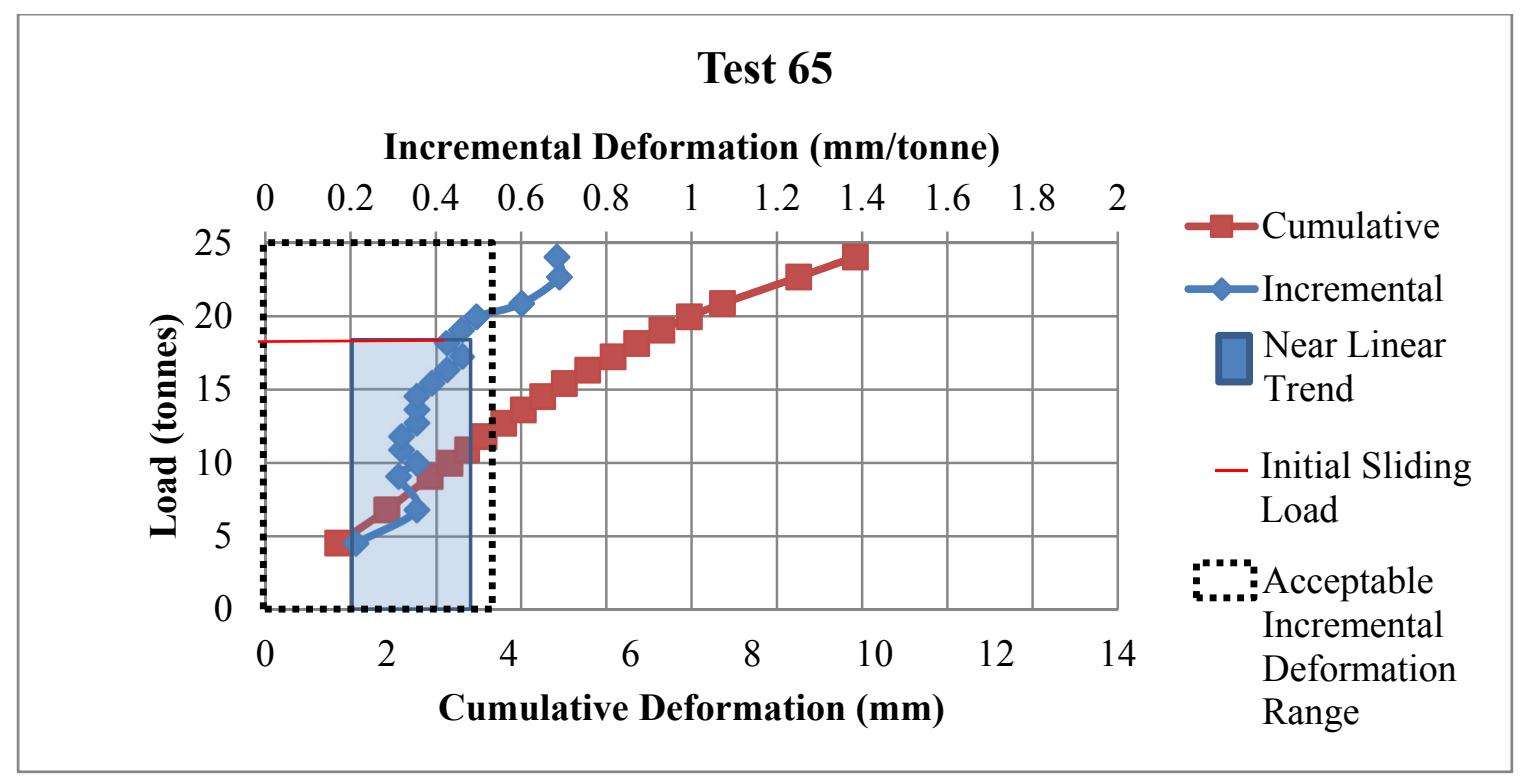

Figure E.56 Pull Test Load vs. Deformation Test 65

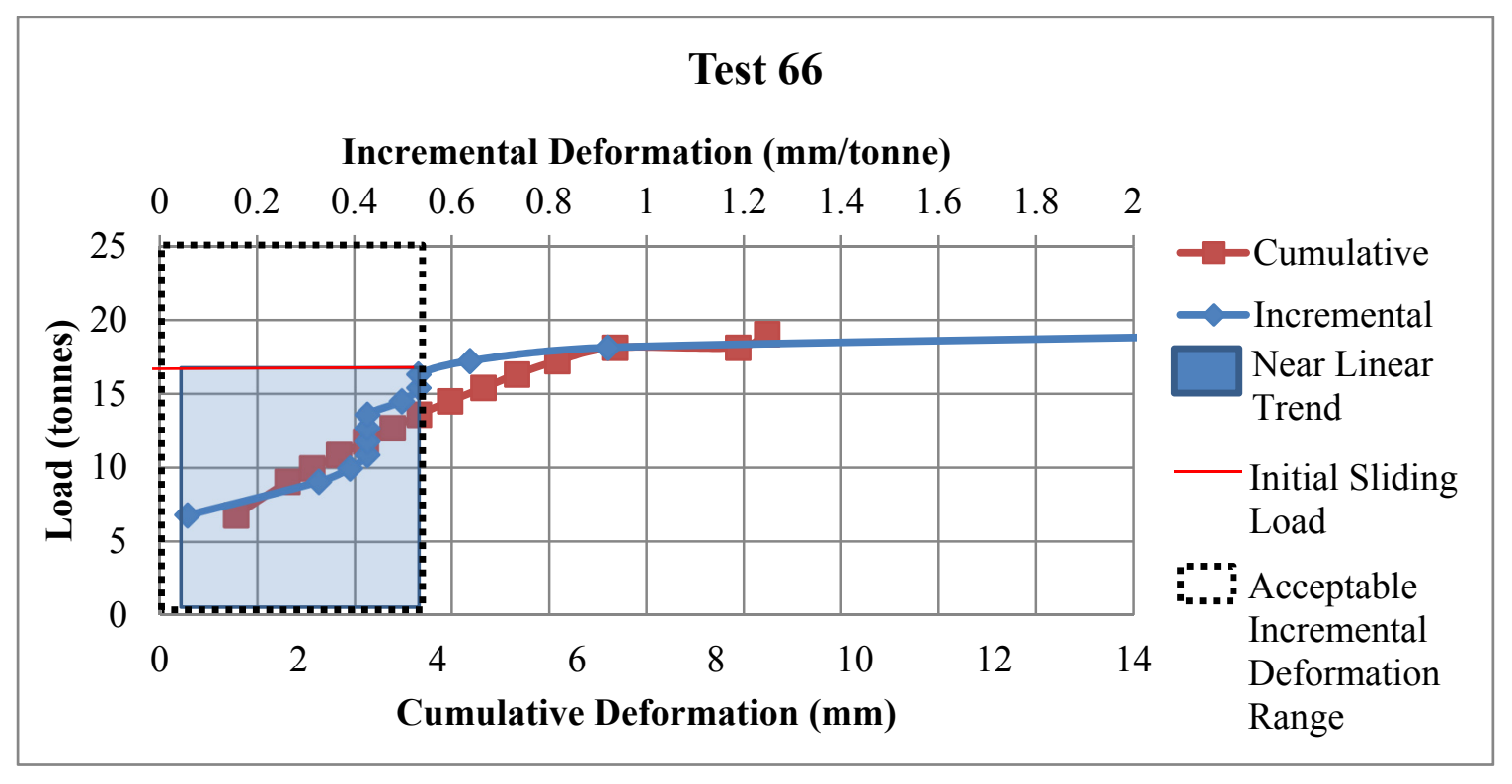

Figure E.57 Pull Test Load vs. Deformation Test 66 


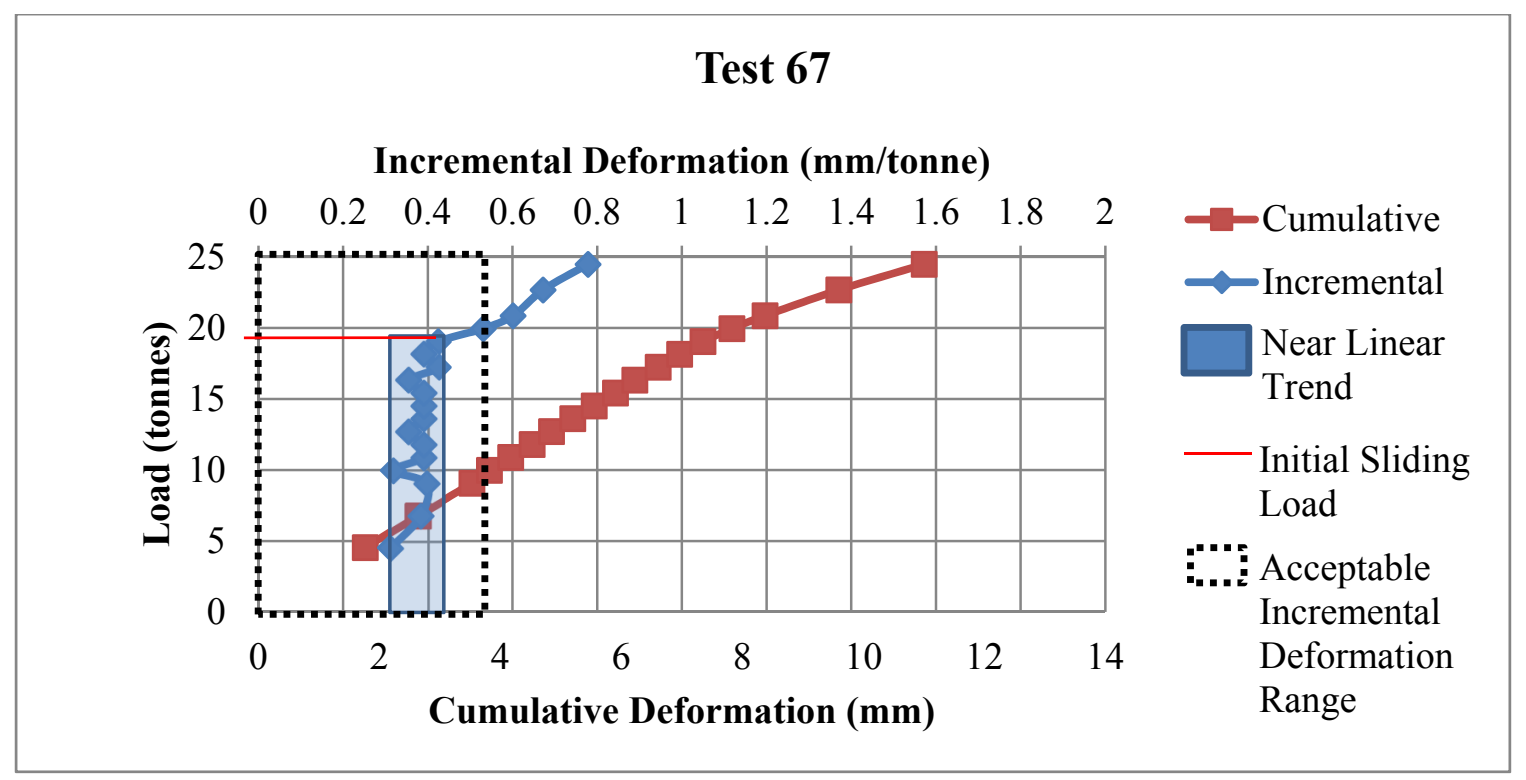

Figure E.58 Pull Test Load vs. Deformation Test 67

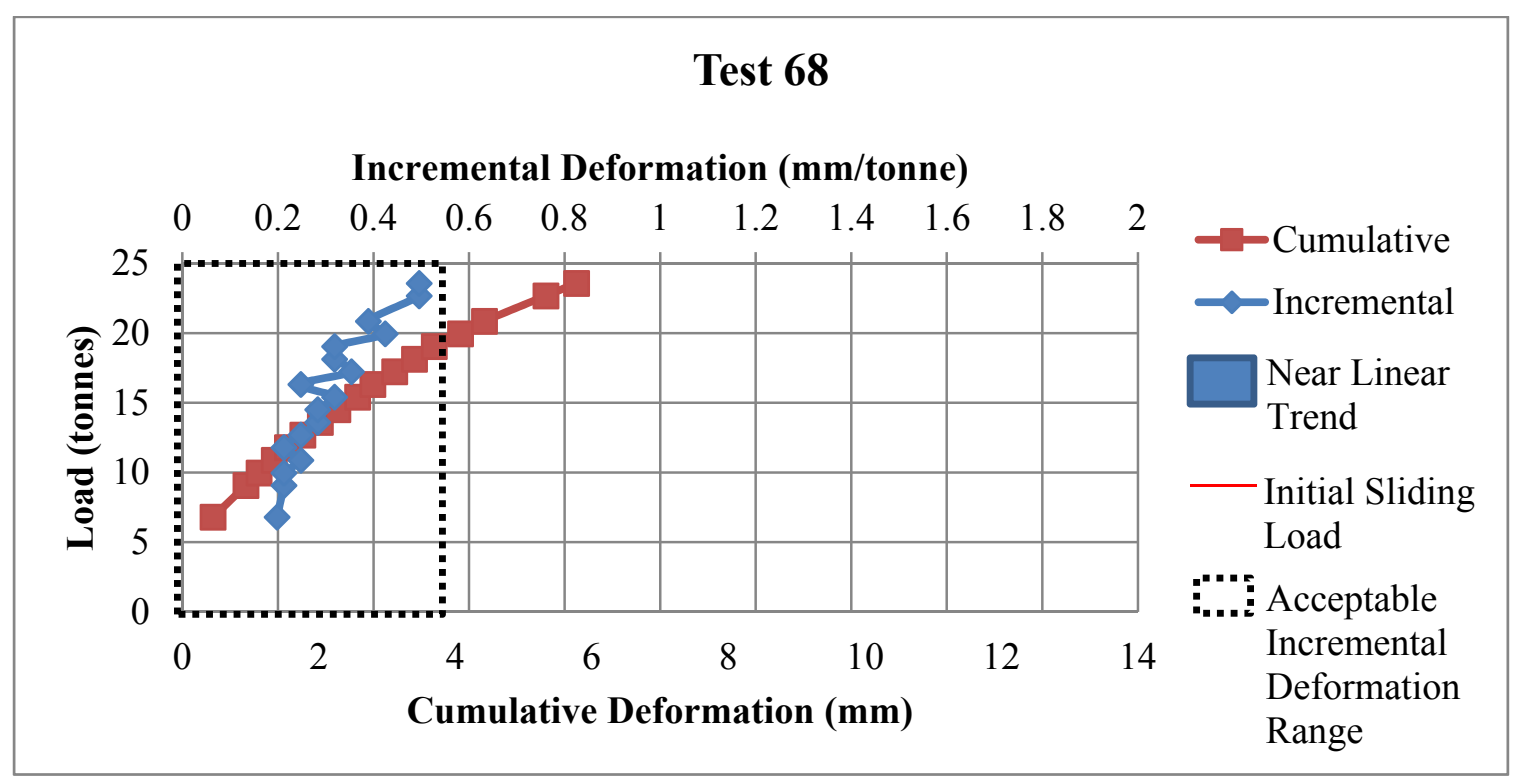

Figure E.59 Pull Test Load vs. Deformation Test 68 


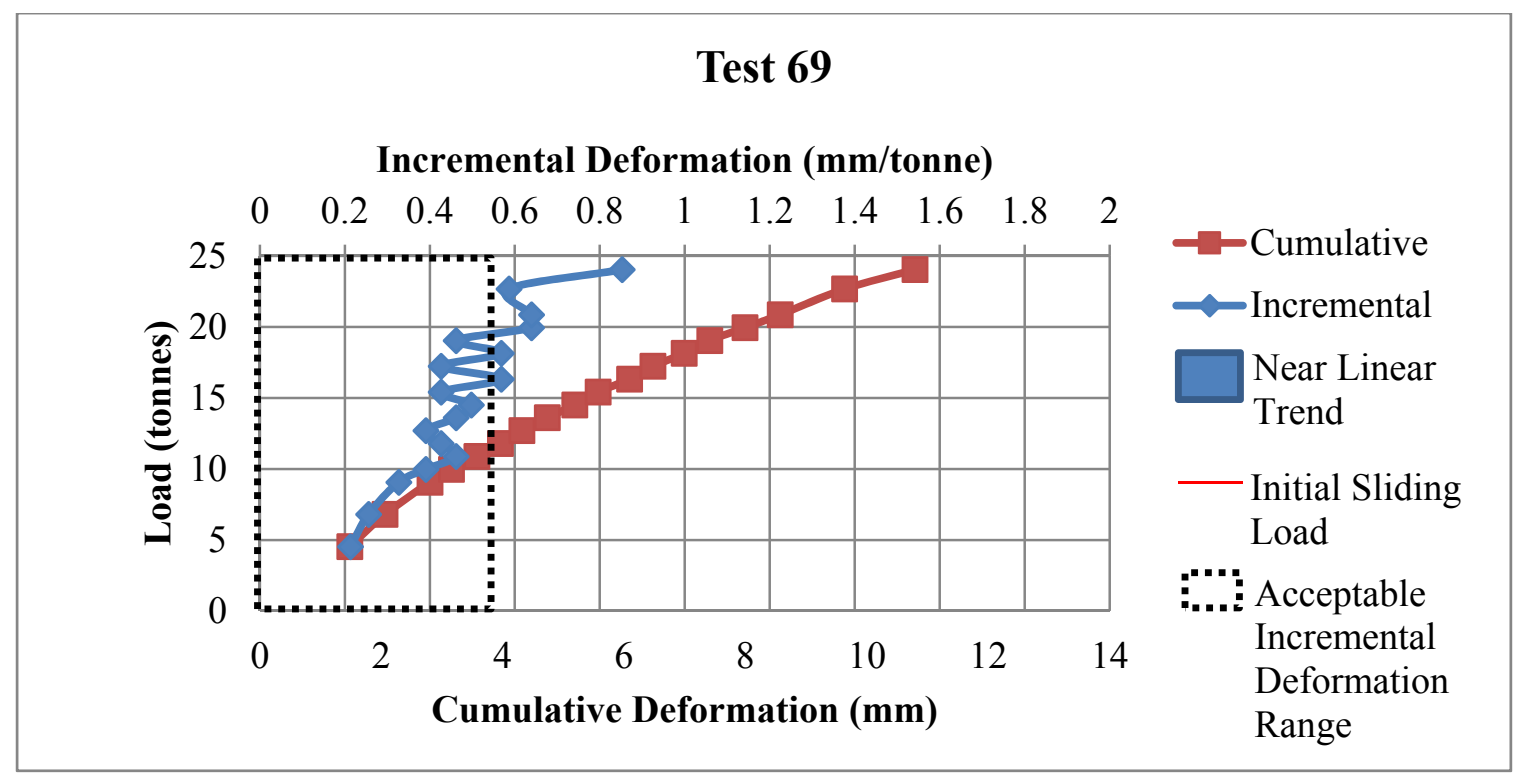

Figure E.60 Pull Test Load vs. Deformation Test 69

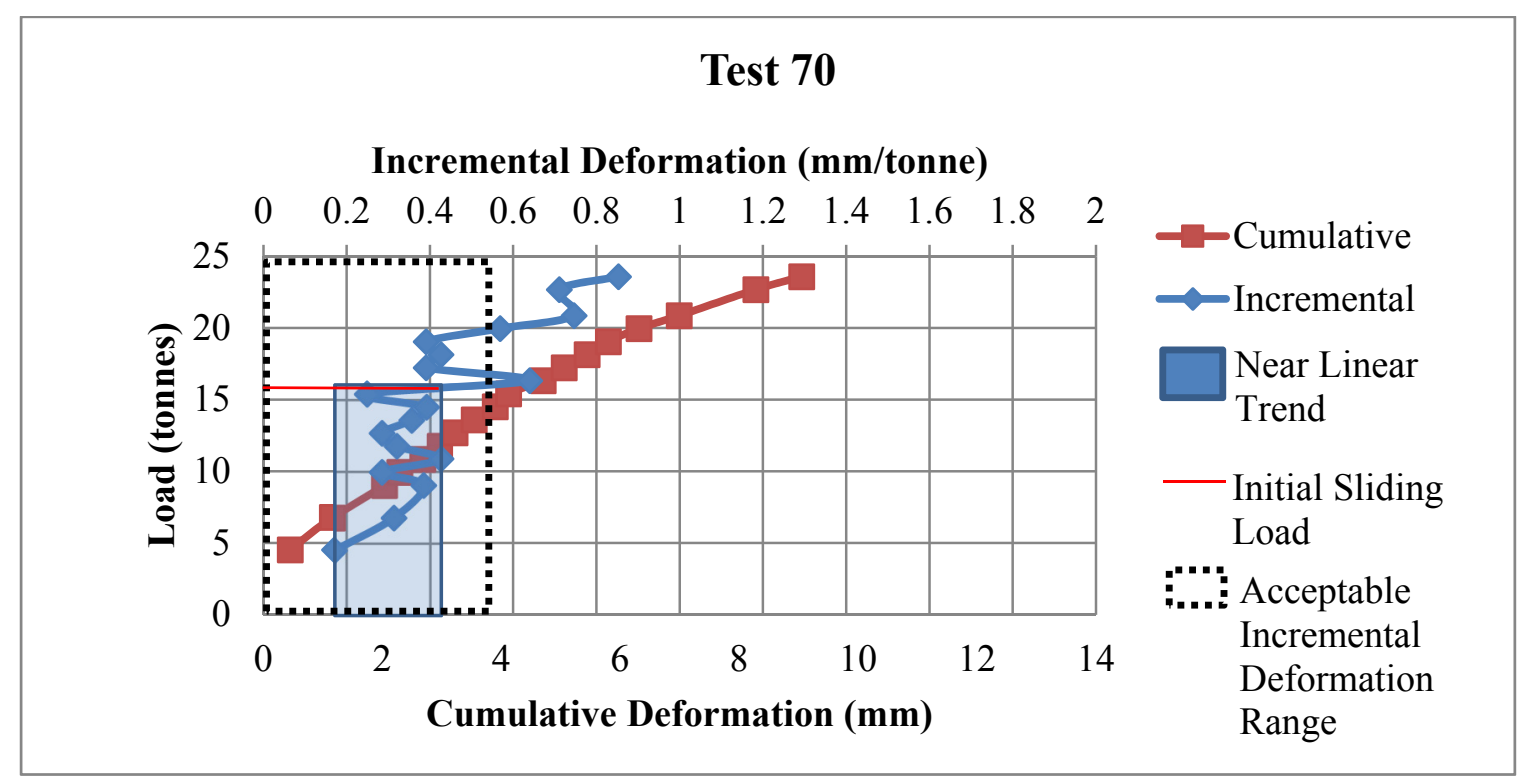

Figure E.61 Pull Test Load vs. Deformation Test 70 


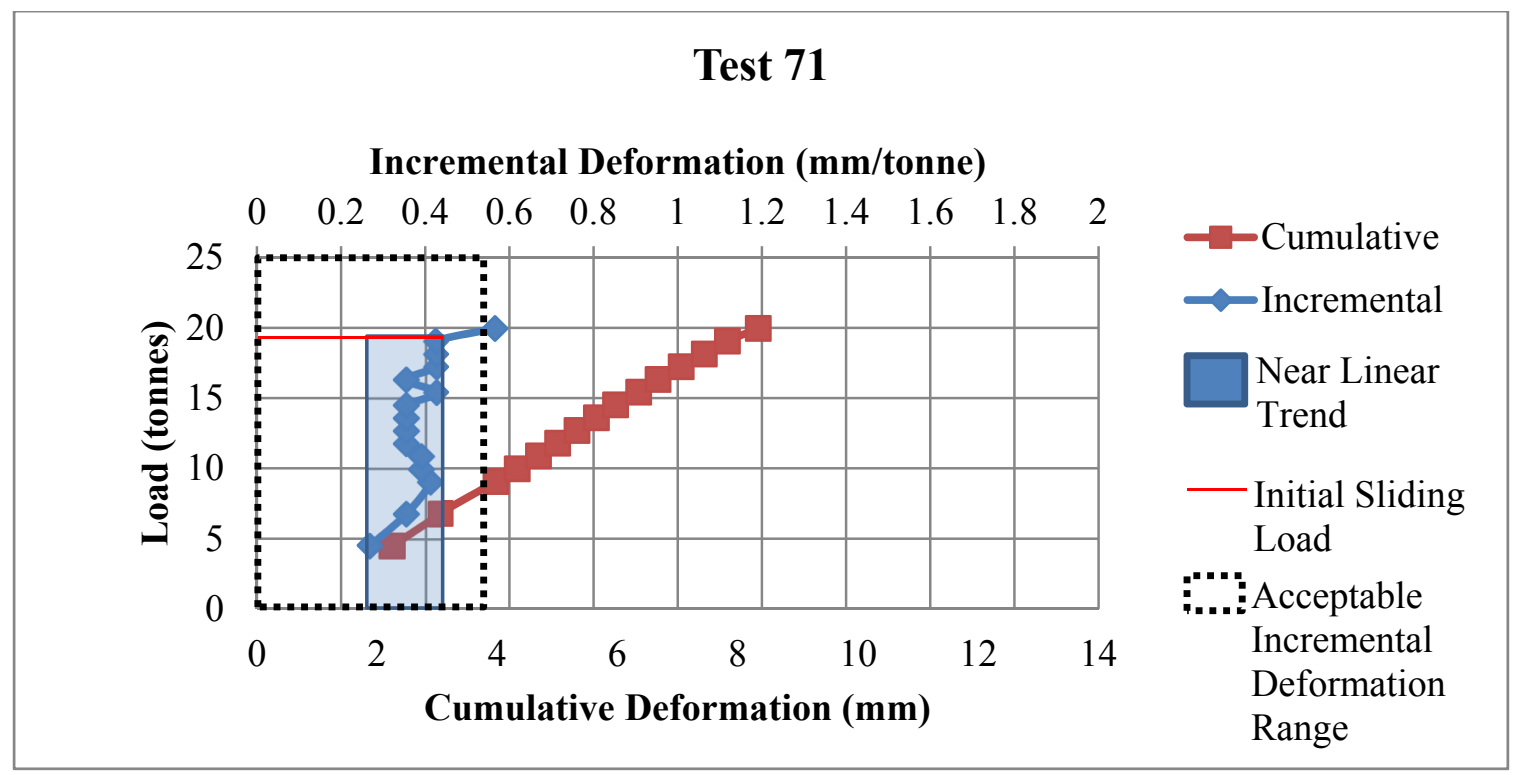

Figure E.62 Pull Test Load vs. Deformation Test 71

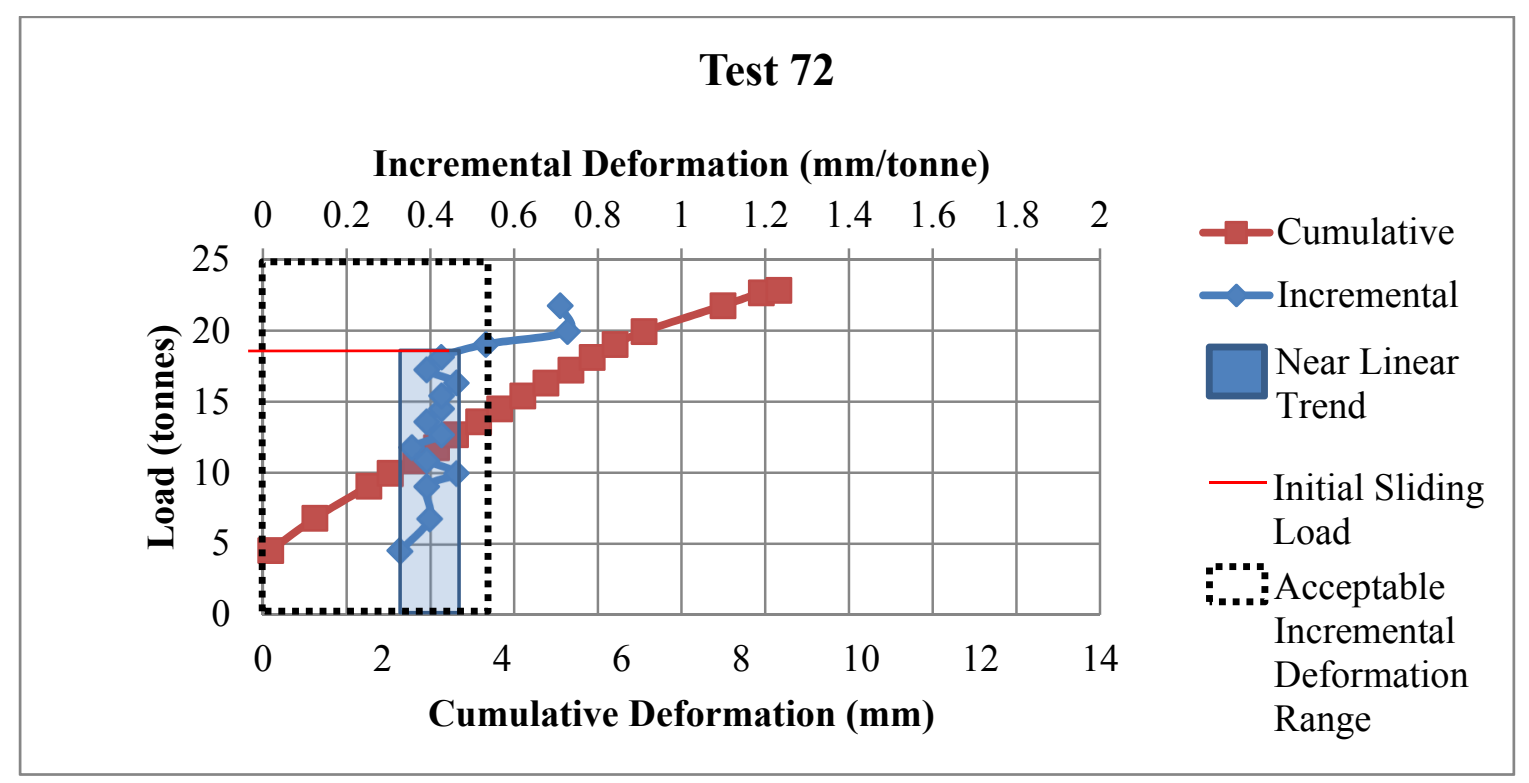

Figure E.63 Pull Test Load vs. Deformation Test 72 


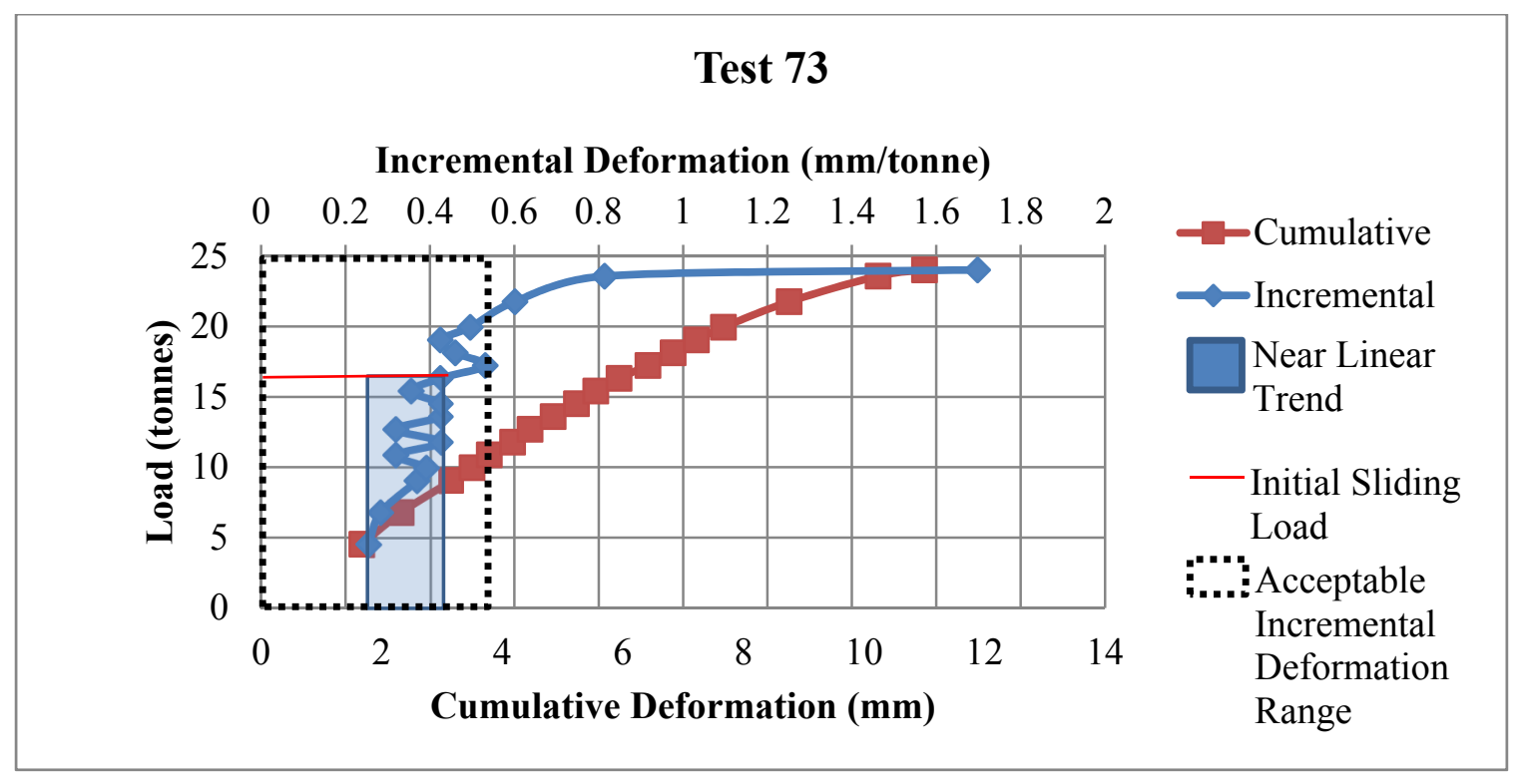

Figure E.64 Pull Test Load vs. Deformation Test 73

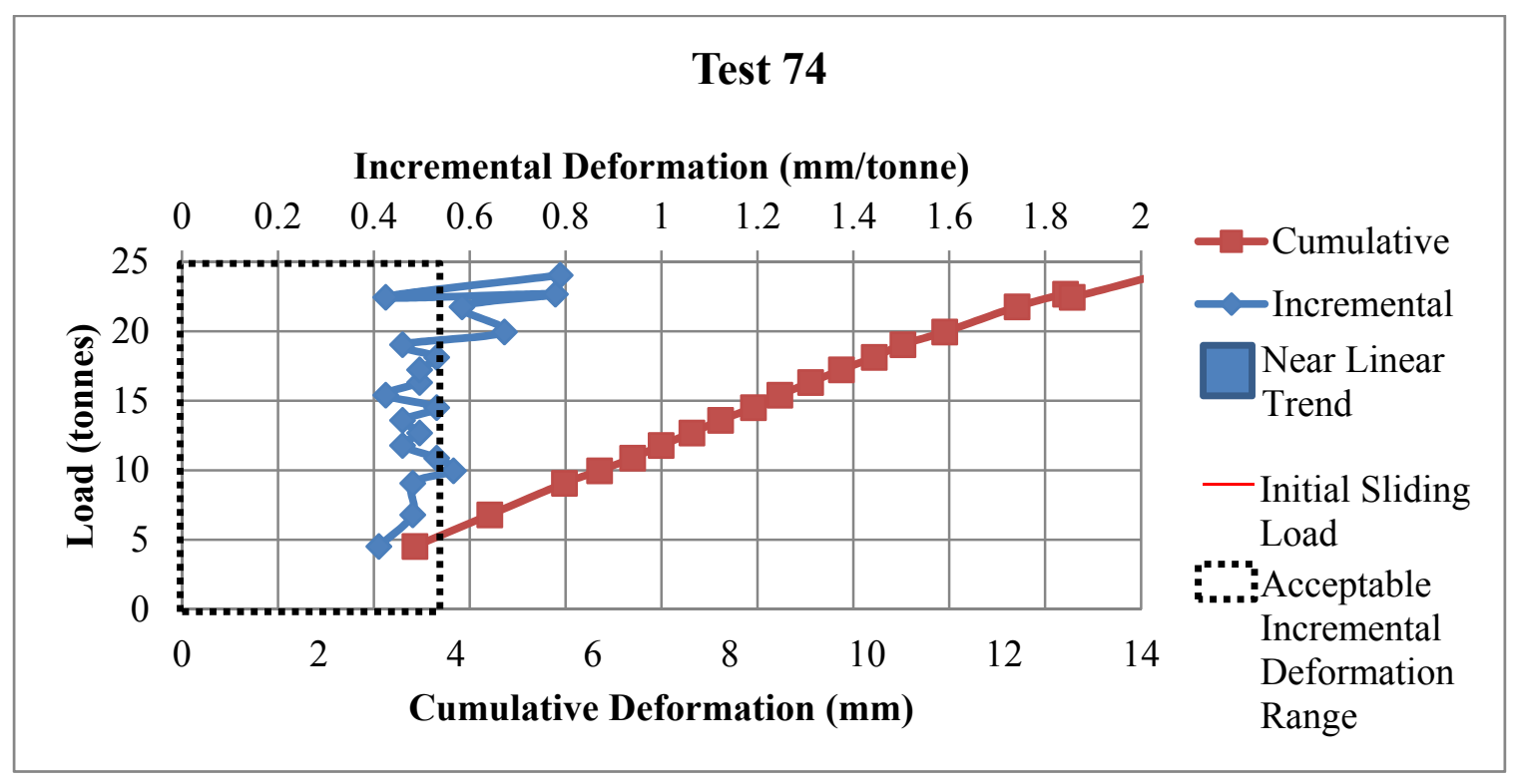

Figure E.65 Pull Test Load vs. Deformation Test 74 


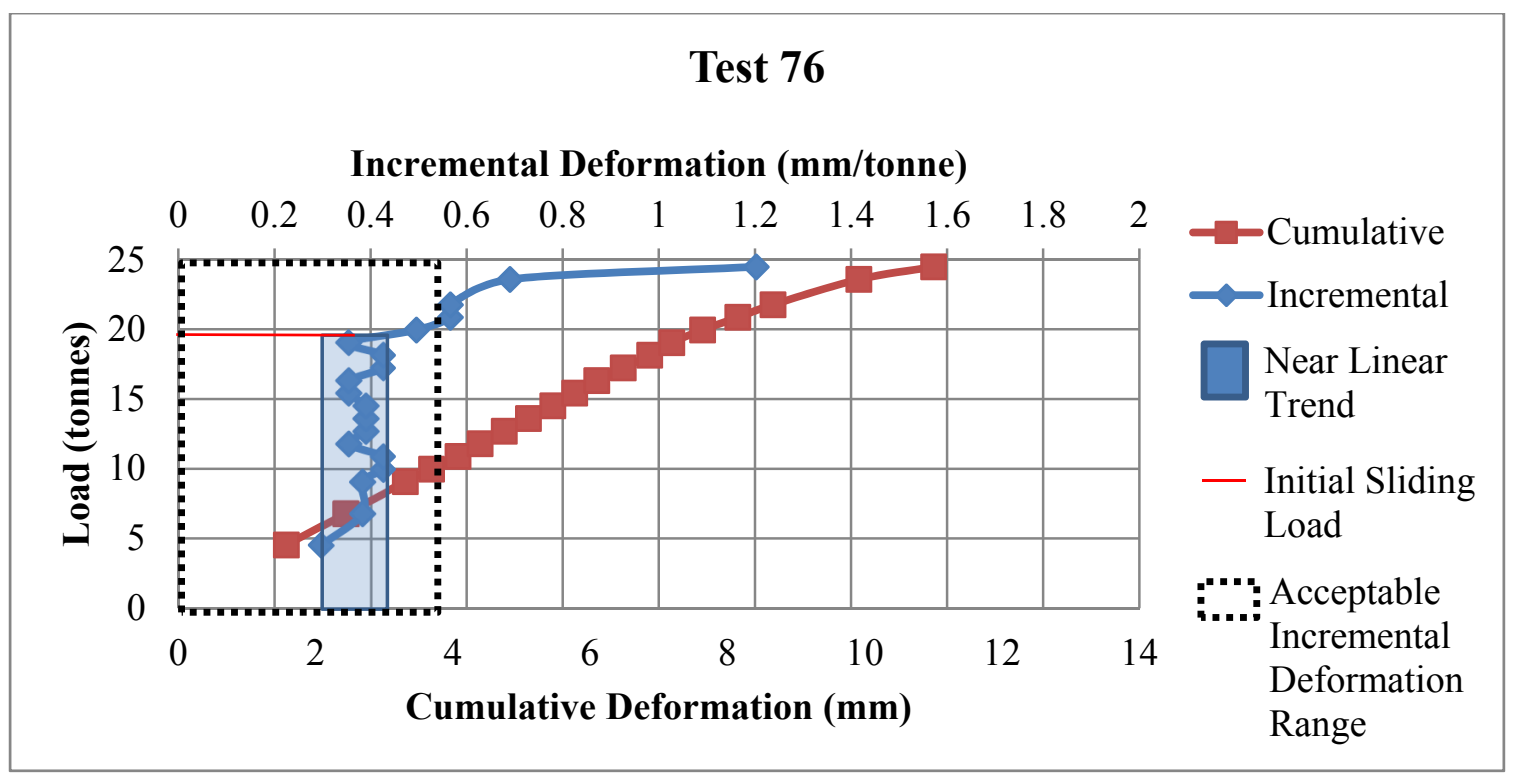

Figure E.66 Pull Test Load vs. Deformation Test 76

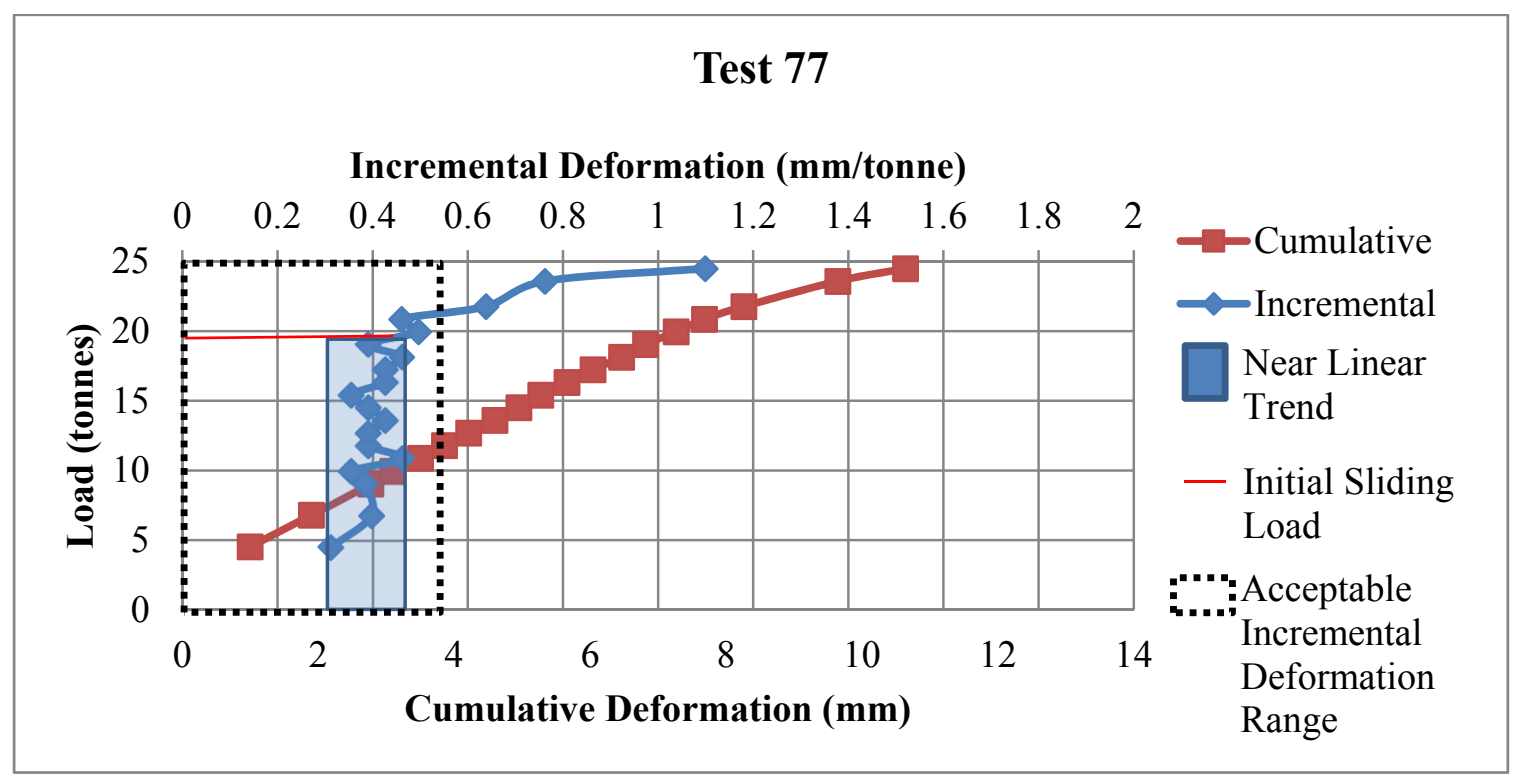

Figure E.67 Pull Test Load vs. Deformation Test 77 


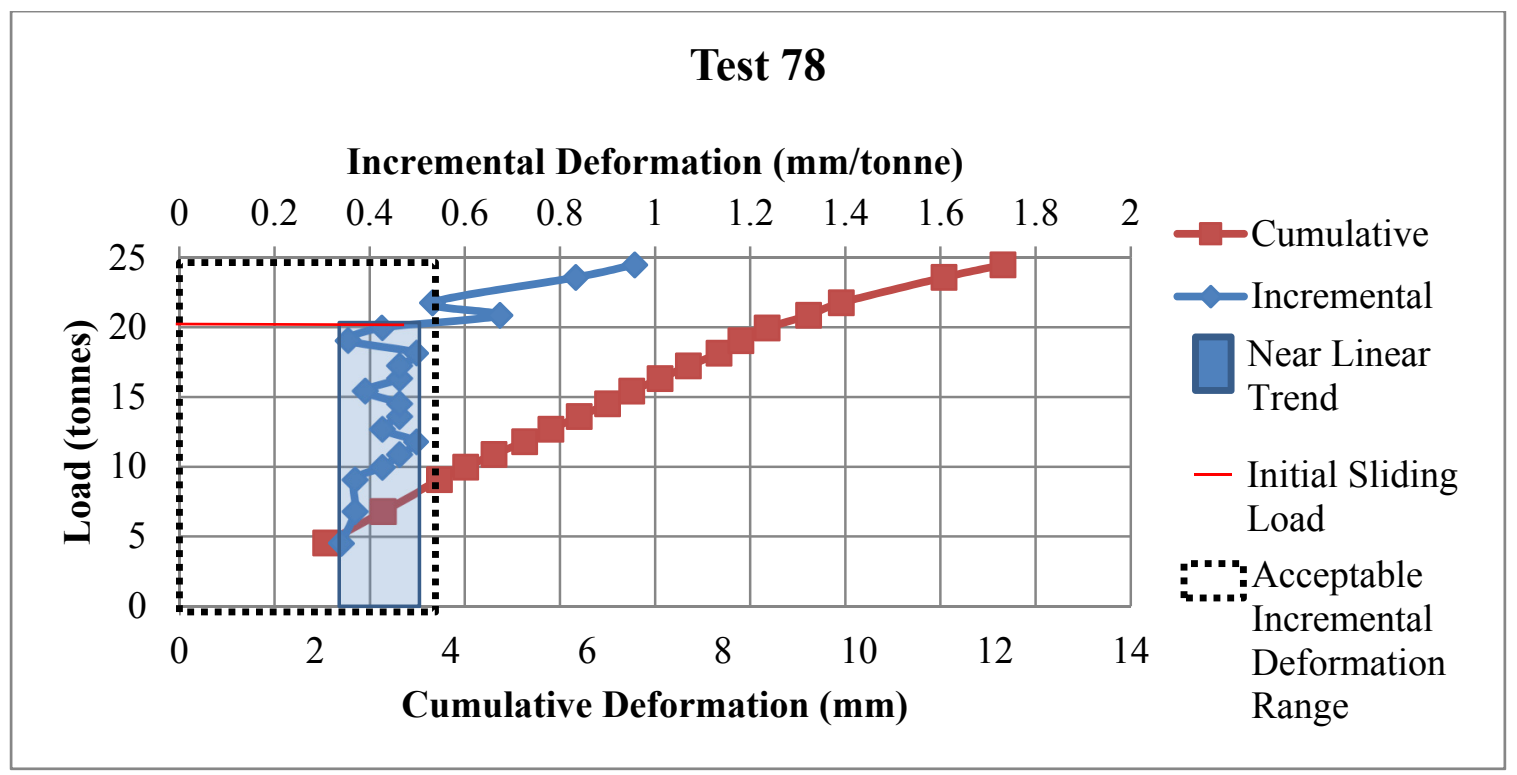

Figure E.68 Pull Test Load vs. Deformation Test 78

\section{Test 79}

Incremental Deformation ( $\mathrm{mm} /$ tonne)

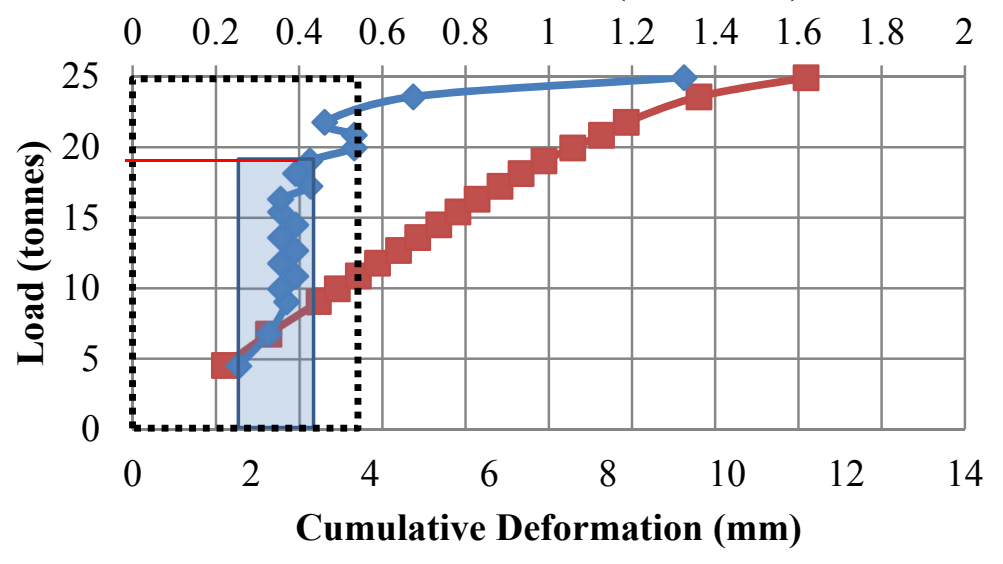

- Cumulative

$\leadsto$ Incremental

Near Linear

Trend

- Initial Sliding Load

:-.'Acceptable Incremental Deformation Range

Figure E.69 Pull Test Load vs. Deformation Test 79 


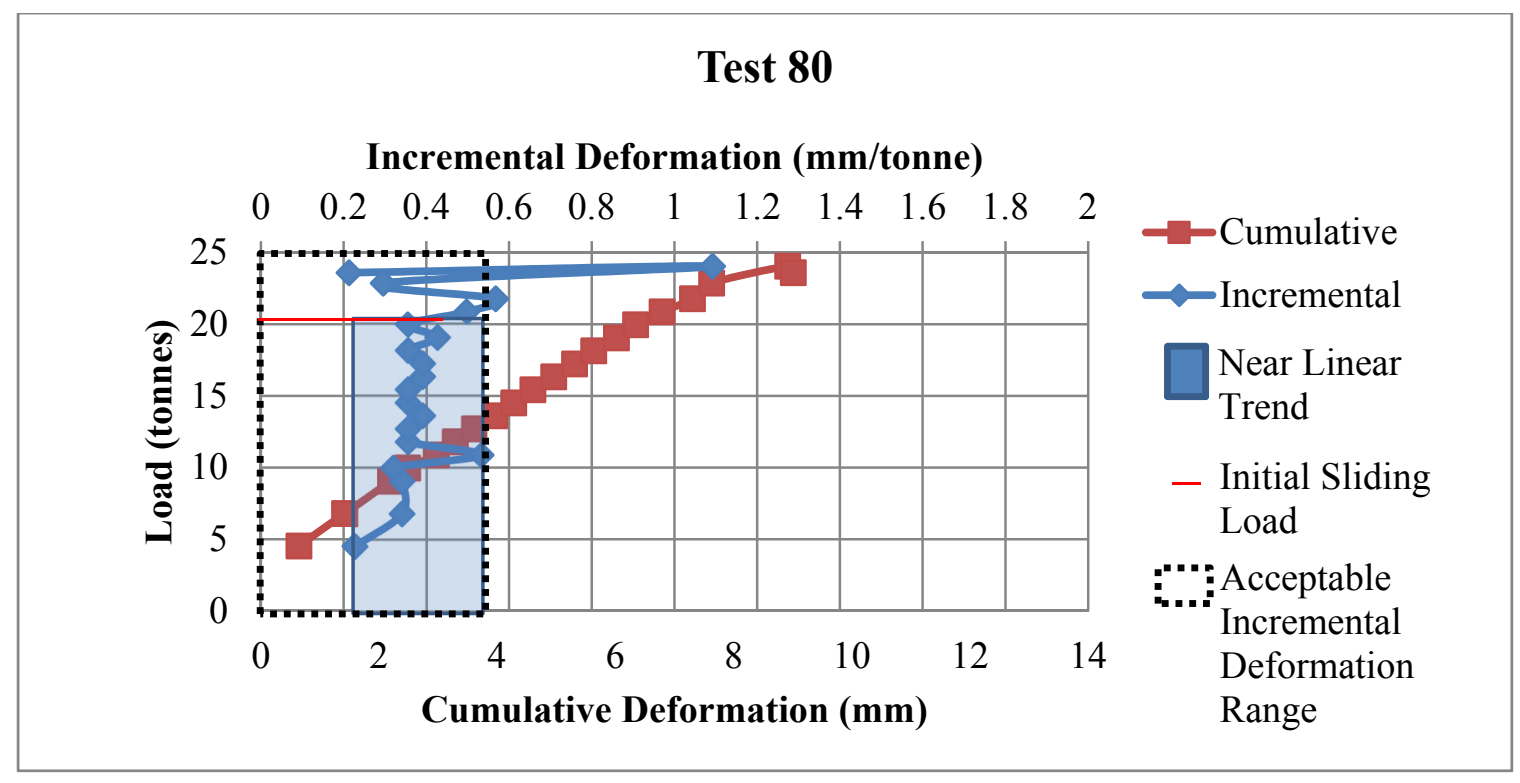

Figure E.70 Pull Test Load vs. Deformation Test 80

\section{"South Storage Bin" Testing Site Data (Non-Active Site on Halite Horizon)}

Table E.4 shows the data collected from the "South Storage Bin" testing site. The following figures show the load versus deformation plots for each test conducted.

Table E.4 "South Storage Bin" Testing Site Data

\begin{tabular}{|c|c|c|c|c|c|}
\hline Test No. & $\begin{array}{l}\text { Cure Time } \\
\text { (days) }\end{array}$ & $\begin{array}{c}\text { Initial Sliding } \\
\text { Load } \\
\text { (tonnes) }\end{array}$ & $\begin{array}{c}\text { Bond } \\
\text { Strength } \\
\text { (Linear) } \\
\text { (tonnes/m) }\end{array}$ & $\begin{array}{c}\text { Resin-Rebar } \\
\text { Bond } \\
\text { Strength } \\
\text { (MPa) }\end{array}$ & $\begin{array}{c}\text { Resin-Rock } \\
\text { Bond } \\
\text { Strength } \\
\text { (MPa) }\end{array}$ \\
\hline 81 & 26.1 & 13.5 & 26.6 & 3.4 & 2.3 \\
\hline 82 & \multirow{2}{*}{\multicolumn{5}{|c|}{ Hydraulic Cylinder Malfunctioned (Stopped Venting) - Test Discontinued }} \\
\hline 83 & & & & & \\
\hline 84 & 26.0 & 21.5 & 42.3 & 5.4 & 3.6 \\
\hline 85 & 25.9 & 20.5 & 40.4 & 5.2 & 3.5 \\
\hline 86 & 26.0 & \multicolumn{4}{|l|}{ Indeterminate } \\
\hline 87 & 26.0 & \multicolumn{4}{|l|}{ Indeterminate } \\
\hline 88 & 26.0 & \multicolumn{4}{|l|}{ Indeterminate } \\
\hline 89 & 26.0 & 16.0 & 31.5 & 4.0 & 2.7 \\
\hline 90 & 26.0 & \multicolumn{4}{|l|}{ Indeterminate } \\
\hline
\end{tabular}




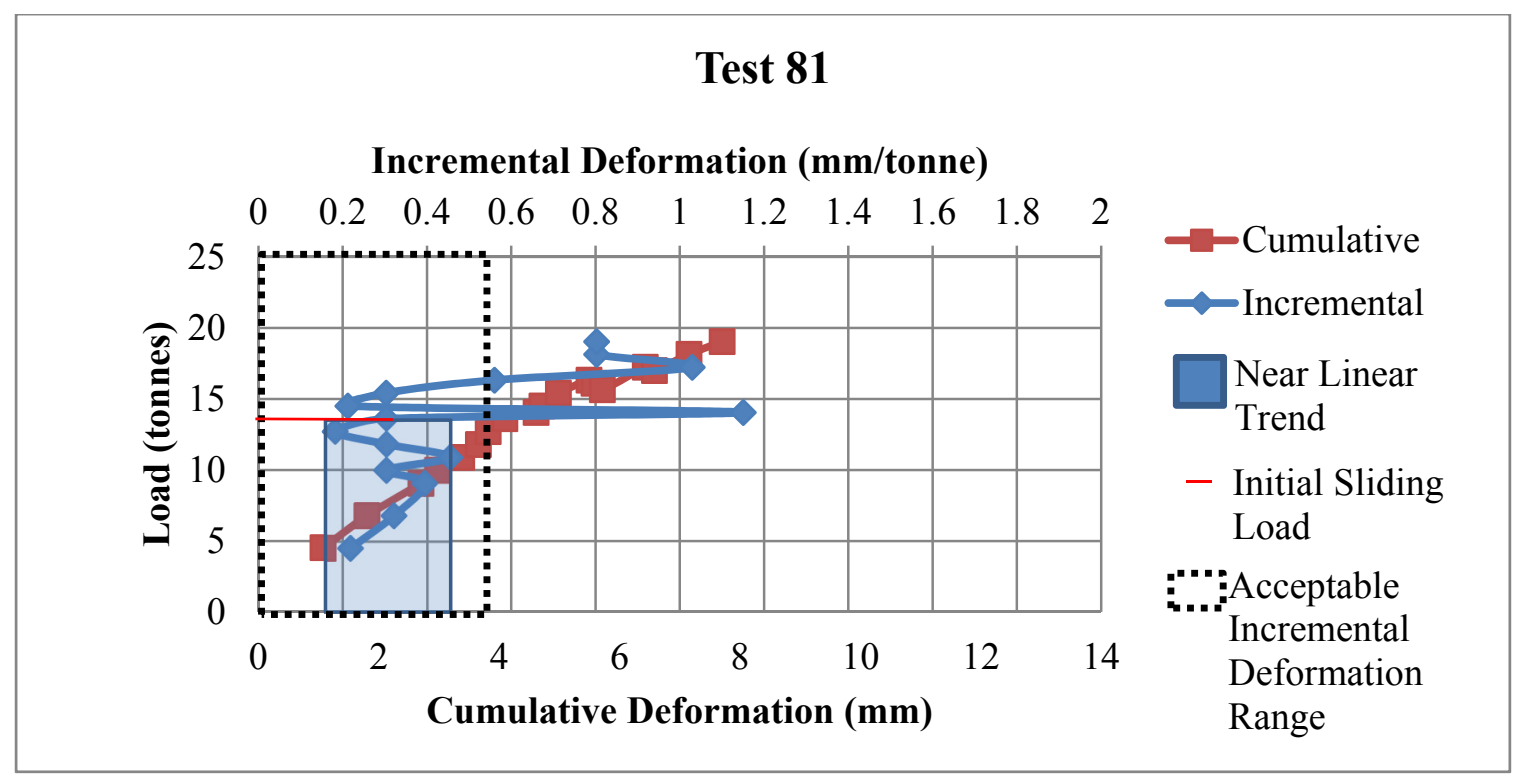

Figure E.71 Pull Test Load vs. Deformation Test 81

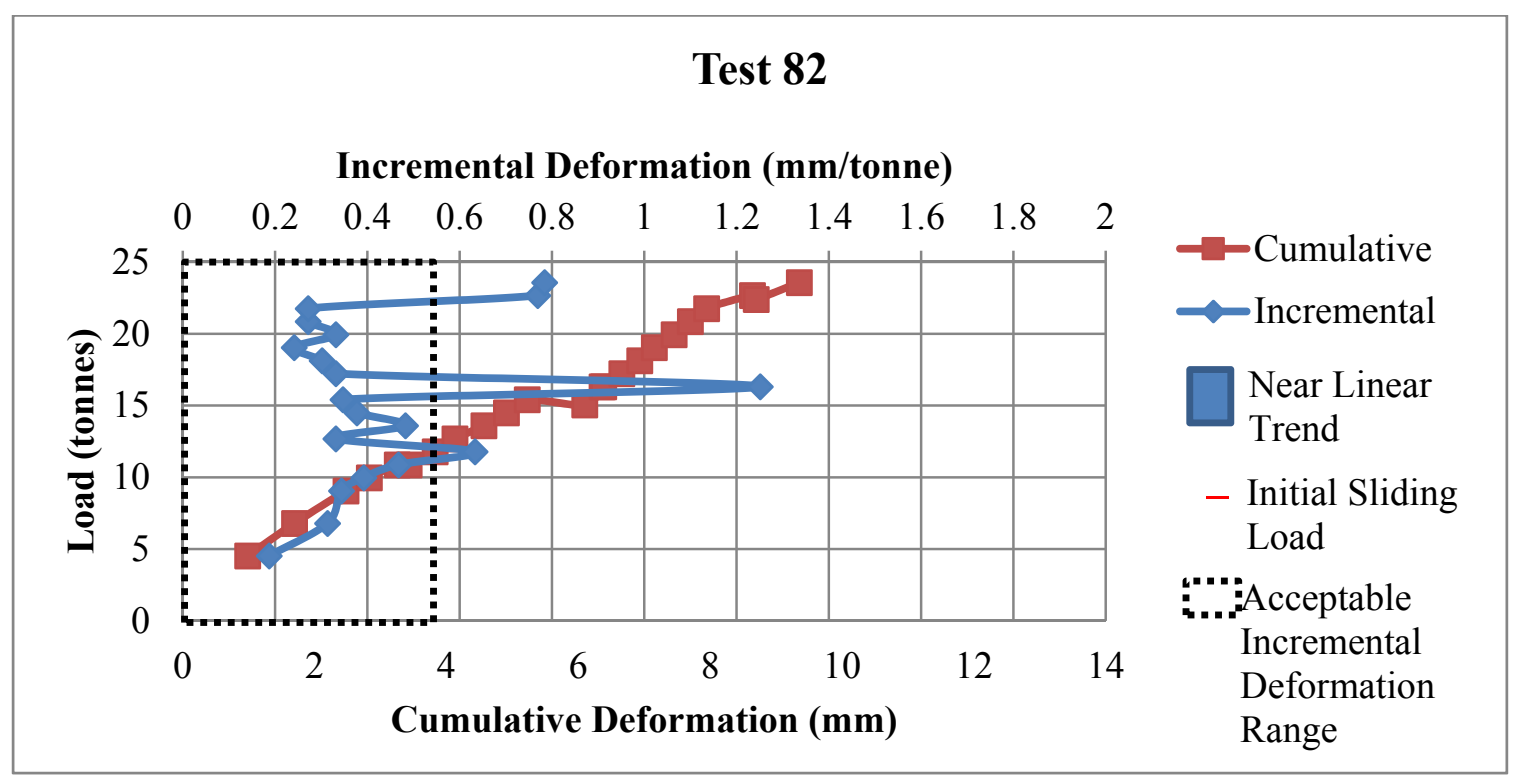

Figure E.72 Pull Test Load vs. Deformation Test 82 


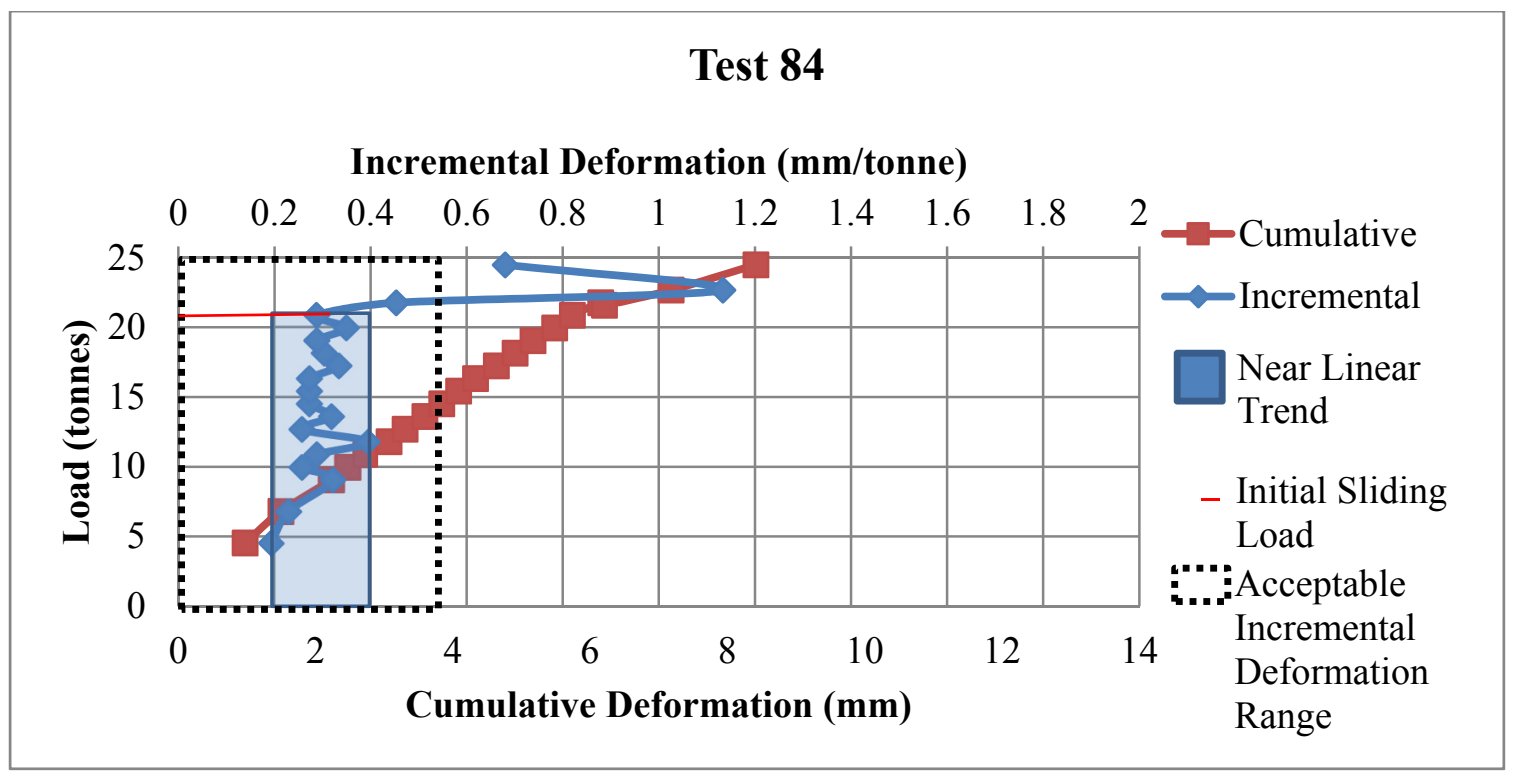

Figure E.73 Pull Test Load vs. Deformation Test 84

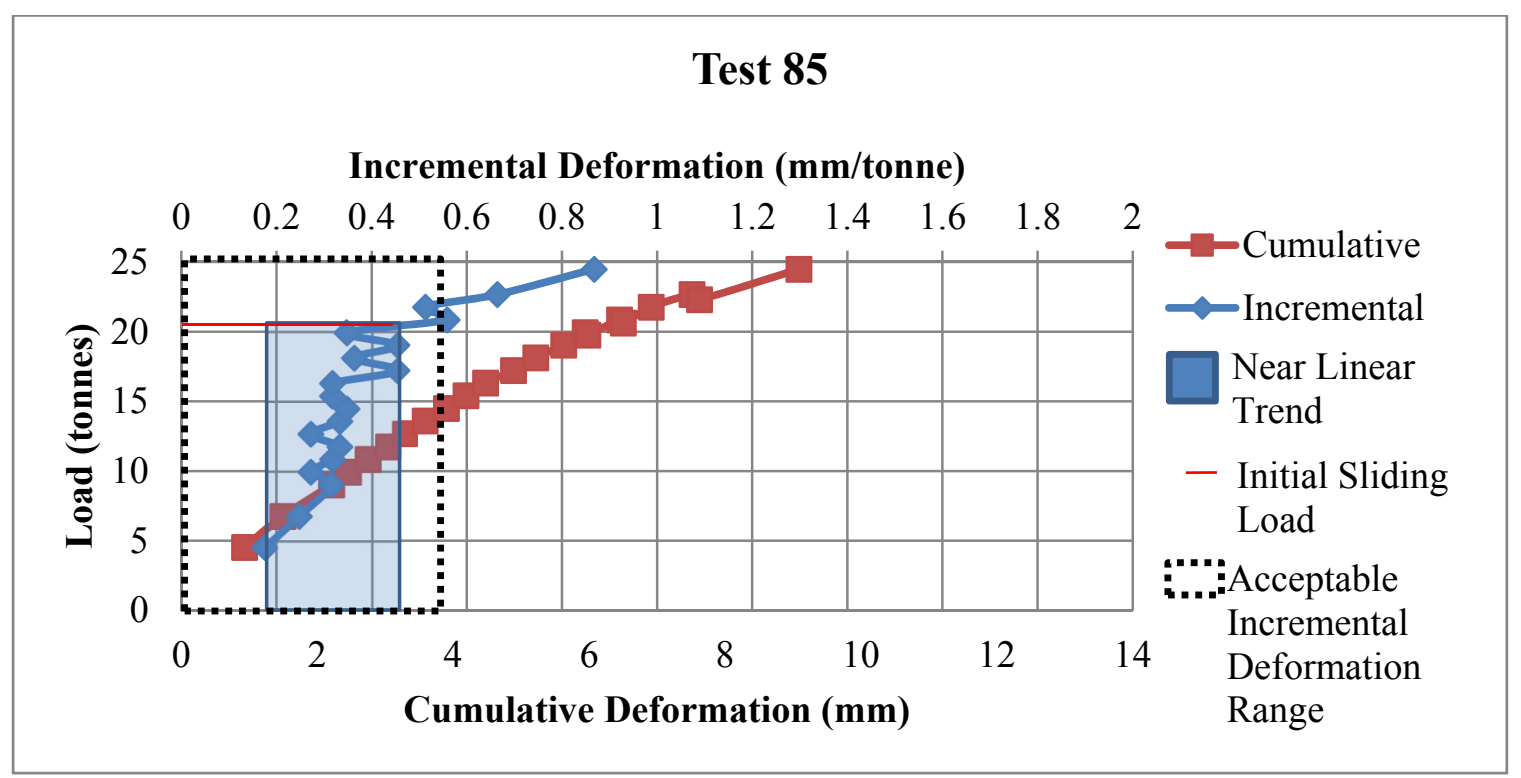

Figure E.74 Pull Test Load vs. Deformation Test 85 


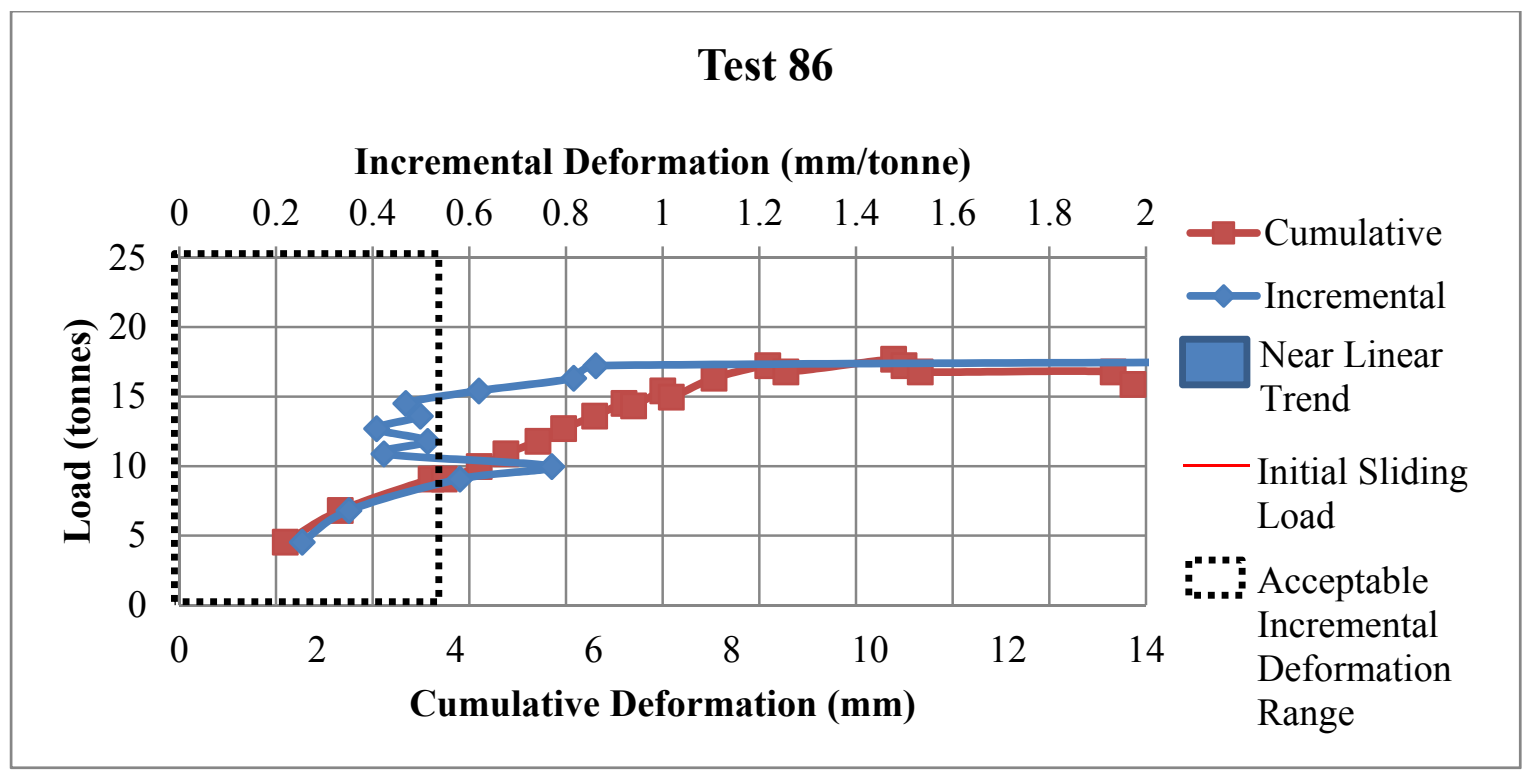

Figure E.75 Pull Test Load vs. Deformation Test 86

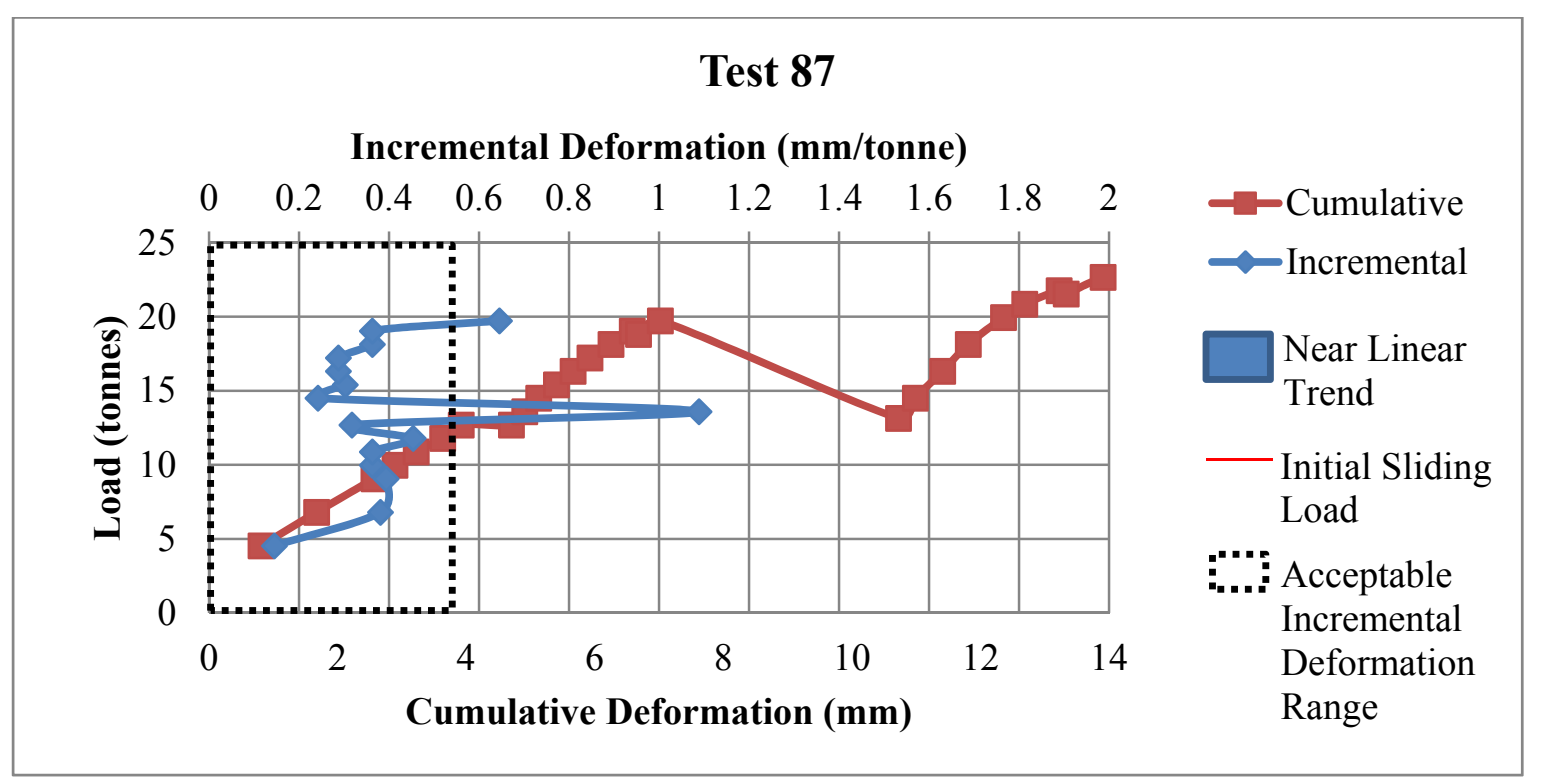

Figure E.76 Pull Test Load vs. Deformation Test 87 


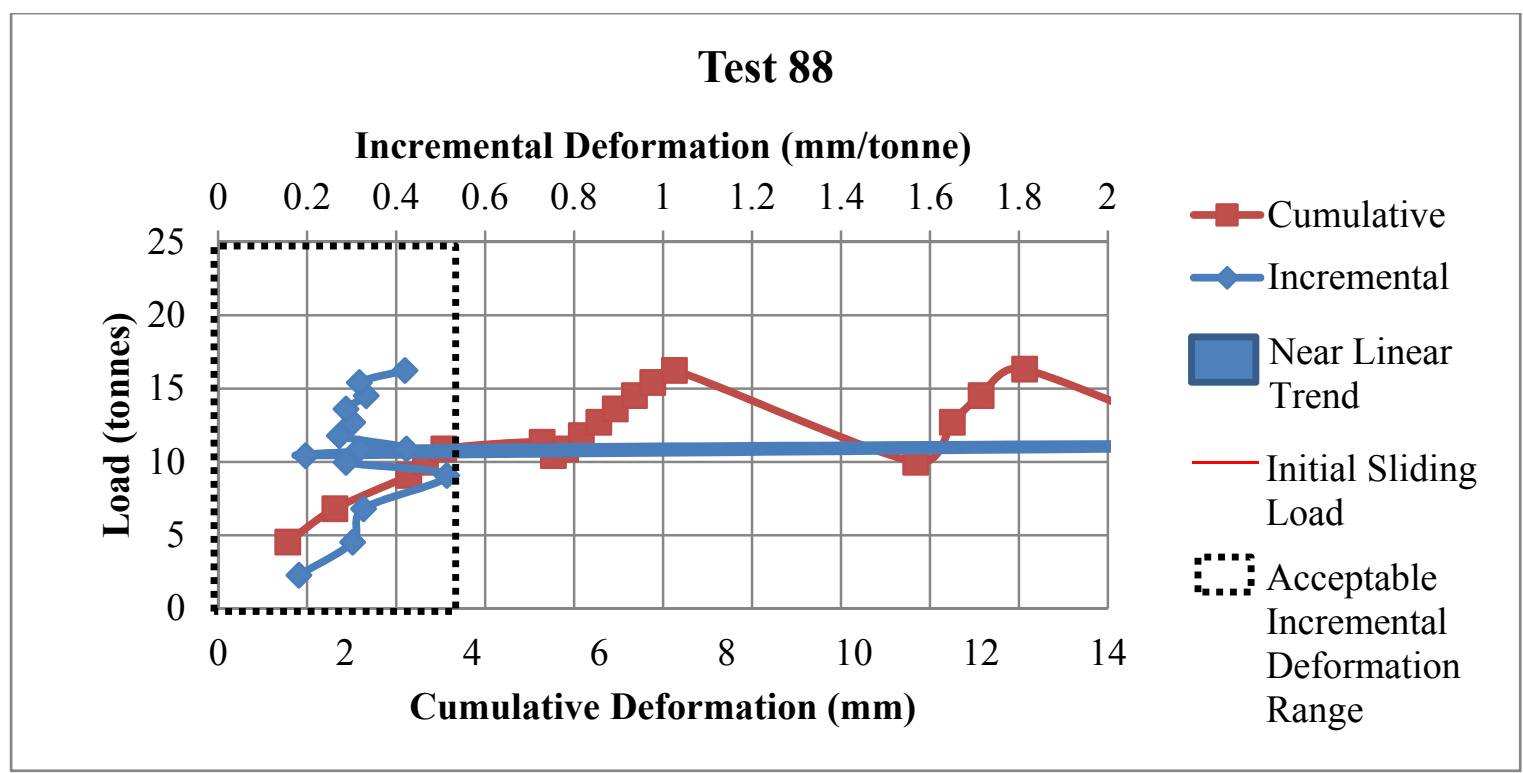

Figure E.77 Pull Test Load vs. Deformation Test 88

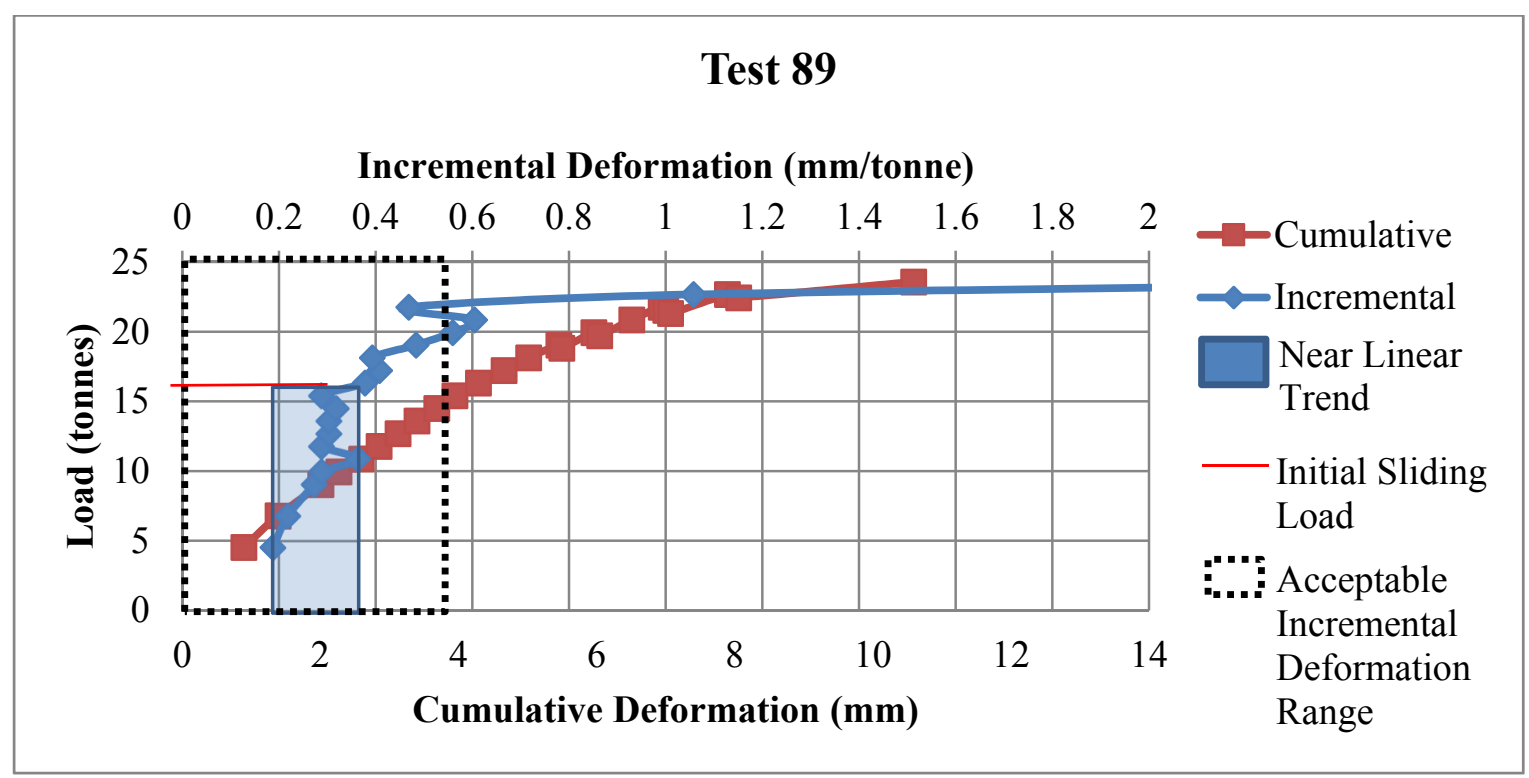

Figure E.78 Pull Test Load vs. Deformation Test 89 


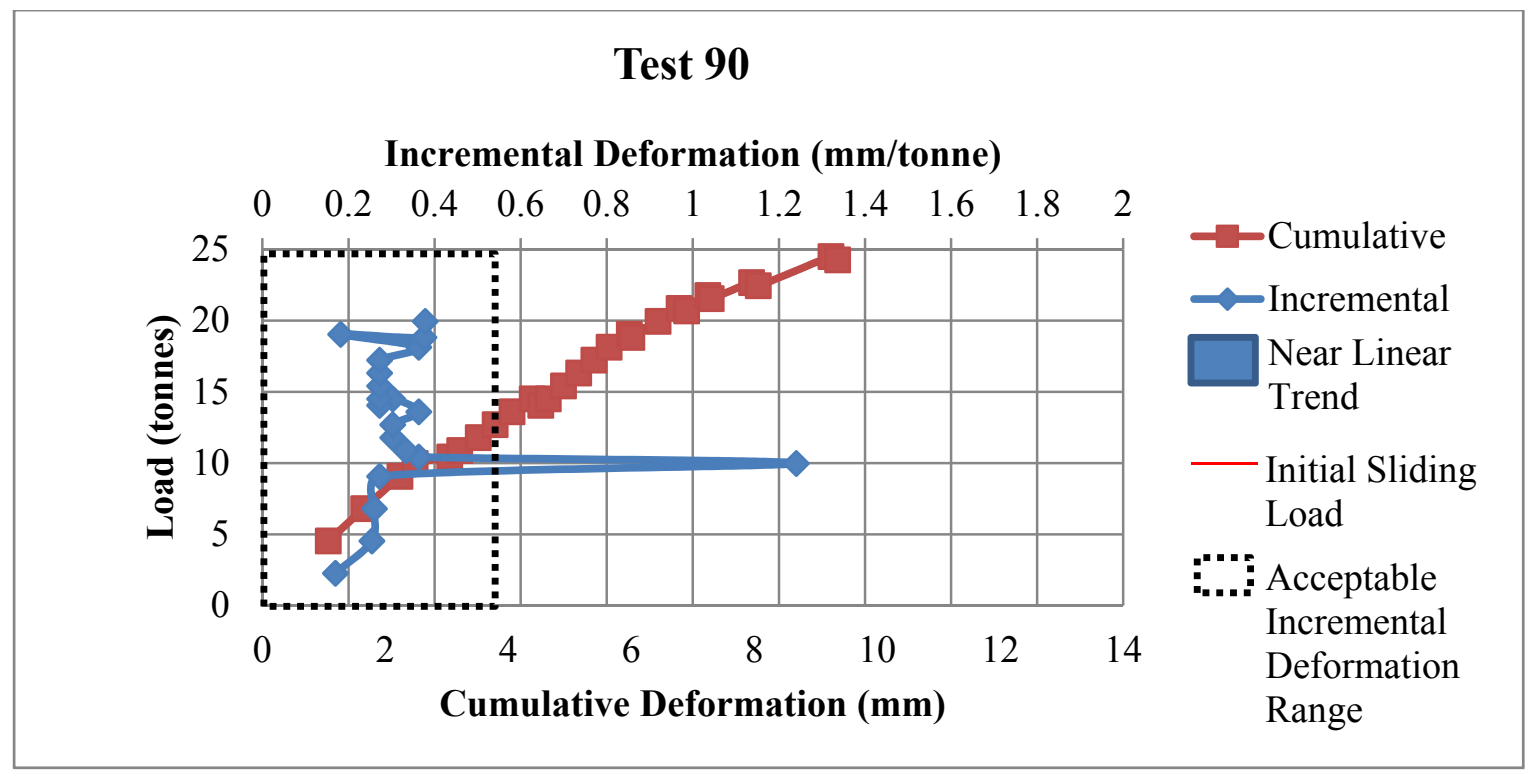

Figure E.79 Pull Test Load vs. Deformation Test 90

\section{Short Embedment Length Test Data}

Table E.5 shows the data collected from the short embedment length tests. Since only maximum load was recorded in these tests, there are no plots of load versus deformation.

Table E.5 Short Embedment Length Test Data

\begin{tabular}{|c|c|c|}
\hline Test No. & Maximum Load (tonnes) & Result of Test \\
\hline 91 & 5.4 & Full Stroke of Cylinder Reached - Test \\
Discontinued
\end{tabular}




\section{"East305" Testing Site Data (16mm Rebar, Non-Active Site, Potash Horizon)}

Table E.6 shows the data collected from the "East305" testing site. The following figures show the load versus deformation plots for each $16 \mathrm{~mm}$ rebar tested.

Table E.6 "East 305" Testing Site Data

\begin{tabular}{|c|c|c|c|c|c|}
\hline Test No. & $\begin{array}{c}\text { Cure Time } \\
\text { (days) }\end{array}$ & $\begin{array}{c}\text { Initial Sliding } \\
\text { Load } \\
\text { (tonnes) }\end{array}$ & $\begin{array}{c}\text { Bond } \\
\text { Strength } \\
\text { (Linear) } \\
\text { (tonnes/m) }\end{array}$ & $\begin{array}{c}\text { Resin-Rebar } \\
\text { Bond } \\
\text { Strength } \\
\text { (MPa) }\end{array}$ & $\begin{array}{c}\text { Resin-Rock } \\
\text { Bond } \\
\text { Strength } \\
\text { (MPa) }\end{array}$ \\
\hline 101 & 41.0 & 7.0 & 39.4 & 8.0 & 4.3 \\
\hline 102 & 41.0 & 4.4 & 24.7 & 5.0 & 2.7 \\
\hline 103 & 41.0 & 4.6 & 25.9 & 5.2 & 2.8 \\
\hline 104 & 41.0 & 5.2 & 29.2 & 5.9 & 3.2 \\
\hline 105 & 41.0 & 6.4 & 36.0 & 7.3 & 3.9 \\
\hline 106 & 45.8 & 5.3 & 29.8 & 6.0 & 3.3 \\
\hline 107 & 45.8 & 4.7 & 26.4 & 5.3 & 2.9 \\
\hline 108 & 45.8 & 4.2 & 23.6 & 4.8 & 2.6 \\
\hline 109 & 45.8 & 4.8 & 27.0 & 5.5 & 3.0 \\
\hline 110 & 45.8 & 4.6 & 25.9 & 5.2 & 2.8 \\
\hline
\end{tabular}

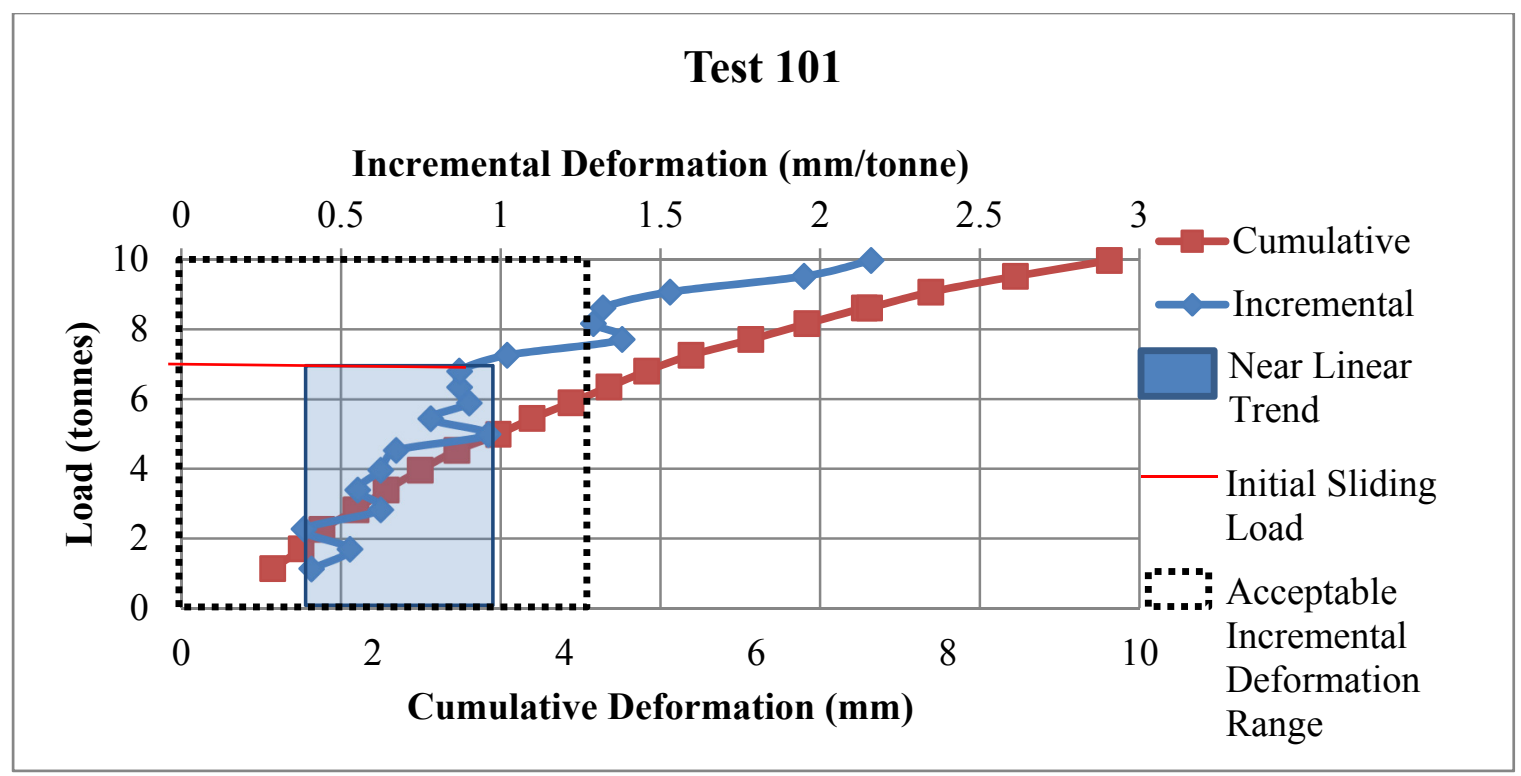

Figure E.80 Pull Test Load vs. Deformation Test 101 


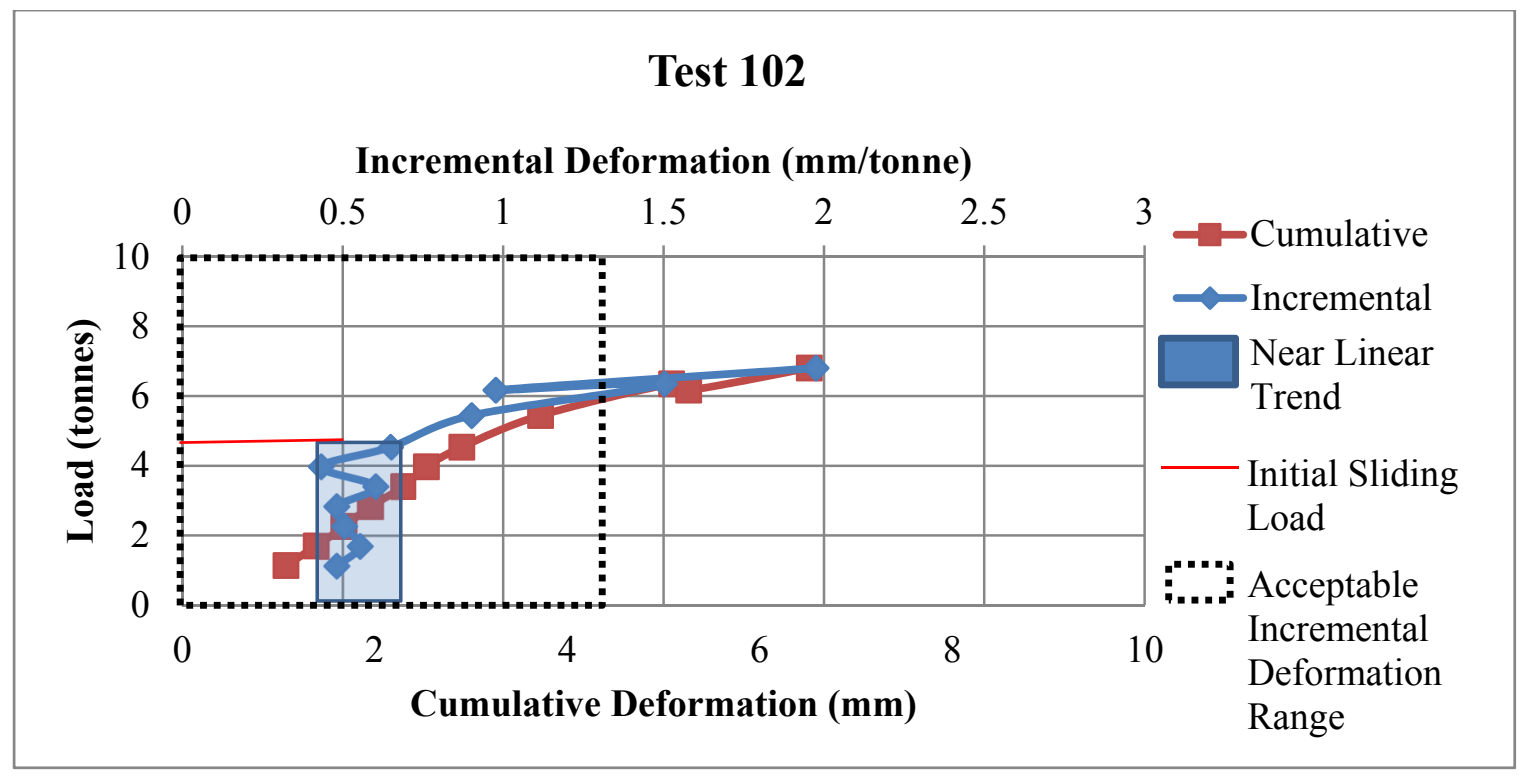

Figure E.81 Pull Test Load vs. Deformation Test 102

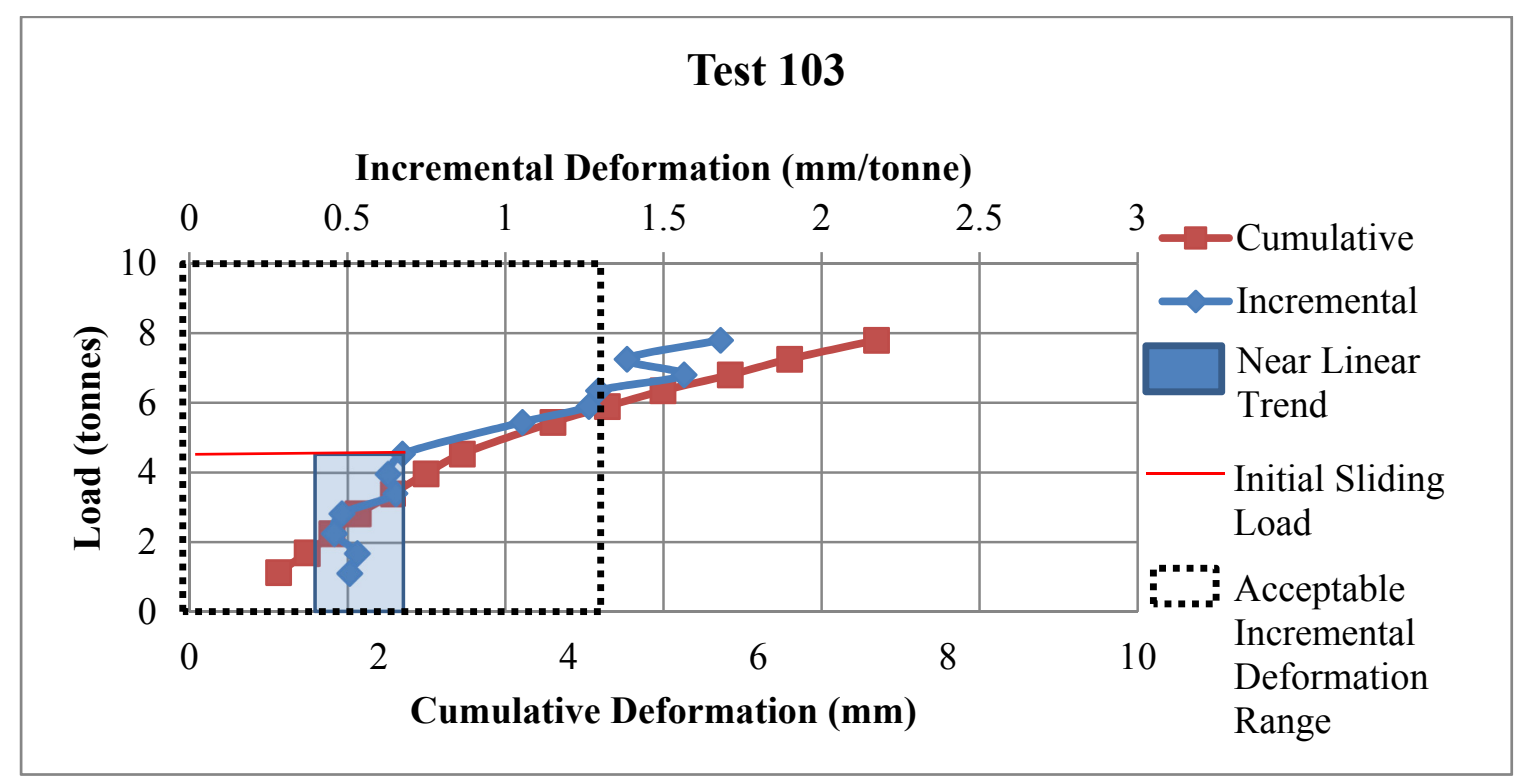

Figure E.82 Pull Test Load vs. Deformation Test 103 


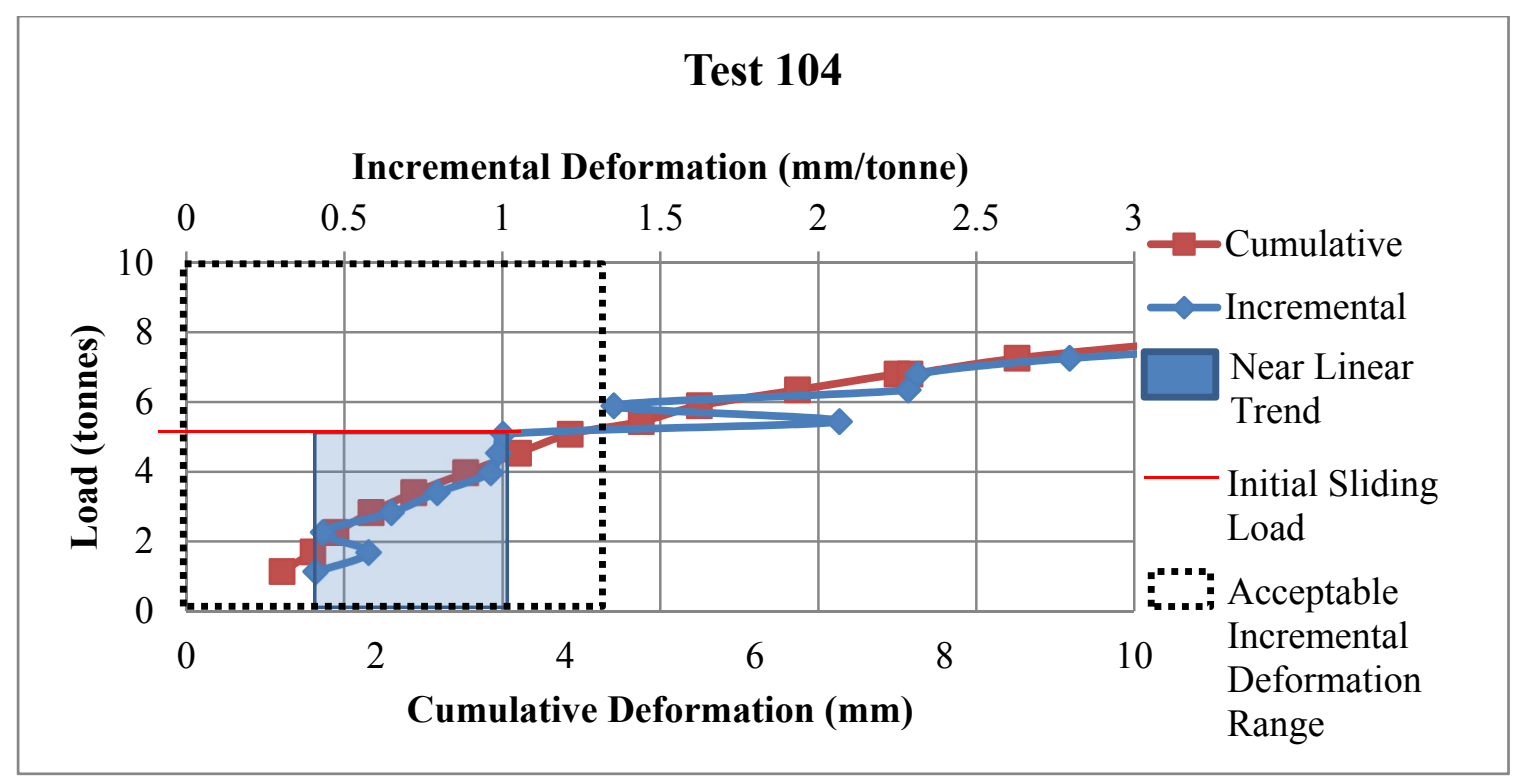

Figure E.83 Pull Test Load vs. Deformation Test 104

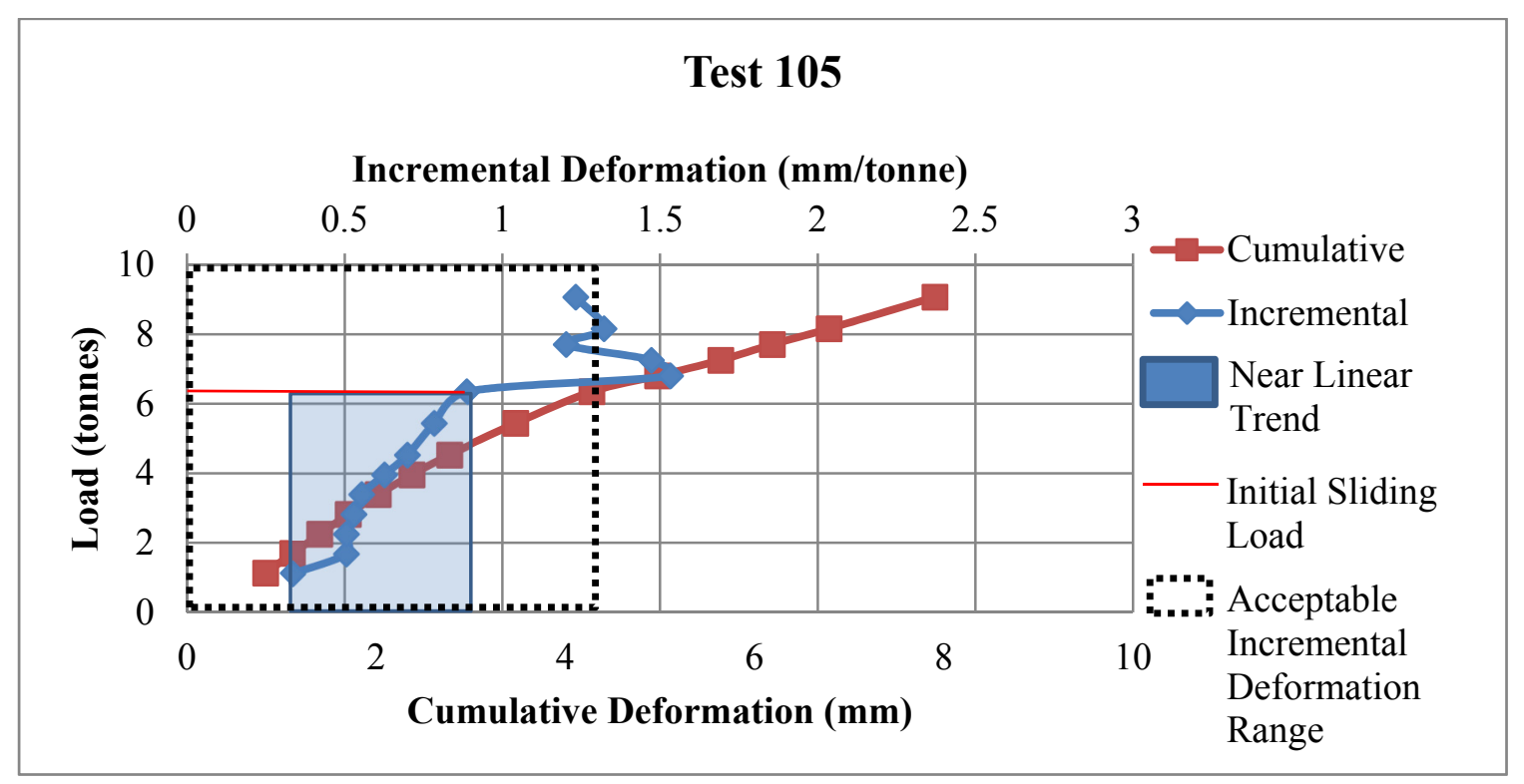

Figure E.84 Pull Test Load vs. Deformation Test 105 


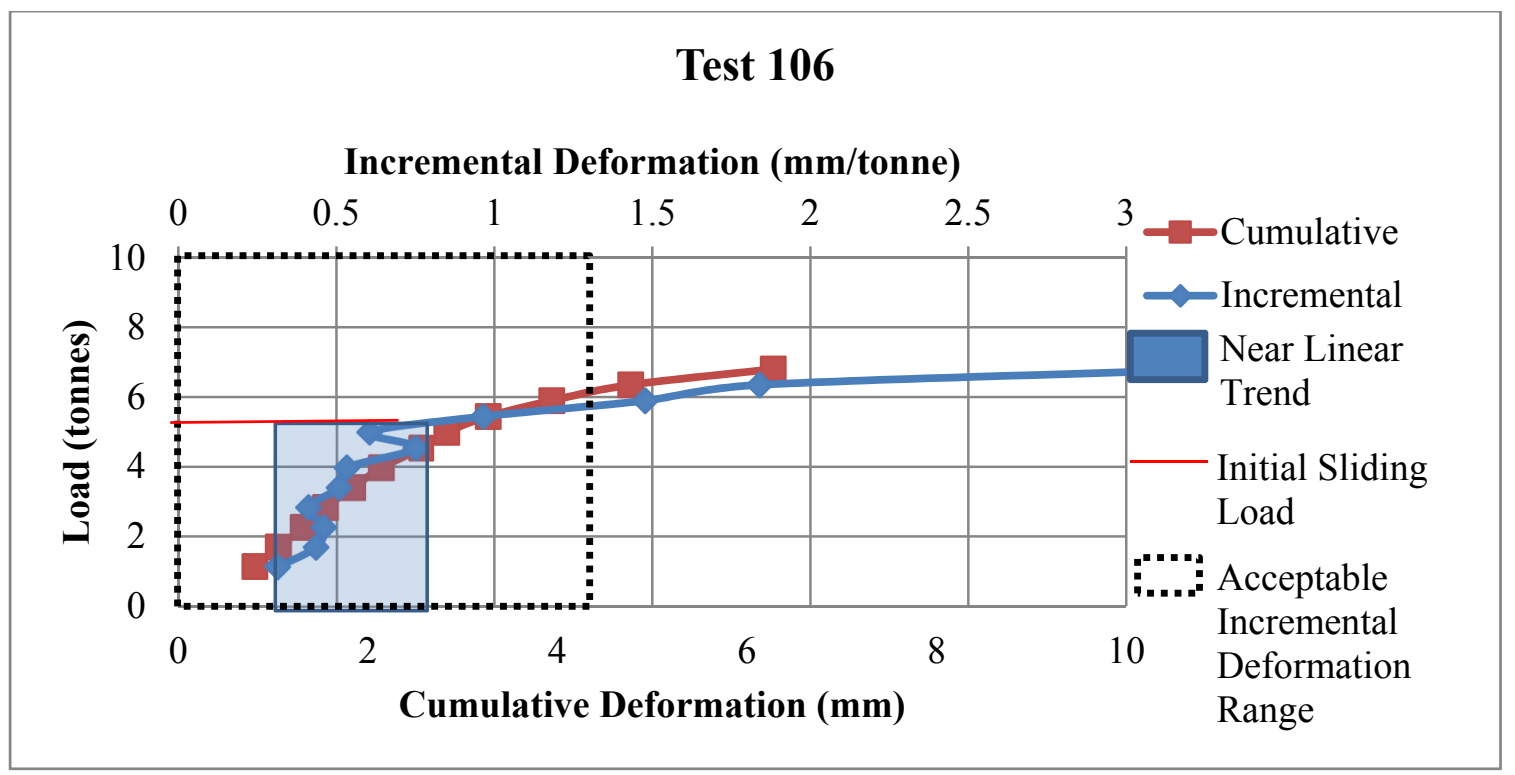

Figure E.85 Pull Test Load vs. Deformation Test 106

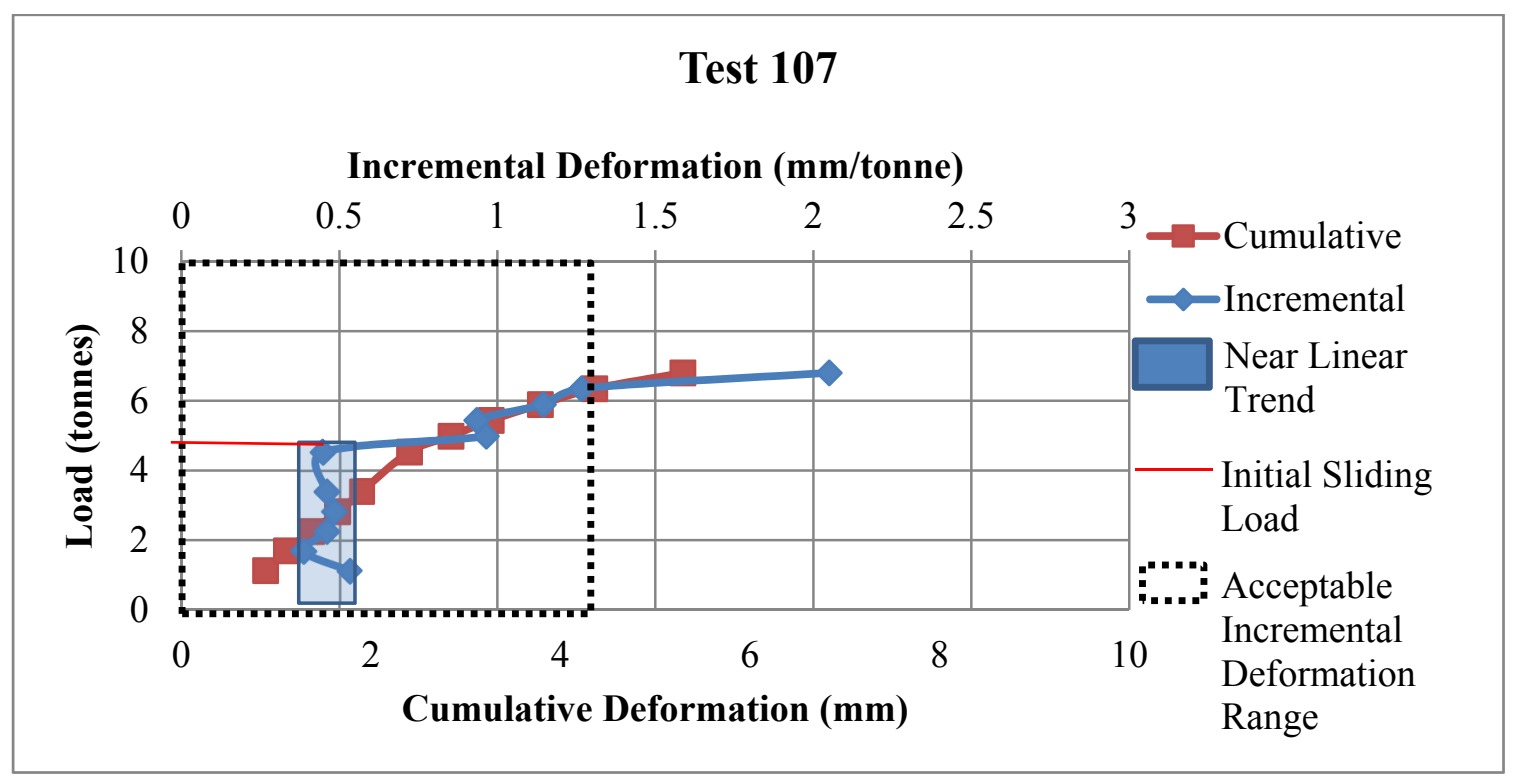

Figure E.86 Pull Test Load vs. Deformation Test 107 


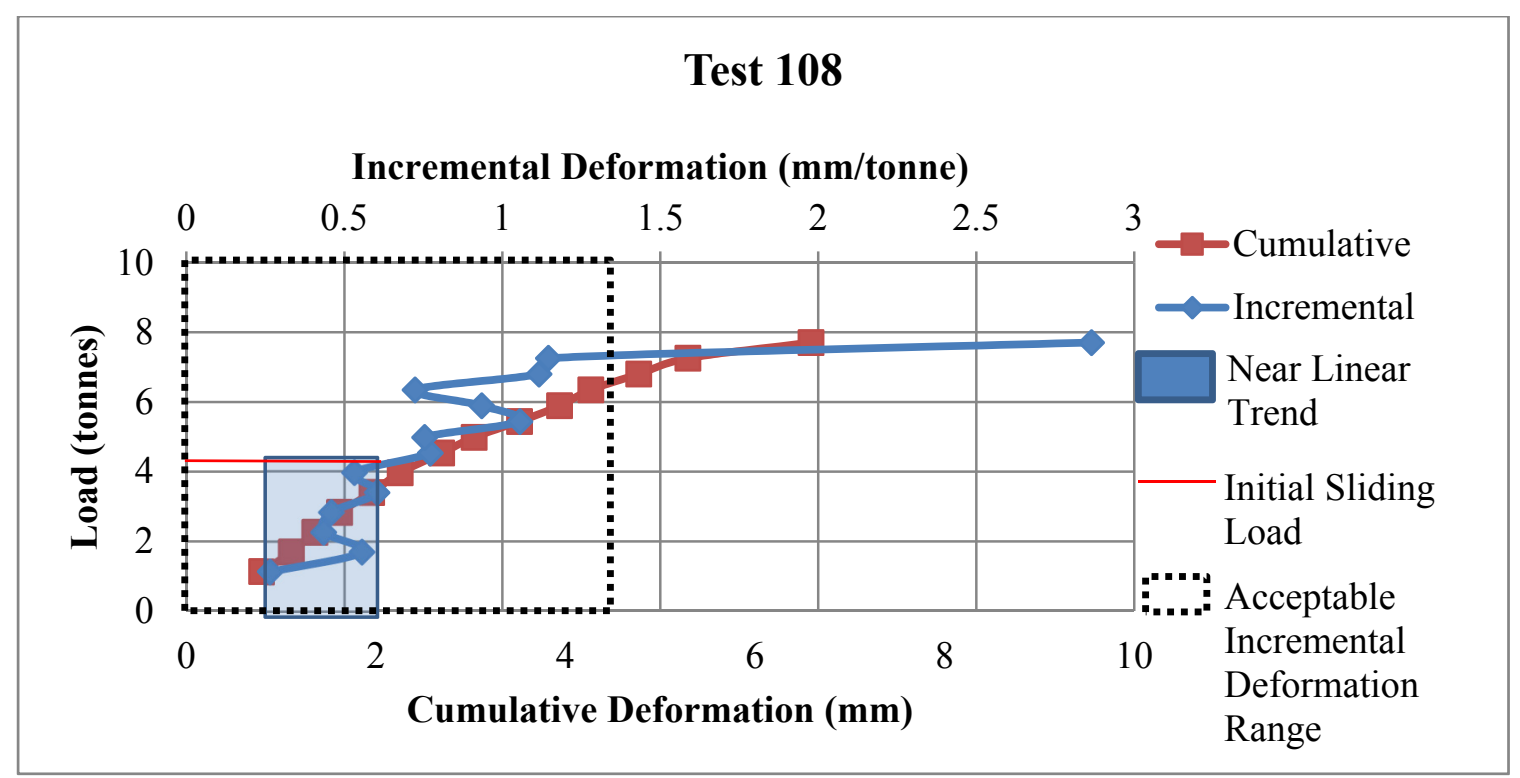

Figure E.87 Pull Test Load vs. Deformation Test 108

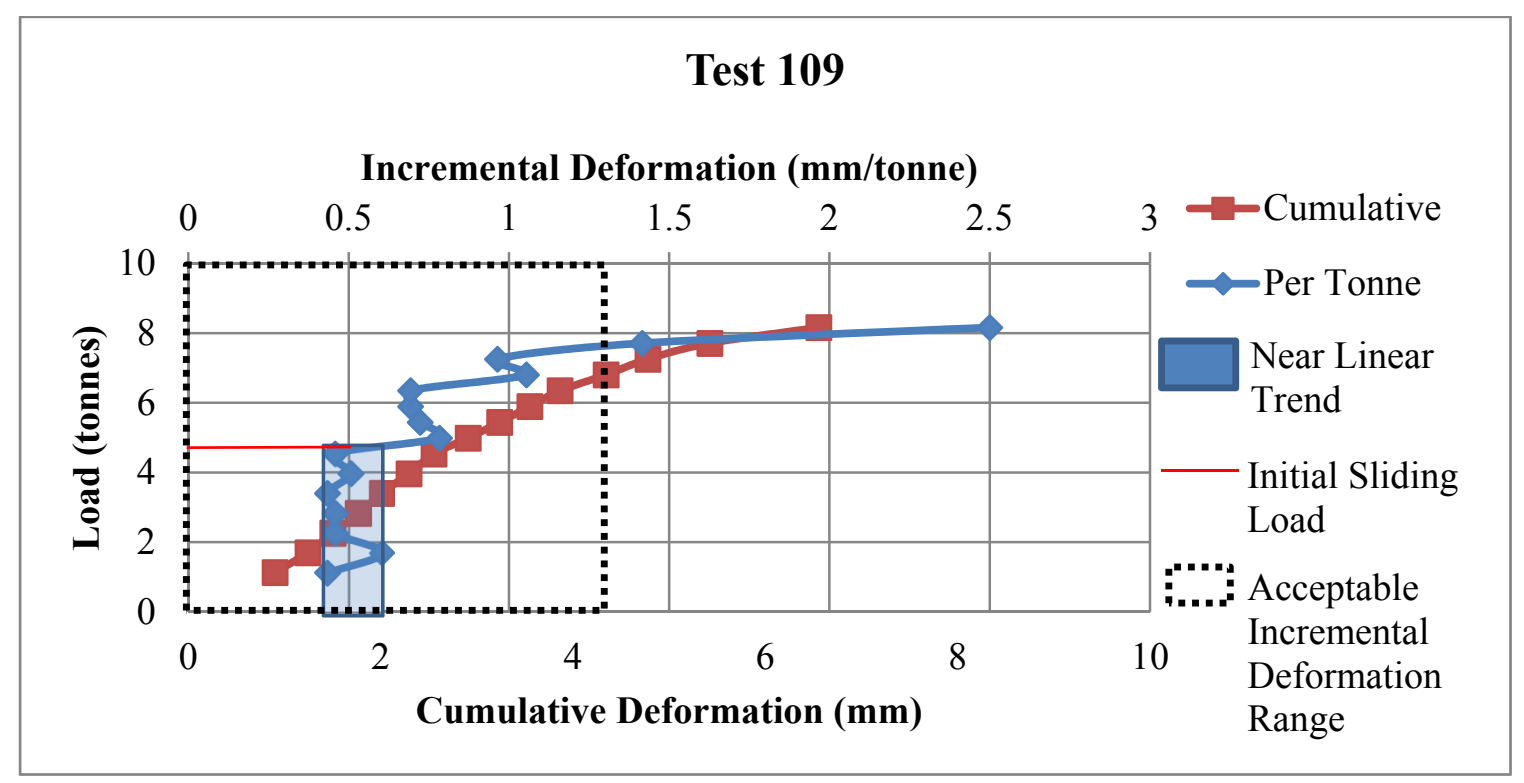

Figure E.88 Pull Test Load vs. Deformation Test 109 


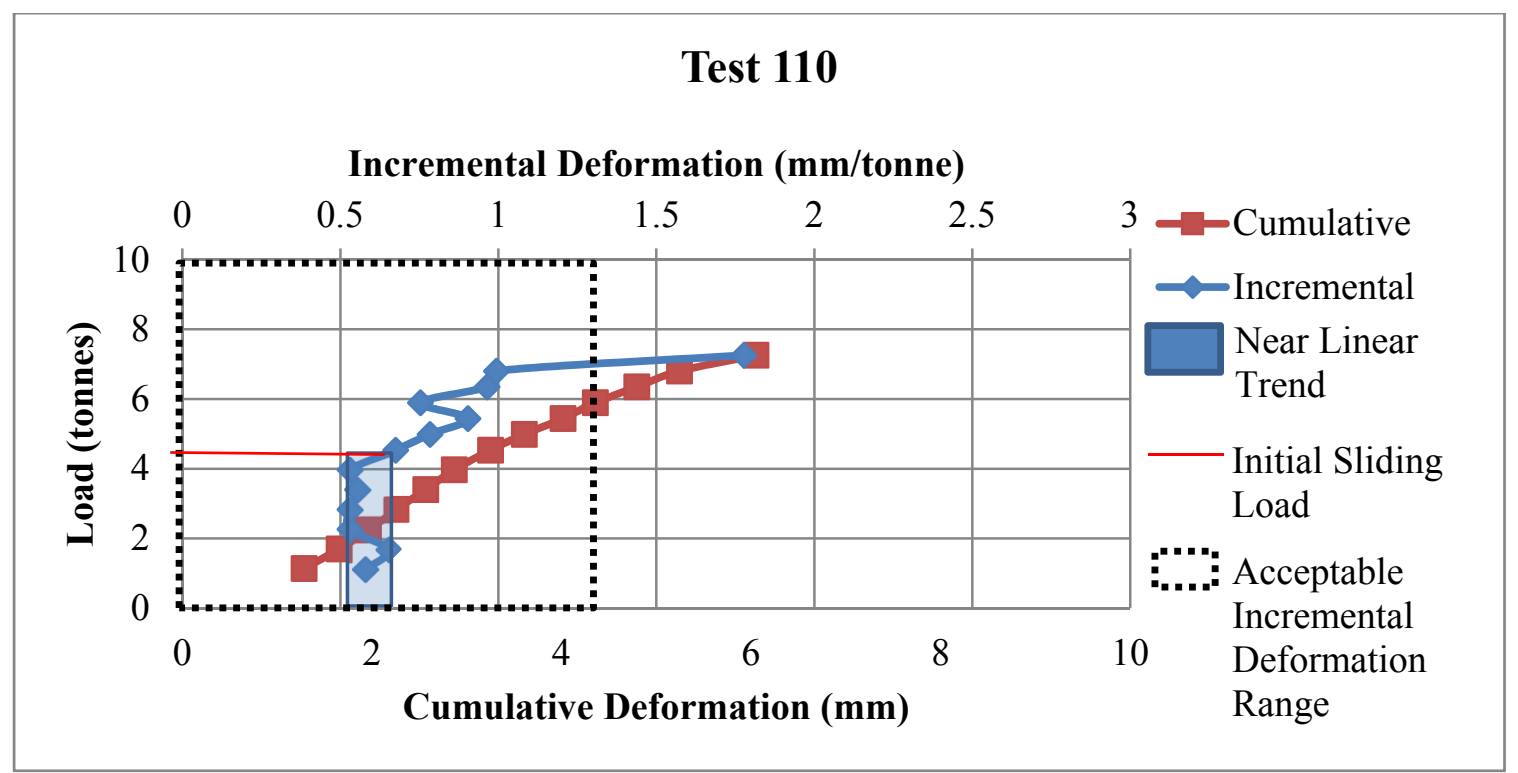

Figure E.89 Pull Test Load vs. Deformation Test 110

\section{T-Test for Proximity to Active Mining Pull Test Results}

To compare results from the active and non-active areas, a two sided t-test was conducted. This was to determine if the means from each population were significantly different. Given that there are unequal sample sizes and an assumed equal variance, the following equation was used to determine the value of $\mathrm{T}$ :

$$
\begin{aligned}
T= & \frac{\mu_{1}-\mu_{1}}{\sqrt{\frac{\left(n_{1}-1\right) s_{\varkappa_{1}}^{2}+\left(n_{2}-1\right) s_{\varkappa_{2}}^{2}}{n_{1}+n_{2}-2}}} \\
& \text { Where: } \\
& \mu=\text { Mean of population; } \\
& \mathrm{s}=\text { Variance of population; and } \\
\mathrm{n} & =\text { Sample size } \\
\mathrm{T} & =\text { Calculated } \mathrm{T} \text { value }
\end{aligned}
$$

The significant $\mathrm{T}$ value taken from the $\mathrm{T}$ distribution table is as follows:

Where degrees of freedom $=\mathrm{n}_{1}+\mathrm{n}_{2}-2$ and $\alpha=0.05$;

$$
\mathrm{T}_{0.05,58}=2.0017
$$


If the calculated $T$ value is less than the significant $T_{\alpha, k}$ value, the null hypothesis is accepted (i.e. the means are not significantly different). If the calculated $T$ value is greater than the $T_{\alpha, k}$ value, the null hypothesis is rejected (i.e. the means are significantly different).

Calculated T value:

Values used are as listed:

$$
\begin{aligned}
& \mu_{\text {active }}=19 \text { tonnes } \quad \mu_{\text {non-active }}=18 \text { tonnes; } \\
& \text { Sactive }=1.9 \text { tonnes } \quad \text { Snon-active }=1.4 \text { tonnes; } \\
& \mathrm{n}_{\text {active }}=40 \quad \mathrm{n}_{\text {non-active }}=20 \\
& \mathrm{~T}=0.5708
\end{aligned}
$$

Since $0.5708<2.0017$ - the null hypothesis is accepted. The means are not significantly different. 